\title{
SOCIOLOGY OF LAW AS THE SCIENCE OF NORMS
}

Håkan Hydén

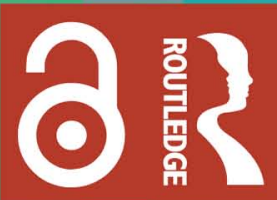




\section{Sociology of Law as the Science of Norms}

This book proposes the study of norms as a method of explaining human choice and behaviour by introducing a new scientific perspective.

The science of norms may here be broadly understood as a social science which includes elements from both the behavioural and legal sciences. It is given that a science of norms is not normative in the sense of prescribing what is right or wrong in various situations. Compared with legal science, sociology of law has an interest in the operational side of legal rules and regulation. This book develops a synthesizing social science approach to better understand societal development in the wake of the increasingly significant digital technology. The underlying idea is that norms as expectations today are not primarily related to social expectations emanating from human interactions but come from systems that mankind has created for fulfilling its needs. Today the economy, via the market, and technology, via digitization, generate stronger and more frequent expectations than the social system.

By expanding the sociological understanding of norms, the book makes comparisons between different parts of society possible and creates a more holistic understanding of contemporary society. The book will be of interest to academics and researchers in the areas of sociology of law, legal theory, philosophy of law, sociology and social psychology.

Håkan Hydén is a senior professor in sociology of law, Lund University, Sweden, and fellow of the World Academy of Arts and Sciences. 
$\because$ Taylor \& Francis Taylor \& Francis Group http://taylorandfrancis.com 


\title{
Sociology of Law as the Science of Norms
}

\author{
Håkan Hydén
}


First published 2022

by Routledge

2 Park Square, Milton Park, Abingdon, Oxon OX14 4RN

and by Routledge

605 Third Avenue, New York, NY 10158

Routledge is an imprint of the Taylor o Francis Group, an informa business

(C) 2022 Håkan Hydén

The right of Håkan Hydén to be identified as author of this work has been asserted in accordance with sections 77 and 78 of the Copyright, Designs and Patents Act 1988.

The Open Access version of this book, available at www.taylorfrancis. com, has been made available under a Creative Commons AttributionNon Commercial-No Derivatives 4.0 license.

Trademark notice: Product or corporate names may be trademarks or registered trademarks, and are used only for identification and explanation without intent to infringe.

British Library Cataloguing-in-Publication Data

A catalogue record for this book is available from the British Library

Library of Congress Cataloging-in-Publication Data

A catalog record for this book has been requested

ISBN: 978-1-032-14947-9 (hbk)

ISBN: 978-1-032-14953-0 (pbk)

ISBN: 978-1-003-24192-8 (ebk)

DOI: $10.4324 / 9781003241928$

Typeset in Galliard

by Apex CoVantage, LLC 


\section{Contents}

Acknowledgement viii

Preface ix

1 Why do we need a science of norms?

1.1 Different perspectives of norms 1

1.1.1 Design of the book 1

1.1.2 Norms from an analytical perspective 2

1.1.3 Norms from an empirical perspective 13

1.1.4 Normative systems 18

1.2 The relation between societal development and changing norms 20

1.2.1 How is a society created? 20

1.2.2 The birth, change and decline of a societal system 29

1.3 Epistemological implications 43

1.3.1 The circle of motives between actor and system theory 43

1.3.2 The need to assemble 45

2 Two competing normative worlds and their internal changes over time

2.1 Introduction 49

2.2 Lifeworld and system 50

2.2.1 Human dualism 50

2.2.2 Social integration 53

2.2.3 System integration 58

2.2.4 The relationship between lifeworld and systems 62

2.3 The S-curve and the developments of the two worlds over time 70

2.3.1 Society's material progress - the successive establishment of the systems 70

2.3.2 Society's ideological progress - the perpetual rise and fall of the lifeworld 78

2.3.3 How society develops and expresses its ideology 85 
3 About norms and action systems

3.1 Social norms 91

3.1.1 Sociological and socio-psychological norms 91

3.1.2 Norms in game theory 97

3.1.3 Other types of social norms 104

3.1.4 How are norms created and reproduced? 105

3.1.5 The concept of norms 107

3.2 The distribution of norms across action systems 108

3.2.1 Action systems 108

3.2.2 Socio-cultural systems 110

3.2.3 The political/administrative system 111

3.2.4 The economic system 113

3.2.5 The ecological system 119

3.2.6 Biotic and abiotic subsystems 123

3.2.7 Summing up 128

4 Law as a system of norms

129

4.1 Legal rules as norms 129

4.2 Legal property spaces 132

4.3 The contents of legal rules and distribution across action systems 140

4.4 When a norm becomes a legal rule, what are the consequences? 154

4.5 What norms become legal rules? 158

4.6 On detecting a norm or system of norms 166

5 The evolution of norms and law

5.1 The evolution of law in the market economy 168

5.1.1 Legal cultures that have shaped Western law 168

5.1.2 The market economy as legal culture 178

5.2 The evolution of law during the industrial age 184

5.3 Law in transitional society 194

5.3.1 Intervening rules and intersystem conflicts 194

5.3.2 Characteristics and problems with intervening rules 202

5.3.3 A discussion on alternative solutions to intersystem conflicts 204

6 Toward a theory of legal change

6.1 A theory of basic normative patterns 213

6.2 The emergence and developmental pattern of environmental law: a basic normative pattern characterized by dominant economic norms 222

6.2.1 The two sides to the right of ownership 222

6.2.2 The institution of immission 223 
6.2.3 The institution of tort law 224

6.2.4 Intervening rules 226

6.3 Are there basic normative patterns that recur in other areas of law? 228

6.4 The development of the legal system within bipolar values 232

6.5 Law as an indicator of societal change 236

6.6 The locomotive of legal development 239

6.7 Concluding remarks 250

7 A science of norms: a science for the 21st century

7.1 Sociology of law: a science of norms 253

7.1.1 Brief summing up 253

7.1.2 Norms as readiness for action: a parallel to genomics 254

7.1.3 Norms between law and society 256

7.1.4 Methodological implications 260

7.2 Strategic normative thinking: normative design to support self-regulation 264

7.2.1 Introduction to a legal innovation 264

7.2.2 Normative design to support self-regulation 265

7.3 Sociology of law in need of a science of norms in the digital era 269

7.3.1 Gene technology and the lag in law 269

7.3.2 The normativity of technology 271

7.3.3 Code is law and algorithms are norms 273

7.3.4 Different orders of normativity: algo norms 276

7.3.5 Methodological implications 283

7.3.6 Regulatory and legal implications 286

7.3.7 Changes in society and the need for a science of norms 291

Bibliography

Index 


\section{Acknowledgement}

Many people and many events over the years have inspired me and contributed to writing this book. It would be difficult to name all colleagues from the Nordic countries who have taken part in the scientific debates within the socio-legal journal Retfaerd over the years. That milieu has been a fertile soil for the advent of many of the ideas in this book.

I have been inspired by colleagues at the Department of Sociology of Law at Lund University during my time as professor in the subject for many years. My first interlocutors were Karsten Åström and Per Wickenberg in the late 1990s and onwards. I will also mention Ulf Stridbeck in this context. Most inspiring has been the discussions with Måns Svensson which have challenged and sharpen my thoughts about norms. Among former doctorates, now established scholars, I want to mention Matthias Baier, Stefan Larsson and Rustam Urinboyev. The main influencer over the years has been the futurologist Anders Ewerman, who is lying behind the ideas about societal development in terms of cycles, which are recurrent in relation to different themes in the book.

Mattias Orre has translated and language-checked the manuscript. Thomas Labik Amanquandor has been most helpful with rewriting all figures and tables and checking the footnotes and bibliography. I would like to thank you both for a competent work.

The series editor of the Studies in the Sociology of Law, Alberto Febbrajo, has been encouraging my work in relation to norm science over the years, especially in organizing the Fermo Summer School. This has meant a lot for me in terms of support when opening up a new scientific field.

Norms are not easy to explain, being such an abstract phenomenon, and the book claims to be theoretical. The value lies in the eyes of the reader, and I hope the book will reach readers who themselves can bring the ideas forward. 


\section{Preface}

Sociology of law (SoL) as a normative science, unlike legal science, does not have anything to do with the study of what is desirable ${ }^{1}$ or what is regarded as morally good. ${ }^{2}$ Yet the norm perspective is not unicellular. It can be subdivided into three dimensions: (1) analytical, (2) empirical and (3) normative. For purpose of this book, I am concentrating on the analytical dimension. After all, it is what is most important in terms of explaining how it compares with other fields. An important point is that people are not always conscious of how norms steer their choices and behaviour. SoL can help uncover what is latent and thus detect motivational forces both at micro and macro levels.

SoL as a norm science confronts and uncovers new and unknown regulatory problems. In an industrialized society, the function of law was to a large extent a question of making compromises between intersystem conflicts as, for instance, when the economy had external effects for the social system, such as labour law, or for the ecological system, as in relation to environmental law, climate law and law about sustainable development. In these and similar cases, law took on the shape of intervening rules where contradictory values and interests had to be balanced de facto mostly in favour of the stronger interest, economy and/or technology. In the digital era, the problems and thereby the law has changed. Here, the question is one of either/or as compared with the "both/and" as in the industrialized era. As is evident in fields such as genetics and public surveillance, questions of ethics press themselves on decision-makers. Instead of law indicating the possibility for compromise, in this situation, it makes the choice between green and red - go forward or stop.

The ambition of this book is to take a first step toward legitimizing the establishment of a new scientific field - norm science - to meet future needs for SoL regarding legal and normative problems in the 21 st century. Virtually all scientific fields are affected by developments in digital technology. New areas of research

1 Badersten, Björn. (2008). Normativ metod att studera det önskvärda. Enskede: TPB, Wedgewood, Ralph. (2007). The nature of normativity. Oxford: Clarendon Press.

2 Rachels, Stuart (2015). The elements of moral philosophy. 8th ed. Dubuque: McGraw-Hill Education. 


\section{x Preface}

have emerged in the wake of genetic engineering and the digital revolution. As a result, new diagnostic methods have been developed in medicine and technology to refine our knowledge of the physical world, etc., such as nanotechnology. Much of this is the result of a growing fragmentation and specialization of the scientific profession. Among other things, this has led to an understanding of nature based on the deconstruction of physical reality into fragmented components. ${ }^{3}$ This understanding is based on theories from scientific fields such as biology, chemistry and physics. Nuclear physics has developed into quantum physics, electronics and genetic engineering. With the help of the computer, the micro and macro cosmic boundaries have been broadened. The development of quantum computers increases these possibilities infinitely. ${ }^{4}$ This extreme level of fragmentation has led to the need for theories that instead take a holistic approach and "reassemble" the fragments.

It is against this background that SoL has a role to play as an analytical tool to understand the role that norms play in the modern, digital world and in so doing helps us see not only the changes underway but also serves as an instrument to bring together much of the fragmented knowledge.

Lund 2021-11-18 Håkan Hydén

3 Ewerman, Anders. (1996). Marknaden 1000 år - Fem eror i Europa. Stockholm: Ewerman Business Intelligence.

4 Atik, J. and Jeutner, V. (2019). 


\section{Why do we need a science of norms?}

\subsection{Different perspectives of norms}

\subsubsection{Design of the book}

The purpose of this book is to propose the study of norms as a method of explaining people's behaviour by introducing a new scientific perspective: a science of norms. This discipline can broadly be understood as a social science which includes elements both from behavioural studies and legal science. I must emphasize at this early point, to avoid any misunderstandings, that a science of norms is not a normative science - that is to say a science that prescribes right from wrong in various situations. The norm science perspective shares studies of the normative landscape, the interpretation and understanding of the world in terms of norms and normative structures. This is what distinguishes sociology of law (SoL) from other social sciences. Compared with legal science, SoL has a broader interest in norms, as well as legal rules and regulations. I should also emphasize that SoL is not a normative science, unlike legal science. SoL is an empirical and theoretical science. Neither does it have anything to do with the study of what is desirable ${ }^{1}$ or what is regarded as morally good ${ }^{2}$ or social dilemmas. ${ }^{3}$ However, the norm perspective is not a unicellular animal. It can be subdivided into three dimensions: (1) analytical, (2) empirical and (3) normative.

In this chapter, I will mainly address the analytical aspect of the science of norms. After all, this is what would uniquely and specifically characterize a science of norms in comparison with other social studies. The concept of norms can be used to detect motivational forces, both at a micro and a macro level. However, we are not always aware of these forces. The brain, which we spontaneously

1 See, for instance, Badersten, Björn (2008). Normativ metod att studera det önskvärda. Enskede: TPB, Biel, Anders, Dahlstrand, Ulf \& Fransson, Niklas (1990). The content of moral values. Gothenburg: Uni.

2 See for instance, Rachels, Stuart (2015). The elements of moral philosophy. 8th ed. Dubuque: McGraw-Hill Education.

3 See Biel, Anders, Eek, Daniel, Gärling, Tommy, \& Gustafsson, Mathias (2008). New issues and paradigms in research on social dilemmas [Elektronisk resurs]. Boston, MA: Springer.

DOI: $10.4324 / 9781003241928-1$ 


\section{Why do we need a science of norms?}

perceive as something that we think with, paradoxically allows us to not have to think about what we do. Our practices are imprinted in the brain through the various experiences stored in every individual. The same applies to norms. They help us act without having to think about it. To draw a parallel on a societal level and on the basis of norms as guidelines for action, this would suggest that we do not act as individuals; rather, we follow existing norms and the normativity that emanates from them. Norms guide us, often without us even being aware of them. Norms are embedded in the organization of companies and public authorities. They are also reflected in what we call tradition. "You do it too! That's how we've always done it!" We've all learned that we should act in a certain way. Sociologists describe this as an internalization of norms, a term that partially covers the phenomenon. We take much for granted - how we act, norms, sitting - as if it were second nature. We do not need to consciously think about them. Norms contain and transfer information across generations on how to act in different situations.

Norms tend not to emerge until changes in circumstances occur, whether it is the individual's or the entire society's circumstances. In this introductory chapter, I will therefore also present a theory of social development, without which it is difficult to understand shifts over time in the normative landscape. This also has repercussions on science which progresses from reductionism to holism, as noted in the conclusion of this introductory chapter. There is a dividing line that runs through the norm - a scientific perspective between lifeworld and system, as developed by Jurgen Habermas. Broadly speaking, this distinction correlates to the difference between social norms and systemic norms, as discussed in Chapter 2. The following chapter addresses the empirical aspects of a science of norms, as further developed in Chapter 3, which traces the source of norms to various systems of knowledge, such as economics and technology. With regard to the normative perspective, the focus lies primarily on the legal system, seen as a normative system, as discussed in Chapter 4 . The point, here, is to link the normative content of law to its social counterpart, the substratum of law. This is then followed by a description of the development of law and changes over time, in Chapter 5, and Chapter 6, which presents a theory of the development of law. The last chapter situates a science of norms between law and society. It also introduces a new innovative concept, i.e. strategic normative thinking, or SNT, which complements legal science's primary, and dogmatic, focus on the content of law. Finally, the book underlines how important a norm-scientific perspective is when studying new, normative phenomena, such as artificial intelligence (AI) and algorithms.

\subsubsection{Norms from an analytical perspective}

A science of norms would fundamentally be an empirically based discipline which focuses on what people believed to be good or bad, right or wrong, in various circumstances and how it influences their inclination to act in a certain way. It presumes that the motivational forces underlying people's actions is the decisive, 
explanatory factor when studying people's behaviour, regardless of whether they realize this or not, whether it is voluntary or enforced. Part of the scientific mission is to find out whether this is true. To the extent that norms that provide guidelines for how to act are generally well-established, it may be possible to predict people's actions. This, however, is not the same thing as prescribing an action. It is merely a factual conclusion that certain values and norms exist in a given social context in time and space.

One of the great challenges for the sciences is how to deal with values. Science is not allowed to be subjective or arbitrary. On the contrary, the essence of science is to be objective and unbiased. At the same time, science is about human behaviour and what determines it. Is it at all possible for scientific analyses to be descriptive without being subjective? The problem, here, is that the object of scientific study consists of human activities, which are a subjective matter. When science discovers regularities in human behaviour, it runs the risk of being content with analysing the contextual factors, as they are easier to identify and determine, thereby neglecting subjective aspects. This problem has to do with how science relates to emotionally loaded and subjective values. The answer to this problem leads us to the paradoxical inherent problem in science: namely, that the sciences are forced to be based in normativity; they must take normativity seriously and provide a transparent explanation of the premises on which the normativity is based in each case. ${ }^{4}$

A socio-legal norm analysis focuses on studying and analysing the norm process and how it is employed. The example of the paradoxical problem, i.e. that in science, subjective and emotionally loaded values are best treated by openly presenting the normative premises on which the actions being studied are based, can be taken one step further. The only scientific approach that is not implicitly normative is that which explicitly studies norms. A science of norms, therefore, is about understanding the motivational forces behind people's actions. ${ }^{5}$ Actions are mediated subjectively despite the fact that they are partly determined by social factors. The social sciences, therefore, are forced to use categories and concepts that address subjectivity on a general level. This is where norms come in. The concept of norms can be seen as the mediating link between what is and what ought to be, or to put it in social scientific terms, between the actor and the system. The sciences articulate and objectify the systems, and their scientific conclusions then become a part of shaping the normative prescriptions that underlie people's actions. The norm acts as an interface between possessing knowledge of the is and various kinds of values-based approaches to how we ought to act in

4 This is not a question of whether the individual scientist's values are such that they risk affecting the scientific results, a key issue, not least for the social sciences, as has been addressed by Myrdal, Gunnar (1983), where he felt that the important thing was not that the scientist openly declares his values, but rather about stating the normative premises that characterize the action or event of study. See also Myrdal, Gunnar (1958).

5 Håkan, Hydén. (2002). Normvetenskap (Norm-science). Lund: Department of Sociology at Lund University, p. 330. 
different situations. ${ }^{6}$ In this case, the concept of norms and the empirical study of norms help us to understand causalities that underlie human behaviour on a collective level. Through the study of norms, human motives for collective action can be captured. ${ }^{7}$ This approach goes beyond Max Weber's Verstehen method. Weber was a methodological individualist who argued that we can only understand social phenomena and historical processes by studying how individuals experience the world and what they find meaningful. ${ }^{8}$ Dissecting existing norms in a descriptive way allows us to capture the preferences and motives that underlie human behaviour on a collective level.

Durkheim's ambition was to establish sociology as a science and keep it separate from psychology. He went so far in his efforts to define sociology as a social science that he argued that social facts were independent of the individual. To gain support for sociology as a science, Durkheim drew parallels to the (natural) sciences, which viewed natural facts as being independent of the individual. Durkheim argued that social facts have the same ontological base, i.e. they exist in society irrespective of the individual. In fact, individuals are forced to relate to them. Social facts influence people's behaviour. They can be studied as objects and thus be measured in the same way as objects in natural science.

Durkheim claimed that sociology was based in its entirety on the objective reality of social facts. ${ }^{9}$ For sociology to be at all possible, it "must above all have an object all its own, a reality which is not in the domain of the other sciences", that object being social facts. Durkheim regarded social facts as a continuum. ${ }^{10}$ At one end, there are structural social phenomena which make up the substratum of collective life, such as demographic factors, infrastructure, different kinds of dwellings, etc. There are also what can be called institutionalized norms, which may be more or less formal. Durkheim refers here to legal and moral rules, religious dogmas, financial systems, etc., i.e. established beliefs and practices. Finally, occupying the remainder of the continuum, Durkheim counts social facts which are not institutionalized but have the same ascendancy over the individual. Here, Durkheim mentioned different kinds of social currents as an example. In his eagerness to argue for sociology as an independent science with its own field of knowledge, Durkheim closed the door to both the individual and to society as explanatory factors for human behaviour. Left remaining were social facts in all their nakedness. Social facts became an object of study in themselves. This prevented Durkheim from being able to generate theories of what governs human behaviour at the collective level. This was the cost of his struggle to establish sociology as a science.

6 Baier, Matthias, Svensson, Måns and Nafstad, Ida. (2019). Understanding sociology of law. Lund: Studentlitteratur.

7 See Section 1.3.1.

8 Weber, Max. (1978). Economy and society: an outline of interpretive sociology. Vol. 1. Berkeley, CA: University of California Press.

9 Lukes, Steven ([1973], 1985, pp. 8-10).

10 Ibid. 
Durkheim's mistake was that he ignored that the objects of knowledge in the social sciences and natural sciences are incompatible. They cannot be studied in the same way, using the same theory and methods. To illustrate this, we could compare an atom to an individual. An atom comprises the minimum unit of an element, which defines its chemical properties. The term atom comes from the Greek ôtouos, átomos, meaning "indivisible”. The name was created because ancient atomic theory viewed the atom as indivisible. I use it here even though it has long been known that is not the case. The atom can nevertheless be said to represent the object of knowledge in natural science. If we look at the social sciences, the individual can be said to be the corresponding equivalent. This terminology comes from the Latin individuum, which in turn means indivisible. If we compare these two entities, the atom and the individual, often they exhibit completely opposing characteristics. The atom has the same properties, no matter where it exists across the globe, while individuals differ, depending on context. Individuals from different countries or different ethnic groups have different cultural backgrounds and therefore behave differently. The atom can be manipulated and experimented with to verify its properties and its relationship to other atoms, etc. Carrying out experiments on and manipulating individuals is often considered unethical. When we study atoms, we have reason to expect that they will behave in the same way, all other things being equal. Individuals, on other hand, are equipped with their own will, which means that when comparing how individuals choose to react and behave, there is no guarantee that similar circumstances will produce the same results. Individuals act depending on different motivational forces, which leads to different outcomes. This does not exclude that individuals might choose to act the same way. This is the case particularly when they occur under the same structural conditions, which then give rise to similar behaviours. It can also have to do with common interests. Another example is group pressure that can exert pressure on individuals to act in the same way.

Motivation means one of two things. Either you see motivational forces as represented by the image (or something that science produces) or we see it as grounds for action. Durkheim's social-realistic approach led to him getting stuck in the first position. In his perspective, the issue of motivations that underlie actions was subordinate to the determining power of social facts, something which is capable of exercising "an external constraint over the individual". Neil MacCormick describes normative orders as the kind of orderliness that we can discern in human behaviour when people, or norm-users as MacCormick calls them, follow common norms of conduct and when individuals in some kind of authoritative position, i.e. norm-givers, regulate and institutionalize these orders via rules. ${ }^{11}$ This is a discussion MacCormick brings up in relation to the definition of law. In the context of informal, normative orders, Tim Murphy has extended

11 MacMormack, Neil. (2007). Institutions of law: an essay in legal theory. Oxford: Oxford University Press. 


\section{Why do we need a science of norms?}

the term norm-giver to include those who set norms, norm-setters. ${ }^{12}$ If the normsetter has legitimate authority and the norm-user agrees with the value expressed in the norm, then he or she will experience an intrinsic obligation to act according to the norm.

This moves us in the right direction, but SoL must go one step further and understand how social facts affect people's incentive to act in certain ways, whether due to social coercion or incentives. Using this approach, social facts have the potential to lay the foundation for an understanding of the normative anatomy of society. ${ }^{13}$ The need to access the motives behind human action are what give us reason to concern ourselves with society's normative anatomy. Based on this, human action can be seen as related to a certain normativity, and based on this concept we refer to the conditions (social facts) or the social climate in which the motives for human action are shaped. The question we must ask ourselves is what motivates us to comply with social facts. What is it that makes people feel obligated or willing to act in a certain way?

What motivates humans is not only determined by what people want or the values that influence them on a societal level. The motivational forces that give birth to norms are more complex than that. This depends on three dimensions or prerequisites: (V) Will and values, (K) knowledge and cognition, and (SP) systems and possibilities. It should be noted that of the social scientific literature on norms presented in Chapters 2 and 3, only Nils Christian Sundby, in his book Om normer, takes the time to dissect the actual concept of norms. We could, perhaps, say that Sundby adopts an internal perspective of norms, while other literature demonstrates an external perspective that is more concerned with what kinds of norms exist, why people follow them, how to get people to follow them, etc. If we wish to study norms from a combined internal and external perspective, we are forced to find our own path and to a large degree create our own frame of reference.

The German/Swedish professor in agricultural information theory, Ulrich Nitsch, argues that people's choices and lifestyles are influenced by knowledge, values and opportunities offered by the given situation. ${ }^{14}$ According to Nitsch, these factors are influenced, in turn, by a framework of institutional factors, such as law, economic instruments, the market, education, etc. Based on this, Nitsch has constructed what he calls an incentive matrix, where the three variables along the horizontal axis - knowledge, values and possibilities - are combined on the vertical level with three levels of individual, situational and institutional factors. ${ }^{15}$ Nitsch operationally translates the knowledge variable

12 Murphy, Tim. (2012). Living law, normative pluralism, and analytic jurisprudence. International Journal of Legal and Political Thought, Vol. 3, No. 1, p. 208.

13 Hydén, Håkan. (2018). The normative anatomy of society. In Febbrajo, Alberto (ed.), Law, Legal Culture and Society: Mirrored Identities of the Legal Order. Vol. 2, Series: Studies in the Sociology of Law. Abingdon: Routledge/Taylor and Francis Group.

14 See Nitsch, Ulrich (1996, pp. 132-136) and the "incitement matrix" he presents there.

15 Nitsch, Ulrich (1995, p. 27 ff). 
into the dichotomy "knows" " does not know". Values determine the preferences "willing" /unwilling". Possibilities, finally, equate to the dichotomy of "can" / "can't". Using this construction, different factors appear as either encouraging or constraining at the different levels. With regard to, for example, a farmer's disposition to adopt new agricultural methods, the example used by Nitsch, factors such as age and health play a role on the individual level; economy, the size of the farm, the climate and how fertile the land is are situational factors; and access to credit, political policies, regulations and market conditions are institutional factors.

In the context of studies of political governance, the Swedish political scientist, Lennart Lundquist (1938-2014), thinks along similar lines. ${ }^{16} \mathrm{He}$ argues that the effect of political governance depends, among other things, on three properties in the governed individual; namely, that he or she understands, is capable and is willing to carry out the intended action. "Understanding", here, means whether the actor understands the content of the rule and what it requires him or her to do. Whether the actor can follow it is a matter of their ability to comply with the rule, i.e. whether he or she has the capacity in the form of influence, knowledge and ability to perform the action. ${ }^{17}$ In other words, the individual actor's capacity. "The will", finally, addresses whether the individual actor is willing to perform the action. There may be a number of reasons for why the actor might not find it acceptable and therefore not be willing to carry out the act. It also has to do with the level of commitment, which has an effect on the quality of work.

With regard to how norms are constructed, these arguments share common ground with the arguments on which this book is based. What distinguishes Nitsch is his system theoretical approach to society, that is to say that systems create a kind of playing field from which the systems and games produce both game rules and game norms relevant to the point of the game. It is this category of normative circumstances, which can almost be classified as stand-alone imperatives, that determine the possibilities, both positive and negative, on a macro level that are applicable in the individual case. What Nitsch and I both agree on is that we both believe that the "Will and Values" and the "Knowledge and Cognition" variables are related to what motivates the individual. Lennart Lundquist also seems to share this point of view. He discusses will and capability in similar terms. Lundquist, however, discusses the term "understanding" as a separate category, probably related to the fact that his terminology lies within the field of relationship governance. Personally, I view the variable "understanding" as being part of the "can" dimension. Setting the context of governance aside for the time being and instead focusing on a more general theory of action, there is reason to view low levels of understanding as the result of inadequate knowledge, or that the act or task facing the actor feels culturally alien to them. Lundquist does not suggest any equivalent to the restrictions linked to a lack of possible actions caused by 
various systemic conditions. The "can" and "will" dimensions, from Lundquist's perspective, are the same as in the circles of motives presented below. However, it does bring up actual, possible actions as a third dimension.

The step from acting to learning, and learning processes, is a short one. Learning, much like acting, depends on the will to learn, on knowledge and possibilities. It is no surprise, then, that this field adopts approaches that resemble norm theory. Thus, in his book Laering - aktuel laeringsteori i spaendingsfeltet mellem Piaget, Freud og Marx ${ }^{18}$ Knud Illeris discusses the fact that all teaching includes three different dimensions - teaching, so to speak, occurs within three counter-poles, and it can be observed and analysed similarly from three different perspectives. ${ }^{19}$ Firstly, Illeris argues that all forms of learning involve a skills-based or meaningful content. The acquisition of this content occurs mainly through a cognitive process. Secondly, learning is also a psychodynamic process; that is to say, a process that involves psychic energy mediated through emotions, attitudes and motivations that can both act as driving forces and are themselves influenced by learning. Thirdly, learning is also a social and ultimately a societal process. Illeris emphasizes

... that the three dimensions are integrated in all forms of learning and that in practice they do not exist as separate functions. From an analytical perspective, however, it may be useful to distinguish between them in order to get a clearer and more differentiated picture of learning, provided that one is aware that the three dimensions are united, in practice. ${ }^{20}$

The creation of norms, much like the learning process, is ultimately about processes that mediate between man as a biologically and genetically developed being and the social structures developed by humans through various systems intended to satisfy man's needs. ${ }^{21}$ The first step in the process of the creation of a motivational force is usually that it is linked to something we desire. It is customary in sociology to see norms as belonging exclusively to the social sphere, a subject further developed in Chapter 3. This has to do with the forces that underlie norms, i.e. motives that are linked to a specific, desirable value. But norms are also based in action systems, whether it is the economic, political/administrative system or one of our natural systems, such as the biotic or the physical systems. With regard to the sociocultural system, norms play the same role that the market does in the economic system and that nature does with regard to the technological system's norms. ${ }^{22}$ Morals develop within relationships. They might originate in

18 See Illeris, Knud (1999).

19 Ibid, Swedish translation, p. 17.

20 Ibid, p. 19.

21 Ibid, p. 228.

22 Moral (from the Latin adjective moralis) is, according to Wikipedia, a qualitative property of an act, a manner, character or proper behaviour in accordance with ethical norms. It can also mean understanding the difference between right and wrong. 
the individual, in what might be referred to as their conscience, but they develop and are articulated through communication and collaboration with other people.

Sven Eric Liedman emphasizes, with reference to Johan Asplund, that social responsiveness is prioritized above the individual or the ego. ${ }^{23}$ Said social responsiveness has over the last centuries, as communication opportunities have increased, evolved into what Asplund calls an abstract sociality. Hundreds of thousands of people sit at home around the country and the world reading or watching the same news and comment independently of one another. Although these people do not know each other, let alone talk to each other, they are part of the same opinions. Radio, television and newspapers are steps along the same path. Digital technology has also increased the possibilities of direct interaction and communication between people. In modern society, people, in addition to living their actual lives, which include families and work, live in an abstract role as members of a general, faceless and in a sense also boundless society. This latter relationship gives rise to human relations characterized by anonymity and abstract sociality. This new, abstract society, according to Asplund, has given rise to a new, modern social science. Liedman adds: “The social sciences have made society an area of knowledge unto itself in a way it has never been used before. In this area, the personal must be united with the impersonal, the individual with the collective". ${ }^{24}$ In parallel with the ongoing, functional, specialization of society, the social sciences have also gradually become specialized. As a result, sociology has increasingly come to narrow in on socio-cultural specialized topics, although in modern, large-scale industrial society, these have become less and less important due to the dependence of social relationships on professional and systemic factors.

Two types of norms belong to the natural systems: norms related to human exploitation of nature and norms related to conserving the natural system, i.e. ecological norms, a theme that is further discussed in Chapter 3. In this context, knowledge becomes an important component of the norm. Without knowledge, the norm cannot be implemented. This is thus the second requirement for the process that create motivational forces, a requirement that also applies to the other systems, including social action systems. If we cannot decipher the mysteries of social interaction, neither can we understand the norms that apply in the socio-cultural system. But this becomes even clearer in connection with norms that go beyond interpersonal interaction and are directed at nature or the economic system. The need for knowledge and an understanding of how the system works becomes more evident.

The third prerequisite associated with the creation of motivations is whether it is possible to realize the desired values that one possesses knowledge of and wants to implement. This has to do with the systemic conditions set up by the social and natural systems. The fact that knowledge of the systems can vary is one 
thing; that is an individual matter. But systemic conditions have to do with general limitations imposed by the social and natural systems. The most obvious of these limitations are the laws of nature, such as the law of gravity, photosynthesis, thermodynamics, etc. To the extent that they affect our daily lives, we internalize them and, therefore, they are usually not counted as a conscious part of the considerations that underlie a norm-governed action. For example, if your office is on the third floor and you're in a hurry to get home, you would not even consider taking a shortcut through the window. We have internalized the law of gravity and its sometimes painful consequences since childhood. Furthermore, we have also discovered and internalized the fragility of mankind's biotic system, which means that we have great difficulties in surviving a jump from the third floor of an office building. Other laws of nature may feel so "distant" to the individual in both space and time that they are not perceived as a restriction when a norm is created. One example is our (norm-governed) relationship to the problems of the greenhouse effect and the climate. Other natural laws are included as a component of the norm's conditions, for example, norms that have to do with exploiting nature, such as technical requirements drawn from decisions based on materials theory, stress calculations, etc. This can be summarized in Figure 1.1.

There are different underlying conditions for each of these categories: (W) Will, (K) Knowledge and (SP) System Possibilities. Will is related to the values that the individual encompasses and the underlying driving forces, i.e. the motives behind human action. These forces can in turn be traced back to various motivational systems, from man's conscience to morals and ethics, and other external influences such as religion, politics and other ideologies. Economic considerations linked to selfish motives, as well as acting on the basis of solidarity with other people, are other examples of possible motivational drivers. What is relevant in
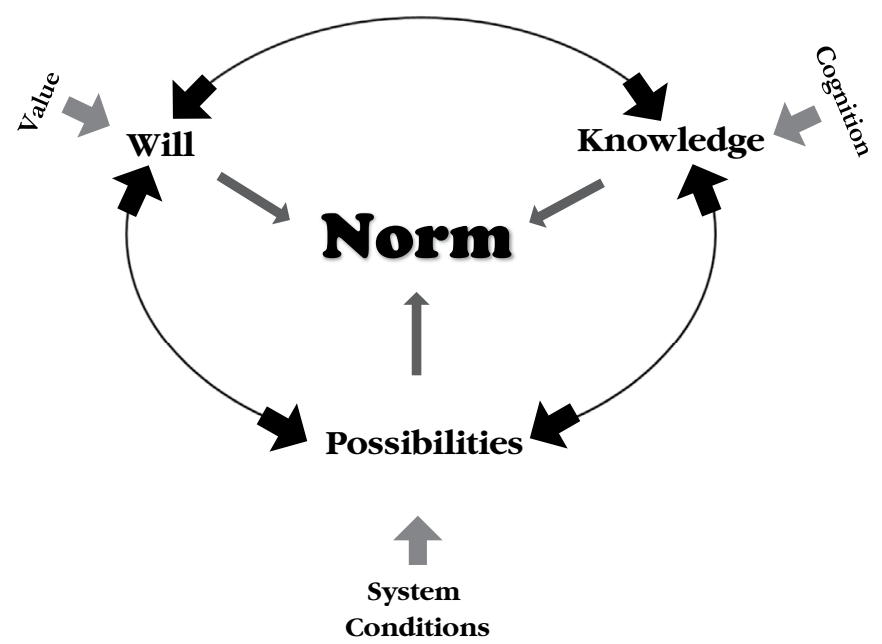

Figure 1.1 The circle of motives 
the particular case is an empirical question. This circle of motives is content, so to speak, with pointing out what kind of analysis is relevant for understanding human behaviour from a norm perspective.

However, this is not enough. When it comes to the second component, knowledge, cognition is key. ${ }^{25}$ Knowledge depends on how we see and perceive the world. Here, differences between gender, ethnicity, education and power apply, but also what social position or vantage point you have when expressing yourself. Women's studies have shown that knowledge is characterized by gender. ${ }^{26}$ In the area of international migration and ethnic relations, so-called IMER research, we have learned just how dependent on ethnic and cultural belonging our views on knowledge are. ${ }^{27}$ The fact that education is important for knowledge is fairly selfevident, but in recent times our view of knowledge has undergone some changes. Knowledge implies a good deal more than mere so-called book learning. It involves both communicative and social skills as a form of "tacit knowledge". ${ }^{28}$ In this context, there is also reason to emphasize an old truth that knowledge is not evenly distributed among the population, but is related to economic and social status, which in turn lays the foundation for power inequalities. All of this has an impact on the creation of norms in society.

But in answer to the question of what knowledge is, it is perhaps even more important to emphasize that there is a fundamental difference between a lifeworld perspective and a systems perspective. As will be elaborated on in Chapter 2 , norms have to do with both the values and understanding of knowledge of primary socialization and the professional skills of secondary socialization. Cognition can be related both to the cultural and the professional level. The influences for knowledge development can come from both $\mathrm{W}$ (the will component of the norm) and SP (systems and possibilities). The norm may thus be described using the combination of initials: $\mathrm{N}=\mathrm{W}, \mathrm{K}, \mathrm{SP}$ or $\mathrm{N}=\mathrm{SP}, \mathrm{W}, \mathrm{K}$, or the norm can be based on the will as well as in systems and possibilities. In the former case, primary socialization's cultural perceptions have an impact on cognition, while in the latter case it is the system-bound, professionally developed knowledge that determines cognition and the knowledge component. This means that the arrow in Figure 1.1 in the first case points from $\mathrm{W}$ to $\mathrm{K}$ and in the second case from SP to K. Various sciences have been developed to support system-based forms of knowledge, which have gradually become more specialized. In Chapter 7, I will discuss how algorithms, seen as norms, within the area of artificial intelligence are based on new knowledge - digital technology - that creates new systemic conditions that in turn govern our preferences, whether we like it or not.

25 Svenaeus, Fredrik. (2019). Det naturliga: en kritik av queerteorin, transhumanismen och det digitala livet. Möklinta: Gidlunds förlag.

26 For more on this, see Widerberg, Karin (1995).

27 See e.g. Olsson, Erik (ed.) (2000).

28 Cf. Rolf, Bertil (1995), Collins, H. M. (2010). 


\section{Why do we need a science of norms?}

The development of culturally based cognition and wisdom requires that people communicate, whether through conversation or through standardized cultural expressions, film, poetry, literature, mass media. Thus, when Jurgen Habermas argues for communicative action, this clashes with instrumentally determined prescriptions for action that follow from the system's logic and inherent values. Habermas' definition of the ideal form of communication is characterized by as little influence as possible from the inevitable distortion that follows from discussions based in systemic starting points. As discussed in Chapter 2, Habermas uses terms that express that systems colonize the lifeworld, that communication is systematically distorted, etc. All of this underlines the tension surrounding the two types of knowledge that accompany the different ways of understanding cognition.

There are two possible approaches to the knowledge component of the circle of motives. In Figure 1.1, they approach the knowledge component "from both directions". The disruptive factors that can occur in each case consist of norm conflicts on the system side and lack of legitimacy with regard to the lifeworld's cultural impact. The third prerequisite for norms with regard to the various systems has to do with systemic conditions, which in turn are determined by structural factors, such as the laws of nature when it comes to the natural systems and the market when it comes to the economic system. Thus, the earlier model can be complemented with the following components (Figure 1.2).

The components of the circle of motives discussed here relate to the question of which of the norm's counter-poles are involved and have a determinant effect on our actions. Furthermore, within the norm creation process itself, there is mutual pressure on the norm's requirements. The will and the value affect what becomes regarded as relevant knowledge, what we wish to happen. At the same time, as commented on above, knowledge is related to, and dependent on, systems and systemic conditions. The circle is closed by systemic conditions, which, in turn, have implications for generally accepted social values and motivational forces. For example, the normative implications of sustainable development. ${ }^{29}$ This is linked to and ultimately determined by the natural systems and, as such, has consequences for the values that are to be conveyed and the knowledge required. One could say that the SP systems and the possibilities they afford serve to exert selective pressure on the norm's W and K properties. Some norms are allowed to grow, while others are not. In order for a norm to be established, the will component must be in agreement with the conditions of the system in question. With reference to Talcott Parsons, John Heritage expresses it thus: "Through this process, Parsons proposed, social actors come to want to do what the institutionalized normative patterns require them to do". ${ }^{30}$ Another way of expressing this is to speak of the systems in terms of being a provider of premises for individuals' actions.

29 For a more in-depth discussion on this, see Hydén, Håkan (2004).

30 Heritage, John (1984, p. 75). 

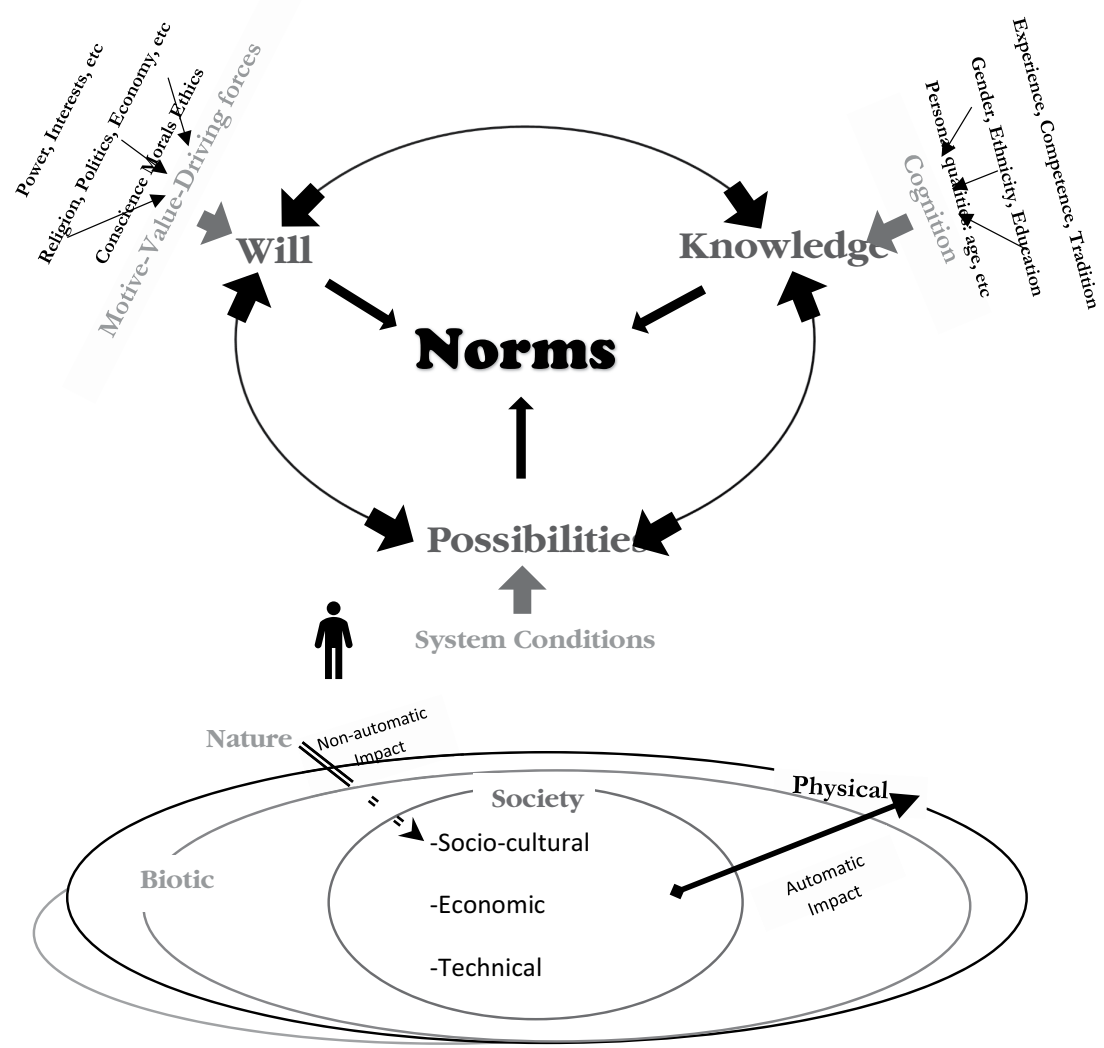

Figure 1.2 Extended circle of motives

\subsubsection{Norms from an empirical perspective}

The term, and concept of, norms can be perceived differently, and the property that you read into the concept tends to determine how you define it. Thus, a norm can be understood as an expression of normal or acceptable behaviour. In this perspective, a norm becomes a yardstick, something used for measuring normality. The norm can also be understood as a prescription for action, in which case the norm has a prescriptive content. It expresses how actors should act.

The Swedish sociologist Goran Therborn emphasizes that norms are involved in defining an object and how it is manifest. ${ }^{31}$ In this context, we could say that the norm has a prescriptive nature. In legal contexts, this is referred to as a legal definition. One basic difference in the study of norms is to be found between the 


\section{Why do we need a science of norms?}

normative and the descriptive approach. ${ }^{32}$ The first is characterized by an ambition to analyse and establish what ought to happen, how to act in certain situations, where the scientific endeavour is to find the correct answer for addressing a given problem or how one is expected to act in a given situation. This approach is most commonly found in dogmatic disciplines such as theology and legal science. Both of these approaches take their normative starting point based on the authority of the supreme power, in both religious and political systems. ${ }^{33}$ More or less concrete dogmas can be derived from these disciplines. In contemporary legal science, legal positivism is not only an accepted but also a dominant branch of law. Positivist law takes its starting point in political positions of various kinds. Theology and legal science are expressions of constructed, consciously normative systems. This also characterizes moral philosophy. Normative positions follow from conclusions made within the framework of moral systems' consistent, logical construction. In these cases, in common with theology and legal science, normativity is based in the faith system, legal system or moral system that one subscribes to. But it is important to emphasize that normativity is always created within a relationship of mutual dependence between the system and the actor. The norm resides ontologically at the intersection between system and actor.

Normative scientific approaches also exist within the framework of some empirical sciences. For example, analysis of social dilemmas in psychology, sociology or economics. These are often based on game theory and on the underlying assumption that some solutions are more rational than others. This approach, with its basis in the study of norms, is further discussed in Chapter 4 . Analyses of social dilemmas therefore result in normative considerations of how one ought to act in a given situation or what the correct solution is. The same applies, albeit not as clearly expressed, to economic analyses. These are based on the notion that there is an underlying rationality that informs us of what is right and wrong..$^{34}$ In certain situations, an investment is the right thing to do and, in other situations, it is not. When faced with choices between different possible economic actions, cost/income analyses within business economics, and the overarching cost/benefit analyses made by political economists aim to give us the correct answers. ${ }^{35}$ The Public Choice and Rational Choice schools of thought within political economy and political science are also relevant in this context. In all cases, there is an implied rationality based in the notion that the actor's self-interest sets the normative foundation. ${ }^{36}$ Such models are based on assumptions constructed to allow

32 Banakar 2015

33 This does not prevent religion in some countries from dominating the political system, as is the case in fundamentalist Muslim countries such as Iran and Saudi Arabia.

34 Bohm, Peter. (1996). Sambällsekonomisk effektivitet, 5., [något rev.] uppl. Stockholm: SNS Studieförb. Näringsliv och samhälle.

35 Bohm, Peter. (1997). The economics of environmental protection: theory and demand revelation. Cheltenham: Elgar.

36 Empirical analysis is carried out through statistical modelling, which in turn is based on highly formalized theory, where intricate mathematical models become increasingly important. 
us to predict and describe individuals' behaviour and actions, both socially and economically, as well as possible.

What is of interest in these and similar cases is that an empirical, scientific approach is employed which aims to identify and analyse the facts that implicitly lead to normative conclusions. How is this possible? How is it possible to proceed from pure description to normative prescriptions for action? In short, how is it possible to proceed from is to ought? This applies particularly when considering the thoughts of David Hume, Scottish philosopher (1711-1776), who claimed that the "ought" can never be derived from the "is". As a science of norms, SoL is supposed to explain normative structures based on their material (empirical) context, which scientific philosophy has traditionally considered impossible. Hans Kelsen (1881-1973) and Émile Durkheim (1858-1917) represent opposite traditions, and their perspectives can be used to illustrate the problem. $^{37}$

This is a similar situation to game theory. ${ }^{38}$ An underlying rationality is taken for granted in the studied system that determines what is right or wrong. Empirically oriented science, in these cases, is concerned with finding out how the system behaves in concrete, individual cases. Economic studies deal with analysing how the economic system behaves and works in different cases, all with the aim of giving us reliable, normative advice on how to act in different situations. It is this element of science that gives it its legitimacy as a non-normative, neutral and objective science.

Rationality, thus, is system-bound. The clearer the design of the system, the more normativity will follow from analyses of the system's relationship to a certain empirical reality. Perhaps this normativity becomes more evident in systems associated with the laws of nature. Phenomena such as the law of gravity, thermodynamics, photosynthesis, etc., give rise to systems of knowledge about how nature is constituted in various respects. By understanding how these phenomena work, it is also possible to give instructions on how to achieve various goals. These norms are both invisible and unknown until they are articulated by science. Thus, the systems give rise to a kind of conditional normativity. If we want to accomplish something, we are forced to comply with the laws of nature, which prescribe how to act to attain a given goal or secure a given value. Generally, this is not a consideration within the social sciences. Lately, with the introduction of the concept of sustainable development, natural science (ecology) has begun to

The models are based on assumptions that are made in order to be able to predict and describe as well as possible individuals' behaviour and actions, both socially and economically, in different situations. Empirical analysis is carried out through statistical modelling, which in turn is based on highly formalized theory, where intricate mathematical models become increasingly important.

37 Hydén, Håkan and Svensson, Måns. (2008). The concept of norms in sociology of law. Contributions in Sociology of Law: Remarks from a Swedish Horizon, Vol. 53, p. 129.

38 Keiding, Hans. (2015). Game theory: a comprehensive introduction. Singapore: World Scientific Publishing Company. 
integrate with the social sciences (economy and sociology) in matters that share the common denominator of norms.

Norms generate guidelines for how to act to achieve or reach a certain goal or value. If, for example, one wants to successfully build a bridge, one should pay attention to insights from the natural sciences concerning weight-bearing capacities and the like. These insights provide prescriptions for how to construct bridges without them toppling over, etc. Such technical prescriptions from the natural sciences display the same characteristics that philosophers of law call authentic/true legal propositions and clauses: that is to say, they are based on conditional propositions and clauses: if a given condition is present, a given effect will occur. In both cases, there is a movement from the abstract to the concrete. The difference lies in that the conditions for the true legal proposition or clause is decided by the rule's open normative property, while the basic conditions in technical and similar knowledge systems are derived from the knowledge system's causally (oriented) consequences.

The type of normativity that I discuss here manifests itself practically within the framework of professional knowledge systems. The natural sciences lay the foundation for technical applications, where engineers in different fields follow prescriptions for action, which derive from a delimited norm system tied to a knowledge system about a naturally defined phenomenon. The normative is defined based in the cognitive. It might not be possible to predict the behaviour, since norms stemming from one system might in practice have negative external effects and collide with other norms and values in society, which give rise to intervention from the state, often using what I refer to as intervening legal rules, something I elaborate on in Chapter 5. Knowledge in these cases works and has the same function in interpreting technical norms as the preparatory work behind a law has for lawyers when the lawyer seeks to understand the content of a law. ${ }^{39}$

Less structured systems give rise to less absolutely binding normativity. The political system, which in itself seeks to determine normative issues on a collective level, does not create normative expectations in the same way as a scientifically determined physical system. The conditions are simply too many for normativity to occur. However, in politics, since groups tend to gather around ideologies and commonly shared interests, this also makes it possible to specify normativity in relation to assumed political affiliations. It should be noted here that this assumption is based on the notion that said ideologies and interest groups are adequate reflections of what a particular society looks like at a given time; there is always a requirement that the system being analysed and the system's assumed rationality is empirically grounded. If this is not the case, specifying rational positions and prescriptions as belonging to a particular political affiliation becomes difficult. The political ideologies and interest groups that determine the relevant political arena today do not fully represent contemporary society and, more importantly, not where it is headed, as will be commented on later. The lack of congruence 
between assumptions about systems and how systems actually work in practice creates a discrepancy between our expectations of current developments and the direction they are taking, and thus political confusion, a theme further developed in the next section.

The social system appears to be the least structured and thus the least normative. ${ }^{40}$ However, it does not prevent a social system from being, and acting as, a norm. There are social contexts in which behavioural expectations may appear to be clear to those involved. This also relates to both peer pressure and social control. In all social systems, a system of reward and punishment encourages the members to follow the rules, whether mediated via their family, friends, work mates or the entire society. The consequence of breaking a norm depends on how important the violation is, e.g. murder is punished harder than a parking offence because the norm not to kill is more compelling than a parking offence.

Social control may become evident when a group rewards a member with appreciation and praise for behaving in line with the group's goals (Black 1976). The reward may be to gain popularity and social appreciation. Control can also be exerted by criticizing a member who loses prestige if he violates the norm. Blame, criticism or rejection are some examples of punishments to which a deviant member may be subjected. Norms exist in all groups, as further developed in Chapter 4. Being a member of a group means that you are subject to norms. There are always game rules that members must follow. These norms may vary and be more or less coercive. There are norms for desirable behaviours, norms for how we ought to dress and how to communicate within the group. There are also norms that determine which thoughts and opinions are considered acceptable. Social control can be strong in some societies and cultures. Family, friends and social spheres strongly depend on each other and therefore also keep an eye out for each other. Informal social control is weaker in societies marked by individualism and anonymity.

Tradition and custom can be powerful forces in uncertain situations. However, power, used to create expectations of how we ought to behave through various kinds of sanctions, may not be quite as innocent. Thus, power itself can be a decisive factor in the creation of norms. ${ }^{41}$ The driving force or the determining factor in these cases is that actors follow these norms to avoid being subjected to some form of punishment or criticism. One dominant form of punishment is based on the use of force. The ability to use violence when maintaining a system of norms can be a decisive factor. ${ }^{42}$ State monopolization on violence is not only, as legal philosopher Karl Olivecrona puts it, a prerequisite for the rule of law but

40 That is probably the reason for Jurgen Habermas' and other social scientists' interest for what Habermas calls the lifeworld and discourse on an equal basis.

41 Haugaard, Mark and Clegg, Stewart (red.). (2012). Power and politics. Los Angeles, CA: SAGE Publications Ltd.

42 In his book Social transformations: a general theory of historical development, 1999, p. 57, Stephen K. Sanderson emphasizes the monopolization of violence as a general factor that characterizes all societies. 
also a guarantee for the creation of democratic norms. ${ }^{43}$ This is why individuals or groups that could resort to various kinds of violence to pursue their own normative views are perceived as a threat to both democracy and to state power. When terrorists place themselves outside the law, it is a symptom of weakening state power, that a new era may be in the making. The terrorist attacks on September 11 in the United States are also a sign that state power sovereignty is being challenged. The Cold War between states has been replaced by civil war within states or independent of states.

Using the norm-scientific approach thus presented, we have seen that socialpsychological theories are necessary to explain how individuals learn and create norms through interaction. Internalization and socialization processes are important concepts in this context. There is some disagreement about what a norm actually is. A norm may be related to stable expectations (Aubert 1976), routinized behaviours (Stjernquist 1973), sanctions and social control. ${ }^{44}$ But norms can also be linked to core normative areas, where a common core of moral values forms the starting point for the creation of norms. This can be seen in religious legal systems. We have also demonstrated that, for example, game theory can help us explain the emergence of norms, i.e. how different interactive situations require norms to coordinate actions. According to Coleman, the need for a norm arises when a reciprocal relationship or other phenomenon has consequences for others than those directly involved. Based in the assumption that norms are real, according to Therborn, the situation in which the actors find themselves has an impact on whether they comply with the norms, mainly due to the following factors: how visible the actor's action will be, how dependent the actor is on the social sphere that maintains the norm and how strongly the actor identifies with the norm source.

\subsubsection{Normative systems}

Normative systems are created in a certain authoritative order, a certain political order or they may be expressions of a religious belief. They are characterized by the fact that they rely on written legal sources. In terms of terminology, there is a distinction between legal rules, whose power to issue sanctions is based in the political system, even if they ultimately rely on some form of superior religious source. ${ }^{45}$ A prominent example of this is Sharia law, which is an idea based in divine right. ${ }^{46}$ The legal interpretation Figh provides concrete laws and norms. These are based on the rules contained in the 350 verses of the Qur'an (Muhammad's revelation),

43 Olivecrona, Karl (1966).

44 Axelrod, Robert (1984). The evolution of cooperation. New York: Basic Books, Coleman, James. (1990). Foundations of a social theory. Cambridge, MA: Harvard University Press..

45 Neusner, Jacob and Sonn, Tamara. (1999). Comparing religions through law: Judaism and Islam. London: Psychology Press.

46 Sajoo, Amyn. (2020). After identity politics? Faith in liberal citizenship. Canadian Political Science Review, Vol. 14, No. 1, p. 77. 
as well as examples from Sunni (The Life of Muhammad) found in the Hadiths. Islamic law is practiced in Islam-dominant countries. ${ }^{47}$ Sharia is a supreme source of law - a basic norm - which ultimately determines disputed interpretations of written law in these countries. ${ }^{48}$ It can also take precedence over written law in certain situations.

Sweden was also characterized by religious law for a period. I refer here to Mosaic law, which was introduced in 1607-1608 by Charles IX of Sweden alongside national law. In Sweden, up until the 20th century, the courts would exact justice in accordance with "the Law of God and Sweden", which meant that Mosaic law was also regarded as law in a worldly sense.

At this point, to avoid any misunderstanding, I should clarify the terminology I propose to use. Some norms rely on written law. To the extent that these norms are created within a political order, I refer to them as legal rules. ${ }^{49}$ But written law can also be created within interpersonal relationships. Thus, in these situations I prefer to simply use the term "rules". This concerns primarily norms created within contracts between two or more parties. It may also be related to an association's written statutes or a limited company's articles of association. There are, I argue, strong arguments to regard norms as an overarching concept and legal rules and other rules as subcategories to norms. Social norms are another subcategory of overarching norms. The same applies to economic and technical norms.

If we relate the circle of motives to legal rules, we can, based on the discussion on the different types of legal rules in Chapter 5, make the following succinct conclusion: the normative content of goal-oriented rules is weaker than for duty rules. ${ }^{50}$ Goal-oriented rules are policy-oriented and require knowledge from fields other than law. ${ }^{51}$ With regard to duty rules, all three dimensions of the circle of motives are fulfilled. The rule takes a clear position to the Will, that is, what is to happen, the conditions are such that the required knowledge exists and, finally, it assumes that the actions are possible to carry out once the systemic requirements have been fulfilled. Goal-oriented rules are vague in terms of will; they require various kinds of knowledge and are dependent on system conditions. In conjunction with intersystem conflicts and balancing rules, (SP) exerts pressure and makes contradictory demands of $(\mathrm{W})$, resulting in different kinds of knowledge requirements $(\mathrm{K})$. This theme is further developed in Chapter 6.

47 Otto, Jan Michiel (red.). (2010). Sharia incorporated [Elektronisk resurs] a comparative overview of the legal systems of twelve Muslim countries in past and present. Leiden: Leiden University Press.

48 Banakar, Reza. (2016). Driving culture in Iran: law and society on the roads of the Islamic republic. London: I.B. Tauris.

49 Hydén, Håkan and Hydén, Therese. (2001). Rättsregler. 5: e uppl. Lund: Studentlitteratur.

50 Aleksander Peczenik distinguishes between action norms and goal-oriented norms and uses the term regulatory norms as a common term for these; see Peczenik, Aleksander (1987, p. 15). Cf. also Graver, Hans Petter (1988).

51 For an example of goal-oriented rules, see Hayek, Friedrich A. von (1993, p. 138 ff). 


\subsection{The relation between societal development and changing norms}

\subsubsection{How is a society created?}

Observable common patterns, especially from an economic point of view, have given rise to theories using the biological organism as a metaphor that social development occurs cyclically, i.e. that societies go through different stages that are common to all systems. ${ }^{52}$ There is a large corpus of literature based on this understanding of history. Society, like any other system, begins, expands, stabilizes and decays before finally withering away to be replaced by another societal model. ${ }^{53}$ This cyclical way of looking at societal development occurs in many disciplines. Some of the most influential works on this are attributed to Wallerstein ${ }^{54}$ and his theory about world systems. Ewerman has described and analysed social development in terms of S-curves. ${ }^{55}$ See Figure 1.3 for a development of the last three centuries:

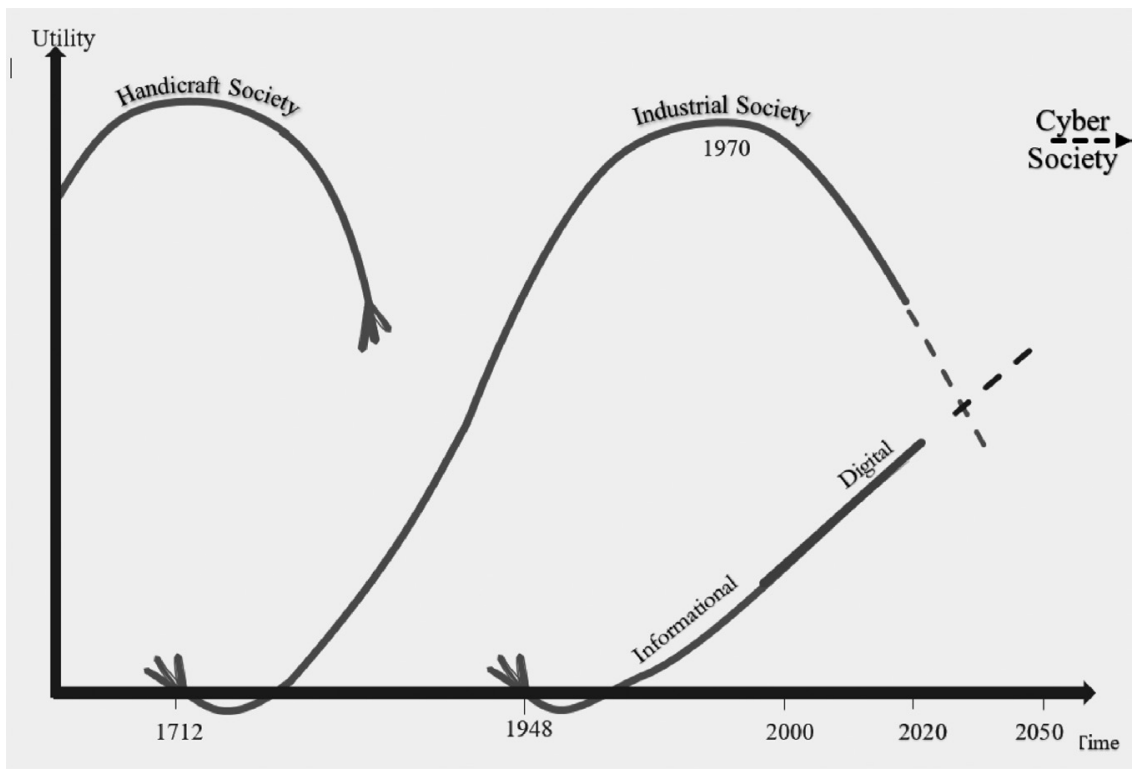

Figure 1.3 Societal development as S-curves

52 Ewerman, Anders. (1996). Marknaden 1000 ar - Fem eror i Europa [ The market 1000 yearfive eras in Europe]. Stockholm: Ewerman Business Intelligence.

53 Barnett, V. (2016). Kondratiev and the dynamics of economic development: long cycles and industrial growth in historical context. New York: Springer.

54 Wallerstein, Immanuel Maurice. (2004). World-systems analysis: an introduction. Durham: Duke University Press.

55 Ewerman, Ander (1996). 
This idea is based on Joseph Schumpeter's business cycles and his study of economic fluctuations. ${ }^{56}$ Schumpeter discussed creative destruction, which can be regarded as a kind of forerunner to the concept of disruptive innovation. ${ }^{57} \mathrm{~A}$ strong proponent of this argument within economic theory is Kondratiev (1892-1938). He discusses cycles between boom and depression of around 60 years. ${ }^{58}$ Kondratiev calls these business cycles waves ${ }^{59}$ According to Wilenius and Kurki, ${ }^{60}$ a new, sixth wave is on its way between 2010 and 2050, which the authors refer to as a new wave of 40 years of global change. ${ }^{61}$ Another scholar inspired by Kondratiev is Carlota Perez. ${ }^{62}$ She counts five major technical-economic cycles. Those scholars have studied economic development in terms of waves, while Wallerstein and Ewerman capture a broader spectrum of influential factors, which cover all of society.

This is also the case with history, where the so-called Annales school used similar ideas of recurrent events. Among other things, they use the concept of "the history of mentalities". By mentality, they meant ideas which were not necessarily conscious ones. They are shared within a collective, and they change slowly. Perhaps the most prominent member of the Annales school, divided historical time into different rhythms (la longue durée). ${ }^{63}$ This expression refers to the analysis of trends as a study of continuities and discontinuities, where society was regarded as a totality of economic, social and mental patterns. In the longue durée of economic history, beyond, or underlying, the cycles and structural crises lie "old attitudes of thought and action, resistant frameworks dying hard, at times against all logic". The industrial model itself can be seen as an example of the latter. ${ }^{64}$ Perhaps the state, in its role as defender of collective interests, is another example. Both are subject to pressure to change due to the disruptive nature of digital technology. These ideas are in themselves fertile ground for critical reflections on what will shape the future. But the key aspect of theories on cyclical social development is that they can provide us clues from similar periods in the development of previous societies. ${ }^{65}$

56 Schumpeter, Joseph A. (1939). See also Schumpeter (1934 and reprint 1983).

57 Ibid.

58 Kondratiev, Nikolai D. (1935). The long waves in economic life. Review of Economic Statistics, No. 17, pp. 105-115, Kondratieff, N. (1984). The long wave cycle. New York: Richardson \& Snyder.

59 Perez, Carlota. (2009). Technological revolutions and techno-economic paradigms. Working Papers in Technology Governance and Economic Dynamics No. 20.

60 Wilenius, Markku and Kurki, Sofi. (2012). Surfing the sixth wave. Exploring the next 40 years of global change. Finland Futures Research Centre. e-book. Vol. 10.

61 Clark, Stuart. (1999). The Annales school: Fernand Braudel. Abingdon: Taylor \& Francis.

62 Long-term techno-economic cycles, September 4, 2004, Reviewer: Leonard J. Wilson (VA, United States).

63 Braudel, Fernand (1982). Civilization and capitalism: 15th-18th century. Vol. 2, The wheels of commerce. London: Collins.

64 Toynbee (1957).

65 My own understanding of societal development in terms of waves is inspired by the expert on future studies, Anders Ewerman; see Ewerman, Anders (1996) and Ewerman, Anders och Hydén, Håkan (1997). 
The Russian-American social scientist Pitirim A. Sorokin has developed a theory in which he claims that Western culture has changed over the past 2,500 years from being an ideational culture, to an idealistic to a sensual culture, and then returning to become ideational again. Ideational values are values that have to do with the divine and spiritual. Sensory values are linked to the world that can be perceived with the senses, that is, the world that is physical by nature. Idealistic values unite the ideational and the sensory worlds by highlighting the elevated and aesthetic sides of the material world. ${ }^{66}$ Sorokin argues that our current sensory-based culture began in the 13th century, reached its peak in the 17 th and 18 th centuries and has now ended, which foreshadows a new ideational era.

Similarly, Lindholm divides history into approximately millennial civilizations. ${ }^{67}$ Using this approach, the longest fluctuations can be counted in millennia and are linked to different civilizations. With regard to the West and the cultures that have directly and indirectly affected our country, reference can be made to Greek culture, (Western) Roman culture, Christianity and the market society. ${ }^{68}$ These cultures or eras lived side by side for a time and fought over ideological dominance. The epochs progress in different directions and have different natures. Lindholm distinguishes between, on the one hand, religious, non-materialistic cultures and, on the other hand, sensory cultures with a focus on the tangible world. This division is closely related to Sorokin's theory. The various cultures oscillate over time between faith-based cultures and sensory cultures. We can thus conclude that cultures with a logical or spiritual orientation (dogmatic religion) are replaced by cultures that have a material or physical orientation (dogmatic politics) and are in turn followed by a culture that has a logical and spiritual orientation, etc. A culture emerges as a reaction to an earlier one. ${ }^{69}$

Greek culture, for example, was based in logic. It was a time when philosophers laid the foundation for understanding the great questions facing human life and society. This era was slowly out-competed by Roman culture, which was physically and materially oriented. At the time of the birth of Jesus, much of Europe was dominated by the Roman Empire. Roman culture was materially oriented and was highly advanced for its time. In turn, it was replaced by the Christian epoch, which was a faith-based culture. Christianity was elevated to the status of state religion in 380 A.D., after which the church embarked on a period of geographic and power expansion, eventually reaching Scandinavia. Christianity was established during the Great Migration Era between 375 and 568 A.D. and matured and gained dominance during the first centuries of the first millennia, lagging slightly behind the farther north in Europe one travelled. The most significant event in this development was the papal revolution initiated by Gregory VII in 1075, when he declared the pope's sovereignty over the Church

66 Østerberg, Dag (1991, p. 81).

67 Lindholm, Stig (1985).

68 The market society emerged within the framework of a feudal society, i.e. before capitalism.

69 Cf. also Alexander, Jeffrey. C. (1989) and och Eder, K. (1990). 
and its independence and supremacy over world power. ${ }^{70}$ This revolution continued until 1122, when a final agreement was reached between the papal and the imperial powers. By then, Europe was completely dominated by Catholic doctrine, and the Bible had replaced the coin as a symbol of value. Ewerman (a.a.) describes this transformation as follows:

The Roman state's unilateral investment in international trade and scalability created an imbalance between 'the small and local' and 'the big and global', whereby the local, that is, the sales market, was annihilated, and thus the demand for 'the global', that is, production and trade, disappeared. Rural life for the ancient Roman city-dwellers included more important, psychological elements than merely material ones - an aspect that strongly contributed to the establishment and spread of Christian faith-based culture. It was not until the 12th century, that is, 900 years later, that trade and crafts resumed and the cities began to grow so large that they once again extended to the ancient Roman walls.

At the same time, a new material-based epoch had begun to emerge, this time in response to Christianity's faith-based culture. This was the market epoch. This era was initiated by the merchant era, which occurred at the same time as Christianity rose to dominance in the early first millennium. The starting point was the coin-based trade between monasteries and liberated peasants, which took place in the year $1000 . .^{71}$ This was the birth of the market society ${ }^{72}$ and a new relationship between the town and countryside (ibid Chapter 3 ). It can be regarded as a breakthrough for the market society, which gave rise to coins and safe trade between the monasteries.

There is an overlap between the S-curves that express each epoch. According to Ewerman, it is to be expected that societies pass through different stages of a cyclic nature, each of different periodicities. The two first phases of the cycle can be described as basically holistic, while the last two are reductionist.

The market epoch, much like other cultures, has also progressed through various eras. ${ }^{73}$ In addition to the merchant era, Ewerman lists the trading era, the

70 This is a recurring theme in Berman, Harold J. (1983), see inter alia p. $99 \mathrm{ff}$.

71 Bois, Guy. (2002). The transformation of the year one thousand the village of Lournand from antiquity to feudalism. Enskede: TPB.

72 In 1075 Robert of Molesme from Cluny founded the monastery Molesme in Bourgogne. In 1098 he, together with 21 monks, set up the monastery Citaux (Latin: Cistercium) as a parent monastery for Cisteriensorden, the huge business monastic order. In 1115 Bernard of Clairvaux was appointed together with a group of monks to establish a monastery in Clairvaux. The concept was built on centralization and hierarchical power. This proved to be a successful concept. Soon a lot of subsidiary monasteries emerged. In Sweden the Vreta monastery from 1100 to 1162 was converted into a convent within the Cisterciensorden. The monasteries of Alvastra and Nydala were the first monasteries in Sweden within the Cisterciensorden, in 1143.

73 Cf. Schön, Lennart (2001, p. 526). 
agricultural or mechanical era and the industrial era. The industrial area emerged in the 18th century and dominated the last centuries of the last millennium. Through technology, we are advancing toward a new millennial epoch which we shall designate, for the time being, the cyber epoch. Based in our experiences from previous eras, it is time for the pendulum to once again swing back toward a logical or spiritually oriented faith-based culture - a cyber epoch. This is based on the strategy of atomization that has dominated the specialized, industrial technology of the market epoch. The cyber epoch can be said to have begun simultaneously with the market epoch's final era, the industrial era, and is currently transitioning from an information phase to a second era, the digital era, which marks the end of the market epoch.

By the turn of the millennium, a kind of dualism arose between the ceding and the subsequent epoch. A 1,000-year epoch can be divided into four waves, each one lasting approximately 250 years. Each wave represents an era. This dualist relationship, i.e. when an era peaks, a new era is born as a sort of counter-response to the old, is the same within the framework of an epoch. Ulrich Beck states that we are living in a time when we want to "have our cake and eat it", which has come to replace the rational "either-or" belief system of industrial modernism. ${ }^{74}$ The unique feature of this period of development is such that it might be given a special designation, that of a society transitioning between two different eras. In these periods, social development is both political and intricately tied to the epoch being phased out, as well as technological and related to the incoming era's initial stages. This leads to a competitive "have your cake and eat it" period. ${ }^{75}$ At the same time, this transition from one to another means that we are facing a mega-social shift. The market epoch is suffering through the last stages of industrial society and is about to be replaced by a new cultural epoch, the cyber epoch. It is still too early to comment on what this will entail and what it will be characterized by.

This theory is of crucial importance for understanding the times we live in, and thus for the need for a science of norms. It is the theoretical starting point for the present work that allows us to see established knowledge within the social sciences in a new light. Ewerman describes and analyses social progress in the form of S-curves. ${ }^{76}$ The $S$-curve passes through an inflection point, which marks the transition from increasing to diminishing returns. For Ewerman, an S-curve mainly describes an era in the history of a society's development. But an S-curve can also indicate longer periods of time, as discussed here, i.e. epochs as well as shorter, cyclical phases. An era during the market epoch was initiated by the emergence of a certain core technology in accordance with Figure 1.4.

74 Beck, Ulrich (1995, p. 57).

75 On an international level, both Brexit and Donald Trump's slogan "America first" are signs of this tendency.

76 Ewerman, Anders (1996). 


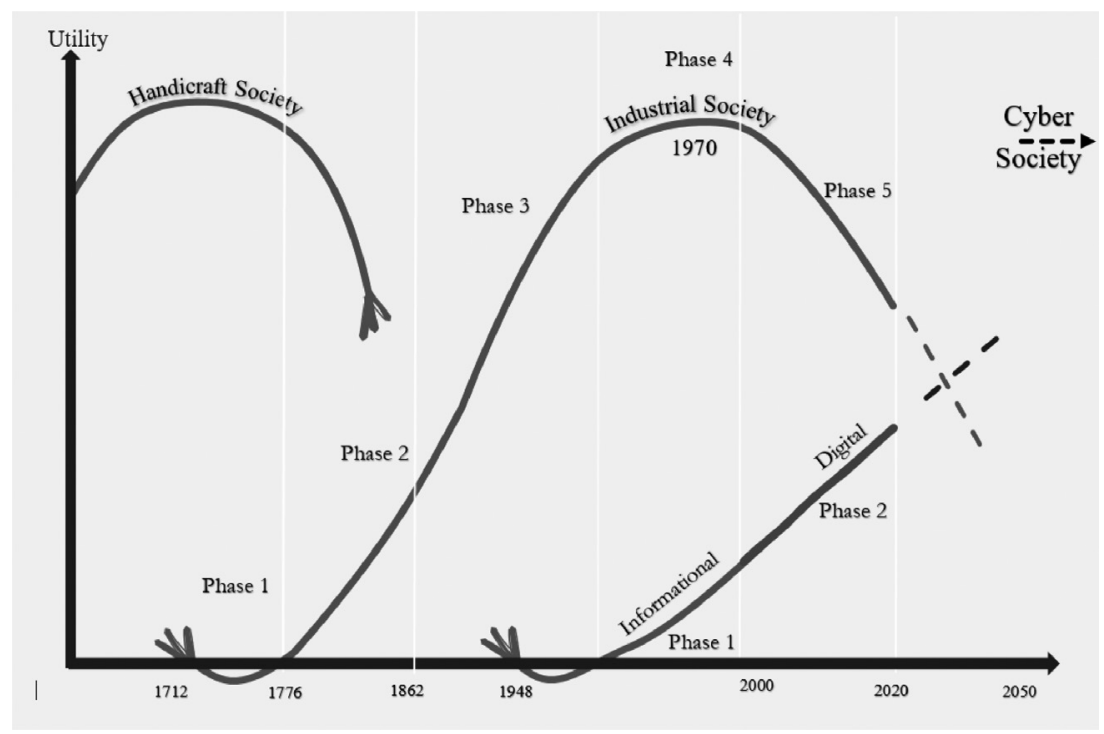

Figure 1.4 The S-curve

During the market epoch, what calls for a new era is the need for technological renewal, which is linked to the material and commercial orientation of the market economy era. Ultimately, the driving force behind this is commercial trade, which requires new goods. A new phase is begun with the establishment of a new core technology, thereby increasing productivity. Therefore, in the market economy epoch, each era is based in its technological approach to the world.

To summarize so far, we can conclude that the technological shift we currently are witnessing might be regarded as the first step in the transformation of society. This has an impact on the circle of motives and the combination of the categories - W, K, SP - that dominate in each phase. With reference to the division of phases above, it could be argued that systemic possibilities belonging to the last phase in the previous societal S-curve to a large extent are overlapping and dominating Phase 1 in the new societal phase and thereby over the will, influencing in its turn what counts as knowledge in society. ${ }^{77}$ It is an expression of what Jürgen Habermas refers to as the system's dominance and colonization of the lifeworld. This does not exclude the fact that narrow sectors of society already make room for the will during this phase. Normative development is voluntarily free among inventors and innovators, as is the development of knowledge. This feature grows stronger during Phase 2, where different kinds of entrepreneurs

77 This is an effect of a time lag caused by the fact that references, power, institutions, etc., still are influenced by the old society. 
"spread free will" and contribute to breaking old boundaries. ${ }^{78}$ Phase 3 is about developing the necessary knowledge and spreading it among enough people to realize the core technology that voluntary forces have helped to develop to enable it to be reproduced on a large scale. At the actor level, we thus move from amateur to imitator. The emphasis, here, lies in the knowledge aspect of the circle of motives. Knowledge needs to be mass-produced and spread (not least by academics). At this stage, education and research become increasingly important. These features are further amplified in Phase 4 as we reach a situation of mass education on various stratifications, not least as a result of universities and colleges. In Phase 4, we gradually return to systemic dominance and the importance of structural relationships with regard to how we judge good and bad, which in turn determines what we regard as useful knowledge and further consolidates the dominance of the existing systems within a cyclic progression.

The only thing that can break the circle is the declining legitimacy of the systems as a result of their failure to benefit the people, which leads to the pursuit of renewal. For example, in our time, new systems in the form of ecological thinking and ideas for sustainable development are emerging, which can be seen as a reaction to the problems caused by the external effects of large-scale industrial society. From this perspective, it should be pointed out that in Phase 4, tensions occur within the circle of motives, which can lead to asymmetry between the norm's various dimensions, with fatal, practical consequences and loss of legitimacy as a result. ${ }^{79}$ In this situation, $\mathrm{W}, \mathrm{K}$ and $\mathrm{SP}$ are all weakened. When the system becomes overripe, legitimacy is lost. The system no longer provides the same social benefits, which in turn weaken W. Knowledge produced by the old system becomes obsolete in the new society. The paradigm shift problem becomes relevant here. In turn, the systems are weakened as a result of a lack of rationality. Existing economic and technological systems become out-competed by new methods for producing goods and services.

Thus, the circle of motives becomes an important instrument for the study of norms when analysing these kinds of tensions and contradictions in society. The circle of motives becomes even more important when one wishes to identify the normative changes that precede each change in society. It is from this perspective that a science of norms should be seen as a unique science for the 21 st century. Based on the cyclical theories presented by Anders Ewerman, with support of the Annales school of thought and economic history research as presented in several sections of the present book, we are likely to face a mega-social change due to the current transition from one era to another - from industrial society to digital society - and partly due to a shift from a 1,000-year-old civilization to another, from one market society to a new society, for which we do not yet have a name.

78 This also applies to setting our own limits or risk being burnt out or face irregular working hours.

79 This can be compared to the case of Hallandsas, where the normative asymmetry had dire consequences, both environmentally and economically. See Baier, Matthias (2003). 
The first indications of this social change will be normative changes resulting from changes in social codes and values.

These are partly related to the actor's level of knowledge and thus their ability to act and partly to the possibilities to follow one's own will, of which one already has knowledge. In the latter case, this has to do with determining the objective conditions and possibilities to carry out a particular act. It has to do with the systemic conditions and requirements of both natural - unconditional - systems and societal - man-made, conditional - systems. Both natural and social laws set out limits for the individual, while laying the foundation for the actions that are possible within that context.

In establishing a science of norms, I am attempting to do something very unusual: I use knowledge from the legal sciences to develop the social sciences rather than the other way around. What we need is a synthesizing science, i.e. a science that is able to assemble rather than disassemble.

A science of norms means a new way of looking at things that is pertinent to most scientific fields. Norms are not only linked to actions in social life. To the extent that we divide society into economics, politics, administration, technology, etc., we can also add to the list economic norms, political and administrative norms, technical norms, etc. The advantage of the concept of norms is that it shares interfaces - interconnectedness - with virtually all of the subsystems and the associated sciences which have developed as a result of the functional specialization that has given us the material prosperity of the welfare and industrial society in recent years. The concept of norms provides a common denominator that allows us to translate and understand human and organizational actions that are based in different and sometimes competing backgrounds. The concept of norms can also be used as a kind of screening device, a tool that makes us responsive to forces that drive new patterns of action and new practices in society. This becomes particularly important during a transitional period, such as the times in which we are now living in, which are characterized by new methods for satisfying human demand, while the practices and patterns of thought that have been predominant in industrial society are simultaneously displaced by the advent of the information society. In this sense, a science of norms is a science for the 21 st century.

Social development is driven by technology, but this does not mean that technology determines social and cultural development. This takes place within an interaction that is more sophisticated than that. That is to say, there is reason to regard society as an evolutionary process which should rather be seen as part of an ecological system than an organism, as has been standard practice in the social sciences. ${ }^{80}$ The analogue is, then, that human reproduction corresponds to the

80 See e.g. Durkheim, Émile (1982), Luhmann, Niklas (1989) and Teubner, Günther (1987a). Teubner is inspired by Humberto R. Maturana et al.'s theories of self-organization or autopoiesis. See e.g. Zeleny, Milan (1981). When studying the connections between different parts of the "body politic" it may be useful to see society as an organism, but it is not 
germline of the organic system, which stands for continuity, while society has its counterpart in somatic hereditary lines. The latter is characterized by mortality; that is, it has a limited life span and during its life cycle it progresses from an undifferentiated to a differentiated stage. Torbjörn Fagerström states the following in his informative book, Den skapande evolutionen:

Seen over many generations, therefore, we can say that the continuity of an organism's life is produced by a continual pendulum movement - an ontogenetic pendulum - between an undifferentiated and a differentiated stage. While the details of the differentiated stages vary and the characteristic time scale of the pendulum movement varies from one species to another, the principle of the pendulum movement is universal.

This applies similarly to the development of society. Seen over several generations of societies, we see how societal continuity is achieved through a continuous pendulum movement between a relatively undifferentiated stage to an increasingly differentiated stage that eventually outlives itself and leads to the death of the social system, while a new social system takes seed in the fertile soil of the old. To create new complexity, a constantly recurring ontogenetic process is necessary, which sends the phenotype back to the drawing board. ${ }^{81}$ "This constant recurrence of ontogeny allows the emergence of an organism that is distinct from its ancestors", Fagerström writes. ${ }^{82}$ The same applies to society. According to the above arguments, each new $S$-curve represents a new beginning that is based in a new core technology. But the new society taking shape begins at a more or less undifferentiated stage where humanity, supported by the new technology, seeks new ways to satisfy needs and demands. The forward to basics principle becomes relevant, here, i.e. a return to old principles, but with new tools that signify the forward movement.

Thus, a free, macro-sociological interpretation of this ecological parallel entails that man is the genotype and society the phenotype. Just as in ecological systems, some phenotypic traits are wholly a function of the individual's genotype, while others are more or less independent of it. Thus, there is a relationship between phenotype and genotype whose properties may vary in strength. But technological development does not determine social and cultural development. Each new phenotype, or society, has to deal with the same problem, but the difference is that it occurs in tandem with new core technologies that change the conditions of material human needs. In ecology, this relation is called the ontogenetic function of the genes principle, a function with the consequence that an individual's

appropriate here, where we aim to highlight processes of change in which one social system is replaced by another and the mechanisms that then apply and what holds them together.

81 Fagerström, Torbjörn (1995, pp. 30).

82 Ibid. 
phenotypic characteristics are partly determined by their genotype. ${ }^{83}$ In parallel to society, the ontogenetic principle in all societies is forced to confront the socalled eternal questions of good and evil, right and wrong, democracy or dictatorship, etc.

\subsubsection{The birth, change and decline of a societal system}

New core technologies give birth to new social systems which, during the market economy epoch, formed the basis for the phenotype. A core technology is a technology that depends on itself to evolve and is sufficiently broad and deep to capture people's imagination and creativity for a sufficient period of time. Ewerman states: ${ }^{84}$

Hand tools were needed to produce more, new and improved tools. Mechanical precision instruments were needed to make new mechanical precision instruments, such as clocks. Machines were needed to produce new machines. Steam engines were needed to produce more, new and improved steam engines. Computers are necessary to develop new computers. In recent decades, the life cycle of computers and components has been about 18 months on average (Moore's Law, Author's comment). ${ }^{85}$ We may think that technology is developing rapidly, but we will not be able to exploit this processing power fully for many years to come.

The last three steps of the developmental process of the market society show that the transition from mechanical to industrial society was characterized by man learning to master and utilize energy for his own purposes, hence, the starting point in Figure 1.4 located in the year 1712, symbolic of the year in which the first steam engine was invented. It continued with the mechanical loom in 1738 and Watts steam engine, patented in two stages in 1769 and 1781. This freed production from geographical, natural constraints that linked production to specific locations. The steam engine came to be the most important factor behind industrialized urbanity in the 19th century. ${ }^{86}$ It became the common engine for almost all mechanical work. In this way, new methods for using iron could be developed in the iron industry, which in turn enabled the production of sheet metal and precision components that made it possible to further develop the steam engine. The first steam hammer was introduced in 1781 and the first steam rolling mill in 1786 . The most unique characteristic of this period was the

83 Ibid.

84 Ewerman, Anders (1996, p. 26). See also Forbes, Robert J. (1958, p. 150).

85 After Gordon Moore, the former president of Intel - the legendary company in Silicon Valley, which today is the world's largest and one of the most profitable processor manufacturers - coined this expression.

86 See Heckscher, Eli F. (1953, p. 81 ff). 
creation of a special mechanical industry that fulfilled the developmental potential of the mechanical era. ${ }^{87}$

This process became more efficient with the introduction of the combustion engine, chemical processes, oil and electricity. The general use of electricity from the 1870s transformed methods of transportation, telegraphy, lighting and, not least, factory work, by distributing power generated by the electric motor. ${ }^{88}$ This made the construction of infrastructure necessary for industrial production possible. The electric motor both encouraged and made it possible to organize labour on a large scale. ${ }^{89}$ Each of these events marks a leap in social development that means that the $S$-curve is actually more varied than is indicated in Figure 1.4. While the steam engine can be seen as a "spatially" oriented technology that gave rise to railways and steamers, electricity can be said to have made steam power portable, thereby laying the foundation for a new technology: digital technology. The final stage in the development of energy is nuclear power, which both provided power and engendered anxiety. It symbolizes, together with problems like a lack of sustainable development and climate change, the dilemma of the industrial age, namely, that man has learned to master technology for his own purposes but cannot foresee and therefore ignores its consequences. ${ }^{90}$ This applies similarly to the emergence of digital society. Here, too, social development occurs in the wake of technological leaps. With regard to the development of the digital society, we might reference the transition from the transistor to the microchip, the mainframe to the household computer, which received a boost through the introduction of the internet and in turn gave rise to social media, which has led to revolutionary changes. What began as an information society has, through technological development, transformed into a digital society that is about to completely overthrow the old industrial society's norms and institutions.

This leads us to the question of what brings about the destruction of a social system and replaces it with a new one. The general answer to this question is related to the tendency of all systems to grow too big and eventually collapse under their own weight. The eras that emerged specifically during the market economy epoch were contingent upon their material benefits. This means that at a certain point in time, the marginal benefit of the old system's technology will tip over to the new technology, which simply appears to be more efficient and useful. This is partly related to the over-maturity of the old system, i.e. a process of counter-productivity that occurs when the system outlives itself, cf. the downward development curve in Figure 1.4, and partly to the new technology's

87 In the same way as when the digital technique today has its primary role in developing the industrial production and administrative processes.

88 See Castells, Manuel (1999, p. 50 f).

89 For an overview, see Forbes, Robert J. (1958).

90 Cf. Beck, Ulrich (1986) and Bauman, Zygmunt (1995, p. 247), where, in commenting on Beck's work, he states that from the definition of risk it follows that what makes hazards a risk is that they are problems for technology, not just problems that result from technology. See also Douglas, Mary (1992). 
improved ability to satisfy human needs and the successive social acceptance of the new technology. In his book, Manuel Castells describes what he calls the emergence of the network society and that even if we take into account unique conditions in some countries, it is clear that we are witnessing a stagnation in productivity, which began approximately at the same time as the informationtechnological revolution emerged in the early 1970s.91 "It is not goal-oriented rationality (as in the theory of simple modernization) but their side effects that have become the motor of social history", Ulrich Beck writes. ${ }^{92}$ According to Beck, the recipe for change lies in reflexivity that encompasses an awareness of these external effects. During the course of reflexive modernization, Beck's hope is that the evidential self-truths of the industrial era will self-decay and leave room for individual action, thereby changing the norms. ${ }^{93}$ I shall return to this subject with a more detailed analysis of the interaction between different factors of the change process.

In this context, the results of Figure 1.4 should be emphasized, i.e. social adaptation to new technology takes approximately the same length of time as it takes to develop the technology before we are ripe for full-scale economic exploitation of the new technology. We are dealing, here, with roughly 60-year-long periods. The social changes are significant and dramatic. In connection with the establishment of industrial society, we can point out that the emergence of industrial cities, as well as the migration from the countryside to the cities as agriculture became increasingly mechanized, made the agricultural workforce almost superfluous at the same time as industry demanded factory workers. This process of adjustment placed great demands on social adaptation. It also led to the emergence of a working class, which was formed through large-scale factory production and held together by common working and living conditions. We might say that factory work led to a general proletarianization. This gave rise to the so-called labour issue, and this social question dominated politics for the second half of the 19th-century.

Although we may try and test different systemic and structural explanations, we should not lose sight of the fact that historical changes require human action. They do not occur by themselves. One way of emphasizing this is to refer to my previous comments on the importance of social phases for technology and social development. I will briefly comment on the importance of this factor here. It also has an influence on the subject of this book, the development of norms. A prominent component of our awareness of the forces at work in social development is the class struggle; the struggle between classes, between those who have and those who have not, which, in industrial society, exists mainly between exploited workers and capitalists who enjoy the fruits of their labour. Karl Marx et al.'s theories on class struggle as the engine of history have also surfaced in

91 See Castells, Manuel (1999, p. 81).

92 Beck, Ulrich (1986, p. 80).

93 Ibid, p. 85. 
political groups and in numerous physical conflicts during the course of industrial society. While Marx believed that the conflict between the working classes and the capitalist class and their allies, the bourgeoisie, would intensify over time and lead to the overthrow of old industrial society, in hindsight we can conclude that this has not been the case. Rather, workers and capitalists have grown closer and closer over time, united in their protection of the institutions and structures of industrial society and guided by economic growth. Meanwhile, new conflicts have emerged in the form of tensions between economic growth and ecology on a macro level, between minorities and majority populations on a meso level and between the genders on a micro level. Manuel Castells argues that in the network society, capital is coordinated globally while labour is individualized. According to Castells, the struggle between capitalists and the working class is reorganized according to the more fundamental contradiction that exists between the pure logic of capital flow and the cultural values of human experience. ${ }^{94}$

One might ask why. These new contradictions are related to the problems related to our progression from an industrial society to and information/digital society. As in all such transitions, there is a development from large-scale to small-scale. This has to do with the logic inherent in the development process, that large-scale societies grow overripe and partly counterproductive, not least due to the unforeseen, external effects of this blind obsession with technology and in combination with a lack of political alternatives. ${ }^{95}$ As mentioned previously, in this situation, a need to progress "forward to basics" arises. The task of applying new technology to new ways of satisfying human needs begins anew. Satisfying demand becomes the main guiding line, rather than economic growth. This comes with the new technology anyway, but it is not what controls developments in productivity. Instead, consumption and demand, together with the new technology, gain control. In this way, environmental and consumer movements in new and old forms will also be able to challenge industrial society's production methods and products, which are detrimental to our health and ecology. But this does not explain why the main contradiction, the class conflict between labour and capital, dissolved and failed to become a force of historical change.

I concur with Manuel Castell in that history does not follow a pre-determined direction. ${ }^{96}$ Rather, I believe, once again, that it is appropriate to draw a parallel with ecology. The aforementioned professor of theoretical ecology, Torbjörn Fagerström's, favourite example when demonstrating that evolution lacks foresight is the butterfly orchid and its relationship with its pollinators. ${ }^{97}$ This popular orchid that perfumes the early summer nights with its vanilla scent has an extremely deep spore. The flower gathers nectar in its base for the few nightly

94 See Castells, Manuel (1999, p. 477).

95 Cf. Beck, Ulrich (1995, p. 231), where he criticizes technology for becoming a closed system in which the more problems that technology creates, the more technology is needed. See also Beck's account of Hans Jonas' critique of technology in this context, Ibid, p. $26 \mathrm{f}$.

96 Castells, Manuel (2000) Vol. III p. $380 \mathrm{ff}$.

97 Fagerström, Torbjörn (1995, p. 63 ff). 
moths that have a long enough proboscis to reach down to the desired fluid. For the flower, the fact that the moth is forced to penetrate far enough into the flower cup to receive two sticky pollen containers - pollinia - which it then transports to the next flower, thereby promoting the pollination process, is a matter of life or death. The problem, from the moth's point of view, is to get as close to the nectar as possible without having to transport the burdensome pollen containers. Therefore, from their perspective, having as long a proboscis as possible is a benefit. From the orchid's point of view, it makes sense to develop a deep a spore as possible to force the moth to stick its proboscis deep down and allow the pollen containers to stick to it. How does nature solve this problem?

Well, this is where the blind logic of evolution comes in. Fagerström explains:

Suppose that orchids possess a genetically conditioned variation for spore lengths. Varieties that have a slightly deeper spore than the average will certainly be pollinated to a greater extent than varieties that have a slightly shallower spore, since the former forces the moth to reach deeper into the spore. Thus, genes that provide a longer spore will spread to the next generation to a greater extent than genes that provide shorter spores.

Fagerström concludes by noting that the only possible evolutionary change in spore length is that which results in a gradual increase in average spore length in each generation. Thus, one might suppose that the orchid would emerge victorious. A victory for the working class. But that would mean that we have not taken into account developments among the exploitative moths. What is their response? Fagerström explains that since variants of orchids with deep spores are an abomination from the moth's point of view, this leads to a genetically conditioned variation that favours a longer proboscis that enables extraction with as little work in return as possible.

The point Fagerström wishes to make with this example is that the flower and the moth are caught in a mutual process of evolution in which one species exerts the natural pressure of selection on the other. In ecology, this is known as co-evolution, a process that Fagerström argues is similar to the arms race. This co-evolution cannot continue indefinitely, since neither the insect's proboscis nor the flower's spores can continue to grow indefinitely. Therefore, at some point, the relationship between the species breaks down, the loser being the nectarproducing orchid. The exploitative moth has many other nectar-producing varieties of flowers to choose from. The orchid's pollination process, on the other hand, is completely dependent on the few moths with a long enough proboscis. Should the moths ever tire of this relationship, as Fagerström puts it, the orchid will no longer be able to reproduce, and the species will become extinct.

There is a parallel to be drawn between workers and capitalists and the orchid and the moth when it comes to co-evolution. They are caught in a partially antagonistic relationship, while simultaneously being dependent on each another. This leads to a process of mutual development that ends with both reaching a maximum level of development, their historically conditioned relationship broken and 
replaced with new relationships. Production relationships in industrial society, and thus the entire class structure of industrial society, consist of workers and capitalists. This contradiction was evident at an early stage, and at the time, Karl Marx et al. viewed it as antagonistic and unreasonable. However, with the passing of time, both classes grew increasingly dependent on each other, and at the peak of the industrial era in the early 1970s, the working class was earning wages at a rate that the capitalists were not able to maintain to the same extent as previously. This meant that capitalism was no longer being pollinated to the same extent as previously. In recent times, we have witnessed a general, relative decline in wages in manufacturing work.

The question is how many degrees of freedom the working and capitalist classes have in comparison with the flower and the moth. Torbjörn Fagerström uses the example as one of his favourite arguments for how evolution lacks foresight and follows a development curve to the bitter end. Could relationships between workers and capitalists have developed any differently? The orchids would not be able to prevent their catastrophe, but would the working class be able to? In fact, there is an example of a full-scale experiment whereby the working class tried to do away with the conflict with the capitalists and the bourgeoisie, and that is the Communist takeover of Russia in 1918 through the formation of the former Soviet Union. However, this attempt to bridge the conflict between labour and capital was no longer viable as information technology began to be applied worldwide. It was in this context that the arms race and the Cold War ended, and 1991 can be counted as the real breakthrough for the information society. Capital, much like the moth, was forced to find new pastures. The politically sluggish Soviet system failed to make the adjustments required by the new economy, which led to a strong decline in the Soviet model and left oversized factory facilities like petrified dinosaurs to remind us of this former system. ${ }^{98}$

Thus, it seems that the relationship between labour and capital is intimately connected with the industrial society and its structures. One-sided dominance does not help matters. Unilateral dominance in a co-evolutionary relationship only leads to the demise of the system itself, a result of one side overexploiting the other, whether it be the labour force or the capitalists, orchids or moths. One difference is that while the evolutionary process is blind and lacks foresight, societal processes can be influenced within the limits set by each system. However, as economic globalization increases, there is a decline in degrees of freedom. One example is the capacity to adapt seen in Western and, not least, Scandinavian industrial societies. Through the establishment of the welfare state, the capitalists in these countries managed to shift a large part of the burden of the "pollen containers" to the state, which has been made responsible for providing better conditions for the working class. In our society model, this is so cleverly arranged that the working class itself is invited to administrate the system required to carry

98 Cf. Castells, Manuel (2000a), Volume III, where he discusses "The Crisis of Industrial Statism and the Collapse of the Soviet". 
these pollen containers, or pension insurance funds, unemployment insurance, insurance funds, etc. Whether this hastens or delays industrial society's maturation and decay process is difficult to evaluate. From the perspective of the working class, the process is delayed by the fact that it safeguards the welfare system. However, from the capitalists' and industry's point of view, it speeds up the process of decay, since state intervention drives and increases the cost of labour. This, in turn, leads to innovations that endeavour to replace man with machines, i.e. robotization. As digital technology continues its march and eliminates manual work, we are entering a state of jobless production and an increase in productivity combined with a reduction in the number of industrial employees. The ongoing restructuring of the workforce as a result of technological developments in combination with social change is shown in Figure 1.5.

The political system also formally succeeds in dissolving class identity. This prevents natural, cultural selection that would otherwise arise. But this, too, comes at an evolutionary cost. A social-democratic party that becomes a governing party cannot help but surrender some of the old political ideals that were related to a stage of conflict that no longer exists.

The historical perspective presented in this work states that you cannot learn anything from history simply by drawing a linear extrapolation in the belief that society will develop in the same direction to which we have become accustomed. This is possible during certain historical periods, when the S-curve and the new social system have been established and need to be reproduced on a large scale. But today, in the midst of a transition from one era to another, we can only learn by studying similar, historical turning points. In comparing to past development curves, we find that we are witnessing a mega-social shift today - partly between the market epoch and the cyber epoch and partly between the industrial and the information eras.

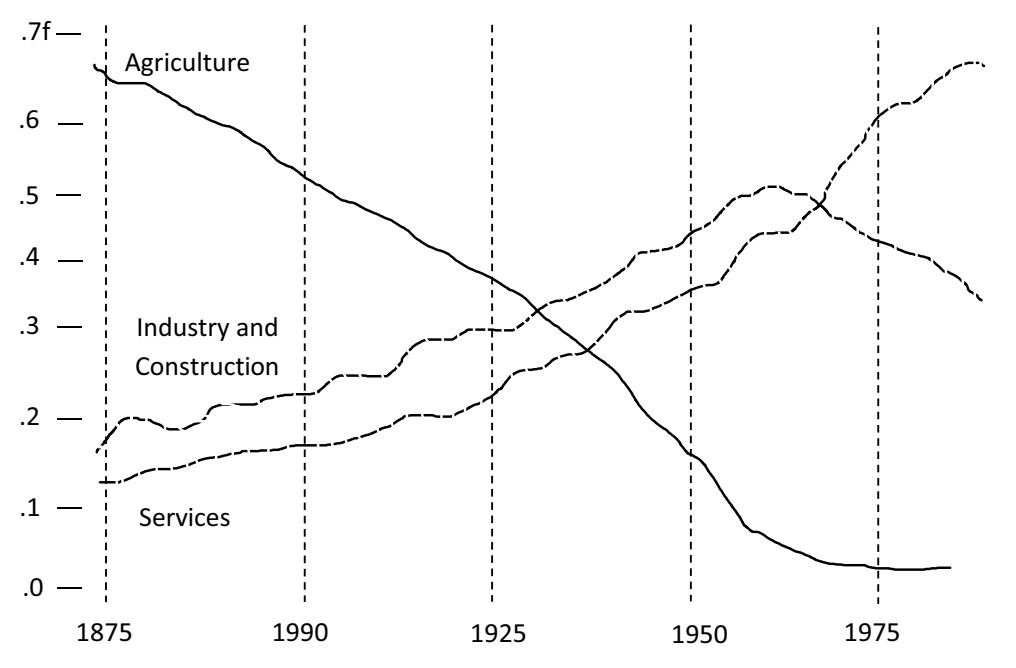

Figure 1.5 Technological developments in combination with social change 
With regard to the slightly shorter period of time constituted by the transition between the two eras, the commencement of the information era can be dated to the year 1948, i.e. the same year that the transistor saw the light of day in Bell Laboratories in the USA, when the semiconductor technology lay the foundation for modern electronics. The transistor should be seen as a precursor to the microchip. This means that roughly 75 years later, fairly well into the new millennium, there is reason to assume that there will be a transition to a social phase as the information society develops and turns into a digital society where the technology and development are disruptive. We can already see indications of this in the platform society ${ }^{99}$ and the increase in e-commerce. ${ }^{100}$

Manuel Castells points out the contradiction between the process of globalization and identity inherent in what he calls the network society. Thus, volume II of his trilogy on the information age is entitled, The Power of Identity. ${ }^{101}$ Castells argues that the fundamental contradiction in the information society is to be found between the "network" and "the individual", and one of his main arguments is that there is an increase in the distance between these two polar points. The conflict between systems and the lifeworld in transitional society, as Habermas pointed out, would be exasperated in the information society and take the form of a conflict between an ungraspable, impersonal network and an ego that, through lack of interaction with others due to social media, becomes more isolated and insecure in its identity.

As man learned to harness energy, mechanics evolved as a core industrial technology. By connecting artificial energy to previously invented machines, we were able to radically change society. We were able to increase productivity enormously. It is generally assumed that a change in an S-curve, i.e. the method of production and, indirectly, the social system, increases productivity by a factor of 100 . This was the case in the transition from mechanical to industrial technology. Today, as mechanical technology is being replaced by electronics, the terms old and new economy have become commonplace. In the USA, they have even been assigned their own stock exchanges (the NYSE and Nasdaq). But for the time being, they coexist. ${ }^{102}$ Although some question how long the two economic systems will be able to coexist and be judged by the same yardstick, i.e. money, it will take time to reach a point where we would approach anything like increases in productivity by a factor of $100 .{ }^{103}$

99 Dijk, J.T. van Poell \& Waal, M. dew. (2018). In Andersson Schwarz, J. \& Larsson, S. (eds.), Plattformssambället: Den digitala utvecklingens politik, innovation och reglering. Stockholm: Fores.

100 Laudon, Kenneth C. \& Traver, Carol Guercio. (2019). E-commerce: business, technology, society. Fourteenth edition, Global edition. Boston: Pearson.

101 Castells, Manuel (2000).

102 See Castells, Manuel (1999, p. 42).

103 This is already evident in the size of IT corporations. The golden egg of industrial society, the car, is about to be replaced by the golden egg of digital society, the computer. Major car manufacturers will be reduced to Lilliputians compared to the IT industry's major 
Digital technology allows us to use information to develop production and knowledge in a way that goes far beyond what was possible in earlier societies. Let us speculate on the question of this period of transition and what it may lead to in terms of societal changes. Scientific studies of the subject are scant. Sociology and the social sciences in general have only now realized that the old is about to disappear. In economic history talks about the fourth industrial revolution. There is talk of post-industrialism, post-modernism, post-Fordism, etc., but there is no discussion on the potential consequences for the organization of society or for people's daily life. One reason for this may be that science is impeded by the "burden" of empirical proof. This makes it difficult to relate to something that is still in the making, and even more difficult to speculate on something that has not yet occurred. ${ }^{104}$ That it is not yet evident, despite the fact that it exists, means that it has not been articulated and made evident. This situation also means that science, in this area, is treading on shaky ground. In the scientific community, it pays off better to continue working on old, established theories that everyone can relate to and recognize. ${ }^{105}$ The structure of the financial system also guarantees that research remains politically correct. But this cannot continue indefinitely. Sooner or later, the industrial bubble must burst.

Cultural and social movements reconstruct social institutions by letting technology be guided by people's needs and demands. However, in order to act as agents of change, they must evolve from collectively gathering around a resistance identity to gathering around a project identity, Castells argues. They must take the step from resistance to the systems that shaped the reconstruction of modernism (the social movements of 1968) and postmodernist deconstruction, to a constructive approach that is based on their own visions and values, cultivated within a cultural process. The key question, Castells emphasizes, is therefore the emergence of project identities with the potential ability to build a new civil society of some kind and possibly a new state. ${ }^{106}$

In his final, third volume, The End of Millennium, Castells attempts to interpret the ongoing historical transition as a result of the processes studied in his first two volumes. It is here that the three aspects, production, experience and power, are summarized in his final conclusions on the nature of power relations and change, as proposed above. The prevailing logic of the network community triggers its own challenges in the form of collective resistance identities and project identities. According to Castells, in order for resistance identity to transform

corporations, such as "the big five", Apple, Amazon, Facebook, Google and Microsoft and others like Intel, Oracle, Broadcom, Cisco, etc. According to NewsVoice 2016, of the world's 200 top listed economic entities, 153 are companies.

104 It is important to study social problems in real time, which complicates matters when trying to be scientifically precise. Instead of well-established, scientifically documented sources, it becomes necessary to refer to what is happening in practice, to study advanced practice. See more on this in Hydén (2019).

105 The peer review system acts here as a gate keeper.

106 Castells, Manuel (1999) Vol. 2, p. 365. 
into project identity, a new body of politics must emerge first. ${ }^{107} \mathrm{He}$ continues: "Society is still controlled by power", Castello writes, "it continues to shape and dominate us". ${ }^{108}$ This new form of power required to change society resides in the information codes and representative images around which societies organize their institutions and around which people form their lives. This form of power is the result of an endless struggle over society's cultural codes. It is a struggle between submitting to system imperatives versus adhering to independent views of the conditions of life made within a communicative process. This power struggle, Castell argues, ultimately plays out in people's inner worlds.

"This is not a book about books", Castell declares in this book's opening passage. ${ }^{109}$ With this statement, Castells means that he is inspired by the reality we live in and not by theories of the reality that we exist in. It is the same with norm science - it does not claim to be a theory, but a perspective on the reality which might lay the foundation for new theories, particularly important in a time when more and more people feel that we are living in a time of systematic change. Quite simply, we are facing a gigantic paradigm shift that is not driven by the (social) sciences, but by changes in society itself. In such a situation, it is not very productive to stare in the rear mirror looking for a linear progression from then to now. Manuel Castells' main merit is that he shows us that we are faced with somewhat different conditions than those on which the social sciences presently are based. The problems may be the same, but the conditions and the solutions are different. This also applies to my contribution to a science of norms. This means that, inevitably, these theories contain a certain degree of speculation. But in my view, the social sciences should contribute to producing depictions of the future to orient ourselves in the present. Thus, for the sake of brevity, I am constrained to prioritising and submitting my arguments and hypotheses rather than providing counter-arguments, which, I argue, is the task of an empirically oriented effort.

Among the social scientists who have gone the furthest in drawing our attention to the fact that something new is occurring is the German social scientist, Ulrich Beck. In his book from 1986, he commented on the risk society and that we are facing something new. The phrase he uses - the risk society - is, however, only a description of a natural component of transitional society. In fact, what Beck captures in his illustration of the risk society is the problems inherent in transitional society. In his book The Reinvention of Politics, published in German in 1993, Beck seems to agree. ${ }^{110}$ Here, Beck introduces the concept of "reflexive modernization", which he argues is a solution to the problems of the risk society, which he now seems to interpret as a sort of transitional society. He is

107 Castells, Manuel (2000) Vol. 2, p. 396.

108 Ibid, p. 368.

109 Ibid, p. 16.

110 Here, for example, Beck argues that "the concept of risk society denotes only one aspect". The theory of reflexive modernization goes much further, as will be shown. 
simultaneously aware of this transition toward a new society ${ }^{111}$ and unaware of it. Reflexive modernization does not entail a revolution toward a new society, Beck states. He sees the transition from one social era to another as an unintended occurrence, independent of all political decision-making forums, lines of conflict and party-political controversies, and which thereby contradicts society's selfperceptions of democracy, as well as its fundamental, sociological values. ${ }^{12}$ This means that Beck agrees with the idea of unplanned social development and that it is, to some extent, a temporary condition, as described above. Paradoxically, he proposes a method to "come to terms" with this state of affairs, i.e. reflexive modernization. However, in my view, this is primarily an expression of empirical science's inherent tendency to be normative. My question would be, to employ the same kind of critique as Beck uses in his critique of Luhmann: Where do we find this tendency towards reflexive modernization, who implements it and what are the results?

If we ignore this objection and follow Beck's reasoning, it captures some key elements of the dilemmas of transitional society. He states: ${ }^{113}$

The uncovering of the immanent conflicts of institutions still programmed in terms of industrial society, which are already being reflected on and criticised from the perspective of the concept of the self-endangerment of risk society, allows norms, principles and practices in all society's fields of action to become contradictory.

Beck, with the explicit support of Zygmunt Bauman, views the development from industrial society to risk society as a self-propelled process. ${ }^{114}$ Both would probably make the same claims about the transition to the information society, at least regarding issues they were in agreement on. Beck thus emphasizes that progress is blind and non-predictive and attributes this to the inherent logic of large-scale industrial society: ${ }^{115}$

The ignoring of risks that are in any case imperceptible, which always finds its justification in the elimination of tangible need - and in fact actually has that justification (see the Third World!) - is the cultural and political soil on which the risks and hazards grow, bloom and thrive. In the overlap and competition between the problems of class, industrial and market society on one side and those of the risk society on the other, the logic of wealth production always wins, in accordance with the power relationships and standards of relevance - and for that very reason the risk society is ultimately victorious.

111 Beck, Ulrich (1992, p. 65).

112 Ibid.

113 Ibid, p. 52.

114 See Bauman, Zygmunt (1995, p. 247, ff) under this section which Bauman refers to as the "Risksamhället: teknikens sista bålverk".

115 Ibid. 
Still clearly focusing on transitional society but with a perspective that extends beyond the immediate horizon, Beck argues that "the constellation of industrial society is becoming unpolitical, while what was unpolitical in industrialism is becoming political". ${ }^{116}$ By this, Beck means that we must look in new places for our new politics. The political has to be discovered, and he recommends: ${ }^{117}$

Socially recognized risks, as appears clearly in the discussions of forest destruction, contain a peculiar political explosive: what was until now considered unpolitical becomes political - the elimination of the causes in the industrialization process itself. Suddenly the public and politics extend their rule into the private sphere of plant management - into product planning and technical equipment. What is at stake in the public dispute over the definition of risks is revealed here in an exemplary fashion: not just secondary health problems for nature and mankind, but the social, economic and political consequences of these side effects - collapsing markets, devaluation of capital, bureaucratic checks on plant decisions, the opening of new markets, mammoth costs, legal proceedings and loss of face. In smaller or larger increments - a smog alarm, a toxic spill, etc. - what thus emerges in risk society is the political potential of catastrophes. Averting and managing these can include a reorganization of power and authority. Risk society is a catastrophic society. In it the exceptional condition threatens to become the norm.

An example of this concerns how gender relationships and other gender issues have become key political issues in the wake of the \#MeToo movement. Other examples are when LBTQ questions, positions on euthanasia, lifestyle issues related to climate change, etc., become part of the political agenda.

As a result of the dilemmas related to transitional society, we also must realize that people have different perceptions of time and space. Today, perceptions of identity are linked to where on the societal development map the individual feels most at home. There are at least four ideal types of illustrations of the temporal and spatial world worth experimenting with, here described as World Views 1, 2, 3 and 4 in Figure 1.6.

Tanzi and Schuknecht have studied public spending in the industrialized Western world during the 20 th century. ${ }^{118}$ They point out that in the early 20 th century, average public spending in the industrialized Western countries was lower than $13 \%$ of gross domestic product (GDP). This increased gradually, and by 1937 it had risen by $23 \%$ and to $46 \%$ by the end of the century. Above all, the

116 Beck, Ulrich (1992, p. 139).

117 Ibid, p. 24.

118 Tanzi, Vito and Schuknecht, Ludger. (2000). Tanzi is connected to the International Monetary Fund (IMF) and Schuknecht to the World Trade Organization (WTO). 


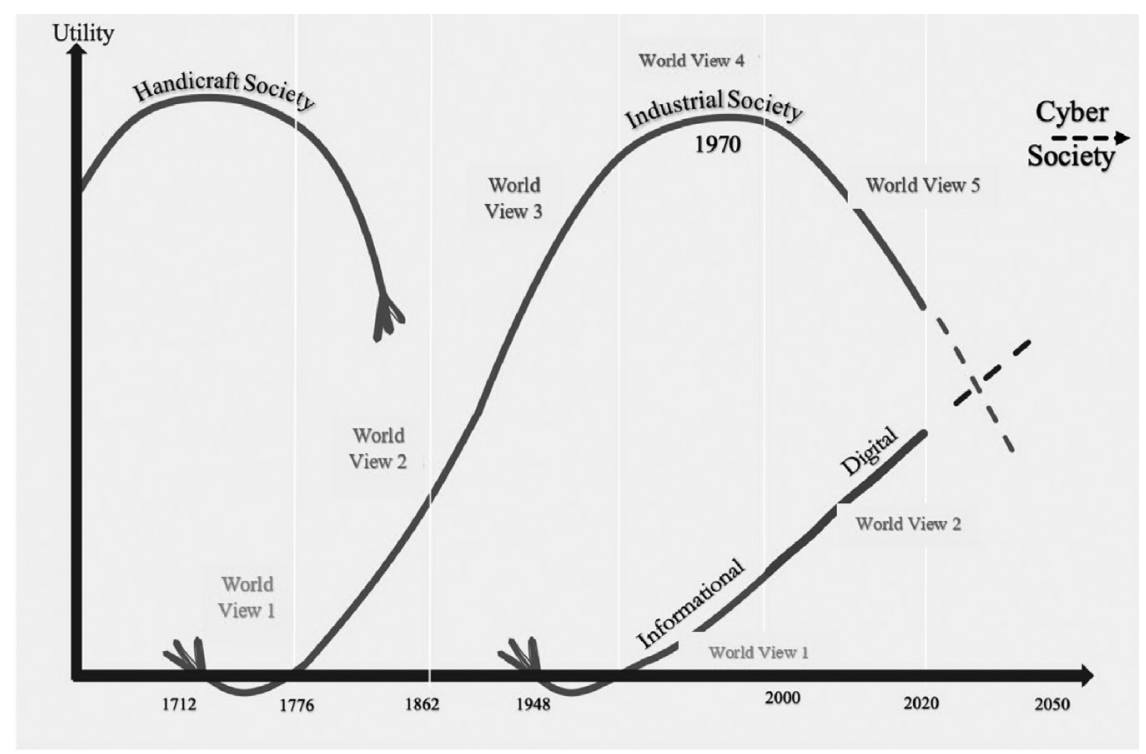

Figure 1.6 Different world views in relation to the development of the industrial society

world wars and the period following industrial society's peak in 1973 contributed to the largest increases in expenditures. In Sweden the public expenditure increased from 1970 to 1982 from $46 \%$ to $62 \%$ of GDP as a way for the government to uphold the welfare state in a situation when the economy slowed down. This pattern is repeated in all industrial nations, although the levels vary somewhat. In 1999, public expenditure in relation to GDP in the USA was 30\%, in France 52\%, in Denmark 54\% and in Sweden 56\%. Over time, there has also been a shift in the functions of government power. Today, much of governmental work is concerned with transferring "individual investments" to "collective consumption". This share of total expenditure has risen from an average of less than $5 \%$ of GDP in the 1930s to $23 \%$ in the 1990s. In the mid-nineties in Sweden, one-third of total income was redistributed. Despite this, actual redistribution was relatively limited due to the related "waste". Tanzi and Schuknecht present figures from the mid-1980s that show that $57 \%$ of transfers went to an intermediate category of $60 \%$ of all income earners, $16 \%$ to the upper fifth and $27 \%$ to the lower fifth. This means, as is argued now and then, that a large portion of the population receives as much as they pay within a transfer system that in many respects is a burden on the political system due to its negative image. The argument put forward by the authors that the public sector does not perform better simply because its resources, and thus costs, have increased, does not help. This is something which has continued to grow. In the digital society these cleavages between rich and 
poor have deepened. This is a typical result of the transitional society and hard to avoid. ${ }^{119}$

One thing that seems to characterize all transitional phases, including the one we find ourselves in now, is that the new society will initially be judged by the standards of the old society. This applies to everything from technological development to new societal problems. Thus, when the car was invented, it was designed to be similar to a horse carriage. There are even claims that the first car was equipped with reins. When we invented energy technology, progress was measured with the old society's measurement of power, horsepower. To this day, we still describe cars as having a certain amount of horsepower. This also applies to changes that take place in the transition from one era to another. They are evaluated and judged on the basis of the past era's visions. This is reflected not least in the development of law.

Therefore, when I focus on certain aspects of social development in this book, I do so not to express my personal preferences, but as an interpretation of trends in which intent and meaning are conspicuous by their absence. Manuel Castells paints a vivid picture of our times: "At the turn of the millennium, the king and the queen, the state and civil society, are both naked, and their children-citizens are wandering around a variety of foster homes". ${ }^{120}$ Faced with this situation, this does not prevent the social sciences from contributing to an increased understanding of these processes. From this perspective, a positivist social science risks producing either platitudes or distortions. The most important approach for the sciences is, rather, to be sensitive to changes in cultural values that for the time being remain obscured or are in the making. Which brings us back to the need for a science of norms.

It becomes particularly important to understand societal development in terms of norms and normative shifts at a time when society is in the midst of changing its social and cultural codes. It is these norms that form the cohesive framework that allows us to understand what characterizes the new society. Manuel Castell's responsiveness to empiricism should thus be complemented by a similarly sensitive responsiveness to the normative changes that are taking place. The coming decades will in all likelihood need a focus on relationship issues, interrelation issues, i.e. a new kind of relationship between people learning to live with new technology. All indications are that this leads to a focus on relationships with our most intimate social spheres, while the social ideal of the industrial model, with its conflicting and competitive working relationships, is overshadowed. The fact that different parts of the world have developed at different paces and that we will therefore see "our own historical conflicts" being played out on the world stage does not change these circumstances.

119 As a result we have seen a growing literature on books which criticize neoliberal politics.

120 Castells, Manuel (2000b). Vol. 2, p. 240. 


\subsection{Epistemological implications}

\subsubsection{The circle of motives between actor and system theory}

The circle of motives contains elements of both actor theory and system theory. The voluntary will component is articulated and asserted by individuals and groups. Similarly, knowledge is also linked to the actor. In this respect, the circle of motives is an actor-oriented theory of action. When we then observe systemic conditions, we necessarily switch to system theory. The systems are constructed differently, and therefore they have different structures. Thus, when we apply the circle of motives to specific cases, we need to consider all these factors, regardless of the fact that the importance of different factors varies with the type of problem and action being studied. But the basic starting point for the circle of motives lies in the question: What determines our actions? This question endows the circle of motives with an action-theoretical content, which is developed from an actor's perspective in relation to relevant values and knowledge. Additionally, a second overarching question needs to be asked: What causes the emergence of a norm in individual cases? This question means that the circle of motives shifts to system theory and discussions about structures. The synthesis consists of the interaction between value, knowledge and opportunities in individual cases, where the longterm systemic conditions can provide premises for the individual and contribute to shaping short-term motivations for action. See Figure 1.7.

Applying the norm in each individual case is always a matter of an individual decision in that the norm has an impact on other people. This is to avoid misunderstandings, even in cases where we study companies and other organizations. The roles that exist there are created by individuals who interpret the meaning of the norm. This means that in Figure 1.7 we could replace the norm with the individual and place him or her at the centre of the influential force that is taking place. Weighing decisions between $(\mathrm{W}),(\mathrm{K})$ and $(\mathrm{SP})$ is ultimately up to the individual. While it is true that the norm often becomes a norm precisely because people tend to comply with it, there is always room for individual considerations, and thus deviations from or adjustments to, the norm.

The trade-off between $(\mathrm{W}),(\mathrm{K})$ and $(\mathrm{SP})$ involves a moral component, even if the norm belongs to one of the goal-oriented systems. In the final analysis, it is up to the individual actor's conscience to determine, for example, to what extent (W) may "conflict with" the requirements of (SP). In extension, this discussion involves aspects such as civil courage and civil disobedience. Social change always requires that $(\mathrm{W})$ is emphasized at the expense of $(\mathrm{SP})$ and $(\mathrm{K})$. That is why the beginning of an S-curve, which represents a new stage of society, is always initiated by individual individuals who go their own way, whether they be inventors or as a result of their internalized duty ethics. Innovations are never created in large organizations through standardized, norm-controlled behavioural patterns. This is also why norm-supporting structures become relevant in cases where society wants to collectively support norms that, for whatever reason, appear to be important. 


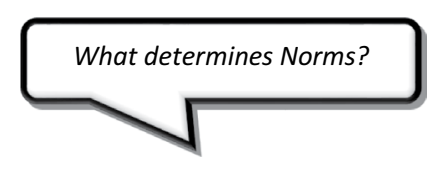

\section{What determines Actions?}

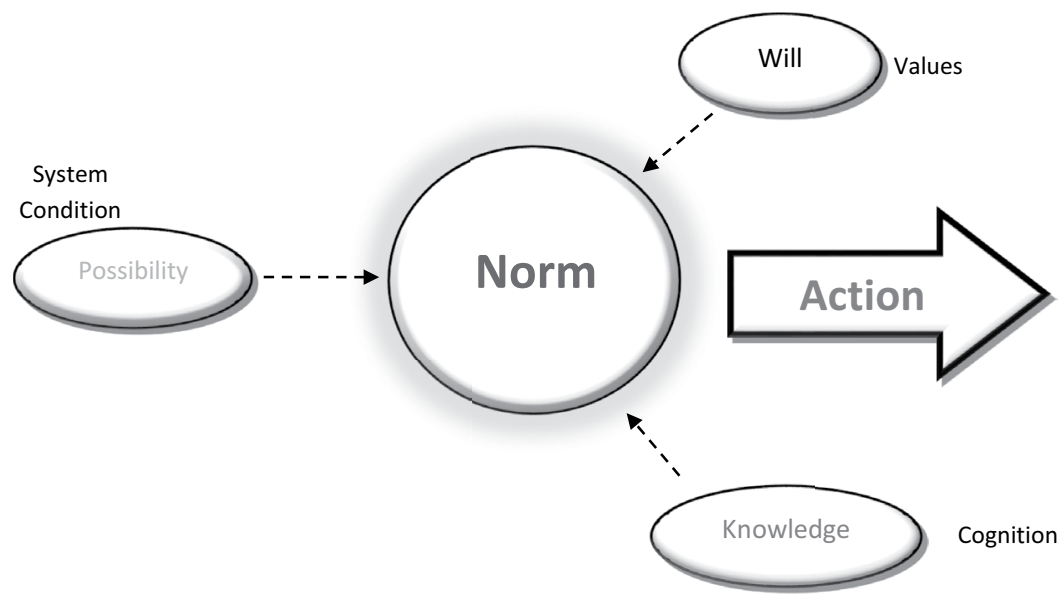

System Theories<smiles>C1=CC=C1</smiles>

Structures

Action Theories

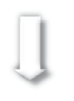

Actors

Figure 1.7 The circle of motives within an action-theoretical context

The starting point for an analysis of norms is that the behaviour is viewed as an individual action despite the fact that it is analysed in terms of norms. Theoretically, therefore, a norm can also be an individual matter. This, too, is an empirical question. The norm may prescribe normal behaviour for me and be based in my system of norms. But if a certain value has a strong position and the knowledge of how to follow the norm is generally widespread and it is physically possible to follow, the norm tends to apply generally. This is particularly evident in norms such as game rules or social rules. Furthermore, one must distinguish between the norm as an actual phenomenon and the norm employed as an analytical instrument. As an instrument of analysis, the circle of motives helps to reconstruct either the conditions of the particular act(s) being studied or the components that comprise generally accepted norms, including legal rules.

In the first case, the circle of motives indicates relevant variables to consider when analysing the factors that apply when an actor decides to act in a certain way. That is not to say that the factors that influence the action are necessarily subject to conscious considerations in the heat of the moment. Different elements of the circle of motives are assumed to play different roles in different 
empirical situations and in different historical phases. With this book, my intention is to lay the foundation for such a kind of empirical science.

\subsubsection{The need to assemble}

For the last century, society has, in many respects, been characterized by atomization. This atomization is a result of increased specialization, both on a micro and a macro level. One of the most important ways of understanding nature has been to break down matter into smaller constituents. ${ }^{121}$ This is what has occurred in the areas of biology, chemistry and physics. Atomic physics developed into quantum physics, electronics and genetic engineering. With the help of the computer, the limits of macrocosm and microcosm have been expanded. An extreme "atomization" has led to a new kind of "assembling". This tendency has also had an impact on the social sciences and humanities, which, however, have maintained a macro orientation, but which have been divided into a number of sub-disciplines, each addressing different aspects of human behaviour. Political science, sociology and economics evolved from law. ${ }^{122}$ In the 20 th century, we invented disciplines such as informatics and studies of social work. The subject of economics has been divided into business economics and political economics, which in turn has been supplemented with economic history. Sociology is a collective term for a number of different scientific areas with a focus on different subjects, such as religion, family, housing, etc. This also includes SoL.

This fragmentation of the social sciences is a reflection of societal processes. Going back to Ewerman ${ }^{123}$ and others, the theory of cyclic social development, which we have commented upon earlier, in every era passes through four phases: establishment, growth, maturity and decay. During the first two phases a strategy of assembly and construction dominates, while the two later phases are concerned with disassembly and atomization. The most intensive assembly period is during the establishment phase, and atomization is most intensive during the maturity phase. This can also be seen in the industrial age. The fact that it has reached its peak and is about to be replaced by the digital era means that we are on the threshold of a transition from disassembly to assembly.

One might question the driving forces behind this development. This is a complex, detailed question. To begin with, we can conclude that it has to do with beneficial aspects. Stephen K. Sanderson expresses its as follows: ${ }^{124}$

As the point of diminishing marginal returns is reached a society is in a weakened condition that makes it especially vulnerable to any particular stresses

121 Ewerman, Anders (1996, p. 406).

122 See Murphy, Tim W. (1997).

123 Ewerman, Anders. (1996). Marknaden 1000 år - Fem eror i Europa. Stockholm: Ewerman Business Intelligence.

124 Sanderson, Stephen K. (1999, p. 128). See also Tainter (2019) and Sanders, William T. and Webster, David (1978). 
or shocks, and it is probably only a matter of time before it collapses. In essence . . . a kind of dialectic in which societies are hoist to the own petard; the more they invest in complexity, and the very nature of the evolutionary trajectory they follow is self-undermining in the long run. Social evolution thus proceeds from lower to higher cost, a fact that Tainter regards as an “immutable fact of societal evolution".

Expressed in terms of $S$-curves, the driving forces can be explained using marginal benefit curves, since the marginal benefit of yet another process of disassembly is exceeded by the marginal benefit of assembling the disassembled parts into new commercial services and products. At this point in time, society shifts its focus from disassembling to assembling. Issues related to functional differentiation are then replaced by issues related to functional coordination. ${ }^{125}$ At this point, we face the challenge of capitalizing on, that is, to put to re-use, that which has been dismantled. This is accomplished by various actors. The actors that dismantle consist of administrators and profiters with the sole goal of atomising (people that focus on details), while those who assemble are inventors, entrepreneurs and innovators (people with a holistic view). ${ }^{126}$ However, for a period they coexist in a struggle for hegemony. When the economic pie of society no longer suffices to meet demand, more space must be given to innovators. In time, this will lead to a new phase of growth. Jean Gimpel talks about psychological drive and technological evolution. ${ }^{127} \mathrm{He}$ divides the stages of development into an era of growth, an era of maturity and an aging era. In the first two eras, the psychological element precedes the technical development. In the last overripe era, the opposite is true, something which causes a shift in norms.

These conditions also have an effect on the sciences. This would mean that we are witnessing a stalemate between reductionism and holism, between quantitative and qualitative methods, between knowledge and faith, etc. ${ }^{128}$ According to Ulrich Beck,

Sociology . . . must become . . . a bit playful, in order to liberate itself from its own intellectual blockades. Oppose pseudo-eternal verities, rub them together, agitate them against one another and fuse them together until the intellectual test tube starts giving off sparks and smoking, smelling and spluttering. ${ }^{129}$

125 Beck, Ulrich (1995, p. 74).

126 Ewerman, Anders (1996, p. 478 ff).

127 Gimpel, Jean. (1976). The medieval machine: the industrial revolution of the middle ages. New York: Holt, Rinehart and Winston.

128 Aspelin, Gunnar. (1955). Tankelinjer och trosformer: huvudriktningar i vår tids idébistoria. Stockholm: Bonnier.

129 Beck et al. (1994, p. 24). 
In contrast with Niklas Luhmann and his dichotomization of the world into true/false, lawful/unlawful, etc., Beck poses the question:

Is it not time to break this great sociological taboo against simplification and, for instance, inquire into code syntheses, to search for where and how these are already being produced today? Is the combination of art and science, of technology and ecology, of economics and politics with the result of something neither-nor, some third entity, as yet unknown and yet to be discovered, really out of the question simply because the basic multiplication table of functionalism, considers it, out of the question? ${ }^{130}$

Sociology must change if it wants to understand and comment on the need for change in society, according to Beck. ${ }^{131}$ However, he argues, this is only possible if we free ourselves of the constraints of sociological theories based in industrial society regarding family, industrial work, organization, social politics, class and stratification analysis, as well as from the institutions that are the central addressees, clients, financiers and users of sociological knowledge. This, too, has had an impact on the development of SoL. Beck does not mince words in his final words of his book The Reinvention of Politics: Rethinking Modernity in the Global Social Order when it comes to describing sociology:

'Administrative' sociology has made the administrative apparatus, the administrative mentality and administrative pigeonholes into the conceptual, specialized and cooperative foundation for its complicated research. Now it is becoming the antiquary's shop of industrial society, the viceroy of obsolescent institutions, the producer of realities existing only in data, confirming with its unchanging institutional categories the self-centred, vapid arrogance of 'self-referential' systems and organizations. ${ }^{132}$

Reductionism stands for detail, division, specialization and atomization. This line of thought means that in a static economy there is a focus on the link between effect and problem, which is seen as the actual object of study, while when searching for solutions in a dynamic economy, there is a focus on the cause. We are faced with the need for a transition from disjunctive, reductionist scientific disciplines to an assembling, holistic science.

Such a science requires two things. One is to address problems that are not scientifically defined from the outset and thus fall under one or more established tradition's or discipline's (reductionist) theoretical frameworks. The future is theoretical and must first be created before we can produce theoretical 
explanations. ${ }^{133}$ The second requirement is that we approach the problem based in the knowledge of several scientific disciplines, which in collaboration can provide a holistic answer. Assemblers and disassemblers are therefore dependent on each other. The components discovered during the atomization process are used by the next generation of assemblers. This new scientific approach thus requires that scientists work together in some form of problem-solving or action groups.

Gathering enough knowledge of the new society's relationships to allow us to understand and conceptualize them in scientific terms and theories will thus take time. Ulrich Beck has coined the phrase "reflexive modernization" to refer to the process in which modern industrial society becomes self-critical and thus ready for change. We must remember that when Henry Maine in his book Ancient Law described the process from status to contract, ${ }^{134}$ and when Émile Dürkheim described the emergence of industrial society as a development from mechanical to organic solidarity, this development had been going on for some time and had, among other things, manifested itself through the emergence of a new type of legal system, civil law, which, although it had existed in Roman law, received a renaissance during the 19th century, beginning with the French Code Civil, issued by Napoleon in 1804. What we can do today is try to establish a scientific, fundamental ethos that is characterized by having as many interfaces with other fields of knowledge and disciplines as possible in order to connect with and make the most of the fragmented knowledge accumulated during the period of atomization. It is time for new sciences to see the light of day.

These new areas of knowledge should be holistic. Holistic in the sense of the whole, holiness, health, assembly and, not least, synthesis. Today, it is more important than ever to bring together areas of knowledge and form new understandings of our world that require new scientific approaches than to produce new knowledge through existing theories and methods.

133 Cf. Schön, Lennart (2000, p. 477).

134 In this famous extract from Chapter V of Ancient Law (1861) Henry Sumner Maine characterizes the evolution towards progressive societies as a passage from status (an ascribed position) to contract (a voluntary stipulation). 


\section{Two competing normative worlds and their internal changes over time}

\subsection{Introduction}

To begin with, we need to distinguish between norms as a practice and norms used as a tool of analysis. In the same way that money has dual properties and is both a facticity, a payment method used in society and a parameter for measuring economic events and transactions, norms also play dual roles, i.e. they are a facticity, but the concept can also be used to evaluate and understand human actions in various contexts. The answer to the question of what constitutes a norm depends, in the first analysis, on whether we perceive norms as a facticity or as a tool of analysis. In the first case, norms may be both descriptive and prescriptive, i.e. they may be explanatory or instructive. In the latter case, norms govern and affect our behaviour. Norms, then, contain action instructions and vary depending on the system within which they exist.

A prescriptive norm consists of a sanction or an order. ${ }^{1}$ Nils Kristian Sundby uses the term "duty-imposing" to designate these kinds of norms. Within legal philosophy, the terms attitudinal norms (Alf Ross) and situational norms (Torstein Eckhoff) are used as synonyms. ${ }^{2}$ The order prescribes that a certain action should be carried out, while the subject of the norm in the case of a sanction is instructed to refrain from a certain activity. Duty-based norms are characterized by their nature. The action is applied as a duty. ${ }^{3}$ The order supports the action, while the sanction opposes it. Sundby also elaborates on what he calls zero modality, i.e. a norm in which the action is neutral in relation to the duty. ${ }^{4}$ In such cases, the action has neither been ordered nor sanctioned, i.e. it is allowed, and therefore we might refer to such action as a third type of norm, i.e. permissible norms.

1 Cf. Sundby, Nils Kristian (1974) Ch. 3 on Direktiviske normer (duty-based norms) and MacCormick, Neil (1999).

2 Cf. Ross, Alf (1953, p. 45) and Eckhoff, Torstein (1987, 2.ed., p. 45). Cf. Strömholm, Stig (1981).

3 Cf. Hart, H.L.A. (1961, p. 147 ff), Raz, Joseph (1970, 1990, p. 27 ff) in which the authors discuss "norms of duty" and "duty-imposing norms".

4 Sundby, Nils Kristian (1978, p. 51). 
As an analysis tool, the norm summarizes information about what causes a certain action or how to understand the construction of a given norm system. There is good reason to distinguish between norms when viewing them from a causal or final perspective. The purpose of the analysis, then, would be to focus on the cause of the norm, the driving force behind the norm or the expected consequences of the norm once it is applied in practice. In the latter case, a preunderstanding of the norm is result-oriented. The norm is determined by a given situation being perceived as desirable or whether it should best be avoided.

However, a norm does not only consist of values and preferences. It also has cognitive aspects. Since norms are system-bound, they are also dependent on conditions of the system that are relevant to the particular case. Applying the norm as an analysis tool relies on analysing the norm as a facticity. The norm has three dimensions that are linked to three approaches when understanding norms as a facticity. These three dimensions have different strengths and levels of significance in all norms, but in practice they do not exist as separate functions. Based in an analytical perspective, it can, however, be beneficial to separate them to obtain a clearer and more differentiated view of how norms work. Norms as an analysis tool should be viewed from a methodological perspective.

The aforementioned norm model's claim to fame is that it functions as a methodological tool when gaining an understanding of the functions and construction of norms. However, in this chapter, we shall view the norm as a facticity that underlies a theoretical understanding of the various components of the norm model. With regard to theoretical point of departure, in this chapter we will highlight two different worlds in which normativity is created. Thereafter, in the next chapter, we will discuss what norms actually are and the various types of norms.

\subsection{Lifeworld and system}

\subsubsection{Human dualism}

The most significant factor when studying the conditions of human life from a societal perspective is linked to the question: Under which reproductive conditions does this take place? In other words, what characterizes the procreation of human life? Animals spend less time with their parents, and then primarily the mother, when learning how to survive on their own, i.e. adapting to the natural conditions of their species. This has mainly to do with whether the young individual is able to develop to the point that it can avoid dangers and find food so that the species can continue to procreate. During this period, the parent also transfers some culturally contingent information about how to best survive, ${ }^{5}$

5 Cf. Bonner, John Tyler (1980), particularly Ch. 2 on Cultural and Genetical Evolution. Bonner defines culture as behaviours that are transferred from one individual to another through learning. He uses the term "meme" to describe the transfer of information, p. 18. A meme 
such as the best hunting method or how to avoid other animals. The point of departure from the animal's perspective is that the conditions for survival are a natural occurrence. They do not vary particularly over time or among populations. For animals, it is sufficient if the majority of the characteristics that the biological being requires for its own and its species' reproduction are genetically determined and passed on.

The human individual requires more cultural lessons to grow up and survive on its own than any other species. In the case of humans, this has more to do with feeding (providing food) and bringing up their children than being forced to protect them. But humans also have to learn to survive on their own eventually. Humans have to learn to create living conditions that allow them to reproduce both as individuals and as a species. Humans are endowed with the unique characteristic of being able to communicate cultural aspects by being aware of their existence and the conditions that affect their existence. ${ }^{6}$ Cultural communication creates meaning by creating an awareness of the conditions of our existence. An animal's behaviour is one thing, but a human's actions are an entirely different story. Human actions are characterized by being semiotic, goal-oriented, transcendent, etc. ${ }^{7}$ It is in this sense that norm science can be termed an action theory.

Humans also exist under genetically determined conditions. The proportions between genetic impact and cultural conditions vary from case to case. Medical science remains uncertain of the proportions and other aspects such as susceptibility to different kinds of diseases. Our behaviour is to some degree, perhaps half of it, given a margin of $10 \%$ each way, determined by our parents' genetic coding. ${ }^{8}$ Today, genetic scientists, according to Paul Lichtenstein, are generally in agreement on how much of our behaviours are governed by genes, how much is governed by shared environmental factors and how much is governed by environmentally unique factors. ${ }^{9}$ What is colloquially referred to as the environment within the context of heritage and environmental influence, such as upbringing and values that one learns as a child, is counted as shared environmental factors. Environmentally unique factors, somewhat simplified, are events of life that the individual encounters and that are unique to that person, such as low birth weight or trauma resulting from stress or injuries. The general consensus is that

can be an idea, a custom, a belief or a process of learning. Bonner states that with regard to cultural evolution, information is transferred via memes, while in genetic evolution it is transferred via genes.

6 Cf. Johnsons', Richard definition of cultural studies, Johnson, Richard (1996), where he states: "For me cultural studies is about the historical forms of consciousness or subjectivity, or the subjective forms we live by, or, in a rather perilous compression, perhaps reduction, the subjective side of social relations", quote from Trondman, Mats (1994, p. 60).

7 Østerberg, Dag (och 1991, p. 72).

8 Lichtenstein, Paul (1993). Genetic and environmental mediation of the association between psychosocial factors and health. Diss. (abstract) Stockholm: Karol. inst.

9 Fortes newsletter abstract March 2015. 


\section{Two competing normative worlds}

$40-50 \%$ of an individual's behaviours can be attributed to genetics, $50-55 \%$ to environmentally unique factors and only $5 \%$ to shared environmental factors results that both the scientific world and the general public have had difficulty accepting.

In this context, it is important to point out that there is a range of variation within humans, and quite a broad one, with regard to genetic make-up. How much is genetically determined is a somewhat controversial question, one which also touches on issues related to the justification of socio-biology, i.e. how much of our social behaviours are based in our genetic make-up as Homo sapiens. There are, however, some characteristics that are specific to humans. Peter Gärdenfors highlights, in his book Hur Homo blev sapiens (How Homo Became Sapien) our unique ability to think and gather information about the world. ${ }^{10}$ Our brains and capacity to think and imagine have developed far beyond any other animals. Our close relatives, the apes, according to Gärdenfors, may be capable of planning, but only humans are able to plan for future needs. This is further related to the ability to make choices. When it comes to satisfying our needs, we have to choose between acting to satisfy immediate needs or future needs. ${ }^{11}$ Furthermore, humans are the only animals that are able to reflect on their own thoughts. This makes humans self-aware, which is a necessary condition for a free will. "The capacity for self-awareness is closely related to the episodic memory", Gärdenfors states (author's translation) ${ }^{12}$ and continues:

To remember yourself at different points in time, you must be able to see yourself from the outside. The liberation of human thought, both evolutionary and at the level of the individual, is the result of humans growing increasingly clever at directing their attention inwards while simultaneously disconnecting input from the outer world. One might say that self-awareness consists of an inner world which is used to observe the individual's inner world.

With regard to humans, therefore, a large number of properties and conditions that are required for procreation are contingent on cultural transference from a previous generation to a later one. For humans, society is therefore as important a factor as nature when it comes to basic survival conditions. Humans are a social animal. "An individual cut off from society has the same survival odds as a liver cell that has been ripped out from the body", as Dag O. Hessen notes (author's translation). ${ }^{13}$ Human reproduction, therefore, is partly about being socialized into society and partly about satisfying material needs within this context. This concerns two different aspects that require that individuals have different

10 Gärdenfors, Peter (2000).

11 Ibid, p. $80 \mathrm{f}$.

12 Ibid, p. $110 \mathrm{f}$.

13 Hylland Eriksen, Thomas and Hessen, Dag O. (2000, p. 201). 
skill-sets. Durkheim refers to the dualism of human nature and argues that it corresponds to the dual conditions of existence we live under as humans, i.e. we are part biological creatures rooted in our organic forms and part social beings that belong to a society. ${ }^{14}$ Durkheim also argues that tension and conflict can arise between these two aspects of human life.

\subsubsection{Social integration}

Jurgen Habermas distinguishes between what he calls the lifeworld and system. ${ }^{15}$ Society can be viewed both as a lifeworld and a system. ${ }^{16}$ According to Habermas, the lifeworld is created via language and culture. This is something that humans are forced to do in order to reproduce. The lifeworld consists of undisputed convictions that members of their society share in common and that can be expected to be applicable. These can be directed at the outer world and/or the inner world's moral expectations that arise within human relations. Convictions are undisputed since they are internalized, i.e. they have, through cultural conditioning and socialization, become a part of the individual's unquestioned conditions of life. The lifeworld is, according to Habermas, based on three factors: society, culture and personality. ${ }^{17}$

Society, in Habermas' point of view, is the legitimate order within which individuals regulate their membership in social communities in order to thereby ensure collaborative solidarity. The key concept when understanding this social glue is trust. Barbara A. Misztal distinguishes between three types of trust-creating social orders. ${ }^{18}$ See Figure 2.8.

\begin{tabular}{lll}
\hline Order & Trust & Practice \\
\hline Stable & Habitus & Habitus, Reputation, Memory \\
Cohesive & Passion & Family, Friends, Society \\
Collaborative & Policy & Solidarity, Toleration, Legitimacy \\
\hline
\end{tabular}

Figure 2.8 Trust-creating social orders

14 Ur Bellah, Robert N. (1973, p. 149 ff).

15 Habermas, Jürgen (1987) Vol 2.

16 Ibid, p. 118.

17 Ibid, p. 138. Cf. also, Alexander, Jeffrey C. 1990 (Analytical debates: Understanding the relative autonomy of culture), p. 4 , in which he presents, in his review article of the cultural concept, a similar view and claims that all actions are simultaneously social, symbolic and purpose - oriented, which is why one must take into consideration all three analytical levels when conducting an empiric analysis.

18 Misztal, Barbara A. (1996, p. 101). 


\section{Two competing normative worlds}

The fundamental norm-scientific question here concerns how this social order is protected and reproduced. ${ }^{19}$ Misztal's answer is that trust plays a crucial role in this context. Trust can be seen in social routines that underlie everyday actions and interactions between humans. ${ }^{20}$ It is through these, Misztal writes, that "(o) ur perception of a collective order as stable is sustained by rule-following behaviour, which makes our world predictable, reliable and legible." ${ }^{21}$ Trust is created, among other things, by what Pierre Bourdieu refers to as habitus. ${ }^{22}$ Misztal views habitus as the process of socialising us into adopting dispositions that are based in social structures. Habitus, according to Bourdieu, is both a principle that generates practices and a system for classifying and thereby understanding these practices. ${ }^{23}$ Bourdieu argues that it is the relationship between these two abilities that defines habitus and how the social world is represented and constituted, i.e. the space inhabited by lifestyles. ${ }^{24}$ Habitus might, in a figurative sense, be seen as an expression of the social practice's core technology. According to Misztal, trust is a specific form of habitus that predisposes us to perceive the social world, or the lifeworld to coin Habermas' phrase, as stable and to act based on this perception.

Habitual trust is, therefore, the mechanism that ensures a stable social order. This is accomplished through various practices or integration mechanisms, to once again refer to Habermas' interpretive schema. The mechanisms at work are habit, reputation and memory. Habits transform everyday life into routine. Reputation is an evaluation of the level of trust attributed to groups or categories of people. It contributes to classifying our experiences to make the world comprehensible and simplify interaction and communication between people. Memory entails reconstructing the past and passing it on into the future, thereby making social life appear less fragmentary and chaotic.

A second requirement of social order, according to Misztal, is that it is coherent, or at least appears to be, particularly with regard to morals and values. ${ }^{25}$ Here, trust is manifest via moral commitment, Misztal argues. It is this passion that binds together emotions, motives and unquestioning beliefs, that gives an impression of trustworthiness. These could also be described as core value-oriented areas. This passion, or these core values, can be found in close

19 Hydén, Håkan. (2018). The normative anatomy of society. In Febbrajo, Alberto (ed.), Mirrors and norms: on the plural identities of law. Routledge/ Taylor and Francis Group, Series: Studies in the Sociology of Law Vol. 2.

20 Cf. Aronsson, Gunnar and Karlsson, Jan Ch (1999, p. 17).

21 Misztal, Barbara A. (1996, p. 97).

22 Cf. Bordieu, Pierre (1977, p. 82 f), where Bordieu describes habitus as "a system of lasting, transposable dispositions which, integrating past experiences, functions at every moment as a matrix of perceptions, appreciations and actions and makes possible the achievement of infinitely diversified tasks, thanks to analogical transfers of schemes permitting the solution of similarly shaped problems ..."

23 For an overview of Pierre Bourdieus' work, please see Broady, Donald and Palme, Mikael (1993).

24 Ibid, p. 298.

25 Aronsson, Gunnar and Karlsson, Jan Ch (1999, p. 17). 
relationships, i.e. primarily between families and friends, but also in that part of society that Tönnies refers to as Gemeinschaft. ${ }^{26}$ Misztal states: "There is a clear continuum of a feeling of confidence and obligation, which starts with the absolute trust in the dearest person and ends with the less intimate feeling of reliance on others who share some of our characteristics (religion, ethnicity, nationhood and so on)". ${ }^{27}$

The third significant factor with regard to social order is a well-functioning cooperative system between people. Trust, as a mechanism, when applied to serve this purpose, is based in voluntary, spontaneous cooperation, not cooperation that is based on punishment or reward. Misztal argues that this kind of cooperation requires solidarity, wherein individual interests are subordinate to the common interests of larger social units. This requires a greater degree of tolerance, thereby allowing everyone to be integrated into the social system under equal conditions. ${ }^{28}$ Finally, it requires a just social system which is supported by its members, i.e. it is deemed to be legitimate.

Culture, in this context, refers, of course, to such knowledge that the members of society rely on when interpreting the world in a way that enables communication between people. The concept of culture refers to people's socially transferred (conditioned) lifestyles and habits. ${ }^{29}$ Culture consists of human activities that are not considered to be biologically determined. Culture has two functions. It partly creates meaning and partly provides norms for social behaviour. Jon Elster describes society as the greater reference group and culture as the local reference group, with regard to which norms and motives become applicable. ${ }^{30}$ Culture can be seen as the sum of knowledge needed for the individual to function within their society. ${ }^{31}$ Generally speaking, the concept of culture is one of the trickiest concepts to define since it is used in so many different contexts. The word culture is derived from the Latin word colere which means to cultivate, nurture, worship. It can be used to designate everything from human creations intended to provide spiritual experiences to the structure within which a larger group of people organize their livelihoods and common affairs. ${ }^{32}$ In the latter perspective, it could be said that a given culture both identifies and reflects a people's thoughts, concepts, habits, skills, sciences, and institutions at a certain point in time. ${ }^{33}$

In an article that has come to be considered a classic in the field, Ann Swidler emphasizes that culture does not govern behaviour by providing definitive values toward which individuals can guide their actions, but that it creates a repertoire of habits, styles, skill sets, etc., which enable people to create behaviour

26 Tönnies, Ferdinand (1979).

27 Misztal, Barbara A. (1996, p. 99).

28 Aronsson, Gunnar and Karlsson, Jan Ch (1999, p. 18).

29 Österberg, Dag (1991, p. 169).

30 Elster, Jon (1989, p. 250).

31 Swedish National Encyclopaedia, volume 11, p. 161.

32 Ibid, p. 162.

33 Chorafas, D.N. and Binder, E.M. (1992, p. 24). 
strategies. ${ }^{34}$ Culture is, according to Swidler ${ }^{35}$ with reference to Hannertz, ${ }^{36}$ not a uniform system that drives actions in a determined direction, but rather a sort of toolbox from which individuals can select various components when constructing their alternatives of action. Culture, seen as a toolbox, consists of symbols, narratives, rituals and world views that people put together in various configurations to solve various problems they encounter. These behaviour strategies are expressed, according to Swidler, as stable ways of organising human behaviour over periods of time. Culture's causal significance, Swidler further argues, is not to define action targets, but to provide cultural tools that can be used to construct different behaviour strategies. ${ }^{37}$ Swidler argues that culture, in this aspect, has more to do with lifestyle and individual qualifications than preferences or desires. ${ }^{38}$ The important thing is to observe how actions are organized rather than their goals and purposes. "For me", Swidler writes, "strategies are the larger ways of trying to organize a life". Different alternatives for action gain their meaning within the context of a given strategy. This strategy also determines which skills and habits will be practised. ${ }^{39}$ This is in agreement with what Bourdieu calls habitus. ${ }^{40}$ By personality, Habermas means such skills that enable the individual to communicate and act in order to thereby establish their identity. It is through everyday communicative actions that society, culture and personalities are reproduced. "A self can arise only where there is a social process within which this self has had its initiation", George Herbert Mead states. ${ }^{41}$ According to Mead, communication and participation are central to this process. He continues: "( $\mathrm{t}$ )hat is the way in which selves have arisen. That is where the individual is in a social process in which he is a part, where he does influences himself as he does other. There the self arises". These reproductive processes are based on the lifeworld's symbolic structures, as Habermas calls them. They have to do with different kinds of memory mechanisms, ranging from gestures and actions that are an expression of care to more organized rituals and traditions, including patterns of organization. This symbolic reproduction occurs within a network of personal relationships between people. The lifeworld's symbolic structures should be viewed against a background of society's material reproduction that is caused by more tangible and substantive

34 Swidler, Ann (1986) Vol. 51 p. 273 ff.

35 Ibid, p. 277.

36 Hannertz, Ulf (1969, p. 186 ff).

37 Ibid.

38 Swidler, Ann refers, here, to a similarity to Pierre Bourdieu's term practice. Cf. Bordieu, Pierre (1977). Bordieu also emphasizes an understanding of culture in terms of strategies.

39 Ibid, p. 276 note 9.

40 Cf. Bordieu, Pierre (1977, p. 82 f), where Bordieu describes habitus as "a system of lasting, transposable dispositions which, integrating past experiences, functions at every moment as a matrix of perceptions, appreciations and actions and makes possible the achievement of infinitely diversified tasks, thanks to analogical transfers of schemes permitting the solution of similarly shaped problems ..."

41 Mead, George Herbert (1936, p. 42). 
actions. This relates to outcome-determined activities which people employ to satisfy their material needs. Weber argues that satisfying human needs can be divided into inner and outer worlds. In extension, one could claim that Habermas divides individuals' spheres of life into inner and outer worlds. Habermas uses the terms symbolic and material reproduction to distinguish between the two. All living systems have two parallel process paths, one physical or material and one logical. ${ }^{42}$ The material process refines and converts minerals and other natural resources into materials and energy that are then used to produce physical goods that humans desire to satisfy their needs. The logical or inner process refines ideas and notions into knowledge and information and thereafter into logical goods and services.

Material reproduction, which is related to the outer world and satisfying people's material needs, has demanded and demands different things of humanity over time. Humans are perpetually involved in creating the world into which they are born. This means that cultural skills required by the individual to procreate change over time. This applies to both the inner, symbolic world and the outer, material world, in which the emergence of or changes in social norms are based. The culturally created and symbolically constructed world has a longer life cycle than the physical world, which is renewed at a more rapid rate. The term cultural lag is sometimes used to refer to when a society's material and technological changes move quicker than its cultural superstructure of values and norms. ${ }^{43}$ This is viewed as a threat to social integration and can result in social unrest. I shall return to this in the following chapter.

Habermas emphasizes what he refers to as communicative actions as the mechanism that creates and maintains the lifeworld. Communicative actions, Habermas argues, are not just a question of arriving at a mutual understanding. Individuals also interact with others to develop and renew both their membership in their social group and their identity. ${ }^{44}$ This communication allows cultural knowledge to be transferred, thereby enabling social integration and the socialization of individuals.

From a reproductive perspective, culture provides a mutual understanding of the world, according to Habermas' interpretive schema. Culture can be seen as a network of interrelated schemas, where analogies comprise bonds that create paths along which generalizations and innovations emerge. ${ }^{45}$ Society consists of those legitimate social orders as described above by Misztal. The individual's personality is based on interactive skills on which the necessary creation of identities is based. ${ }^{46}$ If any of these reproductive mechanisms fail, different kinds of crises arise. If culture fails to provide people with an interpretive schema, a sense of

42 Ewerman, Anders (1996, p. 47).

43 Swedish National Encyclopaedia, volume 11, p. 163.

44 Habermas, Jürgen (1987) Vol 2, p. 139.

45 DiMaggio, Paul (1997, p. 281).

46 Ibid, p. 143. 
disorientation and meaninglessness emerges. This leads to disruptions to legitimacy in society. If social integration in a society does not work, anomie emerges, i.e. the individual experiences a sense of normlessness and alienation. There is thus a relationship between individuals' ability to orient themselves in society and society's reproductive capacity. Alfred Schutz argues that crises occur when "thinking-as-usual" and tried and tested prescriptions for action have broken down. ${ }^{47}$ If socialization fails at the individual level, psycho-pathological conditions emerge. Émile Durkheim studied suicide frequencies as an indicator of such conditions. In our era, and for the same reasons, it might be appropriate to study cases of anorexia among young girls and the harm and pain resulting from self-injuries.

\subsubsection{System integration}

This relates to internal restrictions that are present in social reproduction. Material production can create outer limits around social reproduction. It must be viewed as individuals pursuing goal-oriented activities within the context of the various systems created by humans. When observing how reproduction functions in our society from this perspective, it might be more productive to discuss systemic integration rather than social integration. This has to do with different kinds of action systems that people create to satisfy their material needs. These systems follow a self-regulating model in which logic and construction are dependent on the system's functions, construction and complexity. One can conclude that the more developed these systems are with regard to technology, economy, politics and bureaucracy, the more independent they become. Actions performed within the system are driven by interests tied to such purposes for which the system provides. Within the systems, there are what Habermas refers to as steering media. Within the economic system, money constitutes the steering media. What constitutes good and bad, or rational behaviour, etc., is governed by economic and monetary outcomes. This, then, replaces the communicative consensus which governs actions in the lifeworld. The political and bureaucratic systems are governed by power conditions. Here, one's position within the bureaucracy or political system is what determines one's actions and relationships with other people. Habermas does not touch upon the governing mechanisms of the technological system, perhaps because they are subordinate to steering media in economics and politics. Within the context of these normative points of departure, the technological system is subordinate to the naturally given conditions, which determine what is possible to achieve given the available knowledge at a given point in time. The driving force is to reach this boundary and then expand its limits. ${ }^{48}$ This, in turn, is influenced by the systematically produced knowledge of natural sciences at hand at a given historical point in time. 
In the same way that the lifeworld is composed of society, culture and personality, the social community that the systems are based in could be said to consist of system logic, occupation and role. A system is like a game. It is composed of certain, constructive norms within which a behaviour is acted out. These norms are stable and formal by nature. They can be compared to game rules which explain which actions are allowed and the criteria used to determine success within the system/game. The contents of the actual game/system are based on a completely different matter, however; namely the objective of the system/game. ${ }^{49}$ The objective is to play the game as rationally and well as possible in order to achieve the best possible results, given the logical constraints of the game/system. These types of norms cannot be formalized beforehand in the same way. They are based in the specific conditions of each individual case. They are dependent on the counterpart's actions. They are decidedly more multifaceted and flexible than game rules that are fixed and formalized. It could be said that these norms are established while the game is being played and develop through increased knowledge and proficiency at achieving success in the game (within those activities that the system offers). Therefore, there is reason to distinguish between rules of the game and norms of play. ${ }^{50}$

Elster refers to norms that develop from the objective of the game/system as outcome-oriented, i.e. they are substantively goal-oriented, unlike the lifeworld's social norms, which are a goal in themselves. ${ }^{51}$ System-bound norms look to the future and are conditional by nature. When certain given conditions are present, a specific course of action is expected in response. This conditional element is cognitive by nature. In other words, the norm is activated under certain, actual conditions that have been identified by the actor. To apply the norm, the actor needs to have some knowledge about the purpose-oriented significance of definitive, actual conditions within the context of the system's logic. The driving force that underlies the application of the norm is based in interests that are bound to the logic of the game/system. In other words, the actor is expected to have knowledge about the most rational course of action required to satisfy a (self) interest in a given situation, within the confines of the logic and premises of the system. Applying the lifeworld's norms requires only an insight into the norm's conditional programme. Often, this knowledge also includes unconscious knowledge of the social norm itself. The norm can be internalized and appear to be a natural part of the organization of life. That is simply how one should act, full stop. The lifeworld's culturally determined norms are always present as understated conditions of social life. These norms must be accepted by the affected individuals for the sake of common survival. How they are created is another

49 I have previously expanded on this subject in Hydén, Håkan (1985) Ch. 2.

50 This is also further developed in Woodlock, John and Hydén Håkan, (f)Lex Avionica. How Professional Norms Through Soft Law Become Part of the Hard Law Regulation of European Civil Aviation Maintenance, submitted to Regulation \& Governance Journal, forthcoming 2018.

51 Elster, Jon (1989, p. 98). 
matter. They can prescribe differences in power and status, but they are no less commonly shared when seen from the perspective of the collective.

Knowledge of norms that have become established within the system is developed by the creation of special professions that become experts at playing the game, i.e. fulfilling the requirements of the game/system. A system is kept together by the norms that comprise the rules of the game. These rules define the construction of the actual game/system. The game is played/administered by professions that continue to develop it within the context of the objective of the game. Thus, there is an economic profession that consists of experts on the functions of the economic system. By using the steering media of money as a parameter, they are able to determine optimal behaviour, and against this background issue definitive action instructions for rational behaviour. In this manner, norms that guide behaviours within the context of the economic system are articulated to other involved actors. Similarly, there are technological professions that, based in their specialized skills, establish norms for what is considered necessary behaviour in meeting the requirements of the technological system. Within the politi$\mathrm{cal} / \mathrm{administrative} \mathrm{system,} \mathrm{there} \mathrm{are} \mathrm{professional} \mathrm{bureaucrats} \mathrm{who} \mathrm{articulate} \mathrm{what}$ is formally deemed as rational action based in a normative perspective; different kinds of management cultures develop. ${ }^{52}$ The legal profession can be seen as a special case that authoritatively establishes the contents of the formal rules provided by the legal system. Social services are a profession that lay claim to being the most appropriate profession for deciding which norms are most devoted to social issues, etc. Within the context of these systems, there are, therefore, two types of norms. Some norms are expressed as game rules that the professional actors are "born into", so to speak, and are considered subordinate to others and over which they have little influence. Other norms emerge as a result of the objective of the game/system which is determined by the logic of the system, the norms of play, and which the professional representatives themselves take part in creating.

Within the systems, personality corresponds to the lifeworld terminology used for the role concept. This does not mean that the concept of roles should not be applied, including within the concept of social systems, and therefore it continues to be used. In social contexts, too, playing roles to find one's own identity is a well-known subject. When I refer to the concept of roles here, I refer to a more formal interpretation. We do not play roles - we have certain roles. It is the set of roles, determined by the system via the profession, that creates identity and self-perception. The application of norms is therefore determined by the (public) interest related to the public role, and not to individual interests based in the private personality, which belong to the sphere of the lifeworld. The identity provided by this role may harmonize or conflict with the identity the individual gains via cultural reproduction in the lifeworld. ${ }^{53}$ Berger-Luckmann uses the terms pri- 
mary and secondary socialization to distinguish between socialization processes linked to the lifeworld and the system, respectively. ${ }^{54}$ Primary socialization is mainly provided by the family but also by the education system when it comes to learning communicative skills related to basic functions such as reading, writing and counting. ${ }^{55}$ Primary socialization is mainly a meaning-creating process, as has been discussed above, through which the individual's self and self-perception is created.

As the individual grows up and enters into a profession, the socialization process transfers into a secondary phase, as described by Berger-Luckmann. ${ }^{56} \mathrm{Sec}$ ondary socialization has to do with internalising institutional subsystems, while their nature and distribution depend on the complexity of the division of labour and the division of cultural capital in society. Secondary socialization refers to when an individual gains knowledge that is role-specific. Berger-Luckmann states that the secondary socialization subsystem is an expression of limited realities, unlike the entire lifeworld ( base-world) which is acquired through primary socialization. Internalization of secondary socialization can allow for several disparate realities without requiring that the individual identifies with them. The individual may internalize the new reality without recognising it as his or her reality. Instead, it is a reality that is employed for specific purposes in connection with the actual function of the role. Berger-Luckmann refers to this concept as roledistance, and it is further developed by Erving Goffman. ${ }^{57}$ If this arises in connection with the primary socialization process, the kinds of psychopathological disturbances described by Habermas above develop. I shall return to the topic of role-distancing that can develop as a result of disharmony between primary and secondary socialization's requirements of individuals.

In contrast to Haberman, Berger-Luckmann characterizes both worlds, the lifeworld and the sub-worlds that result from secondary socialization, as consisting of normative and affective as well as cognitive components. Berger-Luckmann argues that "this process of internalization entails subjective identification with the role and its appropriate norms". ${ }^{58}$ Berger-Luckmann also points out that secondary socialization is dependent on cultural skills that are linked to primary socialization's symbolic universe. This changes over time. Berger-Luckmann states that "there is a great deal of socio-historical variability in the representations involved in secondary socialization". 59 The authors emphasize the difference between the anonymous role concepts of secondary socialization and the identity-creating function of primary socialization. The practitioner of the role

54 Berger, Peter and Luchmann, Thomas (1991, 1966).

55 For more on the concept of primary socialization, please see Berger, Peter and Luchmann, Thomas (1991, 1966, p. $149 \mathrm{ff})$.

56 Ibid, p. 157 ff.

57 Ibid, p. 230 note 15. Berger-Luckmann refers to Goffman, Ervin (1961) (Asylums, New York 1961).

58 Ibid, p. 159.

59 Ibid. 
function is assumed to be easily replaced by another individual. He can, without further ado, establish distance between himself and his own reality, on the one hand, and his partial self as determined by his specific role, on the other. The secondary socialization process of the role function is characterized by being rational and emotionally controlled. Induction into a professional role is an exceedingly formal, unemotional and rational learning process. ${ }^{60}$

\subsubsection{The relationship between lifeworld and systems}

There is not much empirical research on the relationship between the two normative worlds. Probably the closest thing we have is the traditional sociological methodology known as life-mode analysis. ${ }^{61}$ "The life-mode concept is an analytical tool that enables us to merge different parts of our lives into a cohesive sum of different practices" (author's translation), as Gunnar Andersson writes in his book Leva för jobbet och jobba för livet. ${ }^{62}$ A practice is understood to consist of several different parts, such as work, family life and leisure. Every life-mode has a basic form in which its practices are based, and this basic form generally consists of the mode of production practised by the individuals. The mode of production belongs to one of the aforementioned outcomedetermined systems.

Gunnar Andersson also discusses where life-modes originate. Perceptions of reality specific to a life-mode are assumed to develop from an internalization of norms and values via the particular type of socialization that the child has been subject to while growing up. This is supplemented with the individual's experiences as he enters into occupational life. It is the individual's position within the production chain, which by functioning as a guarantor of existential conditions, also becomes crucial to the life-mode. This can result in a contradictory process that does not always produce a homogenous perception of reality. "Life-mode methodology is largely silent when it comes to linking childhood socialization with adult practices, or, in general, the mediation between the material and the ideological elements of the life-mode", Andersson states (author's translation). ${ }^{63}$ The different types of practices are based in fundamentally different relationships between work and play. Seen from this perspective, one dominating factor is the impact the basic mode of production, paid employment, has on the life-mode and the resulting ideologies. Leisure is subordinate to the demands of work and is more like a supportive supplement to working life. ${ }^{64}$ Today, social media and

60 Ibid, p. $163 \mathrm{f}$.

61 Højrup, Thomas. (2003). State, culture and life-modes: the foundations of life-mode analysis. Aldershot: Ashgate. The life-mode concept is somewhat controversial, cf. e.g. Bjerén, Gunilla. (1991). Livsformer och samhällsförändring i Sverige. Kvinnovetenskaplig tidskrift, Vol. 12, No. 2, pp. 18-30.

62 Andersson, Gunnar (1993, p. 48).

63 Ibid, p. 49.

64 Ibid, p. 50. 
the possibilities of working from home made possible by the digital revolution also play a role in this context.

The core issue for the social sciences, according to Habermas, is how to satisfactorily merge the two concepts of lifeworld and system in order to increase our understanding of the conditions of human survival and social reproduction. To put it in his words: “( $\mathrm{t}$ )he history of social theory since Marx might be understood as the unmixing of two paradigms that could no longer be integrated into a two-level concept of society connecting system and lifeworld". ${ }^{65}$ Habermas explains that this concerns two different conceptual strategies used for understanding society. ${ }^{66}$ Norm science claims to contribute to scientific developments in this direction. From a norm-scientific perspective, one could say that there are two different worlds that together create the initial starting point when determining normative aspects. In the first case, the systemic starting point, what becomes normative is determined by what is deemed rational according to the logic and construction of the system. In the second case, the culturally influenced lifeworld, what becomes normative is determined by the social norms that comprise the (symbolic) social community. The norm-scientific perspective provides us with tools for studying the conflict between these two worlds and how it is solved through human practices. We shall take a closer look at these two worlds before using analytical tools to study the nature of the conflict.

Habermas' point of departure is that society consists of "systematically stabilized complexes of action of socially integrated groups". ${ }^{67}$ Furthermore, Habermas argues that society, as it develops, becomes increasingly differentiated both in terms of system and lifeworld. Systems develop by increasing their internal (self-) governing capacity, thereby making them increasingly independent. Systems, professions and roles become more closely linked together, while the lifeworld, in contrast, is expressed through a division in society, culture and personality. One could say that while system integration grows stronger, social integration dissolves. In modern societies, lifeworld and system tend to take different paths. ${ }^{68}$ During this process, the lifeworld is downgraded from its dominant position and becomes one of many systems as social differentiation increases, according to Habermas. Systems created by humans to satisfy their material needs become increasingly disconnected from the social structures that have enabled social integration. Habermas describes this as the lifeworld no longer being necessary to coordinate actions. He also states, on the topic of steering media, money and power that "(s)ocietal subsystems differentiated out via such media can render themselves independent of a lifeworld pushed out into the system environment". ${ }^{69}$ Habermas describes this as the "technicizing of the lifeworld". In a similar

65 Habermas, Jürgen (1987) Vol 2, p. 202.

66 Ibid, p. 151.

67 Ibid, p. 152.

68 Ibid, p. 154.

69 Ibid, p. 281. 
manner, Niklas Luhmann emphasizes that social integration is no longer maintained by people interacting with each other within social systems, but by social mechanisms that are determined by functional links and structural relationships. ${ }^{70}$

Habermas' thoughts on the lifeworld correspond with Ann Swidler's comments on the two different situations in which culture plays different roles. ${ }^{71}$ Swidler distinguishes between unsettled and settled cultural situations, and she argues that we need to apply different models to understand these different situations. Unsettled cultural phases display characteristics that can be found in my reference to Habermas' phrase, lifeworld. Swidler situates the unsettled phases in the context of societal changes. In these situations, culture becomes expressive. Ideologies and religions play a significant role in organising social life. They contribute to establishing new lifestyles and/or action strategies. ${ }^{72}$ The importance of culture in these situations is related to people learning new ways of organising individual and collective actions; when they begin to practice something they are not used to, doctrines, symbols and rituals become directly involved in shaping behaviour, Swidler argues. She also describes a continuum from ideology, via tradition, to common sense. An ideology is very much an articulated, self-aware belief system that has its own rituals and which can be expected to provide the individual with unambiguous action instructions. Swidler views ideology as a developmental stage in a cultural meaning-making system. Ideologies emerge in times when competing ways of organising behaviour emerge. Culture has a direct influence on behaviour. Doctrines and propaganda instruct people how to behave and provide models for social lifestyles. Different interests play roles when societies go through change. The role of ideology in this context is to act as a reinforcement of a given interest by constructing and regulating the new - desired - behaviour pattern. Tradition, on the other hand, represents cultural ideas and practices that were expressed in an earlier era and are now taken for granted, and therefore appear to be an inexorable part of life. Since they are diversified rather than unified, partial rather than universal, they are not always received with enthusiasm. People are aware of their existence but do not necessarily participate in them. Common sense is composed of a set of assumptions about the world that reside so deeply in the subconscious that they appear to be a natural and indisputable part of society's structure.

Cohesive ideologies only develop once alternative ways of organising human actions have emerged. Such ideologies, often supported by social movements, act as models for new organizational patterns and influence social structure, Swidler claims. ${ }^{73}$ This leads us to Manuell Castells' distinction between what he calls resistance identities and project identities. ${ }^{74}$ To begin with, Castells argues

70 Luhmann, Niklas (1986, p. 234).

71 Swidler, Ann (1986) Vol. 51 p. $278 \mathrm{ff}$.

72 Cf. e.g. Max Weber's analysis of the role of religion in Max Weber (2009).

73 Swidler, Ann (1986) Vol. 51 p. 280.

74 Castells, Manuel (2000a) Vol. 3, pp. 382. 
that it is necessary to distinguish between social movements that are a part of the existing social structure, such as the labour movement during industrialism, and movements that are based on an alternative form of logic. Castell references nationalism, localism, ethnic separatism and cultural collectives as examples of movements that break off from general society and rebuild their institutions not from the bottom up, but rather from the inside out. This, Castells explains, has to do with who we are versus those who don't belong. He also exemplifies this using the examples of feminism and the environmental movement. Both these movements were founded in a rejection of basic principles on which our societies are based, i.e. patriarchy and productivism. This has, during the establishment of these movements, given birth to a resistance identity, that is to say, they identify by resisting existing systems and cultures. In order to function as a force of ideological change, these movements have to redefine their strategies from reactive to proactive, i.e. they have to move from rejecting the existing conditions to accepting something new. The new may then be based on values that are upheld by these social movements and expressed in such a way that they gain cultural importance, i.e. they become an influence in people's lives. ${ }^{75}$

In stable, social situations (settled lives), culture is an indivisible, but unconscious, part of people's actions. It is here that we find the greatest difficulty in examining what is specifically based in culture, since culture, under these conditions, has become an integrated part of the social structure. Clifford Geertz explains that culture in these cases provides a model for, and of, experience. ${ }^{76}$ It is also difficult to separate the cultural impact on human behaviour under these conditions due to the somewhat vague link between culture and behaviour. Swidler explains: "People profess ideals they do not follow, utter platitudes without examining their validity, or fall into cynicism or indifference with the assurance that the world will go on just the same". ${ }^{77}$ In culturally stable periods, culture and social structure become too closely merged and too separated to allow for analysis. In stable periods, there are no movements competing for different kinds of social organization. Normality rules. The primary function of culture in such times is to restrict the number of alternative strategic actions. Swidler also brings up what she refers to as a "cultural lag", i.e. a sort of postponement between what is culturally possible based on the social structure and what constitutes actual lifestyle. This, according to Swidler, is not because people cherish old, cultural values, but rather because only reluctantly do they abandon familiar, tried and tested strategies.

If we link Swidler's argument to Habermas' discussion on lifeworld and systems, we find that the lifeworld displays properties that Swidler characterizes as unsettled situations. This can be compared to the properties that characterize

75 In her dissertation (1999), Minna Gillberg provides an example of how environmental movements could develop in this direction by influencing actors they oppose to act in a manner that benefits the movement.

76 Geertz, Clifford (1973).

77 Swidler, Ann (1986) Vol. 51 p. 280. 
primary socialization when applied to society in the form of emotional commitment, alternative possibilities and active learning. When social progress, then, crosses over into a phase strongly characterized by systems, culture "retreats into itself". It loses importance and becomes a marginal phenomenon. During this process, the importance and transformation of the role culture plays changes simultaneously with the role assigned to systems in the pursuit of satisfying human needs.

Systems that are constructed to satisfy the outer world's material needs have their own logical system and communication mechanisms, their own norms and values. However, it is the lifeworld that defines good and bad norms within the social system. The outer world's outcome- determined systems must be founded in the culturally influenced lifeworld. They must be institutionalized. This may lead to a period of more or less conflict. Habermas argues that there will be pathological consequences if system integration is based in the symbolic reproduction of the lifeworld. ${ }^{78}$ Erich Fromm, in the book Ett friskare sambälle, Ch. 2 , expressly poses the question: Can a society be sick? - The pathology of the normal. ${ }^{79}$ Fromm defines a healthy society as a society that satisfies people's needs. Based in this definition, Fromm claims the following: ${ }^{80}$

When humans began to construct the new industrial machinery, they were so focused on this new task that it became the primary goal of existence. Instead of focusing her energy on seeking God and redemption, she was now focused on ruling over nature and improving her creature comforts. She ceased to use production as a path to a better life and elevated it to a goal unto itself, more valuable than life itself. Through their continued division of work, mechanization and developing societies' progress, humans became a part of the machinery rather than its master. She began to perceive herself as a product, an investment, and her goal became to have success, to sell herself at as great a profit as possible on the market. Her value as a person came to lie in her marketability rather than in human attributes such as love, common sense or artistic gifts. Happiness became synonymous with the use of newer and better goods, consumption of music and films, pleasures, sexual indulgence, alcohol and cigarettes. Since she now lacked a sense of self, other than that provided by adapting to the majority, she becomes insecure and anxious, and dependent on the approval of others. She becomes a stranger to herself and worships her own accomplishments and leaders that she herself has picked as if they were superior to her rather than owing their existence to

78 Ibid, p. 357.

79 Fromm, Erich (1959).

$80 \mathrm{Ibid}, \mathrm{p}$. $145 \mathrm{f}$. Fromm focused on the conflicts that emerge between society and nature, rather than culture. The fact that society and human nature can place such contrary demands, thus meaning that the entire society is pathological, is emphatically claimed by Sigmund Freud in his book Das Unbehagen in der Kultur, which has also been translated into Swedish: Vi vantrivs $i$ kulturen, Stockholm 1929. 
her. To some degree, she has retreated back to a position she last had before the great development, millennia before Christ.

She cannot love or use her common sense or make decisions, she cannot value life and becomes capable of, in fact desires to destroy everything. The world is once again broken apart into fragments and loses its oneness. Humans still worship things, but now they worship their own constructions rather than nature. Contemporary society has taken its starting point in the dream of a culture that will fulfil their needs. Harmony between individual and social needs is its ideal, an end to the conflict between the nature of Man and the natural order.

Habermas argues that modern democracies are particularly characterized by systems that colonize the lifeworld. He expresses it thus: ${ }^{81}$

In modern societies there is such an expansion of the scope of contingency for interaction loosed from normative contexts that the inner logic of communicative action "becomes practically true" in the deinstitutionalized forms of intercourse of the familial private sphere as well as in a public sphere stamped by the mass media. At the same time, the systemic imperatives of autonomous subsystems penetrate into the lifeworld and, through monetarization and bureaucratisation, force an assimilation of communicative action to formally organise domain of action-even in areas where the action coordinating mechanism of reaching understanding is functionally structures of the lifeworld as a whole in question, can account for why they have become accessible to us. ${ }^{82}$

In societies with a low level of differentiation, the relationship between the outer and the inner worlds' systems are closely intertwined with social integration mechanisms, i.e. the social system's norms. In modern societies, Habermas argues, the relationship between systems and the lifeworld are based on action systems that are governed by media such as power and money. Habermas, erroneously in my opinion, refers to these systems as norm-free structures. ${ }^{83}$ However, they are not free of norms. The difference, compared to explicitly normative moral systems, is that the material (re)production process's normativity is embedded in the construction of the system itself. The normative element is an implicit component of the objective of the game/system. The system acts as a deliverer of premises for how to determine rational actions within the context of the logic of the system. Normativity is therefore not explicitly expressed as an ought condition, but it is based in knowledge about how reality is perceived at the time of a given action, seen from a systemic perspective. This insight leads to conclusions about how one ought to act from a normative perspective. It is the function that determines the

81 Ibid, p. 403.

82 Habermas, Jürgen (1987) Vol. 2, p. 403.

83 Ibid, p. 307. 
rationality that determines the norm. The norm-scientific approach may contribute to highlighting and merging these societal influences.

The fact that Habermas and other social scientists do not perceive action imperatives within the context of the systems as norms is likely due to a weak understanding of norms being determined by and composed of a values system. In the context of system imperatives, values are instead overdetermined and embedded in the system's functional construction. It is the particular interest that is linked to the material (re)production combined with the construction of the system that creates the norm, not the values system. It lays the foundation for the conflict between systems and lifeworld, or as Habermas puts it, systems that colonize lifeworlds.

This could be described as a normativity that is not socially determined. ${ }^{84}$ When defined as above, I agree that there is a norm-free sociality. But the point is that there is another normativity, one which is systemically determined. Habermas' definition implies that a norm must be created in mutual understanding in order to be categorized as a norm. Within economics, technology and politics, the concept of norms is generally not used when referring to causal relationships. Nonetheless, the conclusions that can be drawn from analyses of causal conditions within these systems have the same characteristics as mutually agreed-upon norms. The mutuality in these cases can be said to be created through the acceptance of these systems that have been constructed to satisfy human needs. ${ }^{85}$ This can be seen, for example, in the fact that when said acceptance falters, the systems lose legitimacy and thereby their normative power.

A further reason for why system imperatives are not understood in terms of norms probably has to do with an understanding of norms in terms of senders and receivers. According to this approach, the definition of a norm demands a sender and the receiver. When it comes to systemic norms, however, there is no specific norm sender, since the norms are embedded in the structures resulting from the construction of the system. This is not about following orders from a norm sender, but about deciphering the objective of the game and applying the knowledge to a specific situation. There may, of course, be a coach present who plans tactics and gives instructions, but in the actual moment of action, there is no external norm sender. One could, here, refer to "independent imperatives" ${ }^{86}$ Norms for actions come from within and are based on the individual's application of the rules of the game which provide routinized action instructions, but allow for some space or variations within a theme determined by the game.

Habermas argues that formal organizations not only relinquish their culturally based obligations and positions specifically linked to individual personalities. ${ }^{87}$

84 Banakar (2015).

85 Cf. theories on society in terms of the social contract where Thomas Hobbes, Leviathan, holds a prominent place.

86 Cf. Olivecrona, Karl (1966), where Olivecrona uses this term to designate legal rules in the event that they lack a commanding subject. Cf. Hydén, Håkan (1985, p. 27).

87 Habermas, Jürgen (1987) Vol. 2, p. 309. 
They also release themselves of the demands of the lifeworld by neutralising the normative tapestry of informal, traditional and morally regulated action contexts. The lifeworld and systems do not co-exist in a hierarchic relationship. They stand facing off against each other as socially and systemically integrated spheres of action. I argue that they oppose each other as two normative worlds, each with its own normative characteristics.

The relationship between systems and the lifeworld is not the same as between private and public spheres. The dividing line between systems and lifeworld runs between economy, politics and bureaucratic administration, on the one hand, and private spheres of life such as the family, neighbours, voluntary organizations organized as public spheres that are not subject to steering media, on the other hand. Tendencies toward increasing bureaucratization are perceived as increased independence and standardization of the administrative system as opposed to the culturally based demands of the lifeworld. This has to do with the emergence of tendencies toward formal rationality, which Max Weber linked to the emergence of modern society, in which legal order played a prominent role. ${ }^{88}$ From a civil servant perspective, as well as according to the ideals of the legal state, this dividing line is desirable and important. Habermas also brings up the difference between Karl Marx and Max Weber with regard to Marx and his focus on analyses of systemic integration, while Weber busied himself with the problems that arise from basing an analysis in social integration. ${ }^{89}$ Marx's separation of systems and lifeworld, according to Habermas, becomes evident in the metaphors he employs when referring to the "realm of necessity" and "the realm of freedom". ${ }^{90}$

Habermas emphasizes that even if modern societies are dominated by systems that function together as coordinated mechanisms to maintain social cohesion, the internal weighting between social integration and system integration, between lifeworld and systems, is an issue that can only be addressed empirically. ${ }^{91}$ Habermas refers only in passing to developments in this area. For him, it is the simultaneous conflict between the two worlds that is of interest. All societies must be integrated in both aspects and are therefore confronted with the fundamental problem of how to combine them. ${ }^{92}$ This is the problem Habermas addresses in his texts. As suggested above, Habermas sees developments in modern society and welfare states in terms of an increasing systemic dominance. However, he appears to adhere to a linear understanding of history which leaves him and his reader in a state of bemusement with regard to the future. Therefore, for Habermas, the problem is how to solve the conflict between system and lifeworld. Judging by Habermas' later work, he seems to have placed his trust,

88 Weber, Max (1978) Vol. 1, p. 144 ff.

89 Ibid, p. 313.

90 Ibid, p. 340. Habermas criticizes Marx for lumping together systems and lifeworld, thereby missing the distinction between system differentiation in modern society and the class-based form through which it is institutionalized.

91 Ibid, p. 312.

92 Cf. McCarthy, Thomas (1985, p. 29). 
in this context, in innovations within the legal system. In Fakticitet und Geltung, published in the 1990s, or Between Facts and Norms in English, Habermas developed, as a complement to the legal state's formal, conditional right and outcome-determined legislation, a procedurally based legal paradigm founded in reflexive processes. ${ }^{93}$

Habermas describes the problems he addresses here as a need to reconstruct the terms of social integration that he sees coming under threat in our time. He explains: ${ }^{94}$

The starting point is the problem of how social order is supposed to emerge from processes of consensus formation that are threatened by an explosive tension between facticity and validity. The double contingency that every interaction must absorb assumes an especially precarious form in the case of communicative action, namely, the ever-present risk of disagreement built into the mechanism of reaching understanding, where the costs of dissension are quite high from the viewpoint of action coordination.

However, Habermas does not situate these arguments against a historic background, and therefore his theory gives us a static view of society. He treats the conflict between systems and lifeworld, and not least the legal system's relationship to this conflict, as if it was eternal, despite the fact that he also points out that it emerged in modern society. For Habermas, the notion that the problem can be viewed as a temporary dilemma in history that can be solved is inconceivable - it can only be dismantled over time.

\subsection{The S-curve and the developments of the two worlds over time}

\subsubsection{Society's material progress - the successive establishment of the systems}

In order to establish a dynamic, social theoretic basis for further analysis, we need to revisit the concept that describes social development in terms of S-curves or waves, as described in Chapter 1 . The $S$-curve describes how society follows a course of minor to major events according to four stages: birth, growing up, maturity and death. If we approach the discussion about lifeworlds and systems from this perspective, there is good reason to refer to the lifeworld as part of the fundamental establishment of the social system. In the same way that an individual's course of life is characterized by an introductory phase consisting of primary socialization during which the individual constructs their lifeworld, it could be said that a new social era passes through its formative years during which time the 
lifeworld is constructed. A society is born, according to the perspective laid out in Chapter 1 , in the wake of a new core technology. This is stage 1 of the establishment of a new era. It produces social changes. Society is forced to adapt to the social organization required by this new technology, which in turn creates a need to learn new social patterns, stage 2 . New social norms develop. This phase of social development is characterized by the construction of what Habermas refers to as social integration.

When these conditions have stabilized, society progresses to stage 3 , a maturity phase, which includes economic exploitation of the new core technology. During this period, the focus of social progress shifts from having been dominated by the demands of the primary socialization process of social integration to developing social adaptions to the emerging economic systems that are to be exploited. It is here that the secondary socialization process becomes applicable both at a societal and an individual level. Systems are constructed that require an increasing number of professions. The more differentiated and functionally specialized a society becomes, the greater the fragmentation of knowledge and specialized learning required in the form of secondary socialization becomes. When the economic system and all its supplementary subsystems have developed to the limits of their capacity, the political system steps into the arena. Naturally, it is present in earlier phases as well, but mainly as a supplement to the social order. The cultural attributes of primary socialization have a longer periodicity than do the attributes of secondary socialization, with its various systemic natures sprung from its core technology. In other words, primary socialization is an ongoing process and does not change much, while secondary socialization develops mainly in the wake of a new social era that has had time to become established and mature, as in step 3 and 4 in Figure 2.9.

Based in Swidler's arguments, it could be stated that at the individual level, cultural upbringing in terms of primary socialization continues to be necessary over time, regardless of the stage of development of the society, while secondary socialization requirements, influenced by the social structure at a societal level, result in culture losing importance. During the large-scale phase, systems tend to colonize lifeworlds and the normal mechanisms of primary socialization by infiltrating the lifeworld's institutions. To give an example, the state, via the institution of public education, takes over components of upbringing that are premised on a more passionate relationship than the state can offer. It would seem, in our times, that many people believe that primary socialization is best left to public services. In welfare states, parents place too much responsibility for their child's upbringing in public institutions.

Seen from the perspective of the S-curve, Swidler's most important contribution is that she clarifies that culture interacts with social structures and that this relationship varies over time and adapts to different historical situations. ${ }^{95}$ In the beginning of a social phase, culture plays an important role by bringing 


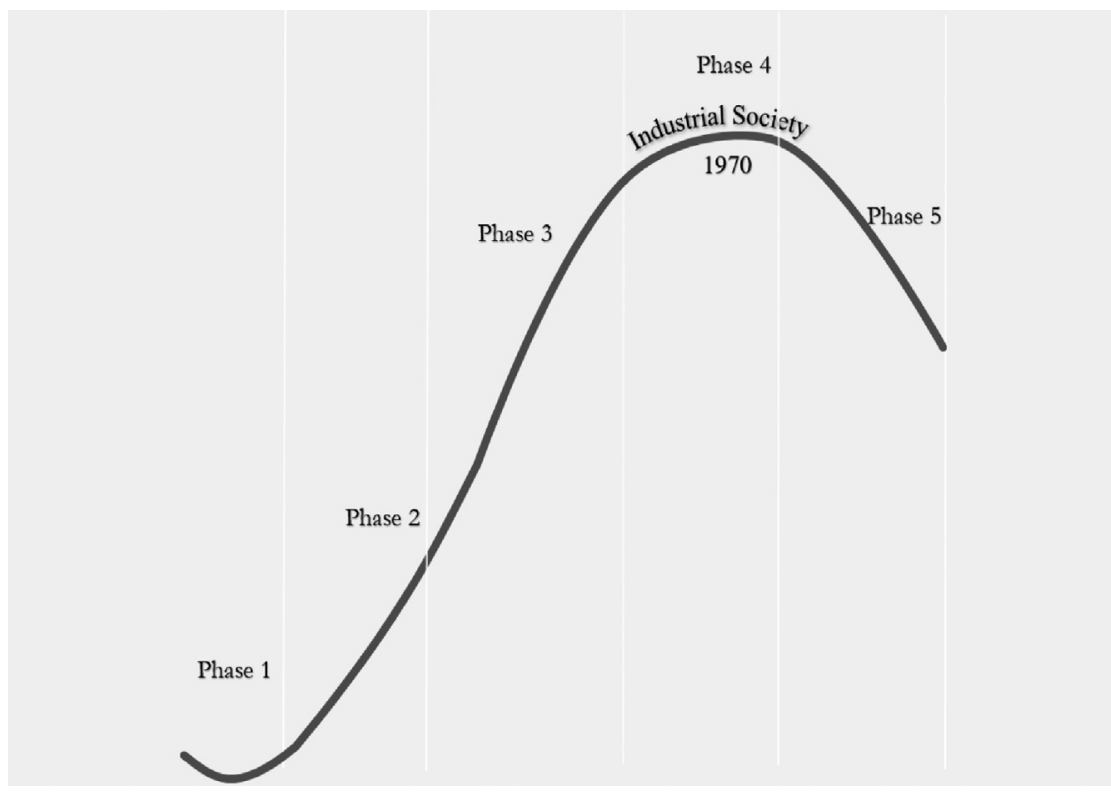

Figure 2.9 The S-curve and the development of trust

visibility to action strategies. Through ideologies that express alternative actions, a new social structure takes shape. In the final analysis, Swidler argues that structural and historical coincidences determine which strategies and therefore which cultural systems are to emerge. When these have been established and become stable, they begin instead to act as restrictions on behaviour. The cultural repertoire restricts the range of possible action strategies. At the same time, the social structure obscures culture. It becomes a system among others and is dismissed to the system's periphery, according to Habermas' analysis. During stable historical stages, culture contributes to reducing the number of possible actions because the costs of cultural reorientation are too high. So what does it take to make a change?

This depends on which system is driving social progress at a given time, something that changes over time. The $S$-curve is based on the logic that a system can only be beneficial up to a certain point, upon which it becomes increasingly counter-productive. In the fourth and last stage, society enters a downward phase which ends in its dissolution and death. This phase is characterized by the political system intervening and supplementing the economic system in order to "suck out" as much as possible of the existing core technology. During this time, a new social era has begun to develop, which means that stage 4 of the old era is equal to stage 1 of the new one. This means that the old social era places restrictions on the cultural repertoire's alternative, strategic actions. The new social era, however, develops in reaction to the old one. We begin again, so to speak, but 
based in a new core technology. The opposite of the components of a new social era, however, can be found at the end of the S-curve, i.e. at the highest point of stage 4.

Social progress can be seen in terms of a progression from an S-curve to another as part of the dialectic process. Society develops according to dialectic logic, i.e. through contradictions. According to Friedrich Hegel, dialectic logic can provide systematic knowledge of how a certain historical period, such as the Enlightenment, progressed to the next period, Romanticism, which was in many aspects the former era's opposite. The conditions of the dialectic process are, according to Hegel, that the formal aspects have not been completely separated from the contents. How one thinks is related to what one thinks. ${ }^{96} \mathrm{Hegel}$ developed a theory of the thought process as a dialectic process that passes through three stages. ${ }^{97}$ The concept in which the premise is based is the thesis. In time, this thesis is forced over to its anti-thesis and the two conflicting ideas are finally united in a synthesis. Hegel's theory on the development of thought begins in the abstract concept of being which then converts to its antithesis, nothing. The synthesis, then, is becoming, in which both polar opposites are consolidated. Becoming includes both birth and death. Together they form the endpoints of the $S$-curve and underline thereby that the synthesis is always at the centre point of the $S$-curve of the social era to follow.

During the first two phases, the core technology's production potentiality is developed. This occurs locally, driven by amateurs exploring and experimenting. They are spurred on by a unified worldview, and they endeavour to produce new things by compiling things in new ways. Digital technology was developed initially by a small sphere of enthusiasts. In the late 1960s, the seed was sown that today has given us the Internet. Early on, communication was carried out using the public telephone system. In the early 1970s, two researchers began communicating with each other by sending files to each other. The file transfer $\mathrm{p}$ they were using was modified and adapted to improve its text message functions, and email was born, something we take for granted today. The exact date of the birth of the Internet depends on who one asks. Some claim it was born on January 1, 1983, when ARPANET converted from two-way communication via NCP, to the more flexible TCP/IPprotocol. IP numbers, precise Internet addresses, were introduced. Each device that connects to the Internet (such as a router) was assigned a unique IP number. This allows computers to find each other when they communicate. This system continues to be the system used on the Internet.

But for a long time, there was another tough competitor. During the 1980s and early 1990s, "The Battle of the Internet" was fought as a result of European telecommunication companies' preference for what is known as the X.25 system, which apart from being safe allowed authorities to charge a fee for traffic. On 
April 7, 1983, the first "real" email was received in Sweden by pioneer Björn Eriksen, who became a leading figure in Internet developments in Sweden. A few years later, he reserved the Swedish top-level domain name ".se". In the early summer of 1984 Sweden received its first Internet node, when research assistant Ulf Bilting at Chalmers University in Gothenburg connected a computer to the Internet.

With regard to Sweden, Internet developments in the 1980s occurred mainly at universities. Via Sunet the Swedish seats of learning are linked together with a network, the Internet - the World Wide Web (WWW) - which became a reality in 1990 when Tim Berners-Lee created a system of addresses, URLs and links allowing different documents to suddenly be connected within a network. Furthermore, it is free to use for both developers and users. The very first website was launched in 1991 for the research centre CERN in Switzerland, and remains in use to this day.

In tandem with the Internet, the more folder-like system Gopher was born, which many people thought would be the browsing tool of the future. However, this system lost its struggle against the WWW in 1993 when the Web browser Mosaic was launched. This allowed the user to also view images, unlike previous versions that only displayed text.

Now things really started to happen. For Sweden, 1994 was a key year for developments. Not only did Carl Bildt email Bill Clinton (as the first state leaders in the world). Later that same year, the government awarded SEK I billion to the newly created KK Foundation to be invested in technology in, among other places, schools. The IT Commission was formed and published the report "Vingar åt människans förmåga" ("Lend wings to people’s abilities") and launched a number of digital projects in schools, among other places. And for the first time, the results of the election were sent out by email. As a result, a number of newspapers published their first websites. The very first newspaper to do so was Aftonbladet.

The same year, 20-year-old Ragnar Lönn kicked off his Internet provider service Algonet (Älgö-nät, named after Älgö in Nacka where Ragnar grew up). He focused on private persons (while hoping to reach 400 paying customers) and persuaded ordinary people to surf the Internet in increasing numbers. Initially, his business was located under a hot tin roof at the shared office of the publishing company Semic, where Ragnar manually rebooted modems. In time, however, his business began to expand significantly. Around this time, the Internet began to become a fashionable word. CEOs wanted @ addresses on their business cards. A new phenomenon arrived on the scene: the web bureau. These companies' employees are often self-taught, male adolescents. In 1995, a new transatlantic cable was laid. It provided a $34 \mathrm{Mbit} / \mathrm{s}$ connection, which increased Sweden's capacity significantly. It was, at the time, the most powerful international connection. The previous record was $6 \mathrm{Mbit} / \mathrm{s}$.

As mentioned, the World Wide Web became available via a client program that went under the name Mosaic. Just like today, information was retrieved via a link or by the user typing the correct Internet address (URL). Mosaic was 
developed by Jim Clark and Marc Andreessen, who later went on to start the company Netscape, whose main product was Netscape Navigator. The software was primarily distributed via the Internet. For a long time, Netscape Navigator almost completely dominated the market. Microsoft didn't release Internet Explorer until 1995, but it wasn't until the development of Internet Explorer 4, in 1997, that Microsoft began to take market shares from Netscape to any significant extent. One of the reasons for Internet Explorer's success was that the browser was integrated with Windows. For much of the 2000s, Internet Explorer completely dominated the market despite the fact that many users remained loyal to Netscape while others switched to new browsers such as Opera. Mozilla Firefox has been around for a few years and has managed to take some market shares, and Google recently released their web browser, Chrome. Internet Explorer has $60-70 \%$ of market shares.

In 2010, a large number of Swedes begin to watch films using services such as Netflix, HBO Nordic, Viaplay and SVT Play. Playing online games has, of course, been a common occurrence since the 1980s. One game that became a major success is Minecraft. It was launched for retail in 2011 and was created by Markus "Notch" Persson from Norsborg, Sweden. The game allows the user to create his or her own worlds within a Lego-like interface. "Notch" sold the company a few years later to Microsoft and became a multimillionaire. The following year, companies and ordinary Swedes were able to access the Internet after Swipnet, part of the Stenbeck group, became the first commercial Internet provider. Televerket could have been first, but their preference for X.25 technology led them to decline the offer.

During this period of development, there were several pretenders who aspired to become the dominant actor. The development of search engines - a key component of the introductory phase of the information society - can be used to illustrate this. ${ }^{98}$ In the early stages of the Internet, search engines did not dominate the sphere, and instead, users largely visited link directories which were organized by category. Today, however, search engines have taken over, and link directories are a memory of past times. The first known search engine, called Archie for "Archive", was created in 1990 by a college student in Montreal. At the time, the Internet had not yet gone global, and therefore the search engine bore little resemblance to search engines as we know them today. It is assumed that the first genuinely sophisticated search engine was Excite, which was capable of doing what no other search engine had yet been able to do - it analysed the contents of webpages and could thereby present relevant pages to a previously unmatched extent. Excite was, seen from our perspective, primitive compared to the next generation of search engines, WebCrawler, Lycos and AltaVista. These were capable of summarising large numbers of pages since they indexed entire websites and not just index pages.

98 Please see, with reference to the following: Battelle, John. (2005). The search: how Google and its rivals rewrote the rules of business and transformed our culture. New York: Portfolio. 
Today, Google is the dominant search engine. This is the search engine that finally won a leading position. ${ }^{99}$ This has enabled Google's parent company Alphabet to amass a market value of approximately USD 495 billion. It is the world's largest search engine and, significantly, it is the dominant engine in Europe. Google began providing their search engine service in 1996, and since then the company has developed into more than just a search engine provider and has added an increasingly broadening range of functions and services. Google's superior position is primarily due to the search engine's capacity to provide relevant pages that have greater relevance than their competitors. For many years, Yahoo was Google's main competitor in the search engine market. However, Yahoo no longer uses their own index, i.e. their own unique search results, and instead uses Bing's index. Another difference is that Yahoo also functions as a sort of news website. Microsoft has provided various search services through the years, but since 2009, their service is provided under the name Bing. Despite attempts to challenge Google by incorporating Bing as the default search engine in Microsoft Explorer, they have only succeeded in taking relatively minor market shares. Globally, Bing is placed after both Baidu (a Chinese search service) and Yandex (a Russian search service). In Sweden it comes in at second place after Google, although it has only about $3 \%$ of market shares.

When the S-curve reaches the centre point and the new era has stabilized, it progresses from production to reproduction, i.e. it becomes focused on exploiting the existing core technology within the context of established social structures. This development is characterized by diminishing marginal benefits, which leads to the expansion of markets and a global focus. Imitators increasingly begin to copy the tried and tested technology and its administrative routines. An advanced functional specialization leads to a focus on details and a deconstructive knowledge strategy as described in Chapter 1. This aspect should be taken into account when understanding norm creation processes in society. When social progress has reached the stage where the old order of production is no longer capable of generating benefits or surplus social value, i.e. when it has reached its peak, systems that have been constructed to maintain this order tend to become counter-productive. As a result of the collapse of social organization, they begin to involuntarily provide what could be called negative citizen and customer benefits. The systems become increasingly monopolistic. It is at this stage of social progress that we find ourselves at present.

The new digital technology is used during a transitional period to strengthen these monopolistic tendencies. Whether it is the taxi business, hotels or the music industry, the most significant innovations in recent years have not been new products. The great "disruptors" of our time seem, instead, to be based on platforms that connect consumers and suppliers in novel ways. These platforms have been difficult for "traditional" companies to cope with since they have given customers greater flexibility, increased availability and lower prices. Furthermore, these

99 Vise, David A. and Malseed, Mark. (2005). The Google story. New York: Delacorte Press. 
platforms allow for new possibilities to create peripheral services and provide the customer with new experiences. At the same time, new ways of producing services develop as a result of new digital technology. These conflict with the logic of the previous society. ${ }^{100}$ The platform-based business model is fundamentally based on creating networks that in turn create value for all participants. The production of value is outsourced from the centralized company to anyone who elects to create value using the platform. So far, they have mainly changed how we as consumers buy products and services, also known as $\mathrm{B} 2 \mathrm{C}$, but the benefits of the "platform model" can also be transferred to both the B2B (business to business) market and various kinds of $\mathrm{C} 2 \mathrm{C}$ (customer to customer) initiatives. One example of this is the sharing economy. ${ }^{101}$ The sharing economy is based on various renting, sharing or borrowing arrangements rather than owning things. ${ }^{102}$ The concept also covers different ways of sharing services, swapping and giving away things. Another name for this phenomenon is collaborative consumption, which focuses on the fact that this arrangement allows a number of people to consume a product rather than each individual having to buy said product. Some examples of areas where various kinds of information technology are used are taxi services such as Uber (Schneider 2017) and GrabTaxi; crowdfunding platform Kickstarter; ${ }^{103}$ Airbnb (Gallagher 2017) which is an online marketplace for renting and booking private accommodations, as is Homeaway, which is a vacation rental marketplace with more than 2,000,000 vacation rentals in 190 countries; and Booking, a company that sells a range of travel services online (Shaw 2017). Carpools and services such as renting out conference rooms $\mathrm{C} 2 \mathrm{C}$, etc., also warrant a mention here.

The market value has risen dramatically for companies that have exploited the possibilities of digital technology. Digital technology has changed the playing field for all successors; the platforms are also the largest businesses in the global market. Facebook, Google, Amazon, Booking, etc., are examples of digital success stories in which their platform comprises their actual business idea. Their market value is many times greater than traditional industrial companies. Swedish multinational company Spotify was launched in 2008 and offers an online music service that provides the listener with access to streaming music, podcasts and videos over the Internet, while the rights holders are renumerated. Today Spotify has been introduced on the New York Stock Exchange with an estimated value of

100 Sundararajan, Arun. (2016). The sharing economy: the end of employment and the rise of crowd-based capitalism. Cambridge, MA: The MIT Press, Widlok, Thomas. (2017). Anthropology and the economy of sharing. Abingdon, Oxon: Routledge is an imprint of the Taylor \& Francis Group, an Informa Business.

101 "Här är årets alla nyord". Språktidningen. http://spraktidningen.se/nyord2015. Retrieved December 282015.

102 Varför äga när man kan hyra? Delningsekonomin och arbetslivet, Arbeidsliv i Norden 2014-12-11.

103 Kickstarter is, according to their own statement, a community of people committed to bringing creative projects to life. 
almost USD 30 billion. Another change has to do with the life cycle of companies. A few decades ago, a company's average life cycle on Standard \& Poor's 500 (stock index) was about 50 year - now it is about 15. Gaining an insight into the platform-based business model is the first step toward understanding the digital change that the economy and society are facing.

In summary, we can conclude that society's material progress occurs mainly in four steps or phases. The first phase is based on technological change in which different technological solutions, based on the same core technology, initially compete for the dominant position and leading future developments. After a while, the technological solutions stabilize to the extent that they also begin to influence social conditions and society in general. Only once this has happened does the third phase of economic exploitation of the new technology take place. In the case of industrial society, this occurred circa 1860-1940. Over time, so much surplus value is produced that a distribution mechanism becomes necessary. At this point, the political system enters as the dominant actor, initially as a collector and distributor of societally produced surplus value via taxes and fees. With regard to Sweden and Europe in general, this occurred after WWII and onwards. By the 1970s, industrial society is at its peak, according to Manuel Castells. Industrial society, according to Castells, peaked in the industrial countries of the developed world, the Organisation for Economic Co-operation and Development (OECD) countries, in the beginning of the 1970s. ${ }^{104}$ The political centre of gravity thereby shifts from distribution to crisis management as a result of increased problems which require state intervention, while simultaneously, a gap emerges between the demands and policies of the welfare state and the actual, available economic resources. This situation creates fertile grounds for the new digital technology to establish itself, as briefly described above.

\subsubsection{Society's ideological progress - the perpetual rise and fall of the lifeworld}

There are many different explanations for social progress. One explanation is that humans continuously strive for improvement during extended eras of civilization. This development occurs within the context of their dominant core technology, such as the field of mechanics during the industrial age and electronics during the digital age. This is related to path dependence. ${ }^{105}$ This progress can be seen as an extrapolation of existing technology. When a given core technology has established itself as the dominant technology, a similar development occurs in social conditions, as well as in economics and politics. This transition from one core technology to another, from one kind of society to another, also displays other

104 Castells, Manuel. (2000). 'Informationsåldern. Nätverksamhällets framväxt'. Göteborg: Daidalos.

105 Larsson, Stefan. (2011). Metaphors and norms: understanding copyright law in a digital society. Diss. (abstract) Lund: Lunds University. 
characteristics. It is characterized by change rather than progress and extrapolation. It is driven by amateurs, by inventors and eventually by innovators who are able to create large-scale benefits from the new technology. The driving force behind this progress, according to Anders Ewerman, is culture. ${ }^{106}$ John Huizinga argues that culture, in turn, is borne from and developed in play and as play. ${ }^{107}$ Myths and rituals are a form of playing - even language is a form of playing. Behind every abstract expression there is a metaphor, and every metaphor can be seen as a play on words. ${ }^{108}$ Almost everything is play at its core, according to Huizinga: law and order, trade and profits, crafts and art, poetry and science. ${ }^{109}$ He characterizes it as a voluntary activity. Force is unthinkable. There are no ulterior motives or purposes, and playing is a goal unto itself. Thirdly, it is an activity that is limited both in time and space. Playing creates order or constitutes order in itself. It follows rules. Playing has its own rules, and these are absolutely binding. Every game is like a culture. Once its form has been defined, it becomes a tradition. New core technologies or new societies are not planned or determined politically. They develop spontaneously, at first in an unorganized manner and thereafter in a more organized fashion.

Swedish social psychologist Johan Asplund poses the question: What is the essence of play? ${ }^{110}$ What makes it enjoyable? His answer is that responsivity is what makes it pleasurable and drives the desire to play. To play is to respond, Asplund claims. Furthermore, he explains, games, in contrast to play, are a form of organizd social responsivity. Games formalize social responsivity. Games abide by binding rules of the game. The rules of the game also indirectly determine the objective of the game, as mentioned previously in this chapter. The objective of the game is related to the logic that characterizes the construction of the game as determined by the rules of the game. Playing precedes the game. At the point when everything has become game and no play, culture ceases and comes to an end. From this point onwards, culture is nothing but one large framework of agreements. Eventually, the objective of the game takes over and determines the actors' actions. Asplund explains that redundancy is an inherent component of a living culture. ${ }^{111}$ Once all redundancy has been chased away and made unlawful, all there is left to do is to "lose it". This characterizes culture in our era. Extreme individualism is all that remains for anyone searching for a culture that supports their identity-creating. Anyone who "loses it" might only be playing, but it is a game that cannot, by definition, amount to more than a pinball game and therefore, due to a lack of responsivity, cannot be incorporated into culture.

106 Ewerman, Anders (1996) Marknaden 1000 år.

107 Huizinga, John (1955).

108 Larsson, Stefan. (2011). Metaphors and norms: understanding copyright law in a digital society. Diss. (abstract) Lund: Lunds universitet, 2011.

109 Ibid, p. 4 f.

110 Asplund, Johan (1987, 1992, p. 63).

111 Ibid, p. 64. 
Another (in part) explanation for the transition from an S-curve to another is that when the gap between the lifeworld and the system has grown too great, when the cultural ideals of the primary socialization process are no longer in agreement with the systemic ideals of the secondary socialization process, fertile ground for cultural renewal emerges. Alfred Schutz indirectly describes this situation when he states that "( $\mathrm{t}$ )he cultural pattern no longer functions as a system of tested recipes at hand; it reveals that its applicability is restricted to a specific historical situation". ${ }^{112}$ During this process of change, social scientists of virtue and principles will appear who adhere to an ethical code that is compatible not only with the theological lessons of previous eras but also with what is necessary to bring about moral renewal and survival. These will be followed by social movements kept together by a common ideology.

The four stages of the S-curve, when viewed as a component of society's material progress, influence which systems, technology, social conditions, economy and politics will come to dominate in a given era. All these perspectives have different normative implications that influence which norms and which legal rules will apply. Before delving further into this, we need to examine another few perspectives of the events that occur during a society's curve of progress. One such perspective deals with morality. Moral comes from the Latin moralis which means "to do with custom", i.e. traits that humans at different points in time have deemed to be good or bad behaviour. These lay the foundation for the norms that develop in the lifeworld. Morals, and the closely related concept of ethics, which is generally understood as the systematic processing of moral phenomena, ${ }^{113}$ give instructions for actions based in a values system, unlike decisions that are based in the technological and economic logic of systems. ${ }^{114}$

There are two kinds of moral values. They can either be used to point out which action-oriented goals are good or desirable or they can prescribe duties, i.e. prescribe what one ought or ought not to do. Generally, a distinction is made between consequentialism and teleologism and duty-based ethics and deontology (from the Greek deon which means duty). The deontologists may, for example, view the motive that underlies an act as the defining aspect, while teleologists claim that the intent of a motive in itself can never make an act good. For this to be possible, there needs to be a theory of values that tells us what is good (e.g. hedonism).

Furthermore, there is a distinction to be made between those that believe that it is the individual action and the results thereof that should be counted and those

112 Schutz, Alfred (1964, p. 96).

113 Filsosofiskt lexikon (1988, p. 143).

114 Cf. Max Weber's distinction between value-oriented and goal-oriented. What I would like to highlight, however, is that technological and economic logic is not only rational in terms of achieving certain goals. The point is that technology and economy also give rise to other, implicit norms that act as action instructions. They are, so to speak, built into the systems that have been constructed for the overall purpose. They are, what I call, outcome-determined and are taken for granted, and the actors are therefore far from being aware of them. 
that argue that the consequences of breaking a rule should also be considered. The former school follows what is known as situational ethics and the latter as rule-based ethics. ${ }^{115}$ In the same way, deontologists can be divided between those that argue that duties can be prescribed via general rules, such as Immanuel Kant, and those that argue that duty is manifest in the individual moment of action, such as Adam Smith.

The question is, what makes morals and ethics good or bad? The school of thought that subscribes to virtue ethics argues that the basic foundation of morality lies in developing an individual's good character, good human characteristics and virtuous behaviour. A virtue is deemed to equate to a morally good human property. Critics have argued that this makes it difficult to determine who is virtuous. Can virtue be determined based on the individual's actions, or does the definition require something more? The concept of virtue is often situated in opposition to the concept of vice. A person is good if he or she is virtuous and has no vices. Courage, strength, moderation, orderliness, trustworthiness and generosity are counted as typical virtuous traits. ${ }^{116}$ Some virtue ethic theorists include as many as around a hundred different virtues that together contribute to making an individual a good person. Plato (427-347 BC) argued that the human soul consisted of three parts: reason, spirit and appetite. In connection with this, Plato developed the concept of the four cardinal virtues. Wisdom was the virtue of reason, bravery of spirit, moderation of appetite, while justice ensured that the three parts of the soul exist within a harmonious relationship. Virtue theory emphasizes moral education since the individual, according to virtue ethics, develops during their upbringing. An individual that fails to adopt said virtues is unvirtuous. These vices are often seen as the opposite of virtues.

Virtue ethics is the oldest of the Western normative traditions and is rooted in ancient Greek civilization. Greek poets and playwrights, such as Homer (700 BC), who is assumed to be the author of the epics the Iliad and the Odyssey, and Sophocles (496-406 BC) in Antigone, describe their heroes and anti-heroes in terms of their virtues and vices. Generally speaking, the narrative plays a key role in virtue ethics. "Man is in his actions and practice, as well as in his fictions, essentially a story-telling animal", as Alasdair MacIntyre states. ${ }^{117} \mathrm{He}$ continues: "To be subject of a narrative that runs from one's birth to one's death is, I remarked earlier, to be accountable for the actions and experiences which compose a narratable life". ${ }^{118}$ When viewed from an action theory perspective, MacIntyre argues that the "(n)arrative history of a certain kind turns out to the basic and essential genre for the characterization of human actions". ${ }^{119}$

115 Ibid, p. 144.

116 The Internet Encyclopedia of Philosophy under Virtue Theory.

117 MacIntyre, Alasdair (1982, p. 216).

118 Ibid, p. 217.

119 Ibid, p. 208. 


\section{Two competing normative worlds}

The earliest and most influential contribution to the development of virtue ethics is Aristotle's work (384-322 BC) Nicomachean Ethics, particularly the second section. There, Aristotle argues that moral virtues have a moderating aspect. One needs to find the right balance between virtue and vice. Of particular interest is the fact that Aristotle distinguishes between intellectual virtues in which humans can receive systematic education, and virtuous traits which develop through continuous practice. His opinion is that the two virtues are linked in a way that allows neither to exist without the other. Against this background, Aristotle proposes the concept of phronesis, i.e. a sense of good judgement, as our guiding star. In actual fact, this can be seen as an argument in favour of combining the lifeworld and the system and that both must be given equal status. Good judgement is to prevent secondary socialization and the systems from taking control and to always maintain values based in the culturally and emotionally influenced primary socialization process in order to distinguish between good and bad. To put it in MacIntyre's words:

(t)he virtues therefore are to be understood as those dispositions which will not only sustain practices and enable us to achieve the goods internal to practices, but which will also sustain us in the relevant kind of quest for the good, by enabling us to overcome the harms, dangers, temptations and distractions which we encounter, and which will furnish us with increasing self-knowledge and increasing knowledge of the good. ${ }^{120}$

Aristotle's ideas were further developed in the Middle Ages by Thomas Aquinas (1225-1274). During this time, the cardinal virtues were expanded to include theological virtues based in the New Testament, such as faith, hope and love. Toward the end of the Middle Ages and the beginning of the Renaissance, Aristotle's virtue ethics began to lose traction. The scientific revolution and the Enlightenment saw the final demise of virtue ethics. They were subjected to criticism and revision. ${ }^{121}$ The greatest challenge to virtue ethics, however, came from the concept of natural rights in the 1600s. Dutch philosopher Hugo Grotius developed a moral school of thought that argued that morality had to do with adapting one's actions to moral norms that were natural laws that not even God could change. In the 1700s, virtue ethics gained renewed prominence through David Humes' moral philosophy. ${ }^{122}$ Hume believed that our perceptions are based partly on impressions and partly on ideas. But impressions are stronger and livelier than ideas. Hume's moral philosophy emphasizes that the evaluation of both social virtues, benevolence and justice, should be based on their benefits. ${ }^{123}$ Hume

120 Ibid, p. 219.

121 Schneewind, J.B. (1990).

122 With regard to David Hume as a virtue ethics theorist, please see Homiak, Marcia L. (2001).

123 David Humes' most renowned moral philosophical work is An enquiry concerning the principles of morals, published in 1751. 
believed that we had a natural sense of others' well-being, and it was on this sense that society was based. The moral sense on which we base our judgement of actions, virtues and vices, is developed from a sense of sympathy for human happiness.

During the 19th century, an obsession with rule-based ethics took over and completely forced out virtue ethics. It is only in recent decades that a renewed interest in virtue ethics has emerged. ${ }^{124}$ Relevant thinkers here are Elizabeth Anscombe and Alasdair MacIntyre. The latter argues that today, we only have fragments of different moral traditions and that we need to reconquer the meaning of life through morals, primarily through virtue ethics. In his book After Virtue, MacIntyre argues that moral philosophy today is in the same situation as the natural sciences would be if one was to burn all the laboratories to the ground, lynch all the physicists and destroy their books and instruments and much later tried to reconstruct an ideology out of the remaining fragments. ${ }^{125}$ MacIntyre shows that a historical review of what has been deemed virtuous by given societies is determined by the kind of society and what stage of development it is at. ${ }^{126}$ In Homer's time, the warrior was depicted as an ideal to strive for. In other words, physical strength and courage were deemed to be the highest virtues. Aristotle admired the characteristics that enabled the free Athenian to become a good citizen. Traits such as meekness only became considered virtuous when Christianity taught us their view of every human as a member of two different communities, the earthly and the celestial.

It would seem, therefore, that virtue as a moral principle is at its peak in the initial stages of an S-curve. Simply put, during the new social era's stages of establishment, individual qualities determine which morals will develop and define good or bad actions. Virtue also means inherent power and ability. In the initial stages of an era, a person is a somebody, i.e. personality is what is important. Selfreliance is what counts here. ${ }^{127}$ The introduction of something new requires that the person takes initiative at the expense of society and culture. Changes require inventors and innovators that take their own initiative. Toward the end of an era, an individual has become something, i.e. it is the assigned role that determines who you are. At that point one follows the rules and imitates. There are few alternative strategies at hand. This developmental tendency runs parallel to the transition from individual to collective societies and a social change from heterogeneity to homogeneity, and thereby from multi-culture to mono-culture.

It can therefore be concluded that virtue ethics have come and gone throughout history. Each time they have lost their key position they have, according to MacIntyre, been replaced by stoic thought and behaviour. ${ }^{128}$ Stoicism

124 Cf. e.g. Danish historian Östergaard, Uffe the Kritik journal, no. 108, 1994.

125 MacIntyre, Alasdair (1982, p. 1 f).

126 Ibid, p. $182 \mathrm{f}$.

127 Cf. Ewerman, Anders (1996, p. 47).

128 MacIntyre, Alasdair (1984, p. 170). 
represents one of the Western world's permanent, potential moral traditions. This school of thought, too, has had its ups and downs. Stoicism has, in one form or another but with the same basic contents, always succeeded phases of virtue ethical thought. Stoicism is a philosophical school of thought that replaced Aristotle's teachings in Ancient Greece on the importance of virtue. It originated with the lesser-known Zenon who held classes for his disciples in Athens around 300 BC. Stoic epistemology was empiric by nature. Everything that happened was assumed to be determined by divine providence and abided by unconditional laws. Ethically, a life led in accordance with reason and common sense constituted the greatest good. People embraced the idea of a state that was more or less cosmopolitan, and laws based in human nature were seen as properties of a good legal system. These are all characteristics of a large-scale phase in the development of a society.

During the course of an era, there is a transition from consequential ethics to duty ethics, as well as from situational ethics to rule-based ethics. As the $S$-curve progresses, we move from judgement and self-reliance, stage 1 , as a guiding principle based in self-regulation, initially without any governmental interference, to stage 2 , and later with the government's support as a guarantor for upholding and maintaining the new rules of the game, to stage 3 , and over to stage 4 which upholds ideal such as legal interventions and compliance with rules. The progress of the ethic, in fact, occurs as a pendulum movement between extreme points rather than as continuous progress. The same applies to legal developments over time, which is a subject I shall return to in Chapter 4 . The $S$-curve describes a pendulum from (individual and local) markets toward centralization and governmental bureaucratization. The latter entails an accelerating uniformity that eventually results in bringing everything to a halt and the death of the system. In the transition from local to national and then global markets, a need for trust-creating mechanisms arises. Trust is, as we have seen previously in Barbara A. Miztals' work, communicated in different forms and through different practices. When spontaneous trust is no longer sufficient, the state steps in with its reinforcement mechanisms in the form of legal measures. The newly awakened interest in the concept of trust that has been visible in recent decades may express a fear that the concept of trust is increasingly coming under threat in our time. The S-curve and its inherent stages can, from a normative perspective, be summarized as seen in Figures 2.8 and 2.9 .

\begin{tabular}{lllll}
\hline Perspective & Phase 1 & Phase 2 & Phase 3 & Phase 4 \\
\hline $\begin{array}{c}\text { Meaning- } \\
\text { Creating }\end{array}$ & Lifeworld & Ideological & Economic & Political System \\
$\begin{array}{l}\text { Moral } \\
\begin{array}{c}\text { Coordinations- } \\
\text { Form }\end{array}\end{array}$ & Virtue & Situational & Consequential & $\begin{array}{c}\text { Rule-based } \\
\text { Ethics } \\
\text { Power }\end{array}$ \\
\hline
\end{tabular}




\begin{tabular}{|c|c|c|c|c|}
\hline Perspective & Phase 1 & Phase 2 & Phase 3 & Phase 4 \\
\hline Mechanism & Deregulations & $\begin{array}{l}\text { Self- } \\
\quad \text { regulations }\end{array}$ & Rule of Game & $\begin{array}{l}\text { Political } \\
\text { Regulation } \\
\text { (State } \\
\text { Intervention) }\end{array}$ \\
\hline Activity & Play & $\begin{array}{l}\text { Game } \\
\quad \text { (amateur) }\end{array}$ & & $\begin{array}{l}\text { Professional } \\
\text { Game }\end{array}$ \\
\hline Driving Force & Responsivity & Game & Objective Win & Fame \\
\hline $\begin{array}{l}\text { Forms of } \\
\text { Expression }\end{array}$ & Effective & Expressive & Professional & $\begin{array}{l}\text { Neutral } \\
\text { (Indifferent) }\end{array}$ \\
\hline Action Systems & $\begin{array}{l}\text { Preserving } \\
\text { Customs }\end{array}$ & Integration & Goal Fulfilment & Adaptation \\
\hline Science & Proto science & $\begin{array}{l}\text { Several } \\
\text { Sciences }\end{array}$ & Normal Science & $\begin{array}{l}\text { Multi-Sciences } \\
\text { (anomie) }\end{array}$ \\
\hline
\end{tabular}

\subsubsection{How society develops and expresses its ideology}

Not only do morals and ethics follow the course of the S-curve. Philosophy and science do too. They can be seen as products of their era and are influenced by the Zeitgeist of the lifeworlds at various stages of the society's progress. I include only some of many notable figures in the Figure 2.8, such as (1) John Locke, 16321704, (2) David Hume, 1711-1766, (3) Adam Smith, 1723-1790, (4) Jeremy Bentham, 1748-1832, (5) David Ricardo, 1772-1823, (6) Friedrich Hegel, 1770-1831, (7) Karl Marx, 1818-1883, (8) John Stuart Mill, 1806-1873, (9) Émile Durkheim, 1858-1917, (10) Max Weber, 1864-1920, (11) Jurgen Habermas, 1929-, (12) Niklas Luhmann, 1927-1998 and finally (13) Manuel Castells, 1942-. These thinkers are not the only ones with the capacity to symbolize or express the thoughts and ideas of their time, but they shall here represent ideological developments in industrial society. They have all participated in observing and articulating tendencies of social progress and were therefore ahead of their times. Here, I shall refer to some elements of their theories that reflect social developments.

We shall begin with John Locke, although he was active toward the end of the 17th century, since he lay the foundation for the school of thought that believed in natural rights, which gained such popularity in the 18th century. ${ }^{129}$ Not of least importance, in this context, is his argument in support of the right to rebel against any state that violated a person's natural rights. His most famous work, Two Treatises on Government was published in 1690 and translated into Swedish in 1726. Locke is often referred to as the first great liberal. He emphasized that freedom and independence were based in individual property rights. Locke advocated a system of separate powers in which the legislative and the executive branches had to be kept apart. He was in agreement with Thomas Hobbes that society could be viewed as an association of independent individuals who all had consented to a 
pact. Unlike Hobbes, however, Locke believed that humans entered into society in order to preserve their rights. The duty of the state was, according to Locke, to restrict the power of each part or member of society and to limit their influence.

David Hume and the part he played as a proponent and interpreter of virtue ethics has been previously described above. Hume presented his general thoughts in the two papers Enquiry concerning human understanding (1748) and An enquiry concerning the principles of morals (1751). He argues that our perceptions are shaped by impressions and ideas. These impressions are communicated via our senses and are stronger and livelier than ideas. The Humesian empiric master thesis is: Every simple idea is based in, and reproduces, an impression. This led him to prescribe key importance to moral impressions.

The two political economists Adam Smith and David Ricardo have both contributed to highlighting and expressing these new economic theories. Adam Smith, known as the father of political economy, laid the foundation for the classical school of thought within political economy in An inquiry into the nature and causes of the wealth of nations, in 1776, as well as for its practical application, economic liberalism. In contrast to the over-reliance on money as a welfare-creating force of mercantilism, Smith highlighted the importance of the actual results of labour. He explained the causes and effects of the division of labour. One value that he shared in common with Locke was to distinguish between value-in-use and value-in-exchange. In common with the physiocrats, Smith believed in economic freedom, and he developed a doctrine that espoused a "natural" regulation of economic life. Adam Smith was also a philosopher, and as such, he was noted for his research on the essence of morals (Theory of moral sentiments, 1759). Much like David Hume, he viewed sympathy as the founding principle of ethics, and he endeavoured to show how it transformed from blind instinct to greater clarity through social progress.

Jeremy Bentham began his authorship by criticising the theory of natural rights. He presented his ethical and legal philosophical views in An introduction to the principles of morals and legislation, 1789. There, he claimed the principle of the Commons was the highest moral principle. This thought became the foundation of the school of thought known as utilitarianism. In turn, this gave birth to a specific British branch of liberalism that in time came to reap great pragmatic triumphs. This school of thought was at its peak at the time prior to and following the first parliamentary reform in England, in 1832. One key component of Bentham's ideas is the idealization of the individual's ego, on which the entire system is based. It is the individual's material interests that are of interest to Bentham, and the individual is further assumed to always be able to make rational decisions that are to his or her advantage. Here, public interests are no longer separable from individual interests. The government and the political sphere should therefore not actively do anything, in line with the principle of laissez-faire. They should, at best, communicate knowledge. All trade needs to function is safety and freedom, Bentham argues. ${ }^{130}$ 
David Ricardo advocated the free market. He fought intensely against sugar duties and the landowning aristocracy in general. ${ }^{131}$ In his paper On the Principles of Political Economy and Taxation, published in 1819, he proposed a system of an uninhibited, international free market which, he argued, would naturally motivate every country to invest their capital and labour in companies that would best benefit them. This quest for gaining an advantage, Ricardo argued, is linked admirably to the common good.

Friedrich Hegel is known mainly for his theory on dialectic social progress, which he developed, inter alia, in, Grundlinien der Philosofi des Rechts (1821). He saw historical progress as a perpetual struggle between opposing forces that simultaneously negate each other and yet are preserved in higher forms. Each stage is a necessary stage of universal progress, of which the most dominant principle is determined by the "Zeitgeist", or the "spirit of the times". The highest, at the time, level of progress therefore gains its legitimacy, in Hegel's perspective, by being the highest manifestation of the world spirit. He also foretold of the superiority of the political system when he espoused that only the state could provide a rational existence. All upbringing, according to Hegel, is based in training the individual to become not a subject but an objective state cog. Hegel could thereby also be said to legitimize the system's dominance. The Hegelian school of thought has also greatly influenced Marxism. According to Marxist dialectic, however, the resolution of opposing forces in the social revolution is not a merging, a synthesis, but rather a complete rejection, a negation of the previous system.

Marx is, of course, a much broader topic, as are the other theorists. In this context, however, I would like to refer to his focus on the structure of society. Marx based his thoughts in Hegel's dialectic, but did not believe dialectics were based in the thought process, but rather in social reality with its inherent class conflicts. Marx's analysis of capitalist society's inherent mechanisms is concerned with pointing out the independent power of the economic system in relation to social progress. In his extensive work, Das Kapital, also known as Capital. Critique of Political Economy, published in three volumes, the first of which was published in 1867 and the two others by Friedrich Engels, in 1885 and 1894, Marx developed his thoughts on how the economic system follows its own laws of progression. In Marx's opinion, the systems were extremely independent. Although Marx did believe that class struggle, as a subjective historical factor, could bring about change, it, too, would be subordinate to structural conditions. By developing the concepts of value-in-use and value-in-exchange, Marx constructed his famous surplus value theory, which in turn, formed the basis of the political project known as Marxism. Surplus value is based in the notion that the workforce, seen as a product, has a value-in-use that is also a source of value-in-exchange and that the value-in-use has less value than the produced value-in-exchange. 
Marx also argued, and this is of relevance to the structure of the S-curve, that social conflicts "amass" until they become unbearable. If this is true, and we discard the notion of class struggle as a historical force of change, which as it happens demonstrably did not pan out, this would explain why social progress follows the curved developmental lines of an S-curve rather than the more linear lines that would otherwise be expected when describing a course of time.

John Stuart Mill brings us to the political philosophers. In his book In Considerations on Representative Government, published in 1861 and immediately translated to Swedish, he wanted to show that the ideal and best form of governance is that in which sovereignty, or the ultimate, decision-making power, belongs to all members of society, where all citizens not only have a voice but also personally practise some form of public task. ${ }^{132}$ Mill, therefore, became the foremost voice to articulate modern society's version of democracy and parliamentarism. He was a great supporter of free speech and free debate.

Émile Durkheim was one of the great forefathers of sociology. He takes his starting point in society's collective unit and emphasizes the importance of a strong collective unit to which the individual feels a strong attachment. When this attachment loses intimacy, it threatens to dissolve society, according to Durkheim. Anomie may arise, i.e. a weakening of social norms and their cohesive force. In perhaps his most famous paper, De la division du travail social, 1893, he claimed to find tendencies of organic solidarity in modern society that resulted from the division of labour created by the increase of functional specialization. When everyone becomes dependent on each other for their survival, a kind of spontaneous bond and solidarity emerges among people in society.

The smallest unit to actually constitute an object of sociology for Max Weber is the social act. ${ }^{133}$ What characterizes a social act, according to Weber's interpretive sociology, is that the meaning that the individual or individuals invest in this behaviour is related to, and guided by, other people's behaviour. As a result, the concept of meaning has come to assume a key position in sociology. This has also meant that people's goals and values have become an object of study in sociology. Therefore, it could be said that Weber complements Marxism's analysis of systems by focusing on social interaction and the meaning of cultural factors, which is particularly expressed in his book The Protestant Ethic and the Spirit of Capitalism. Here, Weber views religion through a retrospective lens as an ideological example to point out the importance of cultural factors in the creation of a new phase of social progress, i.e. capitalism. Weber also emphasized science's role in progress in the West, as well as the emergence and characteristics of the political/ administrative systems in what is known as modern society. ${ }^{134}$

With regard to interpreters of modern society, I propose two German social scientists that were prominent during the final decades of the 20th century, Jurgen

132 Ibid, p. 110.

133 Please see Agne Lundquist's introduction in Weber, Max (1921-22, 1983).

134 Weber, Max (1991, p. 27 ff). 
Habermas and Niklas Luhmann, both with a strong interest in legal issues. My analysis of what I have previously referred to in this chapter as two competing normative worlds, the lifeworld and systems, is largely based in Habermas' theories. This conflict between the two normative worlds can also be said to represent the fundamental social conflicts of our times, a conflict that is likely to occur when enough discontent has amassed and will result in reactions that are so powerful that a new social organization will he created. Niklas Luhmann's most important contribution to creating an understanding of contemporary times has been to highlight the autonomy of the systems. By using the concept of autopoiesis, borrowed from the biology sciences, ${ }^{135}$ Luhmann describes the systems as closed and that they transform external impressions and translate them according to the logic and language of the system for further processing. Thereby, Luhmann emphasizes the independence of the systems and their influence on social progress. He predicts both the normative progress that will follow in the wake of artificial intelligence $(\mathrm{AI})$ and that algorithms will become norm-bearers without visible subjects, a topic I shall return to.

There are also a number of contemporary post-modernists that here might characterize a transitional society caught between industrial and information society. In this category, I shall include deconstructionists such as philosopher Jacques Derrida and sociologist Ulrich Beck. Derrida has criticized philosophical tradition in his deconstructive critique. The primary object of deconstruction is not to analyse individual texts, but rather their conceptual conditions. The problem, for Derrida, can be stated as follows: ${ }^{136}$ How do we go about thinking in ways that differ from the traditions that saturate our way of thinking, our culture? The deconstructionist method is based in the idea that a thing can only be present in relation to another "thing". It can only be perceived when contrasted with something else. Therefore, we view the present in relation to the past. The "other", that which is absent, must therefore, in one way or another, be a component of one's existence. It needs to leave "traces", and only in relation to these traces of something else does it come into being. The deconstructive method has gained prominence primarily within literature theory but has also spread to other sciences. ${ }^{137}$ In coining the phrase risk society and through his analysis of the subject, Ulrich Beck has contributed to a new understanding of the instability inherent in transitional societies. Furthermore, his criticism of sociology calls for a more progressive and relevant approach to social sciences. Zygmunt Bauman has perhaps succeeded best in capturing the general tendencies of post-modernism, among other things, by expressing that everything evaporates. ${ }^{138}$

Manuel Castells is the only established social scientist who has, in earnest, taken the leap over to the new S-curve and the social conditions of the information

135 Maturana, Humberto R. and Varela Francisco J. (1980).

136 Filosofiskt lexikon p. 105.

137 Hit hör även rättsteorin.

138 Bauman, Zygmunt. 
society. He is the first to attempt to articulate the traces left in the wake of the information society, as described by Derrida. Castells, in fact, develops Derrida's thoughts one step further by constructing the traces that lead forward and that allow us to see the past in a new light, i.e. in a historical light. Today, too many people seem to be busy with a newly awakened interest in modernism and postmodernism now that these eras have been made visible in relation to something else, namely, the new tracks being made in the information age. Castells' work on formulating new developmental tendencies of the information society is therefore both necessary and praiseworthy. Castells' work is described quite extensively in the previous chapter. In this chapter, I will only highlight some of Castells' main points about the new society that is emerging.

A new world emerges at the turn of this millennium, Manuel Castells claims toward the end of his trilogy on the information age. ${ }^{139}$ It has been created, he explains, by the historical merging of three independent processes: the information technological revolution, the economic crisis of both capitalism and statism (the former communist states) and the development of cultural social movements such as feminism and environmentalism, human rights and freedom of the individual. The cultural social movements reconstruct society's institutions by allowing technology to be governed by needs and wants. In order to act as agents of change, they must, however, travel the long route from collectives that are based in a resistance identity to a project identity, according to Castells. In other words, they must step away from the resistance against the system which initially gave birth to the reconstruction of modernism (the protests of 1968) and the deconstruction of post-modernism toward a constructive stance based on visions and values that have been nurtured within a cultural process. The key question, Castells emphasizes, is the emergence of the project identities that have the potential capacity to construct some form of new civil society and potentially a new state. ${ }^{140}$

The new kind of power required to change society is to be found in such information codes and representational images around which society organizes its institutions and around which people construct their lives. This power is a function of an eternal battle for ownership of society's cultural codes. It is a battle between the subordination of system imperatives and independent approaches, formed within a communicative process, to the conditions of life. The battlefield on which this battle for power is fought resides, in the final analysis, within us humans. Castells thereby confirms the need for individual initiatives and approaches at the beginning of an S-curve and when establishing a new society. $\mathrm{He}$ also suggests the emergence of a new virtue ethical era.

139 Castells, Manuel (2000) Vol. 3, p. 380.

140 Castells, Manuel (1999) Vol. 2, p. 365. 


\section{About norms and action systems}

\subsection{Social norms}

\subsubsection{Sociological and socio-psychological norms}

Apart from general, colloquial definitions used in casual discourse and in idealistic philosophy, the concept of norms has resisted definition, according to Jack Gibbs. ${ }^{1}$ An overview of the literature, he explains, shows that traditional concepts still linger on. Three late 20th-century authors are noted for their influence on sociology's understanding of norms. These three are French author Émile Durkheim, and William Graham Sumner and Charles H. Cooley from the USA. ${ }^{2}$

For decades, sociology textbooks have referenced William G. Sumner, noted for being one of the most influential sociologists behind the creation of a sociology of norms. ${ }^{3}$ His main work is Folkways. A Study of the Sociological Importance of Usages, Manners, Customs, Mores, and Morals, published in 1909. Common customs, according to Sumner, gain independent power and legitimacy once they have been established. ${ }^{4} \mathrm{He}$ argues that world views, ideology, right and wrong, rights and morals, are all products of custom. Much of Sumner's ideas can be discerned in contemporary sociology's understanding of norms. ${ }^{5}$ Interactionism, e.g. Peter L. Berger et al., understands norms, ethics, ideology and morality as overarching phenomena that are based on a more prosaic, underlying foundation. According to the ethno-methodological school of thought, e.g. Harold Garfinkel et al., innumerable micro-norms can be traced to customs. ${ }^{6}$

Charles H. Cooley's main contribution to a modern sociology of norms is his well-known concept, the primary group. According to sociology of norms in the USA in the 1950s, the primary group is the core group from which norms emanate. This school of thought has also inspired the interactionist school of thought

1 Gibbs, Jack P. (1981, p. 67).

2 Please see Mortensen, Nils (1990, p. 97).

3 Ibid, s. 101.

4 Sumner, William G. (1959, p. 28).

5 Please see Mortensen, Nils (1990, p. 103).

6 Please see Garfinkel, Harold (1967). 
within sociology, primarily Georg Herbert Mead and his successors, to adopt a concept of norms that has its source in interactions between people rather than the more deterministic understanding that behaviourism adopts ${ }^{7}$.

In reviewing various attempts to define norms, we find that Talcott Parsons defined norms as follows: ${ }^{8}$

A norm is a verbal description of a concrete course of action, regarded as desirable, combined with an injunction to make certain future actions conform to this course. An instance of a norm is the statement - "Soldiers should obey the orders of their commanding officers".

Blake and Davis use a similar definition when claiming that a norm indicates a standard or rule that prescribes what people should or should not do under given conditions. ${ }^{9}$ George Homans offers a version on the same theme and defines a norm as follows: ${ }^{10}$

A norm is a statement made by members of a group, not necessarily by all of them, that its members ought to behave a certain way in certain circumstances. The members who make the statement find it rewarding that their own actual behaviour and that of the others should conform to some degree to the ideal behaviour described by the norm.

A crucial point of contention is whether norms are seen as internalized phenomena or maintained through various kinds of symbolic representations. ${ }^{11}$ I would argue that norms can be internalized, but that it is not a necessary requirement. Perhaps they characterize a certain type of norms, namely norms from the primary normative world, as mentioned in the previous chapter in terms of the link between the lifeworld and primary socialization.

The concept of norms is mainly based in an American sociological, behavioural tradition from the 1950 and 1960s inspired by Émile Durkheim's classic theories. ${ }^{12}$ From the perspective of behaviourism, all life is controlled by norms. In agreement with this understanding, sociological dictionaries define norms as standards commonly shared by members of a social group and with which they are expected to comply; said conformity is controlled via positive and negative sanctions. ${ }^{13}$

A common understanding, seen from this perspective, is that a norm is represented by some kind of normative statement. This, in turn, is defined as a modal

7 Mead, George Herbert (1972, 1934).

8 Parsons, Talcott (1937, p. 75).

9 Davis and Blake (1956).

10 Homans (1961, p. 40).

11 Gibbs, Jack P. (1981, p. 69).

12 Mortensen, Nils (1990).

13 Please see Kolb (1964, p. 472). 
predicate. The explicit or implicit verbs, "should", "will", "must" and "deserve" distinguish normative from existential statements, i.e. statements that pertain to actual conditions. ${ }^{14}$ As I will elaborate on further, I argue that a normative position can also be the result of statements about actual conditions, given that the values-based premises are already in place and that the action requires only supplementary information in the form of knowledge about relevant, actual conditions.

Gibbs simply defines norms as patterns of sanctions. ${ }^{15}$ However, he does point out that the concept of norms is an abstraction and that actions are generally influenced by several types of norms. In general, a recurring theme of various concepts of norms is that any deviation from the norm leads to sanctions. But what is important is that the sanction can have several different functions and be constructed in different ways in relation to different kinds of norms. Émile Durkheim distinguishes between two kinds of norms: moral and technical rules. ${ }^{16}$ When you violate a technical norm, injury results automatically as an analytical consequence of the violation, Durkheim argues. One example he mentions is that if a person subjects themself to the risk of infection in violation of the relevant norm which prescribes that they should not do so, there is a high probability that the person will become sick. This applies similarly, as I will discuss further in the book, to norms that have their source in different economic and technical systems. In the case of moral norms, there is no link between an action and its consequences. Durkheim gives the example that the punishment you receive if you violate the rule that forbids murder has no direct relation to the actual crime. The actual act in itself does not trigger the following feeling of shame you experience or the punishment you receive. For that to happen, something more is needed, e.g. that your social environment reacts by condemning the act. Durkheim explains that, in such cases, the consequences are related to the act via what he calls a synthetic (artificial) link rather than an analytical link. Consequences linked to actions via artificial or created links are called sanctions in Durkheimian terminology. ${ }^{17}$

Another point of contention is whether a normative statement can only be considered a norm when it affects another individual's actions, i.e. leads to an act being performed. Gibbs argues that in order to be considered a norm, a normative statement must lead to consequences to the norm-receiver's actions. Personally, I believe that a norm should be seen as being in relation to a potential act; that is to say, something that could trigger an act. A system of norms can be said to consist of norms that potentially may trigger actors affected by the system to act in a certain way.

Baier and Svensson distinguish between the $i$ and ought dimensions of norms. ${ }^{18}$ This distinction is particularly salient when it comes to legal norms, which are a key component of socio-legal studies, a field that focuses on comparing

14 Ibid, p. 70.

15 Gibbs, Jack (1981, p. 72).

16 He does so in a short pamphlet, Durkheim, Émile (1906, p. 35 ff). See Sociology and Philosophy (Routledge Revivals), Émile Durkheim, (2009), London: Routledge, ch.2.

17 Mortensen, Nils (1990, p. 99f).

18 Please see Baier, Matthias and Svensson, Måns. (2009). Om normer. Malmö: Liber. 
prescriptive aspects of law with its descriptive/actual content. The legal norm's social, economic and cultural context influence and have an impact on how it is applied in practice. This also applies to social and other norms, according to Baier and Svensson. There is often tension between the normative and practical dimensions of the norm. ${ }^{19}$

Hardly a single sociology textbook was printed in the 1980s that did not include a definition of the concept of norms. ${ }^{20}$ One internationally published textbook states that a norm is a specific lodestar for actions that are defined as acceptable and appropriate behaviour in specific situations. ${ }^{21}$ Sanctions play an important role. The same author explains: ${ }^{22}$

Norms are implemented by using positive and negative sanctions, i.e. reward and punishment. Sanctions may be informal, such as an appreciative or dismissive glance, or formal, such as fines or fees imposed by authorities.

The term norm, according to one recognized source, in a colloquial context refers to the standard which most of us recognize is the most common way of acting, statistically speaking. ${ }^{23}$ According to the same source, sociology, however, sees norms as cultural rules that bind people's actions to certain sanctions, whether in the form of punishment or reward. Norms regulate behaviours that thereby create unique patterns that distinguish one social system from another. ${ }^{24}$ In this way, social norms maintain boundaries that distinguish between those who belong in a given social context and those who do not. Deviators risk being excluded from the group. Social norms also contribute to maintaining cultural values since sanctions articulate what is considered desirable and undesirable behaviour. Norms thereby reinforce expectations of certain behaviours. According to the aforementioned authoritative source, it is important to distinguish between a more scientific approach to the concept of norms and the layman use and understanding of the concept of norms. ${ }^{25} \mathrm{I}$ personally believe that is important to extend the concept of norms to other areas than the sociocultural area, as well as to take one's point of departure in how norms work and are used in society

19 This is emphasized by Robert K. Merton within the framework of his functionalist approach to sociology. Merton studied the differences between manifest and latent functions. Manifest functions are conscious, deliberate and beneficial, while latent functions are unconscious, unintended and beneficial, and dysfunctions are unconscious, unintended and harmful, Merton, Robert K. (1949). Social theory and social structure: toward the codification of theory and research. Free Press. Please see Berger, Peter L. (1963). Invitation to sociology. Doubleday: Anchor Books.

20 Mortensen, Nils (1990, p. 106).

21 Haralambos, Michael and Chapman, Steve. (2013). Haralambos o Holborn sociology: themes and perspectives (p. 5). 8th ed. London: Collins.

22 Ibid, p. 6.

23 Blackwell Dictionary of Sociology, p. $190 \mathrm{f}$.

24 Ibid, p. 191.

25 Gibbs, Jack P. (1965). Please see Davis, Kingsley and Blake, Judith (1956). 
even when not necessarily recognized as norms. This last point also relates to why it should be emphasized that norms are often concealed or based on hidden premises that are expressed in the form of statements while containing an inherent expectation that a given action will follow.

The most common definition of norms takes its point of departure in social conditions and socio-psychological theories which, in turn, are informed by interactionist theories. "Social norms consist of expectations", as Vilhelm Aubert explains in a classic quote ("Sociala normer er satt samman av forventningar"), and he adds that for something to be a norm, the ensuing expectations must have a certain degree of sustainability and stability. ${ }^{26}$ Based on theories of the ego (the "I") and the alter (the Other), Aubert, in common with many other theorists, emphasizes how the individual is generally able to estimate how rules work based on previous experiences of sanctions and statements. This means that norms are not just manifest in the presence of other people; they also have their own motivational force. Requirements that the surrounding social environment demand of the ego become requirements that the ego demands of itself. They become a part of their internal norm system, their own morals. This process is described as the norm having become internalized. ${ }^{27}$

The importance of the sanction in this context depends. Sanctions, Johan Finley Scott explains in his book, Internalization of Norms, can be seen as conditions of the process of learning what is considered normal behaviour. ${ }^{28}$ Seen from this perspective, sanctions are mainly mechanisms used for social adaption, while norms correspond to a pattern of sanctions. ${ }^{29}$ The same applies to social control that is based on and takes its starting point in norms.

Expectations and norms can also be produced by groups. In this context, it is important to distinguish between primary groups and reference groups, which both act in different ways as sources for the individual. How much influence the norm-sender has depends on different factors, such as how important the norm is to the norm-receiver. In part, the norm has to do with needs. ${ }^{30}$ Similarly, the methods of communication available also play a role in norm-learning. Language, not least, is important, here. Habermas argues that language converts individuals' multi-faceted, subjective perceptions, evaluations and emotions into norms that need to be generalized. ${ }^{31}$ Language rules in themselves are important social norms, as Therborn points out. Both Habermas' theory of communicative action and Anthony Gidden's emphasis on the importance of discourse norms in social life are also pertinent here..$^{32}$

26 Aubert, Vilhelm (1964, p. 30).

27 Ibid, p. $34 \mathrm{f}$.

28 Scott, John Finley (1971, p. 92).

29 Ibid, p. 65 and 72.

30 Cf. Aubert, Vilhelm (1976, p. 17 f).

31 Habermas, Jürgen $(1979$, p. 10).

32 Habermas, Jürgen (1987) and Giddens, Anthony (1984). 
Expectations can be bound to an individual's particular position or status in society. In Swedish, this is often expressed as "living up to a role". A role is defined, according to Aubert, as the sum of all norms linked to a specific task or position. ${ }^{33}$ Society can be seen as a network of paired roles and mutual expectations that govern these relationships. Institutions are composed of a certain set of norms and thereby of roles that are grouped around a given task or function. From this perspective, the social system is constructed of paired roles and institutions.

Furthermore, according to Aubert, the social system should be seen as a system of actions, a network of coordinated practices, partly determined by the requirements and permissions granted by established roles and partly determined by other goals and choices. The general process by which an individual adapts to a social system and learns how to play different roles and observe norms is known in sociology as socialization. ${ }^{34}$ Family, friends, school and occupational life are usually regarded as institutions that have the greatest bearing on an individual's socialization process. This process is usually divided into primary and secondary socialization, as noted in Chapter 3. Training that takes place in other systems can be seen as a form of professionalization.

In summary, we can conclude that norms are generally understood to be actiongoverning phenomena in which sanctions play an important role in maintaining them. There are two different schools of thought in sociology that diverge when it comes to explaining how norms arise. According to the behaviourist school, norms are part of social life and help distinguish right from wrong. Muzafer Sherif is generally recognized as having established the modern understanding of norms in his book An Outline of Social Psychology, ${ }^{35}$ which is based on his previous book The Psychology of Social Norms. ${ }^{36}$ In the 1936 edition, Sherif uses the concept of norms to describe norms that arise in uncertain situations and are based in uniformity resulting from group pressure. The roots of his concept of norms can be traced back to classical antiquity and originally meant an agreed-upon yardstick for measuring goals, validity and other characteristics of an object. ${ }^{37}$ Nils Mortensen argues that this synthesis of moral rules and an ancient concept for evaluating objective characteristics was probably the turning point for how norms are conceptualized within contemporary sociology. ${ }^{38}$ It releases sociology from the conceptual apparatus of moral philosophy and allows it to assume an empirical approach to moral rules.

33 Aubert, Vilhelm $(1964$, p. 46$)$.

34 Please see the review in Habermas (1987) Ch. V.1, p. 31 ff. Habermas follows George Herbert Mead's lead in his analysis of how children "learn how the social world is constructed", Mead (1934).

35 Muzafer Sherif. 'An outline of social psychology' (1948).

36 Muzafer Sherif. 'The psychology of social norms' (1936).

37 Mortensen, Nils (1990, p. 106).

38 Ibid. 


\subsubsection{Norms in game theory}

Edna Ullmann-Margalit argues in the book The Emergence of Norms that social norms are not only created by expectations, they are also capable of channelling expectations and thereby the choice of actions at hand for anonymous actors. ${ }^{39}$ In other words, norms contribute to constituting and coordinating systems of action. I will return to this point. In this chapter, we will discuss a particular school of thought that focuses on norms: namely, game theory.

Robert Axelrod defines a norm as something that exists in a given social context and influences individuals' tendencies to act in a certain way, where individuals who do not conform are generally punished. ${ }^{40}$ Axelrod has studied the emergence and development of norms by constructing a game of norms in which each player can elect to violate a norm or punish any individual who violates a norm. The point of the study, which is based on simulated situations, is to learn more about under which conditions norms develop in order to promote cooperation in conflictual situations. Axelrod uses what he calls an evolutionary method, which means that strategies that prove to be relatively successful can be expected to be more often deployed in the game than less effective strategies. Furthermore, these strategies are randomly changed so that new conditions are intermittently introduced to the group, i.e. the simulated population sample. ${ }^{41}$

Axelrod concluded that the game of norms presented interesting dynamics. Firstly, the rate of norm violations tends to drop rapidly in line with the group's pro-punishment position. However, the pro-punishment group shrank when there was no longer any reason for paying for maintaining the penal system. As pro-punishment stances became rarer, a process began in which the average "rate of crime" rose again to the point that the norm collapsed. This finding led Axelrod to search for mechanisms that would be able to stabilize established norms. One such mechanism that Axelrod worked on was the introduction of a metanorm; a norm that prescribed that not only would the violators of a norm be punished, but so, too would anyone who did not support the punishment. Simulations that employed this complementary condition in the form of a meta-norm showed that it could contribute to stabilising the established norm. This new condition meant that the motivation for sanctioning violators of norms increased such that the "crime rate" could be maintained at a consistently low level.

Other situations that led to the same results were, for example, where a group dominated another group or when the willingness to punish deviators had become internalized, thereby becoming automatic. Similarly, an understanding of the preventive effect of punishment can strengthen the norm, as can taking note of other individuals, not least individuals of reputable social standing, condemning the norm violation. Another aspect is the extent to which a crime signifies the perpetrator's social status. If the violation is seen as a degradation of one's

39 Ullman-Margalit, Edna (1977, p. 85).

40 Axelrod, Robert (1986, pp. 1095-1111).

41 Ibid, p. 1109. 
social status, it has a preventive effect, but if it is socially acceptable, it is harder for the norm to gain a foothold. Another form of support for norms comes about through cooperation in a voluntary organization and working toward a common goal. This leads to a sense of solidarity which promotes maintaining the norm. Finally, Axelrod argues that legislation might be a potential mechanism for creating stability and maintaining a norm. If the social norm has support in legislation, it gains legitimacy by being combined, among other things, with a formalized system of implementation, by gaining respect - the symbolic weight of the law and by increased transparency, Axelrod argues.

Axelrod's evolutionary theory and other socio-psychological theories on the emergence of norms take their basic starting point in the notion that cooperation between individuals generates norms that are important components of the social action system. The explanations offered by these theories range from micro to macro perspectives. Nevertheless, within the social sciences, the concept of norms is often situated in the social system, i.e. at the macro level - a top-down perspective of norms. Durkheim questioned why individual behaviours change depending on the social system they act within. Many theorists, such as Talcott Parsons, see the analysis of social norms as a way of understanding the factors that affect people's behaviour on the micro level. Similarly, the concept of norms has also been used to explain people's behaviour at the micro level, based in conditions at the macro level, with norms often serving as a mediating link.

One theorist who has taken his starting point in both micro and macro conditions in his theory on social systems is James Coleman. As part of his analysis of social systems, he has developed a very sophisticated theory of norms and argues that norms are constructions at the macro level that are based on goal-oriented actions at the micro level, but in order to manifest as norms, they must convert from micro to macro conditions. ${ }^{42}$ The process underlying the creation of a norm must, Coleman argues, be based in individual acts that, when formulated in systemic terms, become independent, which in turn influences individuals' future actions in a sort of dialectic process.

Using Coleman's definition, a norm is in effect when the right to control an actor's actions belongs not to the actor, but to other individuals. ${ }^{43}$ Taking this as his starting point, Coleman broadens the issue of the existence of norms and asks: Under what conditions do individuals agree to relinquish the right to govern their actions to others, and under what conditions can this arrangement be maintained?

To address this, Coleman distinguishes between the receivers of the norm and those that benefit from it, i.e. the norm's target group (targets vs beneficiaries). When they coincide, Coleman refers to them as conjoint norms, and disjoint norms when they do not. ${ }^{44}$ Within that span, Coleman counts on a number of different forms, as shown in Figure 3.10.

42 Coleman, James (1990, p. 244).

43 Ibid, p. 266.

44 Ibid, p. $247 \mathrm{f}$. 


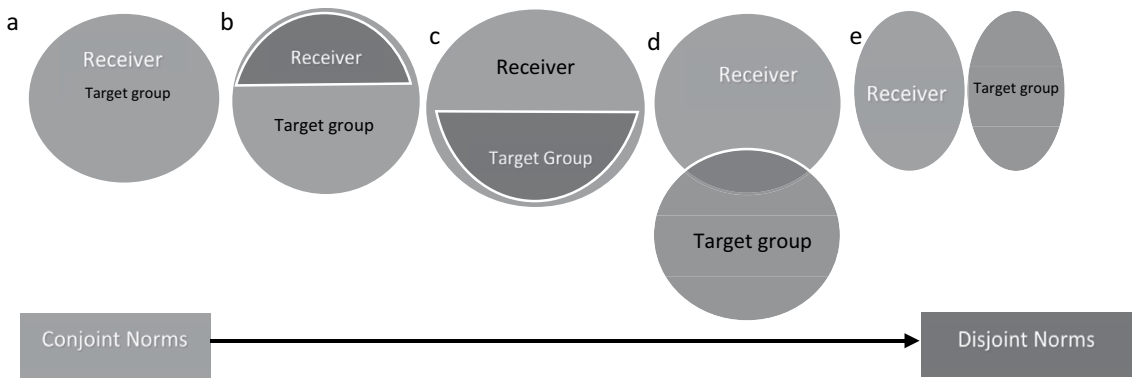

Figure 3.10 From conjoint norms to disjoint norms

Conjoint norms arise when interests that benefit from the norm and those that do not benefit from it affect the same actors or category of actors. Each one of these cases belongs to both the norm's receiver group and its target group. Disjoint norms are norms that benefit a group of actors, the target group, while disfavouring, or at least targeting, a different social group, i.e. the norm-receivers. The receivers and target group of the norm, therefore, belong to different categories of actors.

Coleman argues that you cannot speak of optimal conditions in either social contexts or economic contexts without observing the existing distribution of rights and resources. ${ }^{45}$ If they are distributed very differently, that is to say if the interests of certain groups are awarded decidedly more importance than other groups, it is possible that the most powerful group will be able to steer the emergence of disjoint norms to control the actions of the weaker group. Coleman underlines that in order to analyse these norms in terms of social optimization, one must adopt the starting point that power is unequally distributed. These kinds of norms often require that one group is able to exert force over a weaker group or that the existing societal structure distributes power unequally, such as in the extreme case of slaves. Coleman's examples have to do with women's status in different social systems.

In between these two extreme cases of conjoint and disjoint norms, there are different mixes of norms, as shown in Figure 3.10. In case B, some members of the target group are not the intended receivers of the norm, but benefit from the norm anyway. Case $\mathrm{C}$ is characterized by some individuals being included among the receivers without benefiting from the norm. Finally, as in case D, it is possible for the two to the combined; that is to say, some norm-receivers do not belong to the target group while some members of the target group are not norm-receivers.

Coleman emphasizes that just being able to conclude that some actors have an interest in supporting a norm does not fully explain why a norm emerges and how it is maintained. One also needs to analyse under what conditions the 
affected interests are realized, which is another matter. This requires abandoning functional explanations at a macro sociological level and assuming an actor perspective based on micro sociological action theory.

The emergence of norms is, in Coleman's view, linked to whether an action leads to positive or negative externalities that two parties cannot solve through transactions, upon which other individuals affected by the externalities assume control over the action. ${ }^{46}$ Put another way, the need for a norm, according to Coleman, emerges when a relationship or other actions between two individuals lead to consequences for others than the interested parties. Initially, in a relationship, both parties are assumed to have access to resources that allow them to avoid the impact of negative external effects. This is not the situation in a relationship that includes three or more actors.

Coleman's definition of norms turns the previously referenced sociopsychological theory on the emergence of norms upside down by stating that norm-receivers try to avoid the norm, while the target group has an interest in maintaining it. Clearly, Coleman is focusing on another kind of social norm. Based in this simple starting point, Coleman develops advanced pay-off models based on game theory analyses of the conditions under which norms can be expected or not expected to function. With regard to conjoint norms, Coleman argues, if the benefits each actor gains through their actions are lesser than the costs entailed by all other actors through similar actions, a norm necessarily emerges to achieve a socially optimal outcome. ${ }^{47}$ Since everyone in this situation benefits from the norm, conditions are ripe for it to emerge spontaneously. Everyone has an interest in the norm. This can also be seen as an example of norms created within the framework of the social system.

For the norm to be effective, however, it needs to be able to enforce sanctions against whomever does not voluntarily contribute to the, for all parties, optimal social order. This means that Coleman's game theory-based argument requires that there is a social relationship between two actors that is affected by a third party's actions. A necessary condition for an effective norm to emerge spontaneously is that the members of the target group are either able to share the costs of sanctioning the norm-receivers or that they are at least able to mobilize enough members to enforce sanctions against the receivers. These conditions are dependent on social relationships within the target group.

Coleman argues with support in current empirical research that individuals endowed with power in society are also the most unlikely to be subject to sanctions, while simultaneously being the group that is most likely to violate existing norms ${ }^{48}$ Furthermore, the group at the bottom of the social hierarchy risks being subjected to sanctions, despite the fact that their actions are no less norm-bound than are those at the top of the hierarchy. Another aspect that has an impact on

46 Ibid, p. 251.

47 Ibid, p. 260 and Table 10.2 on p. 256.

48 Ibid, p. 286 ff. 
the use of sanctions is the degree of contact with the surrounding outside world. Individuals who are in contact with people who do not belong to the sphere of receivers or the target group are less likely to follow a norm than are people who are only in contact with people living under the same norms.

The issue that Coleman discusses in connection with externalities is often referred to in economic theory as the free rider theory; that is to say that there are situations in which a number of individuals share the same interests but which can only arise through actions that seemingly would incur greater costs than benefits for each individual. In the absence of an organization that is able to collectively address and solve the problem, necessary measures will not arise spontaneously, despite the fact that it would be possible to achieve results through an appropriate allocation of individual efforts, at a cost for each individual that is lesser than the benefits they would gain. ${ }^{49}$

This kind of situation can be overcome through norms and their entailing sanction systems. This achieves the same effect as the creation of a formal organization: namely, that the actors internalize externalities. The norm makes the benefits of collective action apparent to the group, thereby creating conditions for the actors to accept the action. In order for norms to emerge in such a situation, however, there needs to be an organization or authority recognized as legitimate by the actors, and thereby authorized to take the initiative to declare norms. However, these are not just linked to social life. There are two kinds of expectations: normative and cognitive. ${ }^{50}$ A normative expectation has to do with whether another individual acts in a given way. A cognitive expectation, however, is the expectation that an action or other condition will occur based in one's knowledge of related conditions, such as natural laws, statistical links, etc. If the cognitive expectations are not realized, it is probably a good idea to adjust the expectations, i.e. adapt to reality rather than vice versa. However, in the event that a normative expectation fails to be realized, there might still be reason to maintain it. In order for expectation and reality to meet in these cases, often, we try to harmonize reality with the expectation by using sanctions and other measures. In Niklas Luhmann's view, the entire legal system consists of these kinds of structures of expectations. ${ }^{51}$

There is a field of research related to game theory with an interest in social norms that warrants mentioning. I refer here to the field of research with a research interest in analysing so-called social dilemmas ${ }^{52}$. A social dilemma is a situation in which an individual benefits from selfishness, unless everyone chooses the selfish alternative, in which case the whole group loses. Problems arise when too many group members choose to pursue individual profit and immediate satisfaction

49 Cf. Hardin, Garret (1968, pp. 1243-1248) and Hardin, Garret and Baden, John (eds.) (1977). Please also see Ostrom, Elinor (1990).

50 Sundby, Nils Kristian (1974, p. 139).

51 Luhmann, Niklas (1985).

52 Biel, Anders, Eek, Daniel, Gärling, Tommy and Gustafsson, Mathias (2008). 


\section{2}

rather than behave in the group's best long-term interests. Social dilemmas can take many forms and are studied across disciplines such as psychology, economics and political science. ${ }^{53}$ The field has emerged within decision theory and is mainly of interest to (social) psychologists and economists. ${ }^{54}$ This focus on the social dilemma is based in the notion that game theory has to a large degree ignored the importance of social and moral factors in the context of decision-making-i.e. what kinds of decisions people make. This applies mainly to large-scale situations. Analyses of the social dilemma are particularly well-suited to such situations. ${ }^{55}$ A social dilemma is a situation in which an individual interest conflicts with the public interest. It is furthermore characterized by the "payoff" being greater if the individual behaves selfishly rather than unselfishly, while public interests suffer if the majority acts selfishly. This, in a nutshell, is the dilemma. The social dilemma means that individual outcome not only affects the individual's own choices but also the choices made by other members of the group or society. ${ }^{56}$ This is what makes it a social dilemma. The individual has the choice of maximising either their own self-interest or public interest.

This is where social norms come into the picture. Game theory claims to provide rational criteria for decision-making in social situations that are otherwise ambiguous. ${ }^{57}$ This claim takes its starting point in the assumption that selfinterest overrides other values. Research on the social dilemma problematizes this assumption by pointing out situations in which self-interest does not lead to an unambiguous normative outcome. For example, in some situations, self-interest is dependent on public interest, not least with regard to which era one studies. This takes us back to square one - that is to say, the individual is forced to make a decision. This relates more or less to one's relationships with other individuals in the same social system. If our starting point is that conjoint perceptions emerge and govern these decisions, then it is reasonable to state that social norms govern behaviour. One might say that research on the social dilemma distillates situations and decisions in which social norms "work freely" without being affected by other norm systems.

There is, however, limited research on the impact of social norms ${ }^{58}$ There are no well-developed theories in the area yet. The reason interest in the subject has risen in recent years is that social norms lead to restrictions on self-interest. By norms, I refer here mainly to bans and moral standards. From this perspective, social norms emerge as a response to collective needs. In time, Biel et al. argue, we can expect further research in the area to allow us to conceptualize and

53 See for instance, Biel, Anders et al. (ed.) (2003).

54 Voss, Thomas in Hechter, M. and Opp, K.D. (eds.) (2001, pp. 110-113).

55 Please see Biel, Anders et al. (1998).

56 Please see Biel, Anders et al. (1987).

57 Voss, Thomas opus. cit.

58 Kerr, N. L. (1995). 
measure the effect of social norms on behaviour and decision-making in connection with the social dilemma. ${ }^{59}$

As an example of social norms, Biel mentions adultery. In some countries, it is a punishable offence, while it is not in others. Regardless, people still perceive infidelity as wrong. One reason for this has to do with how important family relationships are to the involved parties. Emotional reactions such as guilt and shame can arise and support the norm. ${ }^{60}$ Such emotional factors reflect the twin functions of the norm, i.e. it works both as an internal standard that the individual demands of himself or herself (guilt) and as an anticipated, external reaction from the actor's social sphere.

The social norm's strength affects its level of penetrability. In situations where people perceive that there is a norm that informs appropriate behaviour and that this norm is strong, they are more likely to cooperate in the interest of the public than in situations where the norm is weak or absent. At this point, it is worth remembering Robert Axelrod's simulations showing that in order for the norm to be maintained in the long-term, compliance with the law is dependent on the surrounding environment actively condemning a criminal action.

Kerr argues that there are three main norms that affect the outcome in decision-making processes in relation to the social dilemma. These are equity, mutuality reciprocity and commitment. ${ }^{61}$ Equity becomes relevant in situations involving the allocation of resources to members of the group. Reciprocity prescribes that affected parties should repay benefits or services in the future. If one expects other individuals to cooperate, in the context of the social dilemma, one must also be prepared to do the same. The principle of reciprocity, therefore, is extended to also cover "generalized Others". Commitment, finally, entails that people act in accordance with their words and perceptions. One problem, in this context, however, is that this social norm basically requires a primary group, which is not the case with regard to large-scale social dilemmas. In these kinds of situations, individuals act behind a high degree of anonymity, there is no group solidarity, communication between individuals is weak and individual efficiency is poor. ${ }^{62}$ In cases like this, one should expect social norms to be at their weakest.

The main body of research on the social dilemma deals with experimental game situations in which individuals are offered several, well-defined alternatives. In reality, however, these conditions are not always present. In recent years, therefore, there has been increasing focus on conducting studies of real situations that demonstrate features of the social dilemma. Many environmental problems belong to this category. One example is the number of people that choose to travel by car instead of public transportation, a choice that is based in perceived comfort and time savings. Analyses of the social dilemma are particularly common in cases

59 Biel, Anders et al. (1998).

60 Ibid.

61 Ibid.

62 Ibid, p. 35. 
that deal with resource issues. Fishermen that maximize their catch despite the fact that it poses a risk to the future of the entire fish supply are an example of a case suitable for analysis. Such cases can be compared to traffic pollution. Since each individual's contribution to the total amount of environmental pollution is so small that it is perceived as negligible, the individual does not feel that it is necessary to abstain from driving their own car, despite the fact that the resultant air pollution affects everyone. Another kind of social dilemma has to do with collective goods that are freely available to group members regardless of whether or not they contribute to maintaining them. There is always a risk in such scenarios that a common resource will be overexploited. In situations like this, an interest in establishing various kinds of cooperation, or a joint setting aside of economic funds in the form of taxes or fees, arises.

\subsubsection{Other types of social norms}

According to sociology dictionaries, there is a sliding transition between the three main types of norms. ${ }^{63}$ Constructive norms describe how we expect an interaction to occur, e.g. football rules, grammar rules or rules for market behaviours. Competence norms describe who is to make, or should make, decisions, carry out agreed actions or take responsibility for the ensuing results. These are seen as important components of social roles. The third category consists of action norms. They prescribe how people must, or ought to, act. They can, in turn, be categorized as either goal-oriented or not.

According to the same source, moral and social norms are commonly separated. There are two kinds of moral norms: goal-oriented, consequential norms and virtue ethic norms which dictate that the act of following a norm has intrinsic value. Most social norms are not goal-oriented, nor are they rational. They indicate what is seen as right and just behaviour. Violation of a law is manifest in the loss of social repute or respect. Social norms are deemed to be operative as a result of having been internalized. This leads to individuals experiencing the norm's instructions as something they voluntarily wish to comply with. We take these norms for granted. We are not always aware of them, and often they are opaque or ambiguous. Therefore, they need to be communicated, interpreted and understood to be applied in practical contexts. Deliberations and discussions on how norms are applied, therefore, are an important component of social life.

Swedish sociologist Göran Therborn argues in a review article, as do many others, that norms relate to normality. ${ }^{64}$ Acting in compliance with a norm means acting like a "normal" person. Therborn argues that norms mainly have three different messages: ${ }^{65}$ They define what something is, its characteristics and how actors ought to act in relation to it. It describes "what we, as actors and observers,

63 Sociologiskt lexikon (1998, p. 221).

64 Therborn, Göran (1993, p. 4).

65 Ibid, p. 3 ff. 
can reasonably expect". ${ }^{66}$ All three normalization processes, according to Therborn, have to do with reducing uncertainty in social life, thereby contributing to social order, that is to say, predictability. However, what is "normal" can be defined very broadly. The function of the norm, then, is to set limits for what is deemed tolerable behaviour. Norms thereby contribute to identifying deviators who do not conform to normal behaviour - according to the unspoken norms.

Schwartz distinguishes between norms that are internalized and social norms and their consequences that are administered by other individuals. ${ }^{67}$ This distinction is reminiscent of Durkheim's distinction between technical norms, in which the sanction is a built-in component of the norm and moral norms that are maintained by way of "artificial" sanctions imposed externally. Internalized norms would in that case consist of social norms that the individual adopts out of fear of being excluded from the group. There is, in other words, an analytical, built-in link between the norm and the sanction. Torstein Eckhoff and Nils Kristian Sundby arrive at a similar conclusion in differentiating between internalized norms and systemic norms, in which the latter are exemplified by norms that are related to the particular game one chooses to play. ${ }^{68}$ The actors are forced to comply with the particular rules of the game, regardless of whether they want to or not.

\subsubsection{How are norms created and reproduced?}

Some theorists, when analysing the emergence of norms, have seized upon other social conditions. For example, in his book, Rättens ursprung och grund, Per Stjernquist makes the following statement: ${ }^{69}$

In order to satisfy their myriad, varying needs, people cooperate with each other. If this cooperation extends beyond a mere temporary solution, specific norms develop to inform each participant how to act in order to benefit from the exchange. Initially, these norms consist of mutual opinions and attitudes, but may be set down as rules at a later stage. People comply with the norms because otherwise the collaboration fails, and everyone loses out.

Stjernquist argues that in the final analysis, cooperation within the group is dependent on whether it fulfils the members' stronger, practical and emotional needs. Stjernquist also gives examples of how fundamental needs spontaneously create norms and references, among others, Malinowski's study of the Melanesian population on the Trobriand Islands, northeast of New Guinea, and how when fishing, inherited norms strictly designate each participant's actions and how the

66 Ibid, p. 3.

67 Schwartz, S.H. (1977, pp. 221-279).

68 Eckhoff, Torstein \& Sundby, Nils Kristian (1991).

69 Stjernquist, Per (1976, p. 35). 
catch is to be distributed. These norms were necessary to allow fishermen to work together, but it was individual need that forced each fisherman to comply with them, Stjernquist argues. In this scenario, norms can be seen as a source of routinized actions borne of practical necessity. Anyone violating the rules was excluded from the fishing group and would suffer from a lack of sustenance.

Many of the examples that Stjernquist mentions deal with other conditions than purely social matters. In other words, there seems to be reason to differentiate between the emergence and development of norms, depending on context. Economic and political life also has an impact on norms. The basic starting point is that norms arise and carry out a function within the framework of the action system and that these systems can revolve around the functions that distinguish them. Norms can be seen as values-based generalizations in these systems or, as legal philosopher Josef Esser argues, as operationalized values. ${ }^{70}$ In principle, there is no difference between norms that belong to these action systems and social norms. When they appear in primitive societies, they conflate as a result of social and systemic integration melding together, as mentioned in the previous chapter. When they follow different paths in modern societies, there is no reason to restrict the concept of norms to imperatives that belong to the social system.

At a more general level, Christine Horne has developed a model that explains the emergence of norms. ${ }^{71}$ This model is based in the fact that social and technological changes lead to cost/benefit allocations which in combination with group pressure influence behaviour. Robert C. Elickson has addressed the topic of the development of social norms. ${ }^{72}$ Elickson introduced the concept of change agents, thereby highlighting the importance of different actors in the emergence and reproduction of norms. With that in mind, Elickson worked on an S-curve that begins with self-motivated leaders and norm entrepreneurs, with opinion leaders following behind in an upward curve. Elickson writes ${ }^{73}$ that "(w)hen a new norm suddenly becomes manifestly advantageous for a group, many selfmotivated individuals with unexceptional leadership abilities may supply it simultaneously", thus making the new norm attributed to particular change agents. One example of a norm creation process similar to the one described by Elickson is a project for children's rights to education under an international training programme. ${ }^{74}$ The programme targets those in a position to initiate change in the education sector in their countries. During the programme, all participating teams initiate a change project in their respective countries aimed at realizing the intention of the Child Rights Convention in policy as well as in practice. Another example deals with the influence of idealists ("souls of fire" in Swedish) in the

70 Esser, Josef (1964).

71 Horne, Christine (2001, pp. 3-34).

72 Elickson, C. Robert (2001, pp. 35-75).

73 Ibid, p. 43.

74 Wickenberg, Per et al. (2019). 
environmental sector. ${ }^{75}$ A soul of fire is, according to Per Wickenberg, "a very dedicated, committed, key actor, who brings his or her personal engagement, beliefs and values into the professional organization and makes a difference in norm-creation processes through her or his influence". ${ }^{76}$

The main body of analyses of norms takes their starting point in social action systems. However, these studies may be based in the perspective of interested parties, or be intended to serve a specific purpose, and are therefore open to individual interpretation. ${ }^{77}$ My perspective is that social action systems are created through interactions between people in line with socio-psychological theories and developed in accordance with the driving forces identified by game theory. This means that the content of a norm, in each single case, is determined by individuals in cooperation with each other, although aspects such as habits, customs and conventions may restrict the set of norms available to the individual. ${ }^{78} \mathrm{How}_{\text {- }}$ ever, some action systems are goal-oriented and constrain the individual's actions. I refer, here, mainly to the economic and the ecological systems. Therefore, in the next section, I will distinguish between different kinds of action systems. Nevertheless, in light of the various aspects of social norms accounted for above, we shall first attempt to define the concept of norms.

\subsubsection{The concept of norms}

The first ontological essence of norms is that they are behavioural instructions (imperatives). This essence can unquestioningly be accepted within the framework of Kelsen's "legal" norms. He views the legal system as a system of “oughts", and for Kelsen, norms become norms precisely because they are action-instructive. But this is also an essence that is acceptable from a socio-legal perspective. Durkheim claims that norm (or in reality social facts) are things in the sense that they can be viewed through their signs.

Norms are inherently inter-subjective. They are perceived and experienced similarly by the people subjected to them. Norms exist in a social context. Also, the longevity of our experiences of them make us confirm their existence. This gives us the second essence of the norm concept, namely that norms are socially reproduced. For example, a mountain slope cannot be a norm in and of itself - despite the fact that it provides information that forms a guide and basis for action. It can probably be claimed that a mountain slope represents an imperative (for example:

75 Wickenberg, Per (1999). Normstödjande strukturer: miljötematiken börjar slå rot $i$ skolan. Diss. Lund: Lund University.

76 Wickenberg, Per. (2013). Souls of fire, change agents and social norms. In Baier, Matthias (ed.) Social and legal norms [Electronic source]: towards a socio-legal understanding of normativity. Farnham, Surrey: Ashgate, p. 12.

77 I see this as one of the reasons behind Habermas' ambition to argue from a critical theory standpoint in favour of a paradigm shift from goal-oriented, instrumental activities to communicative actions, cf. Habermas, Jürgen (1987) Ch. V and (1996).

78 For a more in-depth description: Lloyd, Dennis (1964, p. 228). 
"Walk around me"), but it is not until an opinion on how to relate to the slope is reproduced socially that it becomes meaningful to speak of a norm. In a similar manner, an individual person's "commands" do not become a norm until an opinion as to how to react upon the command is spread. This second essence-defined attribute is highly natural to the social sciences, and the fact that the imperative is given a social context is completely in line with, for example, Durkheim.

The existence of physical objects can be confirmed simply through our senses. I can see a cherry. I can also hear it if I throw it at the window. I can feel it if I press it against my forehead, and I can taste it if I eat it. The testimonies of the senses are interpreted by the mind as corresponding with each other. Everything points toward the same cherry, and therefore we acknowledge its presence. With regard to intellectual and abstract concepts such as norms, the corresponding process is termed cognition. This is a psychological term that in short serves as a collective term for our thought processes. Cognition and perception are the active psychological processes as we interpret the information collected through the senses. ${ }^{79}$ The difference between physical objects and norms is that the latter exist as linguistic and semiotic signs and can only be perceived in terms of their effects. The branch of cognitive science called situated cognition views thought processes as a type of dynamic system where the brain controls the body's interactivity with the surrounding world. In situated cognition there is a basic distinction between signals that describe reality and signals that describe human opinions. In both cases, the result may be that the individual experiences these signals as an expectation to act in a certain manner. Thus, we have established the third essence of norms, namely that norms are the individual's understanding of expectations surrounding their own behaviour. As a result of this third essence, the socio-legal concept of norms shifts towards social psychology. Svensson regards this third essence as beliefs, which he refers to as a psychological and behavioural dimension of the norm. ${ }^{80}$ In my understanding, beliefs may explain why an actor follows a norm, but they are not a condition for the existence of a norm and are thereby not a necessary criterion when defining social norms. Expectations give in my mind a more appropriate understanding of the concept. I will return to this theme in the last chapter.

\subsection{The distribution of norms across action systems}

\subsubsection{Action systems}

Norms are fundamental components of what we call action systems. What makes a system an action system is the fact that the system is based on norms, instructions on how to act. To avoid any misunderstanding, it should be noted that

79 Atoms are physical objects as well, but still carry a different ontological status. For hundreds of years, they existed only in theory, but in the last hundred years, atoms have come within closer reach of our senses.

80 Svensson, Måns, 2013 in Baier, Matthias, Social and Legal Norms. 
I use a different concept of systems than does Niklas Luhmann. ${ }^{81}$ While Luhmann applies a binary code as a kind of theoretical screen to determine what belongs to each system, I adopt an empirical approach, i.e. I attribute certain, similar characteristics to a system when joint norms play a decisive role. In synchronising our norms, our actions create social action systems. These action systems may be determined socio-culturally, politically, economically or ecologically. A system is manifest when individuals in one way or another articulate the contents of the system or when an individual is affected by the system. This leads to a tendency to call all systems social systems. I would argue, however, that for analytical reasons, it is better to examine the background underlying the action systems to study whether they are related to economic or technical deliberations, whether they have been determined politically, etc. This approach provides a better understanding of the unique characteristics of the different kinds of norms.

This does not mean that there is not much to learn from Luhmann's analysis; rather, it is very useful when analysing how a system is delimited and how it functions. Each system has its own criteria for determining what belongs to each individual system. These criteria are deliberated communicatively in line with each system's own method of communication. Thus, an economic system is only receptive to economic arguments, a legal system can only be influenced by legal arguments, etc. In this way, norms are system-bound, i.e. they are dependent on the system they belong to. The political system abides by its own norms; the economic system has, in common with the social system, its own norms; and the ecological systems, the conditions of life as determined by nature, abide by natural laws. Each of these systems has unique conditions and reproduction methods, and norms play - to different extents depending on their support in law - a role in the construction and reproduction of the systems.

The legal system in itself in this context is not in a position, nor does it have the weight in ordinary people's daily lives to be included among the actual, norm-producing systems. The system of norms underlying the legal system (substratum) is not produced by the legal system, but by other social subsystems, or as a result of conflict between them. Once the law has contributed to formulating and clarifying the social, political or economic norm, however, it gains its own legal definition, partly independent of its source. In being a system with its own unique construction and way of operating, the law contributes to re-formulating and changing the content of the original norm. This does not mean, as we shall see in Chapter 5, that law cannot be used to affect existing norms.

I refer here primarily to the relationship between the various systems. They can be divided into ecological systems and societal systems as shown in Figure 3.11 .

81 Luhmann, Niklas (1985). 


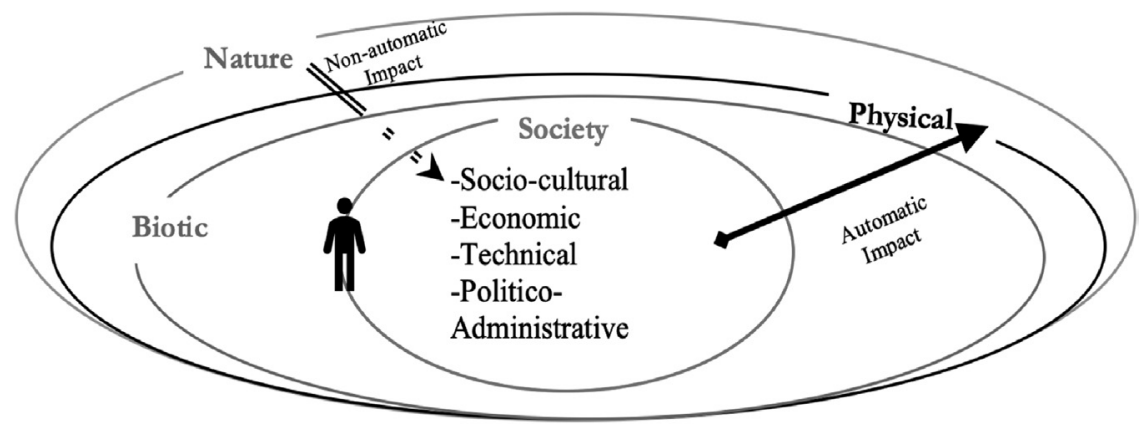

Figure 3.11 The relationship between various systems

\subsubsection{Socio-cultural systems}

According to Therborn, the emergence of norms within social systems has to do with three factors. ${ }^{82}$ Firstly, it has to do with the socialization of the actors. The function of a social system is precisely to socialize people, to encourage individuals to behave socially, to comply with certain socially (collectively) conditioned methods of interaction. Individuals are socialized into a given society, thereby learning a set of given, normal ways of acting. Furthermore, the norms are determined by the social environment in which the individual's social action takes place. The greater the social continuity between the socialization process and the situation in which the action occurs, the more effective the normative, Therborn argues. Similarly, the degree of homogeneity has a cultural influence. The greater the social differentiation, the weaker the norms. This leads us to the third significant factor in the creation of norms: where, within the framework of different social action systems, the context of the action is situated. Therborn emphasizes three aspects of the importance of the context of the actors' action with regard to complying with norms: how visible the actor's actions are, how dependent the actor is on his norm-bearing surrounding social environment and how strongly the actor identifies with the source of the norms.

To belong to a social system is to subject oneself, in terms of behaviour, to more or less predetermined constellations of norms. Therborn refers to conduct, performance and distribution of which conduct and performance norms express the collective's expectations, while distributive norms have to do with the justice or injustice of the system in terms of opportunities, risks, rewards and punishment. ${ }^{83}$ The reciprocity principle is, in this context, a driving force. This so-called golden rule is a fundamental ethical principle and can be found in many religions and philosophical and ethical schools of thought. The oldest known written 
version comes from Confucius, approximately $500 \mathrm{BC} .{ }^{84}$ This principle can be expressed both as a positive rule ("Do unto others as you would have them do unto you") and as a negative rule ("Do not do unto others as you would not have them do unto you"). What the norm creation processes in different social systems share in common, however, is that they require human interaction to be established and maintained.

\subsubsection{The political/administrative system}

This system is more goal-oriented than the social system. The political system was created to represent society's collective interests, i.e. the public interest. ${ }^{85}$ The establishment of a political system is an expression of the need for a collective order which is tasked with making decisions on values-based and normative issues that are of importance to the people affected by the system. ${ }^{86}$ They are implicitly manifest in a constitution that the members of the society create through norms. ${ }^{87}$. Using Coleman's terminology, the members of the society thereby transfer their right to carry out certain individual actions to the collective. ${ }^{88}$

The political system could be described as being particularly focused on the production of norms in situations where they are needed in social action systems. This means that the political system's own norms, to a large degree, depend on under what conditions, and how, norms are determined. In other words, these norms deal with the issue of who is recognized as competent to make political decisions and how they are to go about doing so, i.e. in what order, and how, decisions are made. The norms are like competence rules, i.e. they convey permission to act while also indicating the formulas and procedures surrounding the act. The political system's norms, then, are unique compared to other action systems. They do not provide any concrete action instructions in themselves; instead, they intrinsically imply the application of some actions rather than others. A democratic political system, for example, does not promote the same values as a dictator, while a dictatorial political system may be able to act decisively in a way - for better or worse - that surpasses the more cumbersome decision structures of the democratic political system.

The political system was created to make decisions on how to proceed in various situations. The political system's output largely consists of (created) legal norms. Seen from this perspective, law can be seen as a form of standardized politics: it governs and summarizes policies in a given sub-section of society. ${ }^{89}$

84 Henrikson Alf \& Hwang Tsu-yü (1949, 1997).

85 Rothstein, Bo (2015).

86 This does not exclude the political system, as myriad examples have shown, from being perverted to serve an individual's or group's interests and desire for power.

87 With regard to the legal constitutionalization process, please see Montesquieu (1990) and the introduction by Stig Strömholm.

88 Coleman, James (1990, p. 326).

89 Cf. Hydén (2002b) Ch. 8. 


\section{About norms and action systems}

In areas where individuals decide to transfer tasks to the collective body - the political system - action instructions are activated which in turn create an action system. When the social system has grown to the extent that the decision-making and executive processes need to be separated, decisions need to be passed on to those tasked with executive functions; this is accomplished through norms. These norms have some characteristics of an order or decree, i.e. they describe what actions are expected of the actor. ${ }^{90}$ This leads to a division between politics and administration in which the administrative system can be seen as an action system created for a specific purpose.

The political/administrative systems are based on norms that set out guidelines and principles for collective decision-making. Generally speaking, this often pertains to organising issues around who should be allowed to make decisions, elections, decision-making committees, etc.; how the decision-making process should be conducted, i.e. the principles the process should comply with; or what kinds of issues should be addressed collectively within the political/administrative systems. Furthermore, norms are needed to distribute tasks between the decision-making political system and the executive administrative system. Generally speaking, any organization that is big enough to need to separate decision-making processes from executive processes will result in normative messages being conferred from the decision-maker to executor. The larger the organization and the more differentiated its tasks, the more likely it is that its normative messages will become generalized and change from being a temporary order to a fixed norm. When this happens, some normative positions are taken over by the executive power, giving them a higher degree of independence and allowing them to execute the final task in accordance with their own normative positions.

The political/administrative systems play a role in the economic and social systems. However, they should not, unlike the ecological and economic systems, be seen as imperatives. The administrative system was created to complement various aspects of the other systems. The political system was initiated to carry out functions that spontaneously had not been generated by civil society or the market. The purpose of the political system is to provide and organize a collective decision-making apparatus. However, this does not mean that the political/ administrative systems' norms are of no consequence to norm-creation processes in other action systems. Thus, in an article on the moral logic of the welfare state, political scientist Bo Rothstein argues that "in general, the welfare state, as a political institution, has important implications for among other things the creation of social norms". ${ }^{91}$ To begin with, Rothstein argues, this has to do with the political/administrative system's general understanding of justice, i.e. its nondiscriminatory nature. ${ }^{92}$ Secondly, it is related to procedural justice; that is to say,

90 This also leaves room for moral discussions and arguments in the political sphere, e.g. Mathieu, Chris (1999).

91 Rothsten, Bo (1993a, pp. 5-21). Please also see Rothstein, Bo (1998).

92 Rothstein refers here to Levi, Margaret (1998). 
justice with regard to how the policies are implemented. The third norm relates to the general understanding, whether right or wrong, that all people are treated and act fairly. In other words, that they neither contribute nor receive more or less than they deserve. Rothstein concludes that "it seems as if the welfare state, in general, once having been institutionalized, develops a special set of social norms which work as a positive feedback loop between the voters' political support and the implemented policies". ${ }^{33}$ In the aforementioned article, Rothstein requests more in-depth political science research on the relationship between what he calls actual political institutions and social norms. Generally speaking, research on the normative impact on, and between, various action systems, seems to be required. In other words, there is a need for a norm science.

\subsubsection{The economic system}

This system is extremely action-oriented. Its very existence is based in inherent normativity. For obvious reasons, the need for norms depends on the construction and nature of the system, i.e. what kind of economic system it is. I will not delve further into the normative differences between various economic systems. However, I will briefly point out that a feudal system, much like a handicraftbased system of production, requires a division of labour based on status and hierarchies. That is to say, the economic system is intrinsically constructed to divide people into groups with different statuses and tasks. This is based on a static division of roles. An economic system can, furthermore, be highly centralized, as was the case in former planned economies. These kinds of economic systems become politically lopsided and end up facing the same issues as political/administrative systems: the need to separate decision-making and executive functions requires that the normative message of the political decision is transferred to the executive system. How distant and complex the economic system is determines the need for norms.

In decentralized economic systems, these kinds of norms are not necessary. In market-economy systems, there is less need to separate decision-making processes from executive processes. At most, it may be an internal issue for private organizations, companies, etc. In general, however, the so-called price mechanism, i.e. the process of supply and demand, informs us of preferences. The market system, however, does require other kinds of norms. ${ }^{94}$ Economic rhetoric goes as follows: ${ }^{95}$ The market is based around the notion of competition between private actors who each try to satisfy their own needs. Reconciliation via the price mechanism guarantees a form of balance between supply and demand. The equilibrium

93 Rothstein, Bo (1993, p. 16). However, today (2021), there is reason to take note of the critique and oppugnancies levelled at welfare state policies in general that have emerged in recent years, not least as a result of an increase in migration.

94 Altvater, E. (1993).

95 For the following text, please see Dorfman, Robert (1968, p. $25 \mathrm{ff})$. 


\section{About norms and action systems}

price of a product corresponds to the point where supply and demand are equal. Equilibrium quantity is the level of supply and demand that corresponds to the price. Furthermore, if a product's production costs change, its equilibrium price will change correspondingly but according to a lesser amount, while its equilibrium quantity will change in the opposite direction. Any reduction in the supply of a product at each pricing point can be shown as a downward displacement along the demand curve. This leads to a reduction both in equilibrium price and equilibrium quantity. An increase in demand has the opposite effect.

Any individual who buys and sells goods in the course of their daily business activities can be seen as belonging to the group that comprises the product's market. Describing the numbers of buyers and sellers and their relationships is to describe the actual structure of the market. In order for this system to work, the actors must be prepared to observe some game rules; otherwise, it will fail. Cooperation combined with competition, the market economy's rhetorical motto, requires common game rules to synchronize the actors' actions. A market is deemed a free market when there are enough buyers and sellers to ensure that neither are able to exert noticeable influence on the price or on supply or demand quantities. If the system is disrupted, e.g. by monopolies or oligopolies, corrective norms are needed to balance the market.

There are parallels here to Coleman's game theory-based analyses of the social effectiveness of norms, as mentioned above. Additionally, Coleman explains that his principles of social effectiveness are based on economic effectiveness. In actual fact, many game theory-generated action instructions are based on economic benefit analyses. The economic system focuses on how to achieve economic optimization. The term strategic norm is therefore appropriate when referring to the economic system's norms. Strategic norms within economic system are based on rational analyses that take their starting point in self-interest. The logic underlying the exchange of goods and services between people with different preferences is that it allows many people to satisfy their self-interests. It is also assumed that it is thanks to the market that many individuals can be brought together, thereby creating a socially beneficial situation. Market expansion and free competition allow for effective solutions.

In itself, however, the market does not constitute an economic system. It is merely a large or small part of an economic system. How the market is conceptualized and constructed is presumed to be a matter of indifference to the economic system. However, this does not stop the market from being uniquely characterized by the economic system in which it functions. Generally, when we think of the market economy, we think of an economic system based on capitalist and private ownership principles. This is what characterizes our country and, since the fall of the Iron Curtain economies, and measures by the World Bank and the International Monetary Fund (IMF), a growing share of the global economy. ${ }^{96}$ 
This progress has developed to the point that we now refer to it as being a globalization process.

What, then, does the capitalist version of the market entail in terms of action systems? What kinds of norms does this particular economic system generate? I have previously used games as an analogy in my analysis of society. ${ }^{97} \mathrm{~A}$ game is constituted through its norms, i.e. that which delimits football from other related games are those norms that specifically define football. Similarly, it could be argued that the market economy is constituted through its unique norms. The essence of the market economy, according to capitalism, is to produce exchange value, whether in the form of products or services. Goods are produced to be sold on a more or less anonymous market. As long as the product can be sold at a price that exceeds the cost of producing it, ${ }^{8}$ it will be profitable to produce it; that is to say that as long as someone is willing to buy the product at that price, it will be profitable to produce it. ${ }^{99}$ In other words, the criteria underlying the formation of norms in that particular case are unambiguous. For the individual business owner, the process, according to Marx's surplus value theory, is as shown in Figure 3.12.

This figure represents the circulation and accumulation processes that capital investment must pass through to lead to production and satisfying people's needs. In this economic perspective, it is subordinate to growth in terms of driving force.

What characterizes the capitalistic production of goods is that the production system is based on salaried work. This leads to the conditions of production being subject to a particular organizational principle. Market mechanisms thereby also determine the most fundamental distribution of social surplus. Workers and civil servants are paid according to how the labour market evaluates what they are

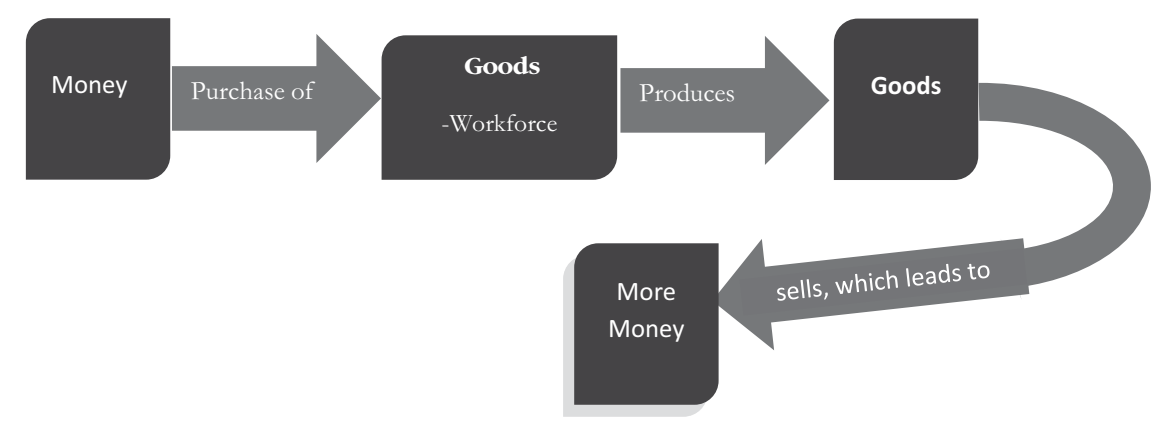

Figure 3.12 Marx's surplus value theory

97 Hydén, Håkan (1985).

98 This also includes the value of the workforce in accordance with Marx's surplus value theory.

99 Dorfman, Robert (1968, p. 45 f). 


\section{About norms and action systems}

selling. ${ }^{100}$ The price of salaried work is determined according to the same principle but also determines the exchange of goods in general. This means that the labour force benefits from organising and acting collectively on the labour market and strengthening their general position vis-a-vis buyers of their services. However, one could also argue that salaried work in combination with the monetary market forces individuals to sell their labour. From this perspective, the purchaser of the workforces' services is seen almost as a beneficiary, not least in times of increasing unemployment. Probably, this is why we use the term employer (in Swedish: "work provider") for the party buying the workforce's services and not the term work purchaser, which would be a more correct application of market economy lingo.

One might wonder whether there are any norms that oppose unlimited exploitation of the workforce. As unemployment in Europe approaches up to 20\% in some groups, one might wonder why the price of labour, i.e. salaries, is not forced down to unsustainable levels, at least with regard to unskilled groups subject to strong competition. A Keynesian perspective would conclude that the market economy not only requires that goods can be produced but also that they can be sold on the market, i.e. that there are buyers out there. ${ }^{101}$ This also requires that the population's purchasing power corresponds to increased productivity. ${ }^{102}$

Mass production requires that purchasing power is distributed among as many people as possible since individual persons can only consume a limited amount of goods. This creates incentive for the capital owners to join up and, together with representatives of the collective employer organizations, establish some form of balanced and reasonable wage level. It even leads to an interest in collective arrangements in which people who are excluded for whatever reason - be it due to illness, age, etc. - and do not participate in the labour market, thereby losing out on revenue opportunities in the market economic system, instead receive some form of support. While these situations benefit all involved parties, they require that the benefits are made obvious enough for the norm-receivers who otherwise only indirectly belong to the norm's target group.

The individual's existential conditions, from the perspective of the economic system, are as shown in Figure 3.13.

What distinguishes the economic system from the social system is that the norms are based in a form of rationality that is embedded in the system itself. Social systems are, as we have seen, based on norms that emerge when two or more individuals interact for whatever, perhaps arbitrary, reason. Norms are created by individuals and are shaped by the involved parties' values and ambitions in that particular context. In the economic system, norms are made obvious through

100 Marxist theory was based on the notion that it was the reproduction costs of labour power that determined its value, a theory which now seems both outdated and, in retrospect, incorrect.

101 The tremendous economic support from State governments and organizations like EU during the corona pandemic to both companies and individuals is underlying this point.

102 Cf. the argument posed in Mathiesen, Thomas (1980, p. 209). 


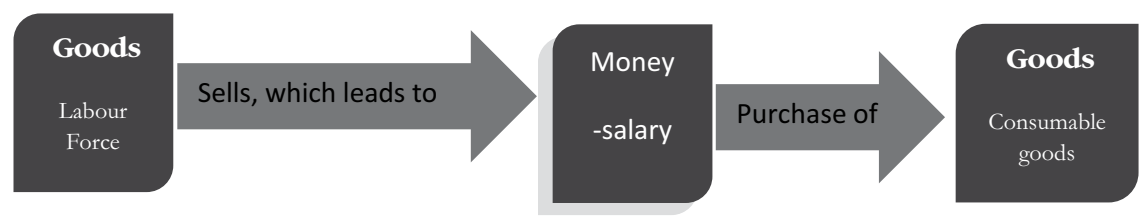

Figure 3.13 The individual's existential conditions

the fundamental principle that characterizes the system. ${ }^{103}$ The economic system is inherently goal-oriented. It produces values-based premises for the actors' actions. The market economy provides both motivation and a driving force for the actors' actions. ${ }^{104}$ The overarching framework decision, i.e. the choice to play a particular game, e.g. "the market economy game", has dynamic effects on people, and their activities could be said to be determined by the game. In describing social rules, Stig Strömholm explains that norms are dependent on decisions made at different levels. ${ }^{105}$ The initial decision is, in a transferred sense, a framework decision to determine what game to play. Strömholm's argument is that this decision determines the entire set of norms that regulate relationships between the involved parties. If you decide to play football, then you agree to comply with football rules. Additionally, this requires a third party, an referee, who is able to determine all the decisions and interpretations in the application of norms in different situations. Was the ball out of play? Was that a handball? Did the ball cross the goal line?

The market economy also promotes certain personal characteristics while simultaneously - without forbidding them - ignoring other qualities. Ergo, the capitalist, production-based market economy has a positive view of growth and believes that more is better, etc. If you choose to play a particular game, some aspects begin to form patterns. The economic system provides a particular pattern as a template for how individuals ought to act. In the football example, one might surmise that specific qualities such as leg strength, speed, physical condition, ball skills, etc., will develop, while other qualities such as arm strength, literacy and swimming ability, to name a few examples, will be ignored. They are not normatively forbidden, but neither will they be developed for the simple reason that the game does not reward these characteristics.

If a player was to pause in the middle of a game, bend down, pick a flower, smell it and gaze upon its colours, it would not be seen as an obvious, illegal action, but it would be seen as so absurd that the likelihood of it ever happening is negligible. It wouldn't happen for the simple reason that it would not be a rational action given the context. Therefore, there is no need to influence the action via

103 Cf. the aforementioned games analogy.

104 For further discussion on this topic, please see Dorfman, Robert (1968, p. 16 f and p. 44 ff). Please also see Coleman, Jules L. (1988).

105 Strömholm, Stig (1975). 


\section{About norms and action systems}

any (external) norm or sanction. The activity (the game) produces an unspoken system in the same way as the capitalistic market economy; an imaginary system that determines what actions are permitted. A secondary effect is that it rewards certain human characteristics while ignoring others, which has an impact on what is produced and, in turn, what is available for consumption in society. People who act within the framework of an economic system internalize the norms of the specific economic system's criteria for what constitutes success. This condition underlies the modernization process that follows in the wake of the capitalist market economy, as well as the uniformity, not to say conformity, that for better or worse characterizes global capitalism currently. The market economy works as a kind of framework decision that, once established, provides definitive structures for continued activities by creating a template for human actions. ${ }^{106}$

The framework decision of the market economy, therefore, has an impact on activities in two respects: partly, it drives forces that influence the direction of its activities, and partly, it creates a pattern for how to behave in different scenarios. Combined, they produce a force field in which social actions take place. This force field represents what I call structural norms. They take their starting point in a form of game theory analysis that differs somewhat from Axelrod's and Coleman's game theories. They assume that the game in itself has inherent implications for how the actors will act. The games are constructed according to different rules, which means that they demand different requirements of the actors. Not only are they subject to the rules of the game, they are also subject to the values-based premises embedded in each game. For lack of a better term, I refer to these norms as structural norms since they are a result of the structure of the game. The economic system, then, has certain game rules and strategic and structural norms, all of which comprise a component of the system; the games by defining the actual system (the game) and the structural norms by articulating the purpose of the game and thereby what actions are rational and should be prioritized.

Structural norms should not, however, be understood as deterministic down to the last detail. They provide normative conditions, but they do not prescribe concrete actions. That requires adopting two additional positions, partly to determine what is strategically right and partly to determine what is actually feasible. Neither do I rule out that strategic actions may violate structural norms. In Axelrod's perspective, however, it does seem as if structural norms become elevated to meta-norms. They describe the principles of the game while strategic norms provide more concrete instructions for action.

Norwegian sociologist of law Thomas Mathiesen describes a similar phenomenon in relation to what he refers to as different kinds of "systems of ideas". Mathiesen distinguishes between bridging, developing and repealing systems of ideas. ${ }^{107}$ The overarching system of ideas corresponds to the structural norms, while the progressive and abolition norms belong to the area of strategic action.

106 Hydén, Håkan (1985, p. 19).

107 Mathiesen, Thomas (1980, p. $163 \mathrm{ff})$. 
The difference between progressive and abolition norms is that the former strengthen and develop the overarching system's norms in order to realize its goals, while the latter norms challenge and threaten to abolish the overarching system of ideas. ${ }^{108}$ Mathiesen argues that systems of abolition ideas - and norms (author's supplementary comment) - have trouble surviving in our society. They are continuously under pressure and threat, which I argue, in this context, should be understood as a representation of the dominance of structural norms. Mathiesen does, however, mention viable strategies for strengthening abolition norms, which I will not delve into further here. ${ }^{109}$

In the context of structural norms, and taking into consideration the social rules as defined by the system, there is room for strategic assessments that promote optimization in each case. These strategic considerations are what provide the underlying basis for game theory assessments of what constitutes socially, or economically, effective actions, which can then be generalized and seen as strategic norms. Ullmann-Margalit even refers to a specific category of norms as "PD norms" which stands for Prisoners Dilemma, i.e. a well-known theorem often discussed in game theory contexts. ${ }^{110}$

These strategic considerations, however, are always dependent on certain social conditions, as Coleman also points out. In accordance with the terminology used here, one might say that the application of strategic norms takes place at the expense of what the structural norms allow. The fields of political economy and business economy focus on systematising knowledge in these areas. This understanding has the same normative function as a legal rule: its purpose is to guide the actor's actions. I refer to the economic system's decrees as independent imperatives for lack of a human subject issuing the orders. The norm-sender is anonymous. They retrieve their content from the logic and conditions of the economic system.

The second, supplementary condition that must be fulfilled before it is possible to assess whether the substantive contents of a norm relate to the immutable nature of the ecological system is an understanding of the ecological sciences and technical conditions. Optimizing one's economic position will therefore largely be based on knowledge of what I call the ecological system, i.e. the system composed of our surrounding nature, environmental factors and ecological resources in terms of biotic and abiotic systems.

\subsubsection{The ecological system}

Norms within the framework of the ecological system have a qualitatively different character compared to the norms that belong to the systems created by man.

108 Cf. Hydén, Håkan (1985, p. 196 f).

109 Toward this objective, please see Mathiesen, Thomas (1980) and Hydén, Håkan (1985, p. $198 \mathrm{ff})$.

110 An introduction: Ullman-Margalit, Edna (1977) Ch. II. 
While norms in the cases hitherto concerned - the social, political/administrative and economic system - are to a greater or lesser degree determined by human interaction, norms in the ecological system originate in the regularities exhibited by nature in those respects man is able to discover and formulate them. Thus, while human actions sometimes show regularities in such a way that we are able to identify social or other norms as underlying explanations, we can observe the regularities in nature that we can formulate in terms of norms and which indicate belonging to a system. These norms are in the last instance based on the laws of nature such as the law of gravity, photosynthesis, the first and the second main principle clause of thermodynamics, etc. Please, see more on this in section 7.1.3. By understanding how these phenomena operate, one can also give advice on how to act to achieve various ends. ${ }^{11}$ These norms are invisible and to a large point unknown. Ecological systems give rise to a sort of conditional normativity. If one wants to accomplish something, one has to pay attention to the laws of nature that can be seen as meta norms that, like principles, generate norms for everyone who has reason to process matter or extract energy or what it is otherwise about in man's conquests of nature.

Belonging to a system also entails action instructions, which are based in conditions needed for the system to remain in place. We will call these norms preservation norms. However, these norms are somewhat opaque and are often obscured by technical norms, or what we can call exploitation norms since they are closest at hand when determining a course of action. In some respects, this corresponds with the economic system's division between strategic and structural norms - the difference being, however, that structural norms are manifest as imperatives to a far greater extent than ecological norms.

While exploitation norms are rewarded with a high degree of spontaneous compliance, the same does not apply to preservation norms. Exploitation norms are easier to apply than reservation norms. They are more visible and palpable. We have learned, through our mistakes, to build boats that do not sink, ${ }^{112}$ habitable housing, bridges that do not crumble, roads that can be driven on, cars that run fast, etc. Due to our desire to satisfy our material needs by developing

111 Tegmark, Max. (2017). Life 3.0: being human in the age of artificial intelligence. New York: Alfred A. Knopf.

112 The ship Vasa was ordered in 1625 by the Swedish king Gustav II Adolf who wanted Vasa for the war against Poland. She would become a floating doomsday weapon with 64 cannon and 300 soldiers on board. Shipbuilders of the 17th century used rules of thumb, not blueprints. Vaasa was well built, but the proportions were wrong. When the stability of the ship was to be tested, they did as usual: a group of sailors had to run back and forth across the deck to see how much she was tilting. Vasa's test was canceled, as it was obvious that the ship was not stable. Still, she was equipped and launched. Vasa sank outside Beckholmen, a small island in central Stockholm, Sweden, on her maiden voyage in 1628. She had only sailed 1,300 meters before a throwing wind caused the ship to edge and take in water through the hatches on the lower battery deck. The investigation after the accident made no one responsible. Gustav II Adolf had himself approved the dimensions. The wreck was salvaged in 1961 and can now be seen at the Vasa Museum in Stockholm. 
technological solutions for various purposes, norms have crystallized in the form of action instructions and become successful simply because they work. A violation of a norm is immediately visible as a manifest failure. Since this has to do with cognitive expectations, we can expect the norm to adapt progressively to action instructions that prove to be successful in the context of the system. The problem with preservation norms is due to the spatial and temporal aspects of action and effect. The negative consequences of an action in nature may not always be immediately apparent or may not appear in the same place as the action. They may be of an accumulative type and only become obvious after 10, 30 or 50 years. There may also be a causal link between an act carried out in Sweden and its effect on the other side of the planet.

In sum, this means that violations of ecological norms - and I speak in general terms here - are rarely discovered. The risk of discovery is minimal, which counteracts spontaneous norm-creation. As exploitation norms begin to have a negative impact on people, so does the need and the collective interest in doing something about them. One example, here, is climate change and the need to reduce carbon dioxide emissions to cool the planet down, which otherwise is headed toward various kinds of ecological catastrophes. This problem expresses a component of the dilemma of ecological norms. Only when the exploitation norms have created sufficiently visible, negative effects are ecological norms implemented. But who needs to take action? There is a kind of free rider problem here in that no one has the incentive to comply voluntarily with preservation norms unless they know that others will also do so. ${ }^{113}$ Diplomatic efforts are therefore necessary for creating international agreements such as the Paris Agreement. In December 2015, countries around the world settled on a new climate agreement that would apply to all countries and enter into force in 2020 , at the latest. The global increase in temperature was to be kept below $2^{\circ}$, and every country was to attempt to keep it below $1.5^{\circ}$. The agreement entered into force in November 2016. Much work remains if the Paris Agreement is to have any impact, since far from all countries have implemented it. For example, President Trump withdrew the USA from the agreement. However, President Biden signed an instrument to bring back the USA into the agreement.

In this context, gaining an awareness of the existence of the norm and examining its content is crucial. Originally, the method of trial and error was used. Eventually, science has emerged. In the ecological system, the norm supersedes human willpower, unlike other systems. That is not to say that we always comply with them or that they govern other actions. Habermas highlights the difference between norms that relate to controlling nature and norms that relate to controlling human activities. He speaks in terms of control of external nature and integration of the inner nature of the social system, and how this is accomplished in different ways. ${ }^{114} \mathrm{He}$ argues that control of external nature is achieved by using

113 The so-called NIMB syndrome, i.e. not in my backyard.

114 Habermas, Jürgen (1979, p. 10 f). 


\section{About norms and action systems}

methods based in factual criteria, while control of society's inner nature requires norms that can be justified and are based on intersubjective validity.

Different system norms and how they relate to individual needs can be classified according to a sliding scale. True, an individual is dependent on the social system to which he or she belongs. The social system itself, however, may be seen as subservient to the will of individuals or groups of actors. This generally applies to the political/administrative system, but with the difference being that this system expresses collective preferences, which means that there can be a gap between what the individual wants and what the collective wants. In the economic system, what individuals want is subordinated even further. It has certain conditions that cannot be abandoned without changing the entire system. This is not the case with regard to the social and the political/administrative systems. These can be adapted progressively to both individual and collective preferences. In the ecological system, what individuals desire is subordinate to its norms.

You could also flip the argument around and conclude that the different systems have an influence on, and variably determine, how individuals act. Some systems require a higher degree of adaption than others. In actual fact, one might expect the systems to be listed in reverse order: i.e., the ecological system first, followed by the economic and so on; this is in light of our claim that these systems allow the least amount of individual preferences. But it is not quite that simple. For these systems to have any weight at all in how individuals act, they must be important and relevant, and they must be visible and easy to understand and comply with.

A peculiarity of ecological systems, however, is that their norms can be applied individually and independently of their affiliation with the ecological systems. We encounter a paradox here. Although nature is to be regarded as a whole, it generates norms of action that are independent of that whole. This is something that can explain the possibility of the specialization of knowledge taking place in the technical field. This specialization leads to a threat to nature as a whole and the ecological system, which has recently created a need for a sustainable development policy, whereby the ecological, economic and social system simultaneously must be taken into account. ${ }^{115}$ It is in this perspective that the need for norm science makes itself felt most strongly, the ability to identify and weigh the ecological, economic and social norms against each other.

The system affiliation also implies instructions for actions for man, which are determined by the requirements of the system's survival. This is what characterizes preservation norms. However, as mentioned, these not so clear to the individuals, because they are overshadowed by the exploitation norms that are more obvious to human action. In some respects we can see a parallel to the economic system's division into strategic and structural norms, with the difference being that the structural norms appear to be actor imperatives in a completely different way than conservation norms. One problem for the impact of conservation 
norms is related to the lack of visibility. Violations of the conservation norms do not appear immediately. Another problem is an extended relationship between cause and effect in time and space, between action and effect, which means that violations of the ecological norms are not clear, and therefore easily ignored in favour of more short-term human interests. ${ }^{116}$ This is of great importance for the preferences that apply in connection with conflicts between, e.g. the norms of the economic and ecological systems (see further in section 5.3.1).

The ecological system, which places the most forceful restrictions on human action, was not created by humans and is furthermore hard to gain an awareness of. In some situations, it is relevant and important, while distant and unimportant in other situations. It can be both close and remote, etc. The ecological system's method of reproduction is an inescapable condition of our existence, and it requires ecological norms to be recognized. However, only when we approach an understanding that the air, water and earth are limited resources do we begin, through necessity, to take notice of the norms of ecological system. The ongoing process of climate change seems to be such a triggering factor. The ecological system's technical norms are, at present, mainly determinant in actions that relate to the exploitation of nature rather than preservation aspects. ${ }^{117}$ Economic system norms interfere with the norm creation process of the ecological system. The goal-driven nature of the economic system tends to dominate the other action systems and their norms. ${ }^{118}$

\subsubsection{Biotic and abiotic subsystems}

Finally, I will comment on a system which has not been prominent for the social sciences and that is the ecosystem with its biotic and abiotic subsystems. I regard these systems as subcategories to ecological systems. An ecosystem is a community of living organisms in conjunction with the non-living components of their environment, interacting as a system. ${ }^{119}$ These biotic and abiotic components are linked together through nutrient cycles and energy flows. ${ }^{120}$ The biotic plus abiotic factors are the environmental and non-living factors that make up an ecosystem. ${ }^{121}$ The biotic factors in an ecosystem are the living organisms, such as animals and insects. The interrelated abiotic and biotic factors in an ecosystem combine to form a biome. Abiotic factors are the non-living elements, like air, water, soil and temperature. Biotic factors are all the living elements of the ecosystem, including the plants, animals, fungi, protists and bacteria. A biotic factor

116 Hydén (2004).

117 Please see more about technical norms in section 7.3.

118 Cf Moore, Jason W. (2016).

119 Chapin, F. Stuart, Kofinas, Gary P. \& Folke, Carl (red.). (2009). Principles of ecosystem stewardship: resilience-based natural resource management in a changing world. New York: Springer.

120 Odum, Eugene P. (1971). Fundamentals of ecology. 3rd ed. New York: Saunders.

121 https://sciencing.com/biotic-factors-ecosystems-5135640.html, retrieved 2020-04-29. 


\section{About norms and action systems}

is a living organism that affects another organism in its ecosystem. Examples include plants and animals that the organism consumes as food and animals that consume the organism. Biotic factors also include human influence, pathogens and disease outbreaks. ${ }^{122}$

Viruses are the smallest biological entities in the ecosystem that can infect living organisms. They are many times smaller than bacteria. We are talking about sizes varying from the extremely minuscule - 17-nanometre-wide porcine circovirus, for example - to monsters that challenge the very definition of 'virus', such as the 2.3-micrometre Tupanvirus. Viruses are not considered a life form, as they lack their own metabolism and cannot reproduce on their own, but are often described as "an intermediate between living and dead matter". As such, it is more accurate to think of viruses as part of the continuum between chemistry and biology, one that is not clearly divided into living and non-living. A virus is genetic material contained within an organic particle that invades living cells and uses their host's metabolic processes to produce a new generation of viral particles. ${ }^{123}$ They cannot reproduce without infecting a living cell. Using the cell's machinery, the virus produces more virus particles. Because viruses are completely dependent on a host cell for metabolism and reproduction, they are defined as obligate intracellular parasites. Only once they are part of a cell do viruses take on living characteristics of their own, borrowing the host's biochemistry to reproduce.

Viruses can thus infect all living organisms, including humans. Diseases caused by viruses are called viral diseases or, more scientifically, viruses. One such is coronavirus. There are at least 600 viruses that can infect humans. Viruses cannot move by their own power but depend on getting into contact with a host cell of the right kind for the type of virus in question. Viruses are often spread through body fluids, the air, physical contact and faeces, direct contact with the source of infection or through the air in aerosols. The body fights viral infections by detecting and eliminating virus-infected cells. In particular, the adaptive immune system consisting of lymphocytes is important in the protection against viral infections. A successful virus has therefore developed mechanisms to hide its existence from the immune system. It is possible to vaccinate against a wide range of viral diseases. Two known diseases caused by the coronavirus are severe acute respiratory syndrome (SARS) and Middle East respiratory syndrome (MERS). The new disease caused by coronavirus has been named COVID-19 (an abbreviation of coronavirus disease 2019).

The infection rapidly spread to a number of countries outside China where it started, and at the end of January it was confirmed that the infection had reached Sweden. The coronavirus is a large family of enveloped, single-stranded RNA viruses that are known to cause illnesses from common colds to more severe illnesses. On March 11, 2019, the World Health Organization (WHO) declared that COVID-19 was now classified as a pandemic. This means that there is an

122 https://biologydictionary.net/biotic-factors/, retrieved 2020-04-29.

123 www.sciencealert.com/virus. 
uncontrolled spread of this coronavirus in the world. The virus was officially named SARS-CoV-2, and it is hitherto unknown exactly how it affects the human organism. As the coronavirus pandemic continues to grow and evolve - so far more than 2.5 million people have been infected and 179,000 have died ${ }^{124}$ researchers are scrambling to learn about the virus and recommend effective responses.

One may ask what does this have to do with norms and the science of norms? The coronavirus as a part of the ecosystem does not generate norms by itself, but the corona pandemic - besides the urgent need for medical treatment - gives rise to a lot of legal and other normative consequences of high relevance for social sciences.125 There is a difference compared to the other systems we have commented upon. In this case, it is a question of what the (eco)system via the coronavirus is doing to man and human society, not what man does to destroy the ecosystem.

During the 20th century, the world suffered three major pandemics: Spanish influenza in 1918, Asian influenza in 1957 and Hong Kong influenza in 1968. These three were all caused by the influenza virus. During the 2000s, there have been two pandemic outbreaks: swine flu and COVID-19. Swine flu erupted in 2009 and was caused by influenza virus. COVID-19 is the first time a coronavirus has caused a pandemic. The earlier pandemics and influenzas have not had any impact on social sciences. However, COVID-19 has brought with it such interventions in society and in peoples' lives that it is unavoidable not to assess it from a social science point of view, and not least from a norm perspective.

When it comes to the ecological system, the problem is that human activities have negative effects threatening the system. When it comes to the coronavirus, it is the other way around. It attacks humans in a way which affects all of society. This pandemic causes problems for trade and, by extension, for the production of goods, which are dependent on spare parts and components produced elsewhere. To limit the outbreak of the COVID-19 pandemic, most countries in March 2020 introduced some form of lockdown strategy. ${ }^{126}$ This meant that factories, schools, etc., were closed and a lot of activities such as public events were prohibited.

124 April 22, 2020.

125 Geoffrey Pleyers FNRS-University of Louvain, Belgium, ISA Vice-President for Research, Social scientists have shown that the CoVID-19 pandemic is not only a sanitary crisis. It is also a social and political crisis, and should be treated as a moment of rupture that will bring major changes into our lives, our societies and our world. www.isa.sociology.org/frontend/ web/uploads/files/Global\%20Sociology\%20in\%20Times\%20of\%20the\%20Coronavirus. pdf.

126 Dineros, Kevin \& Dipasupil, Jan Paolo. (2020, March 15, 21). “COVID-19 crisis management and prevention plan." COVID-19 Crisis Management and Prevention Plan. A preventive lockdown is a pre-emptive action plan implemented to address an unusual scenario or a weakness in system to pre-empt any danger to ensure the safety and security of people, organizations and system. During the 2019-20 coronavirus pandemic, the term lockdown was used for actions related to mass quarantines. Lockdowns can limit movements or activities in a community while allowing most organizations to function normally, or limit 


\section{About norms and action systems}

People were not even allowed to walk outdoors unless it was a question of limited distance and for a specific purpose. People were not allowed to be together in groups of more than five people at a time, and the list goes on. By May 2020, one-third of the world population was under a coronavirus lockdown, meaning under active restriction and control by their respective governments. ${ }^{127}$ While "lockdown" is not a technical term used by public health officials, it can refer to anything from mandatory geographic quarantines to non-mandatory recommendations to stay at home, closures of certain types of businesses or bans on events and gatherings. The biggest lockdown was enforced in India, where 1.3 billion people were ordered to stay inside for 21 days. This lockdown exceeded the scale of those that happened in China even at the height of the epidemic there. ${ }^{128}$ Countries both in Latin America (affecting about 200 million people) and Southeast Asia (affecting approximately 100 million people) enforced lockdowns, often with the help of the military. These countries implemented the world's largest and most restrictive mass quarantines. WHO provides continuous updates on the spread of the virus. ${ }^{129}$

The coronavirus ravages have affected most parts of society, from closed shops and schools to altered court procedures. It has caused an economic crisis comparable with what happened during the Great Depression in the 1930s. Many countries have closed their borders either completely or partially. The consequences are economically devastating, causing bankruptcy for many businesses and closing most airports which made airplane and airports go unused. Factories that have closed in one part of the world, especially in China, have led to a lack of spare parts in other parts of the world. The quarantine strategy people had to follow had a bad impact on social life and peoples' socio-psychological health. The work unemployment rate in Sweden reached levels comparable with the greatest earlier economic crisis in the 1930s. The International Labour Organization

movements or activities such that only organizations supplying basic needs and services can function normally.

127 According to a report by Business Insider, May 1, 2020.

128 Other big lockdowns happened in the USA, where the majority of states enforced strict stay-at-home orders, and in Europe, where there were nationwide lockdowns in France, Spain, the UK, Italy and elsewhere (totalling more than 300 million people). Almost all Russian regions adopted lockdown measures first imposed in the nation's capital, Moscow affecting around 132 million Russians in total.

129 The report for May 4, 2020, shows the following figures: Situation in numbers (by WHO Region) Total (new cases in last 24 hours). Globally 3,349,786 cases $(82,763)$ 238,628 deaths $(8,657)$.

Africa 29,438 cases $(1,465) 1,064$ deaths (51).

Americas 1,384,641 cases $(44,050) 78,409$ deaths $(6,213)$.

Eastern Mediterranean 200,609 cases $(5,618) 7,871$ deaths (130).

Europe $1,518,895$ cases $(27,032) 142,667$ deaths $(2,081)$.

Southeast Asia 64,047 cases (3,557) 2,375 deaths (119).

Western Pacific 151,444 cases (1,041) 6,229 deaths (63). 
(ILO) estimates that as many as $\mathbf{2 5}$ million people globally could become unemployed, with the loss of workers' income reaching as much as US\$3.4 trillion. ${ }^{130}$

Depending on how the disease develops, easing the lockdown is bound to happen. As of May 2020, some countries, including Spain and Germany, started relaxing their lockdown measures. The results have been mixed. France, Russia, India and UK are still struggling with controlling the pandemic. Sweden used a softer strategy built on civic trust, i.e. that people follow recommendations from the public authority in charge of infectious diseases, in Sweden the Public Health Agency. It has expressly and repeatedly spread the following recommendations:

- Be sure to protect yourself and others from the spread of infection by following general advice. Especially it is important to wash your hands.

- It is very important that you stay at home, if you have any symptoms of illness, even mild symptoms.

In Sweden, there is a ban on holding public gatherings and public events, originally set at no more than 500 people, later altered to no more than 50 people. Elementary schools are open as usual, while students in upper secondary school are using online education. This also applies to many workplaces. It seems that these differences when it comes to strategy to deal with the coronavirus can be explained by the level of trust people have in their political/administrative systems: the lower the level of trust, the harder the restrictions placed on people. ${ }^{131}$ In Sweden there is a high degree of trust in the administration; ${ }^{132}$ eight out of ten people trust the political/administrative systems according to index reputation $2018 .^{133}$

So to the extent the Swedish soft strategy in dealing with the coronavirus has been successful, it is related to the high trust in the political/administrative system. When the epidemiologist representing the WHO executive board in a television interview mentioned that Sweden might be a model for work with pandemics like coronavirus in the future, he ignored that the normative conditions in Sweden differ from most other countries, namely regarding the high level of trust between people and between the political/administrative system and the people. In Sweden people rely on and therefore obey expert recommendations

130 www.ilo.org/global/about-the-ilo/newsroom/news/WCMS_739961/lang-en/ index. htm.

131 Sari Hanafi, American University of Beirut, ISA President. www.isa sociology.org/frontend/web/uploads/files/Post-COVID-19\%20Sociology.pdf.

132 This is something Sweden has prioritized. A certain agency has (2016) been set up, "The Delegation for Trust-Based Public Management". The delegation has the task to analyse and propose how the management of welfare services in the public sector can be developed within existing regulatory frameworks. The delegation works with investigations and analysis of how well the public thinks that each authority performs on some relevant factors. The Public Health Agency has a high score in these surveys.

133 www.regeringen.se/regeringens-politik/tillitsreformen/ This kind of survey takes place every fifth year. 
from the public authorities. Furthermore, the public authorities in Sweden are independent from the politicians and the political system. For these reasons, a recommendation to follow the Swedish soft model might not be functioning in those countries where people are not used to following voluntarily the recommendations or the (mandatory) demands from the public authorities or the politicians. As consequence of the pandemic, certain surveillance measures have been introduced to different degrees in different countries to both trace the spread of the virus and control comopliance with the rules and recommendations. There is a risk that the already existing tendency of increased surveillance of citizens will be strengthened and become permanent in the future.

\subsubsection{Summing up}

The first chapter laid out a basic understanding of the influence old industrial society continues to wield over contemporary society's institutions and functions. In the second chapter we focused on the sociocultural system's lifeworldoriented perspective and how that collides with the system imperatives. In this third chapter we have reviewed the characteristics of the system-generated norms and how they are distributed across various systems. Despite different accidental attributes, there are certain essential criteria defining the norm, which we have pointed out. ${ }^{134}$

Thereby, we now have the tools needed to analyse the conflict between these various systems from a norm-scientific perspective, both the internal conflicts within a system - intra-system conflicts - and between systems - intersystem conflicts. Before pursuing this analysis further, we should first pause for a moment and reflect on law as a system of norms and what characterizes its construction and adjustments. There is intrinsic value as well as additional value to be gained in increasing our understanding of norms and how norm systems work. After all, legal norms are the most elaborated on type of norm.

134 Hydén, Håkan \& Svensson, Måns. (2008). The concept of norms in sociology of law. Contributions in Sociology of Law: Remarks from a Swedish Horizon, Vol. 53, p. 129. 


\section{Law as a system of norms}

\subsection{Legal rules as norms}

An analysis of legal rules cannot be based in the legal system if it is to be of any use to the social sciences. We are forced to step outside of law and ask what it is that characterizes rules, what their general purpose is, why or whether we need rules, etc. To do this we need theories of law, which is not the same as legal theory. This difference corresponds to the difference between knowledge of law and legal knowledge, as mentioned previously. We have a vast body of legal knowledge, i.e. knowledge of how to construct and apply law, but we have little knowledge of the causes and consequences of legal rules. ${ }^{1}$ Contemporary legal theories are based in legal philosophy and therefore take their point of departure in legal knowledge. ${ }^{2}$ They deal with the internal aspects of law. This difference between knowledge of law and legal knowledge corresponds to the difference between a legal scientific and a social scientific perspective of law. ${ }^{3}$ A theory of law must take into consideration the law's context, dynamics and conditions and take its starting point in them when developing theoretical explanations. This cannot be accomplished without adopting a broad, social scientific perspective of law.

A theory of norms has much to gain from the body of knowledge of legal rules. These are the most well-developed and evolved kinds of norms. We should bear in mind that legal rules, like norms, have a long tradition and have been developed within the framework of a specific field of knowledge and administrated by a particular profession, i.e. lawyers. This is not the case for norms in general.

Some approaches toward constructing theories of law can be found in studies of the divergent understandings of law conducted within the field of legal anthropology. ${ }^{4}$ One of the more interesting analyses has been carried out by Sally Folk Moore in the book, Law as Process, An Anthropological Approach, where she introduces the concept of a semi-autonomous social field to designate an area of

1 Stig Strömholm distinguishes between knowledge in law and knowledge about law, Strömholm, Stig (1988).

2 See Soper, Philip A. (1984) and the introductory comments there.

3 For more on this, cf. Hydén, Håkan (2002a).

4 See. e.g. Raz, Joseph (1990). 
society within which norms and symbols are established internally, while simultaneously being dependent on the rules, decisions and other forces emanating from the world that circumscribe that area of society. While these studies do contribute to an understanding of the functions of law and its links to other fundamental components of society, they do not help us to establish a basis for a body of knowledge of law in modern society. In general, criminology's interest in norms is restricted to norms that dictate what is or is not allowed. This interest is, however, mainly focused on the violators and not on the norms themselves. ${ }^{5}$ The closest we get to theories of law are found in the discussion on legal progress that was initiated by Marx's and Weber's analysis of law's role in society, ${ }^{6}$ as well as Durkheim's and Maine's studies of legal developments as an indicator of social progress. ${ }^{7}$ This work has been continued by Parsons, Unger, Nonet and Selznick in the USA and Habermas, Luhmann and Teubner in Europe. ${ }^{8}$ We shall return to these theorists in Chapter 6. In a Scandinavian context, Jörgen Dalberg-Larsen's work is of particular interest here. ${ }^{9}$

Although much has been said on the subject, and much has been of interest, there is no basic grounding for a theory of law. I argue that this weakness mainly originates from a lack of understanding of the specific nature of the law. If we wish to establish a theory of law, there are strong arguments for beginning with those characteristics that distinguish law and give it its role in society. Some scientific effort has been put into distinguishing legal rules from social and other norms. ${ }^{10}$ Hoebel argues that a social norm is legal if a violation of said norm is routinely followed by enforced sanctions, as ordered by someone or some group that has been socially entrusted with this right. ${ }^{11}$ In general, all definitions of legal rules, however, seem to focus on the sanction mechanism. Max Weber, for example, writes that the concept of a "guaranteed right" should

5 Cf. Therborn, Göran (1993) and references therein. Criminology is defined in different ways, but probably the most common definition was formulated by Edwin Sutherland et al. $(1992$, p. 3$)$ in their very broad definition: "Criminology is the body of knowledge regarding crime and delinquency as a social phenomena. It includes within its scope the process of making laws, breaking laws, and reaction to the breaking of law".

6 With regard to Marx's legal theory, see. Elvin-Victor (1979), Max Weber's legal sociology can be found in "Economy and Society", An Outline of Interpretive Sociology, pt. 2 (1985).

7 Durkheim, Émile (1983). Durkheim and the law. Oxford: Robertson. See also Lukes, Steven \& Scull, Andrew (1985).

8 Parsons, Talcott $(1937,1968)$, Unger, Roberto Mangabeira (1976), Nonet, Philippe och Selznick, Philip (1978), Habermas, Jürgen (1987), Teubner, Günther (1983, 1987b), Luhmann, Niklas (1987), Rottleuthner, Hubert (1985).

9 Dalberg-Larsen, Jørgen (1991).

10 Therefore, legal anthropology has endeavoured to identify distinctions between customary law and written law. Malinowski explains, Malinowski, Bronislaw (1962, p. 63): "Legal rules distinguish themselves from other rules by being experienced and viewed as one man's obligation and another man's right. They gain their force not only from purely psychological motivations, but also from specific, socially binding mechanisms, based on mutual dependency and realisation, as we have discussed previously, by way of corresponding services and combinations of services into a network of relationships".

11 Hoebel, Edward Adamsson (1954). 
be understood as representing a coercive power, i.e. the presence of one or several persons whose job it is to enforce the rule. ${ }^{12}$ Émile Durkheim also points out the sanction mechanism as being the distinguishing factor between legal rules and other norms. ${ }^{13}$

These attempts at distinguishing legal rules from other norms are, however, somewhat misleading. They risk portraying legal rules as categorically different from norms in general. Legal rules are, according to the present book's point of view, nothing more than norms that have gained some specific characteristics by being endowed with the status of legal rules. By being elevated to legal rules, state authority becomes linked to enforcing the norm. ${ }^{14}$ Émile Durkheim argues that what distinguishes legal rules from other norms is that they are administered and implemented in a particular order. ${ }^{15}$ According to Francis Sejersted, in the book Demokratisk kapitalism (Democratic Capitalism), society consists of the norms and rules applicable when individuals interact. ${ }^{16} \mathrm{~A}$ part of this norm system is codified within a more formal system of laws. Sejersted argues that this part gains unique characteristics by being backed up by legal force. It is also gains particular stability by being put down in writing and being the subject of deliberate interpretation and further elaboration. The famous English legal philosopher H.L.A. Hart argued that law consists of two kinds of rules: primary rules concerning rights and obligations and secondary rules that deal with how to identify, implement and change primary rules. ${ }^{17}$ Secondary rules, in other words, serve the purpose of maintaining a division between norms and legal rules.

Analyses of legal rules have tended to focus on what makes a norm a legal rule rather than on the factors that have contributed to making the norm into a legal rule, or on what characterizes norms as such. A general definition of law, Sejersted argues, must first and foremost see the formal legal system as part of the entire system of norms. ${ }^{18}$ While norms lack an established definition, definitions of law can be criticized for being contextual and for not fulfilling inter-cultural aspects. ${ }^{19}$ Law seems either to be defined as a general normative order or as a method of governmental enforcement. Neither cases provide any guidance for a theoretical discussion on the matter.

Theories of law that so far have emerged tend to link law to different kinds of social conditions. Curiously, however, there are no theories that approach the relationship between legal rules and social rules. An understanding of the development of law must, within the legal sociological paradigm I represent, take its starting point in an understanding of how social norms develop. In other words,

12 Rheinstein, Max (1954).

13 See. Cotterrell, Roger (1998, p. 60) and the references included there.

14 Aubert, Vilhelm (1976, p. 23).

15 Durkheim, Émile (1997, p. 29).

16 Sejersted, Francis (1993).

17 Hart, H.L. (1961, p. 91 ff).

18 Ibid.

19 Please see the interesting discussion by Dutch legal anthropologist Tamanaha, B., Journal of Law and Society, No. 2 (1993). 


\section{Law as a system of norms}

I call for a science of norms that is able to go further than merely distinguishing between formal and informal norms, while simultaneously observing the difference, when relevant. When this has been accomplished, we will have laid down the basic foundation for a scientific theory of law.

In extension, when defining the task of a science of norms, we must first establish some general characteristics of norms, which this book does in Sections 5.2 and 5.3 , and then define what it is that elevates some norms to legal rules, which this book does in Sections 5.4 and 5.5. None of these questions have been the subject of in-depth analyses. As argued by Therborn, the concept of norms has played a somewhat inconspicuous role in sociology. ${ }^{20}$ The same applies to analyses of the emergence and functions of norms. ${ }^{21}$ Neither has the field of legal sociology, with the exception of Vilhelm Aubert, who spent much time on the phenomenon. ${ }^{22}$ I have endeavoured to shine a spotlight on the first question in Chapters 2 and 3. We shall now approach the question of what characterizes norms that become legal rules, i.e. the legal property spaces of the various parts of the legal system.

\subsection{Legal property spaces}

In formulating a starting point for this question, there is reason to begin by highlighting a distinction made by a series of authors with slightly different perspectives, but which can be briefly described, in common with Vilhelm Aubert, as the difference between legal rules that emerge bottom-up and top-down. ${ }^{23}$ In line with this, Austrian lawyer and social scientist Friedrich A. Hayek distinguishes between nomos and thesis. This distinction deals with the differences between legal rules that are based on norms resulting from people's interaction and norms that come about through political processes. The latter form of legal rules is primarily related to the political model that we refer to as representative democracy, where a central authority, i.e. parliament, has been recognized as competent to issue binding norms for a given population. Hayek calls nomos "the law of liberty" and thesis "the law of legislation". The difference between nomos and thesis

20 Therborn, Göran (1993), Sociologisk Forskning 2. For further reading, see Rossi, Peter \& Berk, Richard, Short J. (1984). Rossi and Berk argue that empirical studies of norms have been faced with inadequate conceptualization and definitions, thereby making the discovery and interpretation of norms an uncertain process.

21 The examples that Therborn mentions in his review article are Merton, Robert (1957) in which Ch. V of "Continuities in The Theory of Social Structure and Anomie", based in Durkheim's concept of anomie, first and foremost discusses the importance of cultural norms, and Coleman, James (1990). Coleman addresses the problems in "The Demand for Effective Norms," Ch. 10 and "The Realization of Effective Norms," Ch. 11.

22 Vilhelm Aubert has provided the most thorough analysis of the emergence and presence of norms. Since his book Sociologi was published in 1964, he has returned to the subject in his books Rettens sociale funksjon (1976) and Continuity and Development (1989), Aubert's final work.

23 Aubert, Vilhelm (1989). 
lies in the distinction between two kinds of social orders, as perceived by Hayek: orders that emerge spontaneously, and constructed orders. Hayek acknowledges the following characteristics: ${ }^{24}$

The made order which we have already referred to as an exogenous order or an arrangement may again be described as a construction, an artificial order or, especially where we have to deal with a directed social order, as an organization. The grown order, on the other hand, which we have referred to as self-generating or endogenous order, is in English most conveniently described as a spontaneous order. Classical Greek was more fortunate in possessing distinct single words for the two kinds of order, namely taxis for a made order . . . and kosmos for a grown order.

Norms, and therefore legal rules linked to interactive processes, are the result of the responses of the involved actors and reflect their spontaneous needs in the form of formalized agreements, while norms that are created top-down are created within a political decision process in the form of laws. Similar distinctions have been made by authors such as Jürgen Habermas, who distinguishes between law as an institution and law as a governing mechanism, ${ }^{25}$ and Roberto Mangabeira Unger, who distinguishes between what he calls legal order, on the one hand, and regulation on the other. ${ }^{26}$ Similar distinctions can be said to underlie the concepts of autonomous law and responsive law $^{27}$ and perhaps even the concepts of formal law and reflexive law, although the latter claim to be "more democratic". ${ }^{28}$ Sally Falk Moore also elaborates on a similar type of distinction in her discussions on two kinds of rules: one that is consciously created by some kind of legislator and courts in order to bring about an intended effect and another kind of rules that emerge spontaneously in social life. ${ }^{29}$ This corresponds to the difference between laws that can be implemented by courts and authorities, on the one hand, and by socially binding norms, on the other.

However, this still does not tell us why some norms become legal rules and others do not. The observations made by the aforementioned authors indicate, however, that legal rules are based in one of these two background narratives and that they distinguish themselves on several points. At least, different kinds of legal rules have different properties, according to the literature. We will return to this topic further on.

It is clear, however, that law is about rules and that in our era, these are formally adopted by the political system. Politics is about values and evaluations. Politics is about choosing between different courses of action, and politics is also

24 Hayek, Friedrich A. von (1993, p. 37).

25 Habermas, Jürgen (1995).

26 Unger, Roberto Mangabeira (1978).

27 Nonet, Philippe and Selznick, Philip (1978).

28 Teubner, Günther (1983).

29 Moore, Sally Falk (1978, p. 80). 


\section{Law as a system of norms}

about wanting, that is to say articulating and expressing aspirations toward different kinds of social and individual goals. From this perspective, law, to coin German legal philosopher Josef Esser's phrase, consists of operationalized values. ${ }^{30}$ Law is one of the political system's forms of communication. It is one step closer to actual action than is the political system. Law takes part in the implementation of politics and articulates instructions for actions that are the consequence of certain value-based conditions. For example, if politics focuses on turnover interests, this will have consequences on the rules of conduct in business matters. Similarly, there are specific consequences to how issues in the workplace are solved depending on whether the solutions are based in the value or in the principle that the employer should be able to overrule management.

In some contexts, law can be seen as standardized politics. ${ }^{31}$ This means that politicians have established their perspective of a particular issue through legislation. This relieves the political system of specifically addressing this particular regulated problem anew each time it appears. From a value-based perspective, the issue has already been determined and the law contributes to enforcing this politically determined order. This aspect of law entails administrative benefits and transaction cost benefits. In part, it consists of a system developed to address and manage certain types of social problems, and in part, it also informs affected parties of how society "normally" addresses the problem at hand. The issue has already been thematized, so to speak. ${ }^{32}$ The standardized political solutions offered by law require a particular kind of decision-making process that provides the anticipated results, thereby meeting the requirements of legal security.

Law is a consciously created system of norms. ${ }^{33}$ This means that, in part, it has its own linguistic definitions. Legal definitions are most commonly found in legal areas that belong to the category of created law, to use the previously mentioned terminology. ${ }^{34}$ In contemporary administrative law, each law commonly begins with an introductory legal definitions section on which the law is based. In part, this is because colloquial language is too imprecise to meet the requirements of clarity that a created system of norms - that is furthermore maintained through force - requires. A classic example of this is the concept of waste. What is waste? There have been legal cases that have been forced to address this question. It is related to the separation of different authorities' areas of responsibility. If something is categorized as waste, it is up to the municipal waste utility to address it. If it is not categorizsed as waste, it is up to the responsible individual or owner to address it. This question initially became an issue when it became apparent that some people felt that waste disposal laws were unclear. The issue was finally settled by the Supreme Administrative Court in its role as the highest administrative

30 Esser, Josef (1964).

31 Cf. Hydén, Håkan (1999) ch. 2, where this theme is further developed.

32 Cf. Luhmann, Niklas (1981).

33 See also the division of rules as presented by Peczenik, Aleksander (1995, p. 167).

34 For further reading see, Hydén (2018, p. 215). 
court. In a precedent case in 1976, Justice of the Supreme Administrative Court Gustaf Petrén, whose dissenting opinions had played an important role in legal developments, stated: ${ }^{35}$

Waste is the residual byproduct of various kinds of human activities that the owner has defined as harmful and of which he therefore wishes to be relieved. An object, therefore, is not necessarily considered waste until an owner or possessor deems it so. Broken furniture can be set aside to be repaired at a later date or discarded as waste. A worn out garment can, for example, be used as carpet fabric or discarded as waste. Leftover food can be made into pet food, but it may also end up as waste. Old newspapers can be used to light fires or be thrown away. Fallen leaves can be recycled for fertiliser or treated as garden waste. In each case, it is up to either the owner or the responsible individual to determine whether to endow an item with a function or declare it to be without use, and discard it as waste.

What is interesting about this definition of the concept of waste is that it extends beyond strictly physical or objectively defined concepts, i.e. you can't determine whether an object is waste simply by looking at it. Rather, it depends - as is often the case with law. Waste is not something that is determined objectively, but rather, it is determined subjectively. The decision on whether an object is to be regarded as waste depends on whether the owner intends to keep it or not, as Supreme Administrative Court Justice Petrén stated in his special opinion. The fact that this kind of legal definition can lead to very real consequences is shown by the following case published by a local newspaper in which "the readership" posted letters under the heading "destroyed wheelchairs" 36 :

I sympathise strongly with you and your disabled little daughter, and I understand that you and your family are going through difficult times. Then I read the article about the destroyed wheelchair in the Jönköpings-Posten. I assume that you, like all the other households in the county, also have received a pamphlet informing us on what days heavy refuse is collected, and that they should be left out in an easily visible place. After all, you were planning to take a cab to the dentist, and it's quite feasible that you might have needed to remove some screws from the wheelchair to get it into the taxi, even though you failed. Therefore, you were forced to leave the wheelchair which looked a little bit broken because of the missing screws. Given the situation, surely you can understand the garbage collector's point of view?

Although one can understand his point of view, his actions were not in compliance with legal definitions. It should be noted that following Gustaf Petrén's 
statement, which did not gain approval in that case, the Supreme Administrative Court later came to agree with this position. Rules about waste and producer responsibility were also later included in Chapter 15 of the Environmental Code. Ch. $15 \$ 1$ lays out: "Waste means every object, material or substance included in a waste category and which the holder disposes of or intends to or is obliged to dispose of". As environmentally hazardous waste has increased, in order to complement previous regulations, some obligations concerning the methods of waste disposal have been added. However, this does not change the main point of the example, i.e. to clarify the importance of legal definitions in court situations.

To better understand law as a system of norms, we should conclude that law has both an internal and an external structure. Law can be said to have, as mentioned previously, ${ }^{37}$ three internal dimensions that deal with $\mathrm{WHO}$ is to act, HOW to act and WHAT to do. We will discuss, one at a time, rules of competence, rules of procedure and action rules. Action rules can consist of either orders or prohibitions. Legal regulation and governing, therefore, deals with all three dimensions, which all have different centres of gravity. ${ }^{38}$ Legal influence may, in some cases, be mainly linked to competence rules, i.e. when law decides who is competent to make certain forms of decisions. The law designates who is to be given power in a given context. Competence rules also limit decisions and actions to a relevant framework or context. Svein Eng talar states that competence rules determine (1) who is or is not competent in relation to the rule, (2) the competence of the affected party and (3) the necessary preconditions that determine whether the individual has or does not have that particular competence. ${ }^{39}$ Eckhoff and Sundby discuss three corresponding components in terms of obligated party, action theme and situational conditions. ${ }^{40}$ An authority always receives its competence partly through the provisions of its constitution and partly through special legislation, which determines the authority's particular area of responsibility. The Swedish Mapping, Cadastral and Land Registration Authority's area of responsibility, therefore, is determined in part by 2009:946 Ordinance with Instructions for Land Survey and partly by the Real Property Formation Act.

The legal outcome may also be determined by the applicable rules of procedure. Classic rules of procedure, in administrative law, are rules that regulate party insight into complementary materials from a party other than the involved party. The effects of, for example, rules requiring environmental impact assessments become even more tangible in an environmental context. In the context of penal and civil law, we might mention rules for different kinds of evidence and rules for how to hold a hearing.

37 For more on this, cf. Hydén, Håkan (1984) and Hydén (2002) Ch. 6.

38 This elaboration is based in Scandinavian civil law tradition. For a comparison to common law tradition, please see Pierre LeGrand (1996).

39 Tidskrift for Rettsvitenskap (1990, p. 635 ff).

40 Eckhoff, Torstein and Sundby, Nils Kristian (1991, p. 89). 
Generally, however, with regard to legal governance, people are probably more likely to be aware of material action rules. These inform us of what is to be accomplished. There are different kinds of action rules. The classic action rule is a rule of conduct or duty rule. It is based in various attributes that describe the legal facts that must be present. If these have been adequately fulfilled, the rule also informs of the expected legal order, i.e., the following events. For example, whether to pass sentence, to invalidate a contract or determine that an individual should be entitled to injuries. Duty rules are what is known as proper law clauses that fully declare the conditions under which an action must be taken or refrained from. In addition to duty rules, other action rules are consequentialist rules and weighing-and-balancing rules. Consequentialist rules are distinct from duty rules. They are oriented toward the future, unlike duty rules, which are based on assessments ex post, i.e. after an event has occurred. consequentialist rules describe, as the term indicates, the goals the decision-makers should attempt to achieve as well as the means at their disposal. This means that the normative contents of consequentialist rules are weaker, or at least more generalized. ${ }^{41}$ They are policy-oriented and based on opinions that depend on other forms of knowledge than legal knowledge. ${ }^{42}$ One might also say that legal rules in this context melt together with social norms and other norms.

Weighing-and-balancing rules are even vaguer, seen from a normative perspective. Strictly speaking, they lack action rules that contain instructions on what should be accomplished. Weighing-and-balancing rules only indicate which interests need to be weighed against each other. An example of this is Ch. $2 \$ 7$ of the Environmental Code.

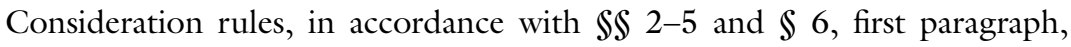
apply within reason. In making decisions here, the benefit of protective and other measures should be carefully weighed against their costs.

Ch. $2 \$ 3$ of the Environmental Code gives examples of such consideration rules as laid out in paragraph 7 . It reads as follows:

Persons who pursue an activity or take a measure, or intend to do so, shall implement protective measures, comply with restrictions and take any other precautions that are necessary in order to prevent, hinder or combat damage or detriment to human health or the environment as a result of the activity or measure. For the same reason, the best possible technology shall be used in connection with professional activities.

41 However, it is important to point out that they exist. Aleksander Peczenik distinguishes between action norms and purposive norms and uses the term regulated norms as a common designation for such norms, cf. Peczenik, Aleksander (1987, p. 15). Cf. also Graver, Hans Petter (1988).

42 For more on consequentialist rules as examples of the law of legislation, please see Hayek, Friedrich A. von (1993, p. 138 ff). 
Such precautions shall be taken as soon as there is cause to assume that an activity or measure may cause damage or detriment to human health or the environment.

What remains, however, is deciding how to weigh these considerations against each other. This crucial issue, from a normative perspective, is not regulated in law or in the legislative histories. It is left to the discretion of the implementer to determine. From this perspective, whoever is designated as being qualified to make decisions, according to the competence rules, has a crucial impact on the outcome and application of the law. How to go about doing this may also have an effect on the outcome, e.g. requirements for environmental impact assessments. ${ }^{43}$

Therefore, we can conclude that there is a dominant relationship between action rules and duty norms, between procedural rules and consequentialist norms and between competence rules and weighing-and-balancing norms. If we further link this to other augmentation models and decision models, a pattern begins to emerge. A specific form of normative rationality is linked to the duty norms. According to this, decisions are based on rules that are applied to the facts at hand. The common method of argumentation here uses subsumption logic by nature; that is to say, it deals with subordinating facts to the rule which, in turn, then provides the solution to the problem. The normative rationality model is based on an assessment of subsequent events, ex post. Here, the consequences of the decision are irrelevant, or at least of subordinate importance. What is important is that the norm is implemented correctly; that is to say, that rational conclusions have been made based on predetermined criteria.

Arguments based in instrumental rationality can be referred to the consequentialist rule model. Here, decisions are made based on assessments of the consequences of the decision. The argument is benefit-oriented and is intended to optimally carry out the target instructions. The assessments that the decisionmaker is forced to make are characterized by deliberations made ex ante, i.e. the decision-maker must assess the benefits of the effects of the decision. This deals with drawing conclusions from causal relationships, which requires knowledge of how the real world is constructed. Ideally, the decision-maker, according to the instrumental rationality model, describes the consequences of different courses of action, calculates the probability of the various consequences and chooses the alternative that will provide the greatest advantage in relation to the relevant goal.

The weighing-and-balancing rules are connected to a relevance-and-weight model where the goal of the decision-making process is to reach a compromise between conflicting interests. By weighing-and-balancing norms, Eckhoff and Sundby refer to norms that are so broad and generalized that the legal decisionmaking process is forced to weigh different factors, such as aspects of reality that are of relevance, other interests, arguments, etc. ${ }^{44}$ Legal argumentation, 
in these cases, is concerned with explicating the various interests relevant to the given decision-making process and promoting a balance between those interests in accordance with the broad, normative references that the weighing-andbalancing norm may carry. Supportive norms in the form of guidelines may be linked to the weighing-and-balancing rules. ${ }^{45}$ Legal decisions are made in relation to the relevant situation, a sort of ex existere decision.

A pattern of the nature of the decision-making entities that emerge in these situations can be linked to these kinds of rules and legal argumentation models. In situations where law is concerned with laying out boundaries for lawful or unlawful behaviour, i.e. when decisions are made according to normative rationality, then it is the lawyers that possess expert knowledge. Judicial methods have been developed for precisely these kinds of situations, and it is traditionally left up to the courts to make these kinds of decisions. This is accomplished by using legal dogmatic methodology, where the legal sources are deemed to provide all necessary information. However, lawyers play a lesser role in decision-making when it comes to the instrumental rationality model and relevance-and-weight model.

The need for expert knowledge and expert participation increases in the instrumental rationality model. In this context, decisions are made based on other scientific and ideological systems. This means that instrumental rationality-based decisions are often made by various authorities, where civil servants make crucial decisions according to a bureaucratic decision model. The relevance-and-weight model is, in turn, based on legal representation in the ruling courts or decisionmaking bodies. Hence, lawyers are complemented with legal representatives depending on the matter at hand, and it is they who have the actual power to make decisions. ${ }^{46}$ This model is applied in Sweden, for example, by the Labour Court and the Environmental Courts. In these scenarios, the lawyer's task is limited mainly to ensuring that procedural rules are correctly applied and that decisions have been made by a competent body in accordance with the competence rules.

We can therefore distinguish a pattern within law's internal structures between action rules in the form of duty rules, normative rationality and the courts' decisions; between competence rules, consequentialist rules, instrumental rationality and authorities in the role of decision-makers; and between procedural rules, weighing-and-balancing rules, relevance-and-weight rules and joint decisionmaking bodies.

Among the legal property spaces, we should also include an external perspective of law. Law's external functions and structures are linked to law's relationship with various systems of motivation that underlie human cooperation. According to Norwegian sociologist Gudmund Hernes, a motivational system is a system that encourages people to act in certain ways in order to reach specific goals. ${ }^{47}$

45 Ibid, p. 109. That there may be a need for weighing interests when interpreting rules is another matter.

46 See Aubert, Vilhelm (1976, p. 33 and 171 ff).

47 Hernes, Gudmund (1983, p. 108). 
He mentions the market as one example. The two main principles, self-interest and competition, promote market efficiency and a decentralized decision-making system. Within the framework of the Norwegian study of power in the 1980s, four such motivational systems were discussed: market, democracy, bureaucracy and interest groups. ${ }^{48}$ This categorization is based in an actor perspective rather than the concept of motivational systems. I estimate that there are three different motivational systems within which this social activity occurs. These three social organizational systems consist of (1) self-regulating systems, (2) planned systems and (3) interventional systems.

In self-regulating systems, the initiative and action are up to the individual actor. They make the decisions and take action. But they do so within an order that directs individual actions toward the same goal. The market is an important example. The three motivational systems can be seen as different degrees of social regulation. Self-regulating systems are spontaneous and can remain in that state, i.e. they can self-regulate autonomously without political/legal intervention. A self-regulating system is characterized by the ability to generate binding norms and to reproduce itself. Self-regulating systems can, however, cross over into a regulatory phase in which the function of law becomes, for example, to strengthen and stabilize the system by providing game rules in the form of boundaries for acceptable behaviour, as well as instruments for interaction. The law provides formal game rules while the system is developed, for all intents and purposes, based in the idea underlying the game. ${ }^{49}$

In the planned system, the governmental or municipal administration assumes complete responsibility of the area, e.g. healthcare, social welfare and various kinds of infrastructure such as the road system. It is in these areas that the motivation for action emerges. The motivational system takes its starting point in the political decisions which the system consist of, but it gains its operative force from the professional motivations for action that appear, depending on the area. In the intervening systems, fundamental decision-making and executive activities are conducted by individuals and organizations, while the political and administrative systems create frameworks and instructions that limit the individuals' freedom of action to various degrees. Examples of such areas are environmental protection, consumer and employee protection laws, work environments rules and restrictions on competition. The purpose of the intervening motivational systems is to influence the involved parties' motivational forces, but they do not otherwise intervene in matters.

\subsection{The contents of legal rules and distribution across action systems}

Awareness of the consequences and functions of law in society tend to end up outside of everyone's responsibility Squeezed between the two major blocs of

48 This study was published in NOU 1982:2.

49 Cf. discussions on this topic in the previous chapter. 
sciences, social science and legal science, these socio-legal aspects belonging to the academic subject of sociology of law (SoL) tend to be ignored (Banakar 1998). The result is that knowledge of the role of law and legal regulation in society is a blind spot from a scientific point of view. German socio-legal scholar, Gunther Teubner, discusses in an article the blind spot in relation to contracts from a system theory - mainly Niklas Luhmann-inspired - approach (Teubner 2006; Luhmann 2004). According to Teubner, the contract is "a multiplicity of separate contracting worlds" (economic transaction, legal promise, productive agreement) and serves as intersystem structural coupling. The unity of contracting is in this view hidden in the blind spot of the distinction between contracting worlds. The contract will then appear, according to Teubner, as a hybrid, an activating relation of tension between the various poles. He uses the term orthogonal, which is primarily used in mathematics, and means the relationship between two lines at right angles to one another. This is what creates the blind spot. One perspective cannot see and understand the other perspective.

Initially, to approach the question of how legal rules emerge, I shall adopt an empirical onset by providing an overview of what legal rules are used for in society, and thereafter try to establish patterns and theoretical explanations. As a side note on this method, I would like to state a few introductory reflections. Different countries have quite similar understandings of what kinds of issues ought to be subject to regulation. However, the contents of the regulations may, of course, vary from country to country. But socio-economic, political and cultural differences do not seem to be reflected in the actual legal rules. Apart from a few exceptions, no comparative legal research has so far exposed any fundamentally different legal orders, at least not in secularized legal systems. ${ }^{50}$ Therefore, the factors that generate legal rules seem to have somewhat general characteristics. ${ }^{51}$ Based in the division of systems in Chapter 3, let us begin with the legal rules of the social system. Henceforth, my use of the word "rules" shall refer to legal rules and "norms" to social, political, economic or natural norms, which are not primarily, but may also be, a component of the legal rules.

In modern societies, social life is not subject to particularly extensive legal regulation. There are no rules at all that dictate how to act in social life in the social system apart from traffic rules. The rules of the social system are not characterized by "you shall" but by "you shall not". In other words, they are solely concerned with prohibitions, not action instructions. I would like to emphasize that this does not apply specifically to Sweden alone to avoid any misunderstanding. This is also why duty rules, in accordance with the earlier text, also come into play $e x$

50 See Moore, Sally Falk: Lipson, 1 and Wheeler, S. (ed.) (1986). A Swedish example of such a comparison can be found in Malmström (1966) Rättsordningarnas system. A few remarks on a classification problem within comparative legal science: Where differences have been established, they have primarily pertained to different legal orders in which religion plays a prominent role. See Hjärpe's, Jan (1995) study of Islamic law and Bogdan, Michael (1993).

51 Cf. Brusiin, Otto (1959). 


\section{Law as a system of norms}

post. They serve as a rule of thumb when assessing whether anyone has violated the rules by crossing the line into a prohibited area.

But, otherwise, rules that prescribe how to behave are only found in traffic situations. The traffic system can be seen as a social action system in itself, and its existence and construction are based on politically established rules. This makes it unique since the action system is constructed by politicians by setting up behavioural norms. The political system also largely controls what the system can be used for by establishing and controlling the network of roads, i.e. the physical basis of the traffic system. Traffic regulation is one of the most extensive systems of regulation.

The traffic system has all the normative characteristics of the social system. It provides rules for who is authorized to drive a vehicle by way of driving licence rules. Furthermore, there are game rules in the form of rules of conduct in traffic. One such fundamental rule dictates that you must drive on a pre-determined side of the road; in some countries on the right-hand side, in other countries, on the left. This rule can be said to be based on a conventionally determined norm. Its most important function is to reach an agreement. If the country adopts righthand traffic rules, they automatically become adopted in situations that prescribe priority in traffic, i.e. in uncertain situations at traffic crossings, vehicles driving on the right have the right of way.

Although the traffic system is unique in having regulated orders for how to act, these orders are in the minority. Traffic rules deal with reckless driving: that you may not escape from the scene of an accident, that your car must maintain a certain standard and that the drivers themselves must also demonstrate a level of competence by obtaining a driving licence, without which one is not allowed to participate in traffic, etc. Traffic rules, therefore, mainly have the characteristics of prohibitive rules.

The most prominent legal rules with regard to the social system in general are the prohibition rules of the Criminal Code. These are rules that prohibit violence against another person, crimes against another person - stealing his property, theft, fraud, embezzlement, etc. - that are considered important mainly within the economic system. There are also rules for breaches of domiciliary peace and other crimes against unity and peace, rape and other sexual offences, as well as disorderly conduct, which all have to do with social relationships. The sanctity of life and body are constituents of the values that the law endeavours to particularly defend. Both life and death are circumscribed by legal definitions. Abortion laws express a position when determining the right to interrupt a pregnancy. There are also a number of other regulations that deal with artificial insemination, etc. Several rules have emerged in the area known as reproduction technology. ${ }^{52}$ In

52 For more on this, see De Gama, Katherine (1993) Also, Nordborg, Gudrun (1985), Zeiler, Kristin (2014). A philosophical defense of the idea that we can hold each other in personhood [electronic resource] intercorporeal personhood in dementia care. Medicine, Health Care and Philosophy. 17:1, 131-141. Available on the Internet: http://urn.kb.se/ 
extension, the HUGO project highlights a series of ethical considerations in relation to the ensuing possibilities of genetic engineering. Whether or not to conduct research on stem cells is a recent example of this kind of problem. Research on stem cells highlights fundamental ethical questions. What considerations will be of importance within stem cell research depend, among other things, on the source of the stem cells, the purpose of the research and who receives access to the knowledge. The use of stem cells is politically controversial in many countries, since the most important source of human stem cells is aborted foetuses (Agovic 2011).

Starting in April 2005, in Sweden, research on fertilized eggs is allowed in cases of serious illnesses. Previously, this has only been allowed when improving in vitro fertilization methods. The law now allows the creation of stem cells by so-called somatic cell nuclear transfer. Somatic cell nuclear transfer entails that the core of an unfertilized egg is removed and replaced with the core of a cell from another human being. Research on fertilized eggs and somatic cell nuclear transfer must, however, first be approved in an ethical hearing. Great Britain was the first country in Europe to formally allow the production of embryos for research purposes (Banchoff 2011). Some EU countries are very restrictive with regard to embryo research and do not even allow stem cell research to be conducted on test-tube embryos. However, Finland, Italy, the Netherlands and Great Britain have rules that are similar to Sweden. Outside of Europe, embryos are allowed to be produced for stem cell research, as is therapeutic cloning, e.g. in Japan. Singapore and China are also reported to give a wide berth. In the USA, President Bush banned all research on stem cells not extracted from already existing stem cell lines; however, Obama later made it legal.

So far, cloning is one of the more spectacular phenomena to have required legal intervention in the form of bans on experiments with foetuses. ${ }^{53}$ Even death is legally defined in Sweden by way of a special law. As a result of developments in medical science and the emergence of transplantation technology, it has become deemed rational to abandon the old concept of cardiac death and instead use brain death as the criterion for the onset of death: "A person is dead when all functions of the brain have totally and irrevocably ceased" (SFS 1987:269, $\$ 1$, Act Concerning Criteria for Determination of Human Death). ${ }^{54}$ An example of how law is dependent on other expert knowledge can be seen by the fact that law demands that a physician pronounce the onset of death in accordance with scientific methods and proven experience.

The primary form of punishment or threat of punishment, according to the social system's rules, consists of the loss of liberty, depriving the offender from

resolve?urn=urn:nbn:se:liu:diva-103820, Bryld, M. (2002). Den uendelige bekymringshistorie: Reprogenetik og reproduktionsteknologi på Christiansborg. Kvinder, Køn er Forskning, No. 3. https://doi.org/10.7146/kkf.v0i3.28300.

53 The Swedish Research Council's decision 2001-12-05.

54 Michailakis, Dimitris (1995). 


\section{Law as a system of norms}

participating in society by way of incarceration. Since crime is seen as a deviation from what is considered normal, society also provides treatment and rehabilitation measures of various kinds to encourage the individual to adapt to the social system's norms. The range of available measures in Sweden, in this context, is limited in comparison with countries like the USA. Today, we have begun to mimic sanctions such as ankle bracelets. This sentence consists of restricting the offender's freedom of movement to their home, although in some cases, the individual may be allowed to combine the bracelet with work.

The only social institution that is subject to legal regulation is the family. In Sweden, laws are largely divided into "codes". The Marriage Code has rules for who is allowed to enter into matrimony and under what forms. These rules enforce the concept of monogamous matrimony by banning the concept of polygamy. Bigamy is punishable in accordance with the Criminal Code. Furthermore, marrying one's closest relatives is also forbidden. The Marriage Code also declares the necessary conditions required under which a marriage may be dissolved. In Sweden, however, there are no substantive conditions in the way of the dissolution of marriage; divorce is always an available option for both married parties. However, a consideration period of six months is stipulated if children are involved or the married parties are not in agreement.

The Children and Parental Code regulates the relationship between parents and children as well as the relationship between the parents and the children. The rules are divided up between guardianship, which lays out the boundaries between children and adults through rules for incompetence, custody and visitation rights, and alimony issues. The rules of the Parental Code deal mainly with the parents' financial matters, e.g. marital property rules, transfer of ownership in some cases, etc. These rules have been established mainly to support third parties that have economic relationships with either one or both married parties. The rules of the Inheritance Code can also be said to be of importance here, even though they are primarily of economic importance.

The Inheritance Code lays out rules that prescribe that relatives, with the limit being set at cousins, are entitled to inherit and that they shall do so in a given order of inheritance. These days, the surviving spouse is counted as belonging to the category entitled to inheritance and is of the highest priority, together with the children. This legally enforced order of inheritance can largely be circumnavigated through wills.

The right to form non-profit associations for whatever purpose also belongs to the rules of social life. There are some basic requirements that non-profit associations have to fulfil. They do not need to be registered, although they can be. Non-profit associations are recognized as independent legal entities. This allows individuals to gather and organize themselves for various social purposes.

In summary, we can conclude that the social system's rules are few and far between and largely consist of prohibitions. Sanctions allow the legal system to lay out boundaries for acceptable behaviour in a number of aspects that are important in social life. Civil law also provides a tool for interaction. From a user perspective, it should be noted that these rules can be used by individuals for 
different purposes. ${ }^{55}$ The only genuinely social institution subject to regulation is the family. However, this regulation is not particularly intrusive when seen from the perspective of the social system. Additionally, cohabitant couples are provided roughly the same legal conditions without being married as are married couples by way of the special provisions of the Cohabitees Act. To generalize, one can say that in secular societies the focus is on "external regulation" of an administrative system and rules about family and private relations are few, while in religious societies it is other way around - there the emphasis lies on the relations within the family.

Legal rules are of a wholly judicial nature, and their decision-making process, as provided by lawyers within the framework of general courts, is based in normative rationality. The legal rules are constructed as conditional clauses, which means that the rule prescribes that when certain conditions are met, a given legal order will be activated. Another result of the social system's rules is that legal judgement is activated only after the event, i.e. after someone has violated a rule and in connection with the ruling of a sanction or sentence.

The economic system's rules are decidedly more extensive than the rules of social life. Here we find aspects both of constitutive who-rules, procedural rules that work as game rules by describing what should happen, and substantive action rules, i.e. orders and prohibitions that describe what must or must not happen.

Constitutive rules define who is deemed a competent actor in the economic system. In legal terminology, we call this legal subject and legal capacity. These concepts pertain, in the market economic system, to any individual who is of legal age and has not been declared legally incompetent. More important from an economic perspective is that organizations are endowed with legal capacity (Fridström Montoya, Therése 2017). To gain this right, the organization must meet the requirements of one of the forms of company that the law dictates, whether it be a limited company, partnership or individual company. Cooperative businesses can also be conducted within the framework of the economic association. Foundations may also conduct economic activities. The provisions regarding what is known as legal persons have important transaction cost benefits. Law provides standardized forms of economic activity which simplifies making contacts, reducing insecurity and the need for large amounts of information, mainly by providing rules for assigning responsibility and determining who is authorizsed to represent the organization, etc. In other words, any rules of significance are mainly found in the relationship between the company and its surrounding social environment. Briefly put, these rules contribute to simplifying transactions and thereby the circulation of products and services on the market.

Unions are allowed to operate in the labour market and are recognized as nonprofit associations. This means that they are responsible for their own internal

55 In his PhD thesis, Staffan Michelson examines different cases and situations in which civil law can, and has, been used to promote environmentally sustainable efforts, Michelson (2018). 
matters as laid out in their articles of association. ${ }^{56}$ With the support of comprehensive regulation as established inter alia in the Codetermination in the Workplace Act, the Work Environment Act and the Employment Protection Act, they are also allowed to conduct negotiations with employers and represent employees in all kinds of substantive matters in connection with the purchase of labour. ${ }^{57}$

The market mechanism in the economic system is constructed in the legal system by way of the contractual instrument. ${ }^{58} \mathrm{~A}$ special law regulates the contract. It defines the concept of contract by, among other things, providing instructions for how to enter into an agreement. The economic term supply corresponds to the legal term offer, while demand corresponds to accept. ${ }^{59}$ The point of legal regulation is to declare the legal effects that are a consequence of the contract, i.e. the contract's binding effect, and precisely under which conditions a contract does not apply, i.e. when it may become subject to annulment. The main unspoken rule is that freedom of contract prevails, i.e. individuals are allowed to enter into agreements with anybody, about anything, in any way.

Furthermore, legal rules are sometimes connected to specific markets. ${ }^{60}$ The goods market is regulated by the Sales Act and Consumer Sales Act. The Sales Act is based in the parties having the freedom, when entering into purchase agreements, to agree on any conditions whatsoever, but if the parties do not regulate a specific issue of crucial importance to the transaction, e.g. delivery and payment deadlines, how to remedy late deliveries or faulty products, etc., then the dispositive Sales Act steps in and provides standardized solutions to problems that may arise between the parties. These recommended solutions are generally mandatory in accordance with provisions of the Consumer Sales Act when a company sells a product to a consumer.

Similarly, dispositive and, in some cases, mandatory solutions for disputes are on offer in a number of markets such as the credit market, the rent and housing market and the labour market. The need for mandatory rules depends on the social importance of the product or service under regulation.

The constitutive elements of the construction of the system are circumscribed by mandatory rules. This applies to the contractual instrument as such, as well as

56 Decisions made by unions can, however, be appealed in court in special circumstances. A common kind of case might concern an individual's right to membership. Stockholm District Court, for example, rejected a decision regarding expulsion of a member by the Svenska Musiker and Kulturarbetarförbundet unions and thereby made clear that a member of a union cannot be expelled for having criticized their own union in the media.

57 In my book Arbetslivets reglering (Regulation of Work Life), I present an overview of how the Swedish regulation system works in Swedish work life. This is explained in more detail in textbooks by Adlercreutz, Axel (2000) and Glavå, Mats (2001).

58 The contractual instrument, as expressed by leading American legal theorist Jules L. Coleman, is "an institution designed to reduce uncertainty and thereby make markets possible". See Coleman, Jules L. (1993).

59 This does not mean that supply, in economic terms, is defined as offers from a legal contractual perspective.

60 Cf. Skog, Göran (1982). 
to property rights and other property rights that regulate relationships between individuals and objects, i.e. jus in rem. For practical reasons, there are detailed rules surrounding property ownership, not least with regard to the surrounding social environment. ${ }^{61}$ Some forms of ownership, such as property, require registration of ownership. The concept of ownership also plays an important technical role in its function as an intermediary concept to which other rights are linked. ${ }^{62}$ It relieves the legislator of having to lay out all the legal effects who can, instead, merely notify under what conditions an individual is entitled to the legal title of property owner, upon which a body of rights and obligations are automatically activated. There are different kinds of property rights and mandatory rules to enforce them as well as regulate the relationship between owners with different kinds of rights to the property, such as owners, mortgage owners, tenants, etc. In acute situations where somebody lacks sufficient liquidity, e.g. in connection with bankruptcy or execution, an order of payment decides who is to get paid and in what order.

Another aspect that led to the introduction of mandatory rules in market economies has to do with what is known in legal terms as protection for third parties, i.e. protection for anyone who may have a general economic interest in one of the parties involved in the contractual relationship. For example, a lender who has lent money against collateral in the form of a mortgage or a claim on a married party who is about to transfer their property to their other spouse or children. In these kinds of situations, so-called third-party interests require that there are enforceable rules that demand transparency and the provision of information to the involved group and other rules that protect the third party. There is a link between Jules L. Coleman's (1993) argument in connection with reciprocal relationships, namely that there is an assumption in these situations that both parties possess resources that enable them to avoid negative effects. This does not exclude each party, whether individually or together, from acting in a way that may have external effects on a third party. The moment this kind of situation arises and there is reason, in general, to suspect any kind of abuse, i.e. when the economic situation requires a response, so does the need for mandatory rules to protect uninvolved third parties.

Another reason for mandatory rules is that employment and housing matters are seen as social rights, and this influences their social, and thereby political, importance. In legal lingo, this is expressed as one of the parties being a weaker party. Such an observation implies a market-oriented point of view. People seeking both work and housing can be expressed as being subject to double coercion. Selling one's labour is not like selling any old product on the market. Individuals selling their manpower are forced to earn money for the livelihood

61 E.g., Baird, Douglas et al. (1994).

62 See more on the concept of property rights, Hohfeld, W.N. ([1919] 1964), Honoré (1961) and an overview in Abrahamsson, Bengt and Broström, Anders (1979), with references therein. 
and, depending on where they live, there may only be a limited number of jobs on offer. Nor are people who want to rent or buy an apartment in an ordinary market position. They are forced to find roofs over their heads They are essential commodities.

These kinds of conditions are what lead to enforceable rules intervening in the free market or other measures implemented by the political/administrative system. Hence, labour market regulations have aspects of enforceable rules. The Employment Protection Act is one example of this. In part, however, dispositive rules remain, based in the argument that the unions' collective representation of employees is guarantee enough that the subject of social interest is preserved. Similarly, home-seekers in the residential market also need special legal protection. An example of this is protected tenancy rules which can be said to correspond to employment protection in the labour market. In negotiations in the labour market, the individual is represented by unions, not least when it comes to wages. Similarly, the Swedish Union of Tenants is legally authorized to represent individual tenants in rent negotiations. A number of parallels can be drawn between regulations in the rental housing market and the labour market.

The need for enforceable rules is not limited to the labour and residential markets. Both the wholesale market and the distribution of goods are areas that are increasingly becoming characterized by oligopolistic tendencies. In his $\mathrm{PhD}$ thesis on electricity legislation and the relationship between electricity subscriber and supplier (1992), Ulf Stridbeck concludes that the consumer, the electricity subscriber, is also subject to double coercion, which puts him in a unique market position. ${ }^{63}$ On the one hand, he is forced to buy the product, electricity, since it is an essential commodity of equal importance to employment and housing, and on the other hand, he is forced to turn to the few electricity suppliers in the market to purchase it. ${ }^{64}$ Stridbeck argues that for these reasons, the contractual situation, and therefore implicitly the market situation, should be judged according to somewhat different rules. He calls for implementing enforceable rules that also weigh in the social aspects when assessing the electricity subscriber's obligations. Hence, Stridbeck argues, in the event that a subscriber does not fulfil their payment obligation, the supplier should not be allowed to interrupt the electricity supply without undue notice. To do so would not be a proportional reaction to the subscriber's failure to fulfil contractual payments, which is why some form of weighing aspects against each other is required, according to Stridbeck. The range of available electricity suppliers is now broader than when Stridbeck wrote this book. This aspect, however, likely does not change the issues experienced by the electricity consumer in Stridbeck's discussion.

Other authors have also made similar arguments. Norwegian legal sociologist Hans Petter Graver argues in favour of social rights in credit matters, ${ }^{65}$ and

63 Stridbeck, Ulf (1992).

64 Ibid.

65 Graver, Hans Petter (1990). 
Finnish legal scientist Tomas Wilhelmsson, who originally initiated the discussion, has conducted an inventory of the entire field of civil law and concludes that there is a need for a new social civil law that rejects market logic by stipulating through regulation social considerations that are not spontaneously generated by the market. ${ }^{66}$

Claes Sandgren, who has, in two articles, analysed the arguments for the introduction of social civil law, is sceptical of social contract law. ${ }^{67}$ Balancing the economic and the legal perspectives within the context of contract law has to do with how limited party autonomy should be in favour of other social factors. Sandgren believes that the answer is more complicated. "Well functioning, civil legal instruments are necessary in a well-functioning market economy", Sandgren concludes. ${ }^{68}$ Therefore, they should not be tasked with assignments that can be carried out by public law instruments or other extra-judicial means. The different systems must be kept apart. Sandgren argues, with reference to German legal and social scientist Niklas Luhmann, that involving public legal considerations can impair the effectiveness of civil law instruments. ${ }^{69}$ The civil law system could be over-exerted as a result of increasing complexity, which could make the entire legal structure unstable. ${ }^{70}$

Therefore, legal rules contribute to constructing the economic system by providing game rules for the market actors. This is the purpose of the majority of civil law rules. Additionally, there are parts of general penal law that address property crimes and economic crimes (the Penal Code, Ch. 8-12). These rules, together with the annulment rules of civil law (such as the rules for annulment laid out in $\$ \$ \$ 28-38$, the Contracts Act) lay out boundaries for acceptable economic behaviour. In that sense, legal rules can be seen as a reinforcement of norms that are spontaneously generated in the market. In other words, legal rules do not imply any other actions than are requested by the economic system. Within this framework, there is freedom of action, i.e. the civil and penal rules "do not interfere" with general market activities. Rather, they are characterized by freedom of contract, freedom of trade and freedom of competition.

What is interesting, however, is that these values are so central to Swedish law that they are not even expressed in the actual legal rules. They are the underlying prerequisites for understanding and interpreting the entire civil legal regulation system. What is considered normal is implicitly embedded in the construction of the economic system. That is to say, paradigmatic conditions. These values are only activated when they are violated. If they are violated, penal and annulment rules are activated. This also applies, in part, to another constitutive element of

66 Wilhelmsson, Thomas (1987). See also Wilhelmsson, Tomas (1993).

67 Sandgren, Claes (1992/93, pp. 456-486 and 643-668).

68 Ibid, p. 661.

69 See also Juha Tolonen (1988).

70 Cf. Luhmann, Niklas (1986). 
market economy, namely, the concept of ownership. What constitutes ownership is, to a degree, an unregulated matter. ${ }^{71}$

The civil legal regulation system contributes yet another factor that we have touched upon that is of structural importance to the market economy. That is to say, the instrument used in interactions and by which the interaction is manifest, namely, the contractual instrument, which in itself is the foundation of the entire market mechanism. In this context, the right of ownership and other property rights laws constitute important, structural elements of the economic system.

Another necessary instrument in economic life is the innovation of the legal person, which allows work and capital to be separated and capital to be accumulated without personal liability. ${ }^{72}$ Since the collective company can act as an individual legal subject, it is also possible through minor adjustments to basically implement the same forms of rules and principles as have been established since Roman law with regard to regulation of the modern market economy. ${ }^{73}$ In some situations, the legal system has worked as a necessary condition of economic progress. In addition to the example of the establishment of the concept of the legal person, we might mention developments within intellectual copyright such as patents and brands, without which much economic development in market economic terms would not have been possible. ${ }^{74}$

In summary, we can conclude that the rules of the economic system provide game rules that are a necessary condition of the market economy system. The rules describe possible ways of acting without ordering a specific action. However, if an individual elects to do business in the market, they are forced to comply with the market rules. Transgressing the market boundaries is prohibited. Should a person do so, they will be sanctioned, and the rules will be manifest as prohibition rules. If an individual causes harm to another by transgressing the rules of the game, a restitutive sanction is enforced in the form of damages that are intended to provide remedy or another comparable form of sanction with the intent to restore the status quo, e.g. revoking a sale, etc.

The instruments provided by the legal rules in the form of contracts, ownership rights, etc., are empowered with the ability to declare a contract void, i.e. an action that deviates from the stipulated rules becomes null and void, non-existent. If it has come about in an inappropriate manner, it can be declared invalid.

In these situations, too, with regard to the social system's rules, legal decisionmaking and normative rationality dominate. This means that these are duty rules, formulated as conditional clauses with attributes that describe the actual conditions that must be fulfilled in order for a particular legal order to be activated. This applies to both civil and penal law. Similarly, the economic system's rules are

71 Cf. Hydén, Håkan (1978, p. 266 ff).

72 See Torpman, Jan (2002). Please also see Hydén, Håkan (1988, p. 203 ff). for more on the importance of the legal system for economic conditions.

73 Cf. Renner, Karl (1949).

74 Hydén, Håkan (1988). This is particularly salient in the markets in financial instruments, please see EU Regulation on markets in financial instruments (MiFiR). 
activated after the event, i.e. only when someone violates the social rules or has not complied with the instructions for the available permitted instruments. In that case, legal proceedings are conducted in connection with passing sentence. The behaviour is encouraged by the economic system's normative logic, and deviations are seen as marginal phenomena that are resolved, as a last resort, in court.

The political system is even more dependent on legal rules than the economic system. Law and politics belong together. Law forms the basis of the political system through its constitutional laws and instruments of government, while the political system simultaneously adopts and promulgates legal rules. Law and politics are, in Western legal tradition, inexorably bound to each other. There is a dualistic relationship between law and politics. ${ }^{75}$ Additionally, both law and politics can assume different manifestations. In order to distinguish the legal system as law, it must enjoy a degree of independence. Once adopted, the law must be separated from politics. Therefore, the law has its own institutions, courts and authorities which are surrounded by authorized functionaries such as lawyers, the police, prosecutors, etc.

In 1974, Sweden adopted a new constitutional law which dictated that parliamentarianism was a fundamental principle, something that had already been established in practice. This indicates the lack of significance that constitutional laws have had in Swedish law. Sweden does not have a constitutional court; nor does it have a tradition of retrying laws or regulations or whether decisions made by the authorities comply with the constitution. A court or authority may revoke a law or regulation if it violates the constitution (the Instrument of Government, Ch. 11, \$14). In fact, the conditions for basic rights and freedoms, as laid out in Chapter 2 of the Instrument of Government, alongside, for example, requirements that authorities must be objective when exercising public power in accordance with $C h .1, \mathbb{S}$, may not be invoked by private persons in court or before an authority. These rules must first be converted into a law or regulation in order to gain legal force.

This would indicate that Sweden lacks a constitutional tradition which has, furthermore, had a negative impact on the entire legal profession and education system. ${ }^{76}$ Political problems are rarely discussed in legal terms. The legalization of social issues that began in the wake of the Second World War has not contributed to promoting a legal culture. There is a tendency to pay more attention to quantitative rather than qualitative aspects (Brännström 2009). Said legalization should instead be seen as part of a process that is characterized by a monopolization of the lifeworld and therefore almost contrary to morally tinted legal arguments. ${ }^{77}$ The capacity for reasoning based on principles and the will to maintain principles

75 For more on the relationship between the legal system and the political system, please see Eckhoff, Torstein and Sundby, Nils Kristian (1991, p. 227 ff). See Whittington, Keith E. \& Kelemen, R. Daniel. (eds.). (2008).

76 From a research perspective, however, Joakim Nergelius' research deserves a mention, here, see Nergelius (1996).

77 Cf. Teubner, Günther (ed.) (1987). 


\section{Law as a system of norms}

of social life therefore becomes glaringly absent. This becomes particularly clear when we compare with other countries that have a constitutional tradition and constitutional courts, such as the USA and Germany. It seems to be mainly federal states that practice constitutional and legal retrials of laws, the result of using legal institutions to create uniformity in a social system that otherwise risks becoming overly heterogenous and unequal (Febbrajo 2016).

To a degree, Sweden employs the same strategy in the relationship between the state and the municipalities. This has become increasingly relevant as a result of two conditions: the growing use of framework laws that allow the applicable authority to endow the law with content and a growing number of governmentally determined tasks that have been assigned to the municipalities ${ }^{78}$ (Esping 1994; Hydén 2002b). A consequence of this is that administrative courts have been tasked with retrying decisions made by municipal authorities. ${ }^{79}$ This means that the administrative courts may end up imposing a particular content upon the municipal authorities' practices. This issue has been noted particularly within the area of social services. ${ }^{80}$

Aside from their constitutional function in the political system, legal rules also play an important role in formalising and clarifying the previously mentioned norms that mediate politically determined decisions to the executive power, the administrative system. This is a significant result of the remoteness and complexity inherent in the political/administrative system that characterizes the nationstate. Legal rules have a communicative function in that they mediate tasks issued by politicians to administrators.

The political system also performs other functions that are important to the market and give rise to what we might refer to as supplementary rules. This has to do with various tasks that the social and/or economic systems request and are not spontaneously generated within market relationships. This can be divided into four infrastructure complexes that create conditions of production as well as demand for the business sector. ${ }^{81}$

Firstly, there is the legal infrastructure. Maintenance of the legal system is based on these kinds of legal rules, i.e. on regulations that regulate the judiciary, the police, the public prosecution services, etc. Legal rules require a third party that is able to intervene and pass rulings in disputes surrounding the contents of the rule, and as a last resort, enforce a rule in the absence of voluntary compliance. Secondly, the administration of physical infrastructure such as communication services, energy, water and sewer systems also requires supplementary rules. The third complex consists of the social infrastructure that is based on health and social care rules, healthcare rules and different kinds of income protection.

78 Hydén, Håkan (1984). Ram eller lag? Om ramlagstiftning och samhällsorganisation. DsC (1984, p. 12).

79 For more on Norwegian conditions, see Eckhoff, Torstein and Graver, Hans Petter (1991).

80 For more on this issue, see Åström, Karsten (1988).

81 Dagens Nyheter August 7, 1993. Tarschys argues in his article that the rise of capitalism is closely connected to the development of the various infrastructures. 
Finally, there is the cultural infrastructure with its rules for education, and "civilisation", in its broadest meaning, the education and university system. Additionally, there is also a need for defence against external threats, which also requires an administrative apparatus and special rules, i.e. the armed forces. There are legal rules in all these areas that mediate tasks from political decision-makers to executive functionaries. The legal rules act as guidelines for the activities and provide basic organizational conditions.

In summary, we can conclude that the political/administrative systems' legal rules differ from the social and economic systems' rules. They are not prohibitive rules. The legal rules, here, do not set up legal boundaries as they do in the other systems. At least, its boundaries are fuzzy, normatively speaking, and are rather based in pragmatic considerations. The boundaries that do exist are primarily based in constitutive rules. The legal rules define the administrative apparatus. Each authority is surrounded by instructions that outline the basics of their tasks and how to organize themselves internally. Should an authority transgress their legally defined domains, their decisions and actions will be declared invalid.

The legal rules surrounding the administrative system are closer to orders than prohibitions. But since they relate to general tasks, the orders do not specifically have the properties of commands. They are not expressed as "you shall", but rather they point toward goals that the authority should strive for. Additionally, the rules describe the means that are permissible in order to fulfil the goal. Hence, the rules of the political/administrative systems are expressed as being consequentialist-oriented, as mentioned previously.

The rules of the political/administrative systems can be said to be purposive rather than conditional. The rules look to future situations and are intended to act as guidance in a way that differs from the rules of the social and economic systems, which are more concerned with providing instruments for interaction, as well as laying out boundaries for acceptable behaviour. This also has an effect on the principles surrounding the decision-making process. ${ }^{82}$ Instead of the normative rationality that characterizes the implementation of rules in the social and economic systems, the administrative system's application of rules is instead characterized by instrumental rationality. ${ }^{83}$ That is to say, the direction and contents of the goal are what determine the logic underlying the decision-making process. Since it is concerned with realising goals, the rules are rendered to being merely a step toward this ambition. The rationality of the decision-making process is subordinated to the system of knowledge that determines the intended goal fulfilment. This applies equally whether the subject is medical expertise in the health sector or technological knowledge such as the road system, etc. The administrative system's rules are therefore mainly implemented by (expert) authorities and only in exceptions - i.e. an appeal - by the administrative courts. Courts allow the

82 Strömholm, Stig (1979).

83 Graver argues that the difference is more of a gradual degree than another species, Graver, Hans Petter (1988). 


\section{Law as a system of norms}

parties to retry a decision in which they have a personal interest if the authority has ruled against the individual.

Within the political/administrative system, the legal rule becomes only a part of issuing guidelines and forms of organization to be implemented. In other cases, the decision-making process is left up to professional expertise rather than legal expertise, ${ }^{84}$ whether it be the natural sciences, technology, medical science, economics, pedagogy or other more or less professionally established knowledge structures. The function of the rules is limited to conveying the political message and establishing how the tasks are to be carried out.

The natural system does not require any legal rules. To the contrary, the natural system exists wholly independent of man and our knowledge of norms. But when we want to exploit nature, rules can be a part of this process. Rules may help us organize and set up as rational an exploitation process as possible, economically speaking, or contribute to setting up limits for how much we may exploit nature in order to protect it. Exploitation norms conflict with conservationist norms. Both can be found in our legal system. However, exploitation norms dominate. Civil law lays out rules that promote the economic system's exploitation of nature. ${ }^{85}$ Laws surrounding the extraction of minerals and mining deposits are concerned with as rational exploitation methods as possible. A concession for extraction may, therefore, not be granted indiscriminately, but rather only to individuals that can be expected to exploit the extraction in a rational manner. The Environmental Code, however, is characterized by environmental protection laws with some aspects of conservation norms, although it also represents a prerequisite in the exploitation of natural resources. ${ }^{86}$ For example, the Forestry Act represents aspects of both purposes, i.e. both rational exploitation and conservation interests. ${ }^{87}$

\subsection{When a norm becomes a legal rule, what are the consequences?}

Let us return to the question previously posed in this section about what it is that characterizes norms that become legal rules. What kind of norms become strengthened, so to speak, by being elevated to rules, and what are the consequences of a norm becoming a rule?

The answer is implicit in the previous discussion. But first, I would like to point out one aspect. When a norm becomes a legal rule, not only is its status changed,

84 For an illustration of this, see Pfannenstill, Annika (2002).

85 This is not an unavoidable effect of the legal system; rather, it depends on for what purposes the rules are used. In his PhD thesis, Staffan Michelson demonstrates how civil law can be applied to promote sustainable development (Michelson 2018).

86 However, none of these laws guarantee absolute protection. Cf. with regard to the Environmental Protection Act, Hydén (1978) Ch. 9 and on natural resource legislation, Eriksson, Lars. (1985), Svenning (1996).

87 Cf. Appelstrand (2007). 
its content may also change once it becomes a part of another system of norms, i.e. the formalized legal system. This system has its own criteria and language and develops according to its own characteristic and reshapes the political system's norms clamouring for attention to become legal rules. The legal system has its own special profession which is trained and schooled to think and to implement rules according to a specific kind of logic: deductive logic, a characteristic of legal dogma.

All legal rules share in common that they belong to one or another legal system, as Eckhoff-Sundby states. ${ }^{88}$ This means that in many cases, the legal system has special rules that indicate what norms are included in the legal system, thereby having the status of legal rules. ${ }^{89}$ This condition is what gives most definitions of law an aspect of circularity. This can be illustrated by English poet Wystan H. Auden's poem "Law like Love", referenced by Vilhelm Aubert in his review of concepts of law. ${ }^{90}$ It reads as follows:

Law, says the judge as he looks down his nose,

Speaking clearly and most severely,

Law is as I've told you before,

Law is as you know I suppose,

Law is but let me explain it once more,

Law is The Law.

Eckhoff-Sundby lists five criteria of a legal system. To begin with, it must have an organized production of rules, some form of legislated organization and an authoritative order tasked with interpreting the rules, generally a Supreme Court. Additionally, there must be a legal conceptual apparatus, a language of norms and a special legal profession. The language of norms is fragmentary and can therefore be put together in myriad different ways. A legal system must also be linked to a nation-state in one way or another. Furthermore, it is linked to a monopoly on violence. Finally, Eckhoff-Sundby notes that the fifth criterion makes certain ethical minimum demands of a legal system. ${ }^{91}$

One consequence of norms that become legal rules is that they become endowed with their own intrinsic value. This is the case, at least, when it comes to the social and economic systems' rules. Being part of a legal system gives them legitimacy, and they no longer need to be justified. Another aspect is that are not applied automatically. They depend on other factors that I shall return to. In its

88 Eckhoff, Torstein and Sundby, Nils Kristian (1991, p. 199).

89 Cf. H.L. Harts' distinction between primary and secondary rules, in which the latter are referred to as rules of recognition, Hart H.L.A. (1961).

90 Auden, Wystan H. (1972, p. 208), reprinted in Aubert, Vilhelm (1989, p. 31 ).

91 The authors reference Aleksander Peczenik's standpoint that if ethical objections can be raised against large parts of the legal system, e.g. Cambodia under Pol Pot or Nazi Germany, then the system does not fulfil the requirements of the legal system, Peczenik, Aleksander (1988, p. 222). 
traditional role, law is not seen as being instrumental, i.e. that its purpose is to promote goals beyond the legal order, e.g. economic efficiency. It views fairness as a value in itself. Reza Banakar argues that the pursuit of justice is an expression of law's normative core (Banakar 2013). One practical outcome of this is, as Sandgren points out, that the legal order protects vulnerable groups and minorities, whether they are indigenous populations or stockholders. ${ }^{92}$

This same condition is what leads Jon Elster to argue, when distinguishing between normative actions and self-interest, that purely normative actions are not affected by the consequences of the action situation or implications thereof for the actor. ${ }^{93}$ Therborn uses the example of the difference between interest-based actions that are governed by situational exchanges of expected costs and benefits, on the one hand, and normative actions based in rules that the actor has learnt and the situational interpretations relevant to the rules, on the other hand. ${ }^{94}$

Such sociological observations are backed up by the fact that the judicial profession has developed principles and methods in order to interpret and implement laws that are independent of the norm's social, economic or political content. One example of such a method within the legal system is the use of analogies to other legal areas, which shifts the legal contents from their social mooring. Legal dogmatic methodology, in its most developed positivist manifestation, endeavours to provide law with contents and applications that are independent of the surrounding social or political conditions and independent of economic fluctuations. This is one of the most important aspects of what we call legal security and rule of law (Sellers, M. N. S. \& Tomaszewski, Tadeusz 2010; Altus Global Alliance 2011; May, Christopher 2014). Indisputably, the legal system has its own form of logic that does not necessarily correspond to the logic of the social conditions that initially gave rise to the norm. Legal autonomy, therefore, is a conscious project that underlies the rule of law.

By being elevated to a rule, the norm becomes linked to a legal enforcement machinery, in addition to being a matter of private conduct. This gives the norm greater weight and reduces costs for the law's target group, who then do not have to resort to private sanctions to force the receiver of the norm to comply. ${ }^{95} \mathrm{How}^{-}$ ever, the symbolic value inherent in law is, in itself, a force. ${ }^{96}$ Robert Axelrod also points out a third advantage of increased clarity of legal rules. In comparison with

92 Sandgren a.a p. 660.

93 Elster, Jon (1989).

94 See Therborn (1993).

95 See Axelrod, Robert (1986).

96 See cf. Arnold, Thurman (1935, 1962, pp. 33-70) and (1937). The inherent symbolic value of the law means that often it is not intended to be applied dogmatically. Thurman Arnold mentions American anti-trust legislation as an example. Despite the implementation of legislation increasing concentration in the business sector. Arnold's conclusion was that the importance of the law was mainly at the symbolic level. It made it possible for Americans to claim to have an ideology that supported free competition while actually implementing a different kind of economic system. In this context, Aubert-Eckhoff-Sveri's (1952) classic study should also be mentioned. 
(informal) norms, rules tend to clearly define the obligations and rights pursuant to the rule. Axelrod further argues that social norms are often most suited when preventing a number of minor social violations that have low maintenance costs, while legal rules, due to having much greater resources, are often better suited for preventing less common, but more significant infractions and damages. ${ }^{97}$

When a norm is transformed into a legal rule, the norm becomes applied more or less generally, independent of its actual function in the social or economic action system as such. This condition has an influence on both judicial training and judicial careers. By converting the norm into a rule, with the help of the legal system, its application can be secured to a greater extent than if the norm was unregulated.

Once it becomes a legal rule, it merges into the legal system and becomes a part of a larger sum. Law is a constructed system of norms with its own, special subcategories. ${ }^{98}$ Based in ancient legal culture, we divide legal matters into penal law, civil law, procedural law, public law with subcategories, constitutional law, administrative law, international civil law and international law. ${ }^{99}$ The last two have come to form special categories in the latter part of the market economy era. This division abides by the legal system's own logic and corresponds only partly to the division of legal branches, as noted in the review above of the rules' relations to action systems. However, some basic characteristics can be discerned.

Penal law is involved in laying out boundaries for basically all kinds of systems but has its emphasis in the social and economic systems. Civil law regulates the social and economic systems by providing game rules and instruments for interaction. Procedural law belongs more specifically and directly to the legal system by providing principles for resolving disputes in penal law, civil law and administrative law decisions. Constitutional law and administrative law are linked to the political/administrative systems. International civil law is a system of rules that is the result of nation-states' dominance in the creation of legal systems. Social conditions such as matrimony and economic transitions that take place across more than one country highlight international, private law deliberations on which country's law to apply. This problem becomes acute from an IT law perspective, in which country borders are erased in a virtual, online world. Major companies use their own definitions of what rules to apply in contractual clauses. This applies not least to platforms that are increasingly becoming mediators of products and services. For example, new business models and regulatory techniques have emerged, none more significant than what has been happening in the field of information technology where the "Big Five" - Apple, Google, Amazon, Facebook and Microsoft - have driven the rise of algorithms in society: Facebook can see what people share, Google what they search for and Amazon what they buy when using the Internet. International law is a system of rules in the making

97 See Axelrod, Robert (1986).

98 For more on the importance of this, see Strömholm, Stig (1991, p. 111 f).

99 For an overview, see Hydén and Hydén (2016) Ch. 2. 
that is concerned with the relationship between states, but which also deals with the possibility of extending binding legal principles across national borders that are of importance in human rights matters. This is becoming increasingly important as globalization progresses. It is also relevant to mention the form of law emerging between states as a result of the EU and under the auspices of the European Court of Justice, the European Court of Justice and the European Court of Human Rights.

These different legal areas have different backgrounds and adhere to different principles. It is curious that this has not received more attention in legal scientific circles. In this context, legal pluralism is of definite relevance. The penal and civil law systems adhere to a normative rationality model which follows duty rules which, in extension, are interpreted and implemented by the courts. One could say that civil law dominates in societies that are characterized by liberal market economies and night-watchman statehood. Societies in which constitutional law and, even more importantly, administrative law dominate generally have socialist legal systems. The importance of penal law in both cases varies. Societies that emphasize civil law could be presumed to have fewer, and more importantly, more humane aspects of penal law than societies that emphasize public law. Societies that practice a mixed economy system, such as the Scandinavian welfare states, have aspects of both civil and public law. In these societies, we also see an increase in interventional rules, as will be discussed further in Chapter 6.

The main point I would like to conclude with here, from a normative perspective, is that the institutionalized context in which legal rules arise have a strong influence on the content and implementation of the norm. Rules that belong in the domain of public law tend, in centralized systems, to result in a mentality that may be equally totalitarian in a welfare state as in a communist one-party state.

\subsection{What norms become legal rules?}

The answer to this depends on one's point of departure. In this context, I will primarily restrict myself to functional explanations combined with an understanding of the specific nature of law, as has been elaborated on in this chapter. Upon comparing the kinds of norms that actually become legal rules, we can conclude that within the social and economic systems, action rules that prescribe a certain behaviour do not become legal rules; rather, prohibitive rules that prescribe how not to act, rules that have more to do with boundaries than behavioural instructions, do. We can also see that both systems are endowed with instruments for various kinds of interaction via legal rules, e.g. family matters related to the social system, the concept of ownership, contractual instruments, the concept of the legal person, security interests and rules for making payments, etc., in the economic system. In sum, this means that the social and economic systems' legal rules lay out the systems' borders while simultaneously coordinating actions by clarifying and providing suitable instruments that the action system requires to fulfil its social functions. 
There is, in other words, some support for the argument that law plays a reproductive role in the social and economic systems. The legal rules simplify reproduction of the systems, thereby securing their existence. Therefore, the legal rules contribute to producing trust in the social and economic systems, as emphasized, not least, by Norwegian sociologist and legal sociologist Vilhelm Aubert. ${ }^{100}$ That there are rules in place means that the relevant expectations have been secured. This simplifies transactions and trading between strangers. The level of trust automatically created by one's relatives, clan, village or primary group can be extended to people one has never met, but who recognize the same rules by subjecting themselves to the same, mutual, governing, legal authorities. ${ }^{101}$

The trust-creating function of law not only provides a strict reproduction of an existing system, it also contributes to expanding it. A necessary condition for an efficient legal system is that it has access to a functioning system of sanctions. Paradoxically, freedom requires enforcement. ${ }^{102}$ The boundaries of the social and economic systems laid out by the legal system and the instruments provided by the law are combined with a high degree of freedom of action in these areas. For such a degree of freedom to be viable, however, the rules must be respected, and this is enforced by the option to issue sanctions against anyone who violates the rules.

In other words, the legal rules support a given, established order with the help of, among other things, sanctions. To the extent that this order implies unfair inequalities between the groups and class differences, the law will also contribute to reproducing them. To put it another way, the legal system has to do with power relationships. This is indisputably the case, although two complementary remarks are needed here. Firstly, potential inequalities may not be a result of a law in itself. The rules we have discussed that belong to the market economy system are in themselves not inherently unfair in the way that earlier social orders based on status hierarchies were. Freedom is the most fundamental element of the market economy system. This does not mean that, to the extent that it contributes to unfair practices, they will not be reinforced by the social and economic systems' rules. The same applies to, for example, environmental problems, where, although the problems have not been caused by the law, law may contribute to preserving the problem without actively causing it. Secondly, there is a limit to the injustices that the system's rules will tolerate. Legal rules are based, as are the social and economic systems' norms, in spontaneous legitimacy. To the extent that the rules are experienced as overly unfair, one should expect that the power structure will become modified or adapted. For this purpose, some mechanisms have already been built into the legal order. One example in work life is the right

100 See Aubert, Vilhelm (1976, p. 257 f, 1989).

101 As a consequence of this argument in a previous context, I emphasized the importance of developing the legal system in the Third World as a condition of progress in relation to aid provided by Sweden and other countries, Bartolomei and Hydén (eds.) (1999).

102 See Hydén (1999). 
to strike if the employees are dissatisfied with their wages or other work conditions, thereby violating other legal duties. ${ }^{103}$

Another example is the previously mentioned discussion on social civil law. Sandgren, however, argues that there is no definitive contradiction between an economic perspective that emphasizes efficiency and a judicial perspective that focuses on reasonability. ${ }^{104}$ If a regulation has the purpose of protecting something that improves market functions, or at least does not impair it, it is hard to object to it, Sandgren argues. Trust in the market, as an instrument for distributing resources, is dependent on consumers being able to trust the products and services and the outcomes. To the extent that the market and its legal rules create disadvantages, or perceived disadvantages, we are then faced with a legal contractual paradox, according to Sandgren; party autonomy must, to a degree, be sidestepped through enforced rules in order to be maintained. This is what characterizes intervention and affirmative action situations, which are mainly found in the area of equality (Schömer 1999; Kellough, J. Edward 2006; Meyer, Susan 2018). This issue has been particularly controversial in connection with discussions on wages (Sveneaus 2017).

In other words, it is to be expected that the legal rules created by the economic system may become modified or changed as a result of the target group lacking legitimacy, to revisit Coleman's terminology. This becomes particularly obvious in situations where external effects on the action system contribute to a division between the target group and the receivers (disjoint norms), cf. section 4.1.2. In these kinds of situations, the economic system's demands for efficiency are not modified due to reasons of reasonability, which would be the legal argument, but for reasons of legitimacy; that is to say, because the market mechanism (or another part of the economic system that is affected) needs to be strengthened in an area where it is vulnerable. These kinds of rules, then, gain an interventional aspect, which we shall return to in Chapter 6.

The reproductive role of law, therefore, does not necessarily, or even primarily, entail that law has a politically conservative function. To begin with, the reproductive function requires that each action system is created within the legal system. Reproduction naturally requires that something has been produced beforehand. First, law has to contribute to establishing that which is to be reproduced. Historically, in situations of social upheaval, this condition gives law and lawyers a radical social function. In some historical situations, law has played an important, germinal role. ${ }^{105}$ Secondly, law's reproductive aspect entails that it assumes responsibility for radical tasks when the action system undergoes a change in conditions. Frequently, law is forced to intervene to create legitimacy in normative conflicts that result from action systems in people's daily lives. This may concern

103 However, this does not mean that the right to strike is wholly free and unregulated, please see $\mathbb{S} S 41-42$, the Co-Determination Act.

104 See Sandgren, Claes (1992/93).

105 Erikssson, Lars D. (1992) and (2002), Unger, Roberto Mangabeira (1996). 
events in occupational life, consumer relationships and environmental problems. A common scenario is for law to be carefully activated once a problem arises in society without changing the basic conditions that cause the problem and then successively intervene as the problem continues or expands. ${ }^{106}$ In relation to this phenomenon, van Rooij uses the expression "law of event" and points out that law many times comes into being after a more or less dramatic event has occurred in society. ${ }^{107}$

In order for an action system to be reproduced, there must be instruments at hand that keep the system together. In other words, there need to be consensuscreating mechanisms that allow the system's actions to be synchronized and harmonized. In the context of the economic system, the contractual instrument is one such important mechanism. The contract enables individual actors in each individual case to establish a relationship over a short or long period of time that can range from merely exchanging products to more long-lasting collaborative projects. The market mechanism with its strategic norms requires a flexible instrument to coordinate mutual goals that may be of an overly individual nature or too time-consuming to call for legal rule status. Via the contract, the legal system provides the individual actors access to the benefits of the legal system in the form of stability, visibility and the threat of sanction in the event of any violation against the (individualized) norm (contents of the contract).

In extension of the contract, there is another consensus-creating mechanism, namely the organization (Taylor, 2018). By directing and establishing certain standardized forms of collaboration in the form of the organization, the legal system is able to synchronize internal decision-making processes among the members of the organization and, partly through external rules, give this organization a position as a separate legal entity with its own legal capacity, etc. In each of these organizations the actors are given, via internal rules, access to democratic decision-making processes that underlie the legitimacy of each decision. Private business can thus be aggregated and synchronized within the framework of associations and companies of various kinds. Within each of these organizations, the actors, through internal rules, have access to democratic decision-making processes that legitimize individual decisions.

These are same mechanisms that on a larger scale are activated through the political system's formalization of the legal rules, as previously described. The purpose of the political system's organization and establishment of rules is to ensure mechanisms that provide for the political system's, and thereby the entire social system's, continued existence. Much of constitutional laws is concerned with laying out the basic conditions for collective decision-making that requires the participation of all citizens (Febbrajo 2016). As a result of this principle of

106 See Randall Peerenboom (2007), Hydén, Håkan (2002a).

107 van Rooij, Land and Pollution Regulation in China. For another example, see Johan Lagerkvist, The Legitimacy of Law in China: The Case of "Black Internet Cafés", in Burell, Mattias and Svensson, Marina (eds.) (2011). 


\section{Law as a system of norms}

representative political democracy, the political system has been separated from the social and economic systems and has limited its participation in daily, political decision-making and, instead, has left this to the professional politicians elected to represent the majority of the people. The latter aspect naturally reinforces the independent nature of the political decision-making process with its own developmental rules and norms.

One of the legal rules' most important tasks here - in addition to providing practical forms for decision-making - is to establish a division of power between different parts of the political/administrative system, as well as between the system and surrounding society. The division of power between legislative, executive and judicial branches is therefore enabled and guaranteed by legal rules. Similarly, rules are established within the political system that lay out boundaries for the administrative system, on the one hand, and the social and economic system, on the other, by establishing rules for the private and public sectors and clear instructions in the event that one sector requires the intervention of the other sector. This is an important component of the values embedded in concepts such as legal security and rule of law.

Yet another important component of the reproductive function of legal roles are dispute resolution mechanisms, which are an integrative part of law. In cases where the action system is threatened by the system or its basic principles, it is up to the legal system to step in as a corrective mechanism. Dispute resolution is a tangible component of law. Its purpose, and its contribution, just like consensuscreating measures, is to keep the action system together. To a large degree, legal dispute resolution is about establishing the events of a given situation afterwards. Who did what? What did the parties agree on? What happened as a result of the dispute? (Westberg, Peter, 2012 and 2016).

The role of the legal machinery is to establish what has occurred within the affected action system. For this purpose, a special branch of law was created at an early stage to deal with court and official procedures. Within procedural law, rules for evidence constitute an important tool when establishing guilt, responsibility, rights and obligations. It appears, as previously mentioned, that the legal dispute resolution process steps in when other action systems fail to solve their problems. When the social system fails to correct deviations from social norms to such a serious extent that they become matters for the legal rules, the legal machinery steps in. Similarly, the economic system also leads to legal intervention if the actors in the economic system fail to solve their own disputes, as stipulated by the logic of the system. ${ }^{108} \mathrm{~A}$ vast number of legal institutions are concerned with resolving disputes, both in civil and penal law, as well as within the political/ administrative systems. If we focus only on the civil and penal law areas, we see that a little over $3 \%$ of the national budget is devoted to maintaining this part of

108 Cf. Stewart Macauley's research on under which conditions legal means were applied in the business sector, Macauley, Stewart (1963), Macaulay, Stewart et al. (2003), Braucher, Jean et al. (ed.) (2013). 
the legal system. ${ }^{109}$ Of these costs, the main portion, almost two-thirds, is spent on measures to combat crime. ${ }^{110}$

In the final analysis, the answer to questions about why and what kind of norms become legal rules has to do with an action system's reproduction process. Norms that are key to the reproduction of the action system tend to be elevated to legal rules. Hence, life and personal privacy are values that receive strong protection in the legal rules surrounding social life. Similarly, crucial parts of the economic system's game rules are maintained through enforced legal rules on contractual protection, ownership, etc. When a norm becomes a legal rule, it becomes endowed with a higher degree of automaticity and autonomy. As previously mentioned, the norm gains independent value and is applied if for no other reason than because it has become an established rule. This does not mean that people comply or do not comply with the norm simply because it has been given the status of a legal rule. In practice, most norms conform to the logic of the action system, i.e. the spontaneous logic that generates the norm within the action system. The legal perspective steps in when there are deviations from basic norms of importance for the reproduction of the action system. In these situations, law steps in with its dispute resolution function. ${ }^{111}$

The action system in the relevant case has not managed to solve its internal problems, and so the legal system takes over, so to speak, and defines the form of logic that will be applied to resolve the dispute. ${ }^{112}$ This is probably why individual actors are so reluctant to resort to legal dispute resolution procedures. However, this consequence does mean that law, to a degree, has a preventive function. But when the individual actors are forced to resort to legal dispute resolution solutions, they also experience a loss of control over the dispute, and thereby the possibility of affecting the outcome. ${ }^{113}$ It also brings added relevance to the distinction between the law's guiding or governing function, on the one hand, and its dispute resolved function, on the other hand. In its capacity as a governing or steering function, the legal rule is subordinate to the norm that it supports, while when resolving a dispute, the legal rule takes over and forces the norm out. When the social or economic problem becomes a matter for legal resolution, the problem is transformed or escalated to a legal level and is subject to the discursive and logical requirements of that context. ${ }^{114}$

This distinction between the law's governing function and its dispute resolution function explains the paradox of law being both reductive in complexity

109 In 2019, the Ministry of Justice received SEK 46.3 billion, which can be seen in relation to the total national budget amounting to SEK 1,019 billion, see Bill 2018/19:1, Sammanställning av förslag till statens budget för 2019 utvisande 27 olika utgiftsområden.

11028.5 billion, to be more precise.

111 Tyler, Tom R. (1990). Why people obey the law. New Haven, CT: Yale University Press.

112 Teubner, Günther (1987a, p. 7 f). discusses the expropriation of conflict. Norwegian criminologist Nils Christie calls this "conflict as property."

113 Hydén, Håkan (1985, p. 161 ff).

114 Hydén, Håkan and Hydén, Therese (2019) Ch. 2 Mathiesen, Thomas (1986, p. 11 ff). 


\section{Law as a system of norms}

while simultaneously producing complexity. ${ }^{115}$ This aspect of interchangeability is often neglected. In general, there is a tendency to apply a broad brush approach to law, and legal sociological studies are no exception, which can easily lead to the wrong conclusions. One theorist who describes law as reductive in complexity is Niklas Luhmann. ${ }^{116}$ His autopoietic theory focuses on the distinction between legal and non-legal aspects rather than coercion and sanctions. In the legal system, social events gain their meaning through the binary code of law: lawful/ unlawful, legal/non-legal. ${ }^{117}$ According to Luhmann, an event cannot be defined as both legal and non-legal or fall under, or outside, the law. These categories are mutually exclusive, Luhmann argues. ${ }^{118}$

I agree that law can be seen as reductive in relation to the complexity of social events. When the law encodes the social problem and translates it to its own language, this entails by necessity a degree of simplification given all the possible interpretations of the event. Each system interprets and describes the same event in different ways. The patterns according to which society's various subsystems are constructed create different, paradigmatic structures of understanding. Elsewhere, I have expanded on how law, by way of being endowed with the attributes of rules, "slices out" specific parts of reality in a given course of events and bestows upon them relevancy in legal understanding, while other parts are neglected. ${ }^{119}$ In this sense, you could say that law reduces complexity. But this only applies in connection with the social system. The fact of the matter is that when the law steps in and "takes over" and defines the problem according to its own perspective, unsuspected opportunities for elaborating on the issue are revealed. In other words, social complexity is replaced with legal complexity.

One theorist who has realized this and focused on this condition is Norwegian peace and conflict researcher Johan Galtung. In a section in which he discusses institutionalized dispute resolution, Galtung emphasizses that if norms carried instructions regarding what is lawful versus unlawful, there would be no need for dispute resolution mechanisms (Galtung 1967). On the contrary, these are constructed in a way that makes it impossible to predict the outcome of the resolution. If it was possible to predict them, it would also be possible to use them strategically against the court by acting in a way that maximizes the chances of a preferred ruling, according to Galtung (Galtung 1967, p. 61). The court is forced to take action in order to defend itself against being "seen through". Galtung argues that this can be compared to a randomising mechanism that introduces an element of uncertainty or unpredictability. It should be impossible for an outsider to establish a combination of variables on which he can base a prediction of the outcome. This,

115 I have pointed this often-neglected aspect out in a review of Vilhelm Aubert's book Continuity and Development, please see Norwegian Journal “Tidskrift för Samfunnsforskning”, no. 4, 1990, p. $379 \mathrm{ff}$.

116 Luhmann, Niklas (1985).

117 See Luhmann, Niklas (1987a).

118 Cf. King, Michael (1993).

119 Cf. Hydén, Håkan \& Hydén, Therese (2019). 
according to Galtung, is one of several structural characteristics to be found in all conflict resolution mechanisms. How this works can be explained by the judicial method and its method of pros and cons argumentation. By arguing the pros and cons of an issue, the sharp edge on which the decision balances grows blunt and the outcome becomes unpredictable. ${ }^{120}$ If the judicial method of argumentation is extended far enough, a ruling, whether for or against, may be issued in the grounds for decision at a later date. ${ }^{121}$ Although the outcome may not be randomly decided, it may seem that way to the outsider, and not least, unpredictable to the trained lawyer who naturally presumes that legal decisions are based only in the legal sources. ${ }^{122}$ As we have seen, law plays a role not only in maintaining the norms most necessary for the reproduction of the system. The legal system also contributes to strengthening and developing the action system. To a degree, it could be argued that action systems would be unthinkable without support from the norms provided by the legal system. Hence, the market's invisible hand would likely not survive for long without the long arm of the law. As a result of the penetration that market economy has had at various levels, backing these game rules up with legal machinery has almost become a necessary prerequisite. Furthermore, the legal system also provides constructions that would not be possible without legal support. One example is the body of rules surrounding the concept of the legal person and corporate law that has enabled the modern business sector to develop.

In summary, it would seem that action norms that are usually generated within each action system are not subject to legal regulation. Rather, they are instruments for interaction, e.g. within the economic system, or for collective decision-making, e.g. within the political system, in coordination with boundaries for acceptable behaviour, e.g. within the social and, to a degree, the economic systems, which require that the norm becomes legally consolidated. By creating legal rules, we complement the system of norms that the affected action system needs to exist and to develop. If action systems consist of norms, the legal system contributes to strengthening some norms that may become obsessively enforced in the event of disintegration or threat to the reproduction of the system. The legal system can also reduce complexity in each system by introducing its own norms and rules. We have mentioned a few examples previously, and there is good reason to return to Coleman's arguments in connection with discussions on external effects. A social or economic system, according to Coleman, can produce situations in which an action that benefits all involved actors will not come about unless a norm is introduced "externally" which coordinates the actors' actions in accordance with the potentially optimal outcome. Subordinating one's interests to the collective's interests can sometimes provide the best outcome for

120 I have described how this process can be manifest in work life in Hydén, Håkan (1985) ch. 4. See Hyden, Håkan and Hyden, Therese (2019), ch. 2.

121 See Flodgren, Boel (1983).

122 A lawyer or other individual who files court cases presumes that the outcome is never guaranteed. This is part of the professional "image", so to speak, note 127 p. 62 . 
the individual. In such situations, using legal rules is expedient. To put it another way, one condition for an optimal outcome is that the norm is introduced as a legal rule; otherwise, it may not come into play at all. This, to a degree, pertains to legal rules that deal with third parties in civil law. If they are not introduced as mandatory rules, transactions made to serve the public's interest would not be possible. The credit sector and economic expansion would not be possible. ${ }^{123}$ The contract, in its capacity as an instrument for interaction, is surrounded by mandatory rules for partly the same reason.

\subsection{On detecting a norm or system of norms}

Finally, a question that deserves a brief mention is how to go about discovering a norm or system of norms. After all, that is what we need to do if a science of norms is to receive nourishment from empirical studies and develop, which is the next step in its establishment. In legal science, this problem is easily solved. A norm, that is to say a legal rule, has its source in an authoritative legal source of some kind, usually legislation. There is a well-established technique for identifying and implementing legal norms. Other kinds of norms are trickier. Implementation of social and other norms in itself follows the same type of logic, albeit in inverted form, i.e. limitation is based on the identification and recognition of social facts which the actor is able to link to a certain way of acting. Social and other norms are thus applied in reverse order compared to legal norms. In the case of legal norms, the rule and its attributes are used to identify legal facts. Certain legal conditions lead to the implementation of a particular rule, which in turn informs us of the steps of the legal procedure, i.e. how to implement it. In the context of social norms, implementation begins with the actor recognising certain social facts that he or she connects to a certain way of acting. The act, then, is an expression of the actual norm.

This means that the presence of a norm can only be identified by studying the actor's actions. By reconstructing the motives behind the actor's actions using the norm model's dimensions and variables, we are able to systematize knowledge of certain norms and their construction. If we already have knowledge of how to act in certain situations, we can address the norm directly and analyse which $\mathrm{W}$, $\mathrm{K}$ and SP factors within $\mathrm{W}, \mathrm{K}$ and SP are relevant and how they relate to each other. This task should be based in solid social and behavioural scientific analysis. Theoretically, it is conceivable that a single norm could consist of different elements, depending on the actors, who nevertheless act in the same way and who attribute the behaviour to the same norm. But the point is that to the extent that human behaviour exhibits regularities, they can be sourced to the same norm. From a methodological point of view, there is reason to improve our competence

123 This lack of such norms is a common problem in legal systems in the Third World. This, in combination with inadequate systems for registering ownership and security interests, make it impossible to exploit a country's wealth as a basis for economic activity. 
in using the norm model to analyse behaviour. Unfortunately, little research has been carried out in this area. I have previously proposed in this chapter elements that need to be considered vis-à-vis particular social problems and the empirical implications that this would entail. But it is also necessary to follow up on the results of the norm model through empirical studies, thereby laying a systematic foundation for a science of norms. Some efforts toward this can already be seen in research carried out by the sociology of law department, or studies inspired by their research, some of which have been mentioned previously. However, more, and more systematic, work is needed, not least using strategic normative thinking (SNT). In sociological discussions, some voices raise concerns that such a scientific approach is doomed to failure and that it should not be recommended in any case, given other failed attempts to establish major theories. ${ }^{124}$ For this reason and for reasons of clarification, I would like to state that my ambition with the normscientific approach is to lay the foundation for a synthesizing science that is able to take advantage of the fragmentary elements of knowledge about nature and society that we have gathered in our obsession with specialization over the last hundred years, combining them in new ways that help us understand the times we are living in.

This is also why I choose norms as the object of study and intersection and not, for example, power relations. ${ }^{125} \mathrm{I}$ have previously presented my reasons for this in this book, and particularly in my concluding "pleading". This may seem like a pretentious task. Thus, a couple of explanatory remarks are needed. I do not claim to have created a major theory of norms, nor is that my ambition in the future. The norm model is an instrument of analysis and a tool for collecting and systematizing relevant information to help us understand human action, both individually and collectively. To the extent that theories of norms, in extension, result from this, this can never be the work of one person. This requires teamwork, not least due to the fragmented nature of the knowledge fed into the norm model and the synthesizing approach.

One question that remains unanswered is: What happens to law in the event that reproduction of the relevant system is threatened? What happens to law if the system is no longer reproduced, and what role does law play in that situation? These are questions that we shall revisit in Chapter 6 in connection with a discussion on a theory of legal and societal progress, where we shall put the discussion on societal development in Chapter $l$ in the context of our conclusions regarding normative and legal developments from the following chapters. First, however, we need to gain an understanding of developments in law over time and also discuss a particular kind of law that can be related to the dissolution or disintegration of transitional societies.

124 Mathiesen, Thomas (1998).

125 Norm analysis requires a number of different scientific approaches and perspectives. What becomes decisive in the particular case is determined by the knowledge interest and the context surrounding the phenomenon being studied. 


\section{The evolution of norms and law}

\subsection{The evolution of law in the market economy}

\subsubsection{Legal cultures that have shaped Western law}

In this chapter, we will link the evolution of norms, and thereby law, to the course of events that together make up an epoch. Our main focus is the law of the millennia-old market economy. In this context, we are, in fact, dealing with the establishment of a legal culture. Within this context, we will analyse the various manifestations of law that emerge in the wake of the different eras of the market economy, as further described in Chapter 1, i.e. merchant capitalism, the trading houses era, the machine age and the industrial age. Furthermore, with a particular focus on the industrial age, we shall illustrate how law changes during the course of an epoch and how it develops from minimalism to maximalism. We will do so by tracing the evolution of law through the various phases of an era: the technical, social, economic and political phases. This perspective allows us to categorize two different kinds of law. But we begin by painting a very basic illustration of the background behind the legal culture of the market economy, which has shaped how we perceive Western law. ${ }^{1}$

He takes his point of departure in the premise that law, in common with society in general, takes on different characteristic traits during the course of the eras that comprise an epoch. An epoch consists of, and is maintained, by a fundamental idea which acts as a normative core around which the social system is constructed. The emergence of a new epoch can be said to be a reaction to a previous epoch. Christianity was a reaction to the Roman Empire. The Roman Empire reached its political apex during the reign of Julius Caesar, between 23 $\mathrm{BC}$ and $\mathrm{AD} 14 .^{2}$ Under Caesar's rule, this political empire that stretched from the

1 Harold J. Berman (1983) wrote a classic work consisting of approximately 600 pages on the subject in which he discusses the creation of Western legal tradition. With regard to European conditions, see Anners, Erik (1990), section 1 and 2, and Munktell, Henrik (1944) for Swedish conditions.

2 Gibbon, Edward. (1990). The decline and fall of the Roman empire. Vol. 1, 2. Chicago: Encyclopædia Britannica.

DOI: $10.4324 / 9781003241928-5$ 
Near East to the Atlantic coast in the west and from the Sahara to the south of the Frisian Islands in the north, enjoyed full economic/material integration. ${ }^{3}$ Caesar had internationalized and created the Roman Empire, the European Union of their times. Caesar also introduced a new symbol of value in the form of gold coins to promote international trade. But while the physical world was being united, the spiritual world was completely divided. ${ }^{4}$ The arrival of Jesus, then, represents a product of his times. Probably, as Anders Ewerman argues, there was a vast, pent-up need for spiritual unity and fellowship. Christianity became a symbol for this psychological need and took its first hesitant steps around AD 45 toward "spiritually uniting" the Roman Empire. The Roman Empire was divided into individual regional missions. Many years later, Sweden would also be drawn into this process.

The Christian Age was a purely religious culture and replaced a former millennia-old culture based on material values and physical structures. A culture of canonical law began to emerge. It was a secular branch of a Christian legal order. Its legal contents partly inspired by Greek legal culture, and its form by Roman legal culture. ${ }^{5}$ Greek legal culture contributed philosophical studies of the theoretical, fundamental problems of law and justice. The Romans contributed practical, technical solutions that, in turn, were influenced by Greek ideas. Each culture seems to pass on their legacy to the following culture. This is partly due to the two cultures coinciding with each other for a period of time, thereby automatically, so to speak, influencing each other, and partly as a result of the ideological parallels shared by the spiritual and logical cultures, on the one hand, and between the material and physically oriented cultures, on the other. This explains, for example, how Greek legal culture came to influence not only Roman legal culture but also canonical legal culture.

The Greek legal system also had many spiritual aspects. The most significant element of classical Greece's jurisprudential legacy is the concept of natural law. ${ }^{6}$ Natural law was understood to be eternal and immutable, a higher law than the laws of human societies. Three different concepts of natural law emerged in Greek law as early as AD 400 and continue to dominate European jurisprudential discussions to this day. In this arena, the arguments for and against the theory of natural law were sharpened and honed. This discussion was continued in Greek legal culture by the Sophists in 400 BC, during classical Greece's equivalent to the Enlightenment. The Sophists went a step further and, based in empirical observations, wondered what a natural legal order might look like. The Sophists claimed that the differences in status and general conditions that exist in human societies are nowhere to be found in nature; this would mean that the natural

3 Ewerman, Anders (1996, p. 51) et seq.

4 Kinder, Hermann and Hilgemann, Werner. (1974-1978). The Penguin atlas of world history. Harmondsworth: Penguin.

5 Berman, Harold J. (1983, p. 132) Seq 253 et seq.

6 Strömholm, Stig (1991, p. 37). 
order would represent true freedom and equality. There were also theories at the time, which resurface at a much later point in history, that social order was based in a contract between humans. Another question that norm-scientific research inherited from the Sophists is the gap between law and morality and between power and law.

The most important contribution to Greek legal culture, however, came from Plato's most renowned student, Aristotle, around $300 \mathrm{AD}$. His legacy to the world was an entire philosophical tradition which focuses on social law from a legal perspective. Aristotle viewed law as passionless reason, the preferred alternative in comparison with dictatorships and popular assemblies. Toward the end of the classical Greek epoch, yet another philosophy emerged in the form of stoicism. ${ }^{7}$ While Aristotle's contribution consisted mainly of tools and methods for analysing legal positivism, stoicism focused on the ethical contents of law. A moderate and rational life was seen as the greatest good. That way of life was virtuous. The Stoicists promoted a cosmopolitan state ideal and based their understanding of what constituted good law in human nature. All events were deemed to be determined by divine providence and inescapable laws.

The emergence of stoicism coincided with the dissolution of classical Greek culture. In $300 \mathrm{BC}$, Greece was incorporated into the new global order, Macedonia, by Alexander the Great. When the Macedonian Empire fell, they were incorporated, together with the Greek petty states, into the new world order, the Roman Empire. Stig Strömholm describes this change as a revolutionary upheaval. Having been the centre of the universe to suddenly being reduced to insignificant parts of an impersonal kingdom ruled by a distant king and his officials was as great an upheaval as the natural science revolution that led to the realization that the sun was, in fact, the centre of our planetary system - not the Earth. ${ }^{8}$

The first advanced legal culture developed in Greece. We see that, as it approached its dissolution, perceptions based in natural law and ethics had begun to emerge. At this point, the Roman Empire, and thereby Roman legal culture, had already begun to have an influence. There was an overlap, here, although not a particularly problematic one, since the two cultures originally developed in geographic separation, until the Roman Empire took over and became culturally dominant. The Romans inherited a culture of philosophical wisdom and intellectual progress from the Greeks. The Greeks believed in the Platonic notion that only he who seeks wisdom, philosophos, is capable of ruling. ${ }^{9}$ Rome, however, came to be dominated by a class of lawyers and officials. Roman legal culture had a highly practical approach and construction. This meant that it learned early on to distinguish between politics and law. ${ }^{10}$ However, the Romans did not use legal

7 Inwood, B. (2018). Stoicism [Elektronisk resurs]. Oxford: Oxford University Press.

8 Strömholm, Stig (1991, p. 44).

9 Berman, Harold J. (1983, p. 135).

10 Strömholm, Stig (1991, p. 47). 
precedence to exemplify legal principles or to establish a more coherent legal system. ${ }^{11}$ They did not believe that the legal process needed to be supplemented with a legal theoretical superstructure. In this sense, Roman legal culture was both pragmatic and goal-oriented. The Roman contribution to the evolution of legal method consisted of their ability to specifically separate legal aspects from irrelevant aspects, thereby establishing more general arguments to support their decisions rather than strictly legal arguments. ${ }^{12}$ This method, which allowed them to isolate and change the nature of commonly recurring conflicts by "setting them aside", so to speak, and subject them to legal conflict resolution, was probably seen as a way of maintaining a peaceful society.

Very little remains of the extensive body of legal literature created during the millennium before the final collapse of the Roman Empire in AD 400. However, there is little doubt that legal developments in the centuries shortly before and after the birth of Christ contributed to establishing legal practice as a specific social activity. Our knowledge of Roman law is mainly based on the collection of texts ordered by the Eastern Roman Emperor Justinian in AD 500. This vast undertaking, the Corpus juris civilis, carried out between AD 529 and 534, also spelt the end of the evolution of Roman law and Roman legal culture. By this time, the Western Roman Empire had collapsed. Anders Ewerman describes the events as follows: ${ }^{13}$

The Roman Empire entered its reductionist period during the lst century of the Common Era. This vast empire was divided into provinces, economic units similar to nation states, that began to emerge in Europe in the 16th century. To keep the empire united politically and militarily, an extensive road network with frequent rest areas was constructed, with Rome as its epicentre. They also built harbours and shipyards that were linked via maritime routes, and erected lighthouses along the coastline. River traffic routes were supplemented with canals. The small-scale craftsmanship of the holistic period was out-competed by the international trading of the reductionist period under the rule of powerful trading companies. Governments began to develop an interest in large-scale international trading, and local trading began to suffer. To meet the needs of the expanding armies and bureaucracy, privately owned one-man companies were outcompeted in the 1st century of the Common Era by large, state-owned workshops - fabricae based in wage labour. Unemployment and insecurity followed in the wake of the ruination of local, urban business structures. Small-scale craftsmen and tradesmen, who had once laid the foundation of the Roman Empire, were now completely proletarianized by the state. In the year AD 200, they began

11 Berman, Harold J. (1983, p. 139).

12 Tamm, Ditlev. (1996). Romersk rätt och europeisk rättsutveckling. 2nd ed. Stockholm: Nerenius \& Santérus.

13 Ewerman, Anders (1996, p. 52) et seq. 
to leave the cities and relocate to the estates of the land-owning aristocracy, where, as an unpropertied class, they were able to escape the tax authorities' abuse; they were free, but dependent on the landowners. No longer were they individual subjects of taxation, the land being the object of taxation. They also found refuge from growing crime and lawlessness within the refuge of the estate. Subsistence economy was introduced.

This resulted in the Roman provinces growing increasingly independent and selfsufficient. They sold their surplus to the "national province" of Italy, which led to a drop in land prices and agricultural land falling into disuse. This continued, and by the 3rd century, the provinces had become fully self-sufficient with regard to food and crafts, which resulted in the national province's farmers and craftsmen losing their outlet markets. ${ }^{14}$

Meanwhile, Christianity was gaining ground rapidly. By AD 324, the number of Christian followers had grown to such an extent that the Roman emperor Constantine the Great, who, during his regency between AD 324 and 337 fulfilled the absolutist Roman state project, decided to try to gain some form of control over Christianity by endowing it with a privileged status. A power struggle then ensued between the Western and Eastern factions of the Church to establish the dominant, dogmatic world view - the Roman Catholic Church or the Greek Orthodox Church. In 330, Emperor Constantine founded a new capital city, Constantinople, which would become the high seat of Christianity. Half a century later, Christianity was elevated to the status of state religion, often regarded as one of the most significant revolutions, ${ }^{15}$ after which the Church began to expand culturally and geographically. Additionally, the Roman Empire was further divided up between Theodosius the Great's sons into the Eastern and Western Roman empires.

The Roman Empire did not only face internal threats. It was also subject to countless conquest attempts and attacks from basically every direction and tribe. ${ }^{16}$ The fate of the Western Roman Empire was finally sealed by the Germanic Langobards, who founded their first empire in the 6th century along the Danube, and their second empire, the Kingdom of Lombardy, in Italy in AD 568. They abolished the Roman system of administration and replaced it with the Germanic system. ${ }^{17}$ The Catholic Church thereby became the foremost unifying power structure in Europe and continued to grow in strength until it reached its apex during the papacy of Pope Leo IX (1049-1054). ${ }^{18}$ The Eastern Roman Empire

14 Kinder and Hilgemann (1987, p. 105).

15 The British historian Edward Gibbon, who lived in the 18th century. See Gibbon, Edward (1999).

16 Kinder and Hilgemann (1987, p. 102) et seq.

17 Kinder and Hilgemann (1987, p. 119).

18 Bokenkotter, Thomas S. (2004). A concise history of the Catholic Church [Elektronisk resurs]. Rev. and expanded ed. New York: Doubleday. 
remained in power until 1453, but had less influence on Western Europe's evolution than the Western Roman Empire.

In the Western Roman Empire, the evolution of Roman law continued almost wholly without any knowledge of Justinian law. This was when, "Vulgar Law", as it is often referred to, emerged. ${ }^{19}$ Vulgar law was a distorted version of classical Roman law and resulted from the division of the Roman Empire into provinces, leading to the demise of expert legal tradition. This vulgarized form of law was a part of imperial law since it was no longer administered by legal experts, but rather by officials with standard, non-specialized education. Furthermore, inadequate legal skills in general and a lack of understanding of the substantive contents of law led to the legal system, handed down through generations, being simplified and laymen implementing their interpretations of legislation. ${ }^{20}$

The Roman Empire's legal legacy to the world - aside from the treasure trove of legal experience provided by the Corpus juris civilis - consists largely of the private aspects of law and legal concepts that we continue to use to describe the individual's legal standing, e.g. contracts, property rights, wills, marriages, rights and obligations. This component of Roman legal culture outlived the empire itself and was revived in the early stages of the next millennium through studies of Roman legal sources at the University of Bologna toward the end of the lst millennium. This led to a new phase in Roman legal history. But before this would happen, spiritually based canonical legal culture needed to be established, mature, die and make way for the next materialistic epoch. The Christian Age, in common with the market economy can be divided into four separate eras, as shown in Figure 5.14.

During the migration era, the Roman bishop's influence grew as a result of the role that Pope Leo I (440-461) had played in the resistance against the Berbers. ${ }^{21}$ By the end of the 5 th century, the Roman bishop's rulership over the Western Church had become generally recognized. In the 6th century, the Pope became dependent on the East Goths and the Eastern Roman emperor. Gregorius I (590-604) strengthened the pope's power and laid the foundation for the papacy's growing influence in worldly matters by arranging to have Church property administrated in Italy. ${ }^{22}$ When the Langobards, a Germanic tribe, later came to pose a threat to the power of the papacy, the pope sought the protection of Pepin, king of the Franks. In the 8th century, this led to the constitution of the so-called Papal State, created by merging regions and thereby laying the foundation for the Carolingian Age. Pope Nicholas I (858-867) claimed a leading position in the West and demanded rulership over both the State and the Church. In 1054, the Great Schism led to the final separation of the papacy and

19 Tamm, Ditlev (1998, p. 242) et seq.

20 Ibid, p. 243.

21 Barraclough, Geoffrey. (1968). The medieval papacy. London: Thames and Hudson.

22 Collins, Roger. (1999). Early medieval Europe 300-1000. 2nd ed. New York: St. Martin's Press. 


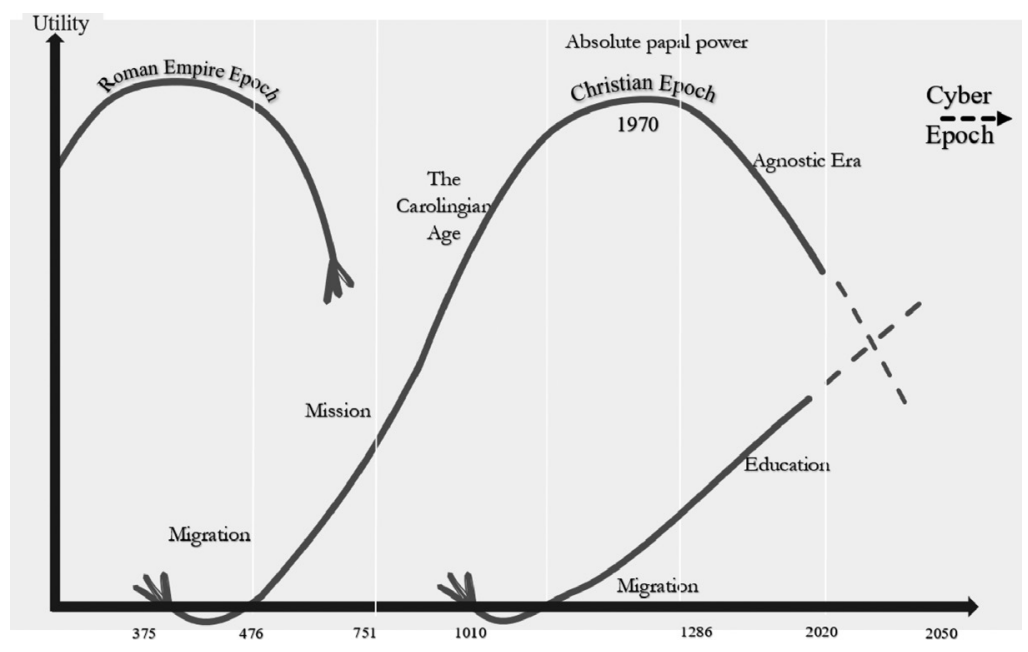

Figure 5.14 Four separate eras of societal development

Constantinople. The first power struggle between the papacy and the imperial power occurred during the reign of Pope Gregory VII and the attempt to establish a universal theocracy with the pope as sovereign ruler. This idea shaped papal politics for the next several hundred years and grew in strength in the 12th century, when absolute papal power was introduced. The Crusades gave the papacy a dominant position in the West. As the German imperial power began to lose ground, the papacy achieved its most powerful position under the rulership of Pope Innocent III (1198-1216). In the 13th century, the papacy was subject to a number of attacks by the empirical power, which gradually weakened and decreased the papacy's power. The defeat of Pope Boniface VIII (1294-1303) by the French emperor (Philip the Fair) led to the papacy becoming dependent on the French Crown and the relocation of Curia (the highest administrative authority) to Avignon.

The popes of Avignon focused on concentrating centralized rulership over the Church to the Curia. To that end, they developed a tax system that, from the perspective of the clergy, escalated into little more than blackmail. For a period thereafter, the papacy became the leading financial power in Europe. Pitted against this system, however, was growing opposition, initially in England with Germany following in their footsteps, which badly diminished the influence of the papacy in the 1300s. Meanwhile, developments in Italy threatened to deprive the papacy of the Papal State, and Gregorius XI (1370-1378) was forced to return to Rome in 1377. After his death, he was succeeded by two popes; one in Avignon and one in Rome. This led to the "Great Schism" (1378-1417) which greatly weakened the papacy's influence. By the 15th century, the papacy had fallen into moral and religious decay. 
With regard to legal developments during the Christian Age, the following can be said: ${ }^{23}$ Canon law is a legal culture based primarily in written tradition. The clergy were a literate group. By the year 100, the Christian parishes had already begun to convene and make joint decisions in administrative matters, so-called "canons", hence "canon law". ${ }^{24}$ In time, many decisions were made by larger ecclesiastical divisions and by the papacy, so-called decrees, which were considered legally binding. This led to a tradition of written law rather than orally communicated customary law. The Catholic Church's legal system, based on "the Rule of the Holy Benedict", played a prominent role. Although canon law initially consisted of written law, it was not compiled into a comprehensive corpus until the 12th century. The first authoritative collection of sources was produced around 1140 in Bologna, influenced by the academic studies of Roman law being pursued there. The first person to begin recording canon law in writing was a monk by the name of Gratian. He based his collection of texts and sources on papal decrees, or Decretum Gratiani. In doing so, Gratian not only compiled and systemized the texts, he also adopted a scholastic approach and reworked the texts into independent legal clauses, distinciones; legal precedents, causae; and legal problems, questiones. ${ }^{25}$ Gratian's research gave birth to a school of thought known as Decretalism, cf. the glossators, which produced a rich corpus of literature on canon law. Due to the powerful influence of the papacy, canon law came to be fashioned after papal decrees. In 1234, these were collected in Liber Extra and supplemented with Liber Sextus in 1298. Finally, in 1317, Bonifacius VIII's later decrees and those of his successors, Clemens V (1305-1314), were compiled under the title Clementinae. Starting in 1580, these four sources were continuously compiled and published as a counterpart to Corpus Juris Civilis under the official title Corpus Juris Canonici.

In the High Middle Ages, the Church attempted to establish a universal Christian State under papal rulership. ${ }^{26}$ Canon law, in this context, became an important tool for consolidating and developing the Church's power and for reshaping the structure of society in accordance with the Church's wishes. To begin with, canon law, which was at its core an administrative legal system, meant that the Church was incomparably better at managing and profiting economically from their property than the worldly powers with similar resources. ${ }^{27}$ Furthermore, as Anners argues, by developing institutions such as the testament and donations, in conjunction with their capacity to exert religious pressure, they amassed great wealth through voluntary contributions to the Church. According to Anners, their tactic was to reshape Roman testament and will law to more closely reflect

23 Latourette, Kenneth Scott. (1975). A history of Christianity. Vol. 1, to A.D. 1500. San Francisco: Harper \& Row.

24 Anners, Erik (1990), del 1, p. 140.

25 Ibid, p. 141 et seq.

26 Latourette, Kenneth Scott. (1975). A history of Christianity. Vol. 1, to A.D. 1500. San Francisco: Harper \& Row.

27 Ibid. 
the interests of the Church. This, then, weakened the strict, formal requirements of Roman law. For a will to become valid, all that was required was that it was drawn up in the presence of a parish priest, a notary and two witnesses. A will written and signed by a testator was also considered valid, without having to fulfil other formal requirements. The Church also changed the law issued by Emperor Justinian that regulated the legal portion for beneficiaries, descendants and paternal siblings to a portion rendered unto Christ - that is to say the Church. This principle can be traced back to the early Church Father Augustinus, who decided that every will should allot a child's portion to Christ. These rules were incorporated into a number of Western European legal sources, including Swedish gothic law.

At the social level, canon law represented an ambition to reshape society and to promote the family nucleus as the primary social unit, rather than lineage. The clan societies did not share the same socio-psychological narrative in which Church ideals were based, where all people were seen as brothers and sisters under the guidance of a celestial father. ${ }^{28}$ From a perspective of power, it could be said that the Church wanted to continue to divide and isolate people. ${ }^{29}$ Another part of this process of social reconstruction that followed in the wake of canonical legal culture was the introduction of strict penal laws that prohibited marital infidelity. With reference to Mosaic penal law, the Church created a system of crimes of morality that would play a major role for over 500 years, both in court practice and in the daily lives of ordinary people. The Church also gained far-reaching control over matrimonial law for the same purpose. It also intervened in worldly legal affairs. By invoking moral theological principles, contracts made under oath, as well as usury and interest, forbidden by canon law, became matters for the Church court. Sexuality and private autonomy also fell under legal regulation.

One of the characteristics we have inherited from canon law is the concept of guilt in penal law and the accusatory principle, i.e. two-party proceedings, within procedural law. Canon law, then, had a major impact throughout all Europe, including Sweden, evidenced, for example, by the Church's Code of Laws. Old Vastgota law begins with the statement, "Christ is the Law". The proliferation and impact of canon law were probably the result of an ever-prevalent clergy that monitored the people and even held household hearings, an institution particular to the Swedish Church right up until the 19th century. The clergy was a unified, ideological power and was strictly organized within a well-structured system of officials and management. Although the spiritual world was united, the economic-material division had reached full bloom. This likely led to a large pent-up need among people to find a common, materialistic grounding. In other words, approximately 1,000 years later, the time had become ripe for the pendulum to swing back toward physical/material values. The market became a symbol for this materialistic need. Currency regained its status as a bearer of value

29 Parallels can be drawn here to the individualization ushered in by post-modernism. 
and replaced the Bible as a unifying entity. Merchants began their arduous trek toward materially uniting the Roman Catholic empire. The dismantling of the popes' worldly power began in 1309 when the French king forced them to move to Avignon, where they remained until 1377. During this period, the papal court and church administration had expanded to such an extent that the costs had become a burden for the Church. Ewerman summarizes this development as: ${ }^{30}$

Corruption and nepotism - the distribution of official positions to the Pope's relatives - were prevalent. To finance the excesses of papal bureaucracy, new fees were invented in a never-ending stream - spolia, the confiscation of the priests' estate (inheritance tax); annates, annual fees for offices, chrismation and pallium fees, i.e., fees for the distribution of official positions (pallium is a garment used by bishops); commissions for giving away official positions; indulgence, waiving penalties (similar to waiving parking fines for incomprehensible parking rules).

Following their relocation to Avignon, the absolute authority of the Church was in tatters. In the early 16th century, the Roman Catholic empire was divided into a southern and a northern branch under the papacy of Pope Leo X, who reigned between 1513 and $1521 .{ }^{31}$ This meant a definitive victory for politics over religion. The Reformation meant that religion had once again become subordinate to the State. ${ }^{32}$ In Sweden, this was carried out by Gustav Vasa, who, on the socalled Reformation Council Day in Västerås in 1527, initiated a process whereby church leadership became the dominion of worldly powers, a project that was successfully implemented by 1540 . At the same time, the "Church Reduction" of Gustav I was implemented, whereby the surplus assets of the Church were remitted to the Crown, which also claimed two-thirds of Church tithes. ${ }^{33}$ In Europe, Martin Luther was busy nailing his thesis to a castle door in 1517, a political manifesto that came to be of major importance for the state when subordinating religion. Calvinism also played a pivotal role in the formation of Western law, especially in England and the United States. ${ }^{34}$ Paradoxically, the Reformation led to biblical law increasing in influence. ${ }^{35}$ The Reformation had attempted to do away with all so-called papal inventions, and therefore, priests naturally tended to react by invoking the clear and pure words of the Bible. This led to Mosaic law gaining influence in the actual application of law. In the 16th century, the priesthood pursued a consistent effort to incorporate the principles of Mosaic law into

30 Ewerman, Anders (1996, p. 58) et seq. See also Kinder och Hilgemann (1987, p. 181).

31 McBrien, Richard P. (red.). (1995). The Harper Collins encyclopedia of Catholicism. San Francisco: Harper San Francisco.

32 Høiris, Ole and Ingesman, Per (ed.). (2017). The Reformation: 1500-talets kulturrevolution. Bind 1 Europa. Aarhus: Aarhus University Press.

33 Neuhaus, Sinikka. (2005). Reformationen. Signums svenska kulturbistoria. Renässansen. pp. 181-219, 474-475, 493-495.

34 Berman, Harold J. (1983, p. 30).

35 See Munktell, Henrik (1944, p. 201) et seq. 
Swedish law. ${ }^{36}$ They failed during Gustav Vasa's reign, but numerous elements of Mosaic law were introduced in the coming decades. ${ }^{37}$

The heyday of canon law, however, had long since passed. We see that canon law still lags on during the first centuries during which the law of the market economy gained strength, similar to how Roman law continued to dominate and live on for many years, until canonical law emerged in the Middle Ages as the dominant force, as noted above. We shall now take a closer look at the construction of the market economy as legal culture.

\subsubsection{The market economy as legal culture}

The Western European market economy emerged in the early 11 th century and is likely to peak in the early 2000s. Europe, as Anders Ewerman points out, is about to become physically united within the European Union borders, borders which have now reached the borders of the "Catholic Union", nearly 1,000 years ago. ${ }^{38}$ Ewerman continues:

If we divide the human need for satisfaction into two parts, an internal and external part, and call the internal need (religious) "faith" and the external need "material" (logical, rational, scientific, technical), we could say that internal (non-material) welfare was superordinate to external (material) welfare, starting around the fall of the Western Roman Empire in AD 476 until the middle of the 11 th century, only to reverse direction at that point. Today, all Europeans have the same sort of material claims, they are materially united, while simultaneously being religiously divided. However, the opposite applied 1,000 years ago.

To satisfy material demands, we need goods. In agrarian societies, bartering was necessary to survive. This was suppressed for several reasons during the canonical epoch. Market-based economic principles ran contrary to religious doctrine. We have previously noted that interest, for example, was forbidden under canon law. But even more important was the social change that occurred through the resurrection of urban life. "As uncertain and insecure as city life had become during the decline of the Roman Empire, so did rural life become during the decline of Catholic rulership, which meant that people began to return to the cities", Ewerman writes. ${ }^{39}$

36 Fundamentalism, the equivalent of Islam's Sharia law, could be noted here.

37 As late as the early 17th century, there were still legal decrees in force that had been created 2,000 years earlier. The wording of Charles IX ratification of Kristoffer's national law in 1608 refers directly to the law of God. As an example of Mosaic law statutes from this period, the punishment for profane language was death by stoning; a person who cursed his father or mother "would die a death", etc.

38 Ewerman, Anders (1996, p. 59) et seq.

39 Ewerman, Anders (1996, p. 60) et seq. 
When merchant capitalism (1010-1343) initially introduced the market economy in the 1lth century, the religious era had reached its apex and was now becoming characterized by politics. Psychologically, it dominated over merchant capitalism, which was based on the technological revolution brought on by hydropower and textiles. However, merchant capitalism also led to the emergence of an epoch which was based around the production, distribution and consumption of goods. In Scandinavia, this development was probably based in Viking traditions, where trade relationships and marketing practices were common. The influence of the Vikings in developing the cities as centres of trade and production and the seat of administrative power was a highly significant factor for the birth of the free market society. ${ }^{40}$

The production of new goods, and the ensuing technological progress, became the main driving force during this epoch. ${ }^{41}$ The leaps and bounds in the market economy are closely tied to the invention of, in Ewerman's words, new core technologies and new ways of producing goods. ${ }^{42}$ The second leap of the free market economy, the second era, the era of trading houses (1286-1510), was characterized by a social revolution based on urban liberation from feudal society. During this era, the system of social norms dominated politics. During the trading houses era, the necessary organizational conditions were laid for the foundation of the capitalist system that continues to this day. The machine age (1447-1776), the third leap, entailed an economic revival. This is when the economic principles underlying the capitalist system were established..$^{43}$ Administrative structures were established during the machine age, which, in turn, laid the groundwork for the industrial revolution of the 18th century. It was during this time that the long-established, predominant idea in Western Europe became articulated as ideology: mercantilism. ${ }^{44}$ The Physiocrats, a group of politicians and political economists in France, presented the first scientifically based theory of political economy in the late 18th century, which gave birth to the term "Mercantilism", from the Latin word mercari, or "to trade". The predecessors who had prepared the way for mercantilism had neglected to include the agricultural sector. Sweden was "mercantalized" at an early stage, under the rule of Axel Oxenstjerna (1583-1654). One of the fundamental notions of mercantilism was the idea that

40 Hall, Richard. (2007). Exploring the world of the Vikings. London: Thames \& Hudson.

41 Stuart, Gilbert. (1778). A view of society in Europe in its progress from rudeness to refinement, or, Inquiries concerning the history of law, government, and manners... [Electronic resource]. Edinburgh: Printed for J. Bell and J. Murray.

42 Landes, David S. (1997). The Unbound Prometheus: Technological change and industrial development in Western Europe from 1750 to the present. Cambridge: Cambridge University Press.

43 Kneidel, Gregory. (2015). John Donne er early modern legal culture: the end of equity in the Satyres. Pittsburgh, PA: Duquesne University Press.

44 Magnusson, Lars. (1994). Mercantilism [Electronic resource] the shaping of an economic language. London: Routledge. 
the nation-state should be an economic unit. ${ }^{45}$ Therefore, great consideration was given to the state, which regulated the right of production through the guilds. It was only when Gustav III and the political economist Chydenius, active in Sweden at the time, arrived on the scene that mercantilism had to make way for the Physiocrats' liberal ideals and their ${ }^{46}$ condemnations of state intervention in economic life. ${ }^{47}$

The guild system was based on small-scale handicraft production..$^{48}$ The invention of the steam engine and other power sources paved the way for the industrial revolution, and large-scale production now became possible. ${ }^{49}$ As people learned how to produce power for specific purposes, the possibilities for production became endless. This opened up mass production, which, in turn, required mass consumption, as Henry Ford, the father of mass-produced vehicles, realized at an early stage. It could therefore be said that the regulation of consumption, or regulation based in consumer needs, was one of the industrial age's key contributions to the legal culture of the market economy.

In using a map as a metaphor to demonstrate the lack of concordance between law in books and in reality, legal sociologist Boaventura de Sousa Santos also demonstrates how scale size when choosing an appropriate map is a factor. ${ }^{50}$ This also applies when describing the evolution of law. How big does the map need to be? Furthermore, the evolution of law has to do with both form and content. I have previously used the term "legal culture" to describe common aspects of an entire epoch's legal rules. In the market economy, this culture is tied to the regulation of production, distribution and the consumption of goods, with varying emphasis on each aspect at different stages of the epoch. One might compare it to a game in which some rules evolve gradually as required during the course of the game.

Laws that regulated the purchase and selling of goods emerged in the early stages of merchant capitalism. The simple, legal principles underlying the exchange of goods meant that the basic rules of the game were obvious. As

45 Heckscher, Eli F. (1931). Merkantilismen: ett led i den ekonomiska politikens historia. Stockholm: Norstedt, Magnusson, Lars (ed.). (1995). Mercantilism. London: Routledge.

46 Herlitz, Lars, Fysiokratismen I svensk tappning 1767-1770. http://hdl.handle.net/ $2077 / 54081$.

47 Two of the most outspoken critics of the guild system were Jean-Jacques Rousseau and Adam Smith, and all over Europe a tendency grew rapidly to oppose government control over trading in favour of laissez-faire free market systems, and this eventually made its way into the political and legal systems. Smith, Adam and Garnier Germain (1828). An inquiry into the nature and causes of the wealth of nations... [Electronic resource]: with a life of the author: also, a view of the doctrine of Smith. Edinburgh: Printed for T. Nelson and P. Brown.

48 Epstein, S.R. \& Prak, Maarten (ed.). (2008). Guilds, innovation and the European economy, 1400-1800 [Electronic resource]. Cambridge: Cambridge University Press.

49 Braudel, Fernand. (1982). Civilization and capitalism: 15th-18th century. Vol. 2, The wheels of commerce. London: Collins.

50 de Sousa Santos, Boaventura (1995, p. 459) et seq. de Sousa Santos writes on the theme "Law: A map of misreading". 
mentioned previously, there was a feverish swarm of legal activity in the University of Bologna from the late 1000s onward. As a result of science flourishing in Northern Italy in general, a jurisprudential school of thought had emerged and busied itself with adapting the texts in Corpus Juris Civilis, primarily the preserved texts of the Digesta. ${ }^{51}$ This was not, however, done in the name of advancing legal education and knowledge, let alone to adapt laws to contemporary social needs. ${ }^{52}$ Rather, this work was inspired by contemporary understandings of knowledge, scholasticism and the ancient scriptures that had absolute authority. ${ }^{53}$. These ancient scriptures contained the actual truth about reality. The only problem was understanding what the texts meant. Special lectures were held on the Digesta, its codices and institutions. In time, a system of annotations - the so-called glossaries, hence the title glossator - became appended to the body of law and included explanations, references and examinations of the relationship between dichotomic aspects of the law. ${ }^{54}$ These explanations were inserted as annotations and remarks in the margins of a work. Irnerius is, perhaps, the most renowned glossator. ${ }^{55}$

This adaption of Roman law during the medieval ages became the foundation for legal science, not only in Italy but also in much of Europe. Sweden had not produced enough legal scholars to maintain their own legal science; instead, lawyers from Sweden travelled to Bologna to study, a city that was teaming with thousands of legal students at the time. ${ }^{56}$ This lay the foundation for Ius commune, common or general law, as this adaption of the code of Justinian I, as practised in Bologna was called. This became the basis for the evolution of law across Europe. At this time, Roman law was subject to changes and adaptions to local legal situations around Europe until it became more or less standardized by the major legal codifications of the 19th century, such as the Code Civil in 1804, and later, the Bürgerlisches Gesetzbuch, in 1896.

51 The Corpus Juris (or Iuris) Civilis ("Body of Civil Law") is the modern title for a collection of fundamental jurisprudential works issued between 529 and 534 by order of Eastern Roman Emperor Justinian I. It had three parts: the Code (Codex) is a compilation, by selection and extraction, of imperial enactments to date; the Digest or Pandects (the Latin title contains both Digesta and Pandectae) is an encyclopedia composed of mostly brief extracts from the writings of Roman jurists; and the Institutes (Institutiones) is a student textbook, mainly introducing the Code, although it has important conceptual elements that are less developed in the Code and the Digest.

52 Anners, Erik (1990), Section 1, p. 126 f, Johnston, David (ed.) (2015). The Cambridge companion to Roman law. Cambridge: Cambridge University Press.

53 Verger, Jacques. (2007). The universities and scholasticism. In The New Cambridge medieval history: volume 5 c. 1198-1300. Cambridge: Cambridge University Press. Scholasticism is a method of critical thought which dominated teaching by the academics of medieval universities in Europe from about 1100 to 1700, and a programme of employing that method in articulating and defending dogma in an increasingly pluralistic context.

54 The scholars of the 11th- and 12th-century legal schools in Italy, France and Germany are identified as glossators in a specific sense. They studied Roman law based on the Digesta.

55 For more on this, please see Ditlev Tamm (1998, p. 259) et seq.

56 Karonen, Petri et al. (eds.) (2017). 
In Sweden, there are still traces of 13th-century mercantile laws, including the "Köpmålabalk" which contains special regulations for how to purchase chattel, livestock, clothes and gold and silver. There were also special rules for the purchase of wax, salt, incense and items that were susceptible to forgery. Two local men were to resolve any dispute. If an individual had purchased an item from a farmer's wife, the value of which, unknown to him, exceeded one Swedish Öre, the farmer had the right to revoke the agreement. Finally, we should mention the regulation of pledges and guarantees that made more advanced forms of trading possible. ${ }^{57}$ Otherwise, the law focuses mainly on what is best described as penal law, or the "Dråpamålsbalkar", the "Såramålsbalkar" and the "Tjuvabalken", but which primarily served as tort law.

Rules for the distribution of goods emerged mainly during the second era, the era of trading houses. This made it necessary to regulate representation and organization as commerce expanded with the introduction of merchant shipping. ${ }^{58}$ The first form of limited partnership was created to encourage interested parties to invest in merchant shipping and trading. It is here that maritime law gains its unique character, with influences from international law. Simple solutions to disputes, based in the customary law of Lex Mercatorum, ${ }^{59}$ were practised in the major European markets. The term Hansa evolves into a specific political and legal expression in this era. ${ }^{60}$ The Hanseatic League was a confederation consisting mainly of North German towns, but the major trading centre in the Baltic Sea was Visby, invade by Valdemar Atterdag in 1361. The Hanseatic League reached its peak of influence in the 14th century, but the Hanseatic towns retained their financial influence in Northern Europe until the early 16th century, when the discovery of new trade routes led to the relocation of the financial centre to Western Europe. Gradually, the Hanseatic League lost influence from the end of the 16th and early 17th centuries. This era's main contribution to legal culture is the development of fundamental principles of commercial law.

By the time of the machine age, conditions were ripe for production to become the object of regulation. A fully regulated system for the organization of production was established during this period. Nobody was allowed to practise a craft that fell under the organization of a particular guild without first being admitted to the relevant guild, in accordance with the skraitvainget (Guild Requirements). ${ }^{61}$ The guilds were organized and established according to guild regulations that were initially approved by the city government, and later by a state authority. General guild regulations were in force between 1669 and 1720. During the

57 Holmbäck-Wessén (1962, p. 152) et seq.

58 Braudel, Fernand. (1979). The wheels of commerce. Civilization and Capitalism 15th18th Century.

59 Anners, Erik (1990), Section 1, p. 163 et seq.

60 Ibid, Section 2 , p. 70 et seq.

61 Entry to the various different guilds requires a certain amount of quest points, skill level and/or completion of a specific quest. Guilds with a skill requirement may be accessed if the skill is temporarily boosted to meet the requirement. 
18th century, at the peak of the Swedish guild system, urban craftsmanship was completely organized under the guild system. Gradually, protests grew in reaction to this system, and the so-called reform mercantilists began to demand less governmental interference, which, in time, led to gradual deregulation. As a result of the industrial revolution, the fourth leap of the market economy, and economic liberalism, freedom of trade gradually grew during the 19th century. The guild system was abandoned, and the system of towns having preferential rights to certain areas of trade was abolished. ${ }^{62}$ In Sweden, this was implemented through the Fabriks och Handtwerksordning and the Handelsordningen of 1846. We shall study the evolution of law in the industrial age in more detail in the next section.

In general, it could be said that when codifying legal developments, the legal system tends to lag behind somewhat. Thus, on the initiative of the Eastern Roman Emperor Justinian I, as noted previously, Roman law became codified by the publication of the vast legal work Corpus Juris Civilis, 529-534. This, at a time when the Roman Empire was collapsing. By AD 476, the Western Roman Empire had fallen as a result of external and internal conflicts, while the Eastern Roman Empire continued to live on. This led to Roman law being forced out by canon law. It was eventually recorded in writing, but the main codification of law was yet to come. With regard to canon law, ${ }^{63}$ there are also traces of it lagging behind while the various legal sources were compiled into a comprehensive legal work. While the religious, Christian epoch, peaked after the 1lth century, canon law was not codified until 1584, in the Corpus Juris Canonici. ${ }^{64}$

The law of the Consolidation of Sweden, the Svea Rikes Lag, adopted by Parliament in 1734, contains none of the legal structures of early industrial society. However, it continues to form the basis underlying the systematization and publication of the Swedish penal code today. The statute book of 2020 should probably be seen as a reflection of market economy law, largely influenced by the legal requirements of the industrial age (although the main body of political/ administrative legislation is not included in the statute book), mixed up with aspects of commercial law, the Handelsbalken (the Commercial Code), and construction law, the Byggningsbalk (the Building Code), which regulated things like "How to gain burghership" and "On grazing pastures, herdsmanship, and harvesting", which are reminiscent of legal principles from an early phase of the market economy. The legal work that will, in time, come to symbolize the law of united Europe will be represented by the Corpus Juris Mercatori that is currently being created within the legal framework of the EU.

62 Almquist, Josef Natanael \& Eriksson, Johan Axel (1949). Skråväsendet - dess fall och atterkomst. Stockholm: Guide and Project Tools (Rule of Law Indicators) [Elektronisk resurs]. United Nations.

63 The Catholic Encyclopedia.: An international work of reference on the constitution, doctrine, discipline, and history of the Catholic Church. Ed. by Charles G. Herbermann. John J. Wynne, assisted by numerous collaborators. (1907-1922). New York.

64 The Corpus Juris Canonici ('Body of Canon Law') is a collection of significant sources of the canon law of the Catholic Church that was applicable to the Latin Church. 
This lag in law can also be found in the evolution of constitutional law. ${ }^{65}$ The Swedish Instrument of Government of 1809 was not an expression of bourgeois society's separation of powers, as per the French model, but rather a reflection of absolutist state autocracy. This Instrument of Government was replaced in 1974. The Instrument of Government of 1974 ratified the parliamentary principle that, in practice, had gradually been introduced since the abolishment of the Riksdag of the Estates system in Sweden in 1866. It is worth pointing out, in this context, that Sweden remains a constitutional monarchy to this day. In accordance with the Instrument of Government, Chap. 1, s. 5, the reigning king or queen is the head of State, pursuant to the Act of Succession.

In order to establish some background information for theories on the evolution of norms and law, we shall now take a closer look at the actual legal developments of the industrial age.

\subsection{The evolution of law during the industrial age}

With regard to the actual volume of regulations, it is generally assumed that legislation increased steadily during the 19th and 20th centuries. However, relevant statistics, not least from a historical perspective, are largely lacking. A summary of the number of royal decrees issued between 1650 and 1820 shows an increase in regulations, particularly in the late 18 th and 19th centuries, although this varies substantially from year to year. ${ }^{66}$

Similarly, the number of registered statutes in the Swedish Code of Statutes, the Svensk Författningssamling (SFS), first issued in 1825, has been increasing steadily since the mid-19th century until the 2020s as shown by the following summary of the number of SFS statutes in 20-year intervals (Figure 5.15).

Due to its legislative activities, the State is assessed to intervene considerably more in the lives of its citizens than previously, thereby restricting freedom in a more tangible manner. Benny Carlsson illustrates the extent of anti-competitive regulations in economic areas in Sweden between 1780 and 1980 with the following sketch (Figure 5.16). ${ }^{67}$

As shown, laws and regulations increased mainly as a result of wartime statutes introduced during the First and Second World Wars and during the depression of the 1930s. Some of the most significant aspects of this legislation follow below.

When an imbalance arose between production and consumption toward the end of the first decade of mass society - the 1920s - politicians gained power and switched their focus from production to consumption. ${ }^{68}$ Two economic models thus collided: the communist and the Keynesian models. The Keynesian model

65 Nergelius, Joakim (1996) and Holmberg, Erik and Stjernquist, Nils (2008).

66 Quiding, Nils Herman. (1865). Swedish code of statutes 1522-1862: entitled so as to depict the objects of the constitutions, with due observance of alphabetical and chronological order, and with the repeal of the official constitutional headings. Stockholm: Norstedt [Translator's note].

67 Carlsson, Benny (1986).

68 Giner, Salvador. (1976). Mass society. New York: Academic Press. 


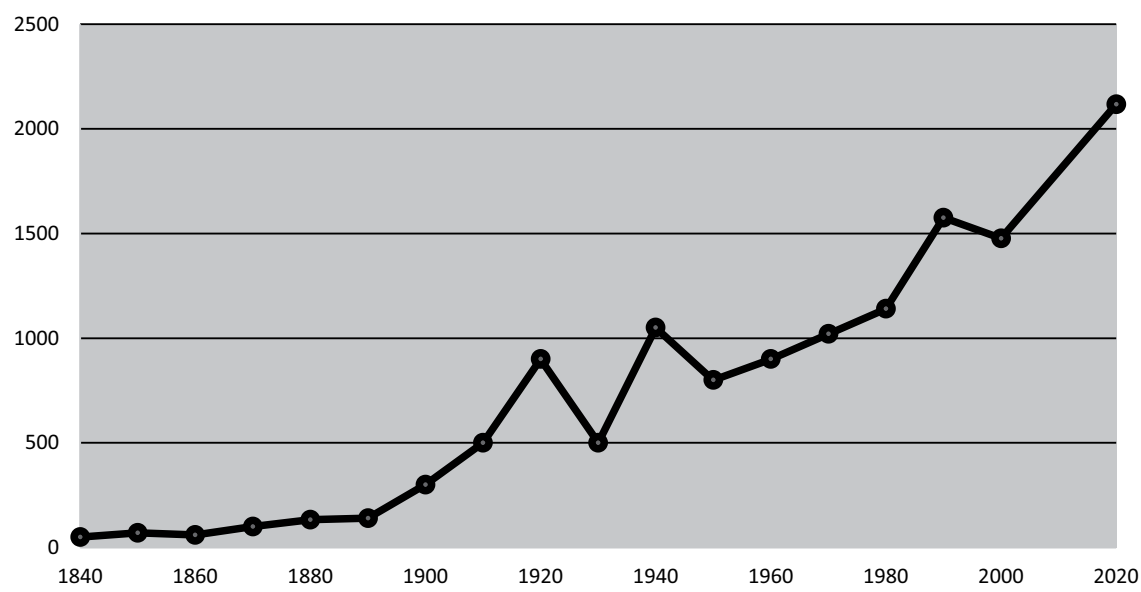

Figure 5.15 Number of SFS statutes $1840-2020^{69}$

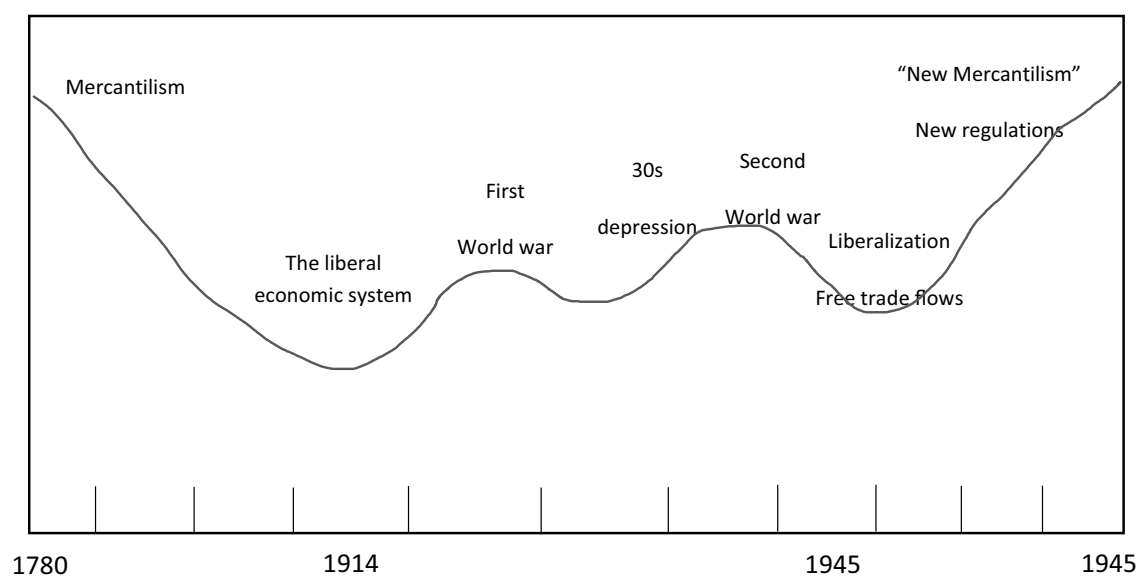

Figure 5.16 The extent of anti-competitive regulations in Sweden between 1780 and 1980

was based on the idea that collective consumption could be raised through taxes at the expense of individual savings. Economic slumps would be offset by budget deficits, thereby maintaining consumption and gross domestic product (GDP). This meant that power was transferred to the Ministry of Finance, the National Institute of Economic Research and the Bank of Sweden. Politically, the spirit

69 The value for 2020 is based on statutes of the SFS between April 1, 2018 and March 31, 2019. 
of consensus was popular at the time, which can be seen in the Saltsjöbadsavtal in Sweden, the New Deal in the USA and Hitler's small business programme in Germany. In the years following the war, in addition to maintaining consumption levels, it became necessary to legislate consumer protection, lay the conditions for the credit sector and establish a social safety net.

There was also a strong increase in laws during the 1970s, which can be seen as the most intense period of legislation in the 20th century. We are here talking mostly about what in this book is labelled interventional or intervening rules within the labour market, consumer protection of different kinds, as well as environmental protection together with planning and building legislation. ${ }^{70}$

After 1991, as the S-curve dipped, the Keynesian strategy was no longer viable. In this situation, private investments were needed to maintain GDP. Due to the mental lag inherent to this kind of historical event, politicians continued to promote public consumption in the hope that private consumption would boost the stock market. The concern, now, was to encourage small companies to invest in new knowledge and new production methods. It seems that the transition from consumption policies to investment policies requires new politicians to gain traction. ${ }^{71}$

All this legislation, then, the sum of the post-war era, is seen by some to lead to restrictions on people's freedoms. In this context, we could reference Björn Tarras-Wahlberg's book Lagstiftning till döds (Legislation to death) from the early 1980s and its message that we are slowly but surely suffocating ourselves with excessive laws and regulations. ${ }^{72}$ Tarras-Wahlberg argued that a new law or regulation is passed every eight hours. And this was by no means limited to Sweden. The situation was similar throughout Scandinavia and other parts of the world. ${ }^{73}$ Dramatic terms like "regulations explosion" 74 and "a flood of norms" became fashionable. ${ }^{75}$ The term "rights inflation" has also been employed. ${ }^{76}$

However, whether the production of statutes, evenly spread over the year, leads to restrictions on people's freedoms depends on whether the increase in the production is due to the superimposition of new laws and regulations on previous regulation or whether the new rules displace and replace old rules. After taking a closer look at the matter, I have concluded that Tarras-Wahlberg's claim that approximately 1,096 laws and ordinances were issued over a five-year period

70 See Section 5.3 below.

71 According to Lennart Schön, one should always expect innovations and social change to create demand for new skills, new work organizations, new intermediate goods, etc., all of which takes time. Further reading, see Schön, Lennart (2001, p. 525).

72 Tarras-Wahlberg, Björn (1980). See also Carlsson, Benny (1986) and Söderström, Hans Tson (ed.) (1985).

73 For further remarks, see Teubner (1987), where he addresses the problem of the Juridification of Social Spheres.

74 Barton, John H. (1975). Behind the legal explosion. Stanford Law Review, No. 27, p. 567 et seq.

75 See Teubner (1987, p. 6) et seq. and references in Note 2.

76 See, e.g., Berner, Georg (1978). Inflation im Recht. Bayrisches Verwaltungsblatt, p. 617 et seq. 
between 1970 and 1974 is not strictly correct, in that only 162 out of the 1,035 statutes in $1970(16 \%)$ can be regarded as new statutes. The remaining were either amendments or included in the Swedish Code of Statutes in order to be repealed. The same applies for the other relevant years.

If we compare the total number of statutes between 1840 and 2020 divided into 20-year intervals, Figure 5.15, with the number of new statutes for the same period, Figure 5.17, we see in Figure 5.18 that new statutes as a share of the total

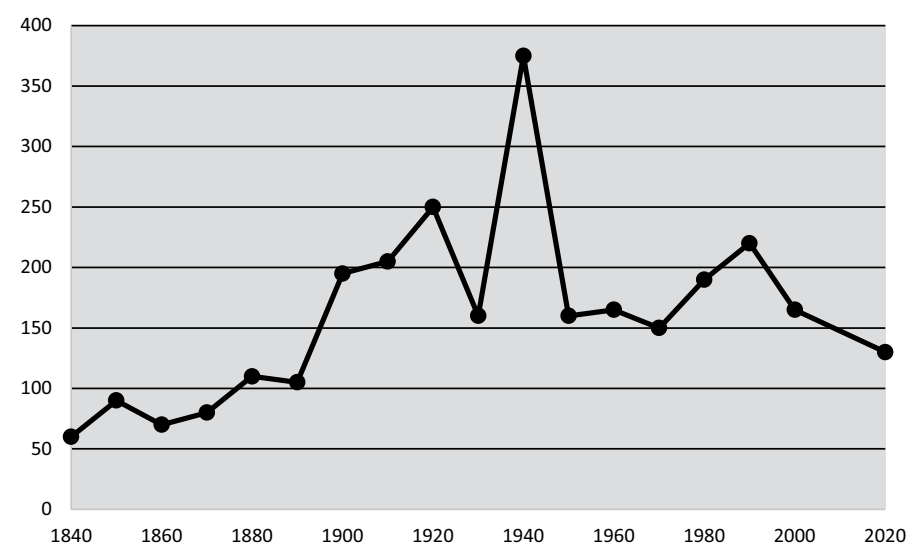

Figure 5.17 New statutes between 1840 and $2020^{77}$

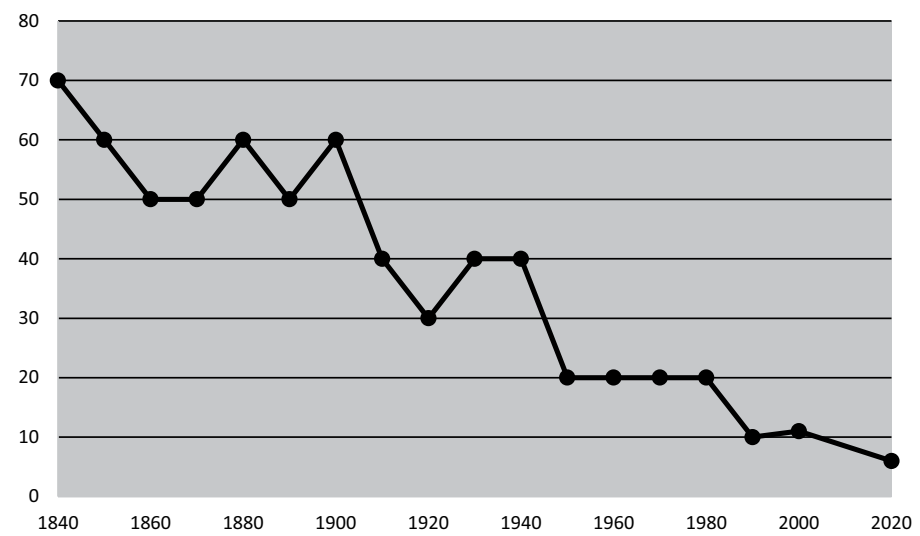

Figure 5.18 Share of new SFS statutes 1840-2020 shown as a share of the total number of statutes ${ }^{78}$

77 The statutes of the SFS between April 1, 2018, and March 31, 2019, have been included for the 2020s

78 The statutes of the SFS between April 1, 2018, and March 31, 2019, have been included for the 2020 s 
number of statutes is constantly diminishing, showing that the pace of change is far higher than the number of new laws and regulations.

The number of statutes each year remained relatively constant throughout the 20th century, with a few deviations in connection with World War I and World War II and the mid-1970s. A study of Norwegian conditions by Aubert shows that the level reached in the 1920 s remains constant to this day. ${ }^{79}$ The number of laws and regulations has, in other words, not increased to the extent that has sometimes been portrayed. Neither have they decreased, as indicated in Figure 5.17; rather, the curve in Figure 5.18 indicates a rapid pace of change in legislation. With regard to statutes, this number has dropped from approximately 4,700 in 1970 to just over 3,600 in 1990 and 2,400 in 2000 and rises again to 4,266 statutes in force as of March 1, 2019. Of these, 1,486 are laws and 2,785 are ordinances. To broaden our understanding of the areas of society affected by laws and regulations, we can conclude that the number of categories of rules for each departmental area in 1990 and 2019 are as shown in Figure 5.19.

One reason for the number of laws and regulations remaining relatively constant throughout the 20th century is the implementation of a legal framework, i.e. a legislative method characterized by the parliament and the government transferring or delegating the power to issue supplementary regulations to various administrative agencies. This allows the government and the parliament to avoid having to revise previous legislation or issue new statutes to keep up with social changes. As a result, government regulations now comprise the main body of social regulations. For each law, there are approximately ten regulations. There were approximately 12,500 government regulations as of September 1992. However, this is almost 4,500 less compared with the 16,900 regulations and general guidelines identified in 1988, as revealed in a review of the authorities' regulations in connection with the begränsningskungörelsen (Delimitation Ordinance).${ }^{80}$ As many as 67 government agencies are allowed to issue their own statutes by the authority vested in them by the government and parliament. Counties and municipalities also have the power to issue their own regulations. These regulations are laid out in the Författningssamlingsförordningen, the Swedish Constitution Collection (1976:725), and amounted in 2019 to 7,600 regulations (government communication $2018 / 19: 75$ p. 358). This has remained at a relatively constant level for the last decade, although the number dropped as a result of the implementation of the registration of government regulations. The distribution across the departments follows the same pattern as the number of SFS statutes, see Figure 5.19.

In other words, the number of statutes increased in the 20th century, not least in the form of government regulations. Government regulations fulfil, to a degree, the same operative functions in political/administrative systems as

79 Aubert, Vilhelm (1976).

80 SFS 1987:1347. This was later replaced by the government agency ordinance Verksförordningen (1995, p. 1322). 


\begin{tabular}{lcr}
\hline Department & \multicolumn{2}{c}{ Number of SFS Statuses } \\
\cline { 2 - 3 } & 1990 & 2019 \\
\hline Ministry of Justice & 725 & 960 \\
Ministry of Foreign Affairs & 138 & 156 \\
Ministry of Defence & 148 & 95 \\
Ministry of Health and Social Welfare & 343 & 512 \\
Ministry of Transportation and Communication* & 234 & 366 \\
Ministry of Finance & 934 & 995 \\
Ministry of Education & 136 & 0 \\
Ministry of Agriculture* & - & 178 \\
Ministry of Employment & 94 & 153 \\
Ministry of Culture & 104 & 130 \\
Ministry of Enterprise, Energy and Communication & 162 & 279 \\
Ministry of Public Administration & 98 & 4 \\
Ministry of Environment & 116 & 184 \\
Sum & 3,418 & $3,837 * * *$ \\
\hline
\end{tabular}

* Reorganized April 1, 2019, and renamed the Ministry of Infrastructure.

** Supplemented in 2019 by the Ministry for Rural Affairs.

$* * *$ The total number of statutes amounts to more due to the fact that they are issued by other offices, such as the Bank of Sweden, the Central Bureau of Statistics, the Prime Minister's Office, etc.

Figure 5.19 Number of statutes per governmental departments

does the contractual instrument in social and economic systems. But what led to this development? To begin with, we can conclude that the large number of government regulations is related to the functions of the political/administrative systems. Since they comprise by far the largest body of statutes, this supports Aubert's theory on the crucial influence that political factors have on the increase in statutes, i.e. in times when politics are the dominant system, legislation becomes a prominent instrument. This tendency toward power of attorney laws or framework laws, as they are called in Sweden, is a natural component in the evolution of state affairs, as Francis Sejersted argues, ${ }^{81}$ and seems to be related to the emergence of modern society, which required increased government control, of which legislation is an integral component. There was a time when legislation regardless of the legal content - was seen as an important and rewarding product of the political system. This was due to its visibility and the symbolic value it held for the "audience", the electorate, and the possibilities to compromise with actors from the political system and resolve their internal conflicts by manipulating the law. ${ }^{82}$ We can conclude that this promoted a rise in new laws and regulations, regardless of the ruling government's political ideology.

81 Ewerman, Anders (1996, p. 272); Sejersted, Francis (2011).

82 Cf. the Swedish expression "skojlagar" ("joke laws"), as professor of implementation research, Benny Hjern, prefers to call laws that purposely allow for a large gap between 
To locate the area of legal activity, we should focus on studying laws and regulations and their distribution across action systems, as described in the previous discussion. With this in mind, I have studied how the increase in statutes is manifest in terms of laws and regulations that target both the political/administrative systems and the social and economic systems (henceforth categorized as the socio-economic systems ${ }^{83}$ ). The year 1840 serves as a reference point for laws and regulations passed each year in ten-year intervals. ${ }^{84}$ See Figure 5.20, where the black bar represents the political/administrative system and the other bar represents the socio-economic systems:

The figure shows that up until 1840, regulations based in the old feudal and crafts society of the machine age linger on, and thereafter, the political/administrative systems' laws and regulations - the black bar - outcompete the socioeconomic systems' rules - the other staple. By 1850, the socio-economic systems had already gained in influence, and it was these systems that underwent the greatest expansion up until World War I. It was during this period that industrialism was established in Sweden. ${ }^{85}$ This corresponds to the economic phase in the evolution of industrialism, in line with the discussion in Chapter 1. Thereafter, the political/administrative systems regain power and are dominant from then on. Furthermore, they are also strongly overrepresented. This is related to the dominance of the political phase during this period, shown by the expansion of the public sector.

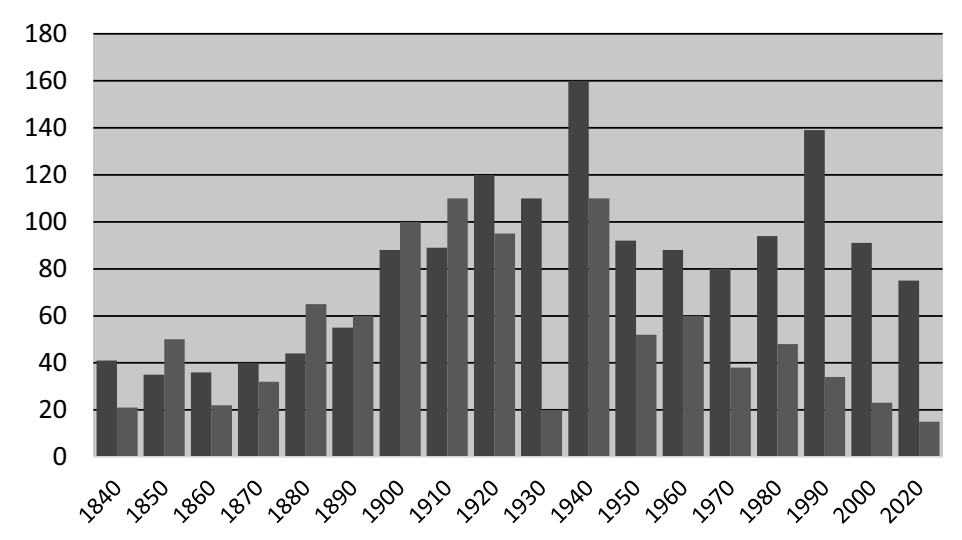

Figure 5.20 Laws and regulations passed each year in ten-year intervals

the letter of the law and the actual implementation of the law, see Bostedt, Göran and Hjern, Benny (1991). In his famous legal-sociological study En lov i søkelyset (1952), AubertEckhoff-Sveri develops a theory of legislation as political compromise.

83 Each respective system is defined and identified by the statute's addressee, i.e. the political/ administrative laws and regulations target the public sector, state authorities and municipalities, while the socio-economic legal rules target individual legal subjects.

84 The value for 2020 is based on the time period April 1, 2018-March 31, 2019.

85 Dalberg-Larsen, Jørgen (1984) calls this capitalism's happy moment. 
The dominance of the political/administrative systems is not only shown by the number of government regulations but also by the distribution of laws and regulations. Once again, we can conclude that despite an increase in statutes (Figure 5.6), the number of new statutes is currently dropping, which is due to the vast majority of the statutes being amendments of current laws and regulations. The Tax Procedures Act (2011, p. 1244) is an example of an act that will have been amended no fewer than 87 times by 2020 . The Alternative Investment Fund Managers Directive (2013, p. 561) has been amended 22 times, the Financial Action Task Force on Money Laundering and Terrorist Financing (2009, p. 92) 11 times, the first time the same year that it was passed, etc. In some cases, this is the result of the introduction of new technology, e.g. self-driving vehicles and the Intelligent Transport Systems Act (2013, p. 315). This Act has already been amended by the Act $(2018$, p. 372) Amending the Intelligent Transport Systems Act $(2013$, p. 315). This indicates that contemporary society is in a state of transition, with rapidly changing needs.

However, the evolution of law is more complicated than we have discussed so far. With the passage of time, beginning early in the late 19th century and thereafter with increasing frequency, a category of rules emerges in the studied regulatory materials that cannot be classified as political/administrative or socioeconomic systems, simply because they target both. The socio-economic systems' norms only target private actors (private legal subjects). Another issue is that maintaining these rules may require access to courts, police, prosecutors and bailiffs, etc.; however, rules in these areas are targeted at the political/administrative system. Norms that belong to the political/administrative system are targeted, in turn, only at government agencies. This does not mean, however, that services produced by the political/administrative system cannot be of use to, and in demand by, individual actors, e.g. education, healthcare, etc.

However, there are some legal rules that target both individual actors in the market and public authorities as a single category. In these cases, the operative definition is used to classify the rules. They belong both to the socio-economic and political/administrative systems simultaneously. The individual is assigned various tasks or is subject to various restrictions, while the public agency is tasked with monitoring compliance with said rules. I refer to these rules as intervening rules $^{86}$ because they are an expression of legal intervention by the political system, with the support of the administrative system, in the social, economic and natural systems. $^{87}$

Normally, that is to say, from the perspective of the socio-economic systems' civil and penal laws and rules, the addressee and target group are one and the same, also known as conjoint norms, to coin a phrase from Coleman, as noted in Chapter 3, while intervening legal rules distinguish between the addressee and

86 Hydén, Håkan (1978).

87 For more on intervening norms, please see Hydén, Håkan (1978), Hydén, Håkan (2002), and in the following text of this chapter. 
the target group. ${ }^{88}$ Therefore, we should not expect the addressees of the law to voluntarily, or at least not spontaneously, abide by the rules. In other words, they have to be "implemented" by government agencies whose job it is to monitor, explain and promote compliance with the rules in support of a target group that is either considered to be too vulnerable to defend its interests or, in some cases, so undefined that public authorities are forced to step in as a sort of representative to protect the uniqueness and value of the object of the rule. This applies, for example, to objects of environmental interest, to which specialized agencies are assigned to protect, e.g. the Environmental Protection Agency (EPA) and county environmental protection agencies assigned to protect public environmental interests. Additionally, we could refer to the similar use of laws and regulations to support the labour force, the disabled, consumers, women, etc.

These rules can be seen as an expression of governmental intervention, i.e. the political/administrative systems intervene in the socio-economic systems. ${ }^{89} \mathrm{We}$ can see the expansion in intervening rules by comparing them with the political/administrative and the socio-economic systems' laws and regulations during the same period. This gives us Figure 5.21, in which the black bar, in common with the previous figure, represents the political/administrative systems, while

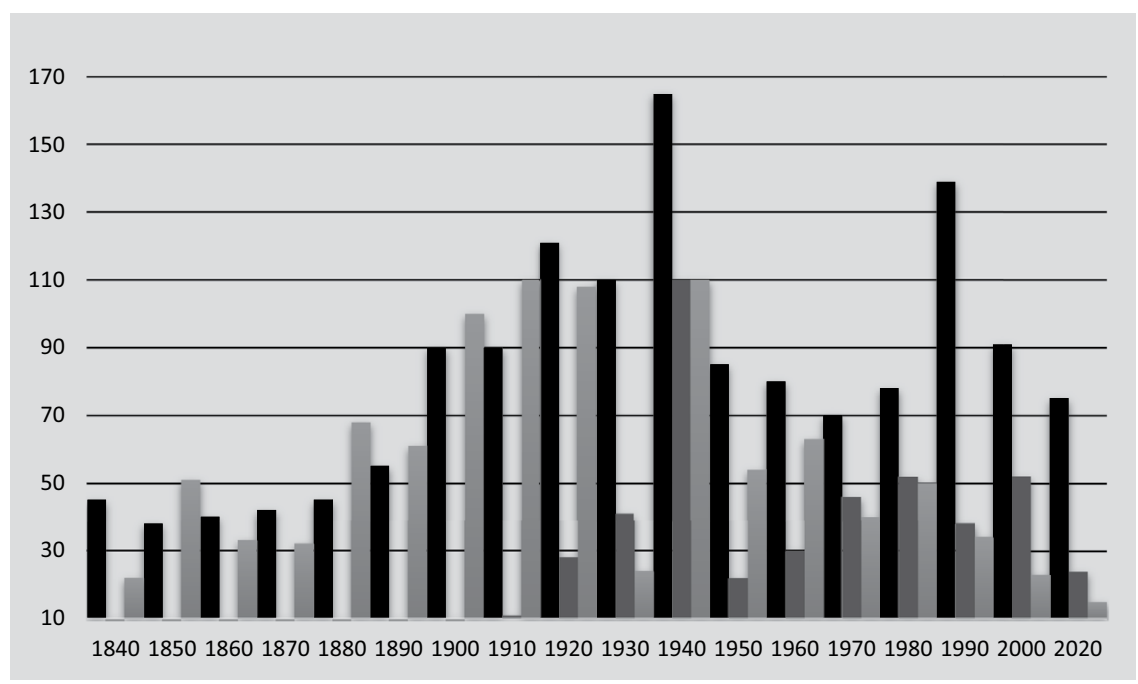

Figure 5.21 Number of statutes per system

88 Coleman, James $(1990$, p. 247$)$ et seq.

89 As the public sector assumes an increasing number of tasks, there are some examples of interventional rules targeted at the administrative systems' own actors, authorities and other representatives of the system, such as government offices or companies. For the sake of clarity, I will not comment further on these. They are fairly uncommon and do not affect the principal argument. 
the bar on the right represents the socio-economic systems, and the bar in the middle represents the interventional rules that gradually emerge in the early 18 th century.

The figure shows that some embryonic, intervening rules - the grey bar to the left for each year - had already begun to emerge by the latter half of the 19th century. One early Swedish example was the yrkesfarelag, introduced in $1889 .{ }^{90}$ There are also instances of legal regulation in the area of health protection. ${ }^{91}$ The increase in intervening rules mainly occurs during and after World War II and is related to the armed forces' political/administrative systems and their requisitions of goods and services, and thus their intervention in both the (private) social system and the economic system. Intervening rules in later years were caused by other circumstances, as described below.

The number of statutes within the political/administrative systems - the grey bar to the left - and the socio-economic systems - the middle bar for each year remained at the same relative level until 1920, at which point the number of statutes addressing the socio-economic systems dropped sharply. The share of statutes within the political/administrative systems remained at around $50 \%$ from the mid-nineteenth century and peaked during World War II. The main difference, however, is that the percentage of intervening rules steadily increased. These rules grew at a greater rate than any other system of rules in the 20th century, and since 1970, they have outcompeted the socio-economic systems' rules and become the second largest category of rules.

We can, therefore, conclude that traditional law has undergone fairly moderate changes. It appears that the rules of the socio-economic systems were established around the turn of the century and have thereafter mainly undergone various updates. Since the rules of the political/administrative systems have generally remained at a constant level, with a slight dip, it might be assumed that they continuously adapt over time as the administrative systems' tasks change. In the 2000s, a new kind of rule emerges, one that is defined by its sender rather than its receiver. These rules are inspired by the EU. In 2018, EU directives were implemented in 63 constitutional amendments (39 laws and 24 ordinances) and 27 new statutes (17 laws and 10 (ordinances), according to the annotations to the preamble of each statute that implements EU directives, ${ }^{92}$ i.e. more new statutes than intervening legal rules. What is interesting about these laws is that any discussion regarding the actual intent and societal function of the legislation has largely been replaced by a discussion on whether the legal proposal is in compliance with the EU source of law or not.

90 See more on this development in intervening rules in working environment issues Hydén $(1990$, p. 175) et seq.

91 Thus, a public health act was introduced in 1875.

92 EU law can be electronically accessed via the EUR-Lex database: http://eurlex.europa.eu/ en/index.htm. 
Civil and penal law and procedural code and administrative judicial procedure have, in other words, generally retained their positions throughout the 20th century. This supports the previous claim that the rules that contribute to the establishment of an action system, in conjunction with rules that enable cooperation or that indicate the limits of an action system, are stable and have merely undergone language changes and updates in connection with developments in technology and internationalization. The question remains, however: What are the forces behind intervening rules? We shall take a closer look at this in the next section.

\subsection{Law in transitional society}

\subsubsection{Intervening rules and intersystem conflicts}

Legal rules based in an action system that spontaneously generates norms do not encounter any particular difficulties in having an impact and working as intended. This applies particularly to rules that emerge bottom-up, so to speak, within the framework of the socio-economic systems, but also applies to rules created within the political/administrative systems. The legal system, however, is not very good at enforcing norms with rules intended to influence the action system in a particular direction, or in a way that it does not spontaneously demand, or may be unfamiliar with. Why is this?

One of the main reasons for this is that the action systems, in actual practice, conflict with each other, or that their demands of each other are incompatible, or that the requirements of one system are foreign to another system. This leads to what is called an intersystem conflict, i.e. a conflict between systems. ${ }^{93}$ There is a conflict of norms. As long as the various action systems are allowed to get on with their own lives and determine the actors' actions without interference, there is no problem. At most, intra-system conflicts may arise, i.e. conflicts within a system. These can be handled internally within each action system. Intersystem conflicts, however, arise when actions decided by one system have consequences on the range of actions available to another system, i.e. when action systems collide in human practice. The situation becomes particularly precarious if these collisions are frequent and strong enough to threaten the existence of one of the systems.

As we now analyse and seek to explain changes in law over time, this theoretical starting point allows us to seek out situations in society that threaten or at least affect each action system's capacity to reproduce. The theory is that when conflicts of norms, as described previously, arise in people's daily lives, they pose a threat to the reproduction of action systems, and voices are raised for legal intervention. This situation arises from structural conflicts between different action systems, i.e. when a system's action instruction systematically tends to collide with another system's norms in a common area of human activity.

93 Norwegian peace scholar Johan Galtung (1970) distinguishes between intersystem and intra-system conflicts. 
Wage labour is one area where this conflict can be found, where labour, much like other goods, is sold on the market. ${ }^{94}$ The labour force is a factor in the production process, and therefore, from the perspective of the economic system, it becomes necessary to apply efficiency criteria. ${ }^{95}$ This means that as much work as possible should be carried out at the lowest possible price, in the shortest possible time, with the lowest possible loss, the highest possible quality, etc. These criteria, perfectly legitimate criteria from the perspective of the economic action system's norms, tend to conflict with the social system's equally legitimate demands on citizens, i.e. to function socially, to be healthy, to have a livelihood, etc. In her PhD thesis, Informell ret på kvindearbejdsplatser ("Informal Law in Female-dominated Workplaces") Hanne Petersen points out the contradiction - largely in femaledominated workplaces - between the demands of wage labour, with its focus on economics, and the demands of social life that primarily target parents trying to combine work while also caring for their children or sick family members. ${ }^{96}$

In this case, the legal system faces a new situation where the law is not able to simply march in and support an action system's norms without colliding with another action system. There is a structural contradiction here that leads to incompatible demands in actual practice. It becomes the task of the legal system to try to resolve the situation, which it does by implementing intervening rules, a fact I shall return to at a later point.

This aspect of the labour force, i.e. that it is both a commodity with economic value and a social creature with needs and expectations, reveals the contradiction between the economic system's norms and the social system's norms. The result of the contradiction is that individuals are faced with contradictory demands in their daily lives as members of the labour force. This contradiction has also, as one might expect, generated a good deal of legislation to support the economic system's reproduction in the face of obstacles caused by individuals' who base their actions in the social system's normative rules. I refer here mainly to the entire area of labour law which, in the early stages of capitalism, led to regulations that grew over time, as this structural contradiction revealed pervasive conflicts between the two action systems. ${ }^{97} \mathrm{New}$ labour law regulations have thus been implemented in stages to keep up with growing contradictions. ${ }^{98}$ Labour law attempts to alleviate the effects of the contradictions by reinforcing the social and humanitarian aspects of the labour force. This puts it at odds with the norms and logic of the economic system. Compare Figure 5.22.

94 For more on the structure of wage labour, please see Christensen, Anna (1984).

95 Hydén, Håkan (1996).

96 Petersen, Hanne (1996).

97 See Teubner, Günther (ed.) (1987). See also Bruun, Niklas et al. (1990).

98 Developments in the field of work environment can be noted, as a typical example, as explained in Hydén, Håkan (1990). The evolution of labour law has been recorded in most standard textbooks, e.g. Adlercreutz, Axel (2000), and Adlercreutz's thesis (1954) has approached the interesting subject of the legal system's adoption of collective labour law, for all intents and purposes a product of the labour market. See also Schmidt, Folke (1962). 


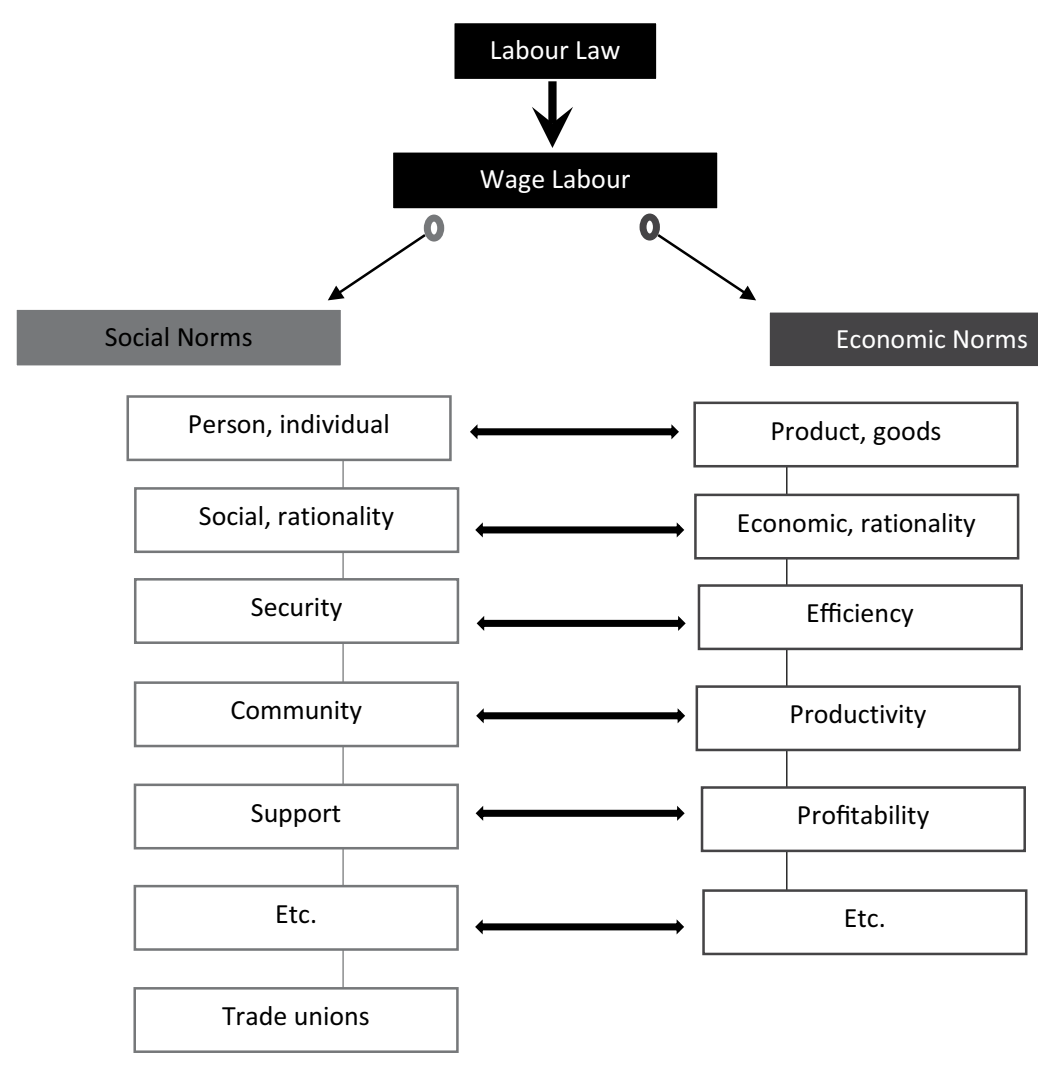

Labour — Law

Figure 5.22 Conflicting norms on the labour market

The organization of production, based in wage labour, in combination with the monetary economy, leads - contrary to self-sustaining lifestyles - to difficulties for the unemployed to support themselves. This also applies to the sick, parents of young children, children and the elderly who are not part of the active workforce. This discrepancy between earning a livelihood by selling one's labour and insufficient employment opportunities, or lack of access to the labour market, leads to governmental intervention in the capitalist market economy. This contradiction has led to a vast transfer system, in which active participants in the labour market are forced to relinquish a portion of their revenue via taxes and social fees to people who are not part of the labour market and from which they themselves may benefit later on in life. This is a common feature of Western industrialized countries. 
Together with the other Scandinavian countries, Sweden tops the list of countries with the largest net redistribution. ${ }^{99}$ This can be seen, among other things, in the Ministry of Health and Social Affairs' vast share of the overall budget, ${ }^{100}$ an amount that is only superseded by the Ministry of Finance, responsible for implementing the transfer system, as well as for the national debt interest. ${ }^{101}$ The budget for the Ministry of Health and Social Affairs consists of approximately a quarter of the entire government budget. The transfer system's influence is also shown by the distribution of the SFS statutes across departments, where the Ministry of Finance "leads" the race, with the Ministry of Health and Social Affairs coming in at a strong third place.

Another structural condition that leads to the collision between different norms from different action systems, and therefore requires legal regulation, can be found in the concepts of exchange value and utility value. These concepts do not represent an absolute contradiction, but they do represent a latent one, and they risk leading to situations that require regulatory intervention. This is because goods are sold on the market according to their exchange value. A good's exchange value, however, is not the same thing as its utility value, i.e. a good may be more or less necessary and useful for one individual and have specific utility value, regardless of its exchange value. But utility value does not determine production; rather, production is determined according to exchange value. This is the economic system's point of focus. Generally, we expect that a good that has been produced and sold in accordance with its exchange value also has a utility value that satisfies the social system's requirements and interests, but this is not always the case.

This potential contradiction between the economic system's driving forces and the social system's norms has, in recent years, led to increasing legal intervention. As long as the production of goods was limited and the demand to satisfy material needs continued, there was no reason to intervene. But as the market grows increasingly saturated, the competition grows tougher, which reveals the contradiction between the production of exchange and utility values. This contradiction is manifest by legally binding elements of dispositive civil law, such as the Consumer Sales Act, the Marketing Act, the Act on Unfair Terms in Consumer Contracts, the Consumer Credit Act, the Consumer Services Act, etc. This development means that what is produced and sold on the market may not necessarily

99 This statement is based on a ranking system composed by Castles and Mitchell (1992). This ranking system is based on so-called Gini coefficients and has also been published in Rothstein, Bo (1993a).

100 In fiscal year 2020, the Ministry of Health and Social Affairs had SEK 325 billion crowns at their disposal, to be compared with the total budget of SEK 1,056 billion, see Bill Prop 2018/19:100.

101 These amount to SEK 232.5 billion and an estimated SEK 28 billion. 
represent an actual demand, as shown by the following regulation, Section 8 of the Consumer Sales Act:

If the goods are sold in violation of prohibitions pursuant to Section 4 of the Marketing Act (1975, p. 1418), or are otherwise in violation of the prohibition to market goods as laid out in the statute, or by an authority, the purpose being to prevent the person using the goods from suffering from illness or accidents, or to otherwise prevent the use of unsafe goods, the goods shall be considered defective. The same applies if the goods are so flawed that their use entails an obvious risk to the buyer's or third-party's life or well-being.

From a social perspective, this contradiction has led to Buy Nothing Day, held on the last Saturday of November in many places around the world. ${ }^{102}$ It is seen as a day for reflection and moderation, and people from Tokyo to Vancouver exercise a sort of passive activism simply by not buying any goods. In other words, it is a symbolic act, much like the Car-Free Day. ${ }^{103}$

An additional contradiction between these action systems has to do with the relationship between what we in Chapter 2, with reference to Jürgen Habermas, discussed in terms of contradictions between two different, normative worlds, i.e. the system world and the lifeworld. During the large-scale phase of industrial society, systems that people create to meet their needs for material satisfaction tend to take over and "live their own lives". It becomes increasingly difficult to control and govern systems, while the complexity and extent of the systems simultaneously tend to produce more and more external effects - an unintended side effect that has negative consequences and makes the systems counter-productive. The German sociology professor Zygmunt Bauman puts it thusly: ${ }^{104}$

In our era, technology has become a system: it sees the rest of the world as an "environment", a source of food, or raw materials to be processed technologically, or a dumping ground for the (hopefully recyclable) waste resulting from this process; and it defines its own failures and misdeeds as the effects of its own inadequacy, and hence, the more "problems" that technology generates, the more technology is needed to solve them. Only technology is able

102 Click Here to Buy Nothing. Joanna Glasner. Wired, November 22, 2000.

103 Behind this campaign, which has reached over 30 countries, is the Adbusters organization, which, using innovative strategies, works to change the power hierarchies that they argue transform people from active citizens to passive consumers. In the USA, President George $\mathrm{W}$. Bush declared that consumption is every citizens' "patriotic duty". It was viewed as the only way to kick-start the economy following the acts of terror on September 11, 2001. As confirmation of how important this issue is, it could be noted that the three major American TV companies, CBS, NBC and ABC, refused to broadcast adverts for the Buy Nothing Day. NBC explained that the adverts were "hostile to our fundamental business interests".

104 Bauman, Zygmunt (1995, p. 231). 
to "improve" technology, and cure the diseases of yesterday with the miracle drugs of today, that is to say, until the side effects of those drugs become apparent tomorrow and require new, improved drugs.

The Swedish professor of civil law, Anna Christensen (1936-2001), ${ }^{105}$ also expressed similar observations. She argues that this conflict is related to the inherent contradiction in wage labour:

The conflict between technology and employment reveals the inherent contradiction between wage labour as a production model and as a social model. The logic of wage labour dictates that it reduces the need for human labour and will eventually lead to the dissolution of wage labour as a social system.

Wage labour society simply isn't capable of resolving this conflict. If we accept technological development, we lose our jobs. If we don't accept technological development, wage labour loses its reason for existing. In the long term, wage labour cannot survive as a social system if it is no longer productive.

Anna Christensen in her paper Lönearbete som sambällsform och ideology (1983)

If we view this development from a normative perspective, in agreement with the former statement, we can conclude that mankind has, so to speak, conquered more and more of the norms generated by the natural system and used them for our own purposes. The result is a conflict between the other systems and the natural systems. The economic system sees natural resources as a cost-free and endless resource, while from the perspective of the natural system, they are finite and often not renewable. This increasingly threatens the reproduction of the natural system. As environmental and natural resources are exploited at an ever-growing rate, demands have been made to restrict the economic system's exploitation of, and interference in, the natural system. The problem here is that the natural system does not have any obvious spokesman or representative. Only in the event of natural disasters or serious environmental damage can we expect people to take an active interest in protecting the environment. The fact that the Swedish teenager Greta Thunberg is on strike for the environment and is invited to speak before the most powerful leaders in the world is an indication that she has managed to engage people all over the world, not least the younger generations. Her initiative gained international attention under the hash tags \#FridaysforFuture, \#Klimatstrejka or \#ClimateStrike and by the end 2019 had received media attention in a number of countries, as well as the attention of Secretary-General of the United Nations António Guterres, the pope and Arnold Schwarzenegger. How long this climate initiative can sustain and the impact it will have remain to be seen.

105 Christensen became the first female professor of law in 1976. 
Humans have primarily developed technology and norms to exploit nature. It is for this purpose that institutes of technology and universities around the world have studied and taught how to master nature for our purposes. Over time, as the negative external effects began to become obvious in the 1970s and onward, this explosion in techniques to master nature has led to a counter-reaction in the form of interventional laws and rules to protect nature. ${ }^{106}$ The problem we face here is that two norm systems are colliding with each other - in this case the economic and the natural systems. The economic action system's norms promote, and are a driving force behind, the exploitation of natural resources and the environment, while the natural system demands that ecological limits are respected. We are once again faced with the previously mentioned situation, in which law is confronted with a new situation where it is not able to simply march in and support an action system's norms without colliding with another action system. Law is not able to protect the natural action system's borders without ending up on a collision course with the economic action system's (structural) norms. In these situations, law finds itself caught in a sort of structurally inherent conflict, similar to the conflict manifest in wage labour. Compare Figure 5.23.

No matter which solution the political system adopts, the legal rules will conflict with one of the action systems, a sort of Catch-22 for the legal system. In these situations, law is forced to provide its own solutions to these kinds of values-based problems; this requires active governance of the rule's addressees, a task that is otherwise carried out by the rule's target group. Neither of the action systems are capable of solving the problem, and therefore the solution must be based on a "third approach".

This problem is emphasized in conflicts with the natural system's norms, since this system does not have any natural social representatives to defend the contents of the law. In these cases, there are secondary effects on the social, economic or political systems, which potentially can generate legal reactions. For example, conflicts between sewage contamination and access to clean water may trigger the economic system's actors to either voluntarily or as a result of political decisions comply with restrictions that are contrary to the economic system's norms. There are also cases where smog and pollution emissions from factories are so obviously negative and harmful that people are willing to accept restrictive rules. ${ }^{107}$

The solutions that have emerged so far in Sweden approach each unique case by studying the contradiction, i.e. each particular case of environmentally hazardous activities must be examined from the perspective of public guidelines. So far, the economic system has dominated over the natural system as a result of the political/administrative system's inability to demand protective measures or restrictions that collide with the economic system's action norms. ${ }^{108}$

106 Michelson, Staffan (2018).

107 Jönsson, Bodil and Wickenberg, Per (1994).

108 Hydén, Håkan (1978). 


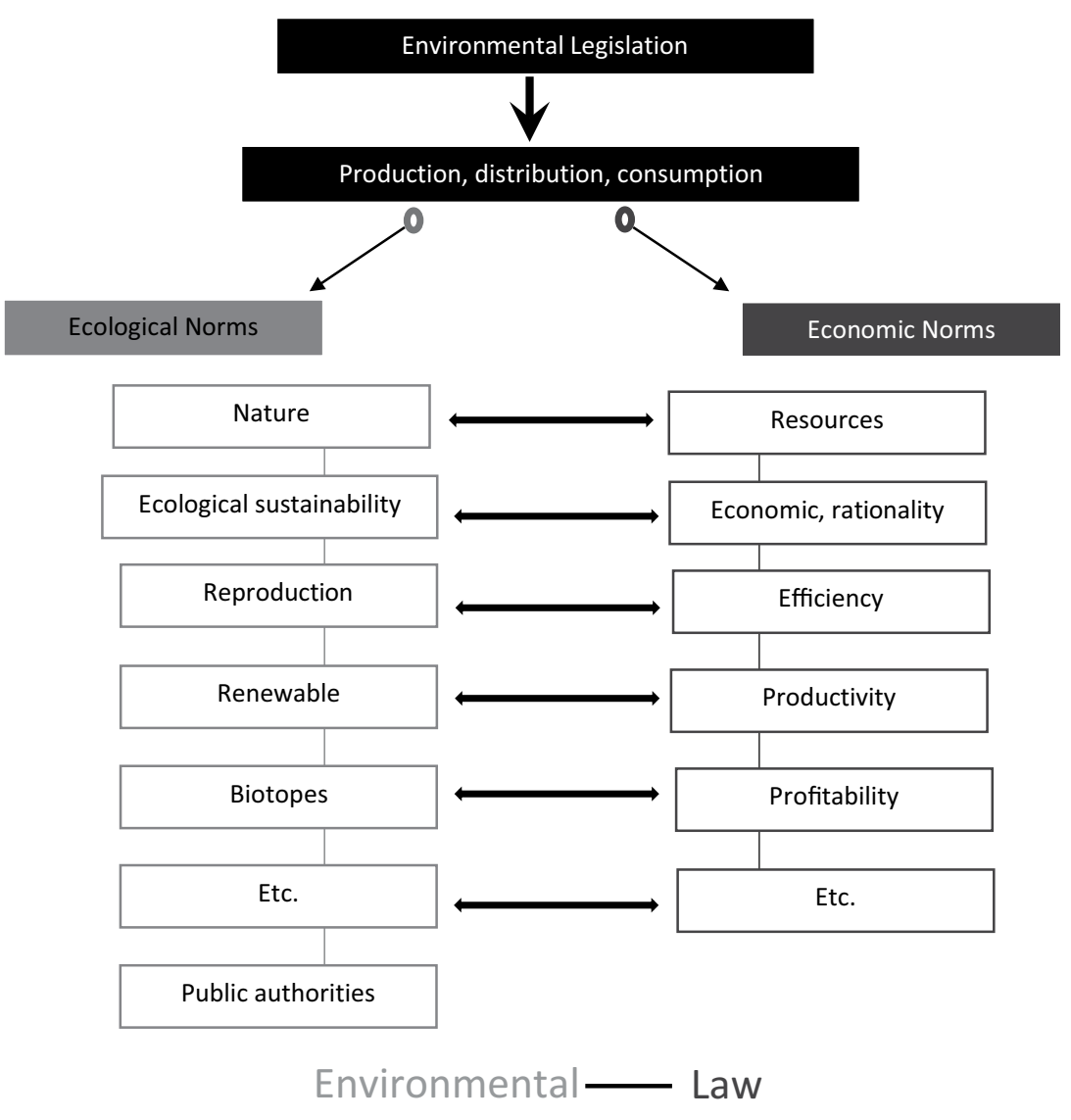

Figure 5.23 Conflicting norms in relation to nature

In general, it should be expected that the economic system adopts a dominant position in conflicts involving the various action systems we have observed. Firstly, the economic system is almost always involved in structural conflicts between various action systems. This is due to a fact we have discussed previously, namely, that the economic system is highly goal-oriented and implicitly requires - as demonstrated in the game analogy - a series of actions and behaviours. The economic system provides both driving forces that influence the evolution of the activity and behavioural patterns that act as a sort of behavioural template. Together, they create a sort of force field in which social events play out. This force field creates what I refer to as structural norms. Secondly, this also leads to demands from the economic system to decide how to solve structural conflicts that arise between action systems in people's daily lives. 
Therefore, one could conclude that the economic system, as a result of its goaloriented nature, creates structural conflicts, and also, and for the same reason, demands to be the action system that resolves the conflict. In other words, there is good reason to argue that the economic action system has played an important role in the social constructions of the market economy that we call the industrial age and that it is involved in both the creation and resolution of conflicts of norms.

\subsubsection{Characteristics and problems with intervening rules}

A peculiarity of intervening rules has to do with the fact that they are created by the legal system and thus do not emanate from any of the action systems. This leads to at least two kinds of problems.

The first has to do with the fact that intervening rules, unlike norms, have an intrusive function. Intervening rules require administrative procedures in order to be controlled. In this respect, they are no different to the political/administrative system. It is when we come to the material content of the rules that the intervening rules encounter problems. Disjoint norms, i.e. a disjoint between the norm's addressee and its target group, as Coleman calls them, create a highly unique situation. This is because the intervening rules target a specific group, e.g. businessmen in environmental cases, and makes demands that benefit a third group, e.g. neighbours, etc., but to be implemented, they require the support of a third category of actors, i.e. public authorities, or at least provide said agencies with the power to monitor regulatory compliance.

In its most natural state, a norm consists of rights and obligations distributed between people. If society provides a given group certain rights that correspond with another group's obligations, the norm will automatically have an impact on society. The group that has been entitled with rights will begin to place demands on others. The fact that social power relationships may be such that extraordinary measures are required to implement the norm does not change this fact significantly. However, the norm cannot gain force without sufficient support. Traditional law that deals with the entire socio-economic area is full of these kinds of rules for the distribution of rights and obligations between various social groups. We have rules and norms for business dealings between buyers and sellers, lessors and lessees, employers and employees, landowners and tenants, creditors and debtors, etc. An individual can belong to several dichotomic groups at the same time.

Similarly, intervening rules also include rules that deal with the distribution of rights and obligations. This applies, for example, to the labour market, the consumer market and the housing market. In these cases, however, the rules must be backed up either by collective organizations endowed with the power to implement and enforce them or government agencies equipped with similar functions. The success rate for these kinds of regulations is determined by whether this supplementary regulation of the power relationship is sufficiently distinct and far-reaching. Working environment regulation in Sweden, regardless of one's 
personal opinion, should be recognized as a successful example of intervening rules. A long-lasting period of peace can be seen similarly.

Intervening rules can also share the same characteristics as the political/administrative system's consequentialist norms, i.e. they may prescribe specific goals that the involved actors should strive to reach. This is the case, for example in the areas of work environment, nature conservation and forestry management. ${ }^{109}$ The problem in these cases is that while the rules of the political/administrative action system are designed by, and in consultation with, experts responsible for implementing the measures - e.g. doctors in healthcare matters, engineers when planning road systems - this is often not the case in the implementation of intervening rules. There is a simple explanation for this to be found in the structural contradiction underlying the conflict that the rules are intended to solve. The problem here is that the rule does not have a direct effect on the object of the rule. For example, the rule cannot, in itself, create a better work environment, at least not directly. The intervening rule can only influence the involved actors to undertake certain measures. This, however, requires that they know what to do, as well as loyalty from the individuals charged with implementing the measures pursuant to the rule, aspects which are often lacking in both cases.

Typically, the intervening rule therefore serves as a balancing norm, i.e. it prescribes what interests are to be protected and weighed against each other during the conflict resolution process, but it does not provide instructions for how to do so. This distinguishes it from the socio-economic system's conditionally constructed legal paragraphs, which are based in necessary prerequisites for a given legal order, much like a rebus riddle, to be able to proceed. It is also distinct from the political/administrative system's consequentialist norms. Rather, intervening rules can be described as relationally programmed, in the words of the German legal theorist Helmut Willke. ${ }^{110}$ Their primary function is to merge coinciding interests, not to determine their internal relationships by implementing distinct rules.

The other type of problem is related to a unique characteristic of intervening rules, i.e. that there is a risk of a gap arising in society between what is desirable and what is possible. As the link between intervening rules and norms from one of the action systems is broken, there is a risk that the political desire to compensate people, based in the social system's values, loses touch with what is possible to achieve, from the perspective of the economic and natural systems. This gap results from overenthusiastic promises, which can be caused by two things. Firstly, politicians might want to claim that the intervening rules have solved the problem. This is often the situation when it comes to the area of work environment and the external environment. Secondly, the political system, well-intended, no doubt, approves entitlements that later prove difficult to live up to due to a lack of resources. This is becoming increasingly common, partly as a result of weaker

109 See, e.g., Stjernquist, Per (1973) and Appelstrand, Maria (2007).

110 Willke, Helmut (1995). See also Teubner, Günther (1987). 
economic conditions and partly due to how the political system works. When political parties compete for votes, there is a risk that they might out-bid each other, leading to a situation where society lacks the material resources to fulfil their promises, particularly, in times calling for tax reductions. These conditions seem to be more commonly found in coalition governments.

To summarize, we can conclude that law has a relationship to other action systems and their norms and that law contributes to the reproduction of these systems and to resolving intra-system conflicts that the other action systems are not capable of resolving spontaneously. We also see that law is used, in cases of intersystem conflict, to protect the reproduction of the social construction itself, i.e. when action systems collide and place incompatible demands on people in their daily lives. This latter function of the legal system is what we refer to as intervening rules. They are distinct from other action system norms, and they also have unique characteristics in comparison with other legal rules.

\subsubsection{A discussion on alternative solutions to intersystem conflicts}

These conditions lead to lawyers getting stuck between a rock and a hard place. They are caught between the political/administrative system and the socioeconomic systems, between the government and the market, with no fixed link between them. ${ }^{111}$ Lawyers find it difficult to deal with modern laws that do not provide clear references to legal dogmatics. Simply put, there is a lack of normative guidelines to navigate the issues that law encounters. This means that there is a need for a new legal-scientific paradigm, a paradigm that is able to accommodate normative (and principled) theories without being based in the same, previously constructed norm. The new scientific paradigm that the intervening rules present us with must be able to produce its own normative solutions, based in empirical conditions that should be understood and interpreted in terms of norms. A future jurisprudential paradigm must therefore be incorporated into a larger body of knowledge on norm science.

Initially, the intervening rules were primarily implemented to support the social system's norms at the expense of the economic system. In recent times, however, intervening rules have increasingly been introduced to support the reproduction of the natural system, once again as the result of conflict with the economic action system's norms. Intervening rules have also increasingly been adopted to support gender issues. Women are no longer prepared to accept the differences generated by the social system and reproduced by the economic and political/ administrative systems. The results of a contemporary example of this conflict can be seen in the introduction of quotas to political decision-making offices and corporate boards. A demand that is far from new, but one that nevertheless only

111 Bertilsson, Margareta (ed.). (1995). Rätten i förvandling: jurister mellan stat och marknad. Stockholm: Nerenius \& Santérus. 
gained force once it received support from intervening rules, is the demand for equal pay for equal work. ${ }^{112}$ From the perspective of the social system, women's integrity is not sufficiently protected solely by implementing "normal" penal measures; rather, special, and dramatic protective measures must sometimes be taken, such as changing identity, assigning security guards to protect women under threat, women's shelters, etc.

In all cases of intervening rules, social and political activities are required to establish them. The labour movement was the driving force behind the implementation of intervening rules to solve intra-system conflicts arising from wage labour. The consumer protection movement has demanded compensation for the tyranny of the exchange value concept. The environmental movement has attempted to soften the negative consequences of the explosion in techniques to master natural resources and has at least attempted to bring them in line with what is socially acceptable. Similarly, the women's movement has had to fight against patriarchal dominance in all corners of society, from political unions to women's shelters.

The peculiarities of intervening rules have not been the topic of much discussion in the legal or social-scientific literature in Scandinavia. The Nordic journal Retferds spalter has made a few attempts at thinking outside the box and considering new paradigms over the years. There was, for many years, a discussion on legal strategy, which could be seen as the search for a new paradigm. ${ }^{113}$ This discussion was related to the Critical Legal Studies Movement, active all around the world and not least in the USA, and it also has a European counterpart. ${ }^{114}$ Aside from this, there have been few attempts to establish new jurisprudential paradigms. Above all, there have been no attempts whatsoever to incorporate modern law into the traditional legal faculties. As always, when an old paradigm is confronted with new problems that cannot be resolved within the existing paradigmatic framework, the reaction is typical. Don't mention them. Pretend they don't exist. In legal training and legal research, intervening rules are only marginally discussed.

Discussions on alternative legal solutions and paradigms have mainly been conducted in universities in Germany and the European University Institute in Florence. There have also been scattered attempts in Italy, England, France and the Netherlands. It would seem that Scandinavia, and in particular Sweden, is too small to allow the establishment of a critical, alternative jurisprudential school of

112 Sveneaus, Lena, Konsten att upprätthålla löneskillnader mellan kvinnor och män, En rättssociologisk studie av regler i lag och avtal om lika lön, ak avh. Lund University.

113 Who could forget, for example, Lars D Eriksson's article on an alternative (Marxist) jurisprudence in Retferd (1979) and the discussion that followed for years, a discussion that now seems to have died out. Perhaps contemporary feminist legal theories will provide an alternative, but so far, they have not risen to the same status of alternatives as established legal dogma. Cf. Smart, Carol (1992).

114 For an overview, see Unger, Roberto Mangabeira (1986). See also Hydén, Håkan (1982). 
thought. ${ }^{115}$ There are not enough trained legal scholars who are also schooled in the social sciences and critical lawyers to have an impact.

In the early 1980s, there was lively discussion on alternative legal forms. ${ }^{116}$ There seems to be some consensus around the notion that there is no way of returning to formalized law to regulate the problems of modern law, nor does the material, goal-oriented legal system have much of a future. ${ }^{117}$ Teubner introduced a new legal model at an early stage, i.e. reflexive law (Teubner, 1983). Teubner proposes three arguments. ${ }^{118}$ Firstly, the social system must be guaranteed a measure of autonomy by way of some kind of "external constitution". Secondly, structural frameworks for effective self-regulation must be constructed, either by decentralising the political/administrative system's tasks and delegating them to private actors or by internal reflexive processes. The reflexive law model, as described by Teubner, focuses on bringing together representatives of conflicting interests in decision-making arenas and solving the problem at hand through communication.

Since then, Teubner has proposed a new paradigm, i.e. the theory known as autopoietic law. ${ }^{119}$ A more comprehensive description of this theory is perhaps beyond the scope of the present text, but some fundamental characteristics can be noted. Teubner sees law as an autopoietic system to the extent that the legal system is capable of producing its own elements, activities, norms, processes, identities, etc., in self-referring cycles. ${ }^{120}$ When these cycles interlink and create a spiral of circles, a hypercycle of self-referring cycles, we can conclude that the legal system has become a fully closed system, thereby making it autopoietic (Teubner, 1988). One practical consequence of the new autopoietic legal paradigm is what Teubner calls the dilemmas of law. ${ }^{121}$ This is based on the observance that legal governance processes are only capable of stimulating self-regulating processes within the system to be governed. They are not capable of directly intervening in the other system. They may have some influence, but only to the extent that they conform with the demands of the affected system's reproduction. Any intervening rule that attempts to accomplish anything else, Teubner explains, will either

115 This does not mean that there have not been occasional contributions, e.g. Gustafsson, Håkan (2002). Rättens polyvalens: en rättsvetenskaplig studie av sociala rättigheter och rättssäkerhet. PhD thesis. Göteborg: University, 2003.

116 One of the earliest contributions to this discussion was, in fact, the Alternativen Rechtsformen und Alternativen zum Recht, which consisted of an anthology edited by Blankenburg, Erhard et al. (1980).

117 In particular, Teubner, Günther (1983) argues this emphatically.

118 See Teubner, Gunther $(1987$, p. 33) et seq. and references.

119 King, Michael (1993) describes this as a new paradigm. The authors are the German theoreticians Niklas Luhmann and Günther Teubner. See especially Teubner, Günther (ed.) (1988) and Teubner, Günther (ed.) (1993), Teubner, Gunther. Autopoietic law [Electronic resource]: a new approach to law and society / edited by Gunther Teubner [Electronic resource]. Oxford.

120 Teubner (1993, s. 27).

121 See also Teubner, Günther (1987, p. 21). 
prove to be irrelevant or have a disruptive effect on the social system, or on the law itself.

The present book shares much in common with Teubner's theories on autopoietic law. Among other things, the theories on law's dependency and subordination to other subsystems' normative constructions are in agreement with the concept of autopoietic law. "(L)egal regulations do not change social institutions at all, they only offer a new challenge for their autopoietic adaptation", as Teubner, coining a phrase from one of the giants of cyber-ethics, puts it. ${ }^{122}$ However, Teubner, and in fact the entire German discussion, in my opinion, suffers from a myopic view of law, if, in fact, law is even problematized at all. I would argue, for example, that based in the theories presented in this book, one must distinguish between the law's functions and the action systems from which they originate, as well as the conflict of norms underlying the intervening rules, as noted previously. It is important to distinguish between the role law plays in intra-system conflicts and in intersystem conflicts. Furthermore, one must also distinguish between the law's action instructions and its function as a resolver of conflicts. What Teubner et al. refer to in terms of a regulation crisis would seem to be related to the inherent problems of governance that necessarily arise from the structural contradictions in intersystem conflicts, as discussed previously. The examples mentioned fall within these areas of the legal system. The regulation crisis is, in other words, structurally determined, a fact that Teubner et al. seem to disregard.

Much of the discussion in Germany is absorbed with the question of how best to structurally link policies, the law and the area of society subject to regulation. ${ }^{123}$ Hence, the problem is depicted as a matter of linking the law to the political system, on the one hand, and on the other hand, to the area of society that will be affected. ${ }^{124}$ The difficulties here are seen as a question of transferring communication from one system to another. "The unlikely event of a successful structural coupling of political decision-making, legal norm-making and social guidance can only occur if relevance thresholds are successfully crossed and if the respective limits of self-reproduction are observed", writes Teubner. ${ }^{125}$

Here, I argue, Teubner goes astray. He draws incorrect conclusions from his own theoretical premises. The belief that society is based in autopoietic systems that communicate with each other does not mean that legal governance is impossible. It could conceivably be understood that way from Teubner's systemsscientific perspective. The problem with legal regulations depends, I argue, mainly on whether the legal intervention collides with the basic construction of

122 Ibid, with reference to Beer, Stafford, "Preface to Autopoiesis" in Maturana, Humberto et al. (1980).

123 Together with Teubner, Luhmann is perhaps the most prominent proponent of this argument, see Teubner (1987, p. 21) However, there are many successors in the ongoing German discussion, see, e.g., Bora's, Alfons, academic thesis (1991).

124 Social fields can be understood here, to coin a phrase by Karl Renner, as the substratum of law, i.e. that part of society that is the object of legal regulation.

125 Teubner (1987, p. 21). 
the social system or other action system. Consider Teubner's own words on the regulatory trilemma. The first questions that need to be answered are: What is the specific subject of the regulation in each particular case? Is there reason to assume that it will collide with the subsystem's own goals?

The answer to these questions would be that, in some cases, the point of legal regulation is to support an action system's existent norms, and in other cases about dismissing them and guiding the action system in a specific direction. In these cases, the economic action system's norms are influenced to the benefit of the social or natural system's normative imperatives. Our analysis of intervening rules and how they interact with intersystem conflicts indicates that in common with the German discussion, there is a perceived regulation crisis where structural links are perceived not as a legal problem, but a political one. This is about adopting a position in a structural conflict where, no matter what action you take, it will conflict with one of the involved action systems. Nothing suggests that this is a result of the communication process or the influence of one system over another. Rather, the problem lies in the fact that legal regulation in interventional situations should always be assumed - contrary to other implementations of law - to encounter resistance from all directions. One might say this is an inherent characteristic of norm conflicts involving interventional measures.

Let us examine a randomly selected, concrete example from the area of work environment studies. When a political decision is made to introduce different kinds of preventive or protective measures, it can also be decided that the legal system is responsible for executing said decision. This is done with the support of (intervening) rules, which demand that various measures be undertaken in the workplace. According to available research in the area, these rules are generally not implemented spontaneously. They compete with the existent action norms and are therefore experienced as foreign, expensive, unnecessary, bureaucratic, etc. This means that legally required norms have difficulty in gaining support; however, this is not due to the structural links. Rather, this is a result of law being used in some situations to influence structural intersystem conflicts: a challenging task. Naturally, we should not expect the involved actors to directly and spontaneously implement rules that seemingly do not have any bearing on their activities; for example, rules that require preventive healthcare options with the ultimate goal of creating a better work environment, systematic work environment improvements, etc., that may lead to interruptions in production and carrying out various kinds of measurements and check-ups. The benefit for those involved is not obvious, and hence, it becomes difficult to create a structural link between politics, the law and the area of society subject to regulation. But this is not because links between structures are inherently hard to construct. It is because some situations are structurally problematic. There are many more examples of intersystem conflicts that generate conflicts of norms in people's daily lives.

It is not surprising that this can be seen as a regulation crisis and as a failure of the legal system, but the main problem is not about how to link structures. However, it does have structural causes. Can anything be done about this? Do 
intervening rules represent an insolvable problem? The logical consequence of the argument that supports the use of intervening rules would be to recommend that society be restructured in such a manner that the structural contradictions underlying the intersystem conflicts and the ensuing conflicts of norms that lead to the intervening rules are eliminated. This, however, cannot be achieved through political solutions, but rather requires that society undergoes radical change. There will always be structural conflict in a society that has progressed past the point at which the law of diminishing returns set in. The further it has progressed, the more frequent and significant the conflicts between different social subsystems.

Today, there are two predominant social movements, each one struggling against the dominance and contradictions of the economic system. One is the women's movement, which promotes the social system's norms by combating the wage labour model on which the economic system is based, as well as patriarchal supremacy, and the other is the environmental movement, which focuses on promoting the natural system's norms by combating the driving forces behind the economic system. Both movements have gained increasing support in a short time. The problem, however, is that they do not have any solution to the structural problem. One could say that both the women's movement and the environmental movement want to promote their "issues" in opposition to the economic system's norms, but they do not want to reconstruct the system such that it would promote a symbiosis of various systems' norms to the extent possible. At least, no such intentions have been presented so far, perhaps one should add. ${ }^{126}$ Any eventual political breakthroughs for these social movements will therefore necessarily, it seems, lead to conflicts in peoples' social practices, although it could lead to resolving conflicts to the benefit of the previously disadvantaged (social and natural) systems to a greater degree.

The most important aspect, I argue, is finding solutions that eliminate or, if that is not possible, reduce the structural intersystem conflict at hand. But if the social constructions cannot be reconstructed, what then? It seems that we need to change the motivations behind our practices. Since this conflict is manifest in people's actual practices - despite the fact that it is contingent on structures and therefore beyond people's direct control - it should be possible to affect those mental structures that are most closely related to people's actual actions. To put it another way, it should be possible to influence people's perceptions of their actual conditions and thereby what motivates them, thus reducing the dominance of the goal-oriented systems. The natural systems are beyond our control, however. Compromise is possible, to some extent, but at some point, nature will react with implacable force. In this sense, the economic system is not an absolute force, despite the fact that it currently rules over the other systems. Therefore, it should be possible to influence it into compromising with the norms of other action systems to a larger extent.

126 Although Greta Thunberg may raise awareness, practical solutions are required. 
One solution to the regulation crisis would be to draw the actual, correct conclusions of the discussion on autopoietic systems. It would seem that economic measures are necessary to influence the economic subsystem. Hence, if one wants to have an influence on the rhetoric used within the economic system, one should stick to economic arguments, even when one wants to support phenomena that originate from sources other than the economic system. This is also becoming more common. By implementing taxes, fees, contributions and subsidies, the political/administrative system attempts to guide economic activity toward a form of compromise with the social and natural action systems' norms. These measures are met with some degree of success. The problem, however, is that each such measure is, in fact, an intervention into the action system's actual functions; it may not destroy the subsystem, but it always leads to some form of, sometimes unpredictable, external effects. The environmental and consumer movements have had some success with this strategy of reframing sustainable development issues from having been seen as an economic liability to being seen as an asset by applying pressure on corporations. ${ }^{127}$ This is the result of a growing environmental awareness since the late 1960s and the fact that corporations have realized that there is money to be made from environmental issues. ${ }^{128}$ Restricting the exploitation of natural resources may directly lead to lower raw material costs. ${ }^{129}$ Sound environmental policies, in common with other sustainable development strategies, such as promoting gender equality, human rights and a healthy work environment, may have a payoff in goodwill in an age when company branding is an important component of a company's value. ${ }^{130}$

Another way of approaching the problem is to increase the influence of the action systems that have been crowded out and have led to different kinds of negative effects. The natural system is always ready to fight back, and does so relentlessly. Already, we see some signs of this. We call them environmental disasters. Probably there is much more in store for us in the future as our knowledge grows of the relationship between our negligence of the natural system's ecological norms and health and well-being. We need only mention increases in asthma and allergies, different kinds of cancers, etc., even if the medical conditions have not always been fully established. After all, they have to be based in proven experience. The problem with the natural system is that if and how it reacts depend on whether or not certain thresholds are breached. The system is generally tolerant of our abuse, but at some point it will react harshly. If that happens, it may already be too late. In other words, this is not a recommended strategy for solving intersystem conflicts. This is why social movements and other forces for good within

127 For an overview, see Hydén, Håkan and Gillberg, Minna (2003).

128 Gillberg, Minna (1999). From green image to green practice: normative action and selfregulation. $\mathrm{PhD}$ thesis. Lund: Lund University.

129 Michelson, Staffan (2019).

130 Please see, Gillberg, Minna (1999) and Amundsdotter, Eva and Gillberg, Minna (2001). 
academia, corporations and authorities who are willing to take responsibility for promoting sustainability issues are vital.

The social system will also react when people feel cornered. From heated union strikes or the Ploughshares movement in Sweden, to rock-throwing youths during EU and World Trade Organization (WTO) conferences, civil disobedience has always been a signal that the social system is being neglected. The problem here, however, is more complicated. Firstly, the social system is not always composed of a single, homogenous population. There are class differences, differences between social groups, ethnic groups, gender differences, cultural and language differences, etc., that all may be in conflict with each other. Furthermore, the collective ambition to achieve sustainable results must also be capable of penetrating the political system. The political system it faces may be a dictatorship, an autocracy or democratic parliamentarianism and democracy. It is beyond the scope of this work to discuss this problem in detail. In fact, this deserves its own area of research. My interest here is solely to refer to the nature of the problem from the perspective of norm science. However, to mention a few concrete examples, we might refer back to the passage on the women's movement. The peace movement could also be mentioned in this context. There are other social movements that have also attempted, and attempt to, support and express the social system's norms, in competition with the logic of the economic system. ${ }^{131}$ Some prominent examples are union movements, the Swedish Hyresgäströrelsen for tenant rights and consumer cooperatives. However, in order for a social movement to play a role as a change agent in these times, one should be mindful of Manuel Castell's distinction between the need to progress from resistance identity to project identity. ${ }^{132}$ Given that, it is hard to predict which social movements are likely to bring about social change.

Attempts to produce solutions to modern society's failure to solve intersystem conflicts through regulation have not made much of an impact. Scientific discussions on the topic also seem to have grown silent, as mentioned in Chapter 2, following Jurgen Habermas' eloquent plea for procedural law in his book published in the early 1990s, Fakticitet und Geltung. In fact, there is reason to see modern law's tendencies toward framework legislation ${ }^{133}$ as a return to a form of vulgar law, which characterized the dissolution of Roman law, following the publication of Corpus Juris Civilis in AD 500, at a time when law and the implementation of law were increasingly becoming the domain of untrained legal practitioners. ${ }^{134}$ Similarly, today, much of our legislation is targeted at, and administrated by,

131 Gustafsson, Håkan, Vinthagen, Stellan and Oskarsson, Patrik. (2013). Law, resistance and transformation: social movements and legal strategies in the Indian Narmada struggle. Lund: Lund University Press.

132 Castells, Manuel. (1996). The information age: economy, society and culture. Vol. 1 The rise of the network society. Malden, MA: Blackwell.

133 Hydén, Håkan (1998).

134 Cf. Anners, Erik (1990, p. 95) et seq. 


\section{The evolution of norms and law}

non-legal professions. ${ }^{135}$ We might refer here to the Swedish Social Insurance Agency's capacity as an interpreter of legislation that is vital to the well-being of individuals, environmental councils and building councils, social services, county housing councils and other social bodies governed by laws that are vital for democracy and for the citizens' acceptance of the social system. ${ }^{136}$ Here, the surface level of law, the level at which law is actually implemented, to coin a phrase by Karlo Tuoris, has completely lost touch with legal culture, and hence with the basic principles of the fundamental structure of law. ${ }^{137}$

The use of intervening rules has allowed law to burst through its own limitations, which over time is detrimental to the legitimacy of law. Ahrne and Brunsson have shown in the book Rule Explosion (2004) how there lately has been a shift from state regulation to private regulation through rules introduced by all kinds of private law bodies, from certification to standardization bodies at the national and international level. In the same way, the contract is becoming increasingly important as a legal instrument at the expense of legislation. ${ }^{138}$ This is especially true in international contexts, where uniform legislation is largely absent. ${ }^{139}$ One might also see these tendencies reflected in the trivialization and demystification of law that Bo Carlsson suggests is apparent in the increasing interest in popular culture and legal fiction literature. ${ }^{140}$ Furthermore, this might be seen as a reaction to the system's colonization of the lifeworld, where the law treads a fine line in being a link between the systems and the lifeworld. In its traditional role to uphold the rule of law, the law protects against violations by systems through obligation norms; however, in its present form as framework law, it opens up for system dominance.

This combination of intersystemic conflicts that in themselves create legal incompatibilities and the absence of a legal profession to manage this development leads to an erosion of industrial society's legal culture, ${ }^{141}$ and as has been the case in other historical shifts in social systems, when a social and legal system reaches maturity, it ages and dies. To gain a better understanding of this process of change, we shall in the next chapter develop a theory which merges the evolution of law and society.

135 Cf. Bertilsson, Margareta (red.) (1995).

136 As an example of how law can sometimes go astray, see Hydén, Håkan and Thoor, Alf (1997), Hetzler, Antoinette et al. (2005). Abelin, Matthias (2019).

137 Tuori, Karlo (1999).

138 Hydén, Håkan, together with Karl Dahlstrand (2020).

139 For a norm-centered approach to International law, see Burchardt, Dana (2017).

140 Carlsson, Bo (2002); see also Sherwin, Robert K. (2000).

141 Modéer, Kjell Å. (2009), Modéer, Kjell Å. (2004). 


\section{Toward a theory of legal change}

\subsection{A theory of basic normative patterns}

Socio-legal studies in the field of jurisprudence are often characterized by the fact that they take their starting point in social theories, which means that the legal phenomena that are the object of study become illustrations rather than objects of study in themselves. One of the few theorists to have approached law as a way of understanding society is Émile Durkheim, in his study, De la division $d u$ travail social. Here, Durkheim argues that by studying law it is possible to gain an understanding of various forms of solidarity that emerge in society. ${ }^{1}$ However, few socio-legal researchers have devoted much time to analysing legal rules or drawing any conclusions of particular value. One exception is Anna Christensen (1936-2001). Another exception is the Danish legal sociologist, Jörgen Dalberg Larsen (1940-2016). ${ }^{2}$

Based in an analysis of the content of law, Anna Christensen maps out normative patterns, thereby laying the basis for a theory of basic normative patterns. "Much of the content of law, not least in the social dimension, is simply a legal codification of the moral practices and basic beliefs that society teaches us", Anna Christensen writes in an article in TfR 1996 which perhaps best summarizes her theory of basic normative patterns. ${ }^{3}$ In her most extensive work, Hemrätt $i$ hyreshuset (Residential Right in the Tenement House), she offers a similar description: ${ }^{4}$

Society's underlying norms are always present in legal thought. They are manifest in different forms, for example, in teleological interpretations of law, different interests when applying balancing norms, 'real considerations' in Eckhoff's theory of law. Even the social interest turns out to be a normative unit, upon closer inspection.

1 Durkheim, Émile (1997), in the English edition, The Division of Labour in Society (1997, pp. 24-28). See also Roger Cotterell $(1999$, p. 31$)$ et seq.

2 See, e.g., Dalberg Larsen, Jörgen (1984, 1991, 1999).

3 "Protection of the established position."

4 Christensen, Anna (1994, p. 4). 


\section{Toward a theory of legal change}

"Some patterns can be observed that recur in different contexts and with a certain constancy", continues Anna Christensen. She calls these patterns basic normative patterns. Each normative pattern has its own inherent core, or area of origin, Christensen argues. ${ }^{5}$ But they can be transferred to new situations. In the following, I will build on Anna Christensen's theory somewhat. ${ }^{6}$

The basic normative pattern is reflected in areas of society where law is active. There are different kinds of basic normative patterns. They work as counterpoles and either attract or repel legal regulation, with different levels of strength. Where, within this area, the legal rules end up depends on the power of attraction exerted by the counter-poles at different points in history. However, Anna Christensen emphasizes that normative patterns in law rarely appear in a purely isolated form. Legal regulation of an aspect of life almost always occurs within a normative sphere that is affected by several different normative patterns. These different patterns, then, result in various modifications.

Basic normative patterns, from Anna Christensen's perspective, seem to emerge in connection with bipolarities. As an example of basic normative patterns, one might consider the patterns that have evolved around counter-poles such as formal and material justice, i.e. between a concept of justice that is based on procedural and equal treatment under the law and a different concept of justice that is based on an assumption that everyone should be, or is, treated equally. Other corresponding basic normative patterns might apply between principles aimed at equal distribution, on the one hand, and the distribution based on needs, on the other. Anna Christensen identifies and describes two basic normative patterns that appear in bipolarity. She calls them "protection of the established position" and "basic market-functional patterns".

Anna Christensen argues that the basic pattern, "protection of the established position", can be found in all legal areas of the social dimension. As an example, she points out the employment protection aspect of labour law, protection for the tenant under the security of tenure law and the principle of loss of income under Swedish social insurance law. This also used to be the case in family law, expressed as rules intended to protect the institution of marriage and spousal maintenance rules. The most salient expression of this basic normative pattern, according to Anna Christensen, are the rights of use afforded the rightful owner. The point of this normative pole is that it only protects the individual who has already established a certain position. It is indifferent to how this position has been established. This means that "protecting the established position" can be combined with any of the other normative poles, as described above, that address equal distribution. However, Anna Christensen argues that conflicts can arise between patterns with incompatible contents. The basic patterns in themselves do not establish a system

5 Ibid, p. 529.

6 She developed this theory in collaboration with Ann Henning within the framework of the NORMA research programme which was managed by them both and funded by the Riksbanken's Swedish Foundation for Humanities and Social Sciences. 
or hierarchy. This theory is partly based on Douglas Hofstadter's thoughts in his book Metamagical Themas, which deals with how people and machines think. ${ }^{7}$

Initially, there are no given relationships between the different, basic normative patterns. Anna Christensen writes: ${ }^{8}$

Although one pattern may dominate in a given area of law, other normative patterns will always lead to modifications. Neither is law a stable force, and is instead constantly affected by other normative forces in the same area, constantly in motion between the two normative poles. When studying a particular normative pattern of law, it therefore becomes necessary to simultaneously observe other normative patterns that also have an impact on the same law.

The second normative pattern that Anna Christensen discusses, the marketfunctional pattern, differs from the "protection of the established position" by being dynamic. Protection of the established position is a basic, conservative pattern that protects and conserves and basically acts as an obstacle to any changes that threaten the status quo. The market-functional concept of ownership consists of the right to property combined with the freedom of contract and freedom of trade. In this way, it contributes to change and to introducing new activities, as well as "continuously redistributing values, thus leading to a change in established positions", according to Anna Christensen. ${ }^{9}$ She links the market-functional concept of ownership to the modern market economy.

In her application of the theory of basic normative patterns, Anna Christensen describes the dynamics of normative development by studying the law's progression over time and its motion within the force field between the different normative poles of the so-called social dimension. I will limit myself primarily to one area of Anna Christensen's theory, the subject she penetrates the deepest and most detailed, namely the area of tenancy law, or residential right, as Anna Christensen calls it. In legal practice, Anna Christensen argues, a perspective of the protection afforded tenants under tenancy law, the security of tenure, has developed which retrieves its contents directly from its grounding in the underlying world of social norms. ${ }^{10}$ Tenancy protection laws have developed within the force field between the two normative poles of property law and tenancy law. ${ }^{11}$ Positioned in contrast to the property owner's right to own property is the tenant's right to full and undisturbed disposal of their home.

The normative contents of property law differ in different societies and different historical contexts. But according to Anna Christensen, we find a normative

7 Hofstadter, Douglas (1985).

8 Ibid, p. 531.

9 Ibid, p. 530.

10 Christensen, Anna (1994, p. 362).

11 Ibid, p. 355. 


\section{Toward a theory of legal change}

core based in tenure security in almost societies. Legal sociologist Karl Renner makes the same argument in his book The Institutions of Private Law and Their Social Functions. ${ }^{12} \mathrm{He}$ argues that the content of property law has remained unchanged since Roman law, although it has had different socio-economic and political implications. According to Renner, this is because property law has been combined with different legal institutions over time. The relationship between property law and other related institutions, such as the contractual institution, has defined the socio-economic function. The context in which the concept of property law originates has therefore progressed from dealing merely with the simple production of goods under Roman law, when each person owned their own production, to the broader version of owning the means of production in the industrial age, which also entailed having a measure of power over other people, and finally to the welfare state's concept of the owner's right of disposal within the boundaries and limitations of the intervening laws that the state imposes.

Despite the concept of property law having expanded and undergone a sort of socialization, it remains, at its core, a component of the most personal and private sphere, that which is essential to life. The basic normative content of the concept of property law is, in Anna Christensen's view, aimed at conserving present conditions. This can be contrasted with another aspect of property law, i.e. the right of disposal. As property is recirculated and reused in new ways, this leads to continuously adapting conditions. ${ }^{13}$ Anna Christensen calls this aspect of property law the dynamic aspect. This aspect is linked to the market economy, and thus she refers to it as a market-functional concept of property law.

The basic normative content of tenancy law, the tenant's right to full and undisturbed disposal and use of their home, the leased apartment that simultaneously is also a home, coincides with the conservative basic, normative content of property law. The conflict arises when property law undergoes an expansion and encompasses property that simultaneously is a component of another person's personal sphere. We can therefore conclude that in the area of tenancy law there is an inherent conflict between, on the one hand, the conservative content of the concept of property law, which is concerned with protection against others violating your property rights, and on the other hand, the market-functional concept which protects the right of disposal of the property - in this case the facility owned by the property owner. The tenant wishes to continue living in the apartment, while the property owner may wish to dispose of it otherwise, perhaps by leasing it to another tenant, or perhaps by putting it up for sale, etc. The same inherent conflict can, as discussed in the previous chapter, be found in the area of working life between, on the one hand, the employee's legitimate interest in demanding to keep their employment, which simultaneously is their livelihood, and on the other hand, the employer's interest in being able to dispose of and adapt the labour force to economic fluctuations. 
Anna Christensen further develops and refines Renner's analysis of the development of the concept of property right by applying her theory of basic normative patterns. Based in Anna Christensen's analysis of the historical development of tenancy law, I would like to describe how the conflict between property law and tenancy law has developed over time. Residential tenancies were introduced as a result of populations concentrating in urban areas in the wake of industrialization. The right to own real property did not, at the time, include the right of disposal, or even the right for the individual to freely sell the property. "Property rights in old agricultural societies were a conservative property right that granted the owner the right to undisturbed disposal and use of the property, under the condition that ownership thereafter be transferred to the heirs", Anna Christensen writes. ${ }^{14}$ Ownership of real property could be seen as a form of stewardship. ${ }^{15}$ The conservative view of property rights was very strong at the time, which resulted in strong protection for a more traditional approach to the disposal and use of property. At the time, rental tenure granted almost unlimited rights of use under the condition that the usufructuary used the land in an approved manner and paid their ground rent. These permanent rental tenancies locked property owners and users into fixed roles that obstructed future, necessary changes. During the 19th century, it was prohibited to grant new rights of use without time limits. This was due to the need for greater flexibility in adapting the right of use of permanent properties for new activities. Arguments in support of the dynamic effects of the owner's right of disposal of their property began to gain credence.

This development gained full force under the Act of 1907 on rental tenure and real property. It laid out that rental tenure was subordinate to the marketfunctional concept of ownership. Chapter 3 of the Act of 1907 laid out tenancy regulations. It allowed full freedom of contract. Judging from the reasoning provided in the legislative drafting, the other alternative would have been to return to permanent tenancy rights based on "a legal perspective that belongs in the past". ${ }^{16}$ During the latter half of the 19th century and culminating in the early 20th century in the Act of 1907 on rental tenure and real property, a legal perspective emerged that morphed from the protection of the established position to the market-functional concept of ownership. This development, however, reversed once again and slowly began to move back in the opposite direction from the market-functional concept of ownership to protection of the established position. This can be likened to the swinging motion of a pendulum as it oscillates back and forth.

The turning point came during WWI when it was decided that it was necessary to introduce temporary tenancy rules in the form of the Rent Increase Act. To ensure that prohibitions on rent increases were effective and to prevent the

14 Ibid, p. 358.

15 Christensen, Anna (1996, p. 533).

16 Proposition for the legislative drafting of the Swedish Land Code of 1905, p. 69, retrieved from Christensen, Anna (1996, p. 538). 


\section{Toward a theory of legal change}

rules from being circumvented, the authorities also felt compelled to introduce some form of tenure security. This law was introduced after much agonising, and it was argued that under no circumstances would any long-term limitations be placed on the property owner's right of disposal. Legal practice, however, as it evolved during the short time the law existed, came to give the law on security of tenure its actual content, as later laid out in the Tenancy Act of 1968. The Rent Increase Act was discontinued in the early 1920s. Simultaneously, the first arguments were raised in favour of the normative-based notion of tenure security. This was accomplished by arguing for the need to introduce residential rights. This argument was put forward in two articles published by legal professor C.G. Bergman in Tiden in 1922, as noted by Anna Christensen in her book Hemrätt $i$ Hyreshuset. Anna Christensen argues that "it is clear that the basic normative pattern on which Bergman bases his arguments, with regard to residential rights, exactly matches the conservative content of property law". ${ }^{17}$

However, residential rights were not introduced at the time. In contrast to Bergman's ideas was the market-functional argument, most notably proposed by social democrat and legal pragmatist Vilhelm Lundstedt, based in his theory of social utility. But as Anna Christensen points out, the notion of having residential rights in rented accommodation had been established and articulated, and it found fertile ground in the tenant movement in Sweden and some corners of the political establishment. Therefore, after tenancy law combined with tenure security had resurfaced again during WWII, trying to discontinue these rules was no easy task. They continued to persist, and by 1956 , the time was ripe to introduce a law on tenure security that was independent of the Rent Increase Act. Although the law was initially temporary, security of tenure eventually became permanent law after being included in the 1968 Tenancy Act. ${ }^{18}$

Over time, the law on tenure security has stabilized and been strengthened in a number of areas. Anna Christensen concludes that tenure security was not designed to provide the right to the actual apartment, but rather as a right to an extension of the contract with the landlord. This right also provides legal protection against the property being taken over by new owners, provided the lease has been agreed to in writing and the tenant has been granted admittance to the apartment. ${ }^{19}$ In principle, the tenancy contract can be extended for as long as the tenant remains there, barring evictions as a result of misbehaviour on behalf of the tenant or other legal conditions. ${ }^{20}$ Anna Christensen points out that modern tenure security laws for rental apartments often follow the same basic normative pattern as the permanent tenancy laws that existed prior to the market-functional era which dominated the early 20th century. Even the concept of inheritance, which was typical of agricultural societies' understanding of the right of use, can

$17 \operatorname{TfR}(1996$, p. 539).

18 Christensen, Anna $(1994$, p. 1$)$.

19 Swedish Land Code of 1905 Ch. 7, s. 13.

20 Swedish Land Code of 1905 Ch. 12, s. 46. 
be traced to modern tenancy laws. Under tenancy law, spouses, partners and children have the right to take over the tenancy.

The inherent nature of the law on tenure security, to protect the established position, thus does not mean that the right of ownership is transferred from the property owner to the tenant. In this regard, the right of ownership remains intact. What has happened is that the right of disposal has been limited, i.e. the market-functional elements have been relegated to the background in favour of protecting the established position. On the other hand, the property serves another purpose, seen from a financial perspective, in its capacity as a lease. In that sense, the property owner does not suffer any injury. The dynamic aspect of the concept of property law is also met by the rules of the Swedish Land Code Ch. 12, s. 46 regarding cancellations of rental contracts in cases where the landlord has given notice that the building is to undergo extensive refurbishing. Tenure security is negated if the building is to be demolished, rebuilt or converted into offices. This means, as Anna Christensen argues, that the property owner's interest in being able to dispose of the property as they see fit is satisfied in cases of a socio-economic nature, while this interest is not strong enough to trump the conservative tenancy protection interest in cases where the property owner only has personal interests at heart, e.g. being able to lease the apartment to relatives or friends. In the same way that the property owner is entitled to compensation in the event that the property is expropriated in the public interest, the tenant is entitled to compensation if the property owner cancels the tenancy under the above conditions; although this does not entitle the tenant to financial compensation, it does entitle them to a comparable substitute apartment.

The legal manifestation of security of tenure, then, is a series of compromises between the market-functional concept of ownership and protection of the established position. Since the right of ownership, in our era, in some cases has come to gain a measure of collectivity and thus a specific social nature, as pointed out by Karl Renner, the state implements intervening rules for the right of ownership. ${ }^{21}$ The social aspect of the right of ownership of public goods, or where there is a need for social protection, is expressed through compromises that are forced through as the result of intervening rules. ${ }^{22}$ They allow the two aspects of the right of ownership - the market-functional concept and its emphasis on the right of disposal, and the conservative element that protects the established position with its limitations on the owner's right of disposal, to coincide. The intervening rules create a balance between society's interest in development and change in relation to the right of ownership to certain types of property, on the one hand, and the need for social protection in relation to the individual, on the other hand.

21 For more on intervening rules, see Hydén, Håkan (1978) and Hydén, Håkan (1999).

22 This theme is addressed in the context of the discussion on social civil law. See Wilhelmsson, Thomas (1987). See also Stridbeck, Ulf (1992) and Sandgren, Claes' critical analysis (1992/93). 
Anna Christensen analyses basic normative patterns in all corners of the social dimension, i.e. in working life, the social sector and the family. In these areas, she notes a development similar to the previously mentioned development in the area of tenancy law. For example, security of tenure has a direct counterpart in employment protection law and progresses through history along a parallel curve from pre-capitalist conditions characterized by protection of the established position and is later dominated, ${ }^{23}$ from around the turn of the century and onward, by the market-functional perspective which favoured the right of disposal, up until the 1970s, after which it regained elements of the protection of the established position through employment law.

The Employment Protection Act expresses the same interventional compromise between the market-functional perspective and the need for social protection as is reflected in the construction of the law on security of tenure. Employment protection is also constructed to leave the market-functional perspective intact in cases where employment terminations are tied to socio-economic interests, i.e. when the dynamic need for change in the business sector demands employment terminations. Employment terminations must be based on objective grounds, according to the law. However, there is a substantive difference between terminating jobs due to redundancy and personal reasons. Redundancy is considered reasonable grounds for terminating employment - under the condition, however, that the employer, in compliance with relevant societal conditions, must terminate jobs according to the last-in-first-out principle. Furthermore, anyone who loses their job due to redundancy has preferential right to employment should the employer begin to recruit staff again within nine months of the termination, and originally within one year. These rules are now being tweaked and relaxed. In cases where employment is terminated due to personal reasons, in other words, when the market-functional argument is not applicable, the employer must prove objective grounds for the termination and refer to aggravated circumstances as laid out in the legislative history.

These rules in the area of labour law are intimately intertwined with the emergence of industrial production in a capitalist society in general and wage labour in particular. It could be said that the social insurance system developed in a similar manner, i.e. as a necessary supplement to the modern wage labour system. ${ }^{24}$ Anna Christensen puts it as follows:

Preindustrial forms of work were integrated into the general social sphere and would, in practice, provide a space and the opportunity for a livelihood for all members of the social unit in which labour was organised. Industrial development and the market economy have resulted in a division between

23 This is clearly shown by the December Compromise of 1906, when LO (the Swedish Trade Union Confederation) approved the employer's right to hire and fire workers and direct and allocate work according to the needs of the organization.

24 Christensen, Anna (1996, p. 550). 
work and other areas of the social sphere, leading to a special kind of contractual relationship which is only concerned with labour and wages and is governed by demands for productivity and profitability. At some point in life, most people encounter events that prevent them from performing at a level that entitles them to a full wage but do not have recourse to aid from any other social units. The social insurance system patches over gaps in-between jobs.

Anna Christensen argues that there are signs in the area of social insurance that indicate a movement in the direction of the basic market-functional normative pattern. There is a clear tendency both toward reduced compensation levels and increasingly stringent requirements for compensation to be approved. ${ }^{25}$ The market-functional perspective demands that people surrender their established positions and accept the labour market's new conditions. The argument is that people should not be chained to a life dependent on social insurance.

There has also been a traceable development in the area of family law that swings back and forth between the basic market-functional pattern and protection of the established position. In preindustrial society, the family was the most important social institution. The function of marriage law, then, was to guarantee the reproduction of this institution. Roman Catholic doctrine tells us that marriage is a lifelong union that can only be terminated by the passing of one of the spouses. Over time, Lutheran ideology came to accept some grounds for divorce. In Sweden, too, the general norm was that divorce could only be approved in extremely rare cases.

This view grew more relaxed as the family's role changed with the advent of industrialism. The concept of the family as a production and supply unit was dissolved and replaced by industrial corporations and wage labour. Urban migration played a role here, too, meaning that earlier forms of social control, and not least the control over daily life wielded by the church, no longer worked. This led to a development of norms that lagged behind and eventually had an impact on legal practice and how laws were applied. The men and women of the new working class tended less to enter into marriage, and bourgeois families began to use these new, special grounds for divorce - matrimonial causes - as a way of mutually consenting to divorce. The new Marriage Code of 1915 introduced new grounds for divorce, deep and lasting disruption. Thus, the development toward a more open-minded view of marriage had begun and would be fully realized in marriage law in the 1970s. According to Anna Christensen, the gradual dissolution of the old insoluble form of marriage in the 1800s and 1900s should mainly be seen as a development from status to contract. She emphasizes that freedom of contract here does not correspond with the basic market-functional pattern, but with a more general normative pattern that is concerned with protecting personal 


\section{Toward a theory of legal change}

freedom and autonomy. ${ }^{26}$ There is probably reason to argue that the need for protection of the established position that women previously were afforded through marriage in modern industrial society has been offset partly by women entering the labour market in the 1970s and onward and partly by the state, through the social security system, taking on the role of "family provider". ${ }^{27}$

Anna Christensen also briefly comments on the need for protection in other legal areas in her article "Protection of the Established Position". She sees similarities between international law on sovereignty and citizenship. Intellectual property protection for designs and trademarks can, according to Anna Christensen, also be seen as an example of protection of the established position. ${ }^{28}$ Clearly, Anna Christensen believes that basic normative patterns can be traced through society and that they recur in different areas of law. ${ }^{29}$ However, she limits herself to describing patterns within the areas of law that can be said to belong to the social dimension. To test the validity of Anna Christensen's theory outside this area, I will compare it to rules in a completely different area, i.e. the environmental area. While the social dimension has to do with one of the pillars of the basic market-functional pattern, i.e. the concept of ownership and freedom of contract, environmental issues relate to freedom of trade. It is therefore of interest to examine whether the same development has occurred in this area.

\subsection{The emergence and developmental pattern of environmental law: a basic normative pattern characterized by dominant economic norms}

\subsubsection{The two sides to the right of ownership}

There is a paradox, as Anna Christensen points out, inherent to modern ownership laws in that they, in fact, combine two conflicting interests. On the one hand, there is the interest in maintaining stability and integrity to be found in the protected possession of property, and on the other, the right to freely dispose of said property, to do with it as you will, thereby having an influence on permanent/fixed conditions. A corresponding contradiction between the two aspects of ownership can be found in the area of environmental law. Here, the right to protect oneself against another person's violation of ownership of property, a counterpart to the protection of the established position, conflicts with the right to freely dispose of the property, an expression of the dynamic content of the market-functional concept of ownership. ${ }^{30}$

26 Ibid, p. 571.

27 Compare the tripartite role of the provider role in terms of family, state and market in Dahl, Tove Stang (1987).

28 Ibid, p. 573.

29 See Statements, Ibid, p. 564.

30 I address this problem in my dissertation, Hydén (1978) Ch. 8. 
During the latter half of the 19th century, the first signs of environmental damage as a result of industrial activities began to emerge in legal practice. ${ }^{31}$ Soot and chimney smoke pollution had become commonplace, industrial machines were noisy, canal companies caused surge waves leading to erosion problems, railway transports caused fires, etc. The first manifestation of these problems in legal practice was in the form of court trials based in general legal principles.

Legal ideology was faced with problems it was not equipped to cope with. The introduction of industrialization revealed the inherent contradiction in the concept of ownership, as pointed out by Anna Christensen. The "right to" perspective leads to the right to freely exploit any property you own, while the "freedom from" perspective gives other owners the right to demand intervention against an exploitative property owner and claim their own rights. ${ }^{32}$. During the latter part of the 19th century and the early 20 th century, two different methods of dealing with this conflict emerged in court practice, and thus two ways of approaching the problem of environmental nuisances. One was an approach based on immission law, the other based on tort law.

The immission law strategy dealt with remedying the owner's violated freedom. The tort law strategy, as a means of resolving the conflict between different ownership interests, is characterized by the exploitative property owner compensating the injured party for any infringement or damages resulting from their activities. In this case, the solution is in the form of a compromise, whereby the person whose ownership rights have been violated is awarded financial compensation. In the first case - the immission law strategy - the solution is based on forbidding the business to continue operations or serving the offender responsible for the environmentally hazardous activities with an order to undertake such protective measures as to eliminate the harmful immissions.

\subsubsection{The institution of immission}

The immission law strategy was never particularly successful and aroused opposition at an early stage. It was regarded as having an inhibitory effect on industrial development and was a threat to the future of the country. ${ }^{33}$ The institution of immission law, therefore, was only used in the initial stages of industrialization. The standpoint immission law takes in approaching the problem is unequivocally based in the normative pole, i.e. protection of the established position. The institution of immission law thus came into conflict with market-functional demands from actors that wished to use property for industrial activities and to dispose of it freely. The emergence of large-scale industrial society meant that the institution of neighbour law, the original legal framework in which immission law was based,

31 Hydén (1978) Ch. 8.2.

32 Hydén (1978) Ch. 8.1.

33 Hydén (1978) Ch. 8.3. 


\section{Toward a theory of legal change}

was no longer adequate. Seen from the opposite perspective, the immission law strategy threatened economic progress.

Normally, immission law reasoning included the demand that the violated right of ownership be remedied. The usual process in immission law procedure, in legal practice, was either to prohibit the operations causing the immission or to order the person responsible to take measures to eliminate the harmful immission. Towards the end of the 19th century and the early 20th century, there were a number of examples where it had become legal practice to order similar kinds of prohibitions and/or injunctions. One example of legal practice in the Supreme Court concerns a case involving industrial steam hammers which generated vibrations in the neighbouring factories and office premises and were banned in one case in $1877 .{ }^{34}$ In some cases from the turn of the century, power equipment that caused vibrations in neighbouring apartments was also banned. ${ }^{35}$ Other examples are the closing of a factory chimney that was deemed an inconvenience to the neighbouring residents and a ban on a gas engine installed in a bakery. ${ }^{36}$ The latter was judged to be such a nuisance that it interfered with the neighbours' sleep. There are also cases of electrical machines installed in farmhouses being banned after causing vibrations that led to cracks and subsidence in the neighbouring buildings. ${ }^{37}$

It did not take long for people to begin to compromise on the principles underlying the institution of immission law. ${ }^{38}$ As far back as the Swedish Land Code Bill of 1909, it was assumed that immissions could not be completely avoided and that property owners therefore must tolerate a certain amount of inconvenience in relation to business activities in adjacent facilities. It was also argued that immission law rules would greatly cripple the industrial sector and that such effects should be prevented through a concession system. ${ }^{39}$ It was against this background that intervening rules emerged in the environmental area.

\subsubsection{The institution of tort law}

The first step toward introducing the market-functional concept of ownership, which was better adapted to coping with the emerging industrial society's demands for expansion, was taken through the institution of tort law. However, this approach turned out to be too narrow and complex to provide an adequate solution within property law. This, in turn, can be attributed to four other specific problems, namely the requirement for subjective responsibility, determining a point of tolerance, the requirement for evidence and investigation and delimiting the number of claimants. ${ }^{40}$

34 NJA $(1877$, p. 514).

35 NJA (1903, p. 365).

36 NJA (1900, p. 189).

37 NJA (1891, p. 129).

38 See the interesting discussion in NJA 1891, p. 129, cited in Bäckman, Anders (1998).

39 Lundgren (1974).

40 For a more thorough review, see the references in Note 31 above. 
The requirement for subjective responsibility loses its significance when the injuries incurred cannot be attributed to an individual's carelessness or negligence, as is the usual practice when claiming liability. The legal concept of culpability is no longer key. The causes of injury switch from the human factor to systematic risks associated with modern production. In this way, responsibility becomes increasingly system-bound and less tied to human error. It is from this perspective that the introduction of strict liability should be regarded as the basic principle of tort law, i.e. responsibility regardless of the individual's culpability, carelessness or negligence. This occurred for the first time in written law through the Environmental Protection Act of 1969, but had been pervasive in legal practice long before. The provisions for strict liability were subsequently transferred to the provisions of the Environmental Code.

The culpability requirement, in practice, came to be replaced partly by demands for fewer restrictions on the use of property and establishing a kind of point of tolerance that leads to liability if exceeded and partly by abandoning strict liability when the activities causing the damage had so-called local or general characteristics. In this way, the solution to the conflict between the two sides of ownership is shifted to a solution that, from an individual, moral, perspective, is an acceptable solution at a socio-rational level. This development thus corresponds to observations in the areas of security of tenure and employment protection, where industrialization led to a compromise that maintained the right of disposal in socio-economically related situations, e.g. the right to terminate employment in case of redundancy, while the need to protect the established position was otherwise maintained in general.

With regard to local and general conditions, if damage to the environment results from what is generally regarded as either a local or general characteristic of said activities, it must be established in one way or another that the owner has either been careless or negligent in order for damage claims to be justified. In other words, there is a higher level of tolerance for activities that are harmful but which are caused by the dominant employer in the region. People living in industrial areas with some level of environmental pollution have to resign themselves to living under unhealthy conditions. People living in areas where some kinds of harmful activities are regarded as commonplace, e.g. sulphate factories, are simply forced to accept the ensuing nuisances. These examples can be seen as compromises that are contingent upon the economic action system's demand for space, leading to the market-functional concept of ownership intruding into the protection of the established position.

The third problem associated with the institution of tort law as a tool for dealing with environmental issues is the requirement for evidence and investigation that arises as a result of the increasingly complex nature of environmental challenges. While reducing the subjective requirement for subjective responsibility through the imposition of strict liability, in some cases, this makes things more complicated for the objective side. The health and environmental problems associated with modern production are characterized by the fact that they are unknown to science. Only once they have emerged and become commonplace is 
science able to identify their causes. Epidemiological studies are a useful method when it comes to health issues. However, they are only able to confirm the problems after they have occurred. Analysing the causes of ecological disturbances is even trickier.

The institution of tort law, in other words, has the inherent disadvantage that it presupposes the presence of that which it is intended to sanction. Only once the injuries have been incurred and, moreover, to such an extent that knowledge of the causal relationships can be established, is it possible to intervene against the harmful event. This is a systematic disadvantage to the protection of the established position, and in practice strengthens demands for the right of free disposal. Finally, the institution of tort law suffers from the disadvantage of being particulate. Only those who appeal through the civil action process are able to receive compensation or effectively bring a halt to harmful activities.

The institution of tort law therefore does not guarantee that the actor behind the harmful activities will be held fully liable for the problems. It depends on who makes the claims and what they are based on. This can have a detrimental effect on the public preventative effect. Additionally, we should also factor in Swedish courts' rather parsimonious attitude when it comes to evaluating health and environmental damages. These conditions also encourage the right of free disposal at the expense of the protection of the established position.

\subsubsection{Intervening rules}

It was therefore clear at an early stage that the legal instruments provided by property law to address environmentally driven legal issues were not suited for the task. As environmental issues grew, the institution of immission law seemed anachronistic while the institution of tort law appeared to be incapable of coping with the increasing complexities of environmental issues. Furthermore, early industrial society saw the institution of tort law as a problem. In their opinion, it was irrational to risk being drawn into damage claims after having invested in certain industrial activities that were beneficial to society. ${ }^{41}$ It was thus argued that the industrial sector needed to be protected. This led to bills being presented before Parliament around the turn of the century that proposed to address this problem. Thus, new legal solutions were produced in the form of concession law. As mentioned above, proposals to introduce intervening rules as a solution to the environmental conflict between the two sides of ownership were already put forward in 1909 by so-called land code experts.

This bill represented a compromise insofar as it took its starting point in the right of free disposal, but in order to protect individuals who were at risk of being affected by environmental disturbances, a system would be introduced whereby the neighbours' environmental demands were made clear from the outset. This gave birth to the notion of concession law. Anyone who plans to run a business 
that conducts environmentally hazardous activities is allowed to do so under the condition that the competent authority gives their approval. In connection with this, the licensing authority determines the conditions under which the activities may be conducted.

Thus, intervening rules entailed a new way of thematizing environmental problems and a new way of resolving the conflict between the basic market-functional pattern and protection of the established position. The bill of 1909 provided relatively far-reaching protection of the established position. It determined that a government agency composed of scientists should be responsible for assessing the environmental issues at hand and providing solutions. Furthermore, this assessment process would also take into consideration, estimate and resolve any damage claims in advance. However, it took all of 60 years for the concessional system bill, introduced in 1909 by the so-called land code experts, to gain force through the 1969 Environmental Protection Act, and then in a highly diluted form. Up until then, the parties involved had preferred to belittle the risks and dangers of environmental disturbances. The industrial sector argued that it had not been proven that the environmental problems were the result of industrial activities and that both capitalism and nature and the environment's own selfhealing processes of dilution, etc., were so strong that they would take care of any environmental disturbances. In other words, they refused to see environmental problems as ecological disturbances that could ultimately interfere with the basi, protective, normative pattern inherent in the right of property.

The damages, as environmental historian Lars J Lundgren has pointed out, did not reach alarming levels as long as the emissions consisted mainly of natural organic and inorganic substances, but it did establish a behaviour, a harmful behaviour, that eventually also came to tolerate emissions from synthetic substances and various forms of toxic substances. Protection of the established position was forced aside by the economic action system's demands for the right of free disposal. The pressure of structural norms began to make itself felt in largescale industrial society. Lundgren has expressed it as follows: ${ }^{42}$

Freedom of competition meant that the rules of production under capitalism served as a coercive law against the individual factory owner. Free competition, thus, limited his freedom of choice to a minimum. He was forced to adapt to established conditions and play by the general rules of the game. Dumping waste into waterways was simply a social fact, a social act that happened regardless of how the individual felt about it. Deviant behavior was "sanctioned". Therefore, pollution was a social problem. Since the polluters were unlikely to change their own behavior, a political decision was needed that would force everyone to follow the new rules. This could entail a rather lengthy and cumbersome process, especially as resistance had been mobilised. 


\section{Toward a theory of legal change}

For the first time, protection of the established position gained recognition through the Environmental Protection Act. Companies were required to apply for permits before initiating activities that were defined by law as environmentally hazardous. Similar rules were later entered into the Environmental Code of 1999. Accordingly, permit applications are now submitted to the environmental courts, of which there are six, linked to district courts in Sweden. In connection with the permit review, the environmental courts also decide the applicable conditions appropriate for each situation. These conditions are essential for protecting the environment. The regulation that provides the requirements for environmentally hazardous activities lays out the obligation to "implement protective measures, comply with restrictions and take any other precautions that are necessary in order to prevent, hinder or combat damage or detriment to human health or the environment" (the Environmental Code, Ch. 2, s. 3).

\subsection{Are there basic normative patterns that recur in other areas of law?}

The Environmental Protection Act introduced a measure of protection for the established position, which was transferred to and strengthened through, the Environmental Code. Protection of the established position shows considerable similarities with tenure security and employment protection. It is based on intervening rules that establish a compromise between the basic market-functional pattern and protection of the established position. It is thus possible for both to coexist simultaneously. The default starting point is that an individual is not allowed to freely start up any kind of business they feel like without first obtaining permission. Freedom of trade is therefore not an absolute freedom. However, environmental law also has built in mechanisms, similar to the areas of tenancy law and employment protection, which do not threaten the right of free disposal as long as they are applied in accordance with the basic market-functional pattern's social rationale. The structural norms, then, remain intact.

Although businesses are obliged to take precautionary measures, these conditions need not be more intrusive than is financially and technically defensible. Therefore, economic norms determine how far-reaching the demands to support the environment's need for protection of an established position may be. Under certain conditions, for example, even "significant damage or detriment to human health or the environment" (Environmental Code, Ch. 2, s. 9) may be considered acceptable if there are "special reasons", i.e. the business is of economic or other importance to society. Even in cases involving health or environmental threats, social and ecological conservation norms are forced aside by powerful economic norms characterized by large-scale social rationality.

This construction also means that there can only be a demand for already developed technology used in industrial operations. Freedom of trade is absolute in the sense that the environmental courts cannot demand that technology be developed for purification or protective purposes. Neither may authorities or courts interfere in any chosen method of production by demanding that a 
company produce another product or use production methods that are less harmful to the environment. Another important fact, here, is that the law is structured in such a way that roughly the same demands will be made within each individual industry. Competitive neutrality is a guiding principle here. Profiting and gaining advantages from an unhealthy environment is not permitted. In this way, the law also intervenes and supports another pillar of the basic market-functional pattern, i.e. freedom of competition.

Interestingly, this can be compared to the areas of social security of tenure and particularly employment protection in legal developments based in general principles set out by law. The requirement for material grounds for dismissal pursuant to the Employment Protection Act constitutes, as we have seen, an acceptance of redundancy, i.e. economic grounds for dismissal, but is otherwise based in protection of the established position in relation to the specific case. Similarly, the line is drawn for the protection of the established position in environmental issues in the space where it convenes with economic interests. Courts and authorities are not allowed to impose stiffer requirements pursuant to a so-called industryspecific assessment than the affected company is capable of meeting. In addition, decisions on what conditions should apply are based on individual assessments that, furthermore, are based on the information that the company itself presents in its application.

The question is whether similar incipient tendencies can be established in the environmental area toward a return to the market-functional pattern that can be observed in the areas of tenancy and employment. It would seem that the transition from protection of the established position to the market-functional pattern is, in fact, a transition to a new basic pattern, in which demands, borne of the social relationships of the new era, will be posed to protect the established position. From this perspective, we note the emergence of self-regulatory processes in the environmental area based in the assumption that environmental issues are undergoing a transformation from being a negative value to becoming a positive value ${ }^{43}$ This is related to the fact that the environment has become a competitive commodity. As environmental awareness has increased, consumers have begun to place greater demands on environmental quality, which in turn has incentivized companies to establish positive environmental profiles. We might describe this as a systemic coalition. This has led to the business sector undertaking self-regulatory initiatives that go beyond protecting the established position as dictated by the Environmental Code. ${ }^{44}$ Furthermore, support structures, such as EMAS and ISO 14001, have been developed to support this new legal development. ${ }^{45}$ This, then, lays the basis for a new normative progression away from

43 See inter alia Hydén, Håkan (1998).

44 Cf. the discussion in Minna Gillberg's thesis (1999), and Hydén, Håkan and Minna Gillberg (2002, to be published).

45 Ibid. For more on the development of norm-supporting structures in the initial phase of a judicial procedure, see Per Wickenberg's thesis (1999). 
the protection of the established position to a basic market-functional pattern, with reservation for the possibility that the new basic normative pattern could develop in a direction that would make the market-functional designation somewhat redundant. But the progression tends toward the same direction as in the areas of tenancy and employment protection.

The basic normative basic pattern in the social dimension that Anna Christensen describes thus finds support in the environmental area as well. This recurrence is very significant in Anna Christensen's view. ${ }^{46}$ She continues:

It becomes evident in different areas of law (family law, public law, etc.), and in various "external" situations (employment situations, tenancies, payments from the Social Insurance Office). There can be no doubt that this same pattern can be found in maintenance rules in family law and rules on widow's pensions in public law, as well as in employment protection and security of tenure.

This has to do with a basic, underlying pattern. It is a historical constant. The same pattern that characterized security of tenure in old Swedish agricultural society reappears in the rules on security of tenure in modern tenancy laws. It is a pattern widely distributed throughout the entire system of norms. It is found in all legal areas of the social dimension. It is also a powerful pattern with a clear impact on the content of the rules. Admittedly, it may disappear for a time while a particular area of law is undergoing regulation, but it remains in the normative field and reappears in legislation over and over again, in new shapes and forms.

Anna Christensen also explains that these norms and conceptions arise through normative practices in people's daily lives and deal with managing relationships with other people and which are furthermore confirmed by law. ${ }^{47}$ This suggests that the basic normative patterns deal with more or less "eternal" issues that arise from relationships and are moderated by the prevailing, contemporary social context. Anna Christensen is mainly concerned with how protection of the established position emerges. In her summary, she argues that the development of labour law and tenancy law during the last century can be described as a shift in the normative field between two poles: on the one hand, protection of the established position and, on the other, its market-functional polar opposite. This shift in both legal areas has largely occurred in tandem, and we can also observe parallels in the area of environmental protection.

The processes behind the creation of the different legal systems occur within strikingly similar timeframes. The Act of 1907 on rental tenure and real property can be compared to the 1909 Land Code bill which, in itself, did not become law at the time, but which indirectly helped to consolidate the market-functional concept of ownership in the environmental area.

46 Christensen, Anna (1996, p. 564).

47 Ibid, p. 565. 
In 1956, both tenure security law and the Water Act underwent changes. Eventually, tenure security gained legal force via the Tenancy Act of 1968 and environmental protection gained force via the 1969 Environmental Protection Act. A similar trend can be found in labour law. In 1906, the labour market parties, LO (the Swedish Trade Union Confederation) and SAF (the Swedish Employers Association), entered into the so-called December Agreement, which essentially meant recognizing the employer's right to hire and fire workers and direct and allocate work in turn for respecting the workers' right to organize themselves. ${ }^{48}$ In the 1970 s, comprehensive legislation was introduced to protect workers and their established position. In the same way that security of tenure without the right to sell, as Anna Christensen argues ${ }^{49}$ creates an overly inflexible and conservative order from a market perspective, employment protection without the right of notice, or environmental protection without the right of establishment, leads to an excessive breach of the premises underlying the financial system that favour protecting the established position. We might also mention that in 1974, the ACT ON RESPECTING CERTAIN MEASURES FOR THE PROMOTION OF EMPLOYMENT (1974, p. 13) was introduced. This act contained provisions and obligations in addition to notifications of restrictions on any operational activities to submit information to the County Labour Board regarding information pertaining to the possible, legislated recruitment of former employees or employees with disabilities. These provisions can be seen as examples of legal regulation that intervenes too far in its endeavour to protect the labour force against market-functional logic, i.e. in practice, the law has not been implemented as intended. The limit for judicial intervention in support of social or ecological norms is clearly drawn where it meets the demands of the economic structural norms.

In our times, the two basic normative pattern poles, i.e. the market-functional position and protection of the established position and the right of free disposal represented by the freedom of contract, freedom of trade, and freedom of competition, at one end, and, at the other end, the social welfare interest, expressed through restrictions on private ownership, have entered into an association. This has given birth to a special kind of legal rule, or intervening rule. These kinds of rules not only allow both sides of the concept of ownership to coexist, they have also been able to integrate, thereby creating a specific normative pattern which has come to dominate legal development in modern society. Anna Christensen argues that the residential right she identifies and analyses shares normative characteristics with those unlimited forms of right of use that existed in agricultural societies, which in turn were similar to Roman law's emphyteusis, ${ }^{50}$ which, in ear-

$48 \operatorname{Berg}(2011)$.

49 Christensen, Anna (1994, p. 371).

50 This is a Roman and civil law contract by which a right is granted either perpetually or for a long period to the possession and disposal of originally agricultural land subject to keeping the land cultivated or protected from depreciation, the payment of a fixed annual rent and some other conditions, Merriam-Webster Dictionary. 


\section{Toward a theory of legal change}

lier times granted unlimited, hereditary and generous rights of use to fixed properties under the obligation to pay a fee to the landowner and which was based in even older role models over 2,000 years ago. ${ }^{51}$ The progression from the basic market-functional pattern to protection of the established position and then back again to the market-functional perspective has probably occurred in societies that existed prior to the period analysed in this chapter.

\subsection{The development of the legal system within bipolar values}

The categories in which Anna Christensen examines the pattern of market functions and protection of established positions can presumptively be associated to a tense relationship, which occurs in larger or smaller scales within all society systems between an interest in exploitation and a protection of the implementation of human needs. Cases in which exploitation coincides with or leads to the implementation of human needs cause a decrease in the significance of the protection of established positions. And vice versa, one can assume that if such exploitation actually threatens the implementation of human needs, the importance of safety precautions would increase. We can claim that economic values oppose human values, economic rationality against human rationality. There may be several reasons for why this opposition occurs. The fundamental organising principles of society are determinant during certain circumstances. Another consistent feature is that a social system that has reached a certain large degree of scale tends to retreat from the "people it serves". To use Jürgen Habermas' terminology, ${ }^{52}$ opposition occurs between the system and lifeworld. It also concerns the external effects that follow in a large-scale society, thus causing it to become counterproductive with regard to the implementation of human needs which once drove forth ambition and the structure of society.

These factors vary over time. During the market epoch, technology advancement led to the separation of production and consumption and laid the foundation for the market as a distribution mechanism. This in turn gave rise to a distinction between a product's utility value as a consumer good and its transactional value in the market as a sales item. The distinction, which was a central aspect in Marx's analysis regarding the capitalistic economy, was accentuated through the invention and application of the concept of a legal person..$^{53}$ This concept made it possible to refer to a company or some other sort of organization as an individual person. However, the fact that there is a difference between a large company and an individual person (with regard to resources) has left the market vulnerable to disturbances in the form of overexploitation of consumers.

51 Ibid, s. 374, This kind of land right - tomträtt in Swedish, is a type of tenure of land, which was introduced in Swedish law via the Act of 1907 on rental tenure and real property.

52 Habermas, Jürgen (1995).

53 Torpman (2002). 
Consumers have demanded compensatory mechanisms in the form of consumer protection legislation.

Hence, there is a connection between the invention of the concept of the legal person and consumer protection legislation. The background behind the establishment of the concept of the legal person in the mid-1800s relates to the fact that industrial production underwent a phase of expansion and required the ability to assemble large numbers of capitalists within the framework of a legal subject. This situation generated the division of what used to be regarded as natural persons into two types of legal subjects: physical persons and legal persons. Through this separation, the entire Roman legal system built on civil rights upon which the market economy in our current phase of society is based could be transferred; the societal phase was based on large-scale industrial production. The invention of the concept of the legal person also made it possible to transcend national borders as a first step towards the need for a global, legal order. The price society had to pay was the wave of intervening consumer protection legislation which was introduced in the 1970s and onwards. This was done in order to express the need for the protection of the established position, i.e. social protections, against a dominating interest for exploitation. Since the individual person has neither equal strength nor equal access to resources as a large company, a consumer ombudsman and consumer agency was set up. Here we find a parallel, as discussed in the previous chapter, to the introduction of the Environmental Protection Agency and the Environmental Courts, which were established during the same period. Their task is to ensure that the individuals' / consumers' wishes are fulfilled in the market through the support of intervening legislations such as the Consumer Sales Act, the Marketing Act, legislation of unreasonable terms in contracts, home sales legislation, etc.

The tense relationships in industrial society, which require compromises between exploitation and protection/preservation and arise as a result of the contradiction between labour and capital, occur as a consequence of the organization of work in the form of wage labour. This inherent contradiction requires intervention to support protection of the wage labourer, first in the area closest to human needs such as health and the work environment, thereafter by respecting livelihoods via income opportunities, followed by the growth of collective labour law ${ }^{54}$ and finally employment protection law. ${ }^{55}$ After a while, the systems come to dominate and force people into specific patterns in order to satisfy their needs. ${ }^{56}$ Since this leads either to overexploitation or to neglect of the human aspect, compensating mechanisms are generated. The development of consumer and environmental legislation, as well as labour law, constitutes such examples. ${ }^{57}$

54 See Schmidt, Folke (1962) and Adlercreutz, Axel (1954).

55 See Numhauser-Henning, Ann (1984).

56 Cf. Habermas' distinction between and discussion of the terms lifeworld and system in Habermas (1987) and Chapter 3 above.

57 I used this juridical area in my doctoral thesis, Hydén (1978), to portray the growth of intervening rules. See also Hydén, Håkan (1999). 


\section{Toward a theory of legal change}

Anna Christensen's theory deals with changes within the normative foundation of the market economy. She regards the market economy as an economic system built upon certain fundamental normative preconditions: ownership, the freedom to conclude contracts and freedom of trade. In this way the protection of established positions may be seen as an expression of the need for social protection, which emerges when these three legal institutions do not generate legitimate consequences in response to human needs.

This leads me to emphasize yet another condition which is important for the understanding of changing processes within the legal system: the relation and correlation between different normative patterns. The normativity, which determines the compromise between the normative patterns based on market functions and the protection of established positions, is not necessarily the same as that normativity which creates the needs and driving forces for regulation. There are several normative poles or dimensions which operate simultaneously and which either support or counteract each other over time. As examples of some other such polarities, we could mention equal distribution versus distribution governed by needs and substantive justice versus formal justice.

The British sociologist of law Roger Cotterrell in his book, Law's Community: Legal Theory in Sociological Perspective ${ }^{58}$ highlighted different social characteristics in the form of polarities which he believes characterize modern law. $\mathrm{He}$ underlines the polarities between order and justice as legitimating attributes, between voluntary and ratio as bipolarities of the juridical doctrine and between empire and community as reflections of society, which are implied and active in juridical doctrine and rhetoric. Cotterrell claims that order and justice relate to one another. However, order is a more basal attribute of society. The logic here, then, is that there is no reason to strive for justice if there is no guarantee that it will be implemented. In the concept of the rule of law, justice and order merge through the accentuation of predictability, according to Cotterrell.

The opposing pair, voluntas and ratio, stand between the will of the supreme, the unquestionable political authority and enforcement power, on the one hand. On the other hand, it also includes elements of considerations and principles, where the unifying force and convincement gain meaning through the idea's logical pattern, i.e. its normative consistency and rational coherence. ${ }^{59}$ Voluntas represents the legal system's need for hierarchy and political control. In the final analysis it is the legal system's political authority that gives it the characteristics of a coherent legal system. Potential inconsistencies and indistinctness in court are concealed through the manipulation and practice of political power. ${ }^{60}$ While voluntas reflects the legal system's political authority, ratio expresses the moral authority's entity and integrity. Voluntas is associated with legal positivism in that

58 Cotterrell, Roger (1995).

59 Cotterrell, Roger (1995, p. 165 f. and 278 ) et seq.

60 For individual examples of this phenomenon, I refer to the case descriptions in Hydén, Håkan and Thoor, Alf. (ed.). (1997). 
if the element of voluntas increases, the institutionalization of the juridical doctrine tends to increase. This benefits the growth of a certain legal profession, which gives law the characteristics of standardized politics, where comments in the preparatory work constitute the main source of law. ${ }^{61}$ Law transforms into (legal) technique instead of art. ${ }^{62}$ The legal system in today's industrialized world is, according to Cotterrell, characterized by the fact that substantial rationality the juridical principles and the moral arguments supporting the contents in law tends to be "piecemeal and localized". ${ }^{63}$

Similarly to the way in which order has priority over justice, voluntas dominates over ratio. Cotterrell suggests that this is shown, amongst other things, by the fact that when executive, legislative and judiciary powers are policy-driven, they continuously interfere with the legal rationality that necessitates a jurisprudential "purification process". The function it serves is that of repairing the loopholes and gaps in the juridical logic. Cotterrell points out that voluntas and ratio both are independent of each other within legal doctrine. ${ }^{64}$ Voluntas can contribute to law and order, whilst ratio similarly can contribute to chiselling out morally founded and systematized principles of justice. However, at the same time, Cotterrell sees these two values as related to and dependant on one another. There are certain limits to how much power centralized government can possess in a legal sense before either being considered illegitimate or imploding like the Soviet system. In addition, there are limits to how far moral rationality is able to spread in the legal system. Morality is closer at hand within various sections of the legal system, whilst other sections depend more on political power struggles.

When studying the polarity between imperium and community, the same reasoning becomes significant. The legal system's imperial characteristic relates to the hierarchical relationship conveyed by the legal system when it enters into communication with individual people. The legal system is somewhat supreme, since it can be enforced physically. To contrast with this description, one could take the legal system and portray it as community; something which is held together by and evolved from a common morality between people who share the same values. This characteristic is linked to the distinction between the legal systems, which are, so to speak, built from the top and developed from the bottom, respectively. ${ }^{65}$ Cotterrell argues that in the industrialized, Western world's legal system, there is a clear link between the depiction of the legal system as an imperium and voluntas, as well as between community and ratio. He writes:

The image of community presupposes a moral grounding of principle which is considered to unite society and which finds its expression in legal doctrine

61 Cf. Hydén, Håkan (1999) Ch. 2.

62 Cf. Strömholm, Stig (1981). Also Høilund, Peter (1992).

63 Cotterrell, Roger (1995, p. 318) and Cotterrell, Roger $(1989$, p. 223) et seq.

64 Cotterrell, Roger (1995, p. 319).

65 Aubert (1989). 
as ratio. If ratio is the element of unifying moral authority in law it implies social arrangements in which principles of justice are derived by elaborating a substantive rationality justified as grounded in shared moral experience.

Both Christensen and Cotterrell highlight the simultaneity in the opposing pairs which the legal system displays. Christensen, however, discusses movements, how the normative poles attract over time and are drawn towards different regulations. Cotterrell perceives the opposing pairs as paradoxes ${ }^{66}$ partly opposing values, which struggle to influence legal doctrine and regulation. I can agree with both, but claim for my own part that the development of norms portrays a pattern which implies movement from one polarity to another and vice versa. The opposing pairs can be perceived as bipolar values that the normative development alternately opposes. When the development reaches its extreme end, it turns in the opposite direction toward the other polarity, only to return once the development again reaches the second polarity's extreme. In my opinion, this can be regarded as a swinging pendulum. Using this as our starting point, we have reason to discuss shifts of focus, where both polarities are constantly present, but where a displacement of dominance occurs simultaneously with the progression of norm development towards one of the polarities. This development is not continuous. Its course of events can be jerky and uneven, but the point is that it follows a trend. The movement is towards a certain direction, in a certain time.

The observation of legal development within various legal systems, which was discussed in relation to the issue concerning Anna Christensen's basic normative patterns, supports the idea of an existing movement between one polarity and another. Given that basic normative patterns are reflections of "moral customs and fundamental positions which evolve in society", the discovery of a social development corresponding to changes in the normative progression patterns is possible. Thus, there is no reason to believe in the existence of a simple causality between legal development and normative and legal changes.

\subsection{Law as an indicator of societal change}

To have an idea and understanding of the developmental processes, we need a theory of law and its nature. Legal theory is generally discussed in a legal philosophical manner. Such theoretical reasoning encounters difficulties in reaching beyond a taxonomic stage that is characterized by divisions of different types of law. The starting point when understanding different laws, then, becomes their mutual relations and characteristics. This can be regarded as a reflection of the circular nature of law at its present stage. Law is nothing more than what is defined as law, which in turn can be divided into different sub-categories. "Relatively little time is spent on the study of law as a system, its differentiation from other social systems, or the interaction of its parts", writes Terence Daintith. The equivalent 
within jurisprudence that takes its starting point in the social sciences could be Niklas Luhmann's and others' description of law as a normatively closed system, where the emphasis lies in the explanations of how different societal subsystems are able to communicate and interact with each other in terms of autopoietic systems.

Neither has sociology of law (SoL) devoted any particular interest to the question of the relationship between legal rules and their societal background and their corresponding societal entities. The obvious question concerning which societal conditions correspond to different types of legal rules has not been addressed, or at any rate, treated in a systematic way. Jørgen Dalberg Larsen states that the legal system has a genetic side that corresponds to the question of what lies behind a certain law and an operational side that deals with the effects in various respects. This is similar to my distinction - between a vertical, deductive perspective of the legal system and a horizontal, cause-oriented approach to law, in which the latter corresponds to Dalberg Larsen's perspective. In both cases, it is either a question of highlighting the one perspective, i.e. the background to why we have rules of law, or the other, i.e. the consequences and functions of law. The two perspectives are not integrated into one cohesive theory of the relationship between law and society.

Another tradition within SoL concerns the implementation of laws and the problems this faces. These studies provide us with knowledge of the conditions under which law can be expected to operate according to its intentions. Some types of legislation require specific institutional arrangements to be maintained. This applies primarily to the laws inserted into social life from the outside and intended to be implemented in a top-down perspective. These studies tend to consider law as a black box, i.e. as if the legal design is meaningless for the implementation. There is therefore no accumulation of knowledge of the relationship between law and society within this research field.

Within SoL, there are also research approaches which aim to describe the legal development in terms of different stages. Even the first sociological studies of relevance to SoL used the law as an indicator to describe the development of society. As the main representative of this scientific approach, Émile Durkheim's study, De la division du travail social, can be noted, in which the author uses changes over time, moving from an emphasis on criminal law to civil law, as an indicator of a society in transition from mechanical to organic solidarity. Another such classic example is historian Henry Maine's study of the development from status to contract. Also Max Weber's analysis of different types of authorities can be pointed out in this context, where legal authority represents modern society.

The American sociologists of law Phillipe Nonet and Philip Selznick have divided legal development in modern time into three phases: repressive law, autonomous law and responsive law. The form of legal system may, in their view, be seen as an indication of societal development. Repressive law responded to the need to legitimize an emerging political order. With the initiation of a new social organization principle followed, according to Nonet-Selznick, a need for change in the legal structure. In response to the repressive phase, autonomous 


\section{8}

law evolved. This law, which was initiated during the previous century, was perceived as standing above social, economic and political problems. This became an ideal to maintain, which created a dividing line between law and politics and between legal and social sciences. Autonomous law corresponds to what Max Weber called a formal legal rationality, characterized by strict rules and normdriven decision-making, universal and precise rules and supervision of a legal profession. Autonomous law also gives rise to a very specific system of rationality that is legitimized through procedural regularity.

Nonet-Selznick claims that we crossed over into a third phase during the post-war era, namely, responsive law. Law became a more flexible social institution, in a position to learn from experience and react flexibly to social needs and human expectations of the surrounding community. In this new legal form, legal decision-making is governed by considerations of purposes, which are based on social scientific knowledge, and different mechanisms of participation, whereby citizens are drawn into the use and development of law. This means in turn that the former, strongly maintained distinction between law, society and politics is weakened.

This orients formal and autonomous law towards a material content. The purpose-oriented law requires goal-oriented funding rules. When trying to establish the purposes of law, the previous norm-oriented decision-making method is to a greater extent replaced by policy analysis. The new responsive form of law also requires new institutional and organizational structures. Integration of legal and moral judgments and legal and political participation is needed. The function of the legal system, according to Nonet-Selznick, is to harmonize the institutional and social contexts, rather than to influence the social contexts as such. Instead of directly entering into a specific, social outcome, law is referred to in structural arrangements such as negotiations, decentralization, planning and channelling of conflict.

Jørgen Dalberg Larsen has touched upon similar ideas in his description of the transition from law to the welfare state. Another sociologist of law to have addressed legal development as a process of stages is Gunther Teubner. In an article published in the Law and Society Review in 1983, he puts forward a theory that law moves from formal to substantive law and onwards to what he calls reflexive law. Teubner agrees with Nonet-Selznick that we have passed a stage of formal law, which is consistent with the concept of autonomous law, and have since entered a stage of material law. Teubner believes the transition from formal to material law should be divided into two types: a "genuine" material law, which is used to realize specific, concrete values - what Teubner calls substantive law - and another type of material law which Teubner has labelled reflexive law. This latter, legal form is characterized by constitutive and procedural rules that put limits on legal developments without specifying concrete material values to be realized. Teubner (1983) summarizes the characteristics of reflexive law by placing it against a background of formal and substantive law as follows: "Reflexive law affects the quality of outcomes without determining that the agreements will be reached. Unlike formal law, it does not take prior distributions as given. 
Unlike substantive law, it does not hold that certain contractual outcomes are desirable".

These legal forms discussed above can also be traced in Swedish legal tradition. For my part, however, I tend not to view development as an evolutionary process in which a legal form replaces another. Rather, I see it as society gradually expressing demands for changes in legal forms, without the former legal forms completely disappearing. Therefore, I am more inclined to emphasize the simultaneous involvement of the various types mentioned. The different types of law exist in parallel with each other, but they have different functions, and in particular, varying levels of strength over time. This rather leads the thought to patterns that legal development takes over time, where one legal form is displaced - without disappearing - in favour of another. I will therefore make use of Anna Christensen's theory on basic normative patterns consisting of different poles that attract or repel law during the development of society.

\subsection{The locomotive of legal development}

The time has now come to introduce a theory of legal development which makes use of the ideas about societal development, the comprehension of norms in society and their development over time. These theoretical explanations must be based on something other than the superficial reflection of the expression of the legal rules at hand. Seen from a long-time perspective and with the facts at hand, the legal rules can be used as indicators of societal development, similarly to how Durkheim worked, for example, or as informers of normative developments, as Anna Christensen's and Roger Cotterrell's analyses of movements within basic normative patterns suggest. To construct the aforementioned theory, I will begin by returning to the discussion on societal development in terms of cycles presented in Chapter 1 . In the second step, I will relate these societal movements to normative and legal changes over time. Keeping in mind the evolution of our own legal culture, we have reason to consider the work of one man, Harold J. Berman, who attempted to combine the two aspects when he, in the conclusions of his great work Law and Revolution: The Formation of the Western Legal Tradition, writes the following:

Thus, Western legal tradition grew - in part - out of the structure of social and economic interrelationships within and among groups on the ground. Behavioural patterns of interrelationships acquired a normative dimension: usages practices were transformed into custom. Eventually custom was transformed into law. The last of these transformations - custom into law is accounted for partly by the emergence of centralized political authorities, when a conscious restructuring at the top was needed to control and direct the slowly changing structure in the middle and at the bottom. Law, then, is custom transformed, and not merely the will or reasoning of the lawmaker. Law spreads upward from the bottom and not only downward from the top. 
Social theory must therefore accept a broader concept of law than that which Marx and Weber adopted. Law was, they believed, an instrument of domination, a means of implementing the lawmaker's will. But this theory of law, usually identified with the positivist school of jurisprudence, only tells us part of the story. Law is also an expression of moral standards as understood by human reasoning. This view of law, which is associated with the theory of natural law, is also partly true. Finally, law is an outgrowth of custom, a product of the community's historically rooted values and norms. This third view, associated with the historical school of legal philosophy, can also lay claim - like the other two schools - to a third of the truth. By combining all three perspectives, it may be possible to provide better answers. Our theoretical foundation depends on our understanding of societal development as the motion of a wave, as presented in Chapter 1. A second point put forward in Chapter 4 emanates from the understanding of norms as imperatives belonging to different systems. This is facilitated by stability, which distinguishes legal development in our country over time. Another ingredient in the theory of legal development can be found in Chapter 5 where the comprehension of the reasoning around the gradual change of dominance and focus within the legal system is discussed. Furthermore, we can base the analysis in the actual legal development, as presented in this current chapter.

We know that the legal system collects its main contents from the constitutive norms of the social, economic and political/administrative systems of action in society, but we also know that the legal system completes these systems by creating its own norms/rules - what I call intervening rules. Moreover, we have been able to establish that the reason for why certain norms within the given system of action are given the status of legal rules is due to the need to secure the reproduction of the respective system of action and the measures it proposes. Those norms, which are of vital significance for the reproduction of the systems, tend to become legal rules. This, however, does not mean that these rules are considered the most important norms by the system of action. The reason for this is that the norms of the system of action lie practically outside the legal system. Those norms which constitute the system of action have been proven to demand empowerment by the legal system. This relationship contributes to granting stability to the respective system. It leads to slow changes over time, in line with the legal system's way of changing successively.

Additionally, the legal system's structure and task are explained by the reproductive function, which requires mechanisms for consensus and solving conflicts. It deals to a great extent with what ought to be considered right and wrong. To a large extent these types of legal rules are distinguished by their stability, which is related to the stability of constituting norms, whilst action-norms vary and transform. Today's rules, which are embedded in civil and penal law and which enclose the social and economic systems, are borne of old traditions. The same conclusion can be made when discussing the procedural laws which lay the foundation for legal conflict resolution. Within the administrative legal system or the public authority's jurisdiction, the principles are dependent on the political systems' historical specification, which gives them a shorter lifespan. They follow 
the development of the societal cycle, which are, at present, equivalent to the developments in the early 1900s, although the amount and extent of the body of rules has increased.

In this situation, there is also reason to remind of the delay which legal development illustrates in comparison to society's development in general. It presumes that the legal principles of an epoch or era are expressed in relation to the fact that the epoch or era has reached its maximum limit and is on the verge of dissolving. It presumes that the legal development illustrates a certain delay in relation to those waves which societal development describes. However, with this reservation in mind, we can establish the fact that legal development follows in the wake of the waves. We therefore rediscover a period of deregulation which is connected to the diminishing agricultural and handicraft eras. At the same time, we can identify a re-regulation in the framework of industrial society's escalation during the mid-1800s and onwards. It sometimes seems as if there is a gap between de-regulation and re-regulation. Legal re-regulation does not directly succeed de-regulation; instead, the amount of rules decreases during the period of de-regulation only to gradually be compensated by new legal regulations, thus increasing again. One can question what ought to be applied in a time when the legal perspective appears to be in a vacuum. The most probable answer to this is that we find ourselves in a stage of self-regulation without legal interference. It is likely that it is this self-regulation that lays the foundation for the codification which takes place afterwards. During this period, the legal system undergoes a reconstruction where the already existing building blocks are combined with new constellations at the same time as original legal institutions might come into existence, as a reaction to the new technology and to the new demands of society.

To return to describing society's development in terms of S-curves, this means that the legal system's developmental changes are visible on the upper half of Figure 6.24 , i.e. it appears historically after a period in which the societal era has left its birth phase and begun its growth phase. Throughout this period, the previous society's political and legal institutions continue to dominate. It is not until the old society, through de-regulation, has let go of its hold on society and the new society has consolidated its positions in which there is reason to expect a legal codification that we get what we call a legal system. In Figure $6.24 \mathrm{dem}$ onstrating societal development, legal regulation is initiated at the point where the two curves intersect. Legal development then crosses through the various stages, which follow the curve's rise to a maximum point, only to be followed by de-regulation, as previously described. The hypothesis generated by the overarching analysis states that legal development is always preceded by a self-generating phase and succeeded by legal codification when the societal development curve approaches the middle. Thereafter, legal regulation dominates until it has lost force and been replaced by a new legal culture.

During the late 1900s, we similarly find a de-regulation of the industrialized Western world from the 1980s and onwards. This de-regulation was introduced after industrial society had reached its peak in the early 1970s. We were taking the first steps towards a re-regulation of digital society's needs. So far, self-regulation 


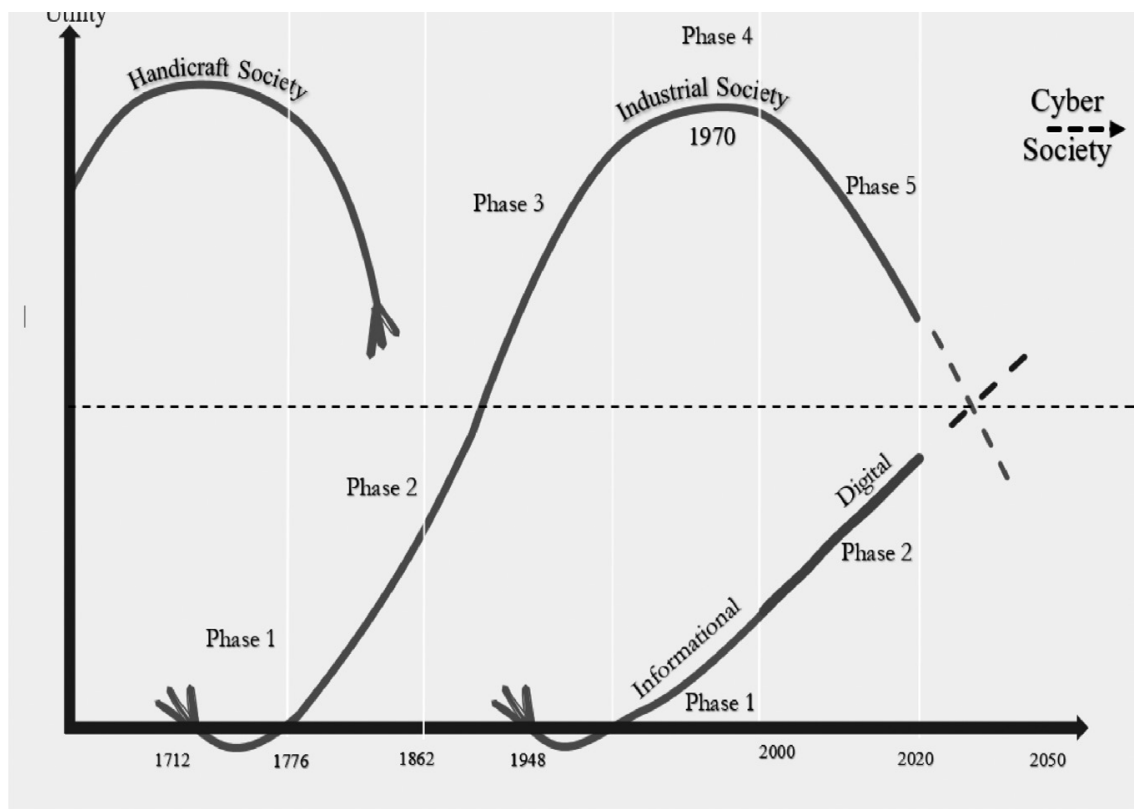

Figure 6.24 Legal regulation at the point where the two curves intersect

dominates within the IT field, where concerned participants are left to find their own way; the legal development is distinguished by the contraction in the introductory stage of a new era, as well as the extraction during the development towards the peak of the cycle. This symbolizes the progression from a state limited to upholding basic security needs and rule of law as ideals during an introductory stage to the growth of the welfare state at the peak of industrial society's development.

The logic behind legal development tends to differ from societal development. Society develops during the market epoch through a series of steps related to the growth of new core technology, thus undergoing system or paradigm changes over time. In contrast, the development of normative and legal history is distinguished by its movements within the frame of bipolar opposites. This is where the expression "the locomotive of societal development" comes in. The word locomotive is formed by combining the two Latin words locus, which means place, and motivus, which in more modern Latin means movement. What is interesting about this combination of words is that it merges two separate and incompatible expressions. It concerns partly something stationary, such as place, while simultaneously depicting something as dynamic as movement. For this reason, the word locomotive can be used to express the principles of the parallel legal and societal developments. The legal system moves in a vertical dimension, within a place, 


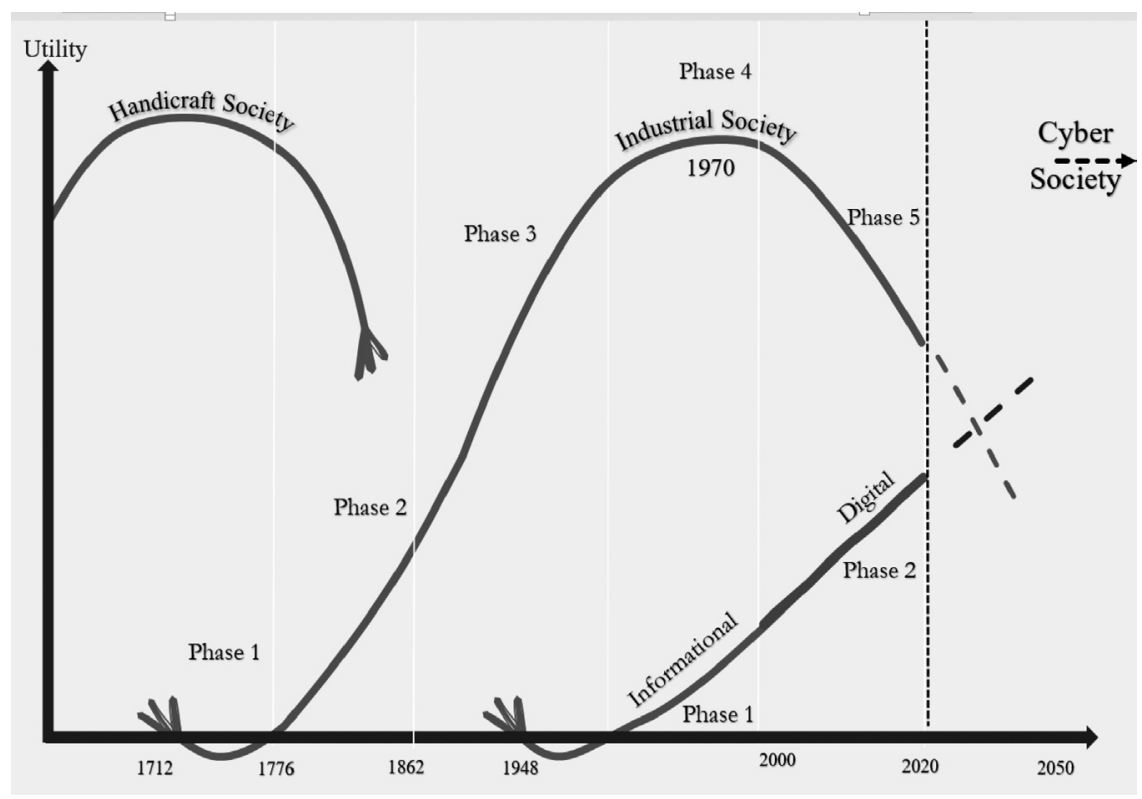

Figure 6.25 Legal system in a vertical dimension

up and down between bipolarities, whilst society moves forward in a constantly changing progression. See Figure 6.25.

With the support of our knowledge of basic normative patterns, there is reason to assume that the legal system describes a movement from a market-functional, basic pattern in the introductory phase of a cycle. It then receives the elements of protection of the established position at the same time as the movement increases, as described by the cycle. When the S-curve reaches its peak, and for the duration following shortly afterwards, the protection of established position is at its greatest. This was manifested in the legal dimension through the growth of the market-functional approach during the late 1800s, which broke through into the legal system at the turn of the century. This is also shown in the consolidated protection of its established position which developed during the post-WWII period and broke through into the legal system by the end of the 1960s and onward. During this period, various compromises were gradually established in the movement from one polarity to the other.

The legal system consists of many of these bipolar continuums (Figure 6.26). The poles are constituted by different opposing values, such as the previously mentioned distinction between substantive justice at the top of the vertical continuum and formal, procedural justice at the bottom, that occur in the initial stage of an emerging society. 


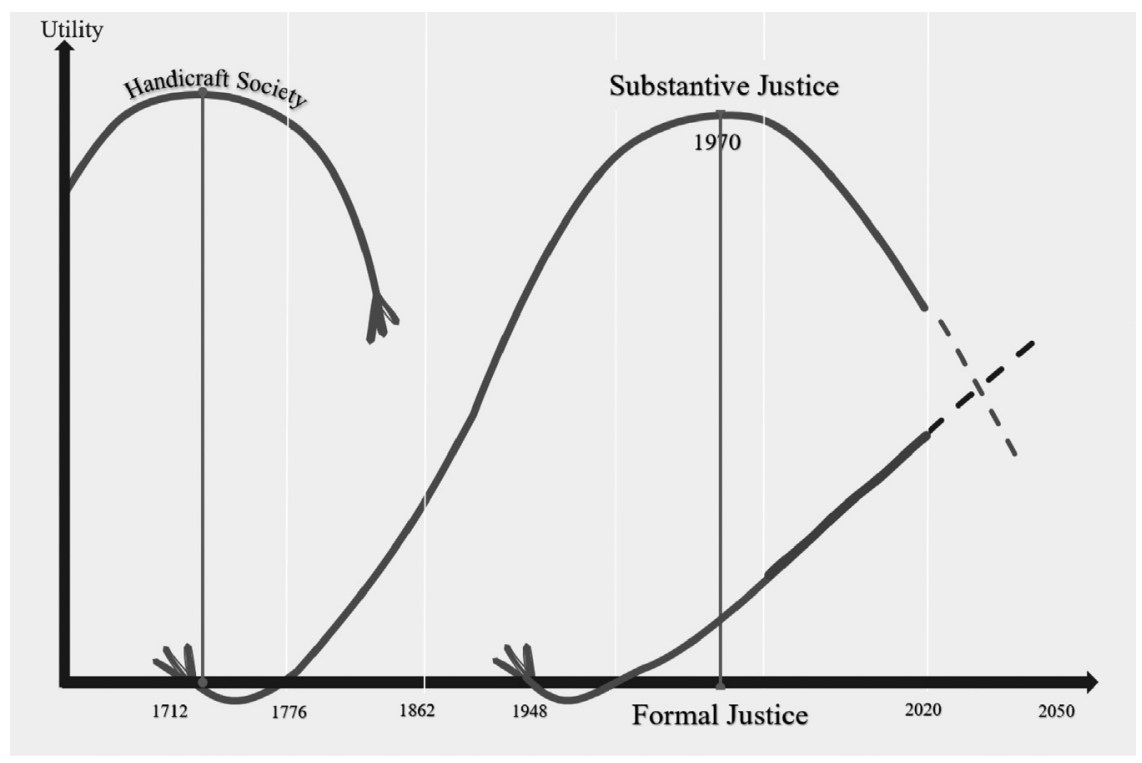

Figure 6.26 The legal system consists of many bipolar continuums

Another example of poles mentioned by Roger Cotterrell is the movement from voluntas at the top and ratio in the lower part of the continuum. Voluntas, as mentioned above, represents the legal system's need for hierarchy and political control. It is above all the legal system's political authority which shapes the nature of a coherent legal system. Ratio expresses the moral authority's entity and integrity. Cotterrell also points out the distinction between imperium and community. Imperium corresponds to the stage at the top of the continuum and dominates when society has reached a large-scale societal phase characterized by hierarchical relations where law is imposed from above, while community can be regarded as something which is held together by and evolved from a common morality between people who share the same values. This is what occurs in the beginning of a societal development. Therefore, community can be placed on the lower part of the continuum (Figure 6.27).

I have described this development in other situations in terms of a tendency for legal institutions to emerge and disappear over time. ${ }^{67}$ They can disappear for some time, becoming what is described as obsolete in legal terms, but they tend, sooner or later, to return. In the same manner, a shift arises from the protection of an established position back to the market functions, or at least to the freedom

67 See Ewerman, Anders and Hydén, Håkan (1997, p. 98), where I discuss shifts in focus in the legal system's development over time, and Hydén, Håkan (1996a). 
The Locomotive of Legal Development

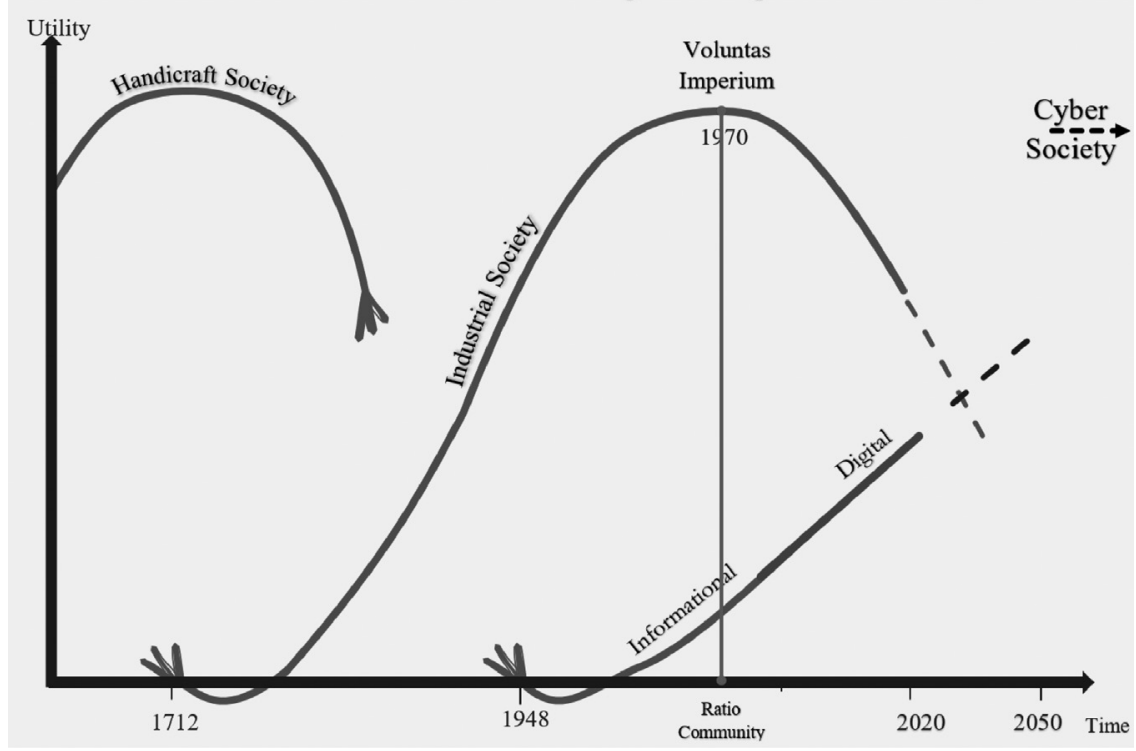

Figure 6.27 The locomotive of legal development

of contract which distinguishes the free disposal of property (ownership, proprietorship). This occurs at a time which coincides with the information society just as it is about to break ground. This indicates that the movement is reversing. The protection of the established position returns, whilst a new era of patterns of market functions is established.

Sociologist of law and Austrian statesman Karl Renner made the same observation, although from another perspective. He claimed that the concept of property has been able to retain the same juridical significance over time, even though its social/economic/political contents have shifted from the Roman legal system's simple production of goods, where everyone owned what was produced, to industrial society's more composite concept of ownership, to means of production in terms of wage labour. This also implies reconciling the concept of property with influence over other people. The last step is the welfare state's mixed concept of property with the right of disposition for the owner within those boundaries and restrictions set up by the government through intervening laws. Renner explains this phenomenon by describing that the concept of property was related to different, linked legal institutions over time. The relation of the concept of property to the contract, security rights and other occurrences all played a part, as did the construction of the concept of the legal person.

The development from one societal system to another shows itself in a progression from collective to individual orientation, which is legally equivalent to a shift 


\section{Toward a theory of legal change}

in focus from law to self-regulation, which in turn increases the significance of the contract as a legal instrument. Every new cycle leads to the process starting over again. The allusion to wave movements is perhaps a more appropriate way of describing it. ${ }^{68} \mathrm{~A}$ wave crashes on the shore and is replaced by a new wave. The reason for why the wave metaphor might be more effective is that the wave describes an ascending curve with a relatively short descent after having reached its peak. We are talking about movements resulting from disruptive technology, which creates the concept of a wave that sweeps away the old way of action. The new wave movement's apostles always engage, over a transitional period, in a struggle against the old society's well-established institutional stakeholders. When the new pattern has had time to establish itself on a larger scale, it will in turn actualize the conflicts between the exploitation interest and the demand for social protection. This will then drive the new juridical pattern for the protection of the established position and so on. In this way, the juridical system describes a varied, ascending and descending movement within the frame of one site that belongs to different bipolar value structures. Simultaneously, the locomotive drives development, i.e. societal development continues onward.

To add to the metaphor of a locomotive, during an epoch one might imagine that while the locomotive moves forward, carriages are attached as the epoch travels through various eras. During the market epoch, the legal system is gradually filled as it goes through merchant, trade house, agricultural and handicraft and industrial eras. The legal system is successively built up from different components. During the merchant era of the 11th and 12th centuries, canon law still dominated. However, at the same time, the actual exchange between merchant and buyer ${ }^{69}$ became established mainly through self-regulation of the basic rules of the market economy. This, then, established lex mercatoria, built upon a revived, modified Roman legal system, the demands specific to the times and gradual, legal expressions in the form of fundamental game rules. In Sweden, there are elements of this in the sales acts of the medieval landscape laws. These rules were primarily concerned with creating security of transactions in terms of the seller becoming the lawful possessor of the sold property. During the trade house era, a large part of the legal system was established around payment liability and security/creditor acts in connection with the need to finance the long travels overseas for oriental goods. Every trip was a huge project which demanded collective financing, thus making these rules necessary. The opportunity to register lawful possession and other guarantees in (ship) registers played a large part in this. The driving force was the demand of the market epoch for new goods. It was the same forces that drove the handicrafts during the mechanical era. As the markets widened, "a greater uniform market, the nation state" ${ }^{70}$ became inevitable. This then led to the now regulated market receiving, through mercantilist

68 Cf. Ervin Tofflers, Alvin (1981), which describes technical advancement in these terms.

69 On the importance of the merchant and trade, see Beard, Miriam (1939).

70 Ewerman, Anders (1996, p. 247). 
principles, an infusion of security customs and such. More goods could now be allocated, which meant that private craft shops began to be replaced by specified occupations and divisions of work. After some time, machines became independent goods. It was during this time that production came to dominate the juridical sphere, regulating through the growth of the city and its system of privileges built upon the guilds. During the industrial era, mercantilism and the guilds finally released their grip on production and "set it free." In return, we obtained a legal regulation of consumption, most of all in the form of public production, parallel to state-upheld consumer security for the consumers and individuals in various respects, from consumer protection law to environmental protection law. ${ }^{71}$

If we connect this to previous research on this subject, it does not reach far enough back in time to be able to verify societal and legal development in terms of cycles or waves for the entire market epoch. However, in the following text I shall attempt to present the available information. This concerns foremost the development over the past century: the transition from an agricultural and handicraft society to an industrial society. In this context, Durkheim's observations concerning the movement from repressive to restitutive law can be mentioned. This development corresponds to what Durkheim has labelled mechanical and organic solidarity, respectively. The repressive stage is related to the introductory stage of the S-curve, which simultaneously represents a separation between two different societal systems. During this period of societal development, there is reason to expect normative disorder in the sense that the normative poles that previously held a force of attraction in the old society lose their force and meet competition from other normative poles emanating from a new societal era. It is not until a societal system has been established and has reached a stage of maturity that we can expect the repressive features to be forced to step back under pressure from the social elements of the penal system, as experienced in Sweden between 1960 and 1990. In a mature society, such as post-WWII Sweden, homogeneity occurs, which changes criminality into a marginal phenomenon and organic solidarity becomes possible since "we're all in the same boat."72 From this perspective, it becomes more logical to emphasize individual prevention, to concentrate on bringing the criminal back to society, than to approach general crime prevention through harsh punishment and the terror it is meant to instil. ${ }^{73}$

If we apply the reasoning on legal changes in the form of movements between binary poles within the normative field, we find ourselves in an era moving towards a new stage of increased repressive elements. ${ }^{74}$ This is not due to the

71 Only the last era of an epoch is distinguished by consumption. The previous eras specialize in investments. Similarly, the last phase of an era is dominated by consumption, while investment occurs during the previous era.

72 Cf. the Swedish welfare state ideology. It concerns political distribution for maximum consumption, what we call the supply economy, with its ideology based in what Ewerman calls "the Keynesian parenthesis" in history.

73 See Strahl, Ivar (1967, p. 14).

74 In this situation, the interest of the victim increases. 


\section{8}

same societal reasons as those which Durkheim refers to in terms of mechanical solidarity. This is based in the previous thesis that society changes while the legal phenomenon remains constant; they come and go over time. The societal context which today gives rise to repression differs completely from the context which was valid in the times Durkheim discusses.

Max Weber makes a distinction between formal and substantial justice, which can also be seen as a dichotomy between bipolar points, where the former answers to a mature phase of legal development and the substantial to an over-mature phase. Reza Banakar highlights Timasheff's distinction between different legal paradigms, which are built around ethics and power. This, in turn, relates to Malinowski's description of social orders that are independent of enforcement and political institutions, as well as the social order which is dependent on them. In this situation, Banakar points to Carol Gilligan's differentiation between caring rationality and legal rationality. ${ }^{75} \mathrm{He}$ personally presents the difference between juridical facts and values. Banakar argues that these dichotomies can be boiled down to a more basic differentiation between an external and an internal perspective of the legal system. ${ }^{76}$ The external perspective makes itself valuable in a historical aspect and is distinguished by the initiation of a new legal form. This fact, which occurs during the establishment phase of a cycle in which the internal perspective stands out in the latter part of a cycle when the actual era has "sunk in" and become internalized on a larger scale in society, is when the structural norms dominate. Let us summarize what has been stated so far about different bipolarities in Figure 6.28.

According to Banakar's reasoning, the dichotomies between attributive characteristics and prescriptive norms, respectively, as well as between the concept pair of legality and rights, can in a similar manner be attributed to the same developmental phases. The fact that these dichotomies, highlighted by Alan Hunt, ${ }^{77}$ can be said to be inherent in all legal phenomena does not exclude, as described previously, that we are dealing with shifts of focus in which one aspect dominates over the other and vice versa in various phases of societal and legal development. ${ }^{78}$

The societal development causes changes in social codes and therefore a shift in opinions of what is right or wrong among people who take their starting point in the old society's normative pattern and those who take their starting point in the new emerging society's norms. Additionally, globalization and all that it contains

75 Gilligan, Carol (1982).

76 See Banakar, Reza (2000).

77 Hunt, Alan (1993).

78 Banakar argues, for example, that Gurvitch's views on justice coincided with the struggle to reach a balance between legal facts and values. My reasoning does not oppose this interpretation; however, it would mean that in certain periods - in the introductory stage of a societal era - values would dominate, while legal facts and legal techniques dominate in the latter half of the societal era's development curve. 


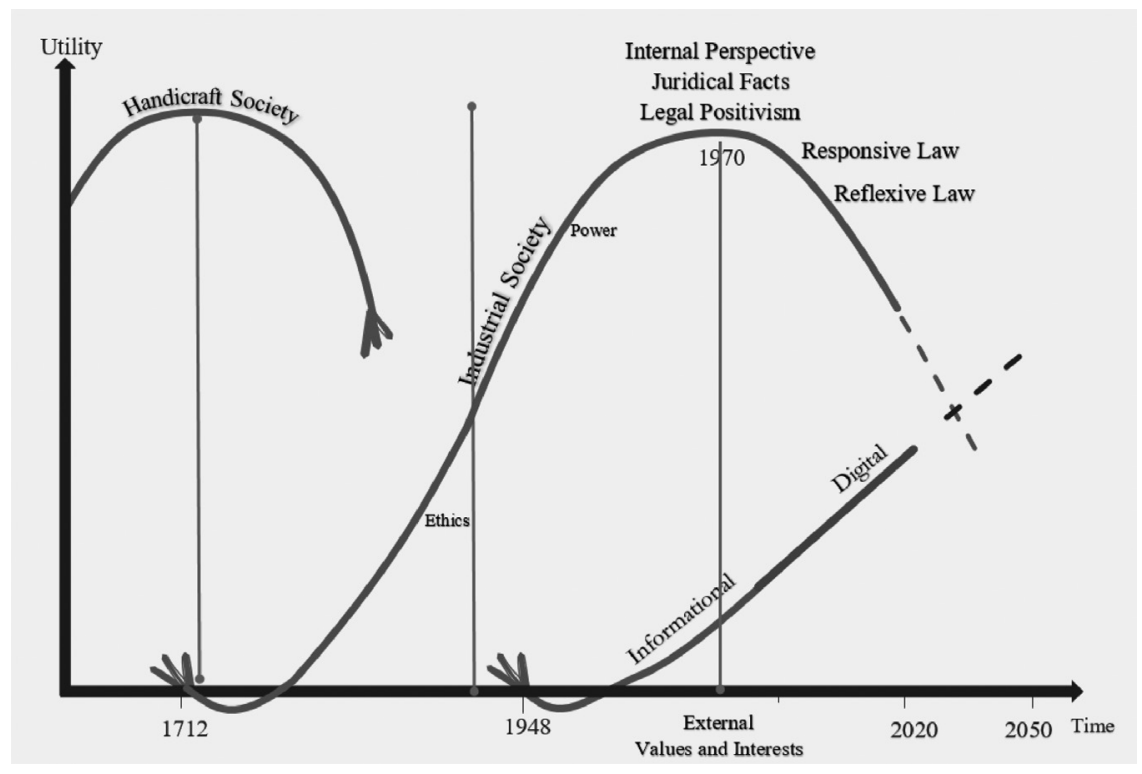

Figure 6.28 A summary of different bipolarities

concerning influences from various places and cultures, as well as the migration flows, have brought great changes and therefore tensions in society. ${ }^{79}$

One can also relate those initiations of legal development, as presented by Nonet, Selznick and Gunther Teubner and described introductorily, to societal development in terms of S-curves, and legal development in the form of progressive changes within the normative field. Nonet's and Selznicks' argumentation about a transition from repressive to autonomous or formal systems, based in Teubner's categories, is represented by a movement through the cycle from an introductory, repressive phase, in agreement with Durkheim, to a more stable normative phase, which corresponds to Durkheim's organic solidarity, where the legal system's ideal consists of process-oriented correctness following on the ideal of the rule of law and state governance. The introduction of the term responsive law corresponds to the point on the cycle in which the societal system in question approaches its peak and distributive politics begin to dominate. It then becomes a case of seeing the individual's demand from a collective perspective. Teubner's argumentation concerning reflexive law can, in this situation, be interpreted as an attempt to solve the problems of transitional society and normative dissolution at a collective level, which means that norm creation is most effective in the affected individuals in each specific case. The legal system's role, in this perspective, is to 
establish an arena for this norm creation. Through this, the interests that are related to the external, and often unintentional, indirect effects of these largescale activities often get the chance to influence the resulting norms.

The advantage of this model of reflexive law is that it compensates for the lacking legal contents with democratic contents, in comparison to the responsive legal system's more expert-oriented solution proposals. The experiences of attempts implemented in order to compensate the lacking democratic content of the responsive model with various participative elements have not been successful. The distance between the system and the individuals' lifeworld (in Habermas' interpretation) is too extreme to make arguments possible from a lifeworld perspective. ${ }^{80}$

Yet another circumstance which is important to highlight is that the "locomotive" maintains several positions within which values change during this progression. Parallel changes in normative patterns cooperate with or counteract each other in legal processes of change over time. One can in this situation, pinpoint the transition from a concept of justice based on fairness to the integration phase of the new society, during which everyone must be afforded equal opportunity to succeed, i.e. a formal or procedural kind of justice. This requires that the walls of the old society are demolished for a substantive concept of justice, which is built upon the idea that everyone must have an equal, preferably double, amount of everything and relies on making the satisfaction of human demands into a part of the political project for which the legal system becomes an instrument. It is when these movements pull in the same direction that we see a change in the basic normative patterns, which in turn cooperate in order to create societal changes. The direction of movement is the same in the entire industrialized world. ${ }^{81}$ The differences in speed and development depend on, amongst other things, the relationship between the different bipolar normative positions that determine the basic normative pattern. This, then, relates to a number of circumstances, from societal and economic levels of development and institutional traditions to technological conditions.

\subsection{Concluding remarks}

Society's direction of movement is at the same time the development of the legal system within the frame of its fixed position, the same value-based dimension, even if there are several such parallel positions. The term locomotive reflects this conflict between static and dynamic, between fixed position and movement. The locomotive unites the synchronic and the diachronic perspective. As society

80 In the environmental area, two doctoral theses in sociology of law can be referred to, Ericsson, Lars (1985) and Svenning, Margaretha (1996), both of which highlight "mechanisms of rejection" which become applicable when the public tries to influence environmental protection issues.

81 The railway is, metaphorically speaking, single-railed. 
develops in the wake of the wave, the position on the vertical axis, the normative dimension, changes and moves up and down depending on the phase of development. The legal system does not control the development. It is even less a driving force behind the development. But the forward movement demands that the development in the normative dimension keep up. Otherwise, problems may arise. Incongruities and anomalies will occur. The development can cease, etc. The locomotive comes to a halt.

During a cycle - simultaneously with the forward movement - the focus shifts from phase 1 , self-regulation; to phase 2 , game rules; to phase 3 , planned system rules; to phase 4 , intervening rules. When we observe different legal systems, we see that the focus shifts from phase 1 , non-legal regulation, in the legal system's development during the societal development's movement, to phase 2 , duty rules; to phase 3 , end/means rules; to phase 4 , consideration rules. There are different models of legal argumentation behind these various rules. We can in legal terms describe the following dominating legal systems during these stages: phase 1, penal law and civil law, in relation to the social system and constitutional law in relation to the political/administrative system; phase 2, civil law, with a focus on the economic system; phase 3 , administrative law, with a focus on public authorities; and phase 4 , intervening rules managed by decision-making bodies representing the involved parties.

I refer here to a specific type of norm formation (spontaneous, game rules, formalizing and intervening) that dominate at specific points in time. However, this does not exclude the simultaneous existence of all legal forms. Certain legal forms characterize their respective time periods. During the first phase one could, from a legal point of view, claim that phase 4 dominates psychologically. Phase 1 has not yet had time to leave a strong enough imprint to have a psychological impact. Also during phase 2, the upper curves of mentalities and legal customs continue to receive a lagging priority. There is a tendency in historical situations of transition from one era to another to perceive what occurs in the new society (the new cyclical perspective) through the old society's terms.

Now, as digital technology drives new ways to fulfil human needs, this lagging mentality becomes manifest in the following manners. Firstly, the old society's rules create obstacles for the establishment of the new, whether it concerns new forms of work, lifestyle or trade. Secondly, the new phenomena are perceived through the eyes of the old society and thereby the problems connected to the old society are projected on to the new phenomenon.

This seems to be the case. A new legal development is approaching when old legal institutions receive a partially new meaning and when the remaining legal development awaits the self-regulation, which takes place within the framework of the new technology. New legal areas built around new functionalities such as e-business can be created by the changed relations between existing institutions, which therefore receive a changed level of significance, as described by Karl Renner. Therefore, it seems as if the new digital technology does not demand changing constructions of rules and legal innovations. The trust and supporting structures which every new phenomenon that is to be regulated requires 


\section{Toward a theory of legal change}

continue, to a large extent, to rely on spontaneous solutions within the area of digital law. These solutions relate to the market's own ways of functioning and its own logic instead of political and legal decision-making in some national or international form. ${ }^{82}$ The jurisprudential competence, which is vital in order to meet this new legal culture, demands a return to times of less dogmatic legal constructions, which historically have distinguished corresponding phases.

Based in these theoretical points of departure, we face an era of societal transformation, which will also give rise to legal changes. Society, here, is not the same thing as the nation-state. The logic of societal development has not been related to the nation-state in previous historical stages, nor will it be in the future. It is only during the industrial era that the nation-state plays a significant role. The development of the legal system dominates already through the pendulum's extreme swings between freedom and self-regulation in phase 1 of digital society in order to move, during phase 2, towards legal regulation in the form of game rules and, in our time, towards a global level. After that, we have reason to believe that law will return in the form of planned and intervening rules.

Technological developments give rise to new phenomena where the primary problem is not normative, but cognitive. We lack experience and thereby knowledge of what and how to regulate. The development of digital technology is characterized as disruptive, which means that it conflicts with previous ways of doing things. One such significant instance of technology is digital technology in general and artificial intelligence (AI) in particular. It presents us with new regulatory mechanisms. In the closing chapter, I will use AI as an illustrative example of how the technology as such takes over more and more of the decision-making processes from individuals, as well as from politicians and lawyers. 


\section{A science of norms \\ A science for the 21 st century}

\subsection{Sociology of law: a science of norms}

\subsubsection{Brief summing up}

In this book I have argued that sociology of law (SoL) ought to broaden its scope to what I call a science of norms. The concept of norms has to be expanded in different respects. ${ }^{1}$ Norms constitute both (1) an existing empirical phenomenon, something "real", and (2) an analytical tool which can be used in order to analyse the driving forces behind human behaviour. In this last respect the study of norms attributes to SoL an important role in the perspective of social science. Moreover, norms, as an analytical tool, contribute to (3) the need for interdisciplinary development. As a consequence, (4) SoL will become more adequate as a legal science and of greater relevance for legal practice. It will also create (5) an understanding of the interplay between norms and (legal) rules and not least (6) an expansion of the scope of the social sciences. Norms provide SoL with a common denominator and become in this way the overall study object for SoL in the same way as law and the legal system for lawyers or politics and the political system for political scientists and the economy and the economic system for economists and business administrators.

In this final chapter I will give some further arguments for SoL as a norm science by explicating how norms operate between law and society and what consequences this has. SoL as a norm science also has certain methodological implications which I bring forward in this chapter. I will also, by introducing the concept of strategic normative thinking (SNT) point out the regulative relevance for SoL as a norm science. Finally, I show how norm science is needed in relation to understanding the normative development in the digital era when law is lagging behind and is inadequate and code becomes law and algorithm norms. However, I will start looking at norms through a parallel to genomics.

1 I have argued for this already in Hydén, Håkan (2011b).

DOI: $10.4324 / 9781003241928-7$ 


\section{A science of norms}

\subsubsection{Norms as readiness for action: a parallel to genomics}

Understanding changes in law as movements between different poles within a normative force field, combined with an interpretation of societal development represented as $S$-curves, allows us to systematize legal material and eventually, perhaps, solve a puzzle that would lead to a better understanding of how changes in law come about and the need to relate these to shifts in basic normative patterns in society. Parallels can be drawn to current research in genomics. Thanks to information and communication technology, we can now accumulate knowledge to such an extent that we are able to map all human genes. However, for this knowledge to serve any useful purpose, we also need to study the functions of, and relationships between, the different genes. This is a cumbersome process, one which has already begun in medical research, but is expected to continue for many years.

Similarly, a science of norms allows us to map norms as well as their functions and relations. From the perspective of the legal and societal sciences, one could compare the genes of the human organism to the norms of human society. They are the smallest components of society. They also carry important information. Basic normative patterns are similar to hereditary traits. They gain their function from the order and relationships between the normative poles, not their source. Norms, much like genes, create a readiness for action. However, norms are not the only deciding factor any more than are genes. Contextual factors also play a role. In both cases, environmental factors more or less determine most actions. Therefore, norms are always "only" a potential course of action, just as legal rules are potential norms. The norm's influence is related to the strength of the material and structural conditions of the situation in which the action takes place. Similarly, how big a role genes play in human action varies depending on their organic combination. The lettered designations of norms, like genes, can be infinitely combined. However, how they are composed, their language, remains unknown to medical research, and this applies similarly, and even more so, to legal and societal research. In the case of norms, there are - as we have seen in Chapter 1 - three different bases: wills and values (W), knowledge and cognition (C) and systems and possibilities (SP) that provide the link between facts and values or - in the case of legal norms - between law and society. The two wound and paired strands within the double helix of a norm are held together by the norms' cross-links between $(\mathrm{W}),(\mathrm{K})$ and $(\mathrm{SP}) .^{2}$

Our current understanding of societal norms is as primitive as our understanding of genes. What is needed is a combined field of legal and societal science that studies the function and links between a given norm and other societal norms.

2 Genes are made up of deoxyribonucleic acid (DNA) which consists of two wound strands in the form of a double helix containing sugar, phosphate and nitrogen bases. There are four different types of bases found in genes: adenine (A), thymine (T), cytosine (C) and guanine (G), which bind the two strands together. These acronyms represent crucial functions of the gene. 
In order to understand how norms relate to legal rules, we need legal and societal scientific research that has the capacity to relate existing legal phenomena to their underlying normativities. In other words, there is a need for legal scientific research and training which combines knowledge of the structure and background of laws in the form of normative basic patterns with knowledge of how rules work in society. To achieve this, a science of norms is needed that is able to bridge the gap between custom and tradition, system imperatives and societal norm developments, on the one hand, and changes in law, on the other.

A good starting point for establishing a science of norms is the field of SoL. Until now, the concept of norms has not been seen as a starting point for research in SoL. Rather, SoL takes its point of departure in existing legal rules and does not problematize the relationships between legal rules and norms. Legal anthropology is devoted to studying the characteristics of legal rules in comparison with other societal norms. Legal pluralism, on the other hand, has a tendency to equate legal rules with societal norms. ${ }^{3}$ The fact that the legal system is allpervasive and exists in more or less all contexts of our lives does not mean that it also serves as our normative source of reference. ${ }^{4}$ The law only becomes relevant when the underlying norm system fails in its capacity as a regulatory system. In that sense, with the exception of intervening (legal) norms, the law is always secondary to society's underlying societal norms. I intentionally avoid the term extra-judicial norms since it is usually reserved in the legal sciences for situations where norms compete with legal rules to decide a particular case. I do want to emphasize, however, that norms/legal rules are activated in two stages. First, the norms stipulate the action, after which - in the event of a conflict - the legal rules are activated. These conflicts can, as we have seen, be either intra-systemic, which is the most common form, or inter-systemic, which calls for intervening legal norms. The primary source of action lies in norms derived from one or several, sometimes conflicting, societal norm systems. The law is only activated "when things go wrong", i.e. the actors involved are not able to solve the problem or conflict themselves. ${ }^{5}$

The fact that we are not able to theoretically separate legal rules and norms is problematic. As developed in Chapter 4, I view legal rules as one category of norms. This means that legal rules can be viewed as general norms, as well as a specific category of norms with their own characteristics. I argue that legal rules quite simply consist of norms; that is, they do not differ from norms in general. Some norms have been elevated to the status of legal rules and thus are endowed

3 See e.g. John Griffiths (1986, pp. 24-25).

4 Cf. Sherwin, Robert K. (2000), who discusses "Law is everywhere," and Ewick, Patricia and Silbey, Susan (1998). When Ewick and Silbey describe law as everyday phenomena and how legal culture is perceived and viewed by the public, they focus more on how the normative issues covered or institutionalized by the law are perceived rather than how legal norms are perceived. See also Carlsson, Bo (2002).

5 See my discussion in Hydén, Håkan (1985) on the regulation of working life in connection with the transition from a freer negotiation strategy and the use of legal arguments. 
with additional force. ${ }^{6}$ It is important to distinguish between norms in general and norms that also have the status of legal rules. As mentioned in Chapter 3, legal rules can be understood as instructions for action generated by various action systems: the socio-cultural action system and the economic, the political/ administrative and the natural systems.

In each of these systems, norms are expressed as new actors use the systems to satisfy their needs. One characteristic of norms is that they spontaneously generate compliance. How well-spread the norm becomes, i.e. how many people embrace the norm, differs, however. But what all norms share in common, with the exception of moral and ethical norms and legal rules, is that the sanction is embedded in the norm. This means that the penalty for violating a norm, and the reward for complying with it, is an inherent component of the norm itself. The penalty is a part of the norm, as can be seen, for example, in the economic norms created by market economy analyses which serve as imperatives if one wants to make a profit or avoid a loss. For example, norms/instructions on how to build bridges that are based on mechanics of materials theory naturally lead to a high level of compliance, because failure would lead to a failed bridge, or whatever is being constructed. Related to this is Émile Durkheim's distinction between moral norms, on the one hand, and technical norms, on the other (Durkheim 1906). Durkheim argues that with regard to moral norms, the sanction is artificial. It is not an automatic consequence of the action, but rather a synthetic addition. The sanction is created and added to the incident externally. The penalty for violating a moral norm usually relies on the options for exacting punishment available to the societal system. This is in contrast to technical norms, where the sanction is a natural part of the norm itself; the norm and the sanction mechanism are part of the same system. If you violate a technical norm, the penalty will occur spontaneously as a result of the violation.

\subsubsection{Norms between law and society}

The fact that certain norms become legal rules means that they are strengthened. If they are not activated spontaneously, the disadvantaged party or general public can demand that the rule be enforced - in theory, at least. The sanction is therefore separate from the norm and can be specially enforced as a means of pressure in cases where the norm, in itself, does not generate an action that matches the content of the norm. As a rule, norms that have been made into legal rules are endowed with a higher degree of potency and clarity, as mentioned in Chapter 4. They are formalized and must also be maintained by a special profession, the legal profession, which, in complicated cases, claims exclusive rights to the interpretation of the content of the rule by way of the judges. All in all, this means that

6 This view is further supported by Strömholm, Stig (1991, p. 157), where he argues that legal rules can be seen as a system of norms among several other systems. Other norms can be contiguous or, in some cases, rivals. 
there is a consistency and reliability to legal rules, which is simultaneously both an advantage and a disadvantage. ${ }^{7}$ The advantage is that the rule of law can be endowed with a predictable content in accordance with the ideals of the rule of law. The disadvantage lies in their rigidity, which may affect their ability to maintain the legitimacy of law and thereby the rule of law. When rules become the specific starting point for legal interpretations, the application of law often comes off as bureaucratic and impersonal. In other words, norms become less flexible when they are transformed into legal rules.

Norms and legal rules can drift apart. A gap can emerge between them. To generalize somewhat, one could argue that the greater the distance between the societal norm and the rule of law, the higher the costs of enforcing the rule. A rule can always be enforced, but the amount of coercion needed to enforce compliance with the rule can vary in practice. In the final analysis, the rule of law is based on the underlying threat of force. Hence, states that abide by the rule of law have a monopoly on the use of force. Legal rules are formally created according to a political decision-making process, although, as norms, they may originate from another action system. In order for a norm to be elevated to a rule, the individuals subject to the rule must either recognize the legitimacy of the governing body, or else the rules are forced upon the populace from above.

With regard to the relationship between law and society, it makes sense to insert the norm systems between the different levels as shown in Figure 7.29.

A number of hitherto unanswered research questions can be distinguished from this figure. Beginning on the right, in general, norms can be seen as a filter between legal rules and society and that have an effect on the outcome of legal rules. This also applies in cases where norms are a product of the legal system itself, as is the case with intervening norms, marked on the far right of the figure. Here, too, the norms affect the outcome of legal regulations by determining their application in each individual case in accordance with the framework legislation. Secondly, there is the issue of the relationship between legal rules and norms. What is the source of the legal rule? Are the norms and rules in agreement with

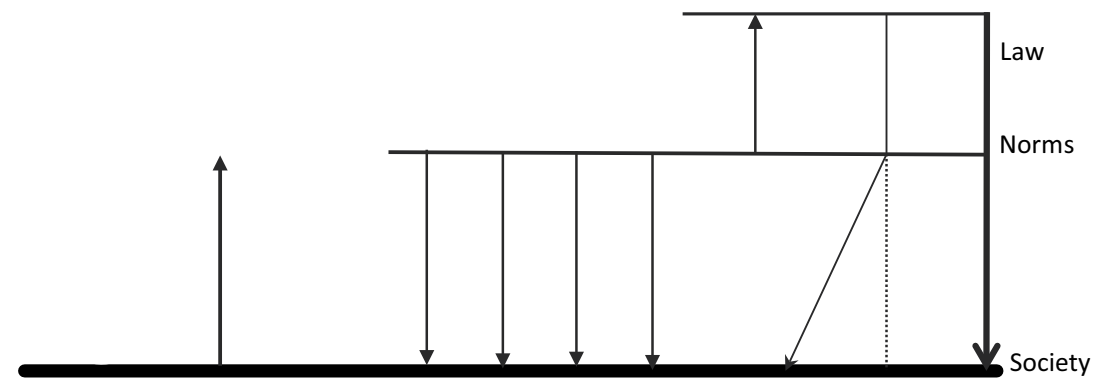

Figure 7.29 Different normative relations between law and society

7 See Hydén and Hydén (2019) Ch. 2. 


\section{8}

each other? In cases where norms and rules collide, there is a risk that the norm will "disturb" the intended content of the rule, as shown in the figure, leading to a different result. Thirdly, this involves questions about the extent to which the norm and the rule interact and whether the rule is supported by the norm. Is it the rule or the norm that is operative in specific cases? In extension of this reasoning, another question concerns which norms, of all the norms applicable in a particular area of law, have been given the status of legal rules. An analysis of these relationships - which so far is sorely lacking - would tell us much about the role law plays in general.

As can be seen in the image in the figure, it is to be expected that large parts of our norm systems exist outside of the domains of the legal system. Therefore, SoL could focus on the relationship between norms and actions and behaviours at the societal level. In this respect, SoL can be said to have a purely norm-scientific focus. In other words, SoL plays a potentially important role in the social sciences by providing a largely unexploited analytical tool to understand human behaviour in a societal context, i.e. norms, normative structures or normativities. Finally, there are situations in which an activity spontaneously emerges which needs norm-supporting structures in order to establish a degree of stability, a theme developed by the Swedish sociologist of law Per Wickenberg (1999).

Seen from a socio-legal perspective, a science of norms would have a sort of hypothesis-reviewing function. Karlo Tuori emphasizes the difference between the two faces of law in its capacity as a legal order: one is a culturally normative phenomenon and the other is a set of societal practices, or legal practices. ${ }^{8}$ Tuori argues that these two aspects of law are what characterize legal science, on the one hand, and the societal sciences, on the other. For legal scholars, Tuori explains, law is primarily a normative phenomenon, a legal order. However, the societal scientist focuses on the other side of law; to the societal scientist, law is primarily a set of specific societal practices. With reference to Bourdieu, Tuori discusses a legal game field, where the legal scientist and the societal scientist face off on opposite sides of the halfway line. The legal scholar participates in the game, while the societal scientist observes the legal field from the outside; from the perspective of the law, he or she is an outside observer. This metaphor agrees with arguments I have made in other contexts, such as the difference between an internal and an external perspective of law. ${ }^{9}$

A science of norms allows the scientist to both participate in the game and observe it from the outside. However, we need to establish a variable which is both immanent and transcendent, i.e. a variable that is capable of merging law into a legal order and societal practice. This is exactly what norms do. Tuori seems to presume that the law gains its normativity from the three different levels in which the legal order can be conceptualized. But it is likely and also

8 Tuori, Karl (1999, p. 9).

9 See Hydén, Håkan (ed.) (2002b) and (1998). 
primarily as a result of influences from the societal practice of law. Law, as has been emphasized in this volume, is an expression of norms that have their sources in one of the systems which humanity creates to satisfy our needs. The fact that the modality of the legal rules is characterized by the three legal levels is a different subject. This means that understanding legal norms should not only be an internal concern for the legal science. As emphasized by Jurgen Habermas, it is necessary to maintain both an internal and an external perspective of the law. ${ }^{10}$ This combined view of law that a science of norms provides helps lay the foundation for studying law as a legal order. The same could, of course, be said about law as a societal practice Above all, a science of norms would have the capacity to determine the relationship between legal practice and the normative content of the legal order. As mentioned previously, the importance of the legal order as a normative phenomenon varies depending on its position on the S-curve and general societal development.

Firstly, norms in themselves contain both cognitive and moral elements. This means that it is possible to study the motives behind the acting subjects' actions at a collective level. This is otherwise only possible in the context of micro-oriented, societal psychology studies of people's behaviour in different situations. Sociological studies of people's opinions or attitudes have been carried out, but these factors do not tell us much about the motives that underlie people's actions at a meso or macro level. Norms, however, do. This is because norms are an expression not only of a relatively stable group characteristic that functions in a specific way but also a reflection of the actors' subjective (knowledge) and objective (system conditions) ability to comply with the norm.

Another advantage of taking an analytical starting point toward norms is that this also allows us to assess the importance of other factors, such as emotions, aesthetics, etc., often excluded from societal scientific theories. All in all, normbased analyses give us the opportunity to evaluate the importance of cognitive factors in conjunction with value-based and emotional factors when it comes to understanding why people act in a certain way. Within environmental research, for example, the societal and natural sciences collaborate fully. Each side fully accepts the other side's knowledge. ${ }^{11}$ In this case, norms, as a level of analysis, provide an opportunity. Norm-based studies of environmental behaviour are able to determine the motive underlying the behaviour, whether it be instrumental motives belonging to the norms of one of the goal-oriented systems or the environmental or socio-cultural systems. In practice, there is a relationship between the two latter systems in that the environmental system's norms are so vague and unclear that in practice they require support from the socio-cultural system's norms.

10 Cf. Ch. 3.

11 See Hydén, Håkan (2004). 


\subsubsection{Methodological implications}

With regard to methodology, socio-legal analysis, in the context of norms, has much to learn from legal dogma. ${ }^{12}$ The difference is that here, the reverse direction from the one that legal dogma moves in is necessary. Legal dogma begins with the rule and then draws conclusions about what action to take based on how the rule is structured. A socio-legal analysis begins, however, with the action or behaviour and poses the following question: What are the normative premises that generated the action or behaviour? In other words, we need to reconstruct the normative content in the context of the behaviour and underlying motives. Having done so, the action's source in the norm system then directs us to the next step of the analysis by tying it to potential conditions at both the macro and the micro level. SoL, as a science of norms, is therefore able to investigate societal events and human action, in this sense, by using methods based in legal science.

One particular theme becomes evident when analysing norms, which is the norm's dependence on moral arguments or arguments originating from the norm's systemic source. Some action systems are, as shown in Chapter 3, more goal-oriented than others. Hence, technical norms linked to the laws of nature, as defined by the natural sciences, are non-negotiable. They are unforgiving and demand obedience. The same should apply to environmental norms that are also linked to the laws of nature, such as photosynthesis and the various elements of thermodynamics. However, in this case, the same unquestioned obedience is not evident, even though the sanction is part of the norm here too. The problem is that their sanctions are often in the distant future and therefore are more difficult to identify. A violation of a norm does not invoke an immediate sanction. Furthermore, the sanction may be vague and unclear. Only when environmental norms are ignored on a large scale do the sanctions in the form of harmful effects become noticeable. At that point, it can be difficult to identify the causal links and link the sanctions to a certain action and subject.

Technical norms, therefore, have an advantage over environmental norms. One could say that technical norms have the same characteristics as the aforementioned duty norms, while environmental norms correspond better with what we could call normative principles, i.e. an action that you are obliged or expected to carry out but which is not necessarily as normatively unambiguous as a duty norm. Economic norms, in turn, determine much of how technical norms are applied. Economic norms are based on strategic assessments of what works well on the market. This also means that the economic system is highly goal-orientated. One could say that the normative elements in these cases are mainly determined by their systemic source and are not discursively determined by opinions of good or bad, right and wrong, other than those determined by the structure of the economic system itself. Economic norms are as effective as technical norms in that the sanction contained in the norm is activated directly if you violate the norm.

12 For more on this, see Christensen, Anna (1994). 
A bad investment, i.e. a deviation from the system's definition of optimal conditions, is visible immediately and therefore signals a change in behaviour. One might object that the economic system is constantly giving different signals for right and wrong. That is true. However, my point remains, namely that it is the economic system that decides what will be seen as normatively correct.

An alternative to the economic system would be the socio-cultural system's way of operating. The socio-cultural system is based on the premise that people decide what is good and bad, right and wrong, discursively, i.e. through communication, etc. This occurs in all systems, one might presume, given that they are created by people and, hence, the norms are expressed by people. But the difference between the socio-cultural system and other action systems is that the sociocultural system is not similarly goal-oriented. This does not rule out potential power struggles and strategies when it comes to how the socio-cultural system operates. For example, the gender struggle can be seen as a factor that interferes with the socio-cultural system's way of operating. Whether the gender problem permeates and is strengthened by other action systems or whether the opposite applies is an open-ended question. ${ }^{13}$ In any case, the question is highly relevant in relation to SoL's norm-scientific research interest. Manuel Castells sees the power of patriarchy as a reflection of other hierarchical power relationships in society. ${ }^{14}$

The fact that the socio-cultural system is a more open system also makes it weaker, which means that it gives way to the more potent norms emanating from the economic or technical systems. This becomes a problem when different norm systems collide in practice, such as when environmental concerns conflict with economic factors, e.g. when a company produces a hazardous product that causes harmful emissions. In these cases, the environmental and socio-cultural norms give way. This is also due to the sanctions being unclear. The socio-cultural system's main sanction is exclusion from the societal group and other more or less stigmatic sanctions. In the conflict with norms from other action systems, the socio-cultural system is mobilized only when these basic societal values are at risk. Of course, this also includes health matters and physical survival. Only when these values are threatened is there reason to expect that the socio-cultural system's norms will prevail over technical and/or economic norms.

However, the socio-cultural system is not static. How influential the norms will be is ultimately determined by the participants involved themselves, who, by expressing their interests and views, can strengthen the socio-cultural system's norms. This leads us to the conflict between systems and lifeworlds discussed in Chapter 2, where the latter deals with the part of the socio-cultural system that is determined by non-systemic perspectives of good and bad. The relationship between the socio-cultural system's norms and the economic or

13 The question has been posed by Ellinor Platzer in relation to a report to the Kvinnomaktutredningen, SOU 1997: 114. "Handlingssystem, makt och frigörelse" ("Action Systems, Power and Liberation").

14 Castells, Manuel (1998) Vol. 2 Ch. 4. 
technical system's norms is not set in stone and are always vulnerable to influence and can shift. There is always a possibility that the socio-cultural system might influence the outcome of the conflict of norms through societal or political mobilization.

Basically, the conflict between the lifeworld and systems can be expressed as a conflict between moral and instrumental motives that emanate from a goal-oriented system. The relationship between these toposes changes over time as society develops. SoL is able to operate as a science of norms in the sense that its research interest lies in empirically studying the existence and importance of moral arguments in society. Morality can derive its sustenance from its own ideological systems, of which religion is the most common and strongest, but political ideologies can also play a similar role. ${ }^{15}$ This can be a way of strengthening morally tinted socio-cultural norms. The paradox, however, is that if these ideologies become dogmatic and mechanically sustained, they risk becoming weaker. When that happens, it does not matter how big the organizations have grown. How strong the socio-cultural norms are is thus determined more by quality and intensity than by the number of people who embrace the ideas.

It should also be noted that members of the socio-cultural system are able to use the economic system to assert socio-cultural norms. The goal-oriented nature of the economic system cannot completely detach itself from its link to the individual's lifeworld in the socio-cultural system. Admittedly, the economic system has long been able to predict and build on consumer acceptance of the economic system's output. As long as material needs are increasingly satisfied through production, the economic system decides what to produce. As the negative externalities increase while demand satisfaction decreases, the economic system's automatic legitimacy is weakened. Consumers begin to question and place demands on certain aspects of the production process. From this perspective, the market is a potential instrument of influence, an instrument that is often significantly more effective than political instruments, where the outcome will still ultimately be decided by sluggish governments and reluctant bureaucrats. ${ }^{16}$

Finally, to return briefly to the curves used here to describe societal development, it should be emphasized for normative reasons that there are two approaches: one vertical and one horizontal, which together create a united space. See the markings in Figure 7.30. The vertical perspective shows that people can experience the present from two perspectives: the upper curve perspective - the old society - where the industrial society's collective consumption and distribution-related issues dominate, and the lower curve

15 Cf. Mathieu, Chris (1999).

16 Hydén and Gillberg touch upon this relationship called "Law as a Safetybelt and Market as an Enforcer," see Hydén, Håkan and Gillberg, Minna (2003). This is also the theme of Minna Gillberg's thesis (1999). 


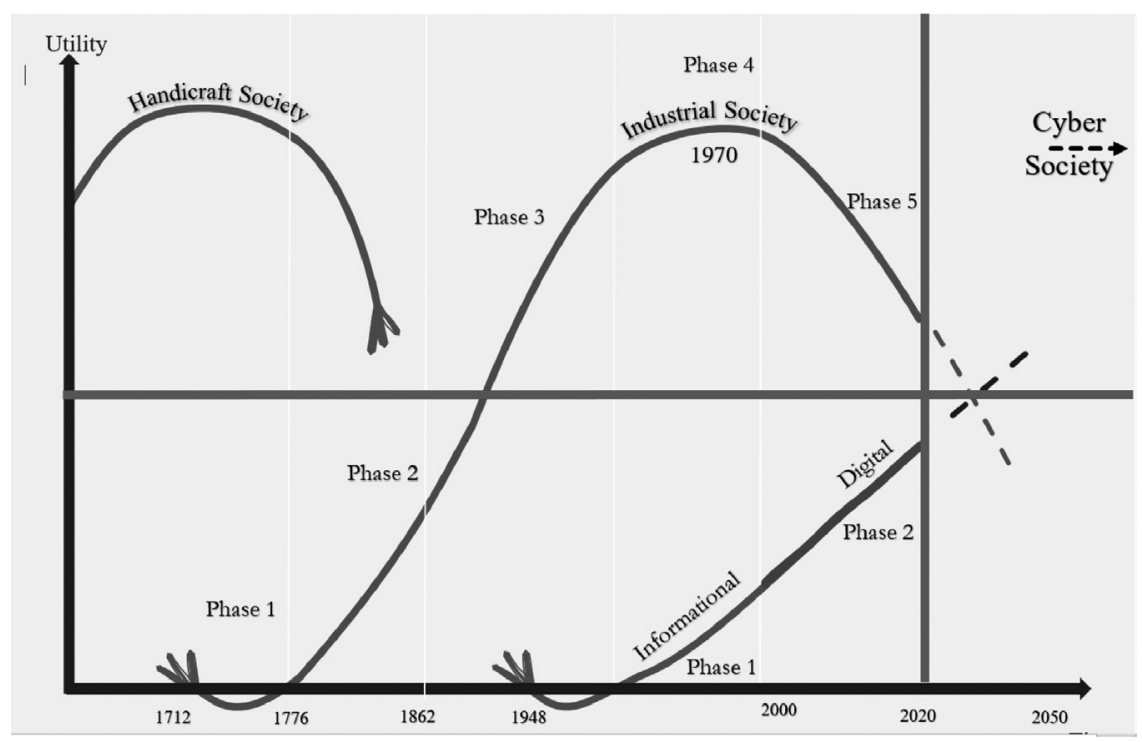

Figure 7.30 Different temporal worlds

perspective - digital society's individual investments. This means that people living in the same time period can still live in different temporal worlds. Similarly, a horizontal approach shows that people living in different parts of the world may "belong" to different temporal stages of development. From this perspective, people who come from cultures that are simultaneously going through different stages of societal development can also be brought together by sharing the same times. See Figure 7.30.

The socio-legal approach discussed here is primarily based in the social sciences. It complements the social sciences and can be a tool for dealing with the greatest societal conflict of our time at a macro level, namely the conflict between systemic imperatives and people's lifeworlds. Since this conflict has no clear societal champion and is vague in general, and therefore difficult to mobilize political activity around, we can expect the conflict to develop in ways that deviate from what the market society's 1,000-year-old history has taught us. Thus, there is a wealth of potential topics at the heart of societal development that could benefit from norm-scientific analyses. The norm-scientific task would be to dissect the components of the norm. Norms are expressions of people's motives. As shown in Chapter 1, motives are shaped by different kinds of societal and individual dimensions or aspects. Each one of these has its own specific background and context. Learning to recognize these factors helps us lay the foundation for a theory of norms. 


\subsection{Strategic normative thinking: normative design to support self-regulation}

\subsubsection{Introduction to a legal innovation}

In legal science, the norm-scientific analysis helps, among other things, to shift focus from the lawyer's quest to find and interpret the normative legal system's solution to both private and societal issues to instead adopting a functional approach to legal regulation. I call this approach "strategic normative thinking” (SNT). This means that the researcher mainly focuses on the involved parties' motives (in a broad sense, including legal persons). In the same way that legal regulation is partly a matter of regulating something in advance and partly of resolving potential disputes in retrospect, SNT can also encompass actions and regulations created to avoid disputes. While legal regulation focuses on the interested parties' self-interest, SNT strives for consensus. Its ambition is to avoid litigation and, if a dispute arises, search for normative solutions that benefit both parties. Conflicts are expensive; therefore, it's best to try to avoid legal proceedings.

When it comes to legal governance, an important task of law in the context of the political/administrative system, the need for SNT and its potential becomes even greater. SNT (neglected by legal science) is more or less a component of all legal applications. There are no fixed points on which we can base our knowledge. Seen from this perspective, a science of norms complements legal positivism. A science of norms and SNT are both natural components of legal dogmatic practice. How important a science of norms is, however, varies in different phases of societal development.

As presented in Section 6.5, norms are normally created during the emergence of a society, the period of establishment shown on the S-curve and expressed as self-regulation. The law of increasing returns creates conditions for spontaneous growth, in which activities are coordinated through norms that are based in the self-interest of all involved parties. In addition, we have to factor in the lag, as discussed in the introductory chapter and Chapter 6, which characterizes the development of norms. Initially, the new society will be interpreted in the terms of the old society. The established institutions of the old society cling desperately to the existing institutions. ${ }^{17}$ Here, there are clear parallels to what caused Lancien régime to fall and pave the way for the French Revolution in 1789 and the emergence of the industrial society in the late 18th century.

In economic theory, the productivity paradox is often discussed in connection with the birth of new technology. This means that it takes a while for new technology to begin to generate generally beneficial effects and increases in productivity. ${ }^{18}$ This applies both to the electric engine and computers alike. The productivity paradox was coined by economist Robert Solow in the mid-1980s, who claimed that computers were now used in all sectors of society except productivity statistics. This explains the seemingly inexplicable fact that when the most advanced

17 A relevant circumstance that explains Stig Johansson's cartoon with the subheading: Being of your time often means opposing it.

18 See Schön, Lennart (2001, p. 525). 
economies adopted the new digital technology, their growth slowed down. From the perspective of a science of norms, one could draw a parallel to the game rules paradox. Despite the emergence of a new society/game, new game rules have not been developed. This takes a while. While the productivity paradox is caused by the fact that it takes time to develop new skills, adapt how work is organized, develop new raw materials, etc., the guidelines of the game rules paradox can be attributed to the mental inertia and unwillingness of old powerbrokers to allow new actors to dominate the playing field. Early stages in innovation face a number of bottlenecks and obstacles. Productivity increases are sluggish until the technology has stabilized, the effects of training have multiplied and the required competence has been disseminated. At that point, the innovation can be applied in other areas and productivity can begin to increase. The same conditions apply to developments in game rules. In order for the rules of the game to become accepted and comprehensive, the game needs first to have become institutionalized to a degree.

Meanwhile, normative developments are like isolated islands of new games played out on the greater field. New games are developed through self-regulation, in which sanctions for norm violations are embedded in the norm itself, as mentioned in our previous description of the difference between norms and rules. It begins as a game in a cellar or garage belonging to one of the participants, supported only by the amateur's unbridled enthusiasm. After a while, it becomes an organized game where self-regulation replaces the lack of commonly applied game rules. How people choose what game to play is determined by each individual's preferences based in personality and cultural background.

\subsubsection{Normative design to support self-regulation}

It is in this situation that the normative crosses over from the application of rules to SNT. Since there are no ready-made rules to apply to the new activity, the coordination of group behaviour must be based in self-interest. In order to convert self-interest into a common, collective, strategic interest, we need SNT. This means reconstructing the motivational structures within which a particular activity takes place and assessing whether it is possible to influence actors' actions under these normative conditions. SNT also allows for the possibility to influence the motivational structure itself. SNT emerges when the need for it arises in society. SNT can, for example, produce a normative design pattern, whether judicial or extra-judicial, in the relevant area.

There are different degrees of self-regulation. One definition describes it as follows: ${ }^{19}$

Self-regulation means systemic measures taken by a company, group of companies, industry or the entire business community to investigate, prevent or solve problems in relation to consumers or other customers. Self-regulation may consist of recommendations (e.g. from an industry organization), joint 
regulation (co-regulation) where the authorities formulate the rules together with the industries or the business community, or self-measures that are selfimposed by the actors.

In the true sense of the word, self-regulation means that self-interest and the general interest coincide in such a way that behaviours, through game rules and/ or rules of conduct, are coordinated and established by the involved parties themselves and the external effects are minor enough to be "managed" by the major interested parties. According to the previously mentioned definition, this version, i.e. "self-imposed measures by the actors", occurs in the final stage as a result of mutual interests. Self-regulation can also allude to measures taken to avoid further regulation. In these cases, aspects of SNT are needed. It is important to find out which normative structures are applicable and how these affect the motivational structures of the actors involved and to base the design of the collaboration, organization, etc., on this. Self-regulation also allows the involved actors the option to establish their own norms for their mutual activities. This invokes legal instruments of the kind that Nils Kristian Sundby calls permissive norms, i.e. norms that neither command nor prohibit and instead only permit. Contractual instruments belong to this category. Contracts allow individual parties to plan and confirm their dealings in a way that can be enforced by the legal apparatus, if necessary. Thus, the content of the rules are determined by the parties themselves. In that sense, self-regulation is an appropriate description in these cases. Neither can any party be forced to enter into an agreement. Voluntary participation is required from all involved parties. However, the design of the agreement and hence the self-imposed rules are mandatory and legally enforced.

How the self-imposed rules finally manifest depends partly on the nature of the mutual activity and partly on how it is organized. When it comes to the content of the activity, reference can be made to the difference between a mutual activity that is aimed at achieving a goal through cooperation versus competition-based activities. I have previously used the metaphor of the difference between building a hut and playing football. ${ }^{20}$ Both cases are characterized by mutual effort, but the difference is that in the case of football, certain rules are required. During the playful stage of a game's development, rules are established spontaneously as disputes and the need for decisions arise. But as soon as the playful stage transforms into a more serious game, actions are per definition decided by rules. The more advanced the game, especially when it advances from being practised by amateurs to professional players, the greater the need for third parties (referees) to apply and enforce the rules. Building a hut, however, does not require any rules. It is an activity that may require some coordination and distribution of tasks, but this can be done without predetermined rules. Those involved may need to delegate work tasks and agree on how decisions are to be made, but even this can be done spontaneously without rules. It is only when the game of building a hut is 
transformed into building a house or other more advanced building project that the external effects can become so far-reaching that it may be necessary to apply rules to protect external parties.

So, certainly, the nature of the activity is important with regard to the need for rules. But how the activity is organized is also important. One thing that immediately comes to mind is that the extent of the activity, whether competitive or not, affects the need for rules; the greater the activity, the greater the need for rules. But size is not the only determining factor. The following can be said about the three levels, the primary group, the secondary group, and the national level. The small primary group, e.g. the family unit, does not need rules to coordinate their activities. Their decisions and the trust required to enter into agreements are maintained through personal ties. The fact that the primary group may exist in a larger context in which rules have been established to protect members of the primary group, e.g. women and children, is another matter, but these rules are established at a higher level and belong to the higher level's system of rules. Neither does the secondary group need coordinating rules. However, there are different kinds of secondary groups.

Families and clans operate according to the same logic as the primary group. Personal ties contribute to ensuring that activities are conducted according to certain patterns without the need to be "enforced" by rules. This can also apply to an entire population group if, for example, the circumstances are such that collaboration becomes a necessity, particularly with regard to the organization's material production or necessary sustenance. Aster Akalus' study of the nomad people of Nuer in Ethiopia is one example of this. ${ }^{21}$

If the secondary group consists of a commercial organization, it will automatically focus on a specific task which, in itself, may be enough to generate cooperation. Again, the fact that common rules may be required to coordinate behaviour in the market is another matter; such rules, then, are determined at a higher level. But the secondary group, the organization's "inner life", does not require any rules, at least not any externally enforced rules. However, the extent and degree of specialization and the distribution of functions within the organization are important factors. Almost without exception, there is a division between decision-making and executive functions in large organizations, between principal and executive power, to use organizational theory terminology. ${ }^{22}$ Here, rules simplify the codification of power relationships and division of functions. In large-scale organizations or societies, this is implemented through internal rules. When it comes to non-commercial organizations, power relationships are established and maintained by a higher body - in the final instance, the government. In a non-profit secondary group, there is no economically measurable, unifying link comparable to that produced by a shared task.

21 Akalu, Aster (1985).

22 Abrahamsson, Bengt (2000), Hassard, John and Pym, Denis (eds.) (1993). 
The need for coordinating rules becomes even more palpable at the national level. The market and the economic systems need game rules. The political/ administrative system is dependent on formalized rules to distribute power and tasks. Even the state claims to protect itself by rules. ${ }^{23}$ Legal rules also put limits on the socio-cultural system. Technology is circumscribed by legal rules, if only to establish legitimacy to deal with external effects. We have discussed all these points previously in Chapter 4. But it is worth repeating: how we organize an activity determines the need for rules. For example, we see how the market has changed some characteristics of trade regulations.

During the market era, rules were needed to ensure the authenticity of the product, i.e. the buyer needed to ensure that nobody could claim at a later stage that they were the rightful producer. According to Chapter XVI of the Commercial Code (Köpmålabalken), the seller was required to be able to prove that he was the rightful owner. ${ }^{24}$ During the merchant house era, goods to be sold had to follow required special legal arrangements for granting credit and rules for how to settle payment obligations. During the machine age, the right to manufacture commercial goods was regulated, and in the industrial era legal protection for the buyer from being misled by the seller or receiving faulty goods was introduced. These changes in necessary regulations are related to the previously discussed core technological shifts that characterized these eras during the establishment of the market era. It is these changes in organized trade that drive new regulatory strategies.

As we now enter the digital society, it would seem that the marketplace has largely been organized to free itself from the need for legal rules. The digital society brings us back to the idea behind the original marketplace and its nature as a meeting point for all buyers and sellers of a certain product, within a delimited area. Advanced communication tools make it possible to bring together all sellers of a particular product, whether cars, refrigerators, etc., to a single marketplace. This means that the market is divided according to different products rather than different sellers. Bringing together all buyers and sellers of a particular product into a single (virtual) marketplace reduces transaction costs and minimizes the need for rules. ${ }^{25}$

The business sector has developed its own tradition of self-regulatory practices. ${ }^{26}$ All self-respecting industrial organizations today follow ethical regulations, sometimes combined with some kind of council or board that reviews issues and policies. ${ }^{27}$ In the business sector, self-measures are seen as a good and effective way of regulating e-commerce, and more efficient than legislation. ${ }^{28}$ Consumers see

23 Töllborg, Dennis (1997).

24 Köpmålabalken was introduced in 1296 in Upplandslagen (a region in Sweden) and it was transformed in 1350 into the nationwide Magnus Erikssons general landslag.

25 See Christina Ramberg's analysis in Ramberg, Christina (2002).

26 Read more in SOU 2000:96 p. 17.

27 Ibid, See also Hoff, David (2003).

28 SOU 2000:96 p. 30. 
these kinds of self-regulating mechanisms as a complement to the law that may even help clarify and interpret it. ${ }^{29}$ The expectations of self-imposed rules are thus fairly modest, and they are primarily seen as an instrument for creating legitimacy.

The state also has an interest in self-regulation that is imposed to stimulate increased e-commerce, which is considered to be beneficial for economic growth. Developments in this field occur at a rapid speed, while the legislative process by tradition is slow. To encourage development, the government believes that there should be alternatives to the traditional legislative process. ${ }^{30}$ The government argues that the market should drive development in applications and services, but that the market players should be encouraged to find solutions that promote e-commerce, while simultaneously promoting accessibility and establishing trust.

The need for SNT became apparent during the large-scale industrial era. The amount of issues that our society requires to be solved by regulations, not least in connection with intersystem conflicts, means that self-regulation emerges as a necessary complement to state regulation. Boaventura de Sousa Santos compares the legal system to the proverbial camel that is forced to carry an increasingly heavy load until it eventually collapses. ${ }^{31}$ In this situation, SNT is called upon to relieve the camel of its load and to find alternative ways of influencing behaviours and including external effects within the intra-systemic regulatory framework. The normative ambivalence inherent in intervening rules needs to be replaced with other solutions than legal regulation.

\subsection{Sociology of law in need of a science of norms in the digital era}

\subsubsection{Gene technology and the lag in law}

The tendency to try to solve all societal problems through legislation is something that belongs to the political phase of the old, large-scale industrial society. The law is, as I have argued in another context, a form of standardized policy. ${ }^{32}$ Due to the old society's - the upper curve in the societal development figure in Chapter 1 - dominance over the mental structures of the emerging new society, a kind of lag occurs. The new society that emerges is valued in the terms of the old. In our times, as we face new technological developments based on digitalization, we have no previous experience to fall back on. We are quite simply facing hitherto unknown problems. Previously, this problem has appeared in the biotechnology field in connection with, among other things, genetic engineering. There is a knee-jerk reflex to expect new legislation to control the new phenomenon. To the extent that the new technology becomes

29 Ibid, p. 32.

30 Ibid, p. 27.

31 See de Sousa Santos, Boaventura (1995).

32 Hydén, Håkan (2002). 
abused, such abuse is already covered under existing criminal and civil law. But the efforts of large-scale society to control and subordinate everything also leads to demands for new activities to be controlled. This has led to the introduction of regulations on genetic engineering in Chapter 13 of the Environmental Code in Sweden. The regulations apply to the use of genetically modified organisms (GMOs) in the laboratory environment, when released in a natural environment and when products containing GMOs are introduced to the market. The regulation has been introduced in environmental legislation, which normally addresses environmental protection, with the aim of sustainable development. However, with regard to GMOs, the purpose of the regulations is primarily to ensure that specific ethical considerations are taken into account. This is tested by the competent authority, the Swedish Board of Agriculture in the case of agricultural products. According to Chapter 13, Section 12, the Environmental Code, it is required to carry out a deliberate release of GMOs in a natural environment or when introducing GMO products to the market. Approval may only be granted if the activity is ethically justifiable. Additionally, a special committee, the Swedish Gene Technology Advisory Board, must also submit their opinion. So far, these opinions and decisions have led to the activities being considered ethically justifiable as a matter of routine. The law and legislative histories are also somewhat vague with regard to what would make a release or product introduction not ethically justifiable.

What, then, does this regulation mean from an SNT perspective? Let us examine the entire matter from a norm-scientific perspective. In this regard, the problems with genetic engineering are related to the unknowns surrounding the consequences of technology. Could plant hybrids harm nature? Would GMO plants dominate and drive other vegetation to extinction, for example? The consequences are largely unknown to science. In particular, science is invested in developing and applying genetic engineering methods to produce new resistant crops which are better at tolerating cold temperatures and infestations, that grow faster, are more nutritious, etc. These are positive attributes that therefore "develop of their own accord". Seen from this perspective, to minimize the risks, the solution would be to demand that greater resources be devoted to research and development (R\&D) and to the possible consequences of genetic engineering. Through the legislation already introduced, the state has societalized and accepted the risk. The fact that the Swedish Board of Agriculture's approval is required before introducing or marketing GMO products means that the state and official bodies have assumed responsibility for any incidents that may arise. Admittedly, the law (Chapter 13, Section 8 of the Environmental Code) requires that when applying for permission, the applicant must submit a report which serves as "the basis for a satisfactory assessment of the harm that the organisms could cause to public health and the environment". According to the same section, the report must be prepared in accordance with scientific methodology and demonstrable competence. The problem, however, is that there is a lack of relevant competence, and the law, due to its construction, contains nothing that would encourage it - to the contrary, in fact. Additionally, receiving approval for 
the activity means that the liable owner is simultaneously granted criminal immunity from environmental crimes.

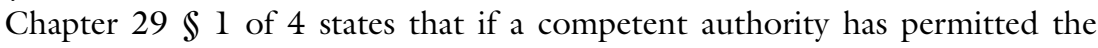
practice or it is generally accepted, or if the act may be deemed to be justifiable in view of the circumstances, no penalty shall be imposed pursuant to this section.

From an SNT perspective, the paradox arises that the situation would have been better off without state intervention. Had the state not assumed responsibility through legislation, the companies and R\&D departments in the relevant areas would have borne full responsibility. This would have put pressure on all actors in the field not to take any chances. Any actor who attempts to take a "shortcut" to success and causes damage in the process could be sued for damages based on civil liability or prosecuted based on criminal liability, pursuant to either the provisions of the Environmental Code or the Criminal Code. This incurs the most severe penalty of all. In addition to potentially damaging the entire industry and thereby being subjected to pressure, their own company's future would be at stake. The financial penalties in these kinds of cases are enormous. It is not necessary to claim these penalties in a court of law, as in the case of violations of legal norms; instead, such acts are condemned by representatives of the systems themselves, and market reactions, at the very least, tend to be harsh. ${ }^{33}$

\subsubsection{The normativity of technology}

In Chapter 3, I pointed out how technology has normative implications. In the industrial era, this is related to the use of technology. In the later stage of industrial development, the benefits of technology became increasingly connected to negative external effects. This led to state interventions being reflected in law in order to balance the positive and negative effects. ${ }^{34}$ Intervening legislation places demands on individuals and companies to take precautionary measures to protect special interests. ${ }^{35}$ In the late 1970 s and 1980s, legislation such as consumer protection, environmental protection, work life regulation, etc., were introduced in the industrialized world. This kind of legislation represented something different compared to private law and administrative law. The intervening piece of

33 This does not mean that I generally advocate an absence of legislation, as has been vulgarly interpreted in the past. We refer, here, to Hydén, Håkan and Gillberg, Minna (2003), where we discuss "Law as a safety belt and market as an enforcer." Only the administrative (framework) legislation needs to be settled, especially the intervening rules. Classic civil and criminal law needs to be made stricter and be applied to the new technological areas. Probably, this will require a new legal culture to be implemented properly. Some steps in this direction can already be observed.

34 This is something ignored in legal science, except from a few examples in socio-legal analysis. Without using the terminology of intervening law, Nonet and Selznick (1978) to a certain extent, dealt with the same problem in terms of responsive law. A still closer example which has bearing on intervening law is Gunther Teubner's innovative concept, reflexive law (1983 and 1986).

35 See Chapter 5. 
legislation contains a compromise between private and public law (cf Chapter 4 ). It has both the citizens and the public authorities as its addressees. It is an expression of wanting both/and - of wanting to both eat the cake and have it. Intervening legislation can also be described as disjoint norms, ${ }^{36}$ which arise when interests that benefit from the legislation and those that do not benefit from it affect the same actors or category of actors. The receivers and target group of the norm therefore belong to different categories of actors.

When digital technology takes over and begins to replace the industrial model, the technology itself becomes norm-setting. A new regulatory logic becomes necessary. It is no longer feasible to rely on conventional cost-benefit analyses and state intervention hoping that one can simultaneously both have the cake and eat it, so to speak. The regulatory logic shifts from providing both $A$ and $B$ to either/or. The notion that legislation is a compromise in the public interest is not enough. It becomes necessary to choose between "this" or "something else". As long as automation and artificial intelligence (AI) remain relatively elementary, their full consequences are not easy to discern, but the further they develop, the stronger ethical issues will pressure law makers. Are we really ready to continue down the road guided by this technology or do we need to develop an alternative? State and law are no longer the sole sources of societal norms. With the advent of digitization and AI, regulatory power is transferred from politicians and state officials to technicians and private-sector actors without formal authority.

This presents society with a new regulatory order that changes the conditions for the SoL. It becomes obvious that normativity in society does not solely emanate from the state and the law. This process started already during the industrial era, when regulation, via intervening rules, abandoned the rule of law and the dogmatic kind of legislation and developed into compromises between system imperatives. As a consequence, a separation between hard and soft law emerged. ${ }^{37}$ A science in this situation that studies regulatory problems cannot any longer only focus on the law and the legal system. It has to find ways to incorporate the normativity that stems from different kinds of manmade systems to cater for its material needs. Thus, the norm concept must extend to capturing expectations from more areas than law and societal norms to include technical, economic and professional norms. These norms do not relate to any particular sender; they are built into these different systems and therefore, from a norm perspective, are exceptional and harder to identify.

This development affects both theory and methodology within SoL. It turns understanding normativity upside down. Searching for motives - the key strategy - begins with a reconstruction of events, i.e. the outcome of a specific

36 Coleman, James (1990, p. 244).

37 Regarding the relation between hard and soft law, see Woodlock, John and Hydén, Håkan (f)Lex avionica; How soft law serves as an instrumental mediator between professional norms and the hard law regulation of European civil aviation maintenance, 2020, I: Safety Science. 121, s. 54-63. 
act. Methodologically, digitization introduces the need to study algorithms in a two-step flow of normativity - the algorithm as a technical design that addresses what to do and as a societal construct with consequences for society (or part of it), what I call algo norms (see Section 7.3.4. below).

Technology has always had inherent normative consequences. Human artifacts - products of human activity - have a decisive influence on people's behaviour and societal relations, e.g. soap, television sets, computers and mobile phones have consequences in different respects. In addition to the intended use of a product, normative instructions are included for how to behave in different situations. It has always been like this. However, with the emergence of digital technology, it becomes highly apparent. It violates previous ways of looking at and doing things. The technical norms have, through digital technology, gained an increasingly strong inherent normativity, represented not least by AI and the use of algorithms.

\subsubsection{Code is law and algorithms are norms}

With the transition from mechanics to electronics as our core technology, we face a transformation that Manuel Castells (2010) regards as "the new economy, society, and culture . . . one of the - if not the - defining characteristics of the contemporary era". As a result of digital technology, technical norms are gaining stronger inherent normativity. This development is mainly manifest in $\mathrm{AI}^{38}$ and the use of algorithms. Digital technology is increasingly becoming a part of our daily lives. It is used in our phones and homes to such an extent that it is hard to imagine a single day passing that isn't in some way or another impacted by AI. ${ }^{39}$

The pace of AI developments is astounding. Organizations across all industries are looking to AI to give them the competitive advantage that will win the hearts and minds of customers. As products of the ongoing digital transformation of society, AI and algorithms have far-reaching, yet under-researched sociological consequences on what we do, how we do it and what can be done. It is expected to change nearly everything, including the relationship between state and individual, and it will drive changes in today's laws, institutions and values. ${ }^{40}$ This revolutionary technology which has taken hold of society in recent decades has been characterized as "disruptive", ${ }^{41}$ meaning it makes former modes of produc-

38 AI can be regarded as the theory and development of computer systems able to perform tasks that normally require human intelligence, such as visual perception, speech recognition, decision-making, etc.

39 So far it is easier to find speculations of different kinds than real applications.

40 Larsson, Stefan, Artificiell intelligens som normativ samhällsutmaning: partiskhet, ansvar och transparens [Elektronisk resurs], Juristförlaget i Lund, Lund, 2019.

41 Christensen, Clayton. (2016). The innovator's dilemma: when new technologies cause great firms to fail. Boston: Harvard Business School Press. 


\section{A science of norms}

ing and living outdated. ${ }^{42}$ This means that existing legal rules and societal norms are affected..$^{43}$ Since this chapter is a sociological analysis of digitization and AI, it takes an external perspective on law and the legal system, which means it looks for principal changes in law and society without going into detail on how positive law is affected. ${ }^{44}$

So far, we have seen how digital technology has forced the law to deal with new phenomena, such as digital currency, robots, autonomous cars, etc. ${ }^{45}$ However, there is nothing which requires new legal solutions. It is more a question of bringing new phenomena under established legal principles. Digital currency, for instance, follows, from a legal point of view, the same principles as promissory notes. Should robots be recognized as legal persons, ${ }^{46}$ and how about liability for robots? These are examples of new problems raised by the digital technology. When it comes to autonomous cars, the legal principles with regard to regulation are the same as for ordinary cars, with the exception of one crucial difference: there is no longer a driver to blame. Digital developments have, however, taken us one step further. It starts with Lawrence Lessig's concept "code is law". ${ }^{47}$

Lawrence Lessig identifies four forces that constrain our actions: the law, societal norms, the market and architecture ${ }^{48}$ Constraints work together, though they function differently, and the effect of each one is distinct. Law constrains through the punishment it threatens to impose. Societal norms constrain through the stigma that a community imposes; markets constrain through the prices they charge, and architecture through the physical burdens they impose. By this, Lessig notes that biological, geographical, technological and other facts constrain our actions. ${ }^{49}$ An analogy for architecture that regulates behaviour in cyberspace is the underlying coding. The software and hardware constitute cyberspace as a set of constraints on how you are able to behave. ${ }^{50}$

How can code be law? The code or software, Lessig claims, includes features selected by the code writers which constrain some behaviours by making other behaviours either possible or impossible. In this sense, code is regulation, just as the architecture of real-space codes consists of regulations. As in real space, the aforementioned four modalities regulate cyberspace. The law, norms, the market

42 Alvarez-Pereira, Carlos. (2017). Disruptive technologies. A Critical Yet Hopeful View, Cadmus, Vol. 3, No. 2.

43 Hilgendorf, Eric (2018). Digitization and the Law [Elektronisk resurs].

44 Here, I refer to Barfield, Woodrow and Pagallo, Ugo (eds.) (2018), and Mak, Vanessa et al. (eds.) (2018).

45 Svensson, Måns and Björkenfeldt, Oscar. (2019). New environmental zones for passenger cars: attitudes, norms and legal compliance, sociology of law. Lund: Lund University Press.

46 On February 2017, the European Parliament adopted a resolution on civil law rules of robotics. This forms the first step in the EU law-making process.

47 Lessig, Lawrence. (2006). Code: version 2.0. New York: Basic Books.

48 Ibid, p. 89.

49 Murray, Andrew D. (2011). Internet regulation. Handbook on Regulation. http://works. bepress.com/andrew_murray/4/.

50 Lessig, Lawrence. (2006). Code: version 2.0. New York: Basic Books. 
and the architecture interact to build the environment for the netizens, those individuals who belong to and act in cyberspace. The author of the code becomes the architect of the societal construction.

If code is law, algorithms are the norms. In this paradigmatic transition. technical norms gain an increasingly stronger, inherent normativity. This is mainly represented by AI and the use of algorithms. AI and related technologies are expected to reshape the business ecosystem toward a more data-centric and datalucrative world. It will affect the law and the legal profession. In particular, technological advances in fields ranging from machine learning to more advanced robots, including sensors, virtual realities, algorithms, bots, drones, self-driving cars and sophisticated "humanlike" robots, are creating new and previously unimagined challenges for regulators. ${ }^{51}$ These advances also give rise to new opportunities for legal professionals to make efficiency gains in the delivery of legal services. ${ }^{52}$ In this way, the normative consequences of the code become visible. With the exponential growth of such technologies, radical disruption seems likely to accelerate in the near future.

Algorithms are not a new phenomenon, but they become particularly essential in the new digital era. Algorithms ${ }^{53}$ are usually included as a component of various software programs and consist of instructions on what to do, with what and in what order. They can be described as recipes that prescribe how to process and mix ingredients. ${ }^{54}$ Algorithms, together with interfaces and service default settings called platforms, encode societal values into the digital architecture that surrounds us and co-create societal and cultural patterns of action ${ }^{55}$ (van Dijck 2013, p. 29). Here we see examples of very advanced SNT. Platforms in combination with e-commerce is the winning concept behind the tremendous economic accumulation ${ }^{56}$ within a company such as Amazon.

A neural network or artificial neural network is a collective name for a number of self-learning algorithms that attempt to mimic the function of biological

51 Bensoussan, Alain and Bensoussan, Jeremy. (2019). Robot law book - a comparative handbook: robotic technologies law. Lexing: Technologies Avancees \& Droit), Groupe Larcier s.a.

52 Atik, J. and Jeutner, V. (2019) Quantum computing and algorithmic law, November 2019.

53 Algorithms are defined by Cormen, T.H., Leiserson, C.E., Rivest, R. L. and Stein, C. (2009). Introduction to algorithms. 3rd ed. (p. 5). MIT Press and McGraw-Hill, as "any well-defined computational procedure that takes some value, or set of values, as input and produces some values, or set of values, as output. An algorithm is thus a sequence of computational steps that transform the input into the output".

54 In this process, there is always a risk of prejudices affecting the programming in a way that gives rise to discrimination.

55 van Dijk, José. (2013). The culture of connectivity: a critical history of social media (p. 29). New York: Oxford University Press.

56 China is the largest digital market in the world, leading all countries in terms of e-commerce, $\mathrm{m}$-commerce and social commerce. It is also home to many of the largest e-commerce conglomerates, including Alibaba and JD.com, who are generating sales at a scale that far exceeds that of companies in the USA - including Amazon. See more on Ethan Cramer-Flood, The Ecommerce Game Is a Tale of Two Countries, and China's Companies Are Pulling Ahead, eMarketer daily, July 5, 2020. 
neuron networks (such as the brain). Algorithms that emulate neural networks can often cope with problems that are difficult to solve using conventional computer science methods. It is precisely the unpredictable solutions to problems and the self-programming aspect of deep-learning technology which raises new questions that the law is forced to consider. ${ }^{57}$ The problem emerging is who will be held responsible for the consequences of coding. ${ }^{58}$ Data mining, pattern recognition, signal processing, control technology, computer games, forecasts, self-organization, medical diagnosis, non-linear optimization and optimization problems with many constraints (for example, scheduling) are some examples of applications. These applications make use of machine learning. In machine learning, an algorithm is a set of rules or instructions that are fed into an AI program, neural network or other machine to help it learn on its own. Thus, in these situations AI, via algorithms, produces its own norms; normativity becomes an integral part of technology. In the paradigmatic shift from mechanics to digital technology, the normativity changes from being connected to the use of technology and becomes, instead, an integral part of the technology as such. ${ }^{59}$

A neuron network must be trained before it can be built up and used for certain purposes. Most neural networks therefore work in two phases: first a learning phase where the network is trained for the task to be performed. Then follows an application phase where the network only uses what it has learned. It is also possible to let the network continue to learn even while being used. A neuron net has a wide range of applications, and new applications are constantly being created.

\subsubsection{Different orders of normativity: algo norms}

Our accumulated knowledge about algorithms is advanced and has developed into AI. ${ }^{60}$ It is only through our capacity to see and comprehend expectations emanating from technological systems that algorithms as norms become visible and become possible to understand as part of the societal consequences of digitization. ${ }^{61}$ Knowledge about technological developments alone, however, does not tell us anything about societal changes; neither do the algorithms and AI.

57 Barfield, Woodrow and Pagallo, Ugo (eds.) (2018). Research handbook on the law of artificial intelligence. Cheltenham: Edward Elgar Publishing Limited.

58 Balkin, Jack. (2015). The path of robotics law. California Law Review Circuit, Vol. 6, p. 45, note 52 .

59 Cf Winner, Langdon, Do Artifacts Have Politics? Daedalus 109, Vol. 1, Modern Technology: Problems or Opportunity? pp. 121-136, The MIT Press.

60 Russell, Stuart Jonathan and Norvig, Peter, Artificial intelligence [Elektronisk resurs] a modern approach, 3rd, Pearson new international edition., Pearson Education Limited, Harlow, 2014, APA, Tomasik, Brian, Artificial Intelligence and Its Implications for Future Suffering, First written: May 14, 2014; last update: June 13, 2017. https://foundational-research. org/artificial-intelligence-and-its-implications-for-future.

61 I use the term algorithms for the sake of simplicity as if they are one single unit, but in reality there are many different sets of sub-algorithms which provide necessary partial calculations as the basis for the calculations of the main algorithm. 
The missing link is the concept of societal norms. The direct, normative effect of algorithms is a question of technical instructions. However, the interesting aspect from a social science perspective is to locate and understand the societal implications of AI. There is a need for the development of a sociology of algorithms ${ }^{62}$ in the same way as SoL as a discipline was invented in the early 20th century in order to complement and compete with legal dogmatics regarding knowledge of functions and the consequences of law. ${ }^{63}$

There is a crucial difference between algorithms in a technical sense and in a social scientific sense. Both are normative but cover different fields of knowledge. A parallel can be drawn with legal norms. They can be understood from a strictly legal point of view and inform us of the correct interpretation and application of the legal rule as an instruction for how to act or how to judge a certain situation. However, legal norms also have - from a social scientific perspective - a broader scope. Legal norms are not neutral, but they do also affect societal functions and have their own consequences to society. I claim that the point is that there are different orders of normativity - the first related to the algorithm as a technical instruction and the second to the consequences springing from the first order. To illustrate this with an example from the legal field: it is one thing to know when a person should be sentenced to imprisonment and another to understand what this means for society, the perpetrator or the victims of the crime. These are distinct spheres of knowledge, which require their own different methodological approaches, the legal dogmatic and the social science perspective within SoL and criminology, respectively. The normativity layers associated with algorithms are special, and understanding the second order calls for a separate concept, or what I call algo norms. They are an indirect effect of the algorithms and it is this indirect effect that is of interest from a SoL perspective. Thus, algo norms are those norms that are related to the societal consequences, which follow from the use of algorithms in different respects.

Let me explain by drawing a parallel between law and AI. In graphical terms, the similarities and differences between legal norms and algo norms could be illustrated in the following way. If we start with the legal knowledge field, Figure 7.31 can help us understand the relationship.

Legal dogmatics can be illustrated in a vertical perspective since they, as an ideal type, are built on the logic of subsumption and deduction. ${ }^{64}$ This process is a question of the technical application of normative standpoints in law on factual situations, which may require more or less sophisticated reasoning. We can also extend the legal knowledge field to include socio-legal aspects covering the

62 Donald MacKenzie has used the term in an unpublished paper about High-Frequency Trading and the Shaping of Markets, second draft 2014.

63 Ehrlich, Eugen, Fundamental principles of the sociology of law. New ed. Transaction Publishers, New Brunswick, 2002[1936] 1913; Pound, Roscoe (1910) Law in Books and Law in Action, American Law Review, vol. 44; Weber, Max, Economy and society: an outline of interpretive sociology. Vol. 1, University of California Press, Berkeley, CA, 1978.

64 Hydén, Håkan and Hydén, Therese (2019), ch 1. 


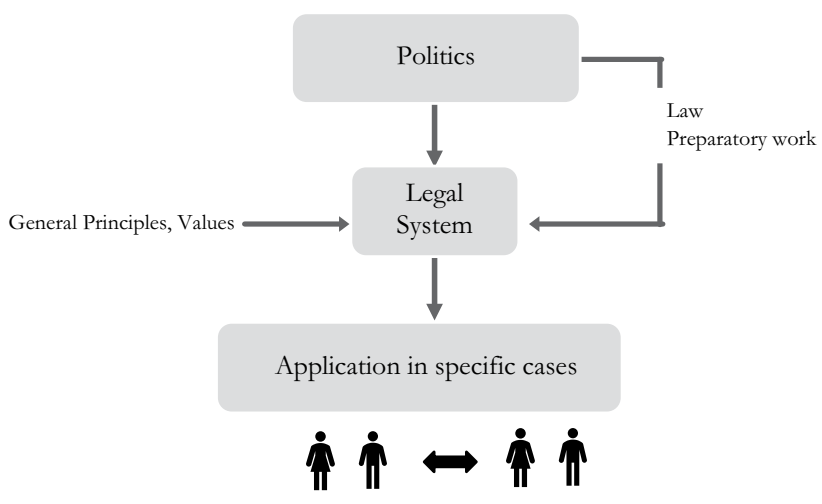

Figure 7.31 Characteristics of legal dogmatics

\begin{tabular}{|c|c|c|c|c|}
\hline Economy & & & & Economic \\
\hline Politics & & & & Political \\
\hline Sociology & Causes & Legal & Consequences & Sociological \\
\hline Religion & Genesic & Order & & Women \\
\hline Legal history & & & Functions & Children \\
\hline Power relations & & & & Minorities \\
\hline Societal structure & & & & Environment \\
\hline etc. & & & & Efficiency \\
\hline
\end{tabular}

Figure 7.32 Causes and consequences of law

causes and consequences of law, i.e. looking at the genesis and the functions of law, which is the focus of SoL ${ }^{65}$. Cf. Figure 7.32.

This horizontal problem area represents something else than legal dogmatic knowledge, although it is of great relevance for understanding the law. It is just another perspective of law that is not regarded as relevant for legal dogmatics. SoL has, so far, not invented a proper concept which covers these normativities related to the genesis and consequences of law when applied to, and confronted with, societal realities. The concept of law in action is not adequate, nor is the concept of living law. Perhaps the concept of socio-legal norms is the most appropriate one. Maybe the parallel to the digital world can help us. If we translate the two illustrations to the algo norm context, we get Figure 7.33.

65 Hydén (2008). 


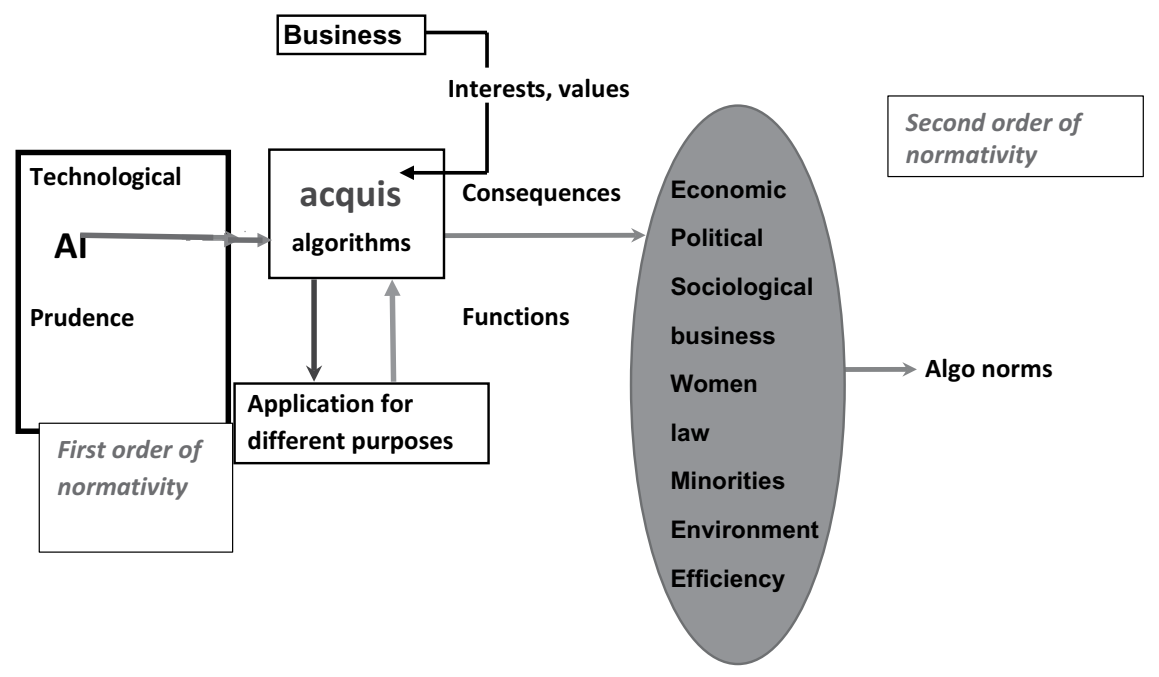

Figure 7.33 The context of algo norms

Algo norms can be regarded as a subcategory of technical norms. The theoretical perspective lying behind the concept of algo norms builds on norm science theory and methodology. ${ }^{66} \mathrm{~A}$ science of norms is about identifying and understanding the driving forces behind human action on a societal level. ${ }^{67}$ The study of norms tends to be divided into two perspectives, one descriptive and one injunctive, ${ }^{68}$ as was noted in the first chapter. Banakar also uses the parallel terminology of external and internal perspectives on norms. However, we can count on a third possible understanding of the norm concept, which is ignored by the social sciences, and that is the analytical perspective; see Chapter 1. According to this third possible understanding, the concept of norms and the empirical study of norms help us to understand causalities behind human behaviour on a collective level. Through the study of norms, human motives for collective action can be captured. ${ }^{69}$ This approach goes beyond Max Weber's Verstehen method. Weber was a methodological individualist who argued that we can only understand societal phenomena and historical processes by studying how individuals experience the world and what individuals find meaningful. ${ }^{70}$ By dissecting existing norms in a descriptive way, it is possible to capture preferences and motives which are behind human behaviour on a collective level. 
To fully grasp the concept of societal norms, it is helpful to distinguish between three different ontological levels: a normative, a sociological and a sociopsychological $^{71}$ (Hydén \& Svensson 2008). Each has its own epistemological implications. ${ }^{72}$ Identifying algo norms as the normative outcome of the algorithm faces its own challenges since its normativity is an indirect, external effect rather than an explicit one. The primary objective of the algorithms is not to produce its own set of norms. The latter are hidden effects that need to be made visible by studying their societal effects. The normative dimension is hidden behind cognitively based instructions on how to act (cf what was said in Chapter 3 on this point).

In order to help us dissect the norm in terms of motives, we can make use of the circle of motives introduced in Chapter 1, which helps us distinguish three dimensions of the norm: (1) Will and Values, (2) Knowledge and Cognition and (3) Systems and Possibilities. Typically, societal norms are initiated by human will or values, which require knowledge to be implemented, including cognitive references to the norm's addressees. The outcome of an applied norm is, in the final instance, dependent on the possibilities for carrying out what the norm prescribes. Systems created by humans have for various purposes set the limits for these possibilities.

The interesting thing about algo norms - compared to societal norms ${ }^{73}$ - is that their genesis is related to new knowledge, digitization, which generates its own systems with different purposes. These systems influence, in turn, our will and values. Thus, the algo norms move from dimension (2) to (3) to (1) as illustrated in Figure 7.34. The difference between societal and algo norms is important, because wherever systemic factors are the independent variables, the scope for human will and values is contained and may become a threat to democracy.

Algo norms thus emerge when the algorithms meet and collide with their surrounding society. Different consequences occur when the technological solutions and design are applied in reality; some can be seen as intended, but many are without intention. They are external effects of the algorithms. There is a kind of two-step causality here. First, the algorithm as a technical instruction perform a certain service. This service is in its turn meant to fulfil a specific purpose, which goes beyond the mere technical aspects of algorithms. The relation between the two steps is often not visible.

71 Hydén and Svensson (2008).

72 Åsberg, Rodney, Ontologi, epistemologi och metodologi: en kritisk genomgång av vissa grundläggande vetenskapsteoretiska begrepp och ansatser, Rev. uppl., Institutionen för pedagogik och didaktik, Göteborgs universitet, Göteborg, 2001.

73 Bicchieri, Cristina. (2006). The grammar of society, the nature and dynamics of social norms. Cambridge: Cambridge University Press, Drobak, John N. (ed.). (2006). Norms and the law. Cambridge: Cambridge University Press, Elickson, C. Robert. (2001). The evolution of social norms: perspectives from the legal academy. In Hechter, M. and Opp, K.D. (eds.), Social norms. New York: Russel Sage Foundation. 


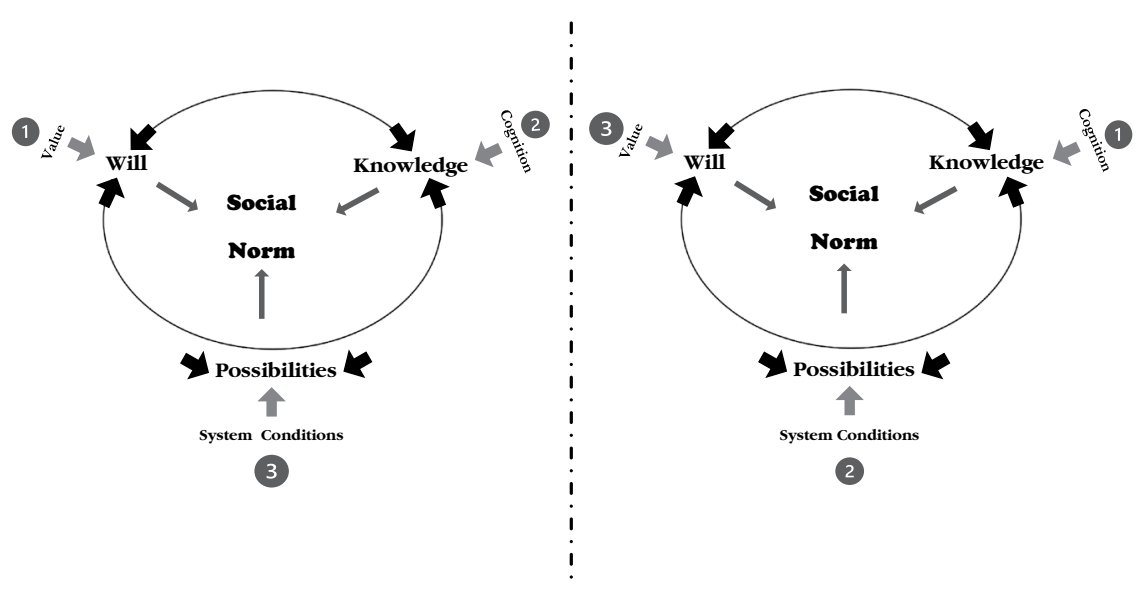

Figure 7.34 The difference between societal and algo norms

Algorithms as norms are unique. The normative consequences are embedded in the technology and determined by the design of the AI. The outcome is an empirical matter. ${ }^{74}$ From the perspective of the addressee, they are structurally conditioned, and they cannot be avoided. Algorithms, as Melvin Kranzberg, the historian of technology, expresses in his first law of technology says, they are neither good nor bad; nor are they neutral. ${ }^{75}$ What he suggests is that

technology's interaction with the societal ecology is such that technical developments frequently have environmental, societal, and human consequences that go far beyond the immediate purposes of the technical devices and practices themselves, and the same technology can have quite different results when introduced into different contexts or under different circumstances.

In this way, Kranzberg confirms the idea of a first and second order of normativity. The first is precise and deals with technology, while the other is diversified and multi-normative. As Adrian Mackenzie has further observed, "[a]n algorithm selects and reinforces one ordering at the expense of others", ${ }^{76}$ often in ways that were not intended or possible to foresee. Algo norms, therefore, are norms to which people are subordinate - but in ways that largely lie outside their control. Algo norms are neither a question of free will, nor of coercion. The design of the

74 Alvarez-Pereira, Carlos. (2017). Disruptive technologies. A Critical Yet Hopeful View, Cadmus, Vol. 3, No. 2.

75 Kranzberg, Melvin, Vol. 27, No. 3 (1986, July), s. 544-560 in Technology and Culture, The Johns Hopkins University Press.

76 Mackenzie, Adrian. (2006). Cutting code: software and sociality. New York: Peter Lang. 
technology, and thereby its normative implications, is made by people with technical expertise. In this perspective, the engineers become our new norm setters, at least as long as AI is logical and in the hands of humans and not determined by the technology as such.

From a social scientific point of view, algo norms are problematic in two interconnected ways. One is the democratic deficit that arises when societal norms are introduced and decided upon by technicians, the system of algorithms itself. They are neither the result of political decision-making in a democratic order nor an outcome of societal or public discourses. SoL's knowledge interest focuses on how decisions are made and the normative implications. Even with the best intentions to create algorithms that improve people's lives, the values and prejudices held by those individuals who feed the algorithm with data and design the code will affect how the algorithms are constructed (Lessig 2006). Furthermore, algorithms to an increasingly larger extent reproduce themselves. The opportunities for public accountability shrink, and citizens face the risk of progressively becoming captives of technical fixes over which they have little, if any, control.

The second related problem concerns manipulation in different respects. One has to do with the market. Algo norms challenge the ideal role of the market as a tool for the consumer to find goods and services. They confront us with a paradox. Our choices are determined by the algorithms and the programmers who have coded them in order to figure out our preferences and thus what we are likely to want more of. We are faced with a situation where the norm provider determines the content. Whenever one uses the Internet to buy products, listens to the news, uses societal media or browses the web, algorithms decide what one finds. This is an inbuilt effect of the technology, actually - its raison d'étre. The market is in itself an algorithm (supply and demand meet in a computer system), but the actors remain mostly human beings; they interact with the market via computer screen, keyboard and mouse. ${ }^{77}$ However, algo norms are so seductive that we do not even notice that information is filtered in ways that affect us. Not even the programmers are always aware of what is going on. ${ }^{78}$ Tracing the results from personalized searches, a website algorithm selectively guesses the information a user would like to find and encapsulates us in a filter bubble. ${ }^{79}$ As a result, users become separate from information that disagrees with their viewpoints, effectively isolating them in their own cultural or ideological bubbles. ${ }^{80}$

77 Mackenzie (2014).

78 A Swedish journalist and writer, Per Grankvist, has argued that the algorithms are manifest according to the same unwritten rules that have always been applied to the upper class's service staff. They never draw attention, never make noise and are never visible. Algorithms have learned what the master wants and provide these services without the master having to tell them. http://pergrankvist.se/perspektiv.

79 Bozdag, Engin. (2013, June 23). Bias in algorithmic filtering and personalization. Ethics and Information Technology, Vol. 15, No. 3, pp. 209-227.

80 Pariser, Eli. (2011, May). The filter bubble: what the internet is hiding from you. New York: Penguin Press. This phenomenon reinforces the confusion and polarization which are 
The choices made by these algorithms are not transparent, and it is difficult to see how they affect our own and other citizens' worldview and/or preferences.

\subsubsection{Methodological implications}

Previously, social scientific research on digital development has primarily concentrated on its technical innovations and its contributions to the emergence of new business models. These digital technologies have given rise to revolutionary changes regarding economic and societal institutions and norms. ${ }^{81}$ The literature on algorithms is quite extensive. ${ }^{82}$ Most publications are in the fields of science and technology, but there is also an increasing number within the social sciences, economics and humanities. Even law and legal science is represented. ${ }^{83}$ The Societal Media Collective at Microsoft Research New England has produced a relevant compilation of the literature in the field. ${ }^{84}$ There is nascent sociological literature on algorithms (e.g., Mackenzie [2006]) which offers an exemplary study of one specific algorithm, but overall there is a tendency in this genre to focus on algorithms with which human beings interact directly, such as the PageRank algorithm in Google. ${ }^{85}$ The SoL study of algorithms will expand the social science research frontier by exploring, with a normative focus, the societal effects of the new technology. The social sciences have so far studied digitization primarily from an economic point of view, and most of it has had a descriptive preponderance. One example of an attempt by researchers to use algorithms as a scientific tool to study norms is an article by Sara Moricz. ${ }^{86}$

We have no systematic knowledge about how algorithms affect us as individuals, how they affect society at large and how they affect the law. As discussed above, digitization entails hidden normative effects on society and law. As research objects, AI and algo norms are moving targets. To explore an ongoing process of change in real time, a novel scientific approach that relates to advanced practice has to be initiated. The research frontier is not to be found at the researcher's desk, but in practice. As a result, more information is available in sources linked

already a consequence of the transition in society from an industrial mode of production to a digital.

81 Golson, Kelly Jo. (eds.). (2016). The digital effect. London: SAGE Publications Ltd.

82 According to the Web of Science January 2016 there were 169,836 articles of which onethird are from the last five years.

83 Barfield, Woodrow and Pagallo, Ugo (eds.). (2018). Research handbook on the law of artificial intelligence. Cheltenham: Edward Elgar Publishing Limited. See also Mak, Vanessa, Tjong Tjin Tai, Eric and Berlee, Anna (red.). (2018). Research handbook in data science and law. Northampton, MA: Edward Elgar Pub., Inc.

84 http://societalmediacollective.org/reading-lists/critical-algorithm-studies/.

85 Hillis, Ken, Petit, Michael and Jarrett, Kylie. (2013). Google and the culture of search. New York: Routledge.

86 Sara Morics, Using artificial intelligence to recapture norms: Did \#metoo change gender norms in Sweden? A PREPRINT, Sara Moricz, Department of Economics, Lund University, March 5, 2019. 
to websites and links from various commercial actors, writers, journalists and bloggers than in the scientific literature. ${ }^{87}$ This could have a negative effect on the scientific credibility of the research. In this context, a researcher's task is to discover and articulate advanced practice, validate it and scientifically systematize it in such a way that it can be communicated and further advanced. ${ }^{88}$ The validity of the information given is extra sensitive from a methodological point of view.

Another problem in relation to this kind of study is the empirical approach. You cannot expect to gain knowledge by conducting empirical studies. They either mirror the old, mechanical solutions to societal problems related to industrial society or reflect a reality that has changed before the scientific results have been published. ${ }^{89}$ Due to the cyclical development of society, lessons can be learned from history, nota bene from that part of history which corresponds to a similar stage of societal development. ${ }^{90}$ That does not exclude the fact that using the technology for certain purposes requires social engineering which might benefit from existing knowledge from the social sciences. ${ }^{91}$ Previous experience can be used and parallels can be drawn to similar situations related to societal development.

Furthermore, there are problems when identifying algo norms. One is the practical problem of finding the algorithms in use. ${ }^{92}$ Companies are not particularly willing to display the algorithms they apply, or their design, which is not necessarily a good thing. ${ }^{93}$ The other, somewhat more complicated, matter is to find and analyse the algo norms. This is mainly a theoretical challenge. Algo norms are

87 Herring, S.C. (2009). Web content analysis: Expanding the paradigm. In International bandbook of internet research (pp. 233-249). Dordrecht: Springer.

88 Advanced practice has, for instance, been used as a research strategy in SoL in a project that followed the construction of the City Tunnel in Malmö, Sweden. In a dialogue with the practitioners who designed and built the tunnel, knowledge of, not least, the environmental implications and legal norms that existed could be systematized and communicated with relevant constructors, as well as with the general public who followed the work. See (Hydén 201la; Wickenberg 2004).

89 Urban, Tim (2015, January 22). The AI revolution: the road to superintelligence, Wait but Why.

90 Braudel, Fernand (1982). Vardagslivets strukturer. Det möjligas gränser. Civilisationer och kaptilism 1400-1800, Band 1, Stockholm 1982: Gidlunds, Kondratieff, Nickolai D. (1925), The long Waves of Business Cycles in Economic Life, in Problems of Economic Fluctuations, Institute for Business Cycles Research, Wallerstein, Immanuel. (2004). World-systems analysis: an introduction. Durham: Duke University Press. See also Cameron, Rondo E. (1996)

91 Mölders, Marc and Schrape, Jan-Felix. (2019, June). Digital deceleration. Protest and societal irritation in the internet age. Österreichische Zeitschrift für Soziologie, Vol. 44, Supplement 1, pp. 199-215.

92 Zarsky, T. (2016). The trouble with algorithmic decisions: an analytic road map to examine efficiency and fairness in automated and opaque decision making. Science, Technology o Human Values, Vol. 41, No. 1, pp. 118-132.

93 Larsson, Stefan. (2017). Conceptions in the code: how metaphors explain legal challenges in digital times. New York: Oxford University Press. 
only made evident by their consequences, ${ }^{94}$ and it is only when a pattern emerges that it becomes possible to talk in terms of the existence of a norm. Here, big data analysis comes into play. ${ }^{95}$ Using a sociological parallel, the algorithms can, much like norms, be regarded as the triggering factor, ${ }^{96}$ thus setting in motion certain activities or even laying the foundation for a certain business model. The researcher has to reconstruct the content of the algo norm by using the end result of the process as a starting point, and from there disentangle the underlying factors. ${ }^{97}$ When the end results display a pattern in big data, this provides the necessary conditions for identifying algo norms.

This analysis does not require a full or correct understanding of algorithms. As is the case in SoL, you do not need to have full insight into the legal construction and interpretation of the law to be able to identify and map the law's societal implications. Compared to legal norms, the logic adopted for understanding algo norms is inverted. In the legal sphere, the search starts with knowledge about what constitutes the legal norm in terms of prerequisites and/or precedents. From there, you are expected to be able to draw conclusions about the kind of actions the legal norm covers in reality. To understand algo norms, you have to start from the opposite direction. You start with the actions, the outcome of algorithms, and from there you search for indicators of the actors' underlying motives and how these relate to the algorithms and the context they create.

Thus, big data and pattern recognition become important methodological tools. Here, digital technology that uses algorithms may be helpful when tracing algo norms. Using web-panel surveys, it is possible to identify general normative changes, such as, the transition from money to information, from customer to user, or changes that follow from the change from transactions based on the industrial-based money economy to the sharing economy related to the network society or on open source. ${ }^{98}$ Pattern recognition becomes an important part of the research. Machine learning becomes a tool. This kind of research using big data depends on the availability of exceptionally large, computational resources that require similarly substantial energy consumption. As a result, these models are costly to train and develop due to the cost of hardware and electricity or cloud compute time. This makes research increasingly challenging for people working

94 This is not the same as the distinction between manifest and latent functions made by Robert Merton (1968).

$95 \mathrm{Big}$ data is the handling and interpretation of large amounts of data that are not suitable for common methods of, for example, statistical analysis. This can be used partly as material for training AI and partly handled by AI to use new ways to find and validate complicated patterns.

96 Bicchieri (2006, p. 57).

97 Hydén (2011).

98 Pattern recognition has its origins in engineering, whereas machine learning grew out of computer science. However, these activities can be viewed as two facets of the same field, and together they have undergone substantial development over the past ten years. 
in academia to contribute to research - something which further underlines the need for studying advanced practice. ${ }^{99}$

\subsubsection{Regulatory and legal implications}

Legal regulation requires knowledge about what is to be regulated. This makes the normative problems related to AI seem philosophical - there is no solid answer. We can only wait and see after having gained some experience. ${ }^{100}$ This turns the problems into empirical questions and the answers become socio-legal, i.e. the advanced practice will provide us with various, tentative, practical solutions, which can lay the foundation for normative assessments.

$\mathrm{AI}$ is used in relation to decision-making, learning and performing tasks based on data, where the data are often complex, ambivalent and difficult to interpret. Areas that require some form of stability, clear goals, measurability and longterm vision can be expected to use AI in the future; for example, fully or partially automated banks (both private and national banks), as well as automated diagnostic and treatment robots (for example, for diabetics). Also, some state administrations such as customs, the police, fire brigades, roads and the Transport Administration could be more data-driven and use AI to improve their capacity to make the right decision when optimizing, for example, budgets, maintenance and expansion and the kind of skills and measures that need to be developed to achieve political goals.

A common denominator regarding the regulation of AI is the uncertainty which prevails and the ambivalence that characterizes policies. Therefore, regularity problems are, in these cases, mostly referred to and discussed in terms of ethics. ${ }^{101}$ AI represents a new regulatory phenomenon. In the transition from the industrial era based on mechanics to a digital society, the related problems change. As has been commented above, the legal principles will not be different, but the substratum (the reality) changes, which makes it necessary to adjust and reformulate the legal regulation. Note the comparison between the fatal accident with the first automobile in the late 19th century and the first fatal accidents with autonomous cars 120 years later. The difference is the driver, or the lack of driver, in the latter case, but the legal problems are otherwise the same. This

99 Hao, Karen, MIT Technology Review, Jun 6, 2019, Strubell, Emma, Ganesh, Ananya, McCallumb, Andrew (2019), Energy and Policy Considerations for Deep Learning in NLP, Cornell University, arXiv:1906.02243v1 [cs.CL].

100 Shimpo, Fumio. (2018). The principal Japanese AI and robot strategy towards establishing basic principles. In Barfield, Woodrow and Pagallo, Ugo (eds.), Research handbook on the law of artificial intelligence. Cheltenham: Edward Elgar Publishing Limited.

101 Ethics Guidelines for Trustworthy AI, High-Level Expert Group on Artificial Intelligence set up by the European Commission 2018. The Trustworthy AI assessment list presented in Chapter 3 of this document from 2019 will undergo a piloting phase by stakeholders to gather practical feedback. A revised version of the assessment list, taking into account the feedback gathered through the piloting phase, will be presented to the European Commission in early 2020 . 
new technology might give rise to a paradigmatic shift in regulation strategies. It seems to follow cycles of societal development. In industrial society, regulation was demanded mainly due to external effects of production, distribution and consumption. Over-production leads, among other things, to over-consumption and energy wastefulness - matters in which the political system, via the law, has intervened. In this situation, regulation is based on compromises between contradictory goals. This kind of regulation requires public authorities for implementation and controlling purposes, which characterizes the industrial world of today.

In the digital era, the nature of the problems related to societal development has changed. This new technology opens up hitherto unknown possibilities. However, we can never predict the future, only anticipate. The discipline of anticipation $^{102}$ seems to be built on two prerequisites: prolongation of trends in society and pattern recognition. How fruitful the method is has to do with the relevance of the identified tendencies in society. ${ }^{103}$ The problem is that we tend to think in straight lines. When we think about the extent to which the world will change in the 21 st century, we just take the progress made in the 20th century and add it to the year 2000. Linear thinking is the most intuitive way of thinking, despite the fact that we should be thinking exponentially. ${ }^{104}$ According to McKinsey Global Institute, compared to the industrial revolution, the AI revolution is "happening ten times faster and at 300 times the scale, or roughly 3,000 times the impact". ${ }^{105}$ However, exponential growth is not completely smooth and uniform. Kurzweil explains that progress happens according to "S-curves", as discussed in the first chapter ${ }^{106}$. Our own experiences blind us to the future. ${ }^{107}$ These factors block us from seeing that we are heading toward a completely new horizon. The regulation problem becomes a question of either/or instead of both/and. Regulation is no longer aimed at external effects. Rather, a choice has to be made between different areas of application. For what purposes should we accept the use of the new technology?

Surveillance may be a case in point. Facial recognition and monitoring of deviant behaviour based on algorithms is common today in both open and closed ecosystems. For instance, privately owned cameras that recognize family and

102 Miller, Riel, Poli, Roberto and Rossel, Pierre. (2013). The discipline of anticipation: exploring key issues, Bellagio Document 4: Working Paper 1.

103 For an application of the theory, see Hyden, H. (2020a). Social cohesion and the anticipated fall of the welfare state. Annals of Social Sciences and Management Studies, Vol. 5, No. 2, p. 555658. DOI: 10.19080/ASM.2020.05.555658 0030.

104 Urban, Tim (2015, January 22), The AI revolution: the road to superintelligence, Wait but Why.

105 Dobbs, Richard, Manyika, James and Jonathan Woetzel (2016). The four global forces breaking all the trends, April 2015, McKinsey Global Institute.

106 Kurzweil, Ray. (2014). How to create a mind: the secret of human thought revealed. London: Duckworth Overlook.

107 According to Urban, we base our ideas about the world on our personal experience and that experience has ingrained the rate of growth of the recent past in our heads as "the way things happen". 
friends but alert the owner to unknown visitors, or cameras used by customs officers and the police in public places to monitor and, in some cases, track people's identities. However, the technology does produce a number of opportunities. It can be used for different purposes. ${ }^{108}$

In the digital era, societal problems are more a matter of choice of future options than compromises within the framework of an alternative. We are faced with a qualitatively new regulatory phenomenon as a result of AI, with surveillance serving as a good example. It is much like the internet itself. The basic principle of the internet is that it should be open and free for everyone. Lawrence Lessig discusses "the norm of open code". ${ }^{109}$ This view of the use of the internet competes with another use; the one that deals with surveillance and limitations to the internet for different purposes. The technological development behind the emergence of the digital society tends to be adopted and used in the first stage within the framework of the earlier society's logic and power centres. Legal regulation, both on a national and on an international level, such as the European Convention on Human Rights (ECHR), protects us from violations of our privacy by the state and public authorities. These rules are not applicable in cases of violations by large private corporations, which are the main offenders with regard to producing threats in an AI context.

The main argument for introducing different kinds of surveillance is to provide security for ordinary people. There are many tools in our daily lives which help the individual to protect their property and privacy. This is regarded as a positive effect of technological, digital developments. However, when these means end up in the wrong hands, they can turn into something evil. This is also what is taking place to a large extent.

In the industrial era, development is a question of prolongation within the same technological area, mechanics. We can talk about many small incremental changes instead of a qualitative shift. The development and refinement of this technology have created external effects, which were addressed using one and the same governance strategy, namely intervening law and controlling public authorities. When mechanical technology characterized by physical production becomes a digital technology working in tandem with virtual reality, there is a lack of reference points. This becomes a problem for regulators when adequate knowledge of what is to be regulated is a prerequisite.

In this situation, a process of trial and error appears. Since we do not really know the potential and consequences of this new technology, it has to be developed together with ethical observances. The use of the new technology appears not to be a practical issue, but a problem of values. Discourses based on values become the forerunner to legal regulation. The ethical and political problem becomes a question of deciding where to draw a limit to different activities. What

108 In China, this kind of surveillance was used during the COVID-19 crisis to ensure that people obeyed outdoor restrictions.

109 Lessig, Lawrence. (2006). Code: version 2.0. New York: Basic Books. 
kind of outcome will we accept? This puts us in a dilemma since we lack experience of the activities. During the industrial era, the external effects functioned as triggering factors for interventions, a strategy built on evaluations ex post, which is problematic to use in the context of phenomena such as AI and algorithms. We do not yet know which leg to stand on. This is reflected in a survey conducted in 2019 called "AI through the eyes of the consumers in the Nordic countries". 110 In response to the question: "To what extent do you think AI would make better/worse and more/less unbiased decisions than humans?" around half of the respondents thought that AI would make just as good/bad or better a decision, in some cases even a much better decision. The strongest support for AI is found in areas like the industrial sector, banking, accountants and public government, while roles based on human-to-human relations, such as nurses, doctors and lawyers have greater trust in humans.

New technology in general emerges without political decisions and needs no support from the legal system. ${ }^{111}$ Quite the opposite - it often demands deregulation of present legislation. ${ }^{112}$ The growing digital technology is a case in point. ${ }^{113}$ It is self-promoting in a way which might collide with laws in the affected legal field. The state can stimulate and promote certain solutions by setting up special zones for empirical testing and development. For example, in the field of AI, the Japanese government has initiated a kind of living lab, called Tokku. ${ }^{114}$ In the field of autonomous vehicles, several EU countries have endorsed similar experiments. Sweden has sponsored a large-scale autonomous driving pilot project in which self-driving cars use public roads under everyday driving conditions.

Law is actualized primarily for preventive reasons in relation to negative aspects of new technology. No major regulatory scheme for AI exists, neither is it likely to. Whenever a need for legislative action and a law for AI is expressed, it is primarily in relation to injuries caused by AI. ${ }^{115}$ The new technology, with its changes to the substratum, will be subsumed to existing legal paradigms and

110 The survey was conducted by YouGov on behalf of Tieto Sweden Ltd called "AI through the eyes of the consumers in the Nordic countries". The survey is based on an analysis of 3,659 computer-assisted web interviews with Swedes, Norwegians and Finnish individuals age 18+ during 10-12 April 2019. Data were weighted according to the dimensions of gender, age and geography in order to be representative for the population.

111 Hildebrandt, Mireille. (2015). Smart technologies and the end(s) of law: novel entanglements of law and technology. Cheltenham: Edward Elgar, Publishing.

$112 \mathrm{Cf}$ the presentation of what was said on this point in relation to legal development in Chapter 5 .

113 Barfield and Pagallo (eds.) (2018, p. xxv).

114 The unique "Tokku” Special Zone for Robotics Empirical Testing and Development (RT special zone) originated in Japan. Since 2003, the world's first RT special zone had already been established in Fukuoka Prefecture, Fukuoka City and Kitakyushu City. Humanoid Robotics Institute of Waseda University had conducted many empirical testing within several different spots of the special zone to evaluate the feasibility for bipedal humanoid robots on public roads from 2004 to 2007 . It's also known as the world's first public roads testing for bipedal robots. See Weng et al., 2015.

115 Barfield, p. xxiii. 
adopted in prevailing legal principles and rules. ${ }^{116}$ Karl Renner pointed out in his study of the institutions of private property and its societal functions that the legal institutes might be combined differently during the specific phases of legal development from the Roman law until the modern law era. The first step in such a transitional process is to draw analogies. ${ }^{117}$ The question that should be asked is "what is similar" to the issue at stake for the legal decision-making process.

Common law has an advantage compared to statutory law since it is based on laws made by a judge and the legal doctrines are established by judicial precedents rather than by statutes. The system is also known as case law. This forces the common law system to confront new societal phenomena at a much earlier stage than do the statutory-based legal systems such as the continental European system. ${ }^{118}$ In the statutory legal systems, a legal matter has to be approved by the legislative body, i.e. the political system. This means that the statutory legal system is characterized by greater inertia than the common law systems. ${ }^{119}$ The judges have to take a stand in a legal matter even if the problem is unknown and without precedent, while it takes longer for politicians, who have different views and opinions, to arrive at a decision, especially in democratic processes. It takes some time before they formulate their political will, which requires having experience of the new phenomenon.

$\mathrm{AI}$ and algorithms lead to interpretation problems and legal policy considerations when the substratum of law undergoes great changes as a consequence of the new conditions for regulation. ${ }^{120}$ These new conditions, which the judge and/or the legislator face are primarily an effect of three factors: ${ }^{121}$ AI's autonomic function, the complexity and transparency problem and, finally, the need for huge amounts of data - big data. Some areas have already been subject to legal regulation due to AI, such as data protection, security and liability rules, robots, antitrust law and consumer protection. ${ }^{122}$ These are areas where the problems already exist but, under the influence of digitization, are scaled up and therefore

116 Renner (1949).

117 Karnow, Curtis E.A. (2018) Foreword to Barfield. In Woodrow Barfield and Pagallo, Ugo (eds.), Research handbook on the law of artificial intelligence (p. xxi). Cheltenham: Edward Elgar Publishing Limited.

118 The legal material regarding AI is therefore to a large extent different in cases before US courts.

119 Horwitz, Morton (1994) traces the development of common law followed by statutory law later on as a function of economic forces. See also, Karnow (2018, p. xix).

120 Barfield, Woodrow and Pagallo (eds.) (2018).

121 Westman (2019).

122 I will not delve into how law in itself can use AI for different purposes, such as COMPAS, an acronym for Correctional Offender Management Profiling for Alternative Sanctions. COMPAS is a case management and decision support tool developed and owned by a private company (now Equivant) used by US courts to assess the likelihood of a defendant becoming a recidivist based on scales using behavioural and psychological big data (https://en.wikipedia.org/wiki/COMPAS). 
require certain precautionary measures. Furthermore, this leads to new causes of discrimination as an indirect effect of machine learning and big data.

\subsubsection{Changes in society and the need for a science of norms}

The new technology seems simultaneously scary and promising. In early industrial society and the developments in physical means of communication, railways and trains, in certain situations a man with a red flag had to walk in front of the train in order to prevent accidents. ${ }^{123}$ Current technological developments will probably leave us with similar kinds of experiences, which in the light of history will appear equally remarkable and regressive.

A science of norms has the potential to capture the consequences of digital technology and algorithms and how these increasingly regulate people's everyday lives. In this way, it is possible to lay the foundation for an assessment of digital technology and AI in different contexts, whether they are regarded as good or bad and are regarded as providing people a better life or not. One specific research task is to study how digital technology and algorithms seem to have a tendency that leads to a weakening of the nation-state. In the long-term perspective, both the direct and indirect effects of digitization contribute to regulatory power in society moving from politics and law to technicians and AI. To highlight these tendencies in society, including a global perspective, seems to be an important research task. This requires scientific innovations, which can be actualized through the development of a science of norms.

Another reason for the need of a science of norms is the problem of governance related to $\mathrm{AI}$, i.e. the matter of a proactive or a reactive regulation strategy. In order to approach this problem, a new research agenda is required which diverts from the social sciences based on the industrial societal model. In the future whether we like it or not - it seems likely that politicians will no longer determine through law or ordinary people via societal norms society's preferences, which will instead be determined by the interplay between technicians and the market.

The market forces are the main allies of algo norms and AI. There are many indications of the economic influence on developments in AI. ${ }^{124}$ If one tries to trace the driving forces behind AI development, the economic system would as in almost any other societal issue - provide the answer. Is it possible, from a

123 The story of "UK's Red Flag Laws" for steam-powered vehicles in the 19th century is a well-known example, see Yueh-Hsuan, Weng. (2018). Robot law. In Barfield, Woodrow and Pagallo, Ugo (eds.), Research handbook on the law of artificial intelligence (p. 617). Cheltenham: Edward Elgar Publishing Limited. According to Chapter 2 on Signals, provision 22 in the Service Regulation for the Swedish Railways from 1862, the following was stipulated: If something happened to a train, causing that route to be closed, the conductor must immediately send a man down the track who displays a red signal and plants an explosive signal every 600 feet (200 steps) and at a distance of 1,800 feet (600 steps) from the location of the train and a second set of signals at 50-foot intervals.

124 Karnow (2018). 


\section{A science of norms}

proactive perspective, to influence this development? That would require research on AI, which makes visible and articulates the driving forces, the content of these norms and their hidden preferences; still, it would be hard to influence proactively. Since we, at least for the time being, lack knowledge about the new digital technology's effects in different societal respects, it is important to stick to the strategy of trial and error, i.e. to wait and see what the consequences are and then make decisions about preventive actions.

At the same time, we are aware that if AI is released, it might be too late for interventions. This calls for a reactive strategy. A unique feature of AI as a regulatory problem is its capacity for self-reproduction, even without human involvement. AI represents not only a system which reproduces and maintains itself - it goes a step further by being able to develop itself in a kind of autonomous process and turn into something else. As a consequence, we are caught in a dilemma between a desirable, proactive and a factual, reactive strategy. Misinformation, threats, fake news and manipulation have to be combated. Warning bells in the form of statistical engines which dynamically, and with the help of AI, collect data across platforms ring if a system grows big enough to threaten societal institutions. In any case, something has to be done. Otherwise, the new technology will take the upper hand and primarily benefit huge companies and totalitarian states. In this perspective, it is imperative that we keep track of the evolution of norms using an interdisciplinary science of norms. New societal problems require that we advance the social sciences, which is the present book's ambition to stimulate. 


\section{Bibliography}

Abelin, Matthias. (2019). A Swedish dilemma: culture and rule of law in Swedish sickness insurance. PhD Thesis. Lund: Lund University.

Abrahamsson, Bengt. (2000). Organisationsteori. Lund: Studentlitteratur.

Abrahamsson, Bengt och Boström, Anders. (1979). Om arbetets rätt. Stockholm: AWE Geber.

Adlercreutz, Axel. (1954). Kollektivavtalet, studier över dess tillkomsthistoria. Lund: Gleerup.

Adlercreutz, Axel. (2000). Svensk arbetsrätt. Upplaga 11. Stockholm: Nordstedts juridikförlag.

Agovic, Amina. (2011). Patents, ethics and stem cell research: the case of hESC innovation in Australia, Europe and the United States. Diss. Helsinki: University of Helsinki.

Ahrne, Göran \& Brunsson, Nils. (2004). Regelexplosionen. Stockholm: Stockholm School of Economics.

Akalu, Aster. (1985). Beyond morals? Experiences of living the life of the Ethiopian Nuer. Malmö: Liber.

Alatas, S.F. (2006). Alternative discourses in Asian social science: responses to Eurocentrism. Singapore: Sage.

Alexander, Jeffrey C. (1989). Between progress and apocalypse: social theory and the dream of reason in the twentieth century. In Alexander, J.C. \& Sztompka, P. (red.), Rethinking progress: movements, forces and ideas at the end of the twentieth century (s. 15-38), Boston, MA: Unwin Hyman.

Almquist, Josef Natanael \& Eriksson, Johan Axel. (1949). Skråväsendet-dess fall och återkomst. Stockholm: Guide and Project Tools (Rule of Law Indicators) [Elektronisk resurs]. United Nations.

Alsworth Ross, Edward. (2009). Social control: a survey of the foundations of order. New Brunswick, NJ: Transaction Publishers.

Altus Global Alliance, University of the Fraser Valley, Harvard University, Vera Institute of Justice \& United Nations. (2011). United Nations Rule of Law Indicators: Implementation Guide and Project Tools (Rule of Law Indicators) [Electronic resource]. United Nations.

Altvater, E. (1993). The future of the market: an essay on the regulation of money and nature after the collapse of actually existing socialism. London: Verso.

Alvarez-Pereira, Carlos. (2017). Disruptive technologies, a critical yet hopeful view. Cadmus Vol. 3, No. 2. 


\section{Bibliography}

Amundsdotter, Eva \& Gillberg, Minna. (2001). Den jämställda arbetsplatsen. En metodbok. Falun: Bilda förlag.

Andersson, Gunnar. (1993). Leva för jobbet och jobba för livet: om chefsfamiljers vardag och samlevnadsformer. Akademisk avhandling, Lunds universitet. Stockholm. Stehag: B Östlings bokförlag. Symposion.

Andersson Schwarz, J. \& Larsson, S. (2019). Plattformssambället: Den digitala utvecklingens politik, innovation och reglering. Stockholm: Fores.

Anners, Erik. (1990). Europeiska Rättens Historia.1. Stockholm: Norstedts Juridik.

Appelstrand, Marie. (2007). Miljömålet i skogsbruket: styrning och frivillighet. Diss. Lund: Lunds universitet.

Arnold, Thurman. (1935, 1962). The symbols government. New Haven, CT: Yale University Press.

Arnold, Thurman W. (1937). The folklore of capitalism. New Haven: Yale University Press.

Aronsson, Gunnar och Karsson, Jan Ch. (red.). (2001). Tillitens ansikten. Lund: Studentlitteratur.

Åsberg, Rodney. (2001). Ontologi, epistemologi och metodologi: en kritisk genomgång av vissa grundläggande vetenskapsteoretiska begrepp och ansatser, Rev. uppl., Institutionen för pedagogik och didaktik. Göteborg: Göteborgs universitet.

Aspelin, Gunnar (1926). Historiens problem: utvecklingsfilosofiska studier. Stockholm: Geber

Asplund, Johan. (1987, 1992). Det sociala livets elementära former. Göteborg: Bokförlaget Korpen.

Åström, Karsten. (1988). Socialtjünstlagstiftningen i politik och förvaltning: en studie av parallella normbildningsprocesser. Akademisk avhandling. Lund: Lund University Press.

Atik, J. \& Jeutner, V. (2019, November). Quantum computing and algorithmic law. Los Angeles Legal Studies Research Paper, Los Angeles.

Aubert, Vilhelm. (1964). Sociologi. Oslo: Universitetsforlaget.

Aubert, Vilhelm. (1976). Rettens sosiale funksjon. Oslo: Universitetsforlet.

Aubert, Vilhelm. (1989). Continuity and development in law and society. Oslo: Universitetsförlaget.

Aubert, Vilhelm, Eckhoff, Torstein \& Sveri, Knut. (1952). En lov i søkelyset. Oslo: Universitetsforlaget.

Auden, Wystan H. (1972). Collected poems. London: Faber \& Faber.

Axelrod, Robert. (1986). An evolutionary approach to norms. I American Political Science Review, Vol. 80, No. 4.

Bäckman, Anders. (1998). Rökprocessen. En miljötvist i början av 1900-talet, Avdelningen för teknik- och vetenskapshistoria. Stockholm: KTH.

Badersten, Björn. (2008). Normativ metod att studera det önskvärda. Enskede: TPB.

Baier, Matthias. (2003). Norm och rättsregel: en undersökning av tunnelbygget genom Hallandsåsen. Diss. Lund: Univ.

Baier, Matthias. (ed.). (2013a). Social and legal norms. London: Ashgate.

Baier, Matthias (red.). (2013b). Social and legal norms [Elektronisk resurs] towards a socio-legal understanding of normativity. Farnham, Surrey: Ashgate.

Baier, Matthias \& Svensson, Måns. (2009). Om normer. Malmö: Liber.

Baier, Matthias, Svensson, Måns \& Nafstad, Ida. (2019). Understanding sociology of law an introduction. 1st ed. Lund: Studentlitteratur; Johanneshov: MTM.

Baird, Douglas G., Gertner, Robert H. \& Picker, Randal C. (1994). Game theory and the law. Cambridge, MA: Harvard University Press. 
Balkin, Jack. (2015). The path of robotics law. California Law Review Circuit, Vol. 6, p. 45 .

Banakar, Reza. (1998). The identity crisis of a 'stepchild' - reflections on the paradigmatic deficiencies of sociology of law. Retfaerd, Vol. 81, pp. 3-19.

Banakar, Reza. (2001). Integrating reciprocal perspectives. On George Gurvitch's theory of immediate jural experience. Canadian Journal of Law and Society. Published online by Cambridge University Press, Cambridge.

Banakar, Reza. (2013). Can legal sociology account for the normativity of law? In Baier, Matthias (red.), Social and legal norms [Elektronisk resurs] towards a sociolegal understanding of normativity. Farnham, Surrey: Ashgate.

Banakar, Reza. (2015). Normativity in legal sociology: methodological reflections on law and regulation in late modernity. Heidelberg: Springer.

Banakar, Reza. (2016). Driving culture in Iran: law and society on the roads of the Islamic republic. London: I.B. Tauris.

Banchoff, Thomas F. (2011). Embryo politics: ethics and policy in Atlantic democracies. Ithaca: Cornell University Press.

Barfield, Woodrow. (2018). Towards a law of artificial intelligence. In Barfield, Woodrow \& Pagallo, Ugo (eds.), Research handbook on the law of artificial intelligence. Cheltenham: Edward Elgar Publishing Limited.

Barfield, Woodrow \& Pagallo, Ugo (eds.). (2018). Research handbook on the law of artificial intelligence. Cheltenham: Edward Elgar Publishing Limited.

Barnett, Randy E. (1998). The structure of liberty: justice and the rule of law. Oxford: Clarendon.

Barnett, V. (1998). Kondratiev and the dynamics of economic development: long cycles and industrial growth in historical context. New York: St. Martin's Press.

Barraclough, Geoffrey. (1968). The medieval papacy. London: Thames and Hudson.

Bartolomei, Maria Luisa och Hydén, Håkan (eds.). (1999). The implementation of human rights in a global world. Lund Studies in Sociology of Law, Vol. 9.

Barton, John H. (1975). Behind the legal explosion. Stanford Law Review, Nr. 27.

Battelle, John. (2005). The search: how Google and its rivals rewrote the rules of business and transformed our culture. New York: Portfolio.

Bauman, Zygmunt. (1995, 2001). Postmodern etik. Göteborg: Daidalos förlag.

Beard, Miriam. (1939). Affürsmannens historia (2 band), Natur och Kultur. Stockholm: (Originalets titel: A History of the Business Man).

Beck, Ulrich. (1986). Risikogesellschaft: auf dem Weg in eine andere Moderne. Frankfurt am Main: Suhrkamp.

Beck, Ulrich. (1992). Risk society: towards a new modernity. London: Sage.

Beck, Ulrich. (1995). The reinvention of politics: rethinking modernity in the global social order/Ulrich Beck, translated by Mark Ritter. Elektronisk resurs. Cambridge: Polity.

Beck, Ulrich. (1997). The reinvention of politics: rethinking modernity in the global social order. Cambridge: Polity Press.

Beck, Ulrich, Giddens, Anthony, Lash, Scott. (1994). Reflexive modernization: politics, tradition and aesthetics in the modern social order. Stanford, CA: Stanford University Press.

Beer, Stafford. (1980). Preface to autopoiesis. Boston: I Maurana, Humberto, Varela, Fransisco \& Uribe R. Autopoiesis and cognition.

Bellah, Robert N. (1973). Durkheim, Émile on morality and society: selected writings/ Émile Durkheim, ed. and with an introd. by Robert N. Bellah. Chicago: Chicago University Press. 
Benner, Mats. (1997). The politics of growth: economic regulation in Sweden 19301994. Diss. Lund: Lund University Press.

Bensoussan, Alain \& Bensoussan, Jeremy. (2019). Robot law book - a comparative handbook: robotic technologies law. Lexing: Technologies Avancees \& Droit. Groupe Larcier s.a.

Berg, Jan O. (2011). På spaning efter en svensk modell [Elektronisk resurs] idéer och vägval i arbetsgivarpolitiken 1897-1909. Diss. Stockholm: Stockholms universitet.

Berger, Peter L och Luchmann, Thomas. (1966, 1991). The social construction of reality. A treatise in the sociology of knowledge. London: Penguin.

Berman, Harold J. (1983). Law and revolution. The formation of the western legal tradition. Cambridge, MA: Harvard University Press.

Berner, Georg. (1978). Inflation im Recht. Munich: Bayrisches Verwaltungsblatt, s. 617 ff. Bertilsson, Margareta (red.). (1995). Rätten i förvandling: jurister mellan stat och marknad. Stockholm: Nerenius \& Santérus.

Bicchieri, Cristina (2006). The grammar of society: the nature and dynamics of social norms. Cambridge: Cambridge University Press.

Biel, Anders, Hansson, Bengt \& Mårtensson, Mona (red.) (2003). Individual and structural determinants of environmental practice. Aldershot: Ashgate.

Biel, Anders, Dahlstrand, Ulf \& Fransson, Niklas. (1990). The content of moral values. Göteborg: Göteborg University Press.

Biel, Anders, Eek, Daniel och Gärling, Tommy. (1987). The importance of fairness for cooperation in public goods dilemmas. In Juslin, P. \& Montgomery, H. (eds.), Judgment and decision making: Lens-modeling and process tracing approaches. London: Erlbaum.

Biel, Anders, Eek, Daniel, Gärling, Tommy \& Gustafsson, Mathias. (2008). New issues and paradigms in research on social dilemmas [electronic resource]. Boston, MA: Springer Science+Business Media, LLC.

Biel, Anders, von Borgstede, Chris och Dahlstrand, Ulf. (1998). Norm perception and co-operation in large-scale societal dilemmas. In Foddy, M., Smithson, M. \& Schneider, S. (eds.), Resolving social dilemmas. Philadelphia, PA: Psychology Press, Blackwell Dictionery of Sociology.

Black, Donald. (1976). The behavior of law. New York: Academic Press.

Blankenburg, E., Ekkehard, K. \& Rottleuthner, H. (1980). Alternativen Rechtsformen und Alternativen zum Recht. Opladen: Westdeutscher Verlag.

Bogdan, Michael. (1993). Komparativ rättskunskap. Falköping: Nordstedts förlag.

Bohm, Peter. (1996). Sambällsekonomisk effektivitet, 5., [något rev.] uppl. Stockholm: SNS (Studieförb. Näringsliv och samhälle.

Bois, Guy. (2002). The transformation of the year one thousand the village of Lournand from antiquity to feudalism. Enskede: TPB.

Bokenkotter, Thomas S. (2004). A concise history of the Catholic Church [Elektronisk resurs]. Rev. and expanded ed. New York: Doubleday.

Bonner, John Tyler. (1980). The evolution of culture in animals. Princeton: Princeton University Press.

Bora, Alfons. (1991). Die Konstitution sozialer Ordnung. Diss. Pfaffenweiler: Centaurus-Verl.-Ges. Freiburg (Breisgau), University.

Bostedt, Göran \& Hjern, Benny. (1991). Regelverk och verklighet: Organisering av lokalt arbetsmiljöarbete $i$ kommunerna: Arbetsmiljöfondens rapportserie. Stockholm: Arbetsmiljöfonden. 
Bourdieu, Pierre (1977). Outline of a theory of practice. Cambridge: Cambridge University Press.

Bourdieu, Pierre, Broady, Donald \& Palme, Mikael. (1993). Kultursociologiska texter. 4. uppl. Stockholm: B. Östlings bokförl. Symposion.

Bozdag, Engin. (2013, June 23). Bias in algorithmic filtering and personalization. Ethics and Information Technology, Vol. 15, No. 3, pp. 209-227.

Brännström, Leila. (2009). Förrättsligande: en studie av rättens risker och möjligheter med fokus på patientens ställning. Diss. Lund: Lunds universitet.

Brante, Thomas, Andersen, Heine \& Korsnes, Olav (red.) (1998). Sociologiskt lexikon. Stockholm: Universitetsforl.

Braucher, Jean, Kidwell, John \& Whitford, William C. (red.). (2013). Revisiting the contracts scholarship of Stewart Macaulay: on the empirical and the lyrical. Oxford: Hart.

Braudel, Fernand. (1982). Civilization and capitalism: 15th-18th century. Vol. 2, the wheels of commerce. London: Collins.

Braudel, Fernand. (1984). Perspective of the world. London: Fontana Press.

Brusiin, Otto. (1959). Zum Ehe-scheidungsproblem. Helsinki: Distribution Akademische Buchhandlung.

Bruun, Niklas m.fl. (1990). Den nordiska modellen. Fackföreningarna och arbetsrätten $i$ Norden - nu och i framtiden. Lund: BTJ Tryck AB.

Bryld, M. (2002). Den uendelige bekymringshistorie: Reprogenetik og reproduktionsteknologi på Christiansborg. Kvinder, Køn \& Forskning, No. 3. https://doi. org/10.7146/kkf.v0i3.28300.

Burchardt, Dana. (2017). Intertwinement of legal spaces in the transnational legal sphere. Leiden Journal of International Law, Vol. 30, pp. 305-326.

Burell, Mattias \& Svensson, Marina (red.). (2011). Making law work: Chinese laws in context. 1st ed. Ithaca, NY: Cornell East Asia Program.

Cameron, Rondo E. (1996). A concise economic history of the world: from Paleolithic times to the present. 3. ed. New York: Oxford University Press.

Carlsson, Benny. (1986). Svenska regleringar under 200 àr. Lund: En svepande översikt.

Carlsson, Bo. (2002). Rättens trivialisering och avmystifiering. I Retfaerd 2001, Nr. 4.

Castells, Manuel. (1996). The information age: economy, society and culture. Vol. 1 The rise of the network society/Manuel Castells. Malden, MA: Blackwell.

Castells, Manuel. (1999). Informationsåldern. Nätverkssambällets framväxt. Band 1. Uddevalla: Daidalos.

Castells, Manuel. (2000a). The information age: economy, society and culture. Vol. 3 End of millennium. 2. ed. Oxford: Blackwell.

Castells, Manuel. (2000b). Informationsåldern. Identitetens makt. Band 2. Göteborg: Daidalos.

Castells, Manuel. (2001). The internet galaxy. Oxford: Sage.

Castells, Manuel (2004). The information age: economy, society and culture. Vol. 2: The power of identity. 2nd ed, Malden, MA: Blackwell.

Castells, Manuel. (2010). The rise of the network society [Elektronisk resurs]. 2nd ed. Chichester, West Sussex: Wiley-Blackwell.

Castells, Manuel. (2019). The rise of the network society with a new preface. Johanneshov: MTM; Castells, Manuel. (2010). The power of identity. 2nd ed. Malden, MA: Blackwell. 


\section{Bibliography}

Castles, F.G. \& Mitchell, D. (1992). Identifying welfare state regimes: the links between politics, instruments and outcomes. Governance, Vol. 5.

Chapin, F. Stuart, Kofinas, Gary P. \& Folke, Carl (red.). (2009). Principles of ecosystem stewardship: resilience-based natural resource management in a changing world. New York: Springer.

Charles, G., Edward, A. Pace, Pallen, Conde B., Shahan, Thomas J., Wynne Herbermann, John J. (1913). The Catholic Encylopedia - Volume X-Mass-Newman an international work of reference on the constitution, doctrine, discipline, and history of the catholic church. The Encyclopedia Press, Inc.

Chorafas, D.N. \& Binder, E.M. (1992). Technoculture and change. Strategic solutions for tomorrow's society/D.N. Chorafas, Eva Maria Binder. London: Adamantine Press.

Christensen, Anna. (1983). Lönearbete som sambällsform och ideolog. Stockholm: Sekretariatet för framtidsstudier.

Christensen, Anna. (1984). Wage labour as social order and ideology. Stockholm: Secretariat for futures studies [Sekretariatet för framtidsstudier], FRN.

Christensen, Anna. (1994). Hemrätt i hyreshuset. En rättsvetenskaplig studie av bostadshyresgästens besittningsskydd. Stockholm: Juristförlaget.

Christensen, Anna. (1996). Skydd för etablerad position - ett normativt grundmönster. I TfR Tidskrift för Rettsvitenskap, Nr. 4.

Christensen, Clayton. (2016). The innovator's dilemma: when new technologies cause great firms to fail. Boston: Harvard Business School Press.

Clark, S. (1999). The Annales school. Vol. 3. Fernand Braudel. Taylor \& Francis.

Coleman, James. (1990). Foundations of a social theory. Cambridge, MA: Harvard University Press.

Coleman, Jules L. (1988). Markets, morals and the law. Cambridge: Cambridge University Press.

Coleman, Jules L. (1993). Risks and wrongs. Cambridge: Cambridge University Press.

Collins, H.M. (2010). Tacit and explicit knowledge. Chicago: The University of Chicago Press.

Collins, Roger. (1999). Early medieval Europe 300-1000. 2nd ed. New York: St. Martin's Press.

Cooley, Charles Horton. (1983). Human nature and the social order. New York: Schocken Books.

Cormen, T.H., Leiserson, C.E., Rivest, R.L. \& Stein, C. (2009). Introduction to algorithms. 3rd ed. Cambridge, MA: MIT Press and McGraw-Hill.

Cotterrell, Roger. (1989). The politics of jurisprudence: a critical introduction to legal philosophy. London: Butterworth.

Cotterell, Roger. (1995). Law's community. Legal theory in sociological perspective. Oxford: Clarendon Press.

Cotterrell, Roger. (1998). Émile Durkheim. Law in a moral domain. Stanford: Stanford University Press.

Cotterrell, Roger. (1999). Émile Durkheim: law in a moral domain. Edinburgh: Edinburgh University Press.

Move this

Tarschy, Daniel, Dagens Nyheter. (1993-08-07). Newspaper. Stockholm, Sweden.

Dahl, Tove Stang. (1987). Women's law. An introduction to feminist jurisprudence. Oslo: Norwegian University Press. 
Daintith, Terence. (1989). Legal research and legal values. The Modern Law Review, Nr. 3, s. 352-368.

Dalberg-Larsen, Jørgen. (1984). Retstaten, Velfardsstaten og hvad så? København: Akad.forl.

Dalberg-Larsen, Jørgen. (1989, 1999). Lovene og livet. København: Akademisk forlag.

Dalberg-Larsen, Jørgen. (1991). Ret Styring og Selfforvaltning. Aarhus: Juridisk Bogformidling.

Davis, Kingsley \& Blake, Judith. (1956, April). Social structure and fertility: an analytic framework. Economic Development and Cultural Change, Vol. 4, No. 3, pp. 211-235.

De Gama, Katherine. (1993). A brave new world? Rights discourse and the politics of reproductive autonomy. Journal of Law and Society, Nr. 1 .

de Sousa Santos, Boaventura. (2018). The end of the cognitive empire: the coming of age of epistemologies of the south. Durham and London: Duke University Press.

Derrida, Jacques. (2007). Jacques Derrida: basic writings. London: Routledge.

Dijk, J.T. van Poell \& Waal, M. dew. (2018). In Andersson Schwarz, J. \& Larsson, S. (eds.), Plattformssambället: Den digitala utvecklingens politik, innovation och reglering. Stockholm: Fores.

DiMaggio, Paul. (1997). Culture and cognition. Annual Reviews Sociology, Vol. 23, pp. 263-87.

Dineros, Kevin \& Dipasupil, Jan Paolo. (2020, March 15, 21). COVID-19 crisis management and prevention plan. COVID-19 Crisis Management and Prevention Plan, Vol. 19.

Dobbs, Richard, Manyika, James \& Woetzel, Jonathan. (2016, April). No ordinary disruption: the four global forces breaking all the trends. New York: PublicAffairs.

Dorfman, Robert. (1968). Priser och marknader. Stockholm: Aldus/Bonnier.

Douglas, Mary. (1992). Risk and danger. London: I Risk and Blame: Essays in Cultural Theory.

Drobak, John N. (ed.). (2006). Norms and the law. Cambridge: Cambridge University Press.

Durkheim, Émile. (1968). Självmordet. Uppsala: Argos.

Durkheim, Émile. (1983). Durkheim and the law. Oxford: Robertson.

Durkheim, Émile. (1997). The division of labor in society. New York: Free press.

Durkheim, Émile (2009). Sociology and Philosophy. (Routledge Revivals) London: Routledge.

Durkheim, Émile (2013). Émile Durkheim: the division of labour in society. Second edition London: Palgrave Macmillan.

Durkheim, Émile. (2014). The rules of sociological method: and selected texts on sociology and its method. Free Press trade paperback edition. New York: Free Press.

Eckhoff, Torstein. (1987). Rettskildelere. 2., rev. utg. Oslo: Tano.

Eckhoff, Torstein och Graver, Hans Petter. (1991). Regelstyring av lokale forvaltningsvedtak. Oslo: Tano.

Eckhoff, Torstein och Sundby, Nils Kristian. (1991). Rettssystemer: systemteoretisk innforing $i$ rettsfilosofien. Upplaga: 2. rev. utg. Oslo: Tano.

Eder, K. (1990). The cultural code of modernity and the problem of nature: a critique of the naturalistic notion of progress. In Alexander, J.C. \& Sztompka, P. (red.), Rethinking progress: movements, forces and ideas at the end of the twentieth century (s. 67-87). London and New York: Unwin Hyman.

Edna, Ullman-Margalit. (1977). The emergence of norms. Oxford: Clarendon Press. 
Elickson, C. Robert. (2001). The evolution of social norms: perspectives from the legal academy. In Hechter, M. \& Opp, K.D. (eds.), Social norms. New York: Russel Sage Foundation.

Ellickson, Robert C. (1991). Order without law: how neighbours settle disputes. Cambridge, MA: Harvard University Press.

Elster, Jon. (1989). The cement of society: a study of social order. Cambridge: Cambridge University Press.

Enzensberger, Hans Magnus. (1992). Till det normalas försvar. Stockholm: Norstedt.

Epstein, S.R. \& Prak, Maarten (ed.). (2008). Guilds, innovation and the European economy, 1400-1800 [Electronic resource]. Cambridge: Cambridge University Press.

Ericsson, Lars. (1985). Ett surt regn kommer att falla. Naturen, myndigheterna och allmänheten. Lund: Akademisk avhandling, Lunds universitet.

Eriksen, Thomas Hylland \& Hessen, Dag O. (2000). Egoismen. Nora: Nya Doxa.

Eriksson, Lars D. (1992). Sociala rättigheter som en ny form av egendom. In Eriksson, Lars D. (ed.). Kritik, moral och rätt: artiklar och diskussionsinlägg. Helsinki: Offentligrättsliga institutionen, Helsingfors universitet.

Eriksson, Lars D. (2002). Making society through legislation. In Wintgens, Luc (ed.), Legisprudence: A new theoretical approach to legislation, pp. 41-47. Proceedings of the fourth Benelux Scandinavian symposium on legal theory, European Academy of legal theory series. Oxford and Portland, Oregon: Hart Publishing.

Esping, Hans. (1994). Ramlagar i förvaltningspolitiken. 1. uppl. Stockholm: SNS (Studieförb. Näringsliv och samhälle).

Esser, Josef. (1964). Grundsatz und Norm in der richterlichen Fortbildung des Privatrechts. 2 uppl. Tubingen: Mohr.

Ewerman, Anders. (1996). Marknaden 1000 àr - Fem eror i Europa. Stockholm: Ewerman Business Intelligence.

Ewerman, Anders och Hydén, Håkan. (1997). IT och social förändring. Stockholm: Byggforskningsrådet.

Ewick, Patricia \& Silbey, Susan S. (1998). The commonplace of law: stories from everyday life. London: University of Chicago Press.

Fagerström, Torbjörn. (1995). Den skapande evolutionen. Om vad evolutionsteorin innebär - och inte innebär. Stockholm: Scandinavian University Press.

Febbrajo, Alberto. (2016). Sociology of constitutions: a paradoxical perspective [Elektronisk resurs]. London: Routledge.

Fitzpatrick, Peter. (2001). Modernism and the grounds of law. Cambridge: Cambridge University Press.

Flodgren, Boel. (1983). Arbetsdomstolen som rättsbildare - Reflexioner kring några monumentalfall frän arbetsdomstolen på senare tid. I Perspektiv på arbetsrätten. Vänbok till Axel Adlercreutz. Lund: Juridiska föreningen.

Forbes, Robert James. (1958). Studies in ancient technology. Vol. 6. Leiden: Brill.

Fridström Montoya, Therése. (2017). Homo juridicus: den kapabla människan i rätten. Upplaga 1. Uppsala: Iustus förlag.

Fromm, Erich. (1959). Ett friskare sambälle. Stockholm: Tidens förlag.

Författningssamlingsförordningen, the Swedish Constitution Collection (1976:725)

Gallagher, Leigh (2017). The Airbnb story: how to disrupt an industry, make billions of dollars... and plenty of enemies. London: Virgin Books.

Galtung, Johan. (1967). Fredsforskning. Stockholm: Prisma.

Galtung, Johan. (1970). Fredsforskning. 3. uppl. Stockholm: Prisma. 
Gärdenfors, Peter. (2000). Hur Homo blev sapiens: om tänkandets evolution. Nora: Nya Doxa.

Garfinkel, Harold. (1967). Studies in ethnomethodology. Englewood Cliffs, NJ: Prentice-Hall.

Geertz, Clifford. (1973). Religion as a cultural system. I the interpretation of cultures. New York: Basic Books.

Gibbon, Edward. (1990). The decline and fall of the Roman empire. Vol. 1, 2. Chicago: Encyclopædia Britannica.

Gibbon, Edward. (1999). Romerska rikets nedgång och fall, Del I - IV i D. M. Lows förkortade version; översättning: Claës Gripenberg. Stockholm: Forum.

Gibbs, Jack P. (1965). Norms: the problem of definition and classification. American Journal of Sociology, Vol. 70, pp. 586-594.

Gibbs, Jack P. (1981). Norms, deviance and social control. New York: Elsevier.

Giddens, Anthony. (1984). The constitution of society. Berkeley and Los Angeles: University of California Press.

Gillberg, Minna. (1999). From green image to green practice. Normative action and self-regulation. Akademisk avhandling, Rättssociologi. Lund: Studies in Sociology of Law Nr. 6.

Gilligan, Carol. (1982). In a different voice. Cambridge, MA: Harvard University Press.

Gimpel, Jean. (1992). The medieval machine - the industrial revolution of the middle ages. London: Pimlico.

Giner, Salvador. (1976). Mass society. New York: Academic Press.

Glasner, Joanna. (2000, November 22). Click here to buy nothing. Wired.

Glavå, Mats. (2001). Arbetsrätt. Göteborg: Studentlitteratur.

Goffman, Ervin. (1961). Asylums. New York: Anchor Books.

Golson, Kelly Jo (red.). (2016). The digital effect. London: SAGE Publications Ltd.

Gould, Julius \& Kolb, William L (red.) (1964). A dictionary of the social sciences. London: Tavistock.

Graver, Hans Petter. (1988). Norms and decisions. Scandinavian Studies in Law, s. 49-67.

Graver, Hans Petter. (1990). Sosiale rettigheder $i$ gjeldsforhold: håndbok $i$ gjeldsrådgivning. Oslo: TANO.

Griffits, John. (1986). What is law? Journal of Legal Pluralism, Vol. 24, pp. 1-55.

Gunningham, Neil och Grabosky, Peter. (1998). Smart regulation. Designing environmental policy. Oxford: Clarendon Press.

Gustafsson, Håkan. (2003). Rättens polyvalens: en rättsvetenskaplig studie av sociala rättigheter och rättssäkerhet, Sociologiska institutionen. Diss. Göteborg: University Press.

Gustafsson, Håkan, Vinthagen, Stellan \& Oskarsson, Patrik. (2013). Law, resistance and transformation: social movements and legal strategies in the Indian Narmada struggle. Lund: Lund University.

Habermas, Jürgen. (1979). Legitimation crises. London: Suhrkamp.

Habermas, Jürgen. (1985). Law as medium and law as institution. In Teubner, Günther (ed.), Dilemmas of law in the welfare state. Berlin and New York: Walter de Gruyter.

Habermas, Jürgen. (1987). The theory of communicative action. Vol. 2: Lifeworld and system: a critique of functionalist reason. Boston: Beacon Press. 
Habermas, Jürgen. (1995). The theory of communicative action, vol. 2. Lifeworld and system: the critique of functionalist reason. Cambridge: Polity Press.

Habermas, Jürgen. (1996). Between facts and norms. Oxford: Polity Press.

Hall, Richard. (2007). Exploring the world of the Vikings. London: Thames \& Hudson.

Hammerslev, Ole \& Rask Madsen, Mikael (red.). (2013). Retssociologi: klassiske og moderne perspektiver. 1 udg. København: Hans Reitzel.

Hanafi, Sari. American University of Beirut. ISA President. www.isa sociology.org/ frontend/web/uploads/files/Post-COVID-19\%20Sociology.pdf.

Hannertz, Ulf. (1969). Soulside. Inquiries into Ghetto culture and community. Chicago: Chicago University Press.

Hao, Karen. (2019, Jun 6). Training a single AI model can emit as much carbon as five cars in their lifetimes. MIT Technology Review.

Haralambos, Michael. (1980). Sociology. Slough.

Haralambos, Michael \& Chapman, Steve Haralambos. (2013). Holborn sociology: themes and perspectives. 8th ed. London: Collins.

Hardin, Garret. (1968, December 13). The tragedy of the commons: The population problem has no technical solution; it requires a fundamental extension in morality. Science New Series, Vol. 162, No. 3859, pp. 1243-1248. Published by: American Association for the Advancement of Science.

Hardin, Garret \& Baden, John (red.). (1977). Managing the commons. San Francisco. Hart, H.L.A. (1961). Concept of law. London: Hart Publishing.

Hassard, John \& Pym, Denis (red.). (1993). The theory and philosophy of organizations: critical issues and new perspectives. New ed. London: Routledge.

Haugaard, Mark \& Clegg, Stewart (red.). (2012). Power and politics. Los Angeles, CA: SAGE Publications Ltd.

Hayek, Friedrich A. von. (1993). The law of legislation and liberty. A new statement of the liberal principles of justice and political economy. London: Routledge.

Hechter, Michael \& Opp, Karl-Dieter (red.). (2001). Social norms. New York: Russell Sage Foundation.

Heckscher, Eli F. (1931). Merkantilismen: ett led $i$ den ekonomiska politikens historia. Stockholm: Norstedt.

Heckscher, Eli F. (1953). Merkantilismen D. 1. 2., rev. uppl. Stockholm: Norstedt.

Henrichsen, Carsten. (2001). Moderne Retsvidenskab. Bidrag till den nordiske debat om.

Henrikson Alf \& Hwang Tsu-yü. (1949). Samtalen med Konfucius. New ed. 1997. Stockholm: Norstedts.

Heritage Herlitz, Lars. Fysiokratismen I svensk tappning 1767-1770. http://hdl.handle.net $/ 2077 / 54081$.

Heritage, John (1984). Garfinkel and ethnomethodology. Cambridge: Polity.

Hernes, Gudmund. (1983). Marknaden som domstol. Kristianstad: I Land i olag.

Herring, S.C. (2009). Web content analysis: expanding the paradigm. In International handbook of internet research (pp. 233-249). Dordrecht: Springer.

Hetzler, Antoinette \& Eriksson, Kjell E. (2000). Beslutsprocessen $i$ arbetssjukdomsärenden en rättssociologisk analys. Enskede: TPB.

Hetzler, Antoinette, Melén, Daniel \& Bjerstedt, Daniel. (2005). Sjuk-Sverige: försäkringskassan, rehabilitering och utslagning från arbetsmarknaden. Eslöv: B. Östlings bokförlag Symposion.

Hildebrandt, Mireille. (2015). Smart technologies and the end(s) of law: novel entanglements of law and technology. Cheltenham: Edward Elgar, Publishing. 
Hilgendorf, Eric. (2018). Digitization and the law [Elektronisk resurs]. Baden-Baden, Germany: Nomos.

Hillis, Ken, Petit, Michael \& Jarrett, Kylie. (2013). Google and the culture of search. New York: Routledge.

Hjärpe, Jan. (1995). Law and the Islamic world past and present. Papers presented to the joint seminar at the universities of Copenhagen and Lund, March 26th-27th, 1993 / organized by Christoher Toll, Jan Hjärpe; edited by Christopher Toll and Jakob Skovgaard-Petersen Copenhagen: Det Kongelige Danske Videnskabernes Selskab: Munksgaard.

Hjern, Benny. (1989). På väg mot politisk målstyrning? Forskningsrapport. Umeå Universitet.

Hobbes, Thomas. (1985). Leviathan (Första gången publ. 651). London: Penguin Books, Ltd.

Hoebel, Edward Adamsson. (1954). The law of primitive man. Cambridge: Harvard University Press, Oxford University Press.

Hoff, David. (2003). Varför etiska kommittéer?. Diss. Lund: Univ.

Hofstadter, Douglas. (1985). Metamagical themas: questing for the essence of mind and pattern. New York: Basic Books.

Hohfeld, Wesley Newcomb. (1964[1919]). Fundamental legal conceptions as applied in judicial reasoning. New Haven: Yale U.P.

Höilund, Peter. (1992). Den forbudte retsfølelse. Om lov og moral. 1 udg. Købehavn: Munksgaard.

Høiris, Ole \& Ingesman, Per (ed.). (2017). The Reformation: 1500-talets kulturrevolution. Bind 1 Europa. Aarhus: Aarhus University Press.

Højrup, Thomas. (2003). State, culture and life-modes: the foundations of life-mode analysis. Aldershot: Ashgate.

Holmbäck, Åke \& Wessén, Elias. (1962). Magnus Erikssons stadslag. I nusvensk tolkning. Skrifter utgivna av Institutet för rättshistorisk forskning. Stockholm: Nord. bokh. (distr.).

Holmberg, Erik \& Stjernquist, Nils. (2008). The constitution of Sweden: the fundamental laws and the Riksdag Act. New ed. Stockholm: Swedish Parliament.

Homans, George Caspar. (1961). Social behaviour: its elementary forms. London: Routledge \& Kegan Paul.

Homiak, Marcia, L. (2001). Does Hume have an ethics of virtue? Some observatins on character and reasoning in Hume and Aristotle. www.bu.edu/wcp/Papers/ Mode.

Honoré, A.M. (1961). Ownership. In Guest, A.G. (ed.), Oxford Essays in Jurisprudence (pp. 107-147). Oxford: Oxford University Press.

Horne, Christine. (2001). Sociological perspective on the emergence of social norms. In Hechter, M. \& Opp, K.D. (eds.), Social norms (pp. 3-34). New York: Russel Sage Foundation.

Horwitz, Morton J. (1994). The transformation of American law, 1870-1960: the crisis of legal orthodoxy. New ed. New York: Oxford University Press.

Huizinga, John. (1955). Homo Ludens. Boston: The Study of Play Elements in Culture.

Hume, D. ([1740], 2003). A treatise of human nature. Mineola, NY: Dover Publications.

Hunt, Alan. (1993). Explorations in law and society: toward a constitutive theory of. New York: Routledge. 


\section{Bibliography}

Hydén, Håkan. (1978). Rättens sambälleliga funktioner (The societal functions of law). Lund: Studentlitteratur.

Hydén, Håkan (1982). Rätten som instrument för social förändring (Law as instrument for social change). Lund: Liber.

Hydén, Håkan. (1984). Ram eller lag? Om ramlagstiftning och samhällsorganisation. DsC, p. 12.

Hydén, Håkan. (1985). Arbetslivets reglering (The regulation of working life). Lund: Studentlitteratur.

Hydén, Håkan. (1988). Förmögenhetsrätten ur ett rättssociologiskt perspektiv (The law of property from a sociology of law perspective). Svensk Juristtidning. 20 pp.

Hydén, Håkan. (1990). Arbetsmiljöreglering i Norden. I Bruun, Niklas, m fl. Lund: Den nordiska modellen.

Hydén, Håkan. (1996). Vad kommer efter lönearbetsrätten? Arbetsmarknad \& Arbetsliv, årg. 2, nr 3, s. 157-175, 29 ref.

Hydén, Håkan. (1998). Rättssociologiska perspektiv på hållbar utveckling. Sociologiska Institutionen, Research Report, p. 1.

Hydén, Håkan. (1999). Even a stepchild eventually grows up: on the identity of sociology of law. Retferd, Nr. 85.

Hydén, Håkan. (2002a). Normvetenskap, (Norm-science). Lund: Department of Sociology at Lund University, p. 330.

Hydén, Håkan. (2002b). Rättssociologi som rättsvetenskap. Lund: Studentlitteratur.

Hydén, Håkan. (2004). Normativa tendenser på miljöområdet (Normative tendencies in the field of environment) $i$ Miljö och hällbar utveckling - sambällsvetenskapliga perspektiv frän en Lundahorisont. Lund: Studentlitteratur.

Hydén, Håkan. (201la). The normative topography of consultations in relation to environmental impact assessments. Retfeard, Vol. 34, No. 2/133.

Hydén, Håkan. (2011b). Looking at the world through the lenses of norms. Nine reasons for norms: a plea for norm science. In Papendorf, Knut, Machura, Stefan och Andenaes, Kristian (eds.), Understandig law in society. Developments in sociolegal studies. Berlin: LIT Verlag.

Hydén, Håkan. (2018). The normative anatomy of society. In Febbrajo, Alberto (ed.), Law, Legal Culture and Society: Mirrored Identities of the Legal Order. Vol. 2, Series: Studies in the Sociology of Law. Abingdon: Routledge/Taylor and Francis Group.

Hydén, Håkan \& Hydén, Therese. (2019). Rättsregler. Lund: Studentlitteratur.

Hyden, Håkan. (2020a). Social cohesion and the anticipated fall of the welfare state. Annals of Social Sciences and Management Studies, Vol. 5, No. 2, p. 555658. DOI: 10.19080/ASM.2020.05.555658 0030 .

Hydén, Håkan. (2020b). Sociology of digital law and artificial intelligences. In Priban, Jiri (ed.), Research handbook on the sociology of law. Cheltenham: Edward Elgar.

Hydén, Håkan \& Dahlstrand, Karl. (2020). Avtalet som rättsligt och socialt instrument för samverkan in Baier, Matthias \& Svensson. Lund: Studentlitteratur.

Hydén, Håkan \& Gillberg, Minna. (2003). Legal and governing strategies-towards a law of sustainable development. Aldershot: Ashgate.

Hydén, Håkan \& Hydén, Therese. (2019). Rättsregler. Lund: Studentlitteratur.

Hydén, Håkan \& Lindén, Anna-Lisa (red.). (1998). Lagen, rätten och den sociala tryggheten: Tunnelbygget genom Hallandsåsen. Sociologiska institutionen, Research Report, p. 14. 
Hydén, Håkan \& Svensson, Måns. (2008). The concept of norms in sociology of law. In Law and society. Stockholm: Scandinavian Studies in Law, Law and Society. Hydén, Håkan \& Thoor, Alf. (red.). (1997). Rätt i förändring. En antologi om kristendenser i svensk rätt. Lund Studies in Sociology of Law, p. 2.

Hylland Eriksen, Thomas \& Hessen, Dag O. (2000). Egoism. Nora: Nya Doxa.

Illeris, Knud. (1999). Laering - aktuel laeringsteori i spaendingsfeltet mellem Piaget, Freud og Marx. Roskilde: Roskilde universitetsforlag, Internet Encyclopedia of Philosophy.

Inwood, B. (2018). Stoicism [Elektronisk resurs]. Oxford: Oxford University Press.

Johnston, David (ed.). (2015). The Cambridge companion to Roman law. Cambridge: Cambridge University Press.

Jönsson, Bodil \& Wickenberg, Per. (1994). På goda grunder. Lund: Liber utbildning. Käll, Jannice. (2020). Governing space through autonomous vehicles. In Finck, Michele, et al. (eds.), Smart urban mobility. Berlin: Springer.

Karnow, Curtis E.A., Barfield, Woodrow \& Pagallo, Ugo (eds.). (2018). Research bandbook on the law of artificial intelligence. Cheltenham: Edward Elgar Publishing Limited.

Karonen, Petri, Hakanen, Marko \& Einonen, Piia (red.). (2017). Personal agency at the Swedish age of greatness 1560-1720. Helsinki: Finnish Literature Society SKS: https://doi.org/10.21435/sfh.23.

Keiding, Hans. (2015). Game theory: a comprehensive introduction. Singapore: World Scientific.

Kellough, J. Edward. (2006). Understanding affirmative action: politics, discrimination, and the search for justice. Washington, DC: Georgetown University Press.

Kerr, N.L. (1995). Norms in social dilemmas. In Schroeder, D. (red.), Social dilemmas: social psychological perspectives. New York: Pergamon Press.

Kinder, Hermann \& Hilgemann, Werner. (1987). Tidens världshistoria. Band 1. Stockholm: Tiden.

King, Michael. (1993). The truth about autopoiesis. Journal of Law and Society, Vol. 20, Nr. 2.

Kloden, C.N., McLean, A.J., Moore, V.M. \& Ponte, G. (1999). Travelling speed and the risk of crash involvement, vol. 1: findings. Adelaide: NHMRC, University of Adelaide.

Kneidel, Gregory. (2015). John Donne er early modern legal culture: the end of equity in the Satyres. Pittsburgh, PA: Duquesne University Press.

Kondratieff, N.D. (1984). The long wave cycle. New York: Richardson \& Snyde.

Kondratieff, N.D. (1925). The long waves of business cycles in economic life. In Problems of economic fluctuations. Moscov: Institute for Business Cycles Research.

Kotler, P., Armstrong, G., Saunders, J. \& Wong, V. (1999). Principles of marketing. Second European ed. London: Prentice Hall.

Kranzberg, Melvin. (1986, July). Technology and history: “Kranzberg's Laws". Technology and Culture, Vol. 27, No. 3, s. 544-560. doi: 10.2307/3105385.

Kurzweil, Ray. (2014). How to create a mind: the secret of human thought revealed. London: Duckworth Overlook.

Landes, David S. (1997). The unbound prometheus: technological change and industrial development in Western Europe from 1750 to the present. Cambridge: Cambridge University Press.

Larsson, Reidar. (1968). Politiska ideologier. En antologi. Stockholm: Almqvist \& Wiksell. 
Larsson, Stefan. (2011). Metaphors and norms: understanding copyright law in a digital society. Diss. Lund University, Department of Sociology of Law, (sammanfattning) Lund: Lunds universitet.

Larsson, Stefan. (2017). Conceptions in the code: how metaphors explain legal challenges in digital times. New York: Oxford University Press.

Larsson, Stefan. (2019). Artificiell intelligens som normativ sambällsutmaning: partiskhet, ansvar och transparens [Elektronisk resurs]. Lund: Juristförlaget i Lund.

Latourette, Kenneth Scott. (1975). A history of Christianity. Vol. 1, to A.D. 1500. San Francisco: Harper \& Row.

Laudon, Kenneth C. \& Traver, Carol Guercio. (2019). E-commerce business, technology, society. Johanneshov: MTM.

LeGrand, Pierre. (1996). European legal systems are not converging. International and Comparative Law Quarterly, s. 52-81.

Lessig, Lawrence. (2006). Code: version 2.0. New York: Basic Books.

Levi, Margaret. (1998). A state of trust. In Trust and governance. S. 77-101.

Lichtenstein, Paul. (1993). Genetic and environmental mediation of the association between psychosocial factors and health, Gotab. Diss. (sammanfattning) Stockholm: Karol. inst.

Liedman, Sven Eric. (2001). Ett oündligt äventyr. Stockholm: Om människans kunskaper.

Lindholm, Stig. (1985). Kunskap, från fragment till helhetssyn. Stockholm: Liber förlag.

Lloyd, Dennis. (1964). The idea of law. London: Penguin Books.

Locke, John. (1690). Two treatises on government (svensk översättning 1726).

Lorents, Yngve \& Aspelin, Gunnar (red.). (1955). Vår egen tids historia 6 Tankelinjer och trosformer: huvudriktningar $i$ vàr tids idéhistoria, 2., omarb. uppl. Stockholm: Bonnier.

Luhmann, Niklas. (1981). Communication about law in interaction systems. In Knorr-Cetina, K. och Cicourel, A.V. (ed.). Advances in social theory and methodology: toward an integration of micro- and macro-sociologies. Boston: Routledge \& Kegan Paul.

Luhmann, Niklas. (1985). A sociological theory of law. London: Routledge and Kegan, Paul.

Luhmann, Niklas. (1986). The self-reproduction of law and its limits. In Teubner, G. (ed.), Dilemmas of law in the welfare state. s. $121 \mathrm{ff}$. Berlin: Walter de Gruyter.

Luhmann, Niklas. (1987a). Closure and openness. In Teubner, G. (ed.), Autopoietic law: a new approach to law and society. Berlin: de Gruyter.

Luhmann, Niklas. (1989). Ecological communication. Cambridge: Polity Press.

Luhmann, Niklas. (2004). Law as a social system. Oxford: Oxford University Press.

Lukes, Steven. ([1973]1985). Émile Durkheim: his life and work: a historical and critical study. Stanford, California: Stanford University Press.

Lukes, Steven \& Scull, Andrew. (1985). Durkheim and the law. Oxford: Clarendon.

Lundblad, Nicklas. (2000). Teknotopier - den nya tekniken och rättens framtid. Kristianstad: Timbro.

Lundgren, Lars J. (1974). Vattenförorening: debatten i Sverige 1890-1921, Gleerup. Diss. Lund: Lund University.

Lundquist, Lennart. (1987). Implementation steering. Lund: Studentlitteratur.

Lundquist, Lennart. (1992). Förvaltning, sambälle och stat. Lund: Studentlitteratur.

Macauley, Stewart. (1963). Non-contractual relations in business: a preliminary study. American Sociological Review, Vol. 28, pp. 55-67. 
Macaulay, Stewart, Kidwell, John \& Whitford, William C. (2003). Contracts: law in action. 2nd ed. Newark, NJ: LexisNexis.

MacCormick, Neil. (1999). Questioning sovereignty: law, stat, and nation in the European Commonwealth. Oxford: Oxford University Press Murphy.

MacCormick, Neil. (2007). Institutions of law: an essay in legal theory. Oxford: Oxford University Press.

MacIntyre, Alasdair. (1984). After virtue. A study in moral theory. Notre Dame: University of Notre Dame Press.

Mackenzie, Adrian. (2006). Cutting code: software and sociality. New York: Peter Lang.

Mackenzie, Donald. (2014, June). A sociology of algorithms: high-frequency trading and the shaping of markets. Unpublished paper.

Magnusson, Lars. (1994). Mercantilism [Electronic resource] the shaping of an economic language. London: Routledge.

Maine, Henry. (1861, omtryck 1959). Ancient law. London: The World Classics.

Mak, Vanessa, Tjong Tjin Tai, Eric \& Berlee, Anna (red.). (2018). Research handbook in data science and law. Northampton, MA: Edward Elgar Pub., Inc.

Malinowski, Bronislaw. (1962). Crime and custom in savage society. New York: Jkegan Paul, Trench, Trubner \& Co., Ltd.

Malmström Å., (1966), Rättsordningarnas system, Festskrift till Håkan Nial. Stockholm: P.A. Norstedt \& Söners förlag.

Marx, Karl. (1867). Kapitalet. Till kritiken av den politiska ekonomin.

Mathiesen, Thomas (1980). Law, society and political action: towards a strategy under late capitalism. London: Academic P.

Mathiesen, Thomas. (1986). Rätten i sambället. Göteborg: Korpen.

Mathiesen, Thomas. (1998). Is it that bad to be a stepchild? Comments on the state of sociology of law. Retfaerd, Nr. 4, s. 67-76.

Mathiesen, Thomas. (1999). Industrisamfunn eller informasjonssamfunn? Inspill til belysning av den byömoderne tid. Oslo: Pax forlag.

Mathieu, Chris. (1999). The moral life of the party. Lund Disseratations in Sociology, Vol. 30.

Maturana, Humberto R. \& Varela, Francisco J. (1980). Autopoiesis and cognition: the realization of the living. Dordrecht: Reidel.

Maturana, Humberto R., Varela, Francisco J. och Uribe, R. (1972 spansk utgåva, 1980 engelsk översättning) Autopoiesis and cognition. The realization of the living with a preface to "Autopoiesis" by Stafford Beer. Dordrecht: Reidel.

Matza, David \& Sykes, Gresham M. (1957). Techniques of neutralization. A theory of delinquency. American Sociological Review, Vol. 22.

May, Christopher. (2014). Rule of law [Elektronisk resurs]: the common sense of global politics. Cheltenham: Edward Elgar.

McBrien, Richard P. (red.). (1995). The Harper Collins encyclopedia of Catholicism. San Francisco: Harper San Francisco.

McCarthy, Thomas. (1985). Complexity and democracy, or the seducements of systems theory. New German Critique, Nr. 35.

Mead, George Herbert. (1972 [1934]). Mind, self, and society: from the standpoint of a social behaviorist. Chicago: University of Chicago Press.

Meads, George, Herbert. (1934). lär sig hur den sociala världen är konstruerad. I Gerberg, Geirge (1934). Chicago: Mind, Self and Society.

Mead, George Herbert. (1936). Movements of thought in the nineteenth century. Moore, Merritt H. (ed.). Chicago: University of Chicago Press. 


\section{Bibliography}

Merton, Robert K. (1949). Social theory and social structure: toward the codification of theory and research. Glencoe, Ill.: The Free Press.

Merton, Robert K. (1957). Social theory and social structure. Rev. and enl. ed. Glencoe, Ill.: Free Press

Meyer, Susan. (2018). Affirmative action [Elektronisk resurs]. New York: Rosen Young Adult.

Michalaikis, Dimitris. (1995). Legislating death: socio-legal studies of the brain death controversy in Sweden. Doctoral Diss. Stockholm: Acta Universitatis Upsaliensis. Almqvist \& Wiksell, International, p. 254.

Michelson, Staffan. (2018). Empowerment and private law: civil impetus for sustainable development. Diss. Lund: Lunds universitet; Stockholm: De Jure förlag.

Mill, John Stuart. (1861). Det representativa styrelsesättet Misztal, Barbara A. (1998). Trust in modern societies: the search for the bases of social order. Oxford: Polity Press.

Miller, Riel, Poli, Roberto \& Rossel, Pierre. (2013). The discipline of anticipation: exploring key issues, Bellagio Document 4: Working Paper 1.

Misztal, Barbara A. (1996). Trust in modern societies [Elektronisk resurs] the search for the bases of social order. Cambridge: Polity Press.

Modéer, Kjell Åke. (2004). LAG OCH RÄTT. In Christensson, Jakob (red.), Signums svenska kulturhistoria Medeltiden. Lund: Signum.

Modéer, Kjell Åke. (2009). Juristernas nära förflutna: rättskulturer i förändring. Stockholm: Santérus.

Mölders, Marc \& Schrape, Jan-Felix. (2019, June). Digital deceleration. Protest and societal irritation in the internet age. Österreichische Zeitschrift für Soziologie, Vol. 44, Supplement 1, pp. 199-215.

Montesquieu, Charles de Secondat, baron de. (1990). Om lagarnas anda med inledning och urval: Stig Strömholm; översättning: Dagmar Lagerberg. Stockholm: Ratio.

Moore, Jason W. (ed.). (2016). Anthropocene or capitalocene? Nature, history, and the crisis of capitalism (pp. 3-15). Oakland: PM Press/Kairos.

Moore, Sally Falk. (1978). Law as process. An anthropological approach. London: Routledge \& Kegan, Paul.

Moore, Sally Falk. (1986). Legal systems of the world. In Lipson, L. \& Wheeler, S. (eds.), Law and the Social Sciences. New York: Russell Sage Foundation.

Morics, Sara. (2019, March 5). Using artificial intelligence to recapture norms: did \#metoo change gender norms in Sweden? A PREPRINT, Sara Moricz, Department of Economics, Lund University.

Mortensen, Nils. (1990). Normer. In Gundelach, Peter, Mortensen, Nils och Tonboe, Jens Chr. (red.), Sociologi under forandring. Köpenhamn: Nordisk förlag Gyldendal.

Munktell, Henrik. (1944). Det svenska rättsarvet. Stockholm: Bonnier.

Murphy, Tim W. (1997). The oldest social science. Configurations of law and modernity. Oxford: Clarendon Press.

Murphy, Tim W. (2012). Living law, normative pluralism, and analytic jurisprudence. An International Journal of Legal and Political Thought, Vol. 3, No. 1, p. 208.

Myrdal, Gunnar. (1958). Value in social theory. London: Harper \& Brothers.

Myrdal, Gunnar. (1983). Objectivity in social research. Middletown, CT: Random House.

Nergelius, Joakim. (1996). Konstitutionellt rättighetsskydd: Svensk rätt $i$ ett komparativt perspektiv. Akademisk avhandling, Lunds universitet. Stockholm: Fritze. 
Neuhaus, Sinikka. (2005). Reformationen. Signums svenska kulturhistoria. Renässansen, pp. 181-219, 474-475, 493-495.

Neusner, Jacob \& Sonn, Tamara. (1999). Comparing religions through law [Elektronisk resurs] Judaism and Islam. London: Routledge.

Nils Herman. (1865). Svenskt allmänt författningsregister för tiden frän år 1522 till och med àr 1862. Stockholm: Norstedt.

Nitsch, Ulrich (1994). From diffusion of innovations to mutual learning: the changing role of the agricultural advisory services. Uppsala: U. Nitsch.

Nitsch, Ulrich. (1996). Miljöinformationens utmaningar i SOU 1996:105 Konsumenterna och miljön. Stockholm: Statens Offentliga Utredningar.

Nonet, Philippe och Selznick, Philip. (1978). Law and society in transition. New York: Toward Responsive Law.

Nordborg, Gudrun. (1985). Konstgjord befruktning - moderskap på det offentliga patriarkatets villkor. Retferd, Nr. 31 .

Numhauser-Henning, Ann. (1984). Tidsbegränsad anställning: en studie av anställningsformsregleringen och dess funktioner. Akademiska avbandling. Lund: Juridiska föreningens förlag.

Odum, Eugene P. (1971). Fundamentals of ecology. 3rd ed. New York: Saunders.

Olivecrona, Karl. (1966). Rättsordningen: idéer och fakta. Lund: Gleerup.

Olsson, Erik (red.). (2000). Etnicitetens gränser och mångfald. Stockholm: Carlssons.

Østerberg, Dag. (1991). Sociologins nyckelbegrepp och deras ursprung. Översatt av Bosse Forsén Upplaga: 2., rev. och utvidgade uppl. Göteborg: Korpen.

Östergaard, Uffe. (1994). Socialisme og borgerdyder. The Kritik Journal, No. 108, pp. 58-68.

Ostrom, Elinor. (1990). Governing the commons: the evolution of institutions for collective action. Cambridge: Cambridge University Press.

Otto, Jan Michiel (red.). (2010). Sharia incorporated [Elektronisk resurs] a comparative overview of the legal systems of twelve Muslim countries in past and present. Leiden: Leiden University Press.

Pariser, Eli. (2011, May). The filter bubble: what the internet is hiding from you. New York: Penguin Press.

Parsons, Talcott. $(1937,1968)$. The structure of social action: a study in social theory with special reference to a group of recent European writers. New York: Free Press.

Peczenik, Aleksander. (1987). Rättsnormer. Stockholm: Norstedts.

Peczenik, Aleksander. (1988). Rätten och förnuftet: en lärobok $i$ allmän rättslära. 2. uppl. Stockholm: Norstedt.

Peczenik, Aleksander. (1995). Vad är rätt? Om demokrati, rättssäkerhet, etik och juridisk argumentation. Stockholm: Fritzes förlag.

Peerenboom, R.P. (2007). China modernizes: threat to the West or model for the rest? Oxford: Oxford University Press.

Perez, Carlota. (2009). Technological revolutions and techno-economic paradigms, Working Papers in Technology Governance and Economic Dynamics no. 20, TECHNOLOGY GOVERNANCE, January 2009 Tallinn University of Technology, Tallinn.

Petersen, Hanne. (1996). Home knitted law: norms and values in gendered rulemaking. Aldershot: Dartmouth.

Pfannenstill, Annika. (2002). Rättstillämpning $i$ en kunskapskonkurrerande miljö fallstudier inom autismområdet. Lund: Lunds Universitet, (ak avh,).

Platzer, Ellinor. (1997). Handlingssystem, makt och frigörelse. En rättssociologisk studie om informella normer hos kvinnor och män. In Jonasdottir, Anna G. (ed.), 


\section{Bibliography}

Styrsystem och jämställdhet. Stockholm: Institutioner i förändring och könsmaktens framtid.

Pound, Roscoe. (1910). Law in books and law in action. American Law Review, Vol. 44.

Rachels, Stuart. (2015). The elements of moral philosophy. 8th ed. Dubuque: McGrawHill Education.

Ramberg, Christina. (2002). Internet marketplaces - the law of auctions and exchanges online. Oxford: Oxford University Press.

Raz, Joseph. (1970, 1990). The concept of a legal system. An introduction to the theory of legal system. Hongkong: Clarendon Press.

Renner, Karl. (1949). The institutions of private law and their social functions. London: Routledge.

Rheinstein, Max. (1954). Max Weber on law in economy and society. Cambridge: Harvard University Press, Oxford University Press.

Rolf, Bertil. (1995). Profession, tradition och tyst kunskap. En studie i Michael Polanyis teori om den professionella kunskapens tysta dimension. Lund: Nya Doxa.

Ross, Alf. (1953). Om ret og retferdighed: en indforelse $i$ den analytiske retsfilosofi / Alf Ross. København: Nyt nordisk forlag Arnold Busck.

Rossi, Peter och Berk, Richard A. (1984, December). A conceptual framework for measuring norms. In Short, J. (red.). The social fabric at risk: toward the social transformation of risk analysis. American Sociological Review. Vol. 49, No. 6, pp. 711-725.

Rothstein, Bo. (1993). Vad bör staten göra? Om välfürdsstatens moraliska och politiska logik. 1 uppl. Stockholm: SNS Studieförbundet Näringsliv och samhälle.

Rothstein, Bo. (1998). Just institutions matter. The moral and political logic of the universal welfare state. Cambridge: Cambridge University Press.

Rothstein, Bo. (2015). De sambälleliga institutionernas kvalitet: slutrapport fràn ett forskningsprogram. Stockholm: Riksbankens jubileumsfond in collaboration with Makadam förlag publishing company. www.rj.se/Publikationer/RJs-skriftserie/.

Rottleuthner, Hubert. (1985). Theories of legal evolution: between empiricism and philosophy of history. Rechtstheori, Supplement 9.

Russell, Stuart Jonathan \& Norvig, Peter. (2014). Artificial intelligence [Elektronisk resurs] a modern approach. 3rd, Pearson new international ed. Harlow: Pearson Education Limited.

Sajoo, Amyn B. (2018). Sharia. I.B. London: Tauris \& Co. Ltd.

Sanders, William T. \& Webster, David. (1978). Unilinealism, multilinealism, and the evolution of complex societies. In Redman, Charles L. (ed.), Social archeology: beyond subsistence and dating. New York: Academic Press.

Sanderson, Stephen K. (1999). Social Transformations: A General Theory of Historical Development. Oxford UK: Blackwell.

Sandgren, Claes. (1992/93). En social avtalsrätt, del och del 2. I Juridisk Tidskrift. Stockholms universitet, Nr. 3.

Sandgren, Claes. (1999-2000). Vad gör juristen? Och hur - del 1 och 2. Juridisk Tidskrift, No. 3 och 4.

Sandström, Torsten. (2017). Svensk aktiebolagsrätt. 6th ed. Stockholm: Wolters Kluwer. Sartre, Jean-Paul \& Elkaïm-Sartre, Arlette. (1960, 1991). Critique of dialectical reason. London: Verso.

Schmidt, Folke. (1962). Kollektiv arbetsrätt. Upplaga 4. Stockholm: Norstedt.

Schneewind, Jerome B. (ed.) (1990). Moral philosophy from Montaigne to Kant: an anthology. Cambridge: Cambridge University Press. 
Schneider, Henrique. (2017). Uber innovation in society. Cham: Springer International Publishing.

Schömer, Eva. (1999). Konstruktion av genus i rätten och samhället. En tvärvetenskaplig studie över svenska kvinnors rätt till jämställdhet i ett formellt jämlikt rättsystem. Akademiska avhandling, Iustus förlag.

Schön, Lennart. (2000). En modern svensk ekonomisk historia: tillväxt och omvandling under två sekel. 1. Uppl. Stockholm: SNS förl.

Schön, Lennart. (2001). Nya tillväxtmönster vid 1900-talets slut. Lund: Studentlitteratur.

Schumpeter, Joseph A. (2011). Capitalism, socialism and democracy. Mansfield Centre: Martino.

Schumpeter, Joseph Alois. (1934). The theory of economic development: an inquiry into profits, capital, credit, interest, and the business cycle. Cambridge, Mass.: Harvard University Press.

Schumpeter, Joseph Alois. (1939). Business cycles: a theoretical, historical, and statistical analysis of the capitalist process. 1st ed. New York: McGraw-Hill.

Schutz, Alfred. (1964). Collected papers II. Studies in social theory, ed. and introd. by Arvid Brodersen. Haag: Martinus Nijhoff.

Schwartz, S.H. (1977). Normative influences on altruism. Leonard Berkowitz, (ed.) Advances in Experimental Social Psychology, Vol. 10, pp. ii-x, 1-341 (1977). Amsterdam: Elsevier.

Scott, John Finley. (1971). Internalization of norms. Englewood Cliffs, NJ: A Sociological Theory of Moral Commitment.

Sejersted, Francis. (1993). Demokratisk kapitalisme. Oslo: Universitetsforlag.

Sejersted, Francis. (2011). The age of social democracy: Norway and Sweden in the twentieth century. Princeton: Princeton University Press.

Sellers, M.N.S. \& Tomaszewski, Tadeusz. (2010). The rule of law in comparative perspective [Elektronisk resurs]. Dordrecht: Springer.

SFS. (1974). p. 13.

Shaw, Randy. (2017). Generation priced out: Who gets to live in the new urban America, with a new preface. New York: University of California Press.

Sherif, Muzafer. (1936). The psychology of social norms. New York: Harper \& Brothers. Sherif, Muzafer. (1948). An outline of social psychology. New York: Harper and Brothers.

Sherwin, Robert K. (2000). When law goes pop: the vanishing line between law and popular culture. Chicago: Chicago University Press.

Shimpo, Fumio. (2018). The principal Japanese AI and robot stratey towards establishing basic principles. In Barfield, Woodrow \& Pagallo, Ugo (eds.), Research handbook on the law of artificial intelligence. Cheltenham: Edward Elgar Publishing Limited.

Skog, Göran. (1982). Marknadens villkor. Normer, köprätt, konsumenträtt samt etablerings- och produktkontroll $i$ sambällsvetenskaplig belysning. Stockholm: Timbro.

Smart, Carol. (1992). Regulating womenhood. London: Routledge.

Smith, Adam \& Garnier, Germain. (1828). An inquiry into the nature and causes of the wealth of nations... [Electronic resource]: with a life of the author: also, a view of the doctrine of Smith. Edinburgh: Printed for T. Nelson and P. Brown.

Smith, H.E. (1990). Sociology and the study of non-western societies. The American Sociologist, Vol. 21, No. 2, pp. 150-163.

Söderström, Hans Tson \& Calmfors, Lars. (1985). Nya spelregler för tillväxt. Stockholm: Studieförbundet. Näringsliv och samhälle ( $\mathrm{SN \& S}$ ). Konjunkturrådets rapportserie 1986. 


\section{Bibliography}

Soper, Philip, A. (1984). A theory of law. Cambridge, MA: Harvard University Press.

Soro, Alessandro, Brereton, Margot \& Roe, Paul (red.). (2019). Social internet of things. Cham: Springer International Publishing.

Sousa Santos, Boaventura de. (1995). Towards a new common sense. New York: Routledge.

Sousa Santos, Boaventura de. (2018). The end of the cognitive empire: the coming of age of epistemologies of the south. Durham and London: Duke University Press.

Strömholm, Stig. (1981). Rätt, rättskällor och rättstillämpning. En lärobok $i$ allmän rättslära. Lund: Norstedts.

Stjernquist, Per. (1973). Laws in the forests: A study of public direction of Swedish private forestry. Lund: Gleerup.

Stjernquist, Per. (1976). Rättens ursprung grund (s. 35). Lund: Ekstrand.

Strahl, Ivar. (1967). Makt och rätt: rättsidéns gång genom historien: från Babylonien till F.N. Upplaga: 4., [omarb.]. Stockholm: Aldus/Bonnier.

Stridbeck, Ulf. (1992). Från kontrakt till social rättighet: en analys av förhållandet mellan eldistributör och abonnent. Diss. Lund: Lunds University Press.

Strömholm, Stig. (1975). Svensk rättskunskap. Lund: Liber Läromedel/Gleerup.

Strömholm, Stig. (1979). Normer och mål-det normbundna beslutsfattandets särart. Stockholm: I Svensk Juristtidning.

Strömholm, Stig. (1981). Rätt, rättskällor och rättstillämpning: en lärobok $i$ allmän rättslära. Stockholm: Norstedt.

Strömholm, Stig. (1988). Rätt, rättskällor och rättstillämpning: en lärobok $i$ allmän rättslära. 3. uppl. Stockholm: Norstedt

Strömholm, Stig. (1991). Europa och rätten. Stockholm: Natur och kultur.

Strubell, Emma, Ganesh, Ananya \& McCallumb, Andrew. (2019). Energy and policy considerations for deep learning in NLP. Cornell University, arXiv:1906.02243vl [cs.CL].

Stuart, Gilbert. (1778). A view of society in Europe in its progress from rudeness to refinement, or, Inquiries concerning the history of law, government, and manners . . [Electronic resource]. Edinburgh: Printed for J. Bell and J. Murray.

Sumner, Graham. (1909). Folkways. A study of the sociological importance of usages, manners, customs, mores and morals. New York: Dover Publications.

Sumner, William Graham. (1959). Folkways: a study of the sociological importance of usages, manners, customs, mores, and morals. New York, NY: Dover Publications.

Sundararajan, Arun. (2016). The sharing economy: the end of employment and the rise of crowd-based capitalism. Cambridge, MA: The MIT Press.

Sundby, Nils Kristian. (1974, 1978). Om normer, uppl 2. Oslo: Universitetsforlaget.

Sundby, Nils Kristian. (1978). Om normer (p. 51). 2. oppl. Oslo: Universitetsforlaget.

Sutherland, E.H., Cressy, D.R. \& Luckenbill, D.F. (1992). Principles of criminology. Lanham MD: Rowman and Littlefield.

Svenaeus, Fredrik. (2019). Det naturliga: en kritik av queerteorin, transhumanismen och det digitala livet. Möklinta: Gidlunds förlag.

Svenaeus, Lena. (2017). Konsten att upprätthålla löneskillnader mellan kvinnor och män: en rättssociologisk studie av regler i lag och avtal om lika lön. Diss. Lund: Lunds universitet. http://lup.lub.lu.se/record/30d328dc-8bf2-4716-a78e-d04fc5b40990

Svenning, Conny. (2003). Metodboken: [sambällsvetenskaplig metod och metodutveckling: klassiska och nya metoder $i$ informationssambället: källkritik på Internet]. 5., omarb. uppl. Eslöv: Lorentz.

Svenning, Margaretha. (1996). Miljökriget. Miljöarenan och politikens möjligheter att styra vair miljö. Lund: Akademisk avhandling. 
Svensson, Måns. (2008). Sociala normer och regelefterlevnad: trafiksäkerhetsfrågor ur ett rättssociologiskt perspektiv. Diss. Lund: Lunds universitet.

Svensson, Måns. (2013). Studying norms and social change in a digital age. In Baier, M. (ed.), Social and legal norms. London: Ashgate.

The Swedish Sociological dictionary. (1998). p. 221.

Swidler, Ann. (1986). Culture in action: symbols and strategies. American Sociological Review, Vol. 51.

Sylwan, Peter. (2005). Tillit: en bok om meningen i livet: från den stora smällen till morgondagens middagsmat/Peter Sylwan. Stockholm: Natur och Kultur.

Tainter, Joseph A. (2019). The collapse of complex societies. Johanneshov: MTM.

Tamanaha, Brian Z. (1993). The folly of the 'social scientific' concept of legal pluralism. I Journal of Law and Society, Nr. 2.

Tamm, Ditlev. (1998). Romersk rätt och europeisk rättsutveckling. Andra upplagan. Stockholm: Nerenius \& Santérus. Originaltitel. Romersk ret og europeisk retsudvikling.

Tanzi, Vito \& Schuknecht, Ludger. (2000). Public spending in the 20th century. Cambridge: Cambridge University Press.

Tarras-Wahlberg, Björn. (1980). Lagstiftning till döds? 1970-talets regleringar av företagen: kartläggning och konsekvenser $=$ [Legislated to death?]: [regulation of business enterprises in the 1970s]: [analysis and effects]. Stockholm: Sv. Arbetsgivarefören.

Taylor, Chris. (2018). Law express: company law. Harlow: Pearson Education Limited.

Tegmark, Max. (2017). Life 3.0: being human in the age of artificial intelligence. New York: Alfred A. Knopf.

Teubner, Günther. (1983). Substantive and reflexive elements in modern law. I Law and Society Review, p. 2.

Teubner, Günther. (1987a). Juridification of social spheres. A comparative analysis in the areas of labor, corporate, antitrust and social welfare law, del II. Berlin and New York: De Gruyter.

Teubner, Günther (ed.). (1987b). Autopoietic law: a new approach to law and society. Berlin: de Gruyter.

Teubner, Günther (ed.). (1993). Law as an autopoietic system. Oxford: Blackwell.

Teubner, Gunther. (2006). In the blind spot: the hybridization of contracting. Theoretical Inquiries in Law, Vol. 7, pp. 51-71.

Therborn, Göran. (1993). Normens vägar och frågetecken [Elektronisk resurs]. Sociologisk forskning, Vol. 30, No. 2, pp. 3-16. http://urn.kb.se/resolve?urn= urn:nbn:se:du-26709.

Tidskrift for Rettsvitenskap, Scandinavian Journal of Law, Universitetsforlaget, Oslo, Norway.

Tillgänglig på Internet. http://lup.lub.lu.se/record/30d328dc-8bf2-4716-a78ed04fc5b40990.

Toffler, Alvin. (1981). The third wave. London: Pan in assoc. with Collins.

Töllborg, Dennis. (1997). National security and the rule of law. Göteborg: Centrum för Europaforskning.

Tolonen, Juha. (1988). Administration, makt och information. In Tuori, Karlo (ed.), Rättsdogmatikens alternative. s. 173-180. Helsingfors: Juridica.

Tomasik, Brian. (2014). Artificial intelligence and its implications for future suffering, first written: May 14, 2014; last update: June 13, 2017. https://foundationalresearch.org/artificial-intelligence-and-its-implications-for-future. 


\section{Bibliography}

Tönnies, Ferdinand. (1979). Gemeinschaft und Gesellschaft: Grundbegriffe der reinen Soziologie [Neuausg.]. Darmstadt: Wissenschaftliche Buchgesellschaft.

Torpman, Jan. (2002). Rättssystemets lärande. Akademisk avhandling. Stockholm: Handelshögskolan i Stockholm.

Toynbee, Arnold. (1957). The industrial revolution. Boston: Beacon Press.

Trondman, Mats. (1994). Bilden av en klassresa: sexton arbetarklassbarn på väg till och $i$ högskolan. Akademiska avhandling, Lunds universitet. Stockholm: Carlsson.

Tuori, Kaarlo. (1999). Från ideologikritik i kritisk positivism. I Retfaerd, Nr. 2.

Tyler, Tom R. (1990). Why people obey the law. New Haven, CT: Yale University Press.

Unger, Roberto Mangabeira. (1996). What should legal analysis become? London: Verso.

Unger, Roberto Mangabeira. (1978). Law in modern society. New York: Free Press.

Unger, Roberto Mangabeira. (1986). The critical legal studies movement. Cambridge, MA: Harvard University Press.

Urban, Tim. (2015, January 22). The AI revolution: the road to superintelligence. Wait but Why. https://waitbuywhy.com/2015/01/artificial-intelligence-revolution-1.html

van Dijk, José. (2013). The culture of connectivity: a critical history of social media. New York: Oxford University Press.

van Rooij, Brenjamin (2006). Regulating Land and Pollution in China: Lawmaking, compliance and enforcement; theory and cases. Leiden: Leiden University Press.

Verger, Jacques. (2007). The universities and scholasticism. In The new Cambridge medieval history: volume 5 c. 1198-1300. Cambridge: Cambridge University Press.

Vise, David A. \& Malseed, Mark. (2005). The Google story. New York: Delacorte Press.

Voss, Thomas. (2001). Game-theoretical perspective on the emergence of social norms. In Hechter, M. \& Opp, K.D. (eds.), Social norms. New York: Russel Sage Foundation.

Wallerstein, Immanuel. (1974). The modern world system. New York: Academic.

Wallerstein, Immanuel. (2000). Globalization or the age of transition? A long-term view of the trajectory of the world system. International Sociology, Vol. 15, s. $249 \mathrm{ff}$.

Wallerstein, Immanuel. (2004). World-systems analysis: an introduction. Durham: Duke University Press.

Weber, Max. (1978). Economy and society: an outline of interpretive sociology. Vol. 1. Berkeley, CA: University of California Press.

Weber, Max. (1991). From Max Weber: essays in sociology. New ed. London: Routledge.

Weber, Max. (2009). The protestant ethic and the spirit of capitalism: with other writings on the rise of the West. 4th ed. New York: Oxford University Press.

Weber, Max (2012). Theory of social and economic organization. Mansfield Centre, CT: Martino Publishing.

Wedgewood, Ralph. (2007). The nature of normativity. Oxford: Clarendon Press.

Weng, Y.H., Sugahara, Y., Hashimoto, K., \& Takanishi, A. (2015). Intersection of "Tokku" special zone, robots, and the law: a case study on legal impacts to humanoid robots. International Journal of Social Robotics, Vol. 7, No. 5, pp. 841-857. https://doi.org/10.1007/s12369-015-0287-x.

Westberg, Peter. (2012). Anskaffning av bevisning $i$ dispositiva tvistemål. Johanneshov: TPB.

Westberg, Peter. (2016). Civilrättskipning. Johanneshov: MTM.

Westman, Daniel. (2019). Den fuärde industriella revolutionen - en immaterialrättslig introduktion (Elektronisk resurs). NIR. 1, 131151.http://urn.kb.se/ resolve?urn=urn:nbn:se:su:diva- 167593 .

Whittington, Keith E. \& Kelemen, R. Daniel (red.). (2008). The Oxford handbook of law and politics (Elektronisk resurs). Oxford: Oxford University Press. 
Whittington, Keith E., Kelemen, R. Daniel \& Caldeira, Gregory A. (eds.). (2008). The internet encyclopedia of philosophy the oxford handbook of law and politics. New York: Oxford University Press, p. 832.

Wickenberg, Per. (1999). Normstödjande strukturer. Miljötematiken börjar slå rot i skolan [Norm supporting structures: the environmental theme begins to take root in schools]. Doctoral Thesis. Lund: Lund Studies in Sociology of Law 5.

Wickenberg, Per. (2003). Brunnarna i Holma: samrådens konkreta genomförande 2000-2002 för Citytunnelprojektet i Malmö. Lund: Sociology of Law, Lund Univ.

Wickenberg, Per. (2013). Souls of fire, change agents and social norms. In Baier, Matthias (ed.), Social and legal norms [Electronic source]: towards a socio-legal understanding of normativity. Farnham, Surrey: Ashgate.

Wickenberg, Per, Rasmusson, Bodil \& Leo, Ulf. (2019). International studies on enactment of children's rights in education: 30 researchers from non-western countries. Lund: Sociology of Law, Lund University.

Widerberg, Karin. (1995). Kunskapenskön. Falun: Norstedts förlag.

Widerberg, Karin. (2001). Patriarkatets slut? Tros-satser á la Castells. I Retferd, No. 2, s. $14 \mathrm{ff}$.

Widlok, Thomas. (2017). Anthropology and the economy of sharing. Abingdon, Oxon: Routledge is an imprint of the Taylor \& Francis Group, an Informa Business.

Wilde, G.J.S. (1978). Mass media communications for pedestrian safety. Report to the road research programme of the organization for economic cooperation and development (Paris) (58 pages). Published by the United Kingdom Transport and Road Research Laboratory, Crowthorne, Berkshire, UK.

Wilenius, M. \& Kurki, S. (2012). Surfing the sixth wave: exploring the next 40 years of global change. The 6th wave and systemic innovation for Finland: success factor for the Years 2010-2050, Finland Futures Research Centre, University of Turku.

Wilhelmsson, Thomas. (1987). Social civilrätt. Om behovsorienterade element $i$ kontraktsrättens allmänna läror. Helsingfors: Lakimiestliiton Kustannus (Juristförb.).

Wilhelmsson, Thomas (red.). (1993). Perspectives of critical contract law. Aldershot: Dartmouth.

Willke, Helmut. (1995). Governance and knowledge: how does the new role of knowledge influence the distinction between the public and the private. Oslo: Universitetsforlaget.

Woodlock, John \& Hydén, Håkan. (2020). (f)Lex avionica; how soft law serves as an instrumental mediator between professional norms and the hard law regulation of European civil aviation maintenance. I: Safety Science, Vol. 121, s. 54-63.

Yueh-Hsuan Weng. (2018). Robot law. In Barfield, Woodrow \& Pagallo, Ugo (eds.), Research handbook on the law of artificial intelligence (p. 617). Cheltenham: Edward Elgar Publishing Limited.

Zarsky, T. (2016). The trouble with algorithmic decisions: an analytic road map to examine efficiency and fairness in automated and opaque decision making. Science, Technology \& Human Values, Vol. 41, No. 1, pp. 118-132.

Zeiler, Kristin. (2014). A philosophical defense of the idea that we can hold each other in personhood [electronic resource] intercorporeal personhood in dementia care. Medicine, Health Care and Philosophy, Vol. 17, No. 1, pp. 131-141. http:// urn.kb.se/resolve? urn=urn:nbn:se:liu:diva-103820.

Zeleny, Milan. (1981). Autopoisis: a theory of living organization. New York: North Holland. 


\section{Index}

Page numbers in italics indicate figures; page numbers in bold indicate tables.

abiotic subsystems, distribution of norms 123-128

accept, term 146

action norms 68,104 ; instruments for interaction 165; will and can 7-8 action rules: duty norms and 138; legal governance 137

action systems: distribution of legal rules 140-154; distribution of norms 108-109, 110; reproduction of $162-163$

action theories: circle of motives 44; system theories and $43-45$

Act of 1907217,230

Act on Unfair Terms in Consumer Contracts 197

administrative law 157; rules of procedure 136

administrative system, distribution of norms 110, 111-113

advanced practice $283-284,284 \mathrm{n} 88$

After Virtue (MacIntyre) 83

Airbnb 77

Akalu Aster 267

Algonet 74

algo norms 273; concept of 277; consumer finding goods and services 282 ; context of 278, 279; digital technology 285-286; orders of normativity 276-283; problems identifying 284-285; societal norms and 280, 281; subcategory of technical norms 279 algorithms: artificial intelligence (AI) and 276-277, 288-289, 290-291; big data 285; consumers finding goods and services 282; digital technology 285-286; platforms for 275; self-learning 275-276; surveillance and 287-288

Alphabet 76

AltaVista 75

Alternative Investment Fund Managers Directive 191

Amazon 77, 157, 275

analysis tool, norm as 49,50

Ancient Law (Maine) 48

Andersson, Gunnar 62

Andreessen, Marc 75

Annales school 21

Antigone (Sophocles) 81

Apple 157

Aquinas, Thomas 82

Archie search engine 75

Aristotle 170; Nicomachean Ethics 82; virtue 84

Arnold, Thurman, America's anti-trust legislation 156n96

ARPANET, Internet and 73 artificial intelligence (AI) 2, 252; algorithms and 276-277, 288-289, 290-291; automation and 272; big data 290; pace of 273-274; regulation of 286-287; surveillance and 287-288

Asplund, Johan 9, 79

assembling society $45-48$

atom, term 5

atomization society 45 
Atterdag, Valdemar 182

Aubert, Vilhelm 155; laws and regulations 188 , 189; legal sociology 132; social norms 95, 96

Auden, Wystan H., "Law like Love" 155

Augustinus, Father 176

Axelrod, Robert: clarity of legal rules 156-157; defining norm 97; evolutionary theory 98 ; meta-norm 97; pro-punishment for deviation 97-98; social norms 103

B2B (business to business) 77

B2C (business to customer) 77

Baidu 76

Banakar, Reza: legal paradigms 248, 248 n78; pursuit of justice 156

base-world 61

Bauman, Zygmunt 89; on technology 198-199; transition to information society 39

Beck, Ulrich: destructive critique 89 ; industrialism 40 ; industrial modernism 24; recipe for change 31 ; reflexive modernization 38-39, 48; The Reinvention of Politics 38, 47; sociology change 46-47

Bell Laboratories 36

Bentham, Jeremy, criticising theory of natural rights 86

Bergman, C. G., Tiden 218

Berman, Harold J., Law and Revolution 239

Berners-Lee, Tim, Internet and 74

Between Facts and Norms (Habermas) 70

Biden, Joe 121

big data 285, 285n95; artificial intelligence (AI) 290

Bildt, Carl 74

Bilting, Ulf, Internet and 74

Bing 76

biotic subsystems 110 ; distribution of norms 123-128

Boniface VIII (Pope) 174

Bonifacius VIII (Pope) 175

Booking 77

Bourdieu, Pierre, habitus 54, $54 \mathrm{n} 22$

brain, norms imprinted in 1-2

Building Code, Swedish 183
Bush, George W., consumption and patriotic duty 198nl03

business cycles, Schumpeter's 21

Buy Nothing Day 198

C2C (customer to customer) 77

Caesar, Julius 168-169

Calvinism 177

can, will and 7-8

canon law 175, 176

Capital (Marx) 87

Car-Free Day 198

Carlsson, Benny, anti-competitive regulations 184

Carlsson, Bo 212

case law 290

Castells, Manuel: emergence of network society 31 ; The End of Millennium 37; industrial society 78; information technology 89, 89-90; network society and 32; The Power of Identity 36; power of patriarchy 261; resistance identities and project identities $64-65$; responsiveness to empiricism 42 ; science of norms 38 ; technology transformation 273

Catholic Church 172, 175, 183n64

change agents, concept of 106

Charles IX of Sweden 19

Children and Parental Code 144

Child Rights Convention 106

China, e-commerce 275n56

Christensen, Anna: concept of ownership 223; concept of property law 217; market economy 234; marriage 221-222; normative patterns 213-217, 220, 230, 236, 239 ; residential right 215 ; social insurance 221 ; tenure security 218 , 231; wage labour 199, 220-221

Christian Age 169, 175

Christianity 22-23; Great Schism 173-174; Roman Empire 168, $172-178$

Chrome 75

Chydenius 180

circle of motives: actor and system theory 43-45; within actiontheoretical context 44 civilizations 22 
Clark, Jim 75

class action rule 137

class struggle, Marx and 31-32

Clemens V (Pope) 175

Clinton, Bill 74

cloning 143

Codetermination in the Workplace Act 146

co-evolution, butterfly orchid and moth example 32-33

Cohabitees Act 145

Coleman, James: conjoint and disjoint norms 98-99, 99; definition of norms 100; emergence of norms 100; free rider theory 101; game theory 100-101; payoff models 100; social systems 98

Coleman, Jules L., external effects 147, 165

combustion engine 30

Commercial Code 268; Swedish 183

common law 290, 290n119

communication, action for 12

communicative actions, culture and $56-57$

competence norms 104

competence rules, weighing-and-

balancing norms 138

computers 29

Confucius 111

conjoint norms 98, 99; phrase 191

consensus-creating mechanism, legal rules in 161

consequentialist rule model 138

Constantine (Emperor) 172

constitutional law 157

constitutive rules, economic system 145

constructive norms 104

Consumer Credit Act 197

consumer protection 233

Consumer Sales Act 146, 197, 198, 233

Consumer Services Act 197

Cooley, Charles H., 91; primary group of norms 91

cooperation, trust and $\mathbf{5 5}$

core technology 29, 36, 71; social practice 54

coronaviruses 124-127; Middle East respiratory syndrome (MERS) 124; SARS-CoV-2 125; severe acute respiratory syndrome (SARS) 124; see also COVID-19

Corpus Juris Canonici 175, 183

Corpus Juris Civilis 171, 173, 175, 181, 183,211

Corpus Juris Mercatori 183

Cotterrell, Roger: example of poles by 244; Law's Community 234-236; movement analyses 239

COVID-19 124-125; lockdowns 125-126nl26, 125-127, 126nl28; Swedish strategy for 127-128; see also coronaviruses

Criminal Code 142, 144, 271

Critical Legal Studies Movement 205

Critique of Political Economy (Marx) 87

Crusades 174

culture: concept of 55 ; cultural lag 65 ; definition $50 \mathrm{n} 5$; influence on behaviour 64 ; society and $55-58$; understanding the world 57-58

cyber epoch 24

cyber society, world views of 41

Daintith, Terence, law as system 236

Dalberg Larsen, Jørgen 130, 213, 237, 238

Das Capital (Marx) 87

December Agreement 231

decision-making process: legal rules in 161-162; weighing-and-balancing rules 138-139

Delimitation Ordinance 188

demand, term 146

Demokratisk kapitalism (Sejersted) 131

Den skapande evolutionen (Fagerström) 28

Derrida, Jacques: destructive critique 89; information society 90

de Sousa Santos, Boaventura 180, 269

Digesta 181

digital technology 9, 11; algo norms 285-286; algorithms and 282, 291-292; artificial intelligence (AI) and 272, 291-292; electricity and 30 ; information use 37 ; gene technology and lag in law 269-271; Internet 73; legal development 251-252; restructuring of workforce 35 ; strengthening monopolistic tendencies 76-77; see also technology 
digital world, China $275 \mathrm{n} 56$

disjoint norms 98, 99, 160, 202

dispute resolution mechanism, legal rules in 162-164

dualism, human nature 50-53

Durkheim, Émile 15, 91; changing

behaviours 98; concept of norms 92; De

la division du travail social 213, 237;

kinds of norms 93; moral and technical norms 256; observations of movement 247-248; organic solidarity 249 ; sanction mechanism 131; on sociology $4-5,88$; suicide frequencies 58 duty-imposing, term 49 duty rules 137

Eckhoff, Torstein 49; internalized and systemic norms 105

ecological system, distribution of norms 119-123

e-commerce $275,275 n 56$

economic system: constitutive rules 145; distribution of norms 110 , 113-119; economic norms 260-261; environmental movement 209-211; humans and nature 200-202; individual's existential conditions 117; legal rules 149-151; technical and environmental norms 260-261; unions and labour market 145-146 education, knowledge and 11 electricity, digital technology and 30 Elickson, Robert C., development of social norms 106

Elster, Jon 55; normative actions and self-interest 156

Emergence of Norms, The (UllmannMargalit) 97

employer, term 116

Employment Protection Act 146, 148, 220,229

End of Millennium, The (Castells) 37

energy technology 42

Eng, Svein, competence rules 136

Engels, Friedrich, Marx and 87

Enlightenment 73, 169

Environmental Code 137, 154, 225, $228,229,270,271$

Environmental Courts 139, 233 environmental factors, human behaviour $51-52$

environmentalism 90; movement $65,65 \mathrm{n} 75$; economic system and 209-211

environmental laws: institution of immission 223-224; institution of tort law 224-226; intervening rules 226-228; right of ownership 222-223

Environmental Protection Act 154n86, 225, 227, 228

Environmental Protection Agency (EPA) 192, 233

Eriksen, Björn, Internet and 74

Esser, Josef: operationalized values 134; values-based generalizations 106 ethics, virtue 81-82, 83, 86

Ett friskare sambälle (Fromm) 66

European Convention on Human Rights (ECHR) 288

European Court of Human Rights 158

European Court of Justice 158

evolution: co-evolution 32-33; mutual process of 33

evolution of law: in industrial age 184-194; in market economy 168-184; political/administrative system 191-194

Ewerman, Anders: collapse of Roman Empire 171-172; corruption and nepotism 177; culture 79; decline of Catholic rulership 178-179; need for spiritual unity 169 ; societal change and 26

exchange value 197

Excite search engine 75

expert knowledge and participation, instrumental rationality 139

Facebook 77, 157

facticity, norm as 49,50

Fagerström, Torbjörn: blind logic of evolution 33; butterfly orchid and moth 32-33; Den skapande evolutionen 28; labour and capital 34

Fakticitet und Geltung (Habermas) 70 feminism 65, 90 fertilization methods 143 
Financial Action Task Force on Money Laundering and Terrorist Financing 191

flood of norms, term 186

Folkways (Sumner) 91

Ford, Henry 180

forward to basics principle 28

freedom of competition 227-228, 229

freedom of trade 228

free rider theory, Coleman on 101

French Code Civil 48; Napoleon 48

French Revolution 264

Fromm, Erich 66; defining healthy society 66

Galtung, Johan 194n93; institutionalized dispute resolution 164-165

game/system: knowledge of norms 60; outcome-oriented norms of 59; play 79; rules and development 266-268; self-regulation 265

game theory 15; Coleman on 100-101; norms in 97-104; social dilemmas 101-104; structural norms in 118 Gärdenfors, Peter, Hur Homo blev sapiens (How Homo Became Sapien) 52

Geertz, Clifford, culture and 65 gender issues 40

genes $254 \mathrm{n} 2$; norms of human society and 254-256; ontogenetic function of 28-29

gene technology, lag in law and 269-271

genetically modified organisms

(GMOs) 270

genetic engineering 143

genetics, human behaviour 51-52

genomics, norms as readiness for action 254-256

Gibbs, Jack, concept of norms 91, 93

Gidden, Anthony, discourse norms 95

Gillberg, Minna, environmental movements $65 \mathrm{n} 75$

Gilligan, Carol, rationality 248

Gimpel, Jean, psychological drive and technological evolution 46

Goffman, Erving 61

golden rule, reciprocity principle 110

Google 75, 76, 77, 157, 283
Gopher, folder-like system 74

governmental work, income redistribution 41

GrabTaxi 77

Grankvist, Per, algorithms 282n78

Graver, Hans Petter, social rights 148

Great Depression 126

Great Migration Era 22

Great Schism 173-174

Greece: Greek culture 22; Greek legal system 169-171; Greek Orthodox Church 172

Gregorius I (Pope) 173

Gregorius XI (Pope) 174

Gregory VII (Pope) 22, 174

gross domestic product (GDP), industrial society $40-41$

Grotius, Hugo, morality 82

guaranteed right, Weber on concept of 130

Gustav II, Adolf 120n112

Gustav III 180

Guterres, António 199

Habermas, Jürgen: Between Facts and Norms 70; communicative action 12,57 ; on differences between norms 121-122; Fakticitet und Geltung 70; internal and external perspective of law 259; law as institution $v s$ governing mechanism 133; legal issue interest, 88-89; lifeworld and system $2,17 \mathrm{n} 40,25$, $36,53,63,64,67,198,232$; on Marx 69, 69n90; norm definition 68; plea for procedural law 211 ; social integration 71 ; social sciences 63; steering media 58; see also lifeworld and system

habitual trust 54

habitus, Bourdieu on $54,54 \mathrm{n} 22$

handicraft society 20,25; bipolar continuums 244; bipolarities 249; legal regulation 242; locomotive of legal development, 245; S-curve 20, 25 ; vertical dimension 243 ; world views of 41

Hansa, term 182

Hanseatic League 182 
Hart, H.L.A., kinds of rules 131

Hayek, Friedrich A., nomos and thesis 132-133

Hegel, Friedrich: dialectic logic 73; dialectic social progress 87

Hemrätt i Hyreshuset (Christensen) 218

hereditary traits, basic normative patterns 254

Heritage, John 12

Hernes, Gudmund, motivational system 139-140

Hessen, Dag O. 52

history of mentalities, concept of 21

Hjern, Benny, joke laws 189-190n82

Hobbes, Thomas, independence of individuals 85-86

Hofstadter, Douglas, Metamagical Themas 215

holistic science $47-48$

Homans, George, defining norms 92

Homer 81

Horne, Christine, emergence of norms 106

Huizinga, John, culture and play 79

human action: cultural lessons 51 ; social development, 31-32

Humanoid Robotics Institute, Waseda University 289n1 14

humans: dualism 50-53; genetics and culture 51-52; nature and economic system 200-202

Hume, David: on “ought”, 15; virtue ethics $82,82-83,86$

Hur Homo blev sapiens (How Homo Became Sapien) (Gärdenfors) 52

ideas, systems of 118-119

ideational values, Sorokin and 22

Illeris, Knud, Laering 8

IMER research, international migration and ethnic relations 11

immission law strategy, industrial development, 223-224

income redistribution 41

In Considerations on Representative Government (Mill) 88

indivisible, atom from term 5

industrial age, evolution of law during

184-194

industrial revolution 183 industrial society: bipolarities 249; Castells 78; constellation of 40; development of 41 ; emergence of 48; labour and capital 34-35; legal regulation 242; locomotive of legal development 245; public spending in 40-41; S-curve 20, 25; unilateral dominance 34 ; vertical dimension 243; world views of 41

informational digital society: bipolarities 249 ; forward to basics 32 ; legal regulation 242; locomotive of legal development 245; S-curve 20, 25; vertical dimension 243; world views of 41

information society, transition to 39

information technology, worldwide 34

Inheritance Code 144

Innocent III (Pope) 174

Institutions of Private Law and Their Social Functions, The (Renner) 216

Instrument of Government, Swedish 184

Intelligent Transport Systems Act, 191

Internalization of Norms (Scott) 95

international civil law 157-158

International Labour Organization (ILO) 126-127

International Monetary Fund

(IMF) 114

Internet, digital technology 73

Internet Explorer 75

intersystem conflicts, alternative solutions to 204-212

intervening rules, environmental issues 226-228

Islamic law 18-19

Japan, Tokku 289, 289n1 14

joke laws 189-190n82

Justinian I (Emperor) 171, 181, 183

Kant, Immanuel 81

Kelsen, Hans 15

Keynesian models 184-185

Kickstarter 77

KK Foundation 74

knowledge: action and system theory 43,44 ; circle of motives $10,10-12$; extended circle of motives 13 ; 
normativity and 16-17; norms 60

Kondratiev, Nikolai D., business cycle waves 21

Kranzberg, Melvin, first law of technology 281

Labour Court, 139

labour force 195-196; conflicting norms in market 196

labour market, unions and 145-146

labour movement, intervening rules 205

Laering (Illeris) 8

Lagstiftning till döds (Legislation to Death) (Tarras-Wahlberg) 186

la longue durée, economic history 21

Land Code 230; experts 226

Langobards 172-173

law(s): action rules for legal governance 137; causes and consequences of 277-278, 278; concept of law in action 278 ; created system of norms 134-135; external functions and structure 139-140; Hayek on nomos and thesis 132-133; as indicator of societal change $236-239$; internal and external structure 136; legal property spaces 132-140; mandatory rules and market, 146-148; moral standards 240 ; of nature 10,15 ; norms between society and 256-259; political system 133-134; reproductive role of 160-161; technology and 289-290; theories of 129, 131-132; see also sociology of law (SoL)

Law and Revolution (Berman) 239

Law and Society Review (journal) 238

Law as Process, An Anthropological Approach (Moore) 129

Law's Community (Cotterrell) 234-236; imperium and community 235, 244; voluntas and ratio 235, 244

learning process 8

legal anthropology 130n10, 255

legal culture: market economy as 178-184; term 180

legal development: digital technology 251-252; locomotive of 239-250, 245; S-curves describing 241-249 legal dogmatics 277-278, 278 legal person, concept of 233

legal rules: analyses of 131 ; collective decision-making 161-162; consensus-creating mechanism 161; consequences of 154-158; dispute resolution mechanism 162-164; distribution across action systems 140-154; economic system 149-151; emergence of 141; establishing order 159-160; intersystem conflicts 194-202; as norms 129-132; norms that become 158-166; penal law 157; political system 151; reasonability of 160; social life and 141-142; traffic regulation 142; trust-creating function 159

legal system: community and ratio 235-236; consisting of bipolar continuums 243,244 ; continuum of 244; criteria of 155; development of 237-238; development with bipolar values 232-236; Greek 169-171; imperium and voluntas 235-236; regulation crisis 207-209; structure and task 240-241; vertical dimension 242-243, 243

Leo I (Pope) 173

Leo IX (Pope) 172

Lessig, Lawrence: forces constraining actions 274-275; norm of open code 288

Leva för jobbet och jobba för livet (Andersson) 62

lex mercatoria 246

Lex Mercantorum 182

Lichtenstein, Paul, factors governing behaviour 51

Liedman, Sven Eric 9

life-modes, origination of 62

lifeworld and system 50-70; communication and participation 56-57; gap between 80 ; Habermas 2, 17n40, 25, 36, 53, 63, $64,67,198,232$; human dualism $50-53$; perpetual risk and fall of 78-84; relationship between $62-70$; social integration 53-58; socialization of $60-62,71$; system integration $58-62$; unsettled situations in 65-66 
lockdowns 125-126n126, 126n128; COVID-19 125-126

Locke, John, natural rights 85-86

locomotive: direction of movement 250-252; forward movement 251; term 250

Lönn, Ragnar 74

Luhmann, Niklas 64, 237; civil law system 149; concept of systems 109; conflict between two normative worlds 89; dichotomization of world 47; law as reductive 164; legal issue interest 89 ; legal system 101 ; system theory 141

Lundgren, Lars J 227

Lundquist, Lennart 7

Luther, Martin 177

Lycos 75

\section{MacCormick, Neil 5}

machine age 179-182

MacIntyre, Alasdair: distinguishing good and bad 82 ; narratives of humans 81

Mackenzie, Adrian, algo norms 281

McKinsey Global Institute 287

Maine, Henry 237; Ancient Law 48

mandatory rules: employment and housing 147-148; ownership forms 146-147

market economy 117; evolution of law in 168-184; as legal culture 178-184; legal cultures shaping Western law 168-178; mandatory rules of 146-147

market epoch 23-25; technology advancement during 232-233

Marketing Act 197, 233

market society, development process of 29-30

Marriage Code 144, 221

Marx, Karl: capitalistic economy 232; on capital society 87 ; class struggle and 31-32, 34; labour market 115-116, $116 \mathrm{n} 100$; surplus value theory 115 ; systemic integration 69

Marxism 87, 88

Mathiesen, Thomas, systems of ideas 118-119

Mead, George Herbert 56 meme, term $50-5 \ln 5$ mercantile laws, Sweden 182

mercantilism 247; ideology of 179

merchant capitalism 179, 180-182

Merton, Robert K., manifest and latent functions $94 \mathrm{n} 19$

Metamagical Themas (Hofstadter) 215

meta-norm 97

\#MeToo movement 40

Michelson, Staffan, civil law 154n85

Microsoft 75, 76, 157

Mill, John Stuart 88

Minecraft (game) 75

Ministry of Health and Social Affairs 197

Misztal, Barbara A. 53

Moore, Sally Falk: kinds of rules 133; Law as Process, An Anthropological Approach 129

moral(s): development of 8-9; kinds of values 80 ; norms 96, 104; qualitative property of an act, $8 \mathrm{n} 22$

morality $80-82$; common, among 244 ; crimes of 176; ideology and 91, 262; law and 170, 235

Moricz, Sara 283

Mortensen, Nils, moral rules and norms 96

Mosaic, Web browser 74

Mosaic law 19, 176, 177-178, 178n37

motivations: achieving goals 139-140; circle of motives 10, 10-11; creation of 9-10; extended circle of motives 13 ; grounds for action 5-6; selfregulation 140

motives: circle of 10,10-11; extended circle of 13

Mozilla Firefox 75

Murphy, Tim, term norm-giver 5-6

Napoleon, French Code Civil 48

National Institute of Economic

Research 185

natural law, Greek legal system 169-170

nature, conflicting norms 200, 201

Netflix 75

Netscape 75

Netscape Navigator 75

New Deal, USA 186

New York Stock Exchange 77

Nicolas I (Pope) 173

Nicomachean Ethics (Aristotle) 82 


\section{Index}

Nitsch, Ulrich, factors influencing people's choices and lifestyles 6-7

Nonet, Phillipe, legal development 237-238

normative patterns: Christensen's theory of 213-217, 220; environmental law 222-228; institution of immission 223-224; institution of tort law 224-226; intervening rules 226-228; right of ownership 222-223; theory of basic 213-222

normative systems $18-19$ normativity, knowledge systems 16 norm-giver, term 6

$\operatorname{norm}(\mathrm{s})$ : analytical perspective $2-12$; becoming legal rules 158-166; behaviour as individual action 44 ; between law and society 256-259, 257; circle of motives 10, 10-11; concept and empirical study of 3-4; concept of 27, 107-108, 132; from conjoint to disjoint, 98-99, 99; creation and reproduction of 105-107; creation of 8; detection of 166-167; ecological system 119-123; empirical perspective 13-18; expectations and 95-96; extended circle of motives 13 ; as facticity 49,50 ; game/system as outcomeoriented 59; in game theory 97-104; generating guidelines 16; Habermas' definition of 68; knowledge of 60 ; legal definition of 13-14; legal rules as 129-132; methodology of 260-263; as practice and analysis tool 49-50; rule of law and 17-18; sanctions and 101; science of 1-2, 24, 27, 38, 131-132, 253-263; social control and 17, 18; societal development 20-29, 42; structural 118; systems of 18-19, 118-119; technical and environmental 260-261; theory of 129; types of 9; see also normative patterns; social norms

norm (system of), distribution of: action systems 108-109, 110; biotic and abiotic subsystems 110, 123-128; ecological system 119-123; economic system 110, 113-119; political/ administrative system 110,111-113; socio-cultural systems 110, 110-111 norm science $38,204,211$; as action theory 51 ; algo norms and 1, 279; need for 113,122 ; social science and 63; SoL as 253

offer, term 146

Olivecrona, Karl, norms and rule of law $17-18$

Om normer (Sundby) 6

On the Principles of Political Economy and Taxation (Ricardo) 87

Organisation for Economic Co-operation and Development (OECD) 78

orthogonal, term 141

Outline of Social Psychology, An (Sherif) 96 ownership: concept of 219; mandatory rules of 146-147; two sides of right of $222-223$

Oxenstjerna, Axel 179-180

pandemics: Asian influenza 125; COVID-19 124-125; Hong Kong influenza 125; lockdowns 125-127; Spanish influenza 125; Swedish strategy for 127-128; viruses 125-127

Parental Code 144

Paris Agreement 121

Parsons, Talcott: defining norms 92; people's behaviors 98; social actors 12 penal law: civil and 150, 162, 191, 194, 240, 251; disputes in 157; general 149; guilt in 176; importance of 158; Mosaic 176; as tort law 182 penetrability, social dilemma 103 people's choices and lifestyles, Nitsch on factors influencing 6-7

Perez, Carlota, technical-economic cycles 21 personality 56

Persson, Markus "Notch" 75

Petersen, Hanne, wage labour 195

Petrén, Gustaf, on waste 135-136 platform model, digital technology 76-77 Plato 81; notion of wisdom 170 play: Asplund 79; games 79; Huizinga on 79

political/administrative system: evolution of law 191-194; formalized 
rules in 268 ; intervening rules 203-204; legal rules of 153-154 political system: distribution of norms 110, 111-113; legal rules of 151 ; normativity and $16-17$; supplementary rules of 152-153; values and evaluations 133-134 possibilities: action and system theory 43,44 ; circle of motives $10,10-12$; extended circle of motives 13 power, changing society 90

Power of Identity, The (Castells) 36 practice, norm as $49-50$

price mechanism 113

prisoners dilemma 119

procedural rules, consequentialist norms 138

prohibition rules, social system and 142-145

property, concept of 245

property law, concept of 216, 217 property rights, mandatory rules 147 protection of established position,

Christensen 214

Protestant Ethic and the Spirit of

Capitalism (Weber) 88

Psychology of Social Norms, The (Sherif) 96 public choice, school of thought 14

Public Health Agency 127

public spending, industrial society 40-41

punishment, social system 143-144

purification process 235

Qur'an 18

rational choice, school of thought 14 rationality, in system 15

Rättens ursprung och grund (Stjernquist) 105

real property, ownership of 217

Real Property Formation Act 136

reciprocity, social dilemma 103

reciprocity principle 110-111

redistribution, income 41

reductionism 47

reflexive law, model of 249-250

reflexive modernization: Beck phrase 48; concept of 38-39

Reformation 177

regulation: crisis 207-208, 210; explosion 186; technology 287 regulatory strategy, artificial intelligence (AI) and 291-292

Reinvention of Politics, The (Beck) 47

Renner, Karl 216, 219; concept of property 245; The Institutions of Private Law and Their Social

Functions 216; private property 290

Rent Increase Act 217-218

reproduction, role of law 160-161

reproduction technology, social system 142-143

research and development (R\&D) 270-271

residential right, Christensen 215

Ricardo, David 86; free market advocate 87

rights inflation, term 186

risk society 89 ; phrase 89

role-distance, concept of 61

Roman Catholic Church 172, 175, $183 n 64$

Roman culture 22-23

Roman Empire: Christianity and 168, 172-178; collapse of 171-172;

Roman legal culture 170-171

Romanticism 73

Ross, Alf 49

Rothstein, Bo, welfare state 112-113

Rule Explosion (Ahrne and Brunsson) 212

rules, term 19

Sales Act 146

sanctions, norms and 94

Sanderson, Stephen K., social development 45-46

Sandgren, Claes, social civil law 149

Schumpeter, Joseph, business cycles 21

Schutz, Alfred 58; cultural renewal 80

Schwarzenegger, Arnold 199

science: essence of 3; holistic 47-48

science of norms $1-2,38$; analytical perspective 2-12; motives behind people's actions $3-4$; sociology of law (SoL) 253-263

Scott, Johan Finley, Internalization of Norms 95

S-curves: four stages of $80,84,84$, 85; Keynesian strategy 186; legal system's development 241-249; Marx on structure of 88 ; moral 
principle at peak of 83 ; philosophy and science and 85 ; from production to reproduction 76 ; progress showing 287; repressive stage 247 ; social development 70-73, 72; transition between lifeworld and system 80 search engines, development of 75-76 Sejersted, Francis: Demokratisk kapitalism 131; laws and regulations 189 self-regulation: definition 265-266; normative design supporting 265-269; systems 140

Selznick, Philip, legal development 237-238

sensory values, world and 22

September 11 terrorist attack 18 services, digital technology 76-77 Sharia law 18-19

Sherif, Muzafer, concept of norms 96 Smith, Adam 81, 86

social change, technological developments and 35

social control, norms 17,18 social development: $S$-curves or waves 70-73, 72, 76; technology driving $27-28$

social dilemmas 101-104

social facts: human action 6; sociology and 4

social life, legal regulation and 141-142 social norms 130; action 104; competence 104; constructive 104; creation and reproduction 105-107; in game theory 97-104; internalized and systemic 105; moral 104-105; normalization 104-105; sanctions 94; sociological and socio-psychological 91-96; see also norm(s)

social order, trust-creating 53 social responsiveness 9 social sciences, fragmentation of 45 social system(s): destruction and replacement of 30-31; emergence of norms 110-111; ; intervening rules and 202, 203; normativity and 17; peace movement 211; political and administrative $110,111-113$; power relations and change $37-38$; prohibition rules 142-145; punishment or threat in 143-144; reproduction technology 142-143; S-curve 35, 36;

S-curve and 35, 35, 35-36

societal change, law as indicator

236-239

societal development: digital technology

287; direction of movement

250-252; eras of 174; legal regulation

241, 242; linear thinking 287;

S-curves 241-249, 263

Societal Media Collective, Microsoft

Research New England 283

societal norms: algo norms vs 280, 281; concept of 277,280 ; understanding of 254-256

society: atomization of 45 ; birth, change and decline of system 29-42; circle of motives 26; creation of 20-29; culture and 55-58; definition of healthy 66 ; development of 28 , 85-90; development of S-curves 20, 20-21; expression of ideology 85-90; extended circle of motives 13; Habermas' point of view 53; ideological progress of 78-84; material progress of 70-78; need to assemble 45-48; norms between law and 256-259; power and 37-38; S-curves 24-26, 25; system and lifeworld 63-64; transformation of 25-26; understanding development 42 socio-cultural system, alternative to economic system 261-263

sociology 37 ; administrative 47 ;

Durkheim on, as science $4-5$; interest of Habermas and Luhman in 88-89; social facts and 4 sociology of law (SoL) 1, 6, 15, 237; academic subject of 141; advanced practice 283-284, 284n88; algo norms 276-283; algorithms as norms 275-276; code as law 273-275; development of 47; gene technology and lag in law 269-271; methodology of 260-263, 283-286; normativity of technology 271-273; norms as readiness for action 254-256; science of norms 253-263; summation of 253 Solow, Robert, productivity paradox 264 Sophists 169-170

Sophocles 81 
Sorokin, Pitirim A. 22

Spotify 77

Standard \& Poor's 500, 78

state monopolization on violence 17

statutory law 290

steam engine 29-30

steering media, actions in system 58

stem cell research 143

stewardship, ownership of real

property 217

Stjernquist, Per, Rättens ursprung och grund 105

stock exchanges 36

stoicism 83-84, 170

strategic norm, term 114

strategic normative thinking (SNT) 2; approach 264; concept of 253; legal innovation 264-265; normative design supporting self-regulation 265-269

Stridbeck, Ulf, electricity suppliers 148

Strömholm, Stig, social rules 117

structural norms 118

substratum of law 2

Sumner, William Graham 91

Sundby, Nils Kristian: internalized and systemic norms 105; Om normer 6; permissive norms 266; term dutyimposing 49

supplementary rules, political system $152-153$

supply, term 146

Supreme Administrative Court 134

surplus value theory, Marx's 115, 115

surveillance, algorithms and 287-288

sustainable development, concept of 15-16

Svea Rikes Lag 183-184

SVT Play 75

Sweden: anti-competitive regulations 185; constitutional law 151-152; relationship between state and municipalities 152

Swedish Board of Agriculture 270

Swedish Church 176-178

Swedish Code of Statutes (Svensk Forfattningssamling SFS) 184-194; number of statutes $184,185,187$, 188,189

Swedish Constitution Collection 188
Swedish Gene Technology Advisory Board 270

Swedish Land Code Bill of 1909, 224

Swedish Mapping, Cadastral and Land Registration Authority 136

Swedish Social Insurance Agency 212

Swedish Union of Tenants 148

Swidler, Ann 55-56; cultural lag 65; cultural roles $64,71-72$

Swipnet 75

system see lifeworld and system

system possibilities: action and system theory 43,44 ; circle of motives 10 , 10-12; extended circle of motives 13

system theories: action theories and $43-45$; circle of motives 44

Tarras-Wahlberg, Björn, laws and regulations 186

Tax Procedures Act 191

teaching, dimensions 8

technical norms, algo norms as subcategory of 279

technology: core 29, 36; developments and social change 35 ; digital 35 ; forward to basics 32 ; law and 289-290; linear thinking 287; normativity of 271-273; S-curve 28; social adaptation to new 31 ; social development 27-28; societal change and science of norms 291-292; see also digital technology

telecommunication, Internet and 73-74

Tenancy Act of 1968 218, 231

tenancy law: Christensen 215; normative content of 216

tenure security 218-219

Teubner, Gunther: legal development 238; legal model 206-208; societal development 249; system theory 141

Theodosius the Great 172

Therborn, Goran: norms and normality 104-105; prescriptive nature of norms 13

thought, Hegel's theory of norms 73

Thunberg, Greta, environment and 199

Tiden (Bergman) 218

Tokku, Japan 289, 289n1 14

tort law: institution of 224-226; penal law as 182; strategy 223 
traffic regulation 142

transfer system, labour market 196

transitional society: alternative solutions to intersystem conflicts 204-212; conflicting norms on labour market 196; exchange value 197; intervening rules and intersystem conflicts 194-202; law in 194-212; problems with intervening rules 202-204; transfer system 196; utility value 197

transplantation technology 143

Trump, Donald 121

trust 53, 54; cooperation and 55; development of 72 ; habitual 54 ; legal rules producing 159; morals and values $54-55$; reasonability of law 160; social orders creating 53; spontaneous 84

Tuori, Karlo 212, 258

Tupanvirus 124

Two Treatises on Government

(Locke) 85

\section{Uber 77}

Ullmann-Margalit, Edna: The Emergence of Norms 97; prisoners dilemma 119 understanding, term 7

Unger, Roberto Mangabeira, legal order and regulation 133

unilateral dominance 34

unions, labour market 145-146

University of Bologna 173

utilitarianism, Bentham on 86

utility value 197

Vasa (ship) 120n112

Vasa, Gustav 177-178

Viaplay 75

Vikings 179

violence, state monopolization on 17

virtue: Aristotle teaching 84; cardinal 82; concept of 81 ; ethics $81-82,83,86$ viruses 124; coronavirus 124-127; infection by 124-125; pandemics 125-127; Tupanvirus 124 wage labour 195-196; Christensen on 220-221

Waseda University 289n114

waste, concept of 135-136

Water Act 231

WebCrawler 75

Weber, Max 237; concept of guaranteed right 130; formal and substantial justice 248 ; legal rationality 238 ; social act of sociology 88 ; systemic integration 69 ; value- and goaloriented 80n1 14; Verstehen method 4,279

weighing-and-balancing norms: competence rules 138; decisionmaking process 138-139

Western law, legal cultures shaping 168-178

Wickenberg, Per 258; norm creation 107 Wilhelmsson, Tomas, civil law 149 will: action and system theory 43,44 ; can and 7-8; circle of motives 10 , 10-12; extended circle of motives 13 ; rule and 19

Willke, Helmut 203

wisdom 170

women's issues: intervening rules and 204-205; movement and economic system 209

Work Environment Act 146

work provider 116

work purchaser 116

World Bank 114

World Health Organization (WHO) $124,126-127$

World Trade Organization (WTO) 211

World War I 184, 185, 188; laws and regulations 190

World War II 151, 184, 185, 188; intervening rules 193

World Wide Web (WWW) 74

Yahoo 76

Yandex 76

Zenon 84 